Selection of Power Plant Elements for Future Reactor Space Electric Power Systems 


\section{DISCLAIMER}

This report was prepared as an account of work sponsored by an agency of the United States Government. Neither the United States Government nor any agency Thereof, nor any of their employees, makes any warranty, express or implied, or assumes any legal liability or responsibility for the accuracy, completeness, or usefulness of any information, apparatus, product, or process disclosed, or represents that its use would not infringe privately owned rights. Reference herein to any specific commercial product, process, or service by trade name, trademark, manufacturer, or otherwise does not necessarily constitute or imply its endorsement, recommendation, or favoring by the United States Government or any agency thereof. The views and opinions of authors expressed herein do not necessarily state or reflect those of the United States Government or any agency thereof. 


\section{DISCLAIMER}

Portions of this document may be illegible in electronic image products. Images are produced from the best available original document. 
An Affirmative Action/Equal Opportunity Employer

This work was supported by the US Department of Energy, Advanced Nuclear Systems and Projects Division, Space and Terrestrial Systems Branch.

This report was prepured as an account of work sponsored by the United States Government. Neither the United Stutes nor the United States Department of Enerzy, nor any of their their employees makes their employees, makes wny warranty. express or implied, of completeness ar usefulness of any infory tor the accuracy. product, or process dieclosed, or any information, apparatus. not infringe privately owned rights. 
Special Distribution

Issued: September 1979

\title{
Selection of Power Plant Elements \\ for Future Reactor Space \\ Electric Power Systems
}

\author{
D. Buden \\ R. Malenfant \\ G. A. Bennett \\ H. Martz \\ K. Cooper \\ W. Ranken \\ K. Davidson \\ R. E. Riley \\ D. Koenig \\ F. Schilling \\ L. B. Lundberg
}
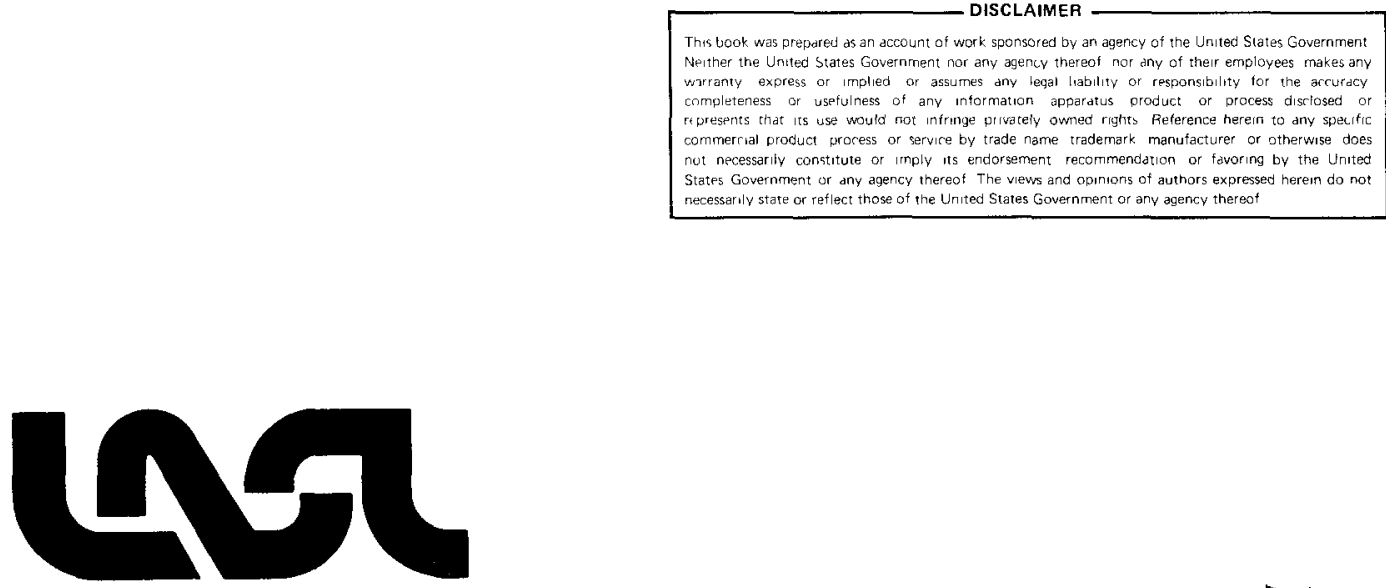


\section{CONTENTS}

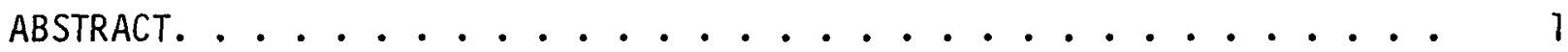

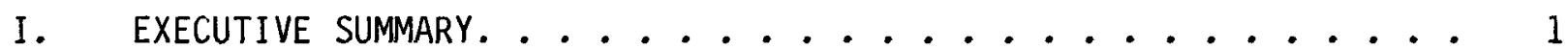

II. MISSION REQUIREMENTS ................. 7

A. Potential DoD Missions.............. 8

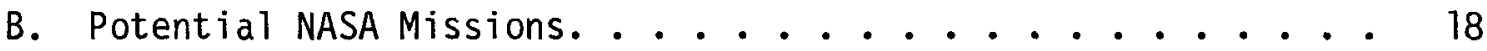

C. Why Reactors Become a Prime Power Source ......... 25

D. Transportation to Geosynchronous Orbit ......... 28

E. Power Plant Requirements for Geosynchronous Orbit Spacecraft . 29

REFERENCES ...................... 34

III. POWER PLANT DESCRIPTIONS . . . . . . . . . . . . . . 35

A. General. ..................... 35

B. Basic Power Plant Configurations ........... 36

C. Specific Power System Descriptions ........... 41

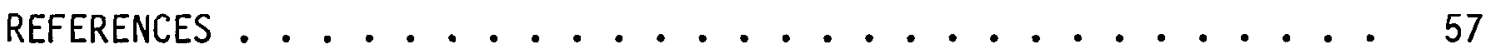

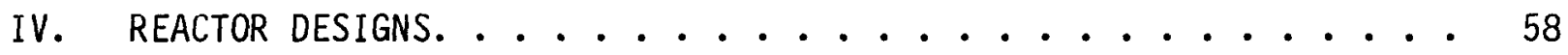

A. Reactor Assembly Design. ................ 59

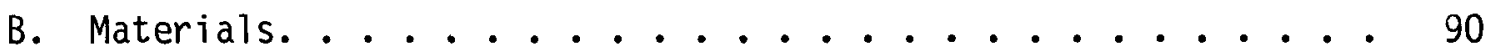

C. Comparison of Reactor Designs. . . . . . . . . 112

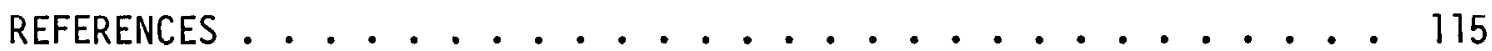

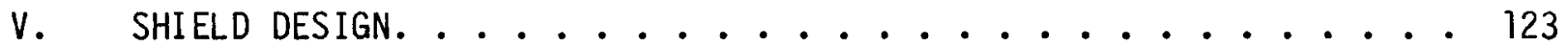

A. Parametric Analysis. . . . . . . . . . . . 123

B. Radiator Analys is Including Scatter. ......... 128

C. Shield Penetrations. .............. 133

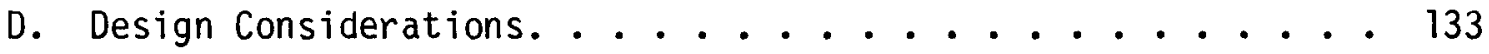

E. Neutron Shield Materials ........... 136

REFERENCES . . . . . . . . . . . . . . . 137

VI. ELECTRIC POWER CONVERTER DESIGN. . . . . . . . . . 138

A. Description of Converters............. 138

B. Relative Characteristics ............. 177

Appendix VI-A. . . . . . . . . . . . . 182

Appendix VI-B. . . . . . . . . . . . . . . 187

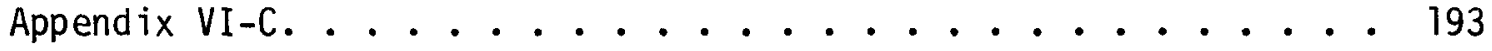

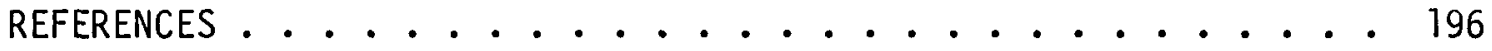


VII. RADIATOR DESIGN. . . . . . . . . . . . . . . . . 198

A. High-Temperature Radiators $(>650 \mathrm{~K}) \ldots . . . . . . .198$

B. Low-Temperature Radiators $(<650 \mathrm{~K}) \ldots \ldots . . \ldots 216$

C. Summary.................. 234

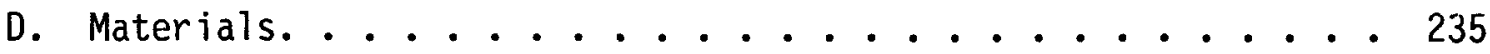

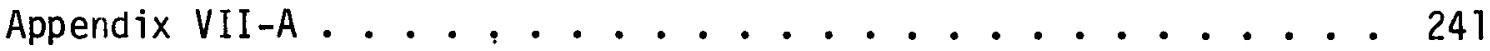

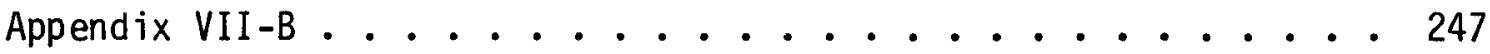

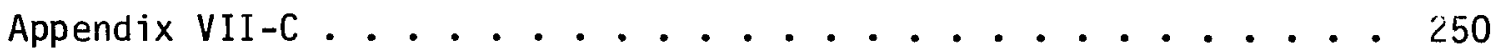

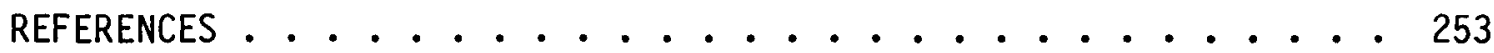

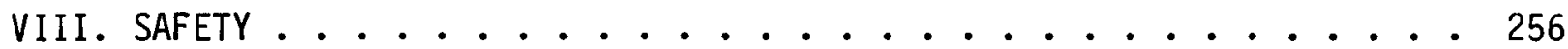

A. Characteristics of the Reactor ........... 258

B. Safety Before Launch ............... 261

C. Accidents at Launch............... 262

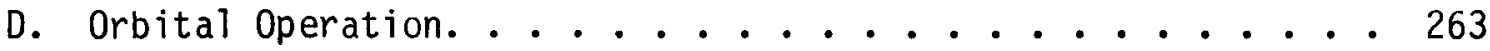

E. Accidental Return to Earth After Operation....... 265

IX. RELIABILITY ANALYSES . . . . . . . . . . . . 268

A. Power Plants with Brayton Converters . . . . . . . 268

B. Power Plants with Thermoelectric Converters. . . . . . 271

X. SYSTEM CONSIDERATIONS. ................. 274

A. Power Plant Design Temperatures. . . . . . . . . 275

B. Reactor Design Power Level . . . . . . . . . . . 284

C. Power Plant Configuration. . . . . . . . . . 287

D. Spacecraft Integration ............. 296

E. Single-Failure Point Analysis. . . . . . . . . 302

F. Combined Converter Cycles. . . . . . . . . . . 317

G. Emergency Coolaown for Man-Rated Systems ........ 318

XI. OVERALL ASSESSMENT . . . . . . . . . . . . 322

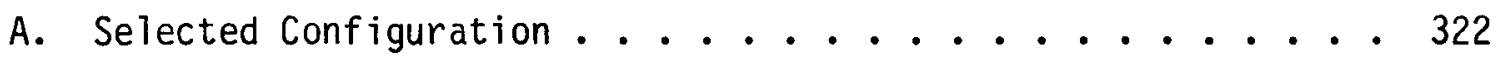

B. Power Plant Configruation Assessment ......... 324

FIGURES

1. Space power production experience ........... 8

2. Maximum single-spacecraft power requirements by year. ..... 11

3. Reactor-powered planar array space radar.......... 11 
4. Solar array plus battery-powered planar array space radar . . . 12

5. Reactor-powered parabolic space radar . . . . . . . . . 15

6. Solar array plus battery-powered parabolic space radar. . . . 15

7. Potential NASA applications in geosynchronous orbit . . . . . 19

8. Space construction base .................... 21

9. Candidate power systems for Earth-orbit space stations. . . . . 23

10. NASA lunar and planetary program trends and propulsion system capabilities........................... 24

11. Payloads in planetary orbit . . . . . . . . . . . 25

12. Radiation hardness of typical electronic components for

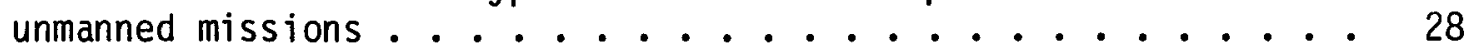

13. Reactor shielding . . . . . . . . . . . 30

14. Possible space power for DoD missions . . . . . . . . . 30

15. Orbit transfer system performance comparison (Low earth orbit to geosynchronous orbit).......................... 31

16. Thermoelectric or thermionic systems. . . . . . . . . 37

17. Alternative thermoelectric and thermionic systems . . . . . 37

18. Basic configuration of Brayton cycle power plant. . . . . . 38

19. Alternative Brayton system. . . . . . . . . . . . 39

20. Basic Rankine liquid-metal system . . . . . . . . . 39

21. Alternative Rankine liquid-metal system .......... 40

22. Nuclear thermoelectric system . . . . . . . . . . . . 42

23. Brayton system. . . . . . . . . . . . . . . 43

24. Thermoelectric design concept and projected converter efficiencies for unmodified SiGe. . . . . . . . . . . 46

25. Thermoelectric coolant module detail. . . . . . . . . 47

26. Typical Brayton cycle power system parameters . . . . . . . . . 48

27. Thermoelectric power plant. . . . . . . . . . . . 4 49

28. Brayton cycle space electric power supply . . . . . . . . 50 
29. Brayton cycle gas-cooled reactor............. 51

30. Gas-cooled reactor component relationship . . . . . . . 52

31. SNAP-50/Spur schematic. ............. 53

32. PWAR-20 (SNAP-50) reactor and shield.......... 54

33. PWAR-20 (SNAP-50) reactor core and pressure vesse1. ..... 55

34. Advanced Rankine power system ............. 56

35. Advanced Rankine engine system. . . . . . . . . . 57

36. Fuel element wafer configuration. .......... 59

37. Wafer core design avoids thermal contact problem
between elements. ....... s9

38. UC-ZrC heat-pipe fuel element ............ 60

39. Heat-pipe fuel element. .............. 61

40. Wafer design heat-pipe reactor. ........... 61

41. Heat-pipe reactor ................ 62

42. Gas-cooled reactor schematic. . . . . . . . . . 63

43. One-dimensional model of reactor used in neutronic calculations . 65

44. Relative fuel concentration and power density vs radial position. 66

45. Effect on radial power density of $2-\mathrm{mm} \mathrm{B}_{4} \mathrm{C}$ layer located

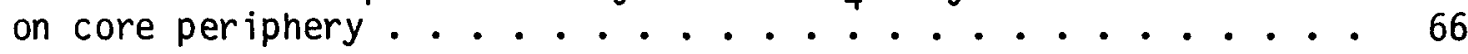

46. Critical core diameter vs non-fuel volume fraction for Uc-ZrC and $\mathrm{UO}_{2}$-Mo reactors with varying $\mathrm{H} / \mathrm{D} \ldots \ldots 66$

47. Minimum UC-ZrC core diameter vs non-fuel volume fraction needed to remove thermal power .............. 67

48. Minimum core size of UC-ZrC reactor is smaller than that of

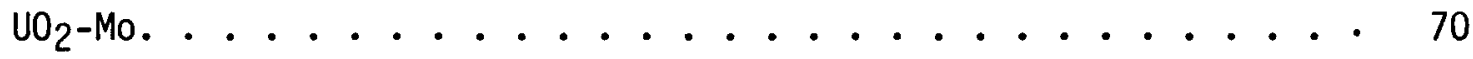

49. Dependence of fuel swelling on fission density and temperature for $\mathrm{UC}, \mathrm{UN}, \mathrm{UO}_{2}$, and $\mathrm{UO}_{2}-60 \mathrm{vol} \% \mathrm{Mo} . . . . . . . . . .71$

50. Weight vs thermal power for $\mathrm{UO}_{2}-40$ vol\% Mo and UC-10 at.\% $\mathrm{ZrC}$ reactors. The weights include a $1-m$ extension of heat pipes outside the reactor................ 
51. $\mathrm{UO}_{2}$ temperatures vs thickness at the coldest molybdenum

location. ....................... 74

52. $\mathrm{UO}_{2}$ temperatures vs thickness at the hottest molybdenum

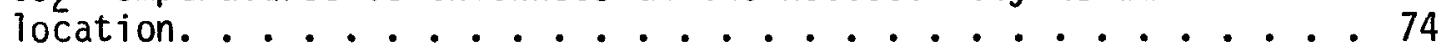

53. Increase in $\mathrm{UO}_{2}$ temperature at the hottest molybdenum location

from 80-20 to 85-15 $\mathrm{UO}_{2}$-Mo................. 74

54. Reactivity vs reflector thickenss for reflector composed of

pure material.................... 76

55. Reactivity changes vs $10_{\mathrm{B}_{4} \mathrm{C}}$ layer thickness for a $\mathrm{BeO}$

reflector assembly having a fixed overall thickness of $100 \mathrm{~mm}$. 76

56. Control effectiveness of several reflector assemblies. . . . 77

57. Fuel temperature vs number of core heat-pipes for a $1-M W_{t}$

UC-10 at.\% ZrC reactor................. 79

58. Typical core partial configuration . . . . . . . . . 81

59. Location of periphery ( $\because)$ and interior $(x)$ failed heat pipes . 81

60. AYER mesh for periphery heat-pipe failure. . . . . . . . . 82

61. AYER-generated isotherms for periphery failure for $1-M_{\mathrm{t}}$

reactor.................... 83

62. Maximum fuel temperature . . . . . . . . . . . . 84

63. Effect of power on reactor weight for gas-cooled reactors. . . 87

64. Effect of reactor pressure drop on reactor weight. . . . . . 88

65. Phase relationships for the UC system. . . . . . . . . . 92

66. Liquidus/solidus curves for the UC-ZrC pseudo-binary system. . . 92

67. Phase relationships for the uranium-oxygen system. . . ... . y2

68. Phase relationships for the UN system. . . . . . . . . . 92

69. Diamond pyramid hardness vs temperatures for various fuels . . . 93

70. Flexure strength vs temperature for $U C, U C-\mathrm{ZrC}$, and $\mathrm{UO}_{2}$

fuels...................... 93

71. Variation of Young's modulus with temperature. . . . . . . . 93

72. Variation of Poisson's ratio with temperature for UC and $\mathrm{UO}_{2}$. 94

73. Creep rate of various fuels. . . . . . . . . . . 94 
74. Thermal conductivity vs temperature for various fuels. . . . . 95

75. Thermal expansion vs temperature for various fuels . . . . . 96

76. Vapor pressure of various fuels. . . . . . . . . . . . 96

77. Vaporization flux for various fuels. . . . . . . . . . . 97

78. Fission gas release from $U C_{1+x}$ as a function of centerline temperature.........................

79. $10^{5}-\mathrm{h}$ rupture stress/density ratios for selected refractory metals.................... 100

80. The ultimate tensile strength and total tensile elongation for irradiated and control samples of molybdenum. Tensile strain rate was $0.03 \mathrm{~min}^{-1}$ except as shown. Solid lines connect results differing only in test temperature. Dashed lines connect results where irradiation conditions or strain rates are not held constant...................

81. Thermal conductivity of tungsten, molybdenum, tantalum, and niobium. . . . . . . . . . . . . . . 103

82. Comparison of free energy of formation . . . . . . . . . 105

83. Comparison of rates of growth of carbide layers on refractory metals heated in contact with hyperstoichiometric UC . . . . 106

84. Volume changes observed in irradiated beryllium as a function of temperature. The reported values have all been normalized to a

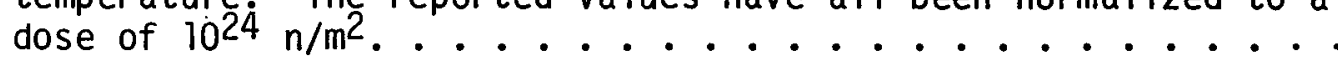

85. Heat flux vs source temperature for a Mo- $\mathrm{ZrO}_{2}$ multi-foil

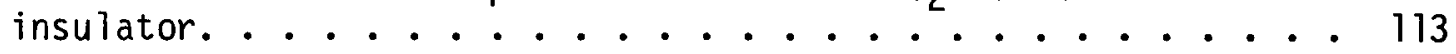

86. Gas-cooled and heat-pipe reactor design mass comparison. . . . 114

87. Reactor shielding. . . . . . . . . . . . . . 124

88. Lithium-hydride neutron radiation attenuation. . . . . . . 125

89. Brayton cycle shield mass for 200-kWt design operating

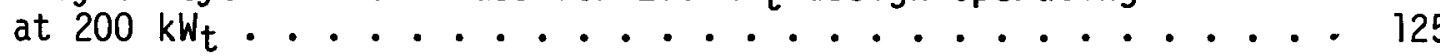

90. Brayton cycle shield masses for 200- and 1000-kWt designs

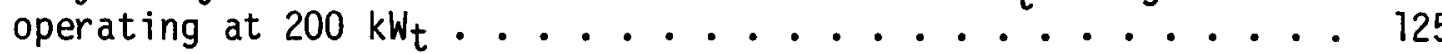

91. Thermoelectric shield mass for 1000-kWt design operating

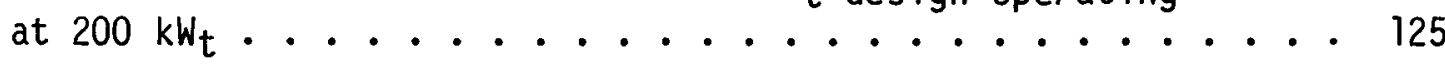

92. Shield thickness vs separation distance. . . . . . . . . . 126 
93. Shield mass based on 25-m separation of core and paylaod . . . 126

94. Shield mass for thermoelectrics. . . . . . . . . . 126

95. Neutron fluence in shield. . . . . . . . . . . 127

96. Energy fluence band from secondary gamma rays. . . . . . . . 127

97. Side cross section for Brayton power plant geometry. . . . . 129

98. Cross section through core for Brayton power plant . . . . . 129

99. Cross section through region 2 header and radiator for Brayton

power plant...................... 129

100. Two-diameter offset shield penetration . . . . . . . 135

101. SNAP shield shape. . . . . . . . . . . . . 135

102. Potential conversion systems . . . . . . . . . . 138

103. Schematic of thermoelectric conversion cell. . . . . . . 139

104. Figures-of-mer it of thermoelectric materials . . . . . . . 141

105. Thermoelectric material resistivity curves . . . . . . . . 143

106. Seebeck coefficient curves . . . . . . . . . . . 143

107. Thermal conductivity curves. . . . . . . . . . . . 144

108. Figure-of-merit as a function of temperature, n-type material. . 146

109. Figure-of-merit as a function of temperature, p-type material. . 147

110. Figure-of-merit for thermoelectric materials . . . . . . . 147

111. Conversion efficiency for thermoelectric materials . . . . . 148

112. Thermoelectric module. . . . . . . . . . . . . 149

113. Computed modular conversion efficiencies . . . . . . . . 150

114. Schematic of basic thermionic converter. . . . . . . . 153

115. NEP system with thermionic power conversion on reactor side 154

116. Brayton cycle schematic. . . . . . . . . . . . 156

117. Predicted Brayton cycle efficiency . . . . . . . . . . 159

118. Effect of loop flow pressure loss on Brayton cycle efficiency. - 159 
119. Effect of recuperator effectiveness on Brayton cycle efficiency.................... 159

120. Muff heat exchanger design ............ 160

121. Helix heat exchanger design. ................ 160

122. Muff exchanger .................. 161

123. Brayton cycle at $50 \mathrm{~kW}$. ................... 162

124. Brayton converter mass vs power. . . . . . . . . 163

125. High-temperature converter materials limited by rupture weight . 166

126. Schematic of a potassium Rankine cycle ......... 169

127. Ideal Stirling cycle . . . . . . . . . 172

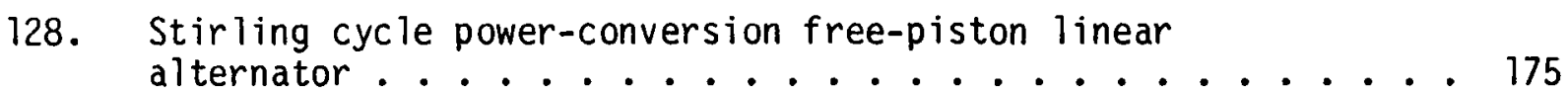

129. Stirling cycle efficiency. ............. 176

130. Comparison of efficiencies as a function of heater and reject heat temperatures.............. 178

131. Near-term potential conversion systems ......... 181

132. Longer-term potential conversion systems . . . . . . 181

133. Space power radiator materials ............ 199

134. Area and mass as function of temperature ......... 199

135. Ninety-one heat-pipe thermoelectric system radiator. . . . 201

136. Beryllium thickness for perforation and dimple failure modes. . . . . . . . . . . . . . . 202

137. System survival probability vs number of surviving stringers . . 203

138. Beryllium thickness vs survival probability. . . . . . . 204

139. Cone frustum ................... 208

140. Geometry for earth shielding factor. . . . . . . . . 210

141. Radiator mass with and without bumper effect ....... 212

142. Radiator mass for six candidate container materials. . . . . 213

143. Radiator mass for three candidate heat-pipe fluids . . . . . 214 
144. Radiator mass with and without shine through base. . . . . . 214

145. Radiator mass for two operating temperatures . . . . . . . 215

146. Radiator mass vs reject heat . . . . . . . . . . . 216

147. Raidator area vs reject heat .............. . . 217

148. Radiator slant height vs reject heat . . . . . . . . 217

149. Brayton cycle with tertiary heat rejection loop. . . . . . 219

150. Brayton cycle direct pumped heat rejection system. . . . . . 220

151. Cooler heat-exchanger schematic. . . . . . . . . . 221

152. Brayton system reject heat exchanger . . . . . . . . . 225

153. Drum heat exchanger mass vs diameter . . . . . . . . . 225

154. Brayton cycle pumped-liquid radiator design. . . . . . . 226

155. Incremental section of radiator. . . . . . . . . . 227

156. Fin and armored tube geometry. . . . . . . . . . . 227

157. Radiator mass as function $F L / R$ at $R=5 \times 10^{-3} \mathrm{~m}$ and $B=3.3 \times 10^{-4} \mathrm{~m} . \ldots . . . . . . . . .228$

158. Radiator mass as a function of $F L$ ? $B$ at $R=5 \times 10^{-3} \mathrm{~m}$ and $\mathrm{FL} / \mathrm{B}=12.2 . . . . . . . . . . . .228$

159. Radiator length as a function of $F L / R$ at $R=3 \times 10^{-3}$ and $B=3.3 \times 10^{-4} \mathrm{~m} . . . . . . . . . .229$

160. Pumped-gas Brayton cycle and reject heat system. . . . . . . 230

161. Brayton system reject heat exchange manifold . . . . . . . 231

162. Gas flow pattern in manifold ............. 232

163. Incremental heat pipes and heat exchanger manifold . . . . . 233

164. Radiator mass vs flow tube diameter. . . . . . . . . . 233

165. Radiator mass vs fin half-length . . . . . . . . . 234

166. Direct pumped Brayton cycle heat exchanger and radiator, $200 \mathrm{~kW}_{\mathrm{t}, \mathrm{n}}=25 \%$, Xe-He gas mol wt $=39.94 \ldots \ldots 235$

167. Thermal conductivity/density ratios of candidate thermoelectric radiator materials. ...... 237 


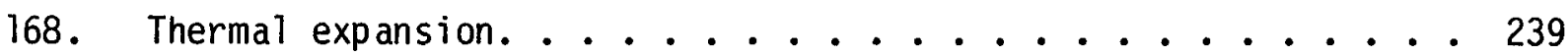

169. Min imum orbit decay time . . . . . . . . . 257

170. Dispersion of particles after atmospheric re-entry . . . . 267

171. Reliability block diagram of a heat-pipe reactor with thermoelectric power conversion system ........ 271

172. Thermoelectric efficiency as a function of hot-side temperature for various sink temperatures based on SiGe compression module................. 276

173. Thermoelectric converter (SiGe) performance data . . . . 276

174. Shield behavior (separation to payload $25 \mathrm{~m}$, cone half-angle $\left.12^{\circ}\right) \ldots \ldots . \ldots . \ldots 276$

175. Radiator weights . . . . . . . . . . . 280

176. Effect of thermoelectric temperature variations on power plant mass .................. 280

177. Effect of thermoelectric temperature variations on power plant mass (efficiencies improved 40\%) .......... 281

178. Effect of thermoelectric efficiency on power plant mass. . . . 281

179. Thermoelectric power plant options for $100 \mathrm{~kW} \ldots \ldots 283$

180. Thermoelectric power plant comparisons ......... 283

181. Reactor mass vs power level. . . . . . . . . . . 286

182. Fuel swelling for customized vs standard designs . . . . . . 287

183. Customized vs standard reactor design. . . . . . . . . 288

184. Space electric power system. . . . . . . . . . . . 290

185. Nuclear reactor heat-pipe thermoelectric power plant (100 kW). . 292

186. SEPS flat radiator $\left(100 \mathrm{~kW}_{\mathrm{e}}\right) \ldots \ldots . \ldots . \ldots 293$

187. Brayton cycle space electric power supply. . . . . . . . 295

188. 50-kWe Brayton space nuclear electric power system . . . . 296

189. 50-kWe Brayton space nuclear electric power system ...... 297

190. Telescoping cylinder for 100-kW electric Brayton system. . . . 298

191. Brayton-cycle power plant with direct-coupled radiator . . . 299 
192. Power plant weight comparison. . . . . . . . . . . 301

193. Schematic layouts for each type of converter . . . . . . 302

194. In-orbit assembly configuration with Brayton reactor power

plant (General Dynamics concept) .......... 303

195. Gas-cooled reactor with dynamic converter. . . . . . . . 305

196. Gas-cooled reactors with dynamic converters. . . . . . . 305

197. Redundant elements in gas-cooled reactor with dynamic converters ............... 309

198. 300-kW SNAP-50/SPUR flow schematic - direct condensing. . . 310

199. Major failure modes for liquid-cooled reactors with dynamic converters .............. 313

200. Redundancy in the converter loop and auxiliary power loops . . 315

201. Redundant elements in heat-pipe reactor with dynamic converters ................. 316

202. Afterheat generation . . . . . . . . . . . . . 320

203. Heat-pipe reactor emergency cooldown . . . . . . . . . 321

204. Ratio of post-shutdown dose rate to that during operation

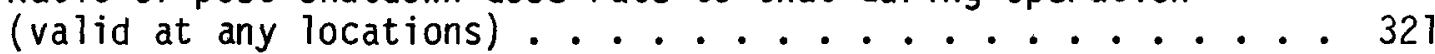

TABLES

I. Grumman 50-kWe Power System Masses for SBR . . . . . . . . 13

II. Grumman SBR Concept. . . . . . . . . . . . . . . . . . .

III. TRW 50-kWe Power System Masses for SBR . . . . . . . . 16

IV. TWR Concept SBR Satellite Mass . . . . . . . . . 16

V. TRW Comparative SBR Costs (\$M) . . . . . . . . . . 17

VI. Electrical Requirements. . . . . . . . . . . 18

VII. Solar Array vs Reactors, Based on Projected Technology . . . . 26

VIII. Power Plant Requirements ............... 33

IX. Applicability of Power Cycles to Reactor Coolant . . . . . 40

X. Design Data for 1200-kWt Heat-Pipe Reactor . . . . . . . . 44 
XI. Design Data for $\mathrm{UO}_{2}-20$ vol\% Mo Heat-Pipe Reactor . . . . . 72

XII. Calculated $\mathrm{UO}_{2}$ Temperatures. ................ 73

XIII. Fuel Element Data............... 80

XIV. Temperature Drops Across Fuel Element Interfaces and Resulting Maximum Fuel Temperatures $(K)$ for $3-M W_{t}$ Reactor...... 82

XV. $\quad 1000-k W_{t}$ Reactor Comparison. ........... 86

XVI. Thermodynamic Brayton Cycle Data . . . . . . . . . . 87

XVII. Melting Point, Theoretical Densities, and Volumes of

Candidate Fuels................... 91

XVIII. Reaction Products of UC and Refractory Metals. . . . . . 98

XIX. Material Descriptions. ................ 130

XX. Leakage Spectrum ................ 131

XXI. Summary of Results ............... 132

XXII. Neutron Spectrum at Point Detector........... 132

XXIII. Relative Detector Response as a Function of Offset From

the Symmetry Axis............... 134

XXIV. Physical Dimensions of Module. ............. 149

XXV. Temperature Profile of Module in Operation Between

1375 and 775 K......................... 150

XXVI. Thermoelectric Converter Applications in Space ....... 151

XXVII. Comparison of Muff and Helix Heat Exchangers . . . . . . 160

XXVIII. Dimensions of Brayton Converter Components . . . . . . 163

XXIX. Stirling Cycle Power-Conversion System . . . . . . . . 174

XXX. Relative Specific Weights (100-kWe Base) . . . . . . 179

XXXI. Properties of Candidate Radiator Materials ........ 211

XXXII. Radiator System Size and Mass Data .......... 218

XXXIII. Properties of Candidate Heat-Pipe Working Fluids . . . . . . 222

XXXIV. Properties of Pumped Working Fluids. . . . . . . 223 
XXXV. Projected Ducting Reliability for Single- or DoubleContainment Welds. ............... 269

XXXVI. Overall Projected System Reliability for Several Alternative Gas-Cooled and Heat-Pipe Brayton Power Conversion System Designs. . . . . . . . . . . . . . 270

XXXVII. Preliminary EOM Reliability for Several Alternative Designs for a Heat-Pipe Thermoelectric Space Nuclear Reactor . . . . 272

XXXVIII. Projected EOM Heat-Pipe Thermoelectric System Reliability for Selected Combinations of Heat-Pipe Reliability and Percentage Path Failure in Subsystem No. . . . . . . . . . 273

IXL. Thermoelectric Performance with UC-10 at.\% ZrC . . . . . . 277

XL. Thermoelectric Converter Efficiency Improved by 40\%. . . . . 279

XLI. Power Plant Performance with Thermoelectric Converter

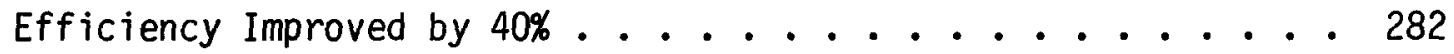

XLII. Brayton Cycle Performance as a Function of Turbine Inlet Temperature. .................. 284

XLIII. Heat Pipe Arrangements . . . . . . . . . . 289

XLIV. Comparison of Power Plant Weights. . . . . . . . . 300

XLV. Gas-Cooled Reactor Single-Failure Points . . . . . . . 306

XLVI. Single-Failure Point Summary for Single-Loop Gas-Cooled systems. . . . . . . . . . . . . 308

XLVII. Liquid-Cooled Reactor Single-Failure Points. . . . . . . . 311

XLVIII. Single-Failure Point Summary for Liquid-Cooled Systems with Single Converters . . . . . . . . . 314

XLIX. Heat-Pipe Reactor Single-Failure Points with Thermoelectric Converters ................ 317

L. Combined Converter Cycles. . . . . . . . . . 319

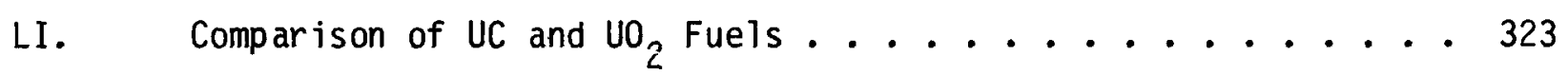

LII. Technology Comparison (Based on Current Designs) . . . . . 325 


\title{
SELECTION OF POWER PLANT ELEMENTS FOR FUTURE REACTOR SPACE ELECTRIC POWER SYSTEMS
}

\author{
by
}

D. Buden, Q-D0; G. A. Bennett, WX-4; K. Cooper, Q-13; K. Davidson, CMB-6; D. Koenig, Q-13; L. B. Lundberg, Q-13; R. Malenfant, Q-14; H. Martz, S-1; W. Ranken, Q-13; R. E. Riley, CMB-6; F. Schilling, WX-4

\begin{abstract}
We studied various types of reactor designs, electric power conversion equipment, and reject-heat systems to be used in nuclear reactor power plants for future space missions. The designs included gas-cooled, liquid-cooled, and heat-pipe reactors. For the power converters, we considered passive types such as thermoelectric and thermionic converters and dynamic types such as Brayton, potassium Rankine, and Stirling cycles. For the radiators, we considered heat pipes for transfer and radiating surface, pumped fluid for heat transfer with fins as the radiating surface, and pumped fluid for heat transfer with heat pipes as the radiating surface.

After careful consideration of weights, sizes, reliabilities, safety, and development cost and time, we selected a heat-pipe reactor design, thermoelectric converters, and a heat-pipe radiator for an experimental program.
\end{abstract}

\section{EXECUTIVE SUMMARY}

We are completing a study on the type of nuclear reactor power plant that should be developed for future space missions. With the advent of the reusable Space Transportation System (STS), more popularly called the Space Shuttle, a new era is opening in space exploration and exploitation. The Department of Defense (DoD) is especially interested in improved surveillance systems and communications. Most of these applications require high 
powered satellites at an altitude known as geosynchronous orbit, an orbit that is stationary above a fixed spot on the earth's surface. The amount of mass that the Space Shuttle will be able to deliver to this altitude is, however, severely limited, resulting in tight restrictions for the allowable mass of candidate power supplies.

We considered various types of reactor designs, electric power conversion equipment, and reject heat systems. The designs included gas-cooled, liquid-cooled, and heat-pipe reactors. The first two have a cooling fluid directly heated by the reactor, whereas the heat-pipe design uses a different configuration. A number of pipes are built into the reactor. A volatile fluid is sealed into the pipes. In the reactor core, the fluid is vaporized and the vapor expands through the center of the pipes. On the end which is located outside the reactor, heat is extracted by means of electrical conversion elements. This causes the vapor to condense. A wick structure located on the inside surface of the pipe provides capillary pumping force and a passage for the liquid to return to the reactor to be reheated. Thus, we achieve a self-pumping heat transfer system without incorporating fluid pumps into the power plant.

For the power converters, we considered passive types such as thermoelectric and thermionic, and dynamic types such as a Brayton, potassium Rankine, and Stirling cycles. The thermoelectric converter uses the enhanced Seebeck coefficient of semiconductor materials to convert heat to electricity. Thermionic devices use an evaporation-condensation cycle of electrons with space-charge neutralization by cesium ions to achieve the same result. The Brayton cycle is a gas system that depends on a turboalternator-compressor to circulate the working fluid through the heat source and extract electrical energy. The potassium Rankine is much like a conventional, earth-based power plant where potassium is substituted for steam and operates as a liquid-vapor system. The Stirling cycle is a gas cycle, designed for constant-volume heating and cooling and constant-temperature expansion and compression to increase the cycle efficiency.

For all the above conversion systems heat must be removed at the low side of the operating temperature interval. In space this must be done by the radiation of thermal energy. Various types of radiators were considered, including heat pipes for heat transfer and radiating surface, 
pumped fluid for heat transfer with fins as the radiating surface, and pumped fluid for heat transfer with heat pipes as the radiating surface.

After careful consideration of power plant configuration weights, sizes, reliabilities, safety, development cost and time, we selected a heat-pipe reactor design, thermoelectric converters, and heat-pipe radiator as the configuration to be used in an experimental program.

Working with DoD personnel, we established a list of requirements to be used as a basis for evaluating various candidate power plants used to provide electric power for spacecraft in geosynchronous orbit. The requirements are:

- Power Output. Electric power requirements in geosynchronous orbit cover the range from $10-100 \mathrm{~kW}$ for potential DoD missions. Potential National Aeronautics and Space Administration (NASA) applications have been projected to cover a range from $15-220 \mathrm{~kW}_{\mathrm{e}}$, but it is not certain that these missions will be undertaken.

- Lifetime. Lifetime, established by anticipated developments in other components in the spacecraft, is set at seven years.

- Reliability. The reliability design goal for the power generation unit is 0.95 . Designs that avoid single-failure points and degrade gradually are favored.

- Mass. For a spacecraft requiring two shuttle launches, the goal is $1910 \mathrm{~kg}$. This is based on using a three-stage Interim Upper Stage (IUS) for transfer from low earth orbit to geosynchronous orbit and applying the general rule of thumb that the power subassembly can constitute up to $30 \%$ of total spacecraft mass.

- Configuration Constraints. The Space Shuttle bay confines the spacecraft to $18.3 \mathrm{~m}$ length and $4.5 \mathrm{~m}$ diameter. The $18.3-\mathrm{m}$ overal1 orbiter bay is further reduced by $7 \mathrm{~m}$ by the three-stage IUS.

- Radiation. The power plant must be able to operate in natural radiation fields. Induced radiation created by nuclear power systems must be reduced to the maximum acceptable radiation level under which spacecraft components can function. For present electronic components, it is $10^{13}$ nvt and $10^{7}$ rad over the mission life.

- Maneuverability. Maneuverability is mission dependent. No missions requiring special maneuverability have been studied. 
- Safety Features. The power subassembly must meet all regulations of NASA, DoD, the Department of Energy (DOE), and the National Range Commanders. The STS safety policy requires that the basic payload design assure the elimination or control of any hazard to the Orbiter, crew, or other payloads.

We made an overall assessment of the various power plant configurations that might meet the requirements. We considered

- heat-pipe, gas and liquid-cooled reactor designs;

- uranium carbide, uranium dioxide, and uranium nitride fuels;

- thermoelectric, thermionic, Brayton, potassium Rankine, and

Stirling converters; and

- heat-pipe, pumped fluid with fins, and pumped fluid with heat pipe radiators.

There were 135 design combinations considered, not including all the variations in design such as different temperature Brayton cycles and variations in thermoelectric materials. Our choices for further design and development are:

1. Heat-pipe reactor design, regardless of electric power converter. Its advantages are

- the inherent high reliability due to redundancy in the design;

- the elimination of single-failure points;

- the ability to accept material swelling, radiation damage and other environmental effects without loss of power;

- the elimination of a need for a pressure vessel or mechanical pumps;

- the minimization of development cost because of the modular nature of the configuration; and

- the reduced susceptibility to fuel erosion and corrosion deterioration.

2. Concentration on molybdenum for the reactor core heat-pipe development. Its advantages are

- fabrication experience exists;

- operation for many thousands of hours at temperatures of interest; and

- relatively light weight. 
3. Fuel development with emphasis on $\mathrm{UO}_{2}-20$ vol\% molybdenum material. Its advantages are

- minimize overall program cost at a reasonable near-term weight penalty;

- provides better compatibility than other fuel materials with the heat pipe

- more highly developed fabrication processes; and

- it can be processed in air.

4. Power conversion by thermoelectric modules. The advantages are

- meeting the mass goal established for the power plant;

- inherent redundancy in the design;

- capability due to the modularity to supply different power levels without redesign;

- relatively low development cost; and

- extensive experience from the radioisotope generators that gives a high degree of confidence in a successful development program.

5. Radiator configuration with a heat pipe design. Its advantages are

- light weight;

- high reliability;

- redundancy without single-failure points and;

- el imination of the need for pumps.

Concerning the overall power plant design, we reached the following conclusions:

Our choice of a reactor design temperature depends mainly on the converter element. To minimize power plant mass and size, a temperature of $1400 \mathrm{~K}$ is needed. However, to accommodate anticipated future improvements in converters, the ability to operate at several hundred degrees higher temperature should be developed.

We selected a standard reactor design for all power levels to save significantly on development cost and time. When we compared the standard to customized designs, we found a reduction to the power that can be provided to a single shuttle spacecraft. Peak power is reduced from 53 to 42 $\mathrm{kW}_{\mathrm{e}}$ with a $1-\mathrm{MW}_{\mathrm{t}}$ standard design, to $35 \mathrm{~kW}_{\mathrm{e}}$ with a $1.1-\mathrm{MW}_{\mathrm{t}}$ standard reactor, and to $23 \mathrm{~kW}_{\mathrm{e}}$ with a $1.5-\mathrm{MW}_{\mathrm{t}}$ standard reactor. Peak power for dual shuttle spacecraft exceeds $100 \mathrm{~kW}$. 
The best packaging means for the power plant configurations in the shuttle bay depends on the particular spacecraft. We found that the radiator dominates the arrangement as it can be packaged in conical, flat-plate, or multiple-panel arrangements. With $50-\mathrm{kW}_{\mathrm{e}}$ power plant configurations having conical-shaped radiators behind the radiation shield, the thermoelectric power plant would be about $6.4 \mathrm{~m}$, the thermionic $3.3 \mathrm{~m}$, Brayton, $10-\mathrm{m}$, potassium Rankine, $3.8 \mathrm{~m}$, and Stirling, $4.5 \mathrm{~m}$ long. The Brayton requires a foldable radiator for storage within the spacecraft and flexible lines between radiator segments.

Our analysis to identify part failures that would result in loss of power below design conditions indicates that a heat-pipe reactor with thermoelectric power conversion inherenty avoids single failure points. If Brayton converters are used with a heat-pipe reactor, dual converter loops can be used to eliminate single failure points. However, this would require the addition of accumulators or other means for regulation of pressure in the two loops between half and full power. The valves from the accumulators can be small and have slow reaction times. If we substitute a gas-cooled reactor for the heat-pipe reactor, we find that we can eliminate singlefailure points by adding dual Brayton converters. However, a matrix of 16 valves is needed for loop isolation with the valves in the inlet and outlet of the gas-cooled reactor. This will necessitate high-temperature and large-flow-area valves leading to additional complex development items. Turning to liquid-cooled power plant designs, we found that they require a significantly more complex design arrangement to eliminate some singlefailure points and, single-failure points from core corrosion with lithium cannot be eliminated. Again, a matrix of 16 high-temperature valves will be needed around the reactor for isolation of redundant flow loops.

The development risks are less for a $\mathrm{UO}_{2}$ than for a UC-fueled reactor even for $\mathrm{UO}_{2}$ operating at $100-\mathrm{K}$ higher temperature than $U \mathrm{C}$. We found that $\mathrm{UO}_{2}$ fuel is easier to manufacture, presents fewer swelling design problems, and chemically interacts less with the molybdenum heat pipes. Growth potential is greater with $\mathrm{UO}_{2}$-fueled reactors. However, development risk on thermoelectric material is greater with a $\mathrm{UO}_{2}$ - than a UC-fueled reactor design because higher converter efficiencies are needed to offset the higher weight of the reactor. 
We performed a cost benefit analysis based on a future demand of 20 power plants as a power source for satellites in geosynchronous orbits. Our estimates for some twenty units include nuclear power plant development costs of $\$ 150$ million and production and delivery cost of $\$ 280 \mathrm{M}$, for a total of $\$ 430 \mathrm{M}$. This is $\$ 830$ million less than the $\$ 1260$ million (excluding development cost) to provide the power with solar arrays with batteries, a savings of $\$ 830 \mathrm{M}$.

We found that combined cycles, even though more efficient, lead to heavier-weight power plants. This was based on an analysis of power plants with thermionic converters for topping and Brayton converters as the bottoming power conversion elements.

We determined that a heat-pipe reactor provides a means for emergency cool down in the design without large emergency cool down-fluid storage systems. This can be done by the addition of fins on the end of the reactor heat pipes with power to the fin section regulated by a gas reservoir.

\section{MISSION REQUIREMENTS}

The US pursued a vigorous program for use of reactors in space from the mid 1950s until the early 1970s. This included the U.S. nuclear powered rocket program, whose prime objective was to provide a propulsion unit for taking men to Mars and an array of space electric power systems for powering sensors and ion propulsion units. As U S mission emphasis changed, the various propulsion and space electric power systems being developed no Tonger were needed and by 1973 the development of reactors for space was largely discontinued.

Launch vehicle and payload size limitations have resulted in electric power requirements generally being a kilowatt or less except for Skylab, where $16 \mathrm{~kW}_{\mathrm{e}}$ was provided. Figure 1, a summary ${ }^{1}$ of some 200 NASA spacecraft, shows that less than $100 \mathrm{~kW}_{e}$ of power has been flown through 1975. This is in contrast with future projections, where we expect that a single spacecraft may require $100 \mathrm{~kW}_{\mathrm{e}}$.

The major factor warranting a fresh look at the need for higher power levels, and thus possibly considering nuclear reactors again for space, is the STS or Space Shuttle. The Space Shuttle provides a reusable system that can be considered a true transportation system. As such, it opens a new space era leading to larger satellites with increased power requirements. 


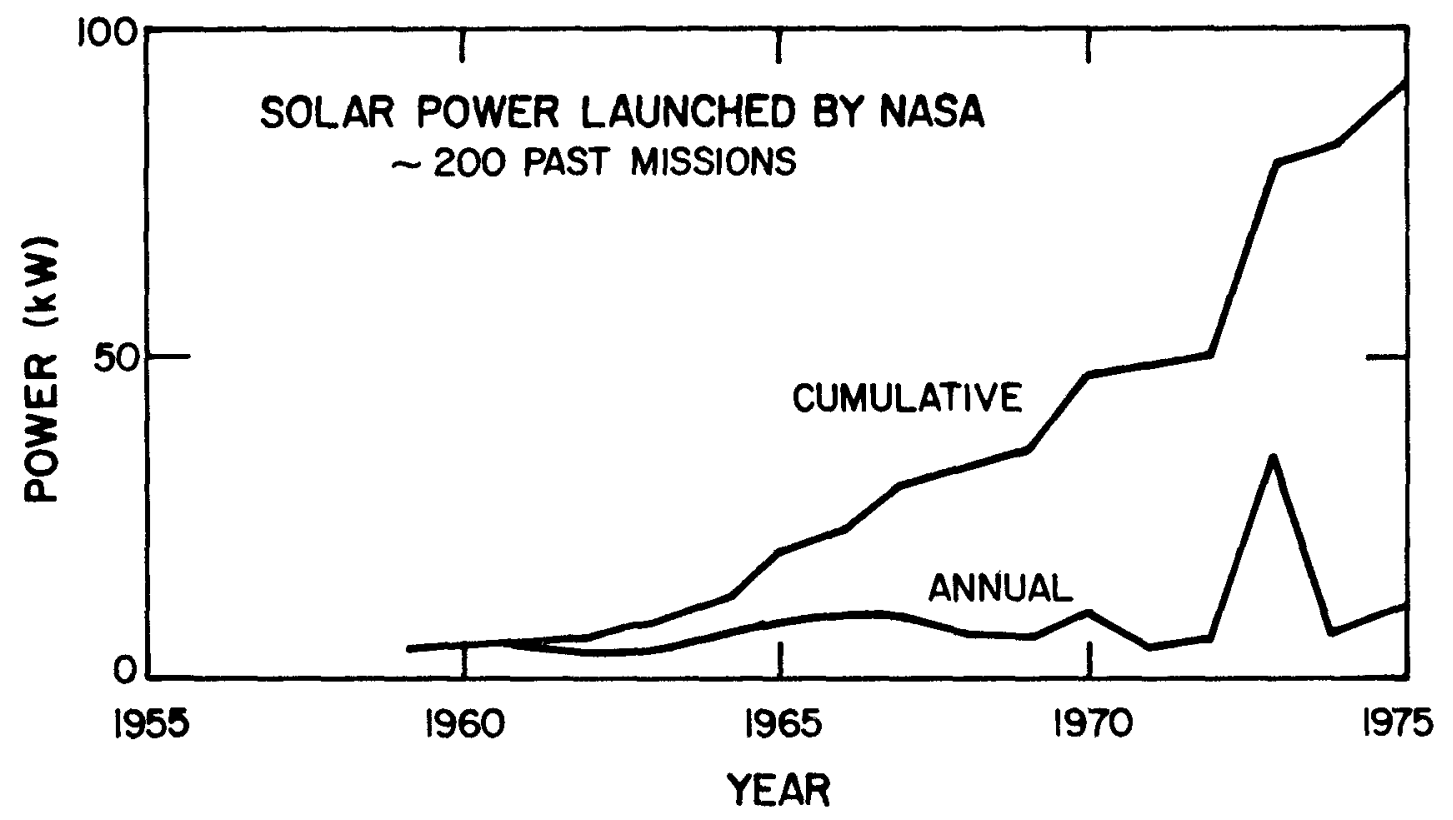

Fig. 1. Space power production experience.

A nuclear power $p$ lant should meet a range of potential mission requirements. Because of long development times, continually evolving definition of potential missions, uncertainties during payload integration, and uncertainties with schedules and budgets, it is not efficient to concentrate reactor power plant development on a single mission. Both DoD and NASA future missions are being analyzed as a basis for establishing power plant requirements.

A. Potential DoD Missions

DoD and Energy Research and Development Administration (ERDA) (now part of DOE) participated in a joint study of future space power requirements between February 1976 and May 1977. This DoD and ERDA Advance Space Power Working Group was established by Supplemental Agreement $I$ to the DoD and ERDA Space Nuclear Applications Steering Group, February 26, 1976. The objectives of the group were: (1) "to determine those future DoD Space power requirements both general and specific, which would best be fulfilled by nuclear power systems," and (2) "to recommend an appropriate technology development program for both nuclear and non-nuclear space power supplies."

To meet these objectives, a series of tasks were to be performed. These tasks were 
- future technical requirements,

- advanced space power technologies,

- matching of power systems to mission requirements,

- spacecraft point designs,

- recommended development program, and

- reporting.

The first two of these tasks have been completed and are reported in Ref. 2. In addition, some limited point design studies were reported which were specifically requested by the Steering Group.

The findings in SPWG 77-1 follow

"1. There are potential $0.5-100-\mathrm{kW}_{\mathrm{e}}$ DoD missions from 1980 to beyond 1995. Though it is uncertain that any particular mission will be performed, these potential higher-power missions will be much more difficult, if not technically infeasible, unless improvements are made in the power subsystems.

2. Although the space shuttle and expendables represent a significant improvement in launch capability, a limit still exists on spacecraft size and weight and, in turn, the power supplies.

3. Both solar and isotope power supplies can provide power in the 0.5-5-kW range. On an electrical power subsystem basis, solar power is lighter and cheaper than the isotope power supplies. However, power subsystem choice will depend on individual spacecraft requirements. Solar technology is now used. Isotope systems have successfully provided ten to many hundred watts in 18 spacecraft. Preliminary planning to flight test a kilowatt dynamic isotope system in 1981-1982 is underway.

4. Solar array plus battery systems and reactors can provide power in the $5-50-\mathrm{kW}_{\mathrm{e}}$ range, the ir selection being based on particular spacecraft mission requirements. Below $25 \mathrm{~kW}_{\mathrm{e}}$, solar arrays plus batteries are generally the choice. Solar arrays have been flight-demonstrated to 16 $\mathrm{kW}_{\mathrm{e}}$ and can be considered demonstrated to $25 \mathrm{~kW}_{\mathrm{e}}$. Above $25 \mathrm{~kW}_{\mathrm{e}}$, weight and volume limitations of the space shuttle and the interim upper stage (IUS) to synchronous orbit must be considered to determine power system selection. Above $50 \mathrm{~kW}_{\mathrm{e}}$, reactors appear to be the best DoD power option."

Recommendations concerning nuclear power in SPWG 77-1 follow

"A modest technology and experimental program to provide a solid basis from which to develop space reactors should be initiated. The present study has ident ified several conceptual $>50-k W_{e}$ DoD missions for which reactors 
could reasonably be the primary power subsystem candidate. To meet these potential DoD requirements, reactor development lead times must be reduced to match overall spacecraft development lead times. This can be done only if a suitable technological base is established. Such a program would give DOD the power options it will need at minimal national expense and in a timely manner."

The projected DoD missions include existing systems, future systems identified in the official DOD mission mode1, future systems that may be incorporated into the model, and systems in preliminary conceptual stages. The official DoD mission model covers a 15-yr period and includes only missions that incorporate flight-demonstrated technology. It is revised as DOD emphasis shifts and proposed systems and technologies become feasible at a reasonable cost. To predict possible future space power system requirements, the Air Force Space and Missile Systems Organization projected beyond the official model and considered the power needs of conceptual systems that may be incorporated into it later.

Several potential high-power missions for the 1990s have been suggested. Many of these that require electrical power in the 10- to 100$\mathrm{kW}_{\mathrm{e}}$ range are in communications and electro-optics and radar surveillance. Not all of these high-power missions will lead to operational systems, but some or similar missions may be incorporated into future mission models.

The plot of peak projected power requirements (Fig. 2) indicates that electric power requirements will grow from a few kilowatts at present to about $50 \mathrm{~kW}$ in the late 1980s and over $100 \mathrm{~kW}$ in the early 1990s.

To better evaluate the effect of different power sources, point design studies were performed. by Grumman and TRW on a power source for space-based radar (SBR) concepts. The radars are postulated for operation in geosynchronous orbit; so the shuttle weight restrictions apply.

Grumman studied a large planar array radar with electronics throughout the antenna face and an antenna feed assembly on a boom $270 \mathrm{~m}$ from the antenna (Figs. 3 and 4). Grumman chose to compare nuclear and solar power systems based on radar performance. They held the total spacecraft weight constant at $6800 \mathrm{~kg}$ and varied the planar array size according to the power system mass. Both the solar arrays and the nuclear power plant were placed 


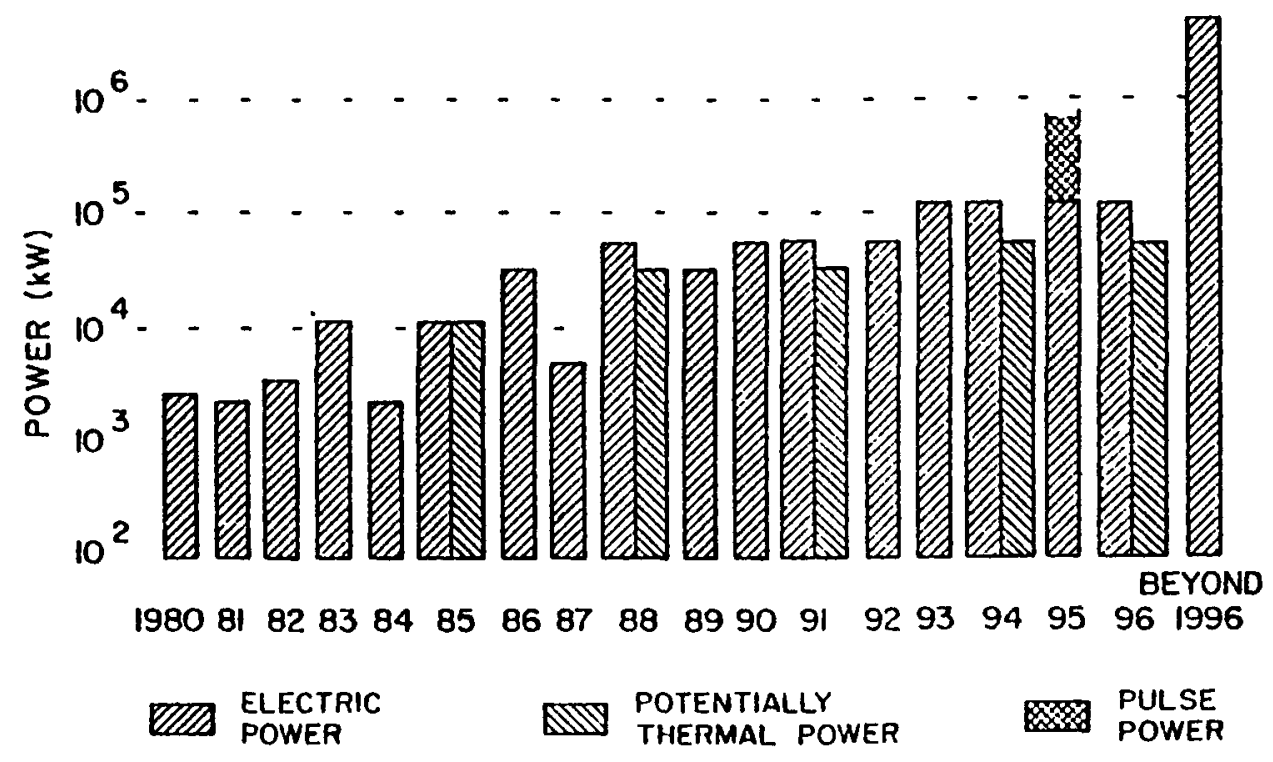

Fig. 2. Maximum single-spacecraft power requirements by year.

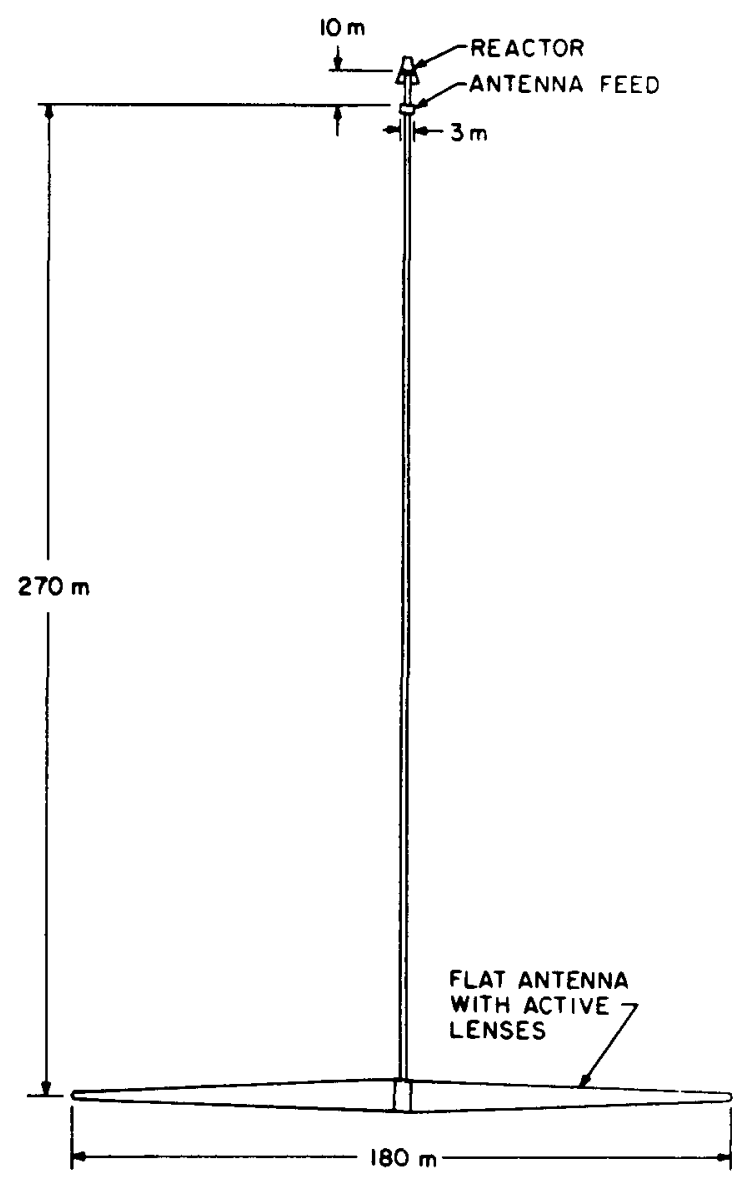

Fig. 3. Reactor-powered planar array space radar. 


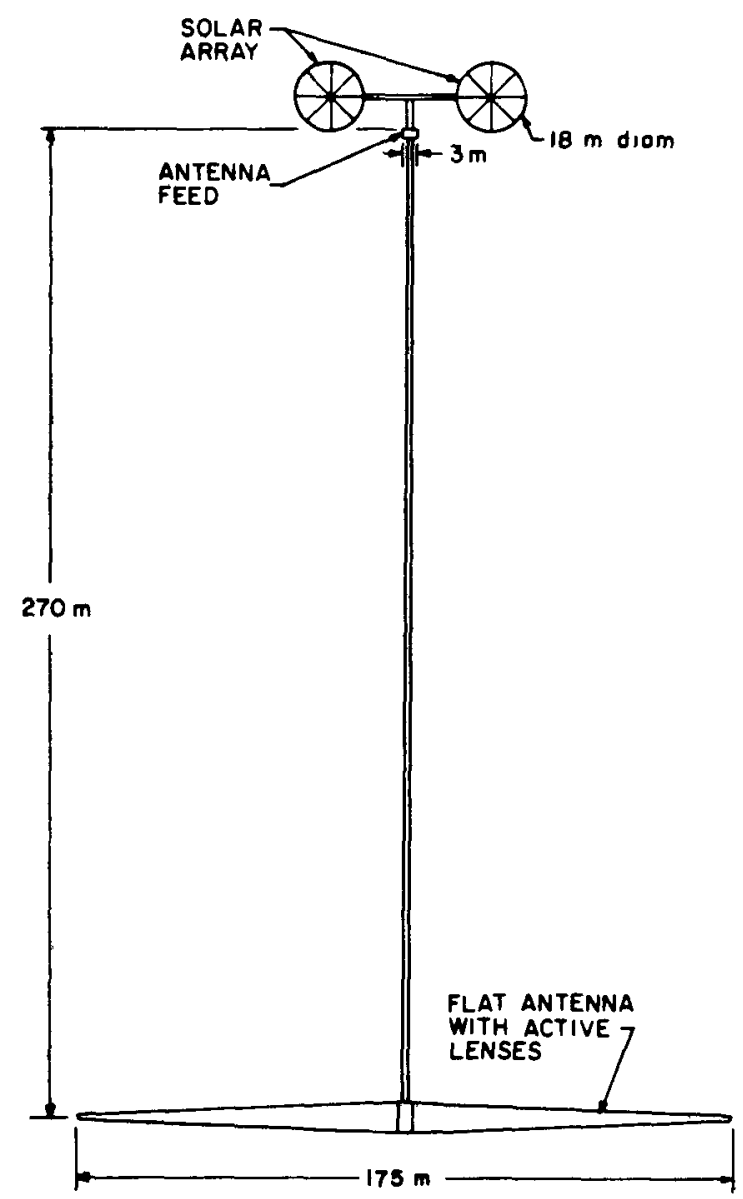

Fig. 4. Solar array plus battery-powered planar array space radar.

on mast extensions beyond the antenna feed systems. The nuclear reactor at this location, rather than in the antenna hub, saved approximately $975 \mathrm{~kg}$ of shielding but added $405 \mathrm{~kg}$ of power transmission cabling. We provided the nuclear system mass data.

The solar array plus battery masses approximately match those that the Air Force Aero Propulsion Laboratory (AFAPL) projected for 1995. Because the technology to be used on an early 1990 operational system must be flightqualified in the mid-1980s, the task study team also included AFAPL projected weights for 1985. If we used 1995 nuclear technology, the system masses would be lighter, (see Table I). The AFAPL projected 1985 solar system weights are nearly twice the nuclear system weight.

Table II shows the entire spacecraft mission performance characteristics. A nuclear system will provide significantly better mission performance than the 1985 solar system; that is, 444 vs 249 target traces (based 
on $1-m^{2}$ radar cross section with a 5-min revisit). This is attributed to the lower mass of the nuclear power system, which allows for a larger antenna.

TRW chose a 55-m-diam, mechanically driven, Cassegrainian parabolic antenna (Figs. 5 and 6) for its point design. All electronics are in small compartments on the antenna center line. The nuclear reactor is on a mast $10 \mathrm{~m}$ behind the electronics package. With this configuration, a relatively light weight shadow shield to protect the electronics and only a small amount of side shielding to prevent secondary backscatter off the main antenna was needed.

TABLE I

GRUMMAN $50-k W_{e}$ POWER SYSTEM MASSES FOR SBR

\begin{tabular}{|c|c|c|c|c|}
\hline \multicolumn{2}{|l|}{ Nuclear } & \multicolumn{3}{|c|}{ Solar } \\
\hline \multirow{2}{*}{ Component } & Mass & & & \\
\hline & $\begin{array}{l}1985 \\
(\mathrm{kq})\end{array}$ & Component & $\begin{array}{l}1985 \\
\text { (kq) }\end{array}$ & $\begin{array}{l}1995 \\
\text { (ka) }\end{array}$ \\
\hline $\begin{array}{l}\text { Reactor, radiator, Brayton } \\
\text { converter }\end{array}$ & 818 & $\begin{array}{l}\text { Solar array } \\
\text { structure }\end{array}$ & 333 & 314 \\
\hline $\begin{array}{l}\text { Shield ( } 10 \mathrm{~m} \text { above antenna } \\
\text { feed) }\end{array}$ & 23 & Structure & 224 & 165 \\
\hline Mast extension $(10 \mathrm{~m})$ & 14 & $\begin{array}{l}\text { Orientation } \\
\text { mechanism }\end{array}$ & 453 & 97 \\
\hline $\begin{array}{l}\text { Antenna feed power control } \\
\text { and distribution }\end{array}$ & 11 & Batteries & 972 & 576 \\
\hline Power transmission cables & 405 & Power controls & 227 & 70 \\
\hline $\begin{array}{l}\text { Antenna power control } \\
\text { and distribution }\end{array}$ & 36 & $\begin{array}{l}\text { Power } \\
\text { transmission }\end{array}$ & 405 & 405 \\
\hline $\begin{array}{l}\text { Central power system } \\
\text { processor }\end{array}$ & 5 & & & \\
\hline $\begin{array}{l}\text { Primary energy storage } \\
\text { (launch through in-orbit } \\
\text { power) }\end{array}$ & 11 & & & \\
\hline Total & 1323 & & 2614 & 1627 \\
\hline
\end{tabular}


TABLE II

GRUMMAN SBR CONCEPT

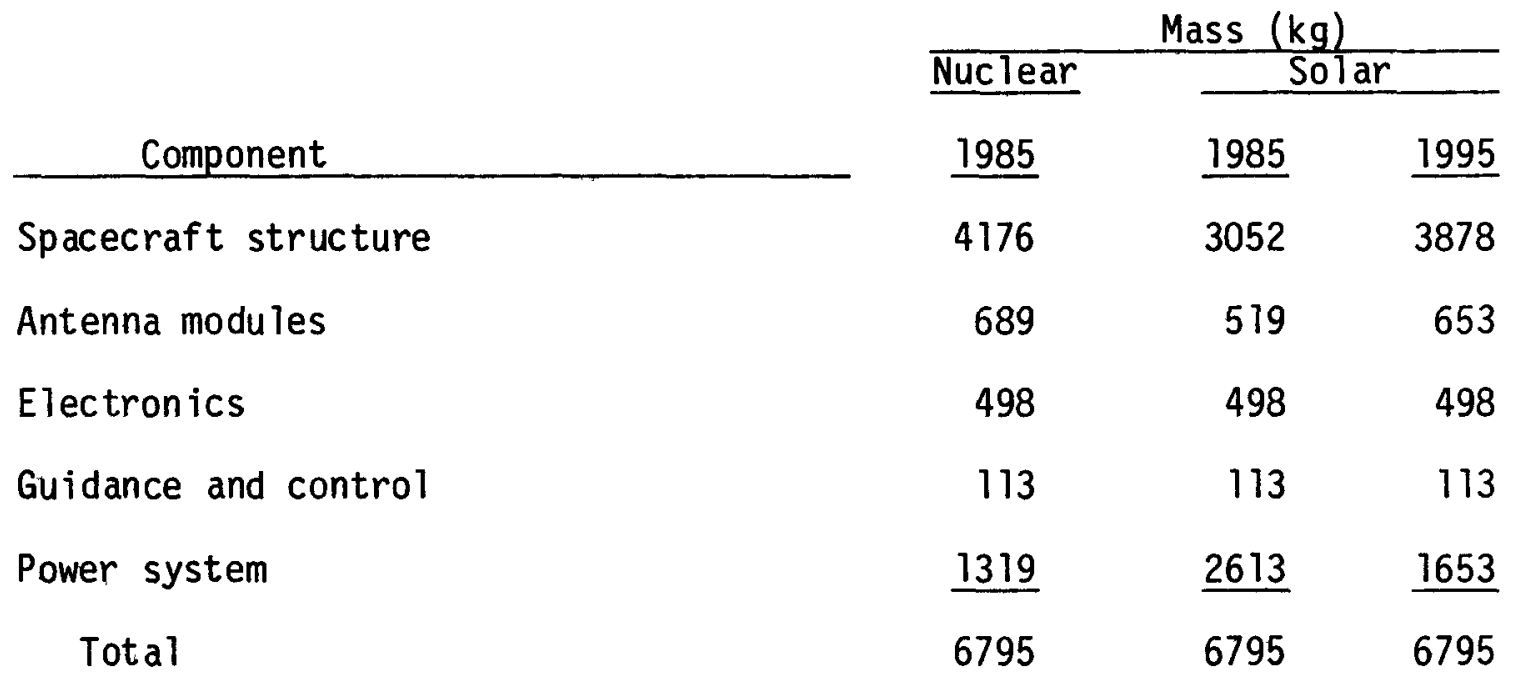

Performance

No. of antenna modules

50715

$\begin{array}{llll}38 & 167 \quad 48 \quad 000\end{array}$

Looks per second for detecting targets with $1-m^{2}$ radar cross section

1.48

0.83

1.32

Looks per second for $10-\mathrm{m}^{2}$ radar cross section (multiple beam)

14.8

8.3

13.2

No. of target traces for $1-\mathrm{m}^{2}$ radar cross section with 5 -min revisit

444

249

396

The Cassegrainian parabolic antenna presented location problems with solar arrays because of shadow effects. TRW resolved the problems by placing the arrays on extensions beyond the outer edge of the antenna.

AFAPL projected use of 1995-type Lis batteries with $132-\mathrm{W} \cdot \mathrm{h} / \mathrm{kg}$ energy density: In a previous part of the space-based radar study, TRW concluded that a realistic 1985 battery system would use $\mathrm{NiH}_{2}$ batteries with 27.4-W. $\mathrm{h} / \mathrm{kg}$ energy density, in agreement with AFAPL 1985 solar technology projections. Tables III and IV show the overall spacecraft satellite mass. The 1995 columns reflect AFAPL solar power system data; the 1985 column reflect the TRW projected technology. The total satellite mass exceeds the $6800-\mathrm{kg}$ dual shuttle launch 1 imit in either case with the solar power system, thus requiring an additional spacecraft to provide coverage during 


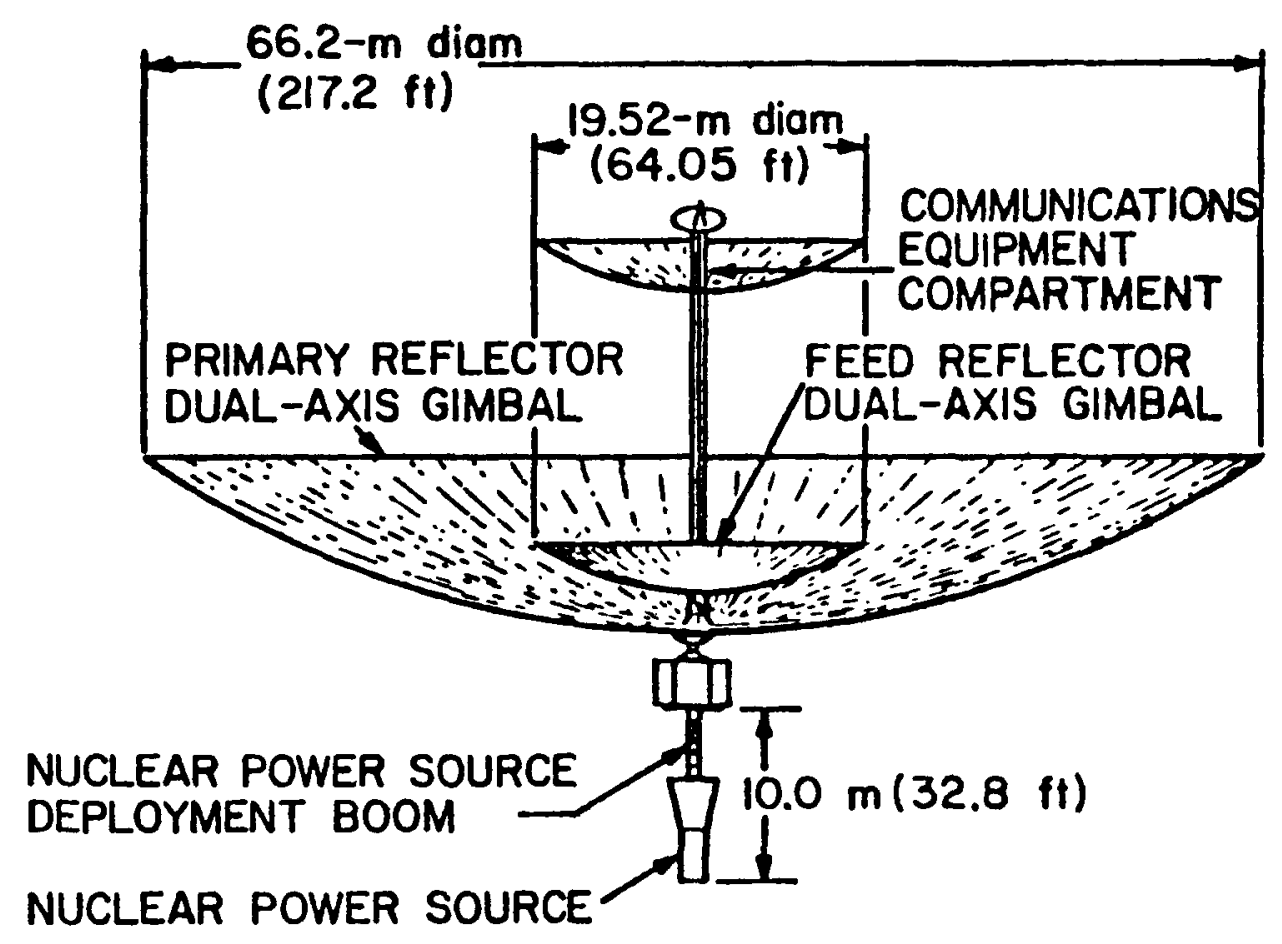

Fig. 5. Reactor-powered parabolic space radar.

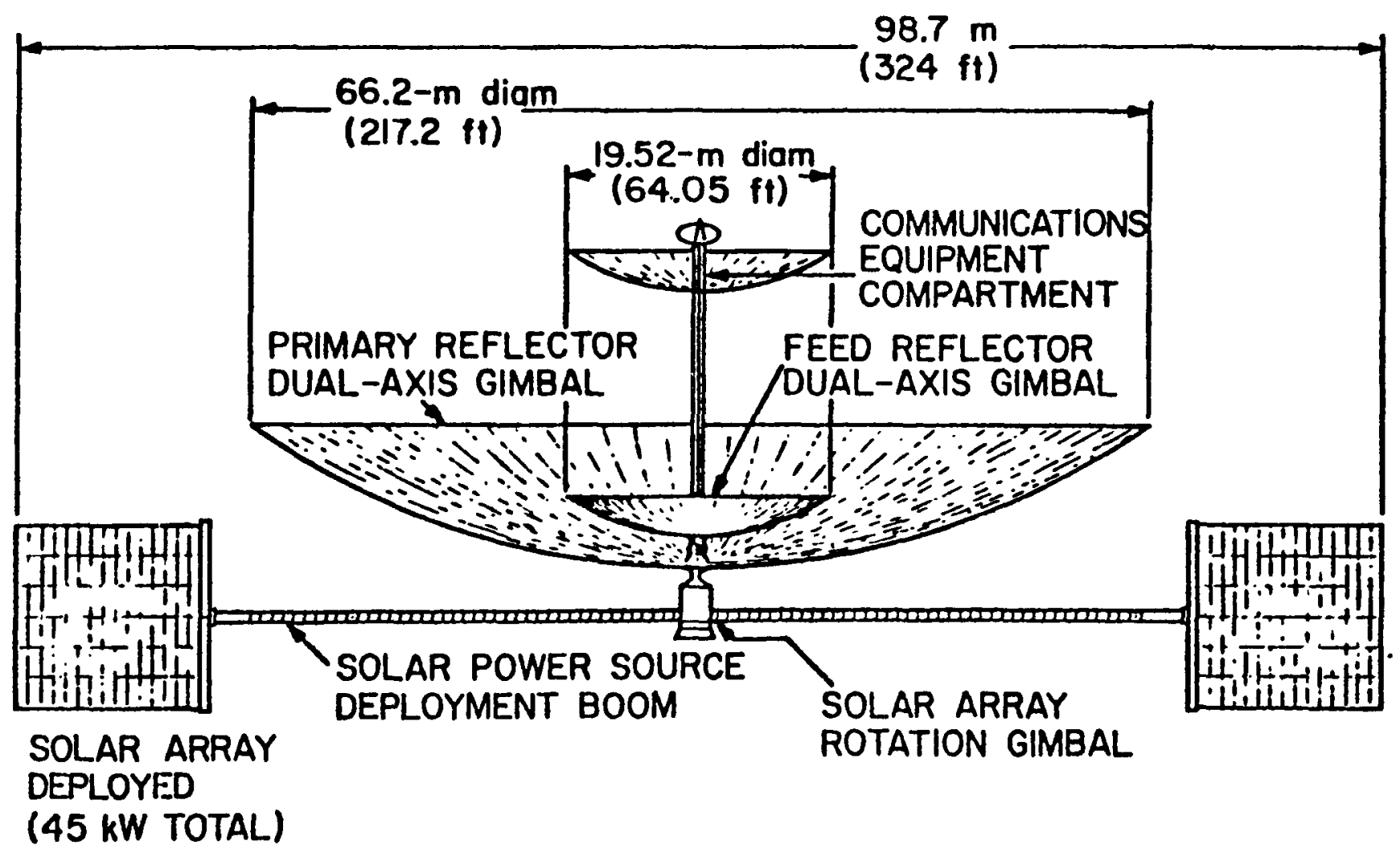

Fig. 6. Solar array plus battery-powered parabolic space radar. 
TABLE III

TRW $50-k W_{e}$ POWER SYSTEM MASSES FOR SBR

\begin{tabular}{|c|c|c|c|c|}
\hline \multicolumn{2}{|l|}{ Nuclear } & \multicolumn{3}{|c|}{ Solar } \\
\hline & & & leclip & \\
\hline Component & $\begin{array}{l}\text { Mass } \\
(\mathrm{kg})\end{array}$ & Component & $\begin{array}{l}\text { Mass } \\
(\mathrm{kg})\end{array}$ & $\begin{array}{l}\text { Mass } \\
(\mathrm{kg})\end{array}$ \\
\hline $\begin{array}{l}\text { Reactor, radiator, Brayton } \\
\text {.converter }\end{array}$ & 815 & Solar array & 685 & 727 \\
\hline $\begin{array}{l}\text { Shield ( } 10 \mathrm{~m} \text { from } \\
\text { electronics }\end{array}$ & 227 & $\begin{array}{l}\text { Power control and } \\
\text { distribution }\end{array}$ & 221 & 221 \\
\hline Harness assembly and & 299 & Harness assembly & 254 & 254 \\
\hline distribution unit & & $\begin{array}{l}\text { Orientation } \\
\text { system }\end{array}$ & 54 & 54 \\
\hline & & Batteries & 12 & 478 \\
\hline Total & 1341 & Total & 1226 & 1734 \\
\hline
\end{tabular}

TABLE IV

TRW CONCEPT SBR SATELLITE MASS

\begin{tabular}{|c|c|c|c|}
\hline \multirow[b]{2}{*}{ Component } & \multicolumn{3}{|c|}{ Mass $(\mathrm{kg})$} \\
\hline & 1985 & 1985 & 1995 \\
\hline Power System & 1341 & $2741^{\mathrm{a}}$ & $1734^{a}$ \\
\hline Attitude control system & 954 & 966 & 966 \\
\hline Structure & 976 & 1035 & 1035 \\
\hline $\begin{array}{l}\text { Antenna, radar electronics and } \\
\text { communications }\end{array}$ & $\underline{3238}$ & $\underline{3238}$ & $\underline{3238}$ \\
\hline Total & 6509 & 7980 & 6973 \\
\hline
\end{tabular}

ancludes batteries to perform eclipse mission (1985: $\mathrm{Ni}-\mathrm{H}_{2} 37.4 \mathrm{~W} \cdot \mathrm{h} / \mathrm{kg}$; 1995: Lis $132 \mathrm{~W}-\mathrm{h} / \mathrm{kg}$ ).

eclipse. However, the 1995 solar system is close enough to the limit that it enough mass may be reduced from other components to stay within the limit.

TRW also compared the costs of the nuclear and solar-powered systems using a computerized cost model specially tailored to military spacecraft operations (see Table V). The nuclear power source based on our cost estimates was priced at $\$ 4.5 \mathrm{million}$ per copy. The solar cells were priced 
TABLE V

TRW COMPARATIVE SBR COSTS (\$M)

\begin{tabular}{|c|c|c|c|}
\hline & Solara & Nuclearb & Difference \\
\hline Space vehicle costs ( $\$$ million) & 370 & 263 & 107 \\
\hline System level costs ( $\$$ million) & $\underline{56}$ & $\underline{42}$ & 14 \\
\hline Total system ( $\$$ million) & 426 & 305 & 121 \\
\hline $\begin{array}{l}\text { Space Shuttle costs ( } \$ \text { million) } \\
14.4 \text { /shuttle }+5 \text { /IUS } \\
\text { two shuttles/spacecraft }\end{array}$ & 155 & 116 & 39 \\
\hline Total-in-orbit & 581 & 421 & $\overline{160}$ \\
\hline
\end{tabular}

a Four operational spacecraft and one spare.

b Three operational spacecraft and one spare.

at $\$ 22.50$ per cell with a $90 \%$ Wright learning curve applied. Space vehicle costs include system engineering, system effectiveness, test and evaluation, project management, data, and launch operations. The nuclear-powered system is significantly less expensive ( $\$ 160$ million) when one considers the solar-powered system's need for an extra spacecraft. Even if the solar-powered mission could be performed with the same number of spacecraft, the nuclear system would still cost approximately $\$ 50$ million less.

As an adjunct to the TRW and Grumman point design studies, Aerospace Corp. made some informal studies of nuclear vs solar power for a conceptualized phased-array space radar. These studies involved trading off aperture and power by using power times aperture and power times aperture squared to evaluate search and track performance, respectively, while holding satellite weight at $6800 \mathrm{~kg}$. Aerospace Corp. concluded that when power was optimized for a constant-weight spacecraft, the nuclear-powered system provided better overall performance and that optimum prime power levels for such a radar system could be up to $250 \mathrm{~kW}_{\mathrm{e}}$.

In conclusion, the space-based radar studies by TRW and Grumman indicate that the nuclear power system is superior to the solar system at the $50-k W_{e}$ power level. This superiority is seen in all the points studies, including mission performance, weight, and cost effectiveness. The 
Aerospace study corroborates these findings for performance. These point designs confirm the parametric data comparisons.

B. Potential NASA Missions

With the reusable Space Shuttle becoming a reality, a new era of space exploration and exploitation is expected. Past spacecraft were restricted in size and weight by the high launch costs of disposable rockets. Nuclear reactors become more attractive as the mission requirements become more demanding by requiring large quantities of electric power in geosynchronous orbit, large payloads to Mars, or exploration of the outer planets. Therefore, a survey was undertaken to identify potential missions between 1985 to the turn of the century that now are feasible with the advent of the Space Shutt le.

Main requirements for electric power are summarized in Table VI. of major interest is the $5-$ to $200-\mathrm{kW}_{\mathrm{e}}$ range because it over laps with potential DoD missions.

\section{TABLE VI}

\section{ELECTRICAL REQUIREMENTS}

\begin{tabular}{|c|c|c|c|c|c|}
\hline Applications & Earth-Orfented & Earth-Orlented & Electrical Propulsion & $\begin{array}{l}\text { Central Power for } \\
\text { Satellites }\end{array}$ & $\begin{array}{l}\text { Power Sate } 11 \text { 1tes } \\
\left(10,000 \mathrm{MW}_{\mathrm{e}}\right)\end{array}$ \\
\hline Range & & $5-200 \mathrm{~kW}_{\mathrm{e}}$ & $200-500 \mathrm{kH}_{\mathrm{e}}$ & $0.5-10 \mathrm{MH}_{\mathrm{e}}$ & Greater than $10 \mathrm{MW}_{\mathrm{e}}$ \\
\hline & $\begin{array}{l}\text { - Personal } \\
\text { navigation } \\
\text { - Diplomattc } \\
\text { "hot-line" } \\
\text { - Meteorological } \\
\text { satellite } \\
\text { - Burgler alarm } \\
\text { - Forest fire } \\
\text { detection } \\
\text { Probes: } \\
\text { - Fly-by } \\
\text { - Orbiters } \\
\text { - Landers } \\
\text { - Rover } \\
\text { - Sample and } \\
\text { return }\end{array}$ & $\begin{array}{l}\text { Wrist } \\
\text { communications } \\
\text { - Police wrist } \\
\text { radio } \\
\text { - Disaster } \\
\text { communications } \\
\text { - Holographic Conf. } \\
\text { - National TV } \\
\text { - Voting wrist } \\
\text { set } \\
\text { Energy monttor } \\
\text { - Border } \\
\text { survellilance } \\
\text { - Natlonal info. } \\
\text { system } \\
\text { - Electrical mall } \\
\text { - Vehicle/package } \\
\text { locator } \\
\text { Near earth: } \\
\text { - Space constructi } \\
\text { base }\end{array}$ & $\begin{array}{l}\text { - Outer planets } \\
\text { exploration } \\
\text { (single shuttle) } \\
\text { - Leo-geo tug } \\
\text { - Remote sensors } \\
\text { - Laser power } \\
\text { supply }\end{array}$ & $\begin{array}{l}\text { - Electrical } \\
\text { propulsion } \\
\text { - Outer planets } \\
\text { - Exploration } \\
\text { (multi-shuttle) } \\
\text { - Leo-geo tug }\end{array}$ & $\begin{array}{l}\text { - Electrical } \\
\text { propulsion } \\
\text { - Space ships }\end{array}$ \\
\hline $\begin{array}{l}\text { Muclear } \\
\text { Technology }\end{array}$ & Radioisotopes & SPAR power plant & NEP pawẹr plant & $\begin{array}{l}\text { Heat plpe/ } \\
\text { Thermionics } \\
\text { (No activity) }\end{array}$ & $\begin{array}{l}\text { Gas-core reactors } \\
\text { with MHD converters } \\
\text { (No activity) }\end{array}$ \\
\hline
\end{tabular}


1. Earth-Orbit Applications. NASA's potential missions for nuclear reactors center on large satellites in geosynchronous Earth orbits and planetary exploration. I. Bekey, H. I. Mayer, and M. G. Wolf ${ }^{3}$ did a comprehensive study categorizing various potential space applications as to function, weight, size, power, orbit, time frame, initial operational cost, and risk. The Space Shuttle ${ }^{4}$ can place up to $29000 \mathrm{~kg}$ in low Earth-orbit, but in geosynchronous orbit, the payload drops to $3180 \mathrm{~kg}$. If the traditional $30 \%$ of the payload is devoted to the power supply, the low Earth-orbit requirements can usually be handled with solar arrays plus batteries. However, the weight restrictions at geosynchronous orbit call for compact, lowweight power supplies, and thus this orbit is a potential application for nuclear power sources.

Various potential missions in geosynchronous orbit requiring $15-220 \mathrm{~kW}_{\mathrm{e}}$ are plotted in Fig. 7. Brief descriptions of the missions follow.

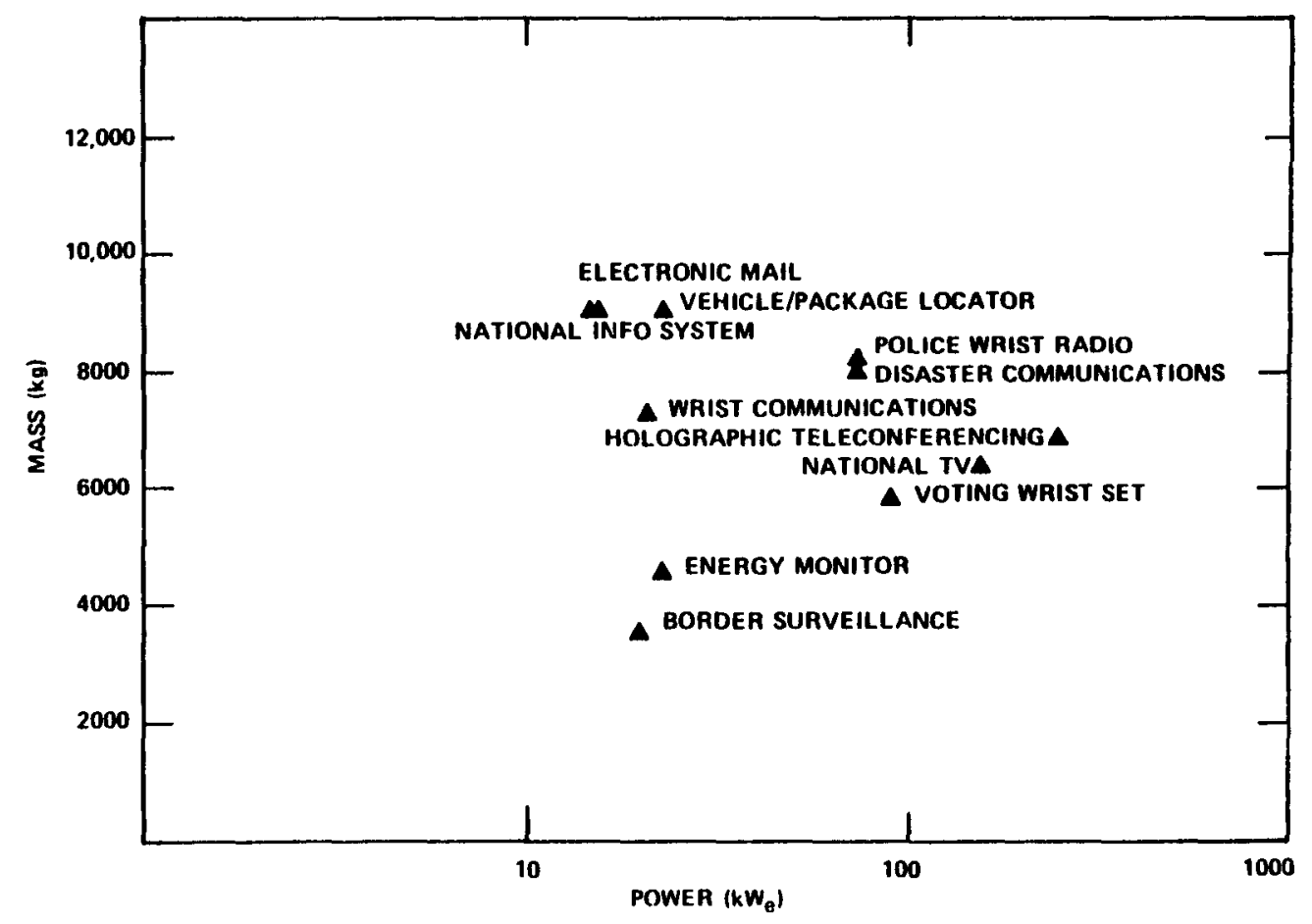

Fig. 7. Potential NASA applications in geosynchronous orbit. ${ }^{4}$ 
a. Border Surveillance. This uses small, sensitive, seismic sensors planted along the border and monitored from space to detect illegal aliens, drug traffickers, and others who are attempting overt or covert crossings of the border. Power level would be $20 \mathrm{~kW}_{\mathrm{e}}$.

b. Police Wrist Radio Communications. This provides real-time, secure, anti-jam, high-coverage, wide-area personal communications for policemen. A large-diameter antenna on the order of $60 \mathrm{~m}$ leads to very light transceivers. Power would be on the order of $75 \mathrm{~kW}_{\mathrm{e}}$.

c. Disaster Communications. This provides command and control to disaster area emergency personnel. About $75 \mathrm{~kW}_{\mathrm{e}}$ of power would be required.

d. Electronic mail. This transmits facsimiles of letters at reduced cost. A satellite would act as a multi-channel repeater for page readers and facsimile equipment at various post offices. Power would be $15 \mathrm{~kW}_{\mathrm{e}}$.

e. Advanced Television Antenna System. This would provide improved television coverage especially to mountainous, rural, and remote areas. The $17-m$ antenna in space would use $150 \mathrm{~kW}_{\mathrm{e}}$ of power.

f. Yoting or Polling Wrist Set. This provides convenient, rapid determination of the electorate's stand on candidates and issues. The 46-m antenna would use $90 \mathrm{~kW}_{\mathrm{e}}$ of power.

g. National Information Services. This provides small users rapid access to information. A $60-\mathrm{m}$ antenna would use $15 \mathrm{~kW}$.

h. Personal Communications Wrist Radio. These mobile telephones worn on the wrist serve 2.5 million people. A $60-\mathrm{m}$ antenna in orbit would use $21 \mathrm{~kW}_{\mathrm{e}}$.

i. Three-Dimensional Holographic Teleconferencing. This reduces the need for travel and thus saves appreciable time and money. Laser illuminators and stereo sound gives the impression that all participants are present and active at the meeting. A $17-\mathrm{m}$ antenna with $220 \mathrm{~kW}_{\mathrm{e}}$ of power would serve 1250 identical conference rooms in 100 urban centers.

j. Vehicle and Package Locators. These could be used to monitor shipments throughout the USA continuously and thus minimize thefts, hijackings, and lost shipments. A transceiver would be attached to each shipment with a $3200-m$ antenna in space and $23 \mathrm{~kW}_{e}$ of power for the system.

k. Energy Monitor. This fine-tunes energy distribution by monitoring current, voltage, or power readings on the network. A 45-m antenna would use $23 \mathrm{kWe}$. 
Considering low Earth-orbit application, Grumman and McDonnell Douglas have completed studies on space construction base concepts. ${ }^{5,6}$ The space construction base could service a variety of applications (Fig. 8), such as

1. Construction facility. To construct solar or nuclear central power satellites to provide electricity that is microwaved back to earth, a facility is needed in space for manufacturing and assemblying large structures.

m. Space Manufacturing. Higher performance materials such as magnets, ultrapure glass, and silicon are possible products. The long-term, reduced-gravity environment on a space platform would minimize or eliminate gravity-induced phenomena (for example convection). Also, containerless processes, such as levitated melting and heat treatment, can eliminate contamination introduced by crucibles on earth. Permanent magnet motors using materials manufactured in space would be $10-15 \%$ more efficient, and automobiles could save 10-15 millions of gallons of gas per year. Certain biological and pharmaceutical processes are also enhanced in space such as with the enzyme urokinase. Urokinase can be used to prevent 15000 deaths a

\section{MISSION CATEGORIES}

- solar power satellite DEVELOPMENT

- INCAEMENTAL STEPS
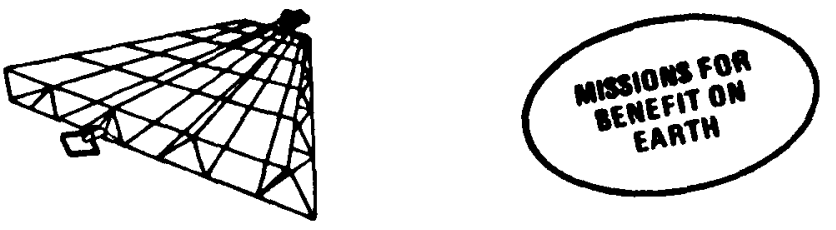

- space manufacturing - hIGHER PERFormance materials

- EXTENDED APPLICATIONS

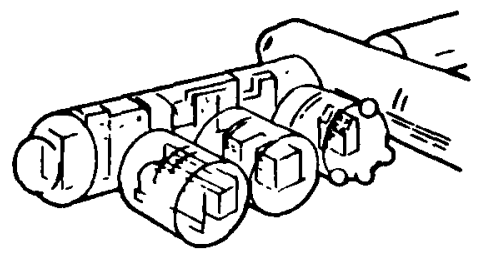

\section{- puglic service platform - gROUPING MULTIPLE FUNCTIONS FOR ECONOMY \\ - LARGE ANTENNAS}

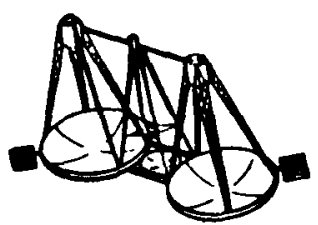

- BenEFICIAL SCIENTIFIC MISSIONS - SOLAR-TERRESTRIAL OBSERVATIONS

- LIFE SCIENCES

- OTHERS

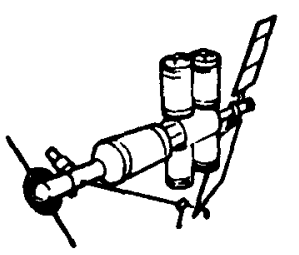

Fig. 8. Space construction base. 
year in the treatment of pulmonary embolisms and thromboembolitic diseases. Tissue culturing in space could fulfill needs to treat anemia, burns, diabetes mellitus, emphysema, malignant neoplasms, and viral infections.

n. Public Service Platform. Large antennas could be constructed with close tolerances for use in communications and navigation.

Personal navigation antennas of $3750 \mathrm{~m}$ by $3750 \mathrm{~m}$, small-craft radar navigation with two linear arrays $3000 \mathrm{~m}$ long, and a border surveillance linear array $3000 \mathrm{~m}$ long could be constructed in space.

o. Scientific Missions. Investigations of the galactic processes, the nature of quasars, the nature of stellar explosions, the composition and dynamics of interstellar matter, the search for other planets and solar systems, and the search for extraterrestrial life requires access to the full electromagnetic spectrum. While certain regions of the spectrum are accessible to earth-based systems, space platforms offer observational advantages in the X-ray, ultraviolet, parts of the infrared, and in the low radio frequency portions of the spectrum. By using an antenna system in space such advantages as eliminating the water absorption bands in the atmosphere can be achieved.

The space construction base has a power requirement of $100-150 \mathrm{~kW}_{\mathrm{e}}$. Figure 9 shows a diagram of various candidate power systems. These include silicon and GaAlAs photovoltaic systems, solar-thermal systems with Brayton or thermionic electric power converters and nuclear reactors with either Brayton, thermionic, or thermoelectric converters.

New technology is not needed for a space construction base. However, if nuclear power plants are developed for other purposes, they could be applied in the space construction base with advantages, including (1) ease of station keeping and less use of propellant, (2) less restriction in docking \pm $6^{\circ}$ with $4 \pi$ radiation attenuation shields vs $\pm 60^{\circ}$ with photovoltaics), and (3) an easier performace of sun-oriented.

Nuclear power is the most expensive option if research and development costs are included, but is the least expensive if these costs are excluded because of being covered in another program.

2. Planetary Exploration. Investigations of the solar system are being performed at greater distances from the earth and in ever increasing detail. The missions begin with reconnaissance probes of bodies in the universe, proceed to the exploration of these bodies with orbiting sensors and 

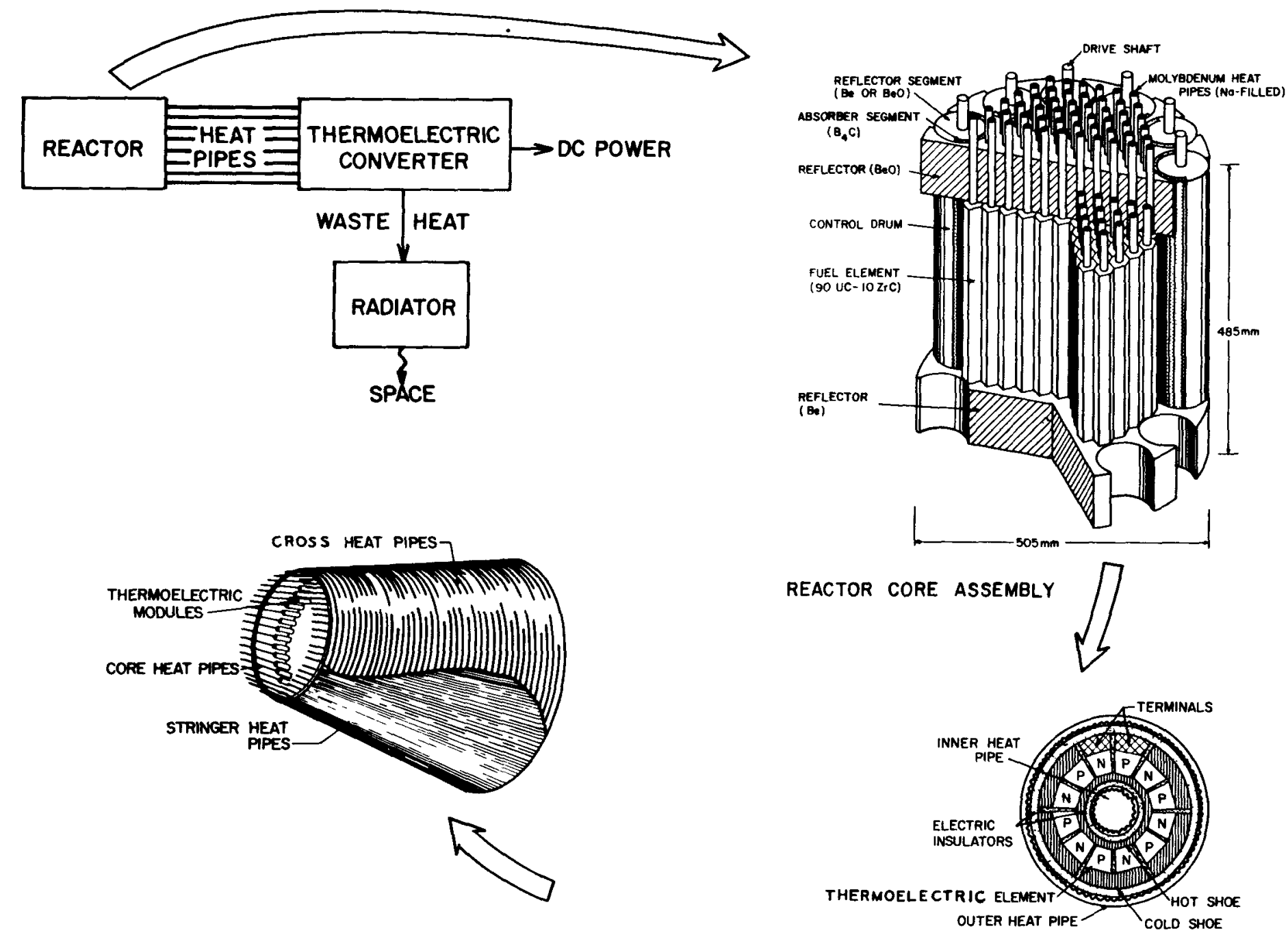

Fig. 9. Candidate power systems for Earth-orbit space stations. 
landers followed by intensive studies using rovers and surface-sample and return techniques, and may finally lead to establishing semipermanent or permanent bases.

Chemical, solar electric propulsion with ion thrusters (SEP) and nuclear electric propulsion with ion thrusters (NEP) can be considered candidates for planetary missions limited to a single shuttle and duration of less than $10 \mathrm{yr}^{7}$ Figure 10 depicts expected growth for planetary missions with the capability expected from various propulsion systems. Chemical power has been the major propulsion source to date, but the limits of its capability will be reached in missions during the 1980s. SEP will extend the ability to perform planetary missions and meet requirements for the late 1980s and early 1990s, but its 1 imit will be reached in the reconnaissance mission to Uranus and exploration mission to Saturn. NEP extends the capability to investigate the outer planets and to perform solar escape missions. The nuclear electric propulsion power supply envisioned in Fig. 10 uses a $400-\mathrm{kW}_{\mathrm{e}}$ power plant.

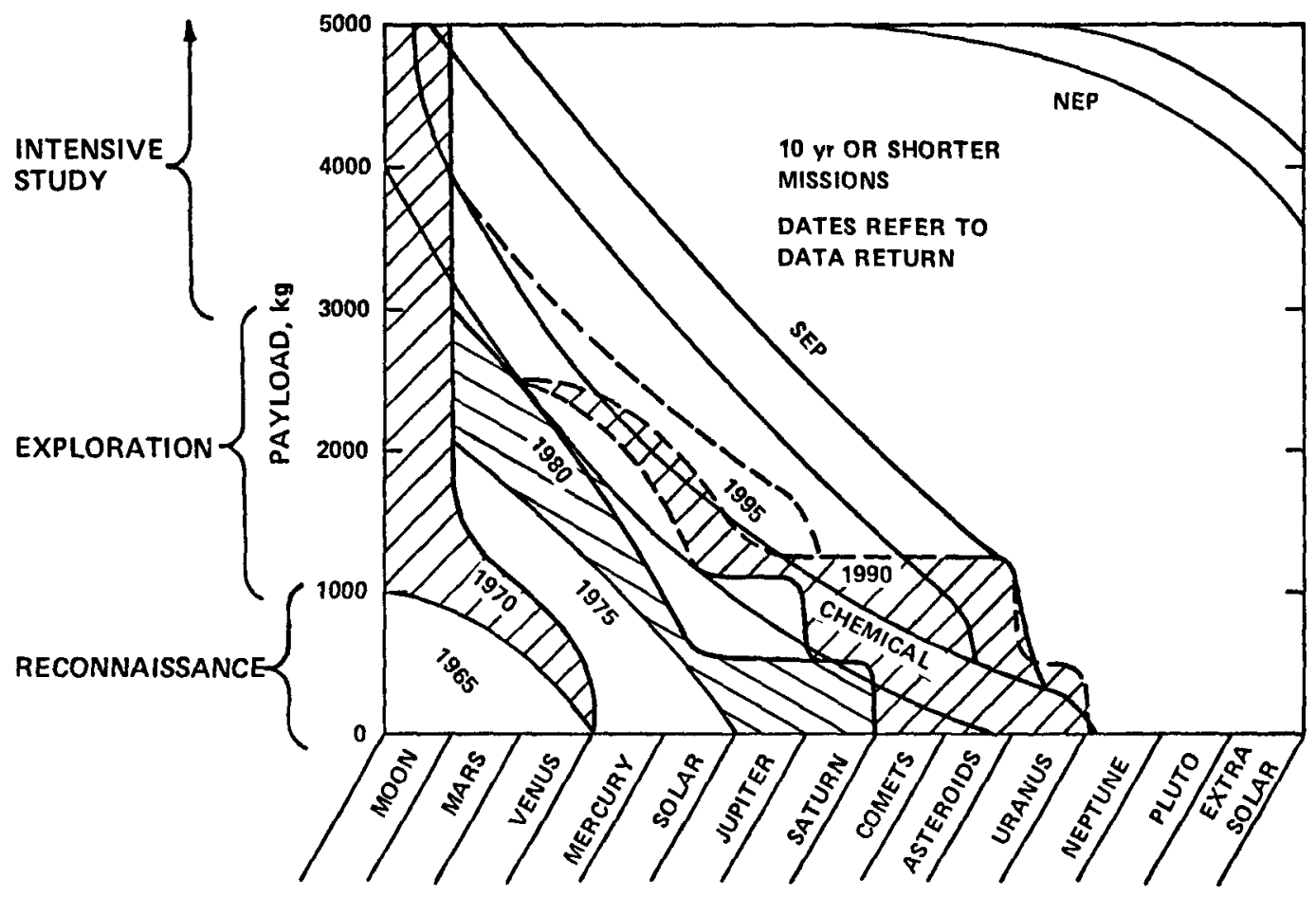

Fig. 10. NASA lunar and planetary program trends and propulsion system capabilities. 7 
Figure 11 cumpares payloads in planetary orbit for SEP and NEP. NEP delivers a much larger payload, especially as the distance from the sun increases.

\section{Why Reactors Become a Prime Power Source}

The DOD/ERDA review (Ref. 2) of projected 1985 power technologies (the technologies that would be used in 1990 missions) showed that solar arrays with batteries are expected to be heavier than reactors above $10-20 \mathrm{~kW}$ (Table VII). At $50 \mathrm{~kW}_{e}$, the nuclear system mass is about $60 \%$ of the solar system mass, and at $100 \mathrm{~kW}_{e}$, it is $40 \%$.

Reactors are less costly. Table VII shows a cost comparison including a factor for launch mass differences. At $10 \mathrm{~kW}_{e}$, the cost of delivery to geosynchronous orbit is almost equal, but at $50 \mathrm{~kW}_{\mathrm{e}}$, the reactor cost is one-third of the solar cost and at $100 \mathrm{~kW}_{e}$, it is one-fifth.

The Space Shuttle is expected to be the main launch vehicle. The practical limits of most missions in about 1990 are two shuttle trips per spacecraft, and $1910 \mathrm{~kg}$ would probably be the most that can be devoted to the

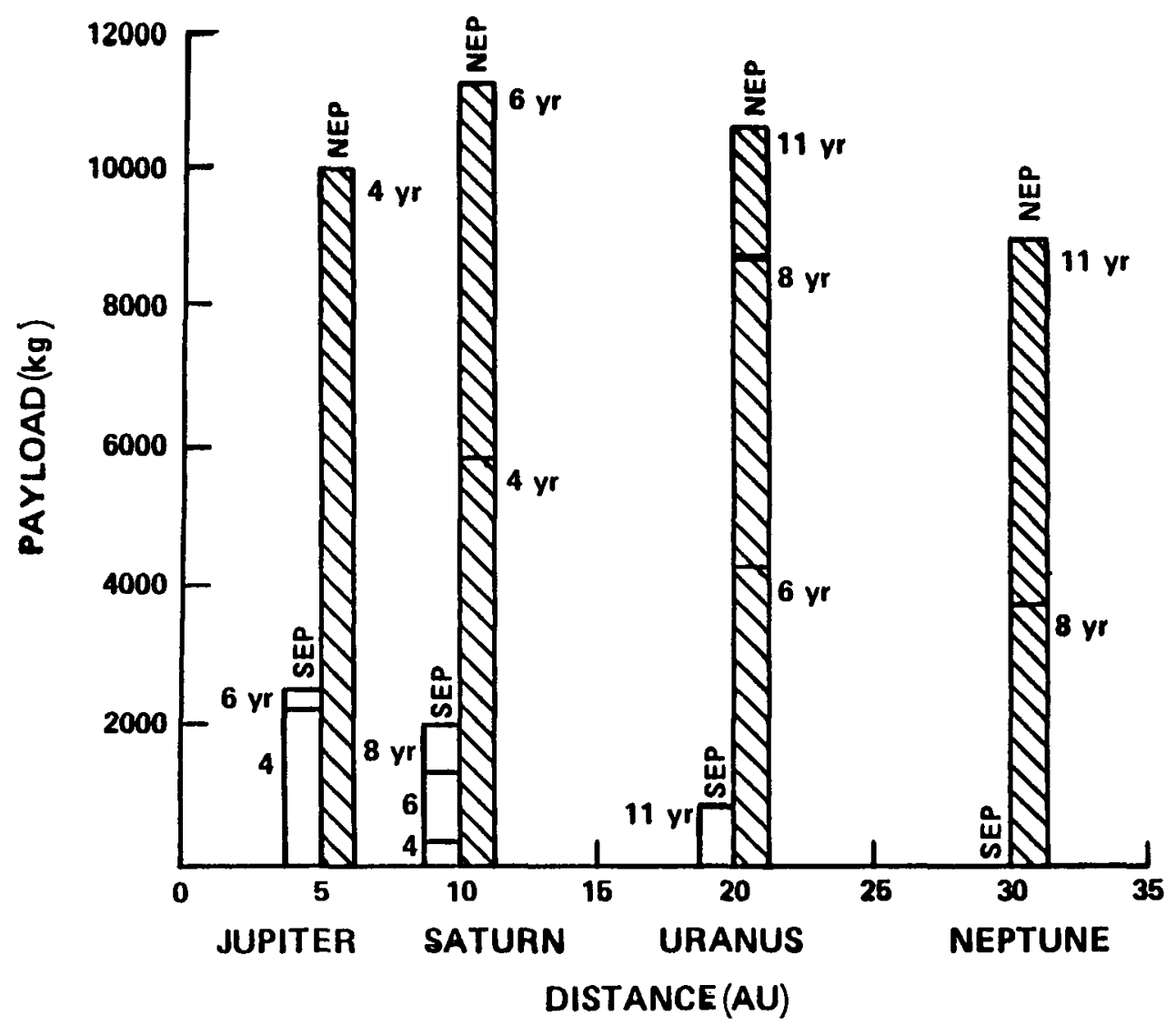

Fig. 11. Payloads in planetary orbit. 
power supply for geosynchronous orbit mission. Solar arrays would have difficulty in providing $50-\mathrm{kW}_{\mathrm{e}}$ power and probably would not be able to provide $100 \mathrm{~kW}_{\mathrm{e}}$. Reactor systems can span the whole range; a $100-\mathrm{kW}_{\mathrm{e}}$ system would weigh between 1600-1900 kg.

Solar arrays have been flight-demonstrated in a $16-\mathrm{kW}_{\mathrm{e}}$ system but, it is doubtful that $50-\mathrm{kW}_{\mathrm{e}}$ power systems can be demonstrated by the mid 1980s. The SNAP 10A is the only flight-demonstrated reactor, and it $r$ an at

TABLE VII

SOLAR ARRAY VS REACTORS, BASED ON PROJECTED TECHNOLOGY

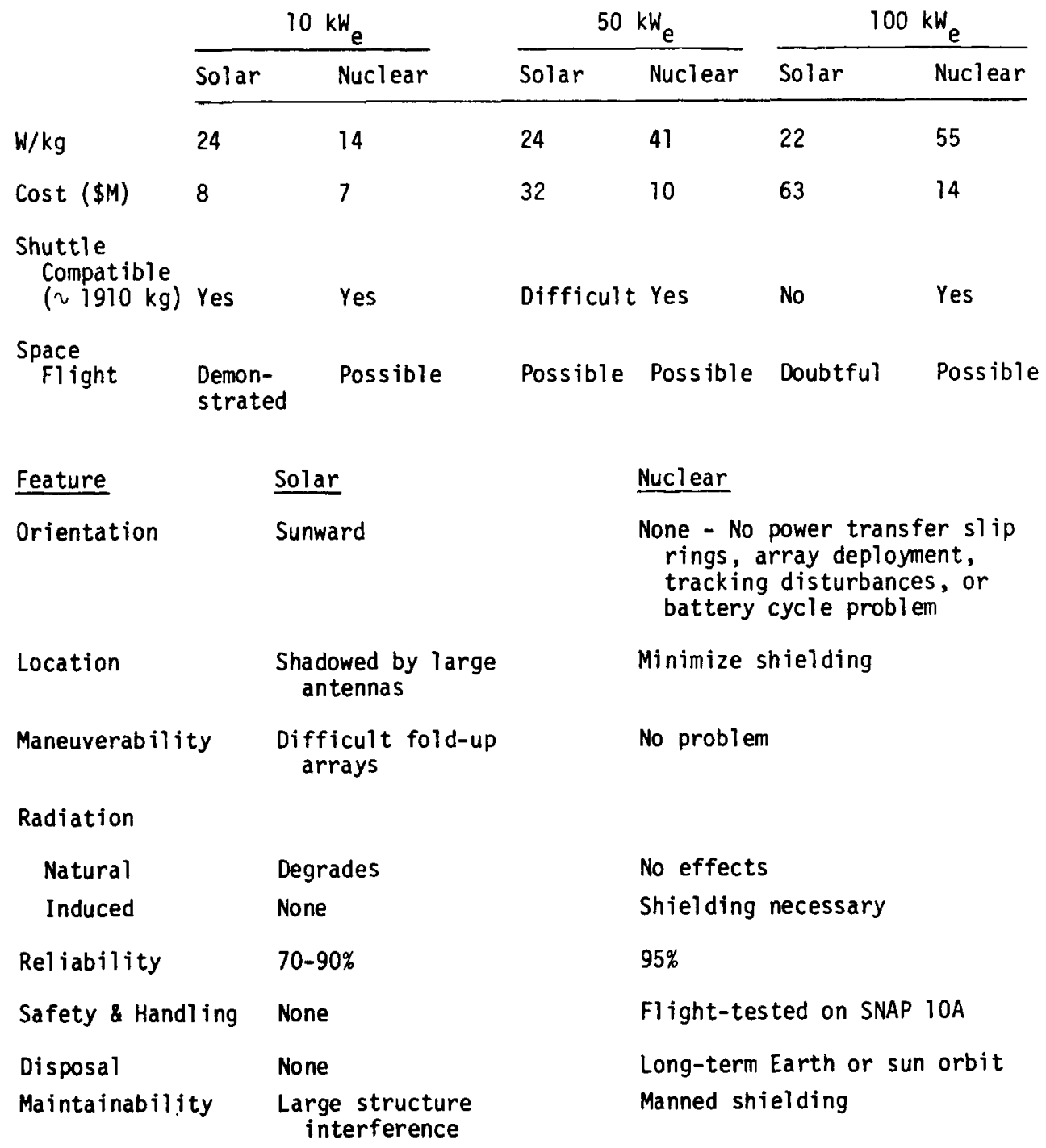


$500 \mathrm{~W}$. The SNAP 10A was a 500-W electric experimental U-ZrH nuclear reactor launched in 1965. It successfully started in orbit on command and operated flawlessly although the mission was terminated prematurely after $1000 \mathrm{~h}$ by a failure in the spacecraft. ${ }^{8}$ Moreover, the 1-yr objective was exceeded in 1966 when the ground test of the FS-4 SNAP 10A completed 10,000 $\mathrm{h}$ of con-

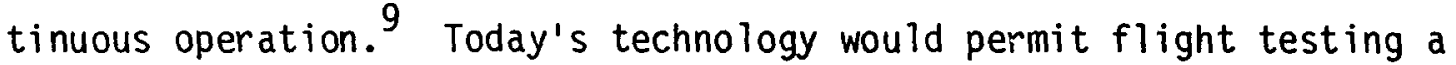
fast, compact reactor system in the mid to late 1980 s.

Large solar arrays will have to be oriented sunward. Reactors will require no orientation mechanism, "power transfer slip rings, array deployment, or mechanism to compensate for tracking disturbances.

Both systems have location limitations. Large antennas and other parts of the spacecraft that cause shadows must be avoided in solar systems because the spacecraft must focus on the sun. Reactors must be positioned to minimize radiation shielding.

Solar arrays restrict maneuverability. Unless a mechanism for retracting and deploying the arrays is included, the spacecraft will have to be moved slowly to minimize acceleration loads. Reactors are compact, making maneuverability feasible.

Natural radiation affects solar array life, but does not harm nuclear reactors. However, solar arrays do not introduce radiation, which is a major problem with reactors. Shielding must be provided to attenuate radiation from the reactor. Radiation rates affect component life by both instantaneous intensity (which ionizes sensitive electronic systems) and integral effects (which cause semipermanent lattice defects that create physical and chemical property changes in materials).

An Atomic International study, AI-AEC- $13072^{10}$ showed that $10^{6}$ nvt of fast neutrons and 1.0 rad of gamma rays deteriorate semiconductor components about equal1y. Figure 12 shows the radiation damage thresholds of typical electronic components that may be used in unmanned spacecraft. Up to a dose equivalent to $10^{11}$ nvt and $10^{5}$ rads, "off-the-shelf" components can be used. The allowable dose may be increased to $10^{12}$ nvt and $10^{6}$ rads by "inspection hardening" (that is, selecting components that on the basis of existing data require no irradiation testing). One more step, to $10^{13} \mathrm{nvt}$ and $10^{7}$ rads, is achievable at only $5 \%$ cost increase. The technology to design circuitry and parts to survive $10^{14}$ nvt and $10^{8}$ rads now appears feasible, but accurate cost estimates are not available. 


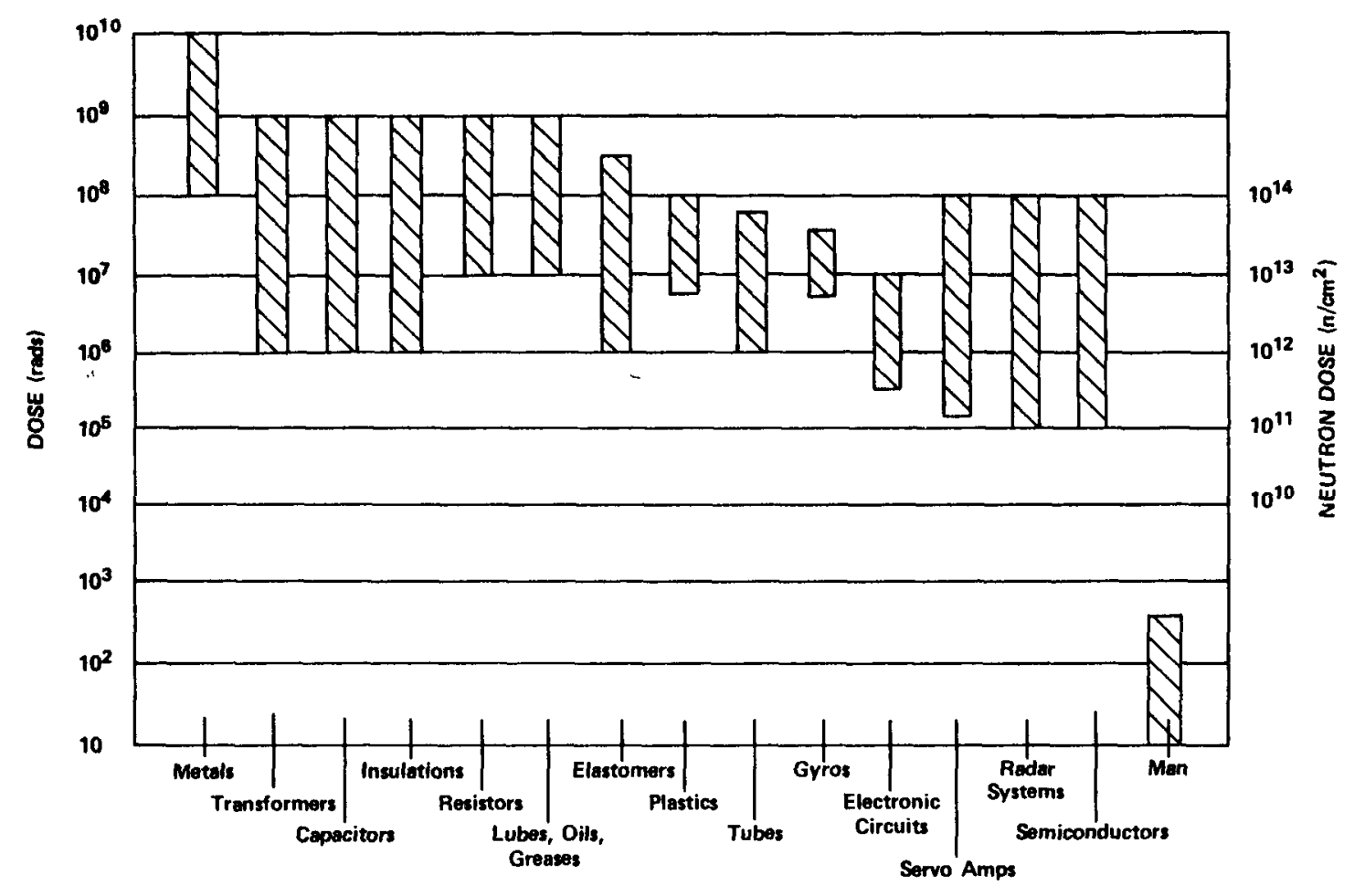

Fig. 12. Radiation hardness of typical electronic components for unmanned missions (Ref. 10).

The amount of shielding depends on the power level, the distance of radiation-sensitive components from the reactor, and their radiation tolerance. Each individual mission's best reactor location must be determined. Figure 13 shows shielding mass change as a function of distance, half-cone angle from the reactor, and power level. Judicious location will usually permit unmanned shieldings of less than a few hundred kilograms.

Solar arrays create no handling and disposal problems. The reactor creates problems, but they have been solved as demonstrated in the SNAP 10A reactor flight test. More about reactor safety will be discussed in following sections.

Figure 14 shows the uses for each technology in future DOD missions. The boundaries will move with time, but not appreciably. Above $50 \mathrm{~kW}_{\mathrm{e}}$, reactors provide the primary means of meeting DoD mission requirements. D. Transportation to Geosynchronous Orbit

A number of candidate systems exist to move satellites from low to geosynchronous orbit. The type of propulsion used is determined by whether 
the transfer occurs once or with a reusable tug. Chemical systems perform the transfer in a period of hours at high acceleration levels. Electric power with ion thrusters takes hundreds of days to perform a similar transfer. However, the stage weights are considerably less with ion thrusters. Chemical rockets can be characterized as high thrust but limited specific impulse systems while electric propulsion rockets are limited thrust but high specific impulse systems.

Currently, an IUS is under development for use as a standard module with the STS. The basic IUS consists of a two-stage vehicle $4.5 \mathrm{~m}$ long, capable of transporting a payload of $2270 \mathrm{~kg}$ to geosynchronous orbit. There is also a three-stage version of the IUS. The three-stage vehicle is formed by adding another large motor as a lower stage to the two-stage vehicle, is 6.4 $\mathrm{m}$ long, and can deliver $3180 \mathrm{~kg}$ to geosynchronous orbit.

Transtage, Agena and Centaur, current upper-stage chemical rockets, provide limited payloads to geosynchronous orbit. A number of advanced chemical stages, Low Thrust Liquid (LTL), All Propulsion Orbit Transfer Vehicle (APOTV) and Aeromaneuvering Orbit Transfer Vehicle (AMOTV), are being investigated (see Fig. 15). The LTL can deliver twice the payload to geosynchronous orbit than a three-stage IUS. The delivery capacity of NEPS is three times that of the three-stage IUS. NEPS can deliver large payloads compared to chemical stages but at a cost in delivery time.

If solar arrays are incorporated into the spacecraft, they can be used as a power source for ion thrusters. But, because of higher mass and larger volume, they can deliver about half the mass and require twice the time of NEP. One reason is that about one-third of the solar array power is lost from degradation in the Van Allen Belts.

Nuclear power is an option for a one-way transfer of spacecraft to geosynchronous orbit or as a space tug (depending on safety aspects) if transfer times close to a year are acceptable. The competitive weight with chemical stages or solar arrays and the ability to endure long time periods in the Van Allen Belts are definite advantages.

E. Power Plant Requirements for Geosynchronous Orbit Spacecraft

1. Power Output. Nuclear power requirements in geosynchronous orbit cover the range from $10-100 \mathrm{~kW}_{\mathrm{e}}$ for potential DoD missions and 15-220 $\mathrm{kW}_{\mathrm{e}}$ for potential NASA applications. Above $50 \mathrm{~kW}_{\mathrm{e}}$, reactors are the major 


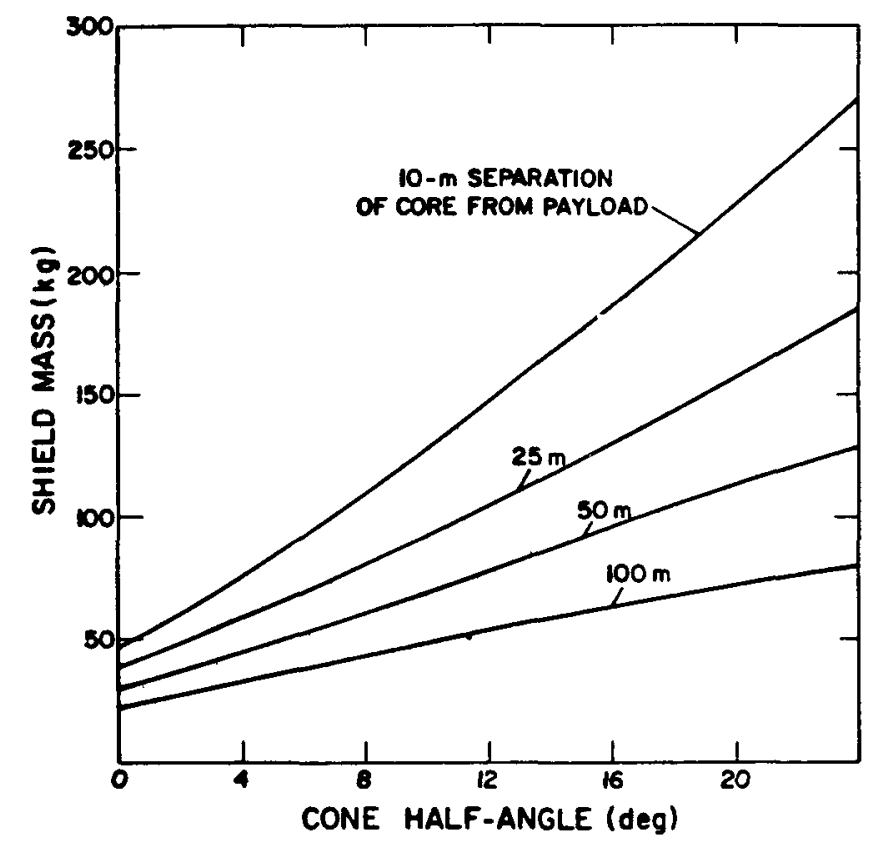

Fig. 13. Reactor shielding.

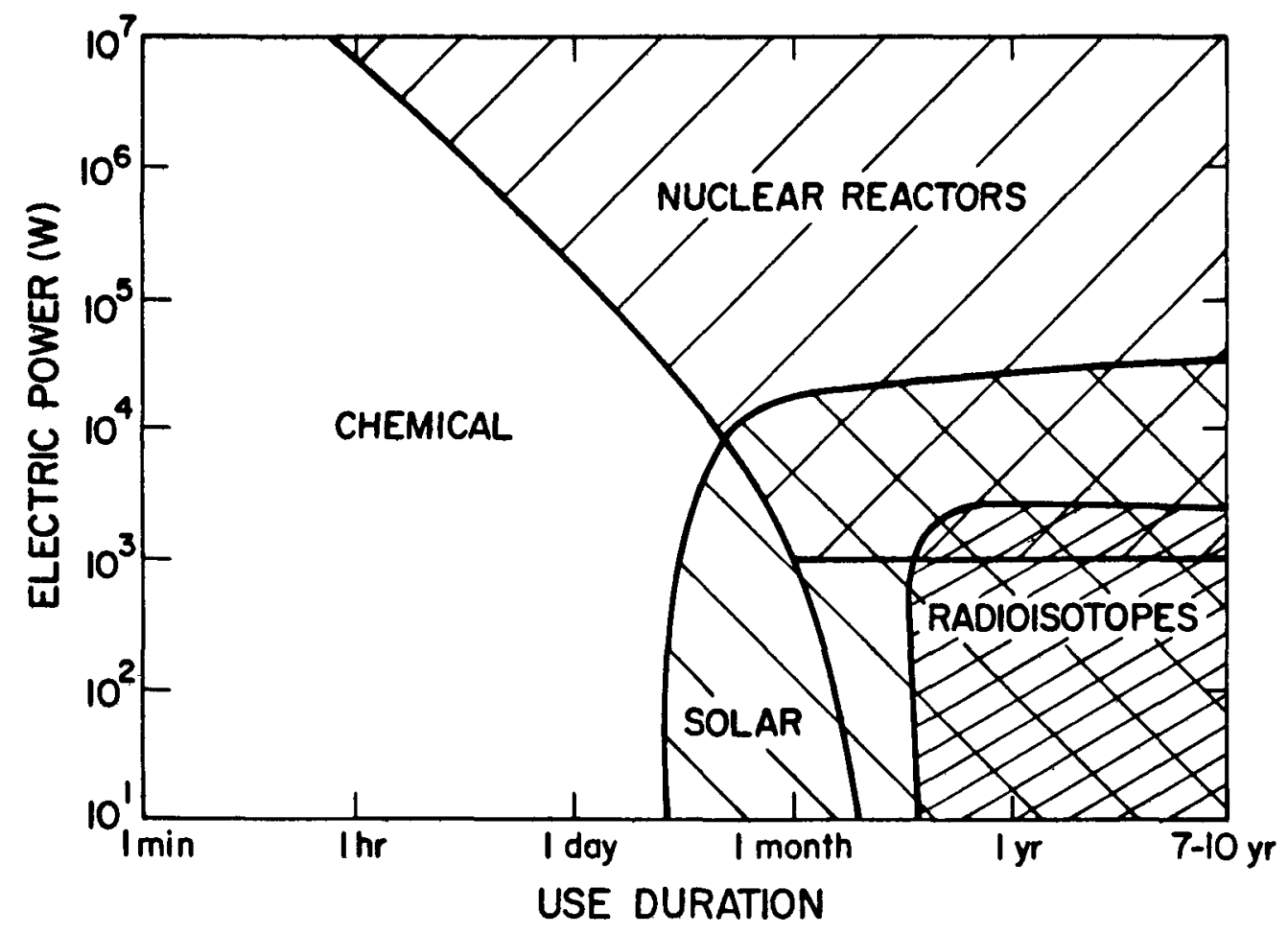

Fig. 14. Possible space power for DoD missions. 


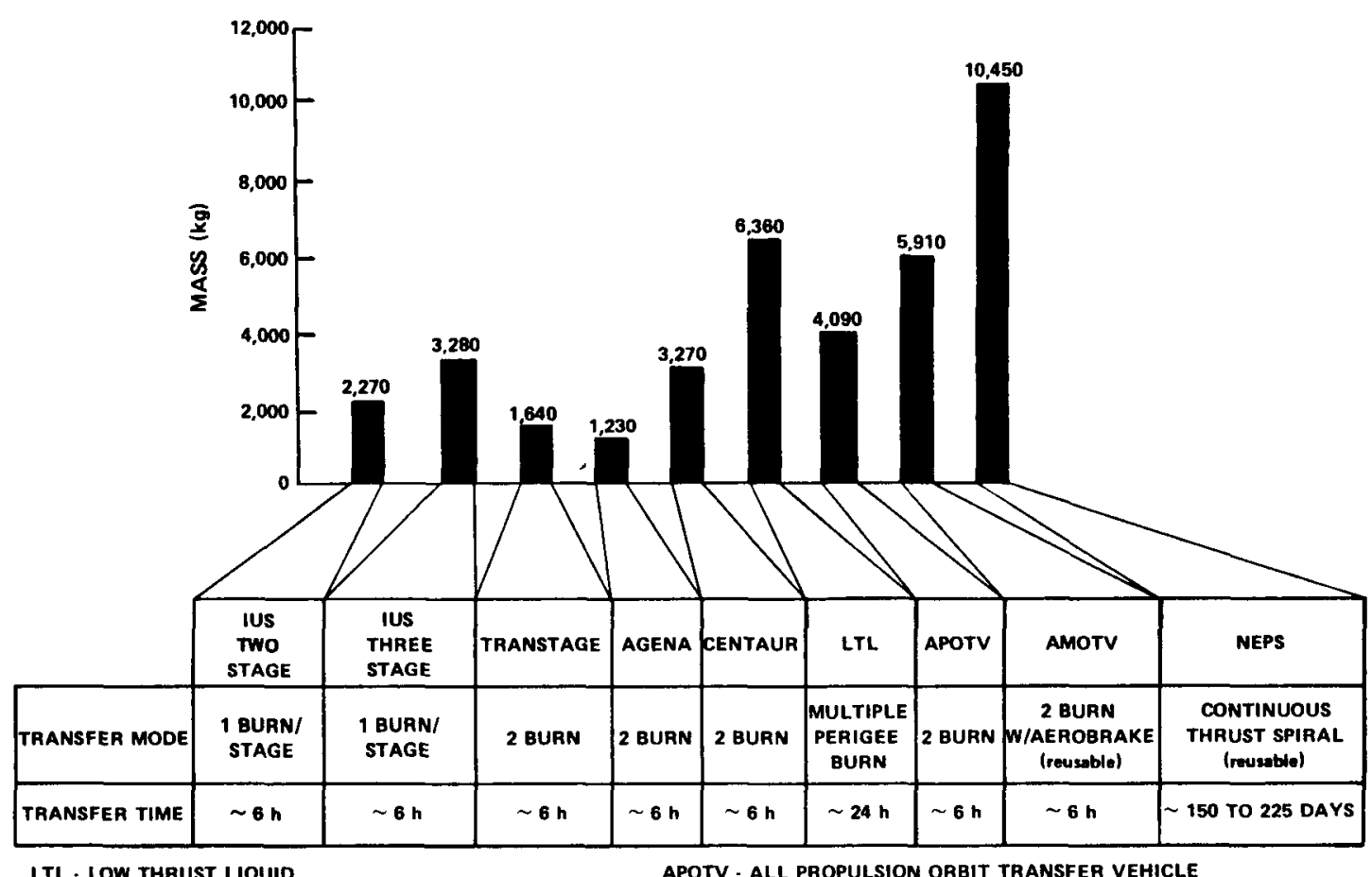

LTL. LOW THRUST LIOUID

AMOTV - AEROMANUVERING ORBIT TRANSFER VEHICLE

APOTV - ALL PROPULSION ORBIT TRANSFER VEHICLE

Fig. 15. Orbit transfer system performance comparison.

(Low earth orbit to qeosynchronous orbit).

option for providing power on an economical basis. No single, dominant mission has been found as a basis for design. Therefore, any development should cover the full range.

2. Lifetimes. Lifetimes are established by anticipated developments of other components in the spacecraft. Goals of 7-10 yr have been established for spacecraft in geosynchronous orbit.

3. Reliability. Power subassembly reliability of 0.95 is the design goal. Designs that avoid single-failure points (a failure of the entire system caused by the failure of any one single component) and degrade gradually are favored.

4. Mass. A general rule of thumb is that the power subassembly can constitute up to $30 \%$ of total spacecraft mass. For a single Space Shuttle launch using a three-stage rather than a two-stage IUS to geosynchronous orbit, this allows a design goal of $955 \mathrm{~kg}$; for a dual-shuttle launched spacecraft, the goal is $1910 \mathrm{~kg}$.

5. Configuration Constraints. The Space Shuttle dimensions of $18.3-\mathrm{m}$ length and $4.5-\mathrm{m}$ diameter 1 imit the volume of the power source. The 18.3-m 
overall Orbiter bay is reduced $7 \mathrm{~m}$ further by the three-stage IUS. The individual spacecraft will determine how much of this actually can be used by the power source.

6. Radiation. The spacecraft must be able to operate in natural radiation fields. Induced radiation created by nuclear power systems must be reduced to an acceptable radiation level determined by spacecraft components. For present electronic components, it is $10^{13} \mathrm{nvt}$ and $10^{7} \mathrm{rad}$ over the mission life.

7. Maneuverability. Maneuverability is mission dependent. No mission requiring special maneuverability has been studied to date.

8. Safety Features. The power subassembly must meet all regulations of NASA, DoD, DOE, and the National Range Commanders. All payloads using the STS are subject to a uniform set of basic safety and interface verification requirements. The safety requirements are tailored to identify the hazard potential of the payload. The Payload Safety Guidelines Handbook (JSC-11123) provides a basis for selecting design options to eliminate hazards. The STS safety policy requires that the basic payload design assure the elimination or control of any hazard to the Orbiter, crew, or other payloads.

9. Costing. Cost comparison should include not only the cost of the power subassembly but also the subassembly and launch costs for the total system.

Table VIII provides a summary of power plant requirements to be used as a basis for making various technology decisions. The $400-k W_{e}$ planetary exploration spacecraft requirement is included for comparison purposes. 
TABLE VIII

POWER PLANT REQUIREMENTS

Requirement

Geosynchronous Planetary

Power output $\left(\mathrm{kW}_{\mathrm{e}}\right)$

$10-100^{a}$

400

Lifet imes ( $y r)$

7

10

Reliability

0.95

High as possible;

no single point

failures

Mass

Single shuttle $(\mathrm{kg})$

955

8000 (this includes additional shielding and power conditioning equipment)

Dual shuttle $(\mathrm{kg})$

Configuration constraints

Radiation attenuation Neutrons (nvt)

Gamma (rad)

Maneuverability

Safety
1910

Minimize packaging volume in shuttle bay

$10^{13}$

$10^{12}$

$10^{7}$

$10^{6}$

Mission dependent Ion thrusters

STS requirements STS requirements

in shuttle bay
Minimize packaging

T NASA requirements could extend this to $200 \mathrm{~kW}_{\mathrm{e}}$. 


\section{REFERENCES}

1. Historical Analysis by JPL, NASA Hq RP 77-237313, 4-15-77.

2. "DOD and ERDA Advanced Space Power Working Group Report, Feb. 1976 thru May 1977," Prepared for DoD and ERDA Space Nuclear Applications Steering Group, Report No. SPWG 77-1.

3. I. Bekey, H. I. Mayer, and M. G. Wolfe, "Advanced Space Systems Concepts and Their Orbital Support Needs (1980-2000)," Aerospace report ATR-76 (7365)-1, Vols. I-IV, April 1976.

4. Space Transportation Systems User Handbook (National Aeronautics Space Administration, July 1977).

5. "Space Station Analys is Study," Final Report, Grumman Aerospace Company, Bethpage, New York, Power systems technical report, NSS-SS-RP025, Vol. 5.

6. McDonne11 Douglas Corp., Huntington Beach, CA, "Space Station Systems Analys is Study," report MDC G6954, September 1977.

7. Wayne M. Phillips and E. V. Pawlik, "Design Considerations for a Nuclear Electric Propulsion System," 13th AIAA Int. Electrical Propulsion Cong., San Diego, California, April 25-27, 1978, Jet Propulsion Laboratory Paper 78-691.

8. J. H. van Osdol, W. B. Thomson, and 0. S. Merrill, "Uranium Zirconium Hydride Reactor Space Power System," Proc. Intern. Astronautical Fed., 27th Cong., Anaheim, California, October 10-16, 1976.

9. "10 to 75 kWe Reactor Power Systems for Space Applications," Rockwell International, Atomics International Division report $\mathrm{N} 652 \mathrm{~T} 1140013$ (March 24, 1976).

10. J. H. Van Osdol, "Design and Integration of Zirconium Hydride Reactor Power Systems," Atomics International Division, Canoga Park, California, report AI-AEC-13072 (June 30, 1973). 


\section{POWER PLANT DESCRIPTIONS}

In this section we provide an overview of the component design and overall power plant assessment sections that follow. If you are familiar with space power technology you need only skim this section.

\section{A. General}

At a minimum, the power plant consists of the following thermodynamic elements: (1) heat source (nuclear reactor) for generation of thermal energy, (2) energy converter to transform thermal energy to electricity, radiator to el iminate waste heat to space, and (4) heat transport system to transfer heat between thermodynamic elements.

other elements such as heat exchangers amd pumps may be needed in some power plants. All power plants have an element for attenuating the radiation to the payload.

The heat source needs to be compact both to minimize its own weight and to minimize the size and weight of the radiation attenuation shield. It must be capable of operating at temperatures compatible with the thermal-toelectric converter, and must hold enough uranium inventory for fuel burnup over its lifetime. The need for compact size implies the use of highly enriched fuel and either a hydrogen-moderated thermal reactor or a fast reactor. Temperature compatibility with the converters implies the need for operating temperatures at 1300-1700 K. This eliminates the hydrogenmoderated thermal reactors, even considering relatively high-temperature metal hydrides, such as zirconium hydride (975-K limit), and leads to concentration on fast reactors concepts. Hydrogen-moderated reactors also have difficulties in meeting the long-life burnup requirements, whereas fast reactors can.

Another reactor concept we considered was a gas-core reactor. This concept is a fissioning gas in a reactor cavity where the gas is held away from the reactor walls by some form of vortex buffer. The fissioning gas is usually a mixture of $\mathrm{UF}_{6}$ and helium or argon. The gas-core can have potentially higher temperatures than a solid-core reactor. A hightemperature electric converter such as magnetohydrodynamics could have been considered. However, we rejected the gas-core system because it is in the research phase and could not be developed for the late 1980's and early 1990's applications. 
Conversion from thermal to electric energy can take a variety of forms. These include passive converters, such as thermoelectric converters in which thermal energy can be converted to electricity by imposing a thermal gradient on a circuit composed of dissimilar materials, and thermionic converters in which electricity is generated by charged particles emitted at high temperature, and dynamic converters which use turbo-machinery such as in a Brayton or Stirling gas cycle, or a Rankine two-phase fluid cycle.

A waste-heat rejection system is needed because all thermodynamic cycles have an efficiency of converting heat to electricity of less than unity. The unconverted heat must be eliminated by radiation to space. The higher the reject temperature, the smaller the radiating surface needed to eliminate a given quantity of heat.

Heat transport between elements in the thermodynamic cycle is usually accomplished by pumping a heat transfer fluid between elements, or by heat pipes. The fluid is a gas in a Brayton cycle and a liquid metal in a Rankine cycle. The heat pipe is a self-contained structure that achieves very high thermal conductances by two-phase flow with capillary circulation. B. Basic Power Plant Configurations

The system designs are primarily governed by the type of converter, and therefore, will be identified by the converter. The simplest version of each system is presented here. Alternative and more complicated versions follows in later sections.

1. Thermoelectric and Thermionic Power Plants. The basic system for thermoelectric and thermionic converters is shown in Fig. 16. These space power systems are completely passive, having no moving parts associated with power production. The reactor (1) generates heat, which is transported from the reactor to the converter by heat pipes (2). Electricity is produced in tise converter (3), waste heat is transported from the converter to the radiator by heat pipes (4), and the radiator (5) rejects the heat.

An alternative system is shown in Fig. 17. Here, the heat is transported by liquid-metal loops ( 3 and 6 ), with electrically driven pumps (2 and 5). Compared to heat pipe transport, the pumped liquid-metal loops are heavier, more complicated, and less reliable.

2. Brayton Power Plant. The basic system for the Brayton converter is shown in Fig. 18. The reactor (1) generates heat and transfers it directly to the inert-gas working fluid in the gas loop (2). The hot gas flows 


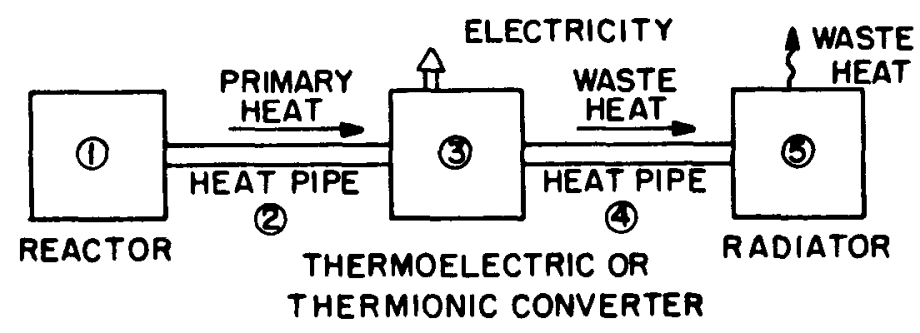

Fig. 16. Thermoelectric or thermionic systems.

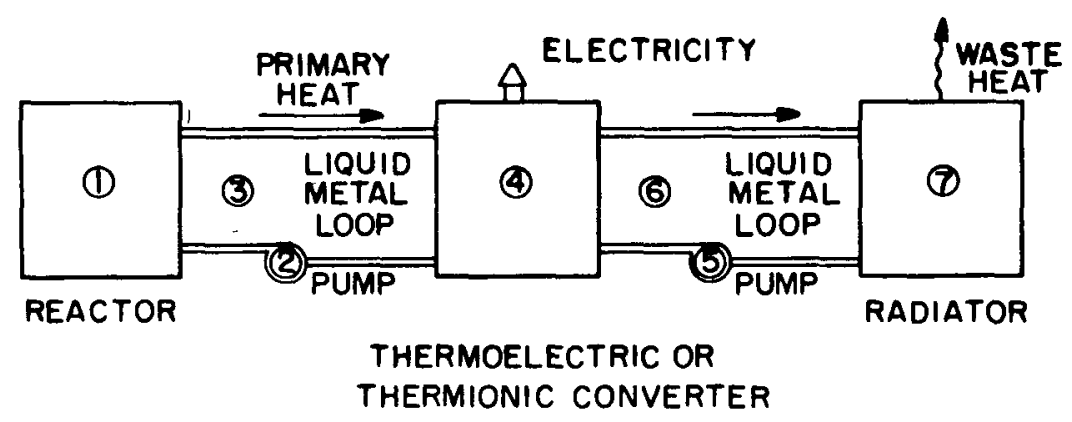

Fig. 17. Alternative thermoelectric and thermionic systems.

through the turbine (3), producing shaft power. The gas is cooled in the recuperator (4), then further cooled in the radiator (5), which rejects the waste heat. The cold gas is compressed in the compressor (6), then heated in the recuperator (4), before re-entering the reactor. The shaft power produced by the turbine drives the compressor (6) and the alternator (7). The compressor raises the gas pressure by compressing the working fluid; it is used to make up for the friction pressure losses in the entire loop. The recuperator (4) is not strictly necessary for the closed Brayton cycle, but without it, the cycle efficiency would be greatly reduced.

An alternative system is shown in Fig. 19. In this system, the reactor no longer heats the working fluid directiy. Instead, it heats a set of heat pipes (8), which heats the working fluid in the heat exchanger (9). This 


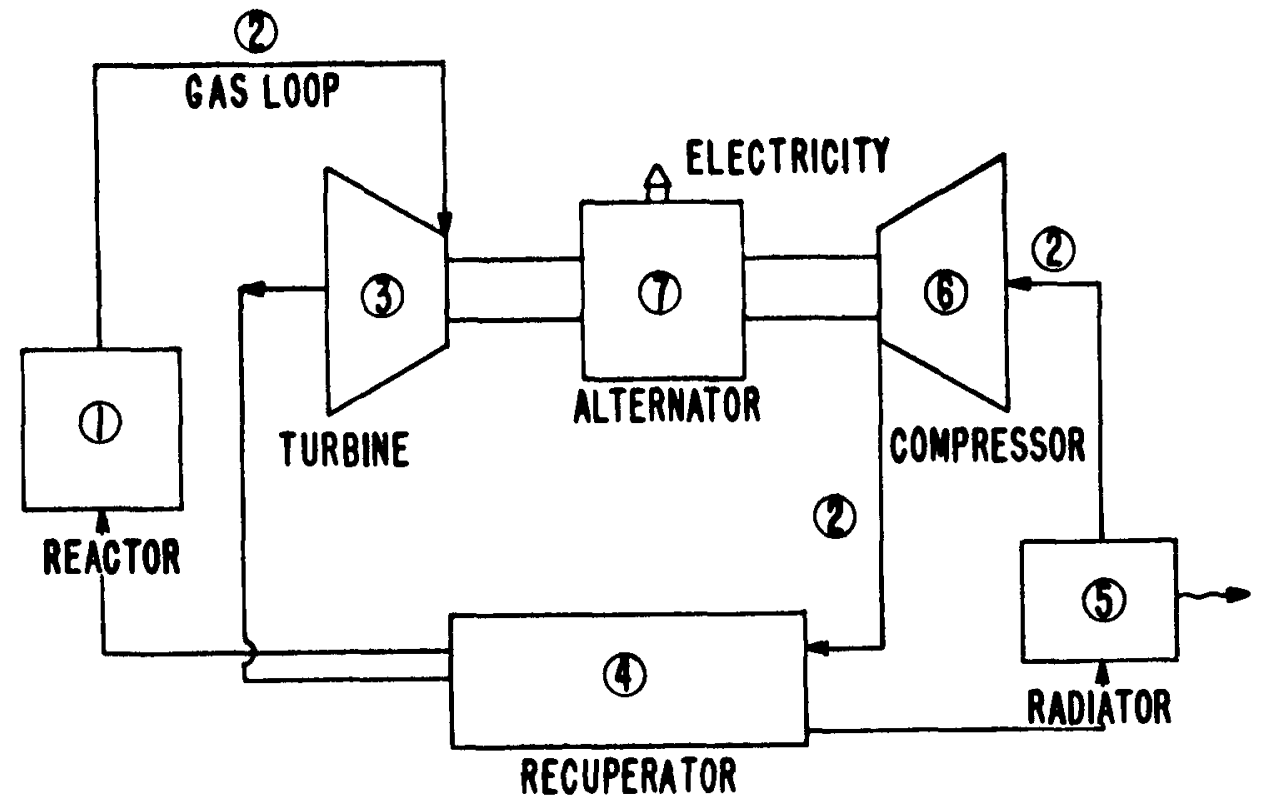

Fig. 18. Basic configuration of Brayton cycle power plant.

uses the same reactor design approach and has the same advantage of providing redundant reactor elements as the reactor for the thermoelectric and thermionic systems. It also has, independent of the above heat exchanger, a heat exchanger (10) to cool the gas going to the compressor. This waste heat is carried by a set of heat pipes (11) to the radiator. This additional heat exchanger keeps the working fluid (inert gas) away from the large exposed area of the radiator.

3. Rankine Liquid-Metal Power Plant. The basic system for the Rankine liquid-metal converter is shown in Fig. 20. (Based on SNAP-50 design, Ref. 1). In this system, the reactor (1) transfers its heat to liquid lithium which flows through the circuit (2), driven by the pump (3). The lithium gives up its heat in the boiler (4) to boiling potassium which flows though the circuit (5). The potassium vapor flows through the turbine (6), which. drives the alternator (7) to produce electricity. The vapor-liquid mixture from the turbine is totally condensed and sub-cooled in the radiator (8), then is pumped back to the boiler by the pump (9).

Figure 20 shows the thermodynamic elements of the Rankine liquid-metal system, but for simplicity omits other elements which are necessary. These include loops for cooling and lubricating the alternator, the lithium pump 
motor, the potassium pump motor; valves for control and startup, accumulators for liquid-metal expansion in each of the circuits; and a jet pump to ensure net positive suction head to the potassium pump.

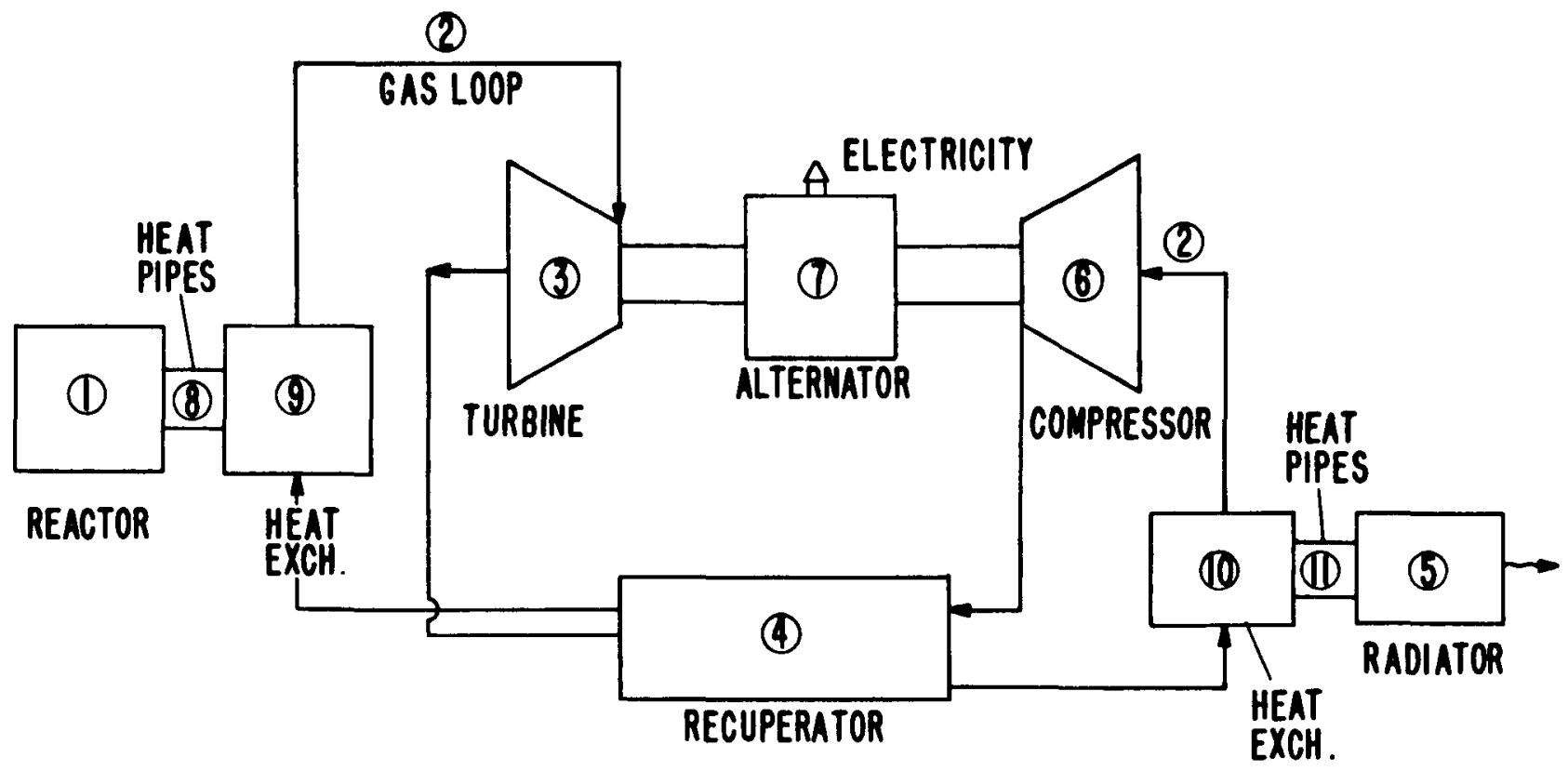

Fig. 19. Alternative Brayton system.

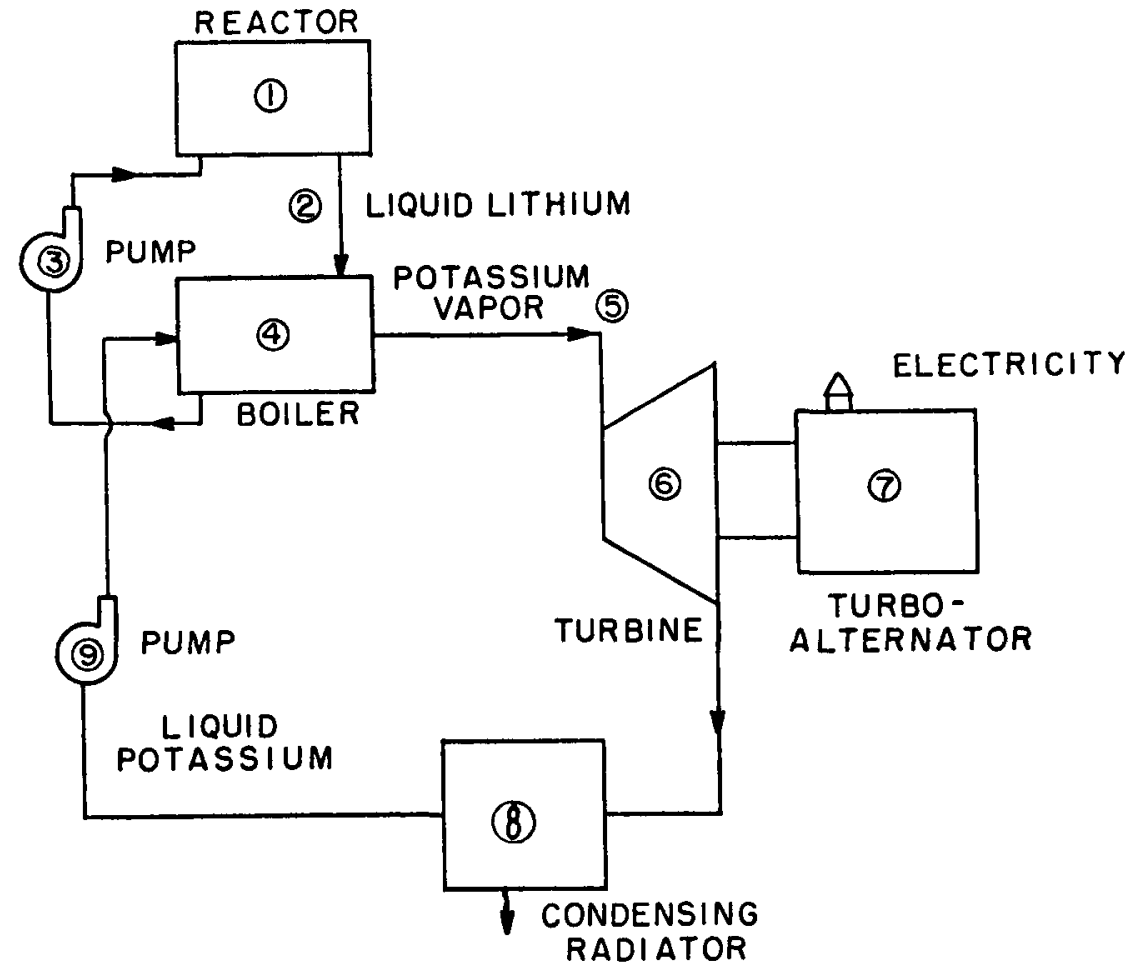

Fig. 20. Basic Rankine liquid-metal system. 
An alternative system using heat pipes instead of a lithium circuit to transfer heat from the reactor to the boiler is shown in Fig. 21 . The reactor heat pipes in this alternative system replace the entire lithium reactor coolant circuit, including pump and accumulator.

These configurations use the power converter as the independent variable. With the reactor coolant as the independent variable, the interrelationships between reactor coolant and power converter are shown in Table IX.

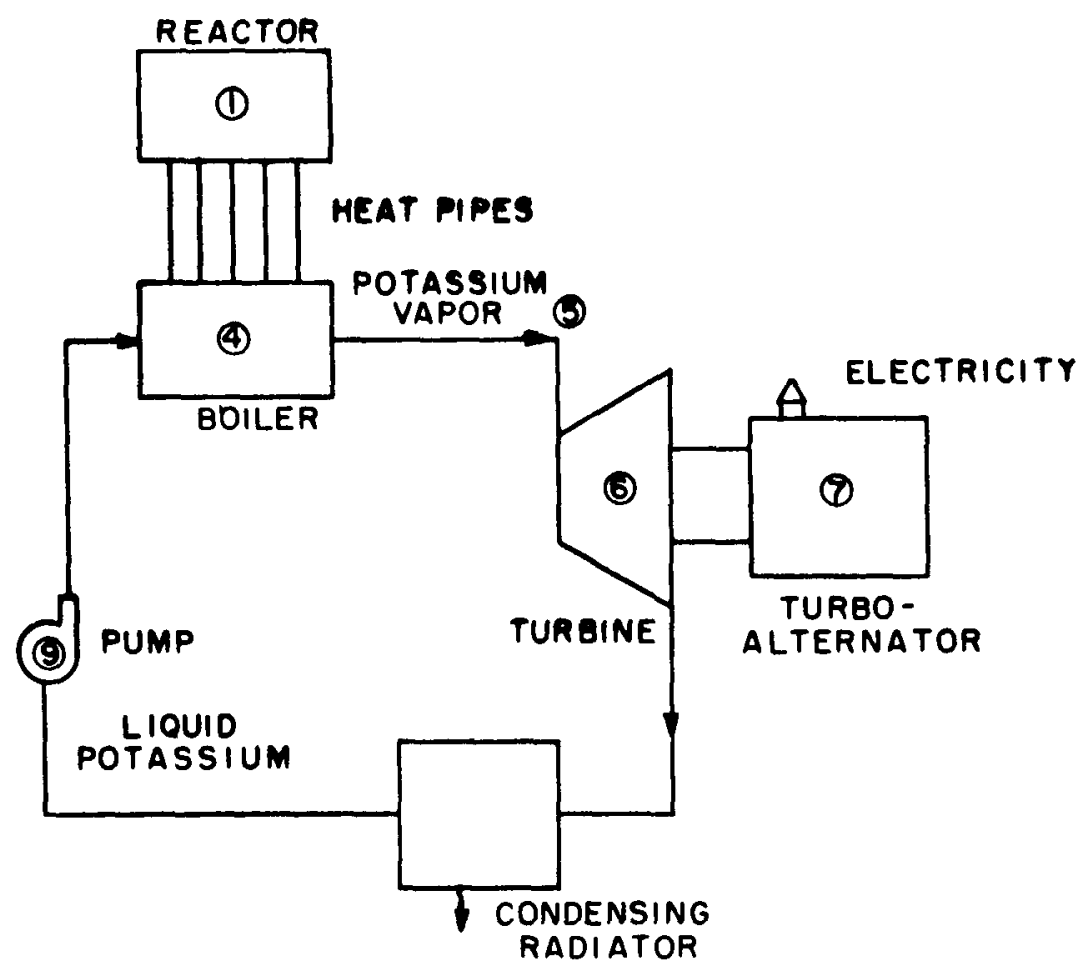

Fig. 21. Alternative Rankine liquid-metal system.

TABLE IX

APPLICABILITY OF POWER CYCLES TO REACTOR COOLANT

Reactor coolant

Thermoelectric

Thermi on ic

Brayton

Rankine liquid-metal
Heat Pipe

Good

Good

Good

Good
Liquid Metal

Possible

Possible

Possible

Good
Gas

No

No

Good

No 


\section{Specific Power System Descriptions}

Four systems have been selected for more detailed description because they are either leading candidates for further work or best illustrate the differences between approaches. These systems are circled in Table IX.

1. Heat-Pipe Reactor Power Plants.

a. Component Description. The heat-pipe reactor power plant includes the reactor, radiation attenuation shield, electric converter, and waste-heat radiator. (See Figs. 22 and 23 ).

(1) Reactor. A typical 1200-kW $\mathrm{t}$ reactor described here could satisfy the $10-$ to $100-\mathrm{kW}_{\mathrm{e}}$ power demands for missions in geosynchronous orbit.

The reactor core (Fig. 22) consists of a large number of heat pipes ( 90) surrounded by fuel (perhaps $\mathrm{UO}_{2}-20$ vol\% molybdenum). The heat pipes transfer the reactor-generated energy to the electric power conversion elements. The fuel is arranged in layers sandwiched between layers of molybdenum. The heat pipes are made of molybdenum.

The core, with its large number of heat pipes, provides redundant, independent loops for removing heat. Loss of one heat pipe results in elevated, but acceptable, temperature rises in the surrounding pipes. Several failures could be sustained without major degradation of performance. The core is enclosed and is kept compressed on the side surface by a series of rings. Multifoil insulation minimizes heat loss from the core to the reflector.

Surrounding the core is a neutron reflector of beryllium or $\mathrm{Be} 0$ on the sides and aft end and $\mathrm{BeO}$ at the forward end. $\mathrm{BeO}$ is required at the end that the heat pipes penetrate because of the higher operating temperature. Power control is achieved by changing the position of neutron-absorbing material within the reflector. Rotating drums containing a $\mathrm{B}_{4} \mathrm{C}$ side have been selected for reactivity control because they perform well in previous space reactor programs. Actuators to position the control surfaces in discrete steps are placed behind the shield to reduce the incident nuclear and thermal radiation. The power level will be controlled to maintain a constant outlet voltage from the power conversion units and to minimize thermal cycling of the reactor. Redundant instrumentation and control electronics are provided to increase reliability and eliminate single failure points. Table $X$ shows typical design parameters for the $1200-k W_{t}$ reactor. 

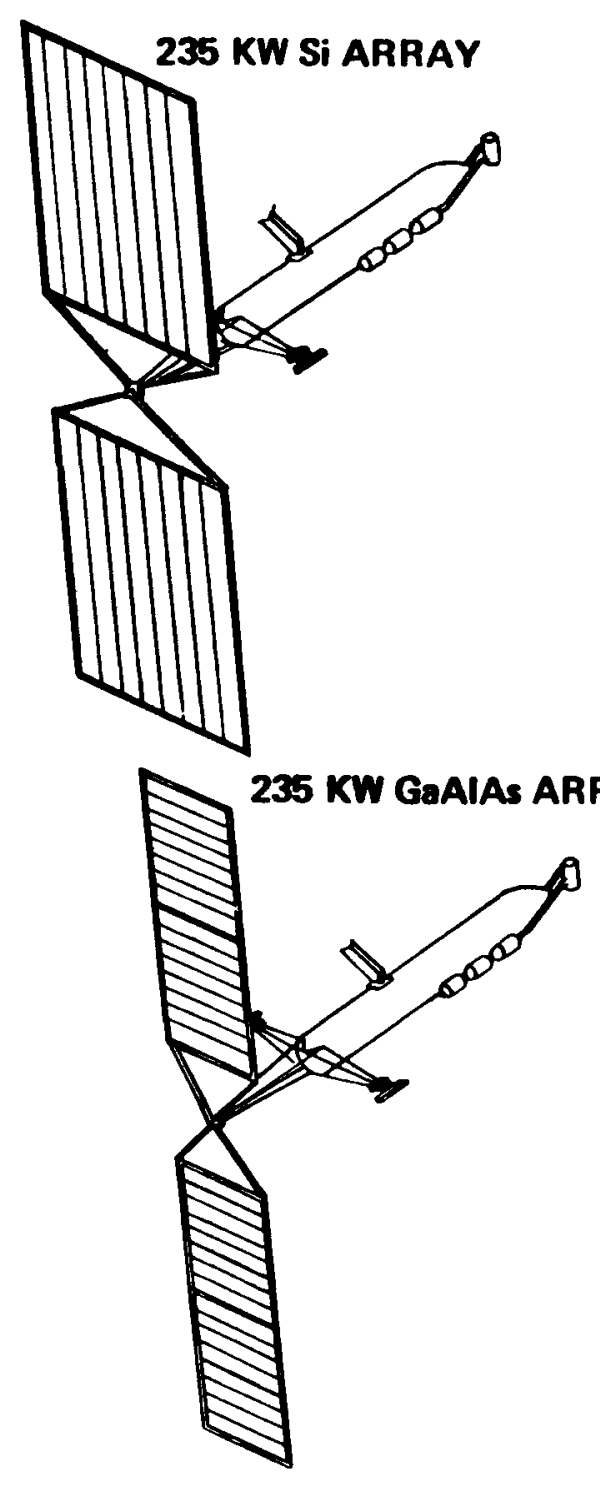

$152 \mathrm{KW}$ SOLAR-BRAYTON

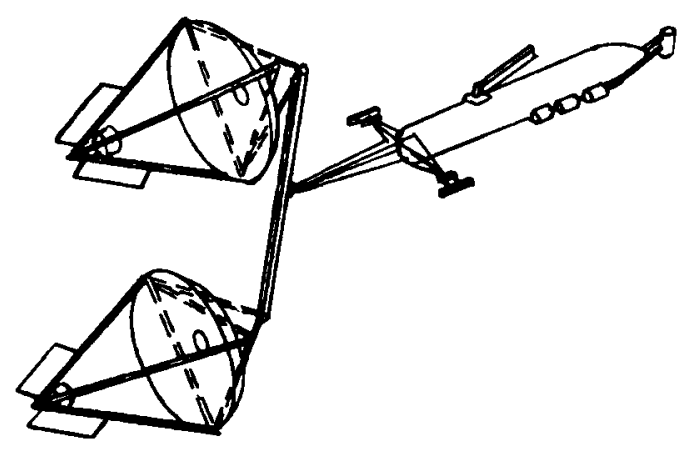

$157 \mathrm{KW}$ SOI.AR-THERMIONIC

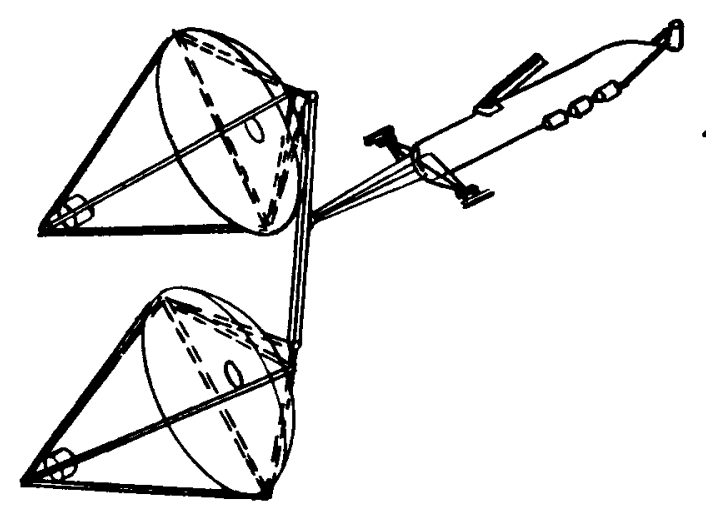

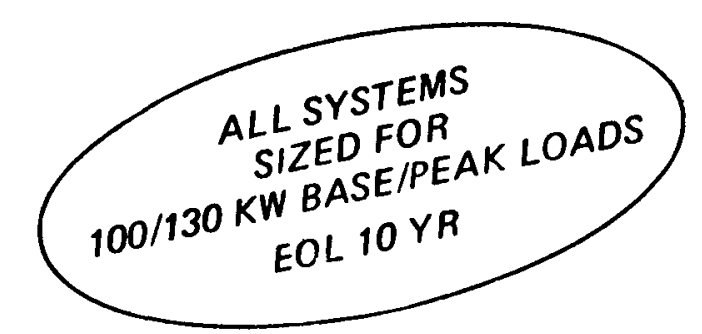

152 KW NUCLEAR.BRAYTON

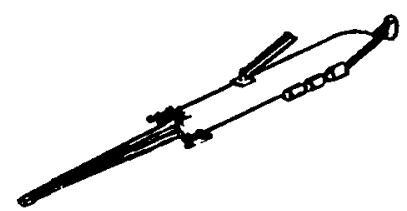

157 KW NUCLEAR-THERMIONIC

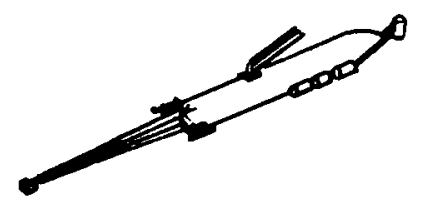

157 KW NUCLEAR-THERMOELECTRIC

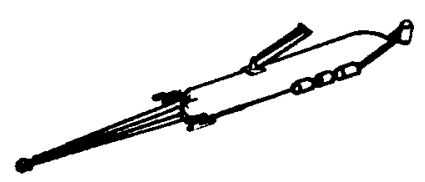

Fig. 22. Nuclear thermoelectric system. 


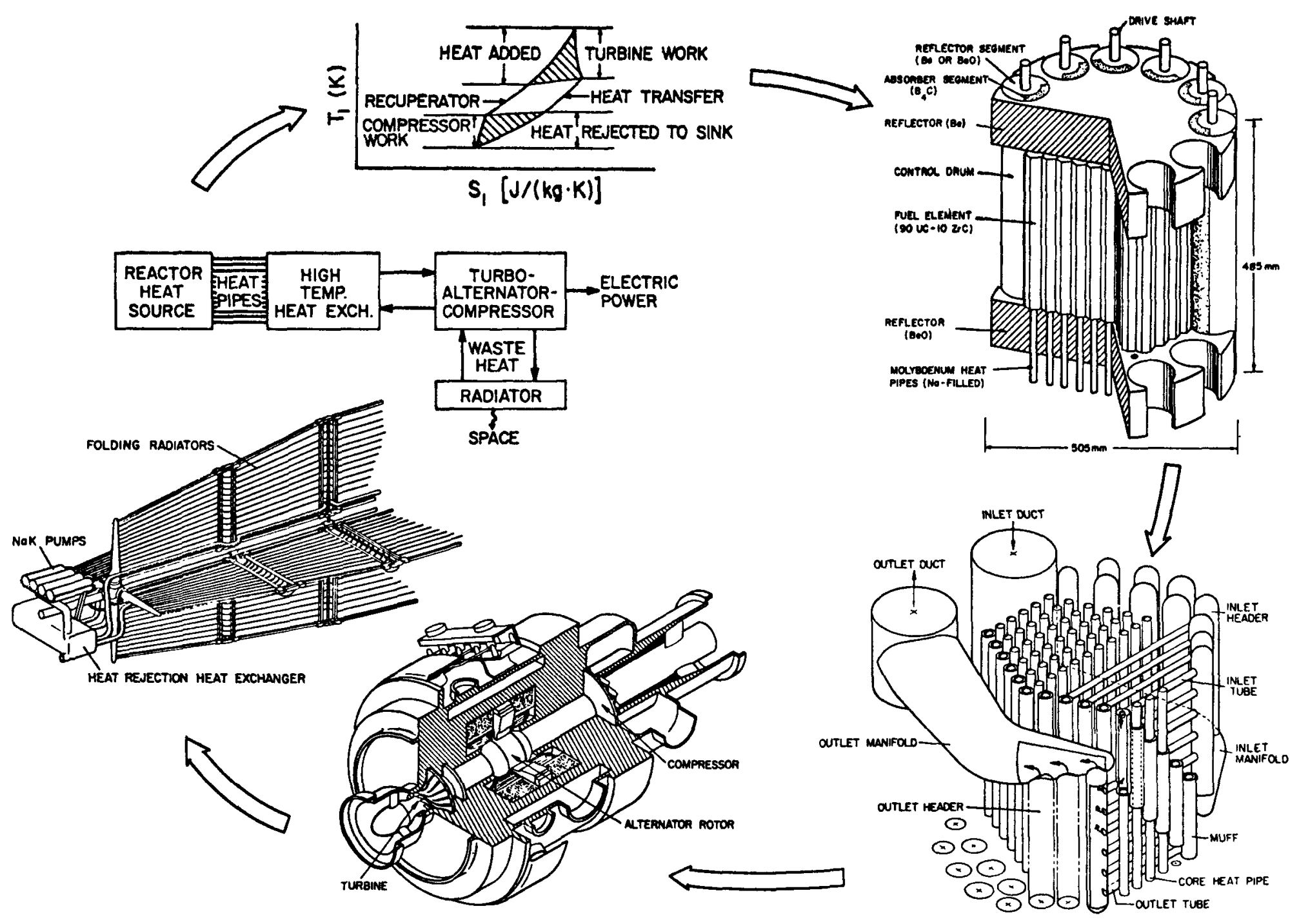

Fig. 23. Brayton system. 
TABLE $X$

DESIGN DATA FOR $1200-k W_{t}$ HEAT-PIPE REACTOR

( $1400 \mathrm{~K}$ heat pipe temperature)

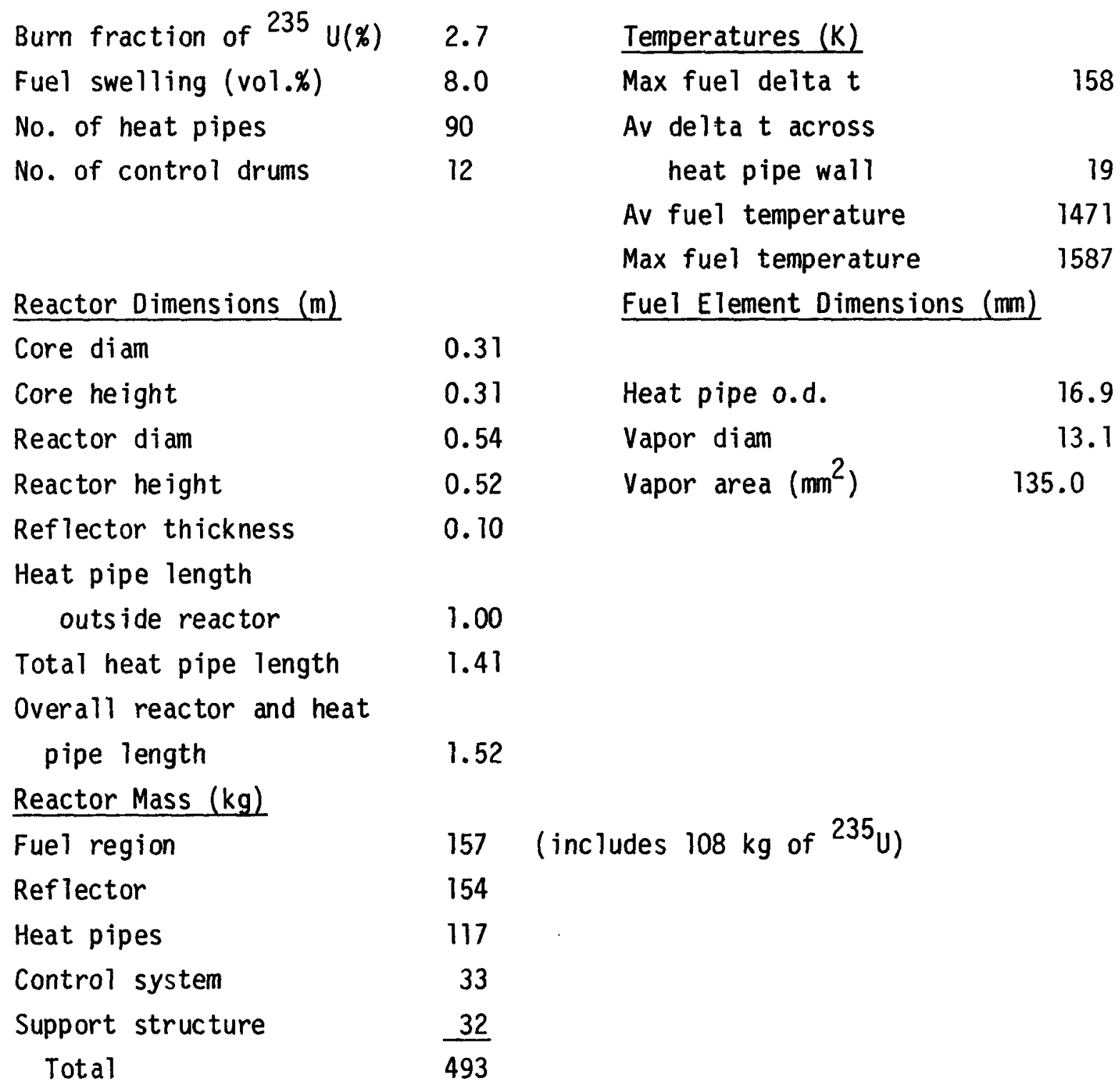

(2) Shield. In the shield design, we expect to use the technology developed from the previous space programs. SNAP 2, 8, and 10A, and ROVER. These reactors have features in common with current designs, namely, small physical size, unmanned space application with comparable allowance of neutron and gamma doses, and comparable radiation flux levels.

only shadow shielding is required because 
- only unmanned power plant operation is considered;

- the reactor will be used only in high Earth orbit, where neutron and gamma scattering from air is negligible; and

- the reactor can be located at one end of the assembly, followed by the shield, control actuators, and radiator, and, finally, the payload.

A neutron attenuation frustrum-shaped shield made with LiH and a heavymetal gamma shield is added at the reactor end of the shield if necessary.

We also use the shield as a structural member that connects to the reactor on one end and to the payload on the other by a boom. The load is carried by the outer conical shield shell. The LiH is encapsulated in a number of pancake-shaped cans, so that pressure containment failure from meteoroid penetration or weld failure, for example, will deplete the hydrogen in only a small part of the shield.

\section{(3) Electric Power Converters.}

(a) Thermoelectrics Converters. Thermoelectric converters have been used in many space missions as the power-conversion element of radioisotope power supplies with demonstrated high reliability.

The heat removed by each reactor heat pipe becomes the heat source of a thermoelectric module. The thermoelectric module will be cooled by heat pipes that are an integral part of the heat-rejection radiator. The coldside temperature is a compromise between the low temperature required for maximum thermoelectric efficiency and the high temperature required by minimum radiator size and weight. Preliminary evaluations have shown that this temperature should be about $775 \mathrm{~K}$.

A number of semiconductor thermoelectric materials have been developed. Silicon-germanium alloys have operated above $1275 \mathrm{~K}$ and have been studied extensively. This is the material in the multi-hundred watt radioisotope generators used in LES 8 and 9, Mars, Jupiter, Saturn, and Voyager missions. Current SiGe alloys can provide $6.5 \%$ efficiency, whereas improved silicon-germanium alloys may give up to $9 \%$ efficiency.

For the thermoelectric module, the heat flux is limited by the semiconductor materials, not the heat source or heat sink capabilities. The reference design is based on a "compression" module that was built and tested several years ago. Other designs have also been made with high-performance thermoelectric modules. Figure 24 is a conceptual drawing of the module and 
shows projected converter efficiencies for unmodified SiGe. The set of modules is interconnected by a ring composed of heat pipes to distribute heat between modules and to conduct heat to the space radiator heat-pipe stringers (Fig. 25). A failure of a heat pipe in the ring would be compensated for by adjacent heat pipes. Likewise, a stringer failure would be isolated and adjacent stringers would compensate.

(b) Dynamic Converters. The Brayton cycle is used to illustrate dynamic converter systems. Mounted on the end of the reactor heat pipes are heat exchangers to feed redundant Brayton loops. The Brayton loop consists of a rotating group (compressor, turbine, and alternator on a single shaft supported on foil gas bearings) and heat exchangers from the reactor, within the recuperator and to the radiator. An inert gas, xenon-helium, is used as a working fluid in the closed-loop system. This gas exits from the radiator heat exchanger or cooler at a low temperature and pressure and enters the compressor where it is discharged into the recuperator at higher pressure. Passing through the recuperator, the working fluid is preheated before it enters the high-temperature heat exchanger, where energy from the reactor heat source is added to the working fluid. When the fluid emerges from the reactor heat exchanger, its temperature is at its highest and it
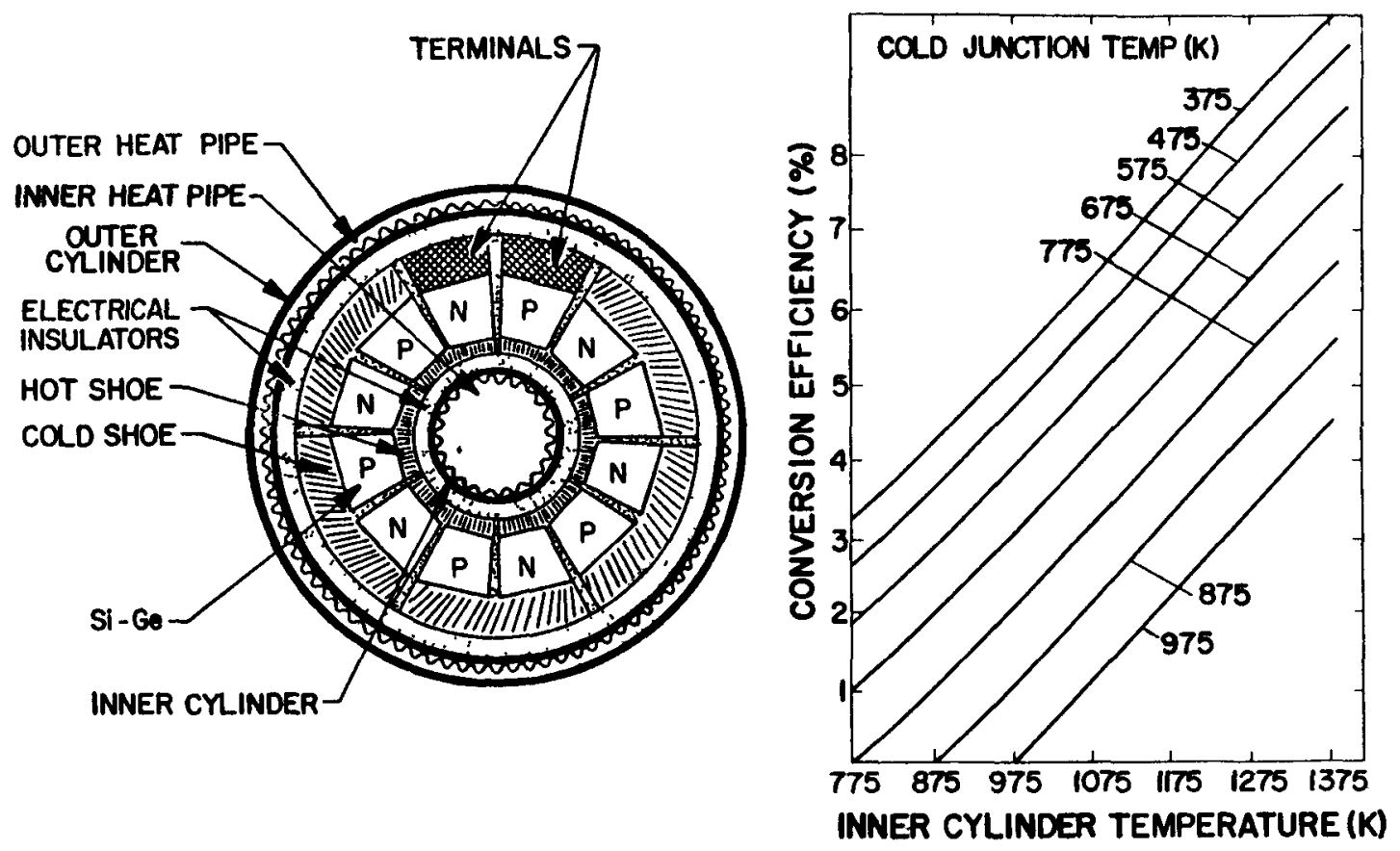

Fig. 24. Thermoelectric design concept and projected converter efficiencies for unmodified SiGe. 


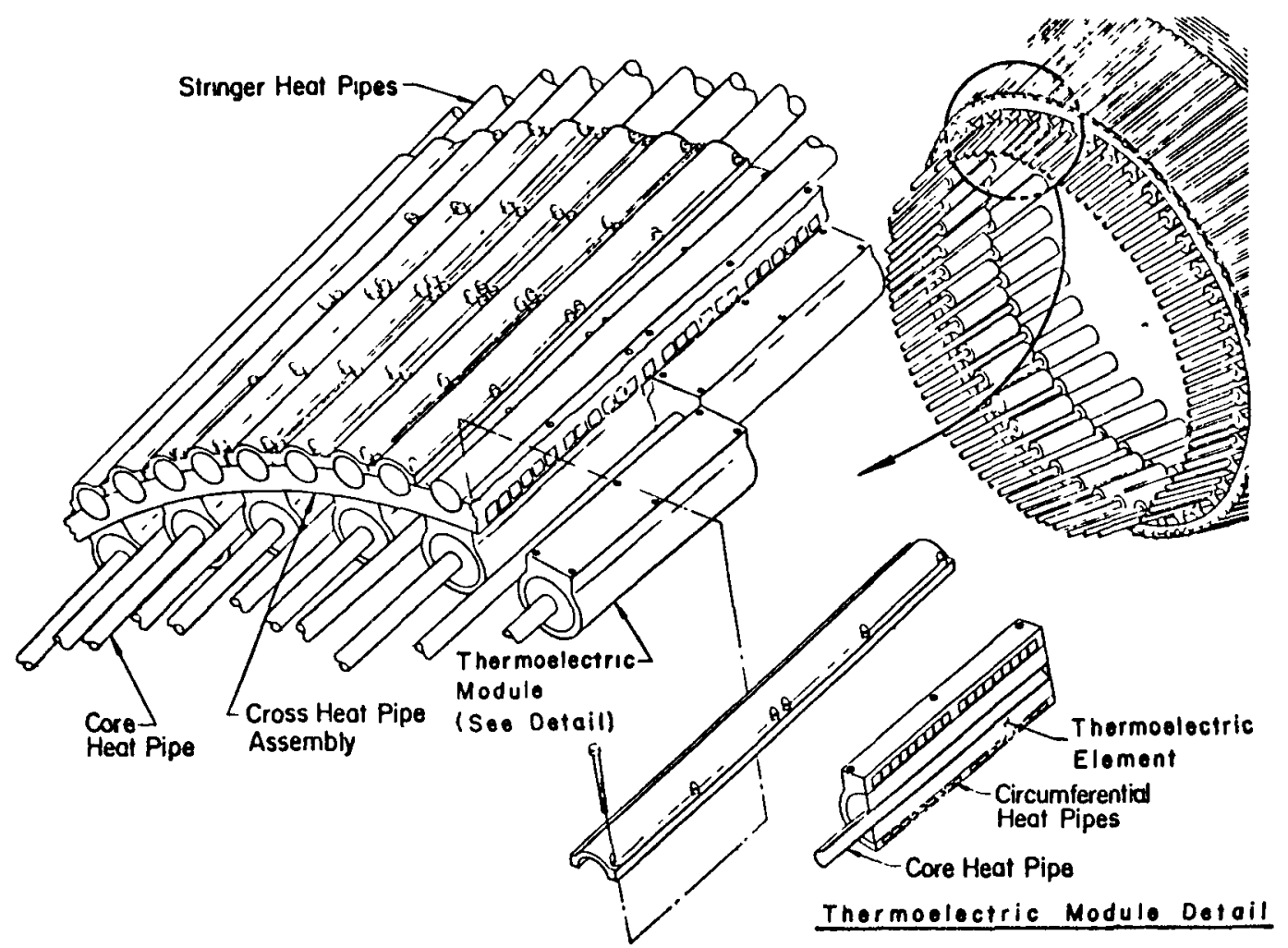

Fig. 25. Thermoelectric coolant module detail.

is then expanded in the turbine to drive the compressor and alternator. The working fluid then releases thermal energy in the recuperator and cooler, and the closed cycle resumes. The recuperator, a key component, minimizes waste-heat rejection and promotes high cycle-efficiency. Cycle efficiencies of $25 \%$ are estimated, with provision for full-power operation even after loss of a redundant loop. Typical temperatures and pressures are shown in Fig. 26.

A single-unit Brayton converter has operated over $30000 \mathrm{~h}$ in tests by NASA-Lewis Research Center ${ }^{5}$ at a turbine inlet temperature of $1145 \mathrm{~K}$, although continuous operation was interrupted to make experimental tests. The demonstrated efficiencies were $30-33 \%$ at $7-8 \mathrm{~kW}_{\mathrm{e}}$.

(4) Radiators. The reject-heat radiating area depends on the converter efficiency, electric power level, heat-rejection temperature, 

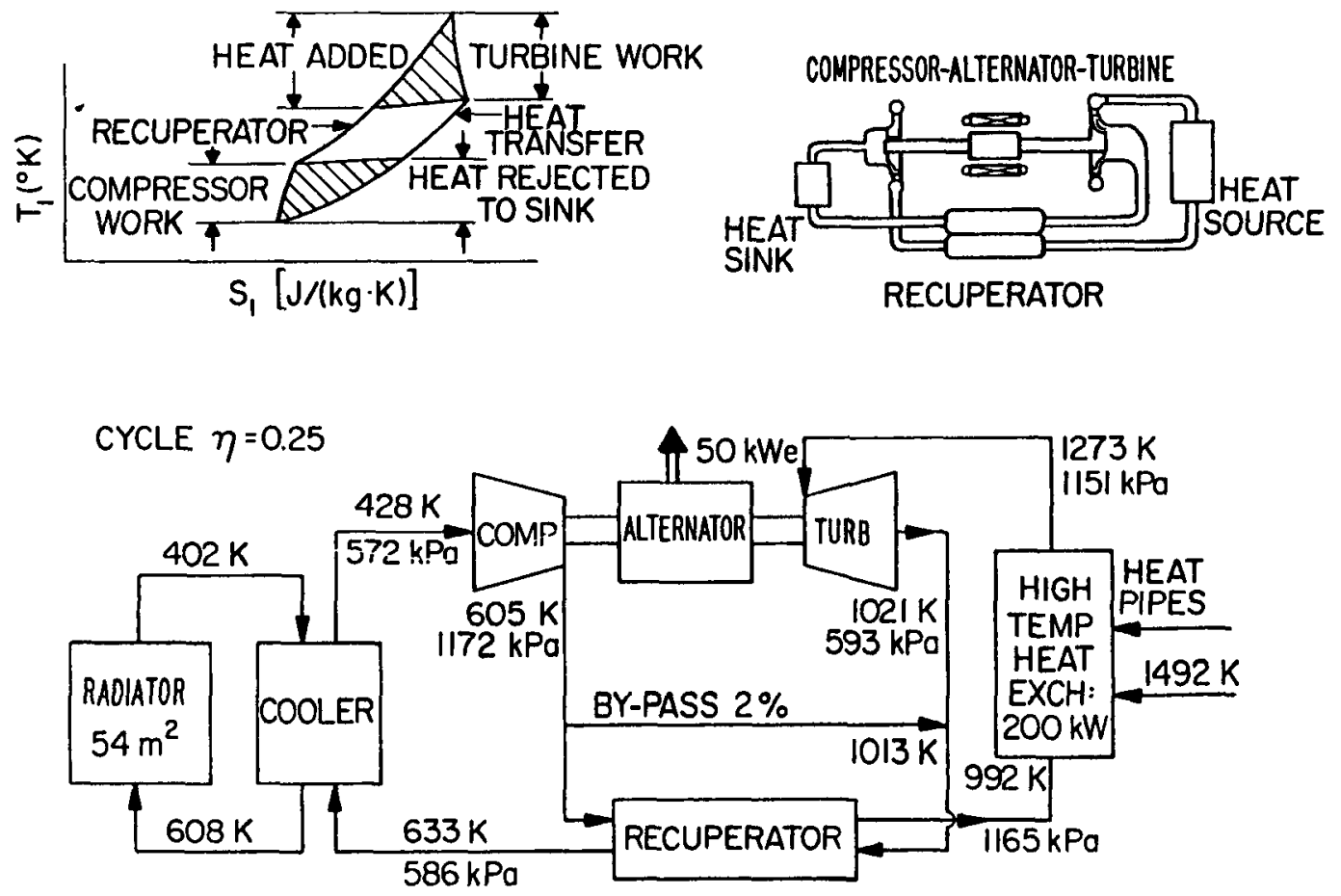

Fig. 26. Typical Brayton cycle power system parameters.

and probability of component failure, caused mainly by meteroids. The radiator is being designed for $99 \%$ reliability and 7-yr lifetime. The thermoelectric converter radiator design maintains a cold-junction temperature of $775 \mathrm{~K}$. Higher converter efficiencies obtained by designing for a lower temperature would increase system mass and size. Our present system is based on heat pipes arrangeed to transport the heat from the thermoelectric cold-junction ring (stringers) and heat pipes (circumferential heat pipes) wrapped around the stringers to distribute the heat and act as a meteoroid bumper and as fins. Calculations of meteoroid penetration were based on NASA Space Shuttle user guidelines for payloads in geosynchronous orbit. To ensure that the heat-pipe radiator survives meteoroid penetration throughout the mission, the radiator is overdesigned and penetration armor added. The circumferential heat pipes are designed such that if only $78 \%$ survive, full power operation will still be maintained. Using them as a bumper for the stringer heat pipes reduces the mass significantly. Beryllium and nickel-laminated beryllium seem the most promising space radiator materials; others are appreciably heavier.

b. Power Plant. Figure 27 shows a thermoelectic system utilizing a reactor module of $1200 \mathrm{~kW}_{\mathrm{t}}$. The reactor and shield are 
separated to provide space to bend the core heat pipes around the shield to the thermoelectric converters. The converters are located in a ring. The radiator extracts the heat from the cold-junction of the converter ring.

A representative power plant layout for the Brayton cycle is shown in Fig. 28. The Brayton cycle has potential efficiencies up to $35 \%$. However, radiator temperatures are low at these high efficiencies, so the radiator becomes quite large. As a compromise between converter efficiency and radiator mass, we use $25 \%$ efficiency in analyzing Brayton-converter weights. To avoid single-failure points and to meet the goal for reliability, duplicate loops, each capable of full-power operation lave been included in the total mass.

In the Brayton converter, as in the thermoelectric converter, there is a compromise between the low radiator temperature requirement for cycle efficiency and the high radiator temperature requirement for small radiator size and weight. The optimal temperature, $425 \mathrm{~K}$, however, is much lower for the Brayton cycle than the $775 \mathrm{~K}$ for the thermoelectric cycle. Thus, even with the higher cycle efficiency, the Brayton radiator is about twice as

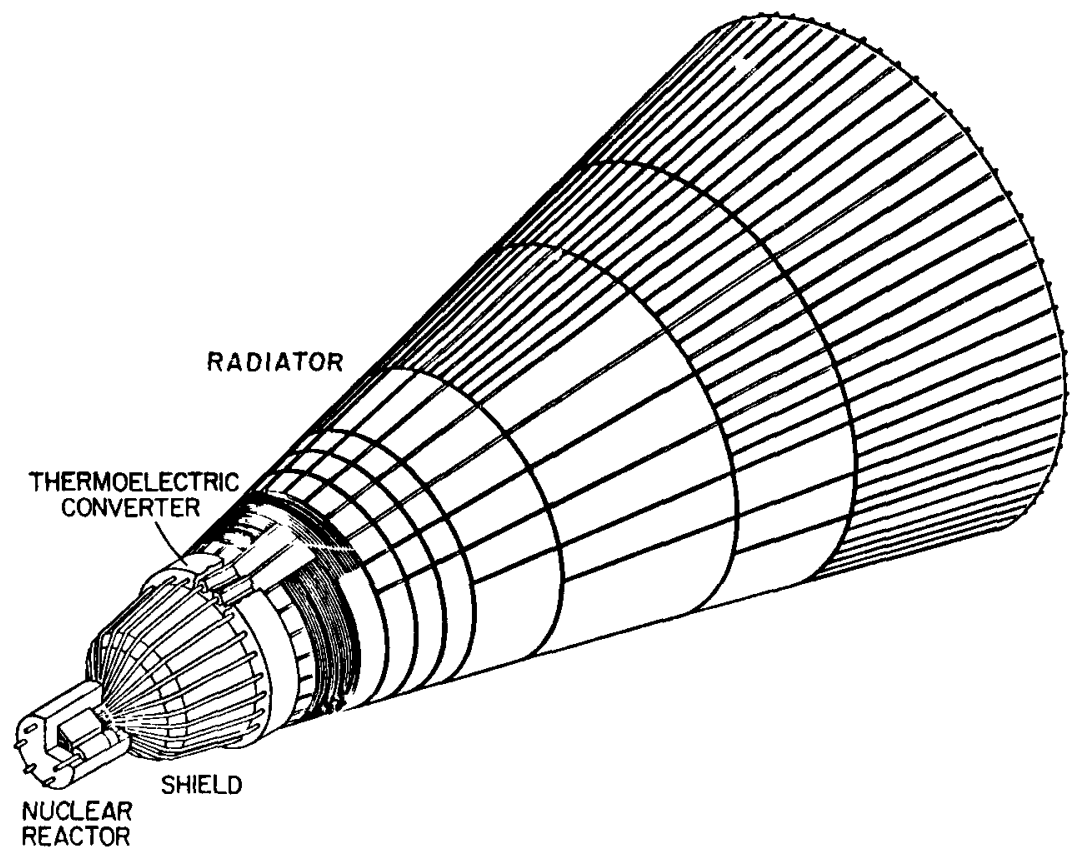

Fig. 27. Thermoelectric power plant. 
large at $100 \mathrm{~kW}_{\mathrm{e}}$ as for the thermoelectric cycle. (This is mainly caused by the 4th power of temperature involved in the heat rejection by radiation.) The large radiator will not fit in a Space Shuttle bay if fully deployed, so a folding design as shown in Fig. 28 is necessary at the higher end of the $10-100 \mathrm{~kW}_{\mathrm{e}}$ range.

2. Gas-Cooled Reactor Power Plant. In the gas-cooled reactor, the Brayton converter is fed by the working fluid which is directly heated by the gas flowing through the reactor. The Brayton converter loop and radiators are identical to the heat-pipe reactor power plant except for the reactor and the method of transferring heat from the reactor to the working fluid.

\section{a. Component Descriptions. A cross-section view of the gas-} cooled reactor is shown in Fig. 29. The principal design features follow

- A pressure vessel is required for the gas-cooled reactor and inlet and outlet plenums for the working fluid. The working fluid is the same helium-xenon mixture that is used in the heat-pipe Brayton cycle.

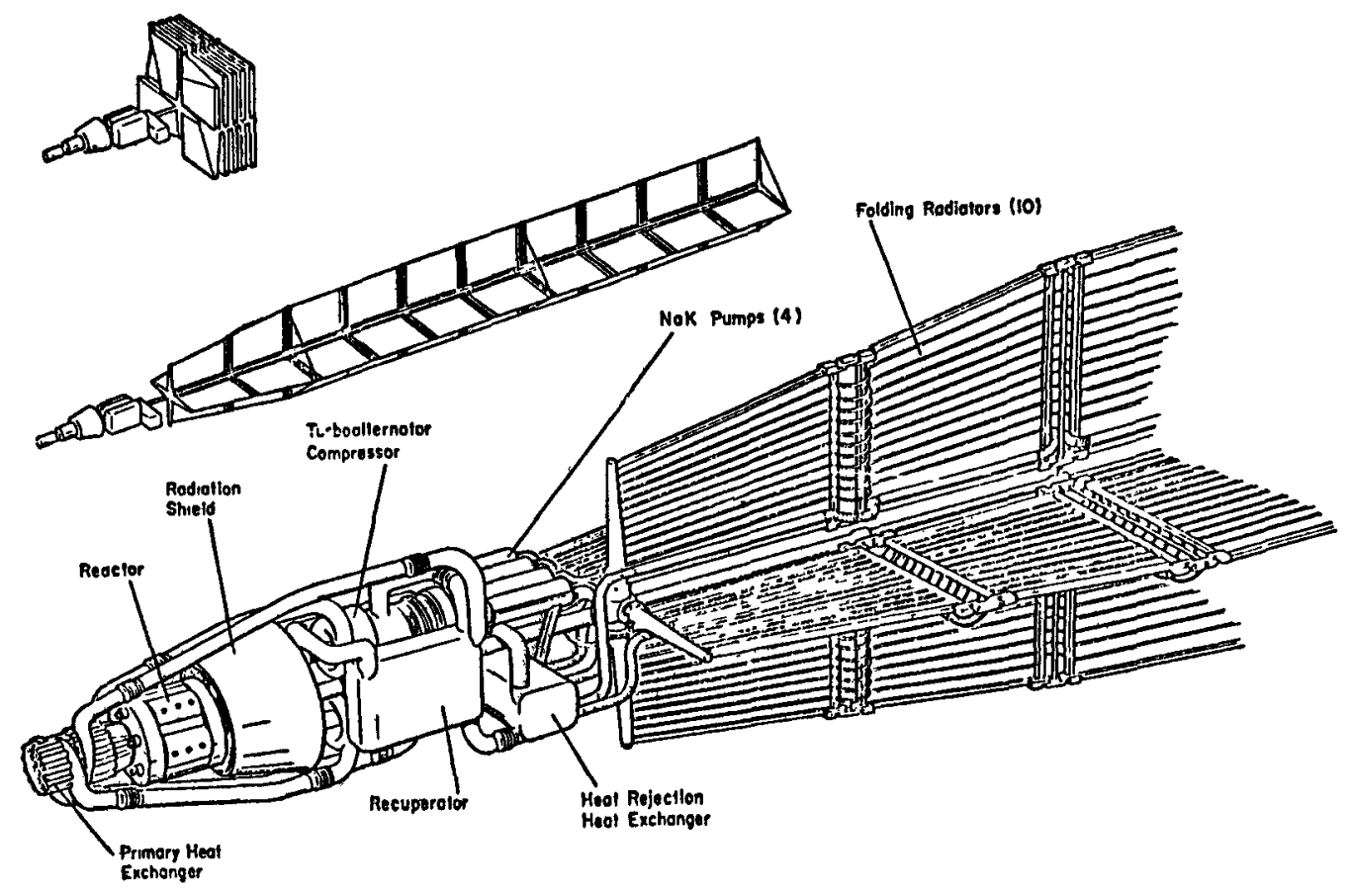

Fig. 28. Brayton cycle space electric power supply. 


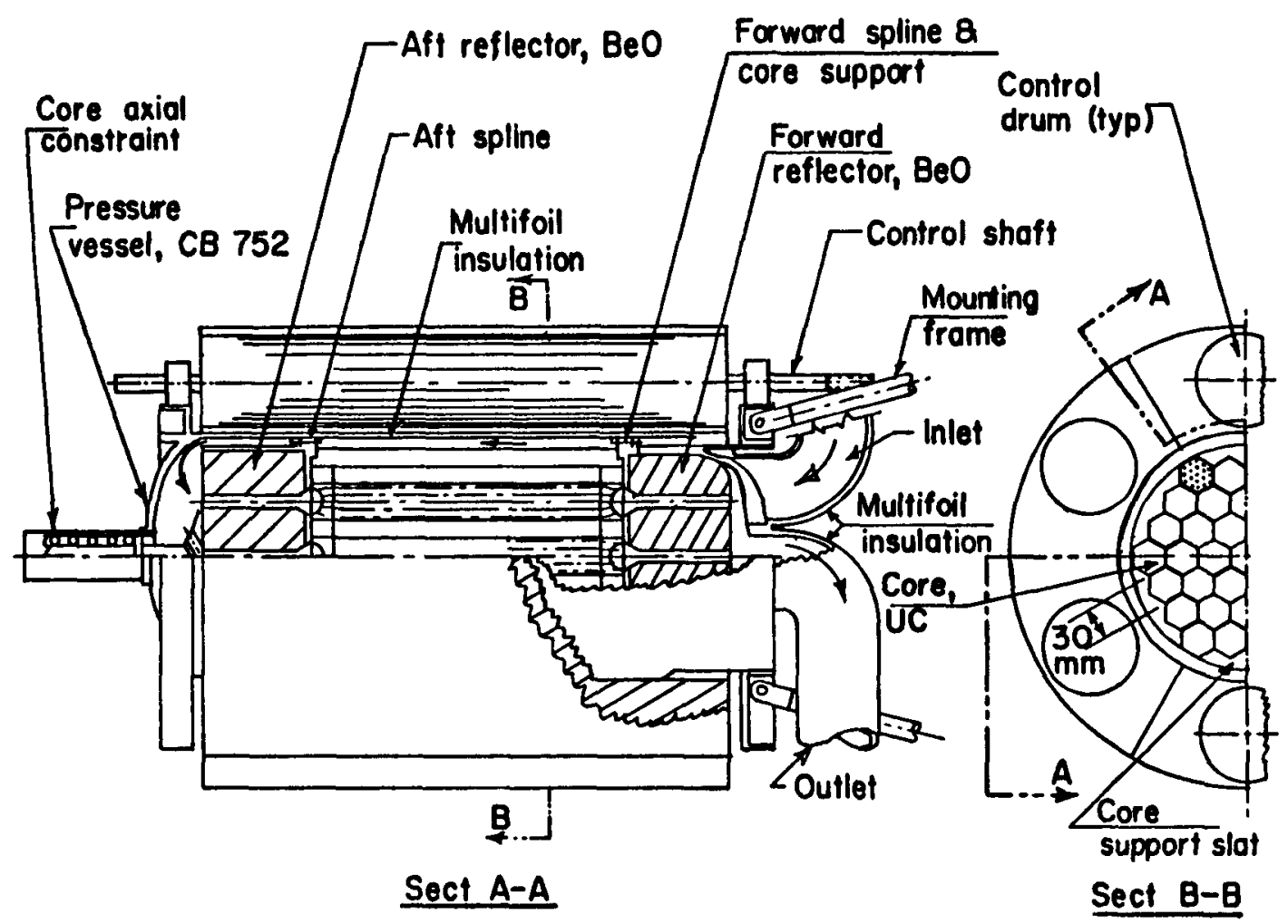

Fig. 29. Brayton cycle gas-cooled reactor.

- An annular passage inside the pressure vessel guides the cool inlet gas from the duct attachment end to the inlet end of the core. The gas in this passage cools the pressure vessel and core periphery.

- Inlet and outlet ducts attach to the same end of the pressure vessel.

- Gas passages are required through both end reflectors.

- Fuel elements are hexagonal in cross section, with many small cooling holes. The fuel elements are made in short lengths and may be coated outside and inside the cooling holes to protect small particles in the gas stream from spalling off.

b. Power Plant. The Brayton unit, radiator, and ducting (except for length) are the same as in the heat-pipe Brayton unit. A schematic of the gas-cooled system up to but not including the Brayton 
unit is shown in Fig. 30. Since the gas ducts are bulky and require a lot of space for turns, the connections with the pressure vessel are made on the end opposite the shield. This permits the shield to be located against the reactor.

3. Liquid-Metal Cooled Reactor Power Plant. An extensive study of the liquid-metal cooled Rankine-converter space power plant was carried out from 1961 to 1965 under Atomic Energy Commission (AEC)-NASA-Air Force sponsorship. This was the SNAP-50 project; Pratt and Whitney Aircraft was the principal contractor, with additional work by Oak Ridge National Laboratory and others. (More work on the liquid-metal Rankine cycle was performed later in the 1960s by NASA and its contractors after SNAP-50 was cancelled.) This study was used as the basis for our analysis. 1-6

The SNAP-50 power plant contained a compact, fast spectrum reactor as the nuclear heat source. As shown in Fig. 31, heat is removed from the reactor and transported to the potassium boiler by molten lithium which is circulated through the reactor and over the boiler tubes by a hightemperature pump. The lithium is delivered to the boiler at a temperature $~ 1400 \mathrm{~K}$.

The entire system with the exception of the electric components, the radiator fins and armor, and a few special parts is constructed of a columbium-1 zirconium alloy that is highly resistant to corrosion by potassium and its vapor as well as by lithium. The space radiator employs stainless steel meteoroid armor and stainless steel-clad copper fins to encase the radiation surface area.

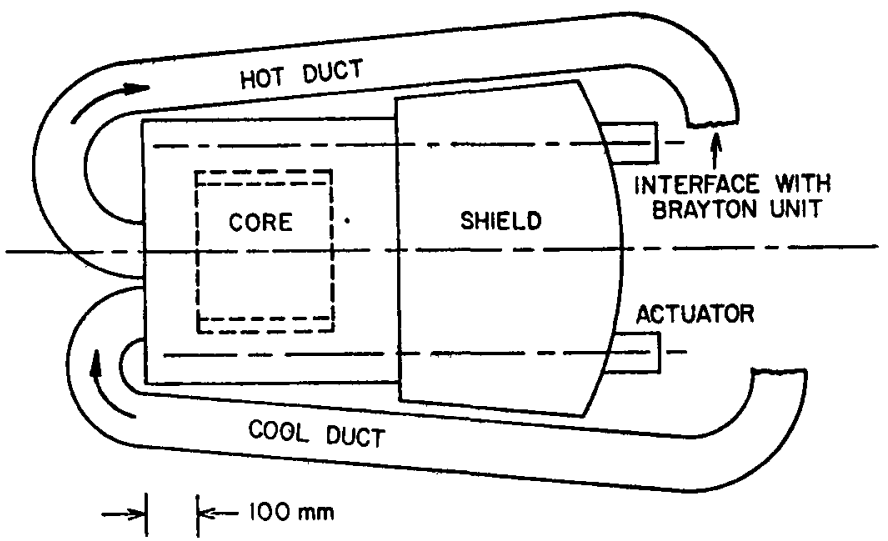

Fig. 30. Gas-cooled reactor component relationship. 


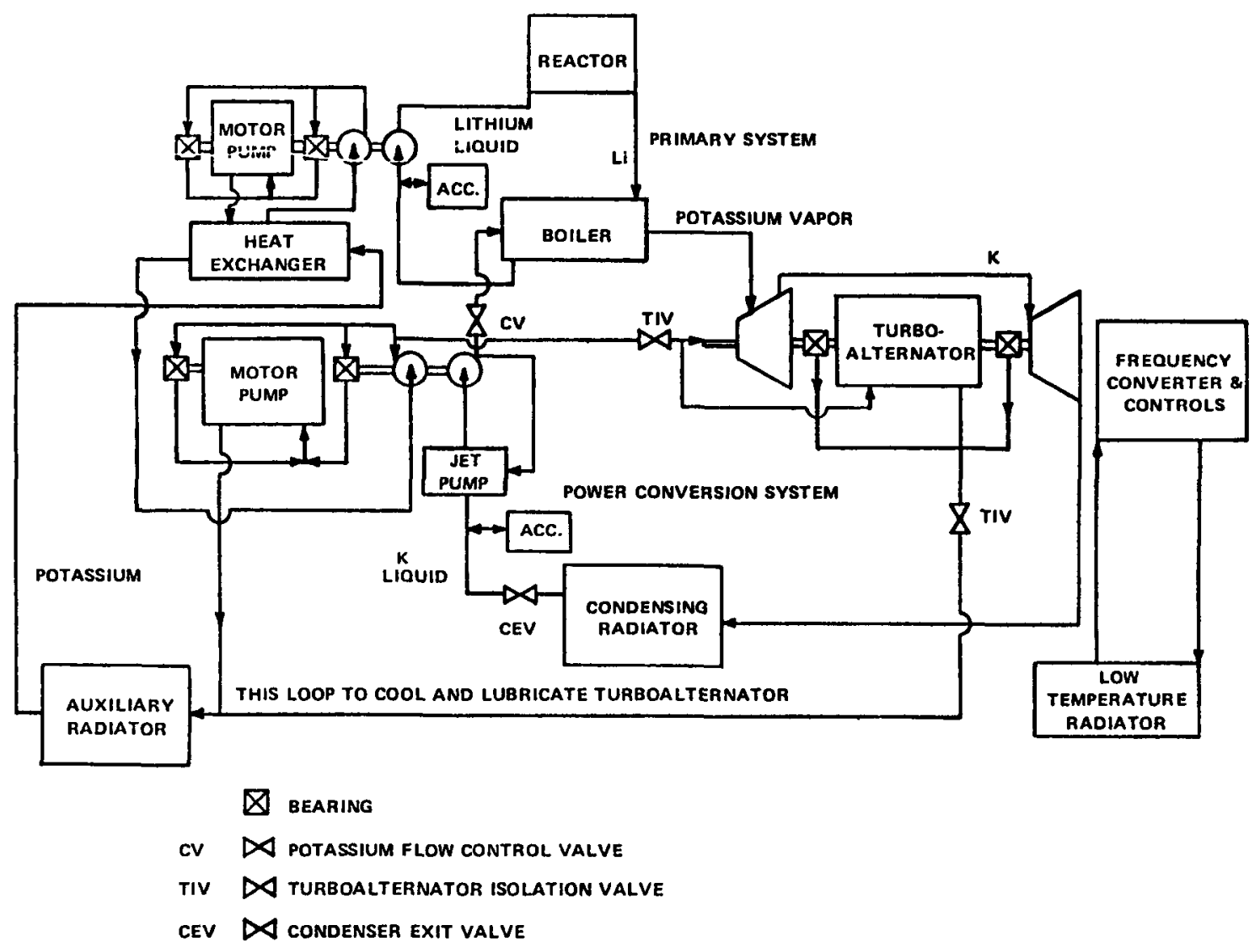

Fig. 31. SNAP-50/Spur schematic.

In principle, the lithium loop could be dispensed with (Ref. 4) by boiling the potassium in the reactor directly. This means of simplifying the system introduces other problems, however, such as unknown behavior of boiling potassium in a gravity-free space environment, unknown nuclear control problems, and difficulty in maintaining high vapor quality at the reactor exit. Therefore, it is more conservative to include the lithium coolant loop in spite of the added complexity.

\section{a. Component Description.}

(1) Reactor and Shield. The reactor, control, and shield arrangement is shown in Fig. 32. The shield is basically the same as the shields for the heat-pipe cooled and the gas-cooled reactors. The shield is separated from the reactor to provide space for the lithium pipes to spread out from the reactor. The control drives are mounted on the other side of the shield from the reactor, with penetrations through the shield for the 
drive shafts. The structure between the shield and the reactor is shown. The Rankine cycle machinery is not shown but it is located behind the shield away from the reactor.

The control of this reactor is by movable reflector segments, which function by varying the neutron leakage. This means of control is easily applied to small fast reactors. Figure 32 shows the segments in the extended position, where reactivity would be minimum. The segments are made of small BeO blocks, held together by metal canning.

Fuel element assemblies are detailed in Fig. 33. The assemblies consist of hexagonal cans with fuel pins stacked loosely inside. The fuel pins are composed of metal tubing, separated from each other by spiral wire wrap and containing the UC or UN ceramic fuel pellets. Each assembly is orificed to control the lithium flow rate. The assemblies are held together by circumferential straps. The lithium flow path is similar to the gas flow path in the gas-cooled reactor previously described. The coolant enters and leaves at the same end of the reactor. After entering, the coolant flows around the periphery of the core, cooling the periphery and the pressure vessel. The preheat jacket is shown in Fig. 33, preheat is needed to melt the coolant before operation of the reactor and the liquid-metal flow system.

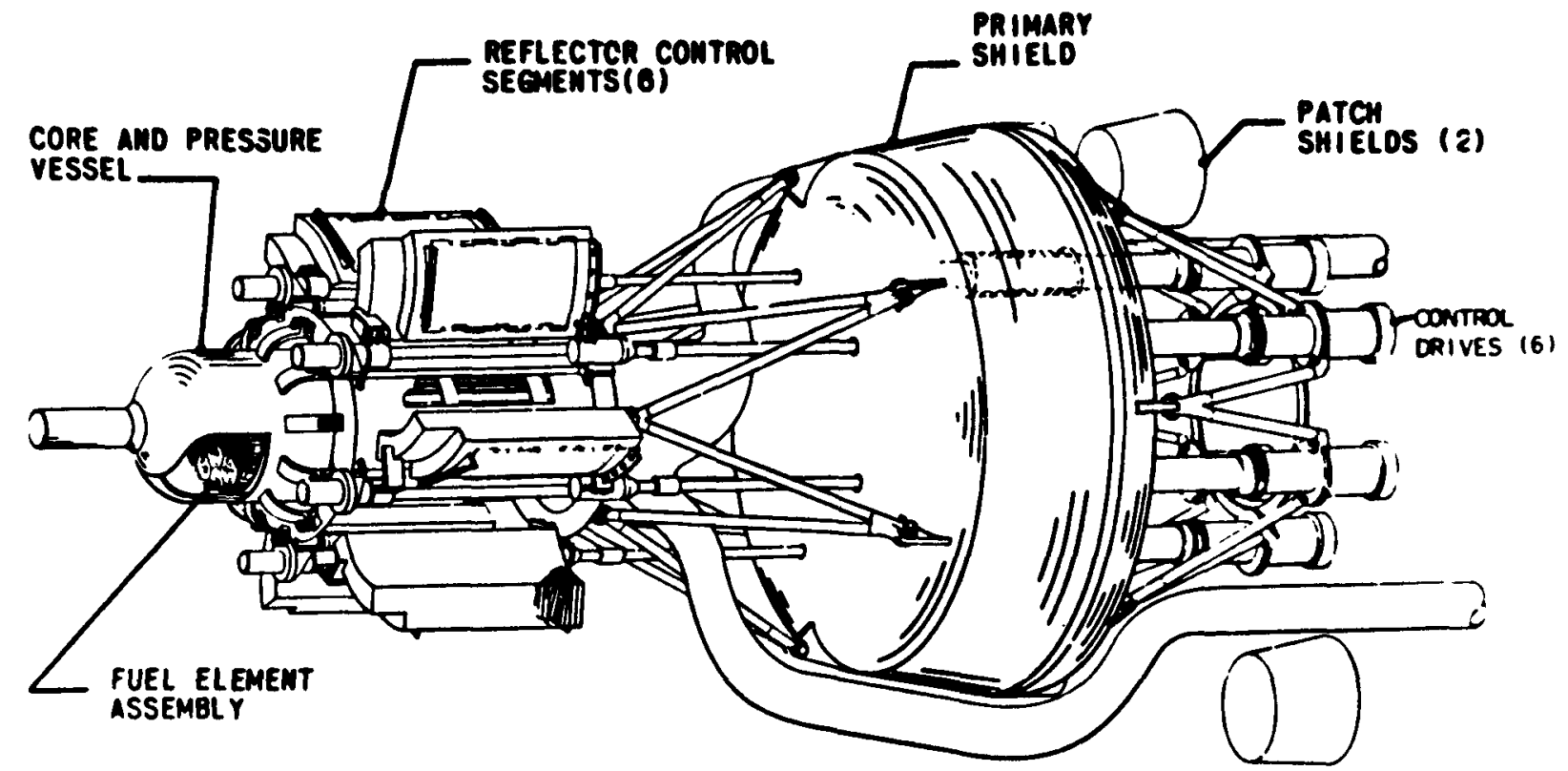

Fig. 32. PWAR-20 (SNAP-50) reactor and shield. 
The liquid-metal cooled reactor also requires a barrier of $W-25 R e$ between the fuel and the clad. A void space is included in the fuel element assemblies for the fission gas.

(2) Converter and Radiator. A representative flow schematic is shown in Fig. 34. The heated lithium from the reactor is passed through a once-through shell and tube-type boiler. This transfers reactor heat to the conversion loop. The potassium in the conversion loop is vaporized in the boiler and then enters the turbine. Here energy is converted to mechanical power to drive an alternator. The alternator produces electric power for the user, to drive the power plant pumps, and to operate the control system. Low-pressure two-phase potassium leaves the turbine and enters the condenser-radiator. The condenser radiator can be an
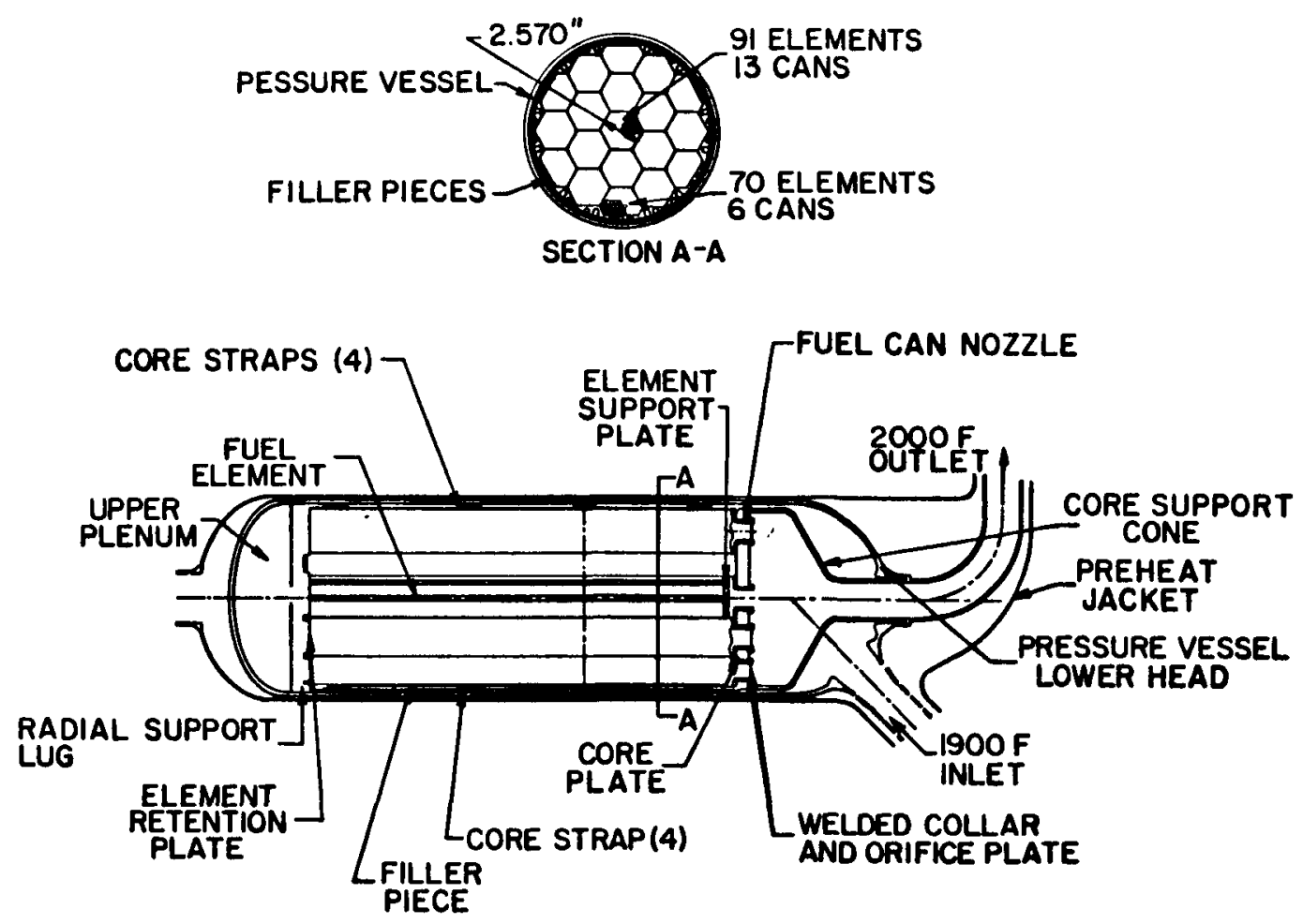

Fig. 33. PWAR-20 (SNAP-50) reactor core and pressure vessel. 
integrated unit or separated depending on the power plant size and physical arrangement. The condenser consists of a number of tubes inside a shell where the potassium is liquified and subcooled by convection. The reject heat is radiated to space. The fluid pressure is then increased by an electromagnetic pump. The cycle is completed with the liquid potassium re-entering the boiler.

A number of auxiliary loops are needed to cool bearings, pumps, etc. An auxiliary radiator is used to reject their heat to space because the temperatures from these loops are lower than the main radiator.

b. Power Plant. A representative power plant is pictured in Fig. 35. Characteristic of the liquid-metal cooled reactor with the Rankine converter are the good efficiencies $(\sim 19 \%)$ and the small radiator (due to of a high heat rejection temperature).

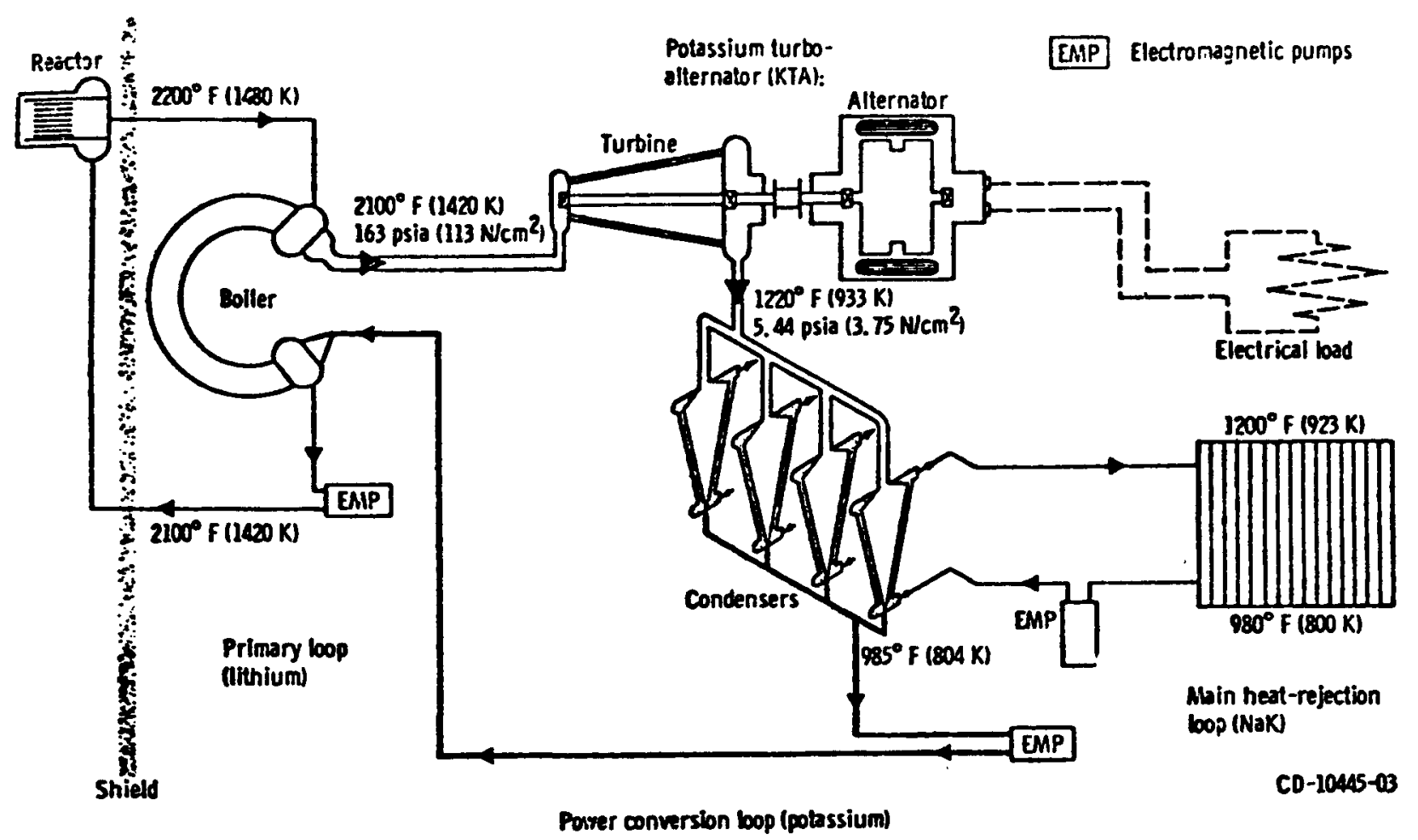

Fig. 34. Advanced Rankine power system. 


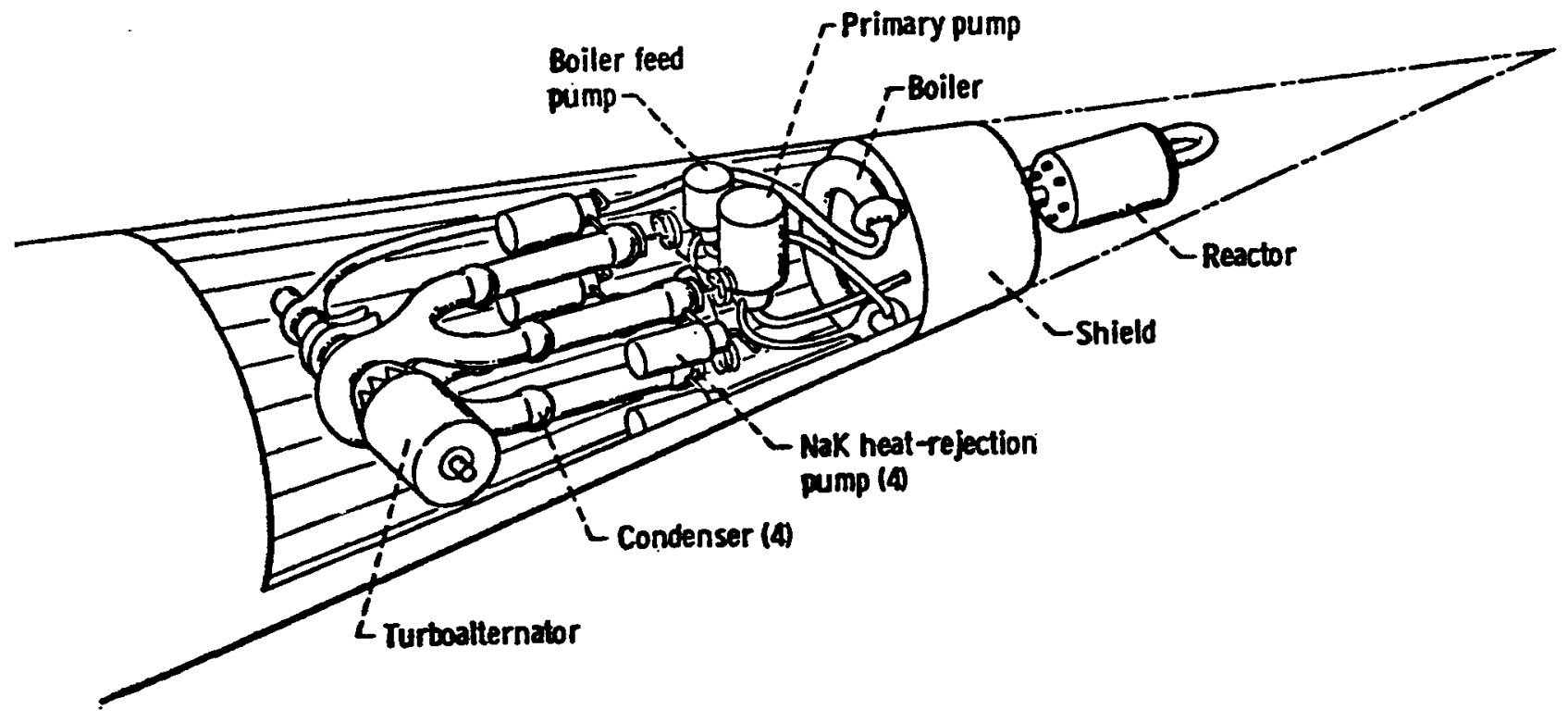

Fig. 35. Advanced Rankine engine system.

\section{REFERENCES}

1. H. J. Banach, "Preliminary Design of the $2 \mathrm{MW}_{t}$ Reactor and Shield. (PWAR-20) for the SNAP-50/SPUR Power Plant," Pratt and Whitney Aircraft, Middletown, Connecticut, report PWAC-445 (December 30 , 1964).

2. J. A. Heller, T. A. Moss, and G. J. Barna, "Study of a 300-Kilowatt Rank ine-Cycle Advanced Nuclear-Electric Space-power System," Lewis Research Center, Cleveland, Ohio, National Aeronautics and Space Administration report NASA TM-X-1919 (November 1969).

3. "Comparison of SNAP-50/SPUR system with MHD, Brayton, Boiling Reactor, and Thermionic," Pratt and Whitney Aircraft, Middletown, Conneticut, report CNLM-6249 (Apri1 27, 1965).

4. "Space Power Program Semiannual Progress Report for Period Ending June 30, 1963," Oak Ridge National Laboratory report ORNL-3489 (11 October 1963).

5. "Reactor and Shield Design Status-SNAP-50," Pratt and Whitney Aircraft, Middletown, Connecticut, report PWAC-471 (September 1965).

6. E. M. Douthett and R. I. Strough, "The SNAP-50/SPUR Program," in Advanced Propulsion Concepts, (Gordon and Breach Science Publishers) 1965. 


\section{REACTOR DESIGNS}

The selected design is a heat-pipe reaçtor with $\mathrm{UO}_{2}-20$ vol\% Mo fuel. The reflector is beryllium except where penetrated by heat pipes. Here, the higher temperatures favor use of Be0. Power level is controlled by positioning neutron absorber material in the radial reflector with rotating drums containing segments of $B_{4} C$.

The mission requirements for high power, small size, and long lifetime call for a fast spectrum, highly enriched reactor that will have a large inventory of fuel in a small volume. The large fuel inventory prevents large reactivity decreases due to fuel burnup. In seven years, a $1-M_{t}$

reactor will burn $\sim 2.5 \mathrm{~kg}$ of ${ }^{235} \mathrm{U}$. To maintain reactor criticality during the mission this amount of burned fuel cannot represent more than a few percent of the total.

The reactor systems that were under consideration all involve the use of refractory nuclear fuels UC-ZrC or $\mathrm{UO}_{2}-\mathrm{Mo}$. (UN was eliminated because it requires nitrogen overpressure at the temperatures of interest). Of primary importance to the power plant design is that these fuels have high uranium densities and that they allow source temperatures of 1400-1500 and possibly $1700 \mathrm{~K}$ for electric conversion systems.

Calculations were performed on heat-pipe reactors and gas-cooled reactors to correspond with the leading converter candidates. Liquid-metal reactors were considered using data from the SNAP-50 programs.

The use of heat pipes to remove heat from the core offers several advantages. Foremost is the avoidance of single-failure point in the core cooling system. In the event of a heat-pipe failure, the adjacent heat pipes carry off the heat generated in the failed element. Electric output may be degraded slightly but the power plant is not shut down, as would be the case when a reactor cooled either by gas or liquid metal developed a leak in the cooling circuit. In addition, heat-pipe reactors should be more reliable because mechanical or electromagnetic pumps are eliminated. $A$ heat exchanger between the core and the electric conversion system is also eliminated in designs where thermoelectric or thermionic converters are bonded directly to core heat pipes. By nature of their operation, heat pipes involve small mass flows. Consequently, the inventory of coolant fluid is much less than that for a liquid-metal system and the problems of 
coolant activation and corrosion are reduced correspondingly. Finally, preliminary systems analys is indicates a slight reactor-weight advantage at low power (below $1 \mathrm{MW}_{t}$ ) for the heat-pipe reactor.

Gas-cooled reactors offer an advantage with Brayton or Stirling converters in that heat exchangers are eliminated between the reactor and the power conversion loops. There is also more experience with this type of reactor.

\section{A. Reactor Assembly Design}

\section{Component Description.}

a. Heat-Pipe Core Subassembly. The $\mathrm{UO}_{2}-\mathrm{Ma}$ fuel is arranged in layers around the heat pipes in one possible configuration. Because $\mathrm{UO}_{2}$ has very poor thermal conductivity, molybdenum is added to improve the conduction of heat from the fuel to the heat pipe in a fin-like arrangement. The core can be composed of modules, each of which can be completely assembled without concern for criticality. Each module is built up of alternate layers of $\mathrm{UO}_{2}$ and molybdenum. The basic $\mathrm{UO}_{2}$ unit is a thin hexagon with a central hole, like an unthreaded nut (Fig. 36). Each unit fits loosely over a heat pipe. When each heat pipe has one $\mathrm{UO}_{2}$ fuel unit, a molybdenum layer is then put in place. The molybdenum sheet covers the cross section of the module, and is perforated for a tight fit over the heat pipes (Fig. 37). The module is thus built up, layer by layer. The molybdenum sheet is thermally bonded to the molybdenum heat pipes by brazing.
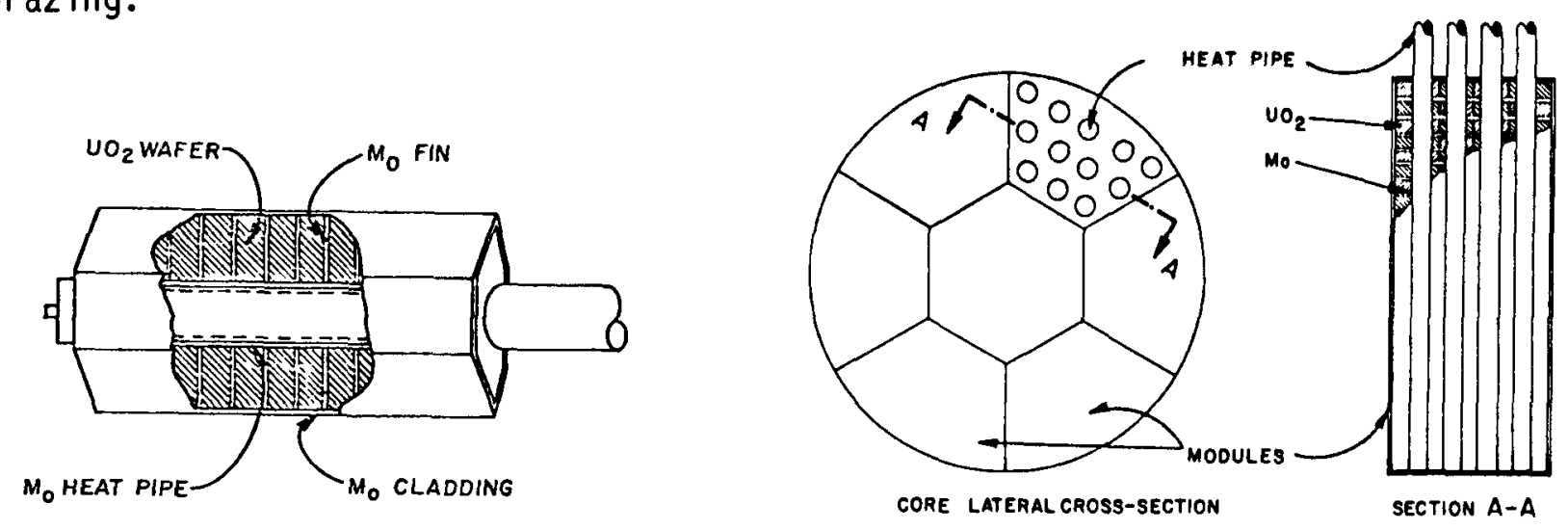

Fig. 36. Fuel element wafer configuration.

Fig. 37. Wafer core design avoids thermal contact problem between elements. 
Another fuel element form considered has a hexagonal shape. Here, a typical fuel element consists of a molybdenum heat pipe bonded along the axis of a hexagonal fuel body. In the case of UC-ZrC, the fuel is segmented radially and longitudinally to allow unrestrained thermal expansion and to provide room for fuel swelling (Fig. 38). The outside of the fuel element is clad with molybdenum.

The UC-ZrC expands more than molybdenum. Advantage is taken of this thermal expansion mismatch to obtain thermal bonding of fuel segments to the heat pipe. However, this mismatch appears to be too large to make diffusion or braze bonding a practical means of establishing thermal contact. If experiments do not show a satisfactory thermal bond, then a bonding material will be needed between the fuel and heat pipe.

With $\mathrm{UO}_{2}-\mathrm{Mo}$, the fuel body is not clad or segmented radially. It consists of solid hexagonal segments of molybdenum drilled with small holes into which $\mathrm{UO}_{2}$ pellets are inserted (Fig. 39). The maximum practical concentration of $\mathrm{UO}_{2}$ within the fuel region yields an average composition of $60 \mathrm{vol}^{\%} \mathrm{UO}_{2}$ and 40 vol\% molybdenum. The fuel section of the heat pipe is followed by a reflector segment of $\mathrm{BeO}$ canned in molybdenum. A thin layer of $B_{4} C$ is placed between the fuel and the BeO segments to absorb low-energy reflected neutrons. $\mathrm{UO}_{2}$-Mo can also take the form of a cermet, in which case the $\mathrm{UO}_{2}$ loading can be increased to $~ 80-85 \%$.

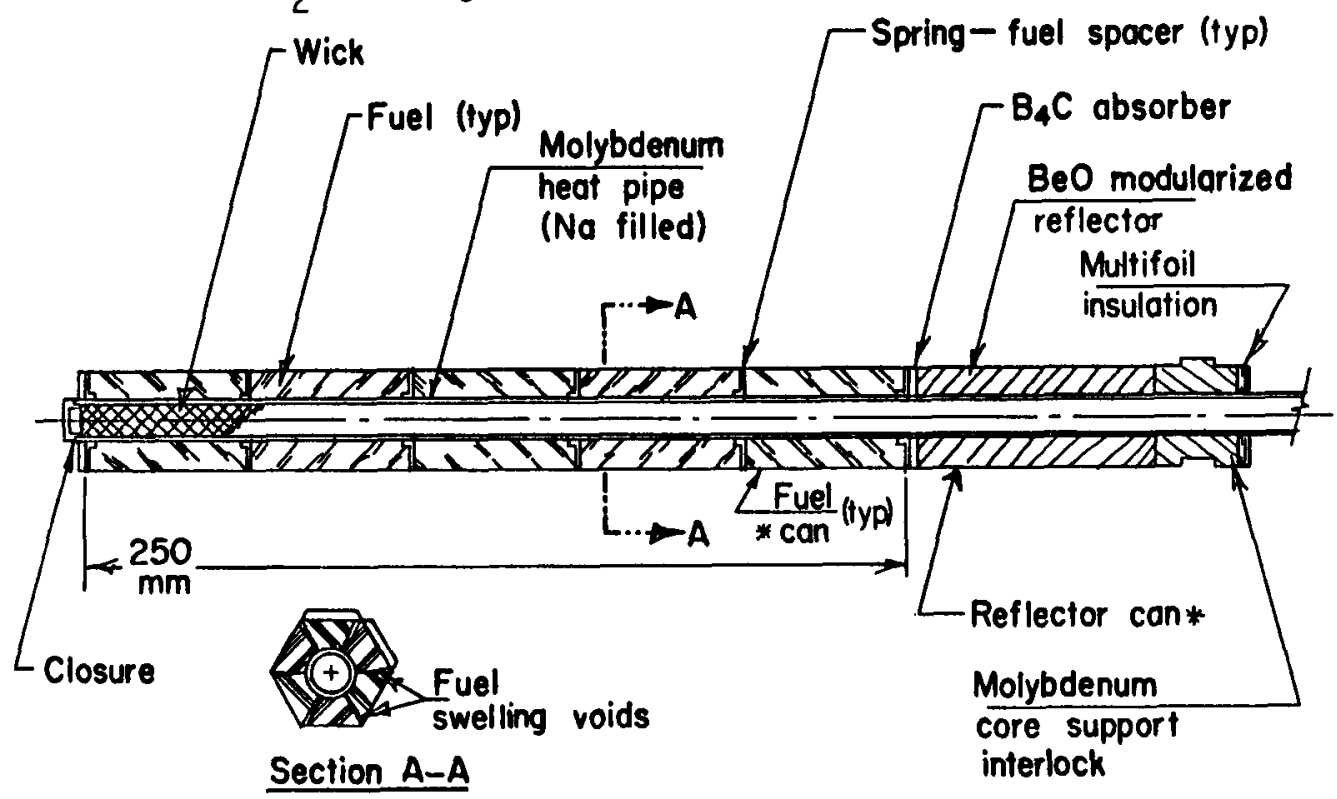

* Thin walled, therefore, not shown.

Fig. 38. UC-ZrC heat-pipe fuel element. 


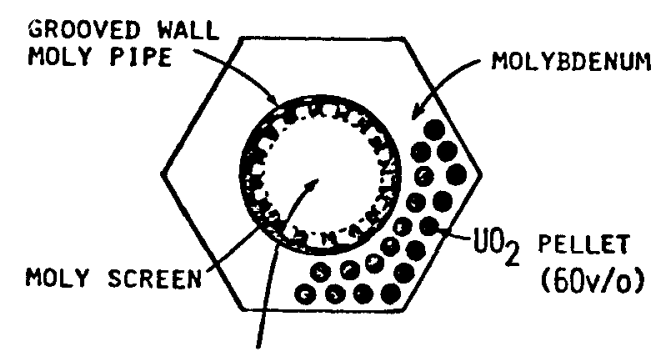

LI OR NA VAPOR

Fig. 39. Heat-pipe fuel element.

The preferred heat-pipe design for the fuel elements is an axiallygrooved wall covered with a fine screen. This wick structure provides multiple redundant low-impedance paths for returning the condenser vapor to the heat-pipe evaporator section. It should be easy to bend and relatively easy to build if an adequate method for grooving molybdenum is developed.

A spacer arrangement for the core is shown in Fig. 40 and a hexagonal array for the fuel elements is shown in Fig. 41. The number of heat pipes in the core depends on the desired power level. This will be examined in

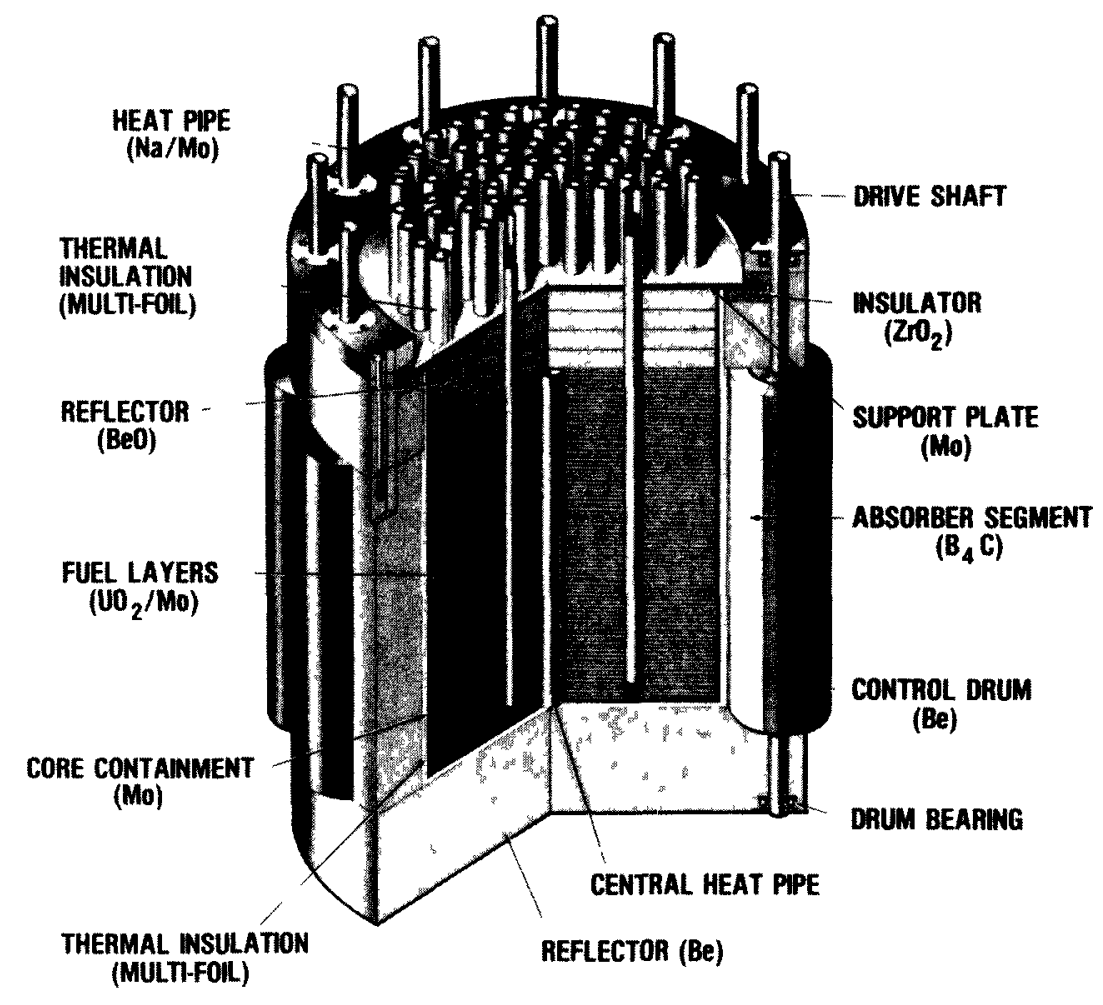

Fig. 40. Wafer design heat-pipe reactor. 


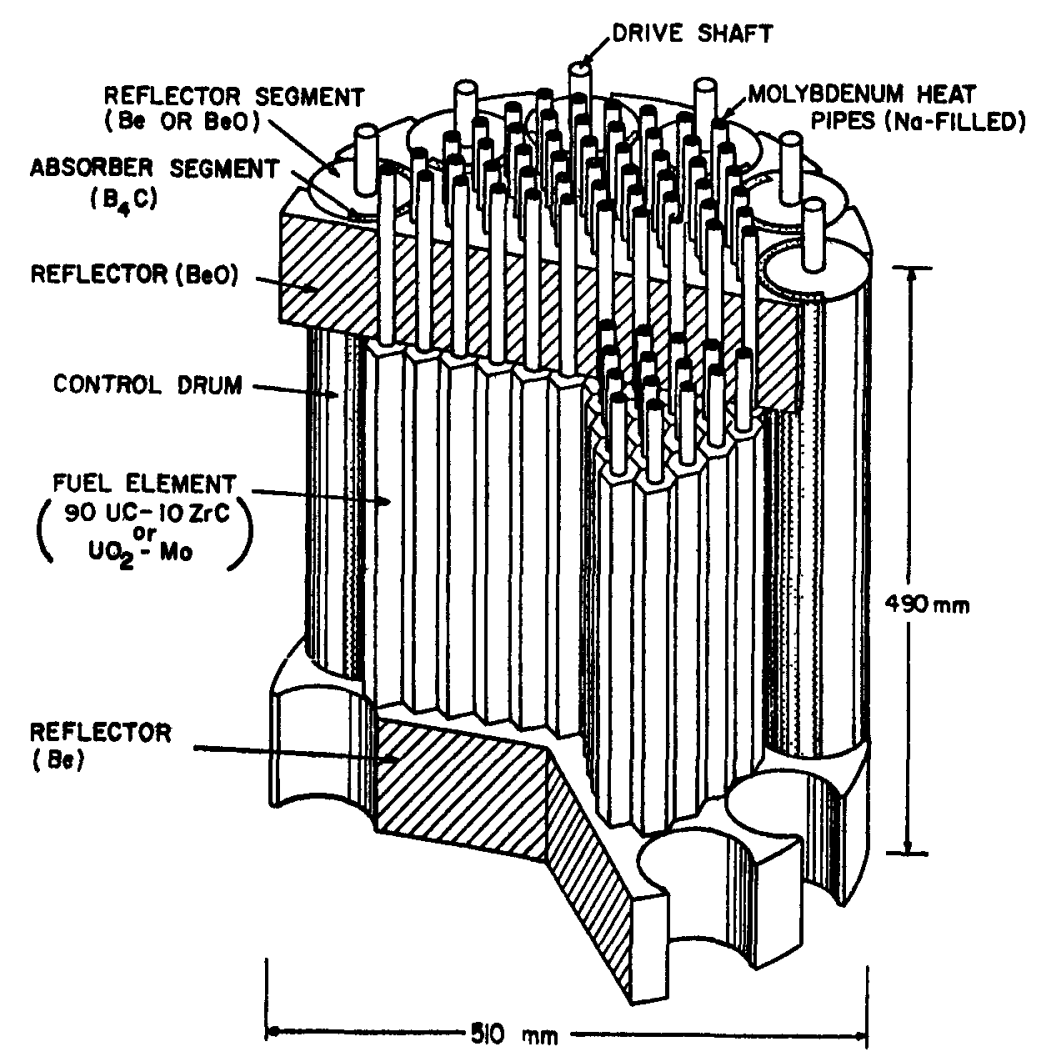

Fig. 41. Heat-pipe reactor.

the section on heat-pipe failures. The core assembly is surrounded by a layer of multifoil thermal insulation and a thin thermal-neutron absorber. The purpose of the absorber is to reduce power peaking along the periphery of the core caused by fissions produced by low-energy reflected neutrons. The core assembly is surrounded by a radial reflector assembly containing the reactor control systems and by an axial reflector located opposite the end where the heat pipes emerge.

Where fuel elements are separated (Fig. 41), the reactor core should be maintained under radial compression to establish good heat transfer paths between them. This maintains a stable geometry for nuclear control. Previously, compression was maintained by a radial spring arrangement. A review of the design indicates that a band arrangement will be lighter and less bulky. This approach is not novel. It was incorporated in the SNAP-50 space reactor design. ${ }^{1}$ A number of thin high-temperature resistant metal hoops are required. These are pretensioned. As the core heats up and expands, the cooler bands may yield, which is acceptable. 
b. Gas-Cooled Core Subassembly. Extensive experience with gas-cooled reactors exists from the ROVER space nuclear rocket program. We modified the basic ROVER design to take advantage of the lower operating tempertures. This included simplifying the core support system and locating the pressure vessel at the core periphery inside the reflector (Fig. 42). Fuel elements are ROVER-type, hexagonal in cross section, with round holes on a triangular spacing. Although the elements are shown in full-length, they could be segmented axially, with the holes lined up between segments.

The gas enters through a duct at one end of the reactor, is distributed around the circumference, and flows in a peripheral annulus. In this first passage, the gas cools the core periphery and the pressure vessel. (The side reflector, not shown on the schematic, is outside the pressure vessel; reflector cooling is by radiation.)

After the first pass, the gas reverses direction, cooling the end reflector, the fuel elements, and the other end reflector. It is collected and leaves through the exit duct.

\section{c. Reflector Subassembly. The most desirable material for re-} flecting neutrons is $\mathrm{Be} 0$, followed by beryllium. The radial reflector and the end reflector that is not penetrated by the core heat pipes will be cool compared to the core, and could be made from beryllium, which may be

AXIAL SECTION

\section{CROSS SECTION}

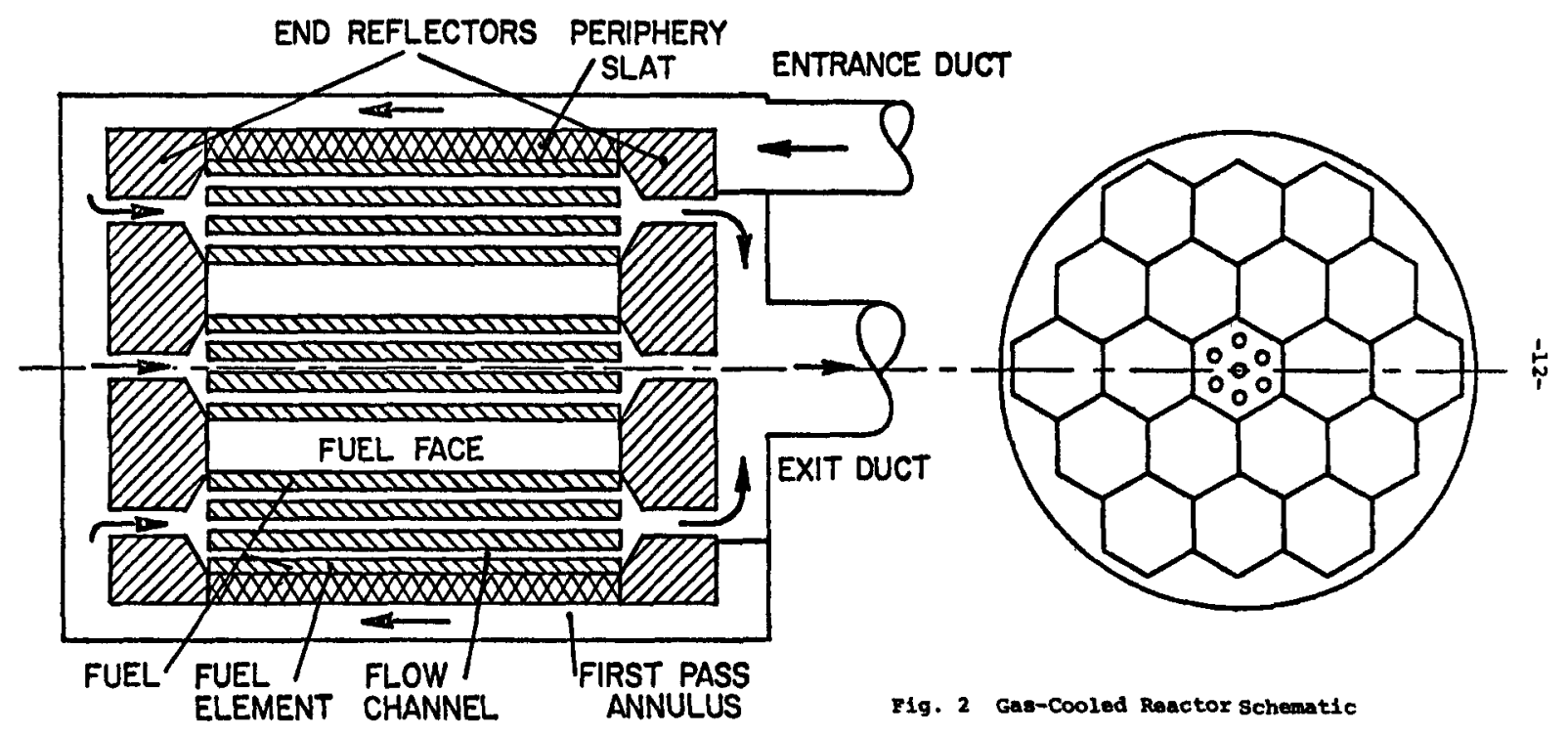

Fig. 42. Gas-cooled reactor schematic. 
easier to fabricate then Be0. Beryllium is lighter than Be0; however, its use does not result in a lighter reactor because a greater thickness of beryllium is required. The nominal reflector thickness is $100 \mathrm{~mm}$; but 80 $\mathrm{mm}$ of $\mathrm{BeO}$ is as effective as $100 \mathrm{~mm}$ of beryllium. Reactivity control for the reactor is provided in the radial reflector by rotating drums containing sectors of $\mathrm{B}_{4} \mathrm{C}$. For maximum control margin the boron should be enriched in ${ }^{10} \mathrm{~B}$ and the thickness of $\mathrm{B}_{4} \mathrm{C}$ should be $20-30 \mathrm{~mm}$. The reflector control is chosen to minimize the complexity and size of the core, and for the enhanced reliability that comes from placing the control elements outside the high-temperature and high-iradiation environment of the core.

The reactivity control could be provided by rotating vanes or shutters instead of $\mathrm{B}_{4} \mathrm{C}$ loaded drums. These control schemes have not been investigated yet.

\section{Design Constraints.}

a. Neutron Reactivity. We determined the critical size of the reactors from one-dimensional neutron transport calculations with the use of the ONE-TRAN code. ${ }^{2}$ This multigroup, discrete ordinates code supersedes the DTF-IV transport code. ${ }^{3}$ The calculations were performed with 30-group neutron cross sections that were generated from the ENDFB/4 cross-section library. The critical configuration of the reactor was modeled in one dimension, as shown in Fig. 43 with the core divided into six zones to allow varying of the fuel composition for radial power flattening. The radial power profile was flattened to $\pm 5 \%$. In the case of $U C-\operatorname{ZrC}$ fuel, power flattening was achieved by varying the volume fraction of the fuel. With $\mathrm{UO}_{2}-\mathrm{Mo}$, it was achieved by adjusting the relative volume fractions of $\mathrm{UO}_{2}$ and molybdenum. The relative radial fuel concentrations for these two fuels are shown in Fig. 44.

The reactor model described in Fig. 43 shows a 2-mm stationary layer of $\mathrm{B}_{4} \mathrm{C}$ around the core assembly. Its purpose is to reduce power peaking on the edge of the core due to fissions produced by low-energy neutrons reflected into the core from the Be or BeO reflector. The effectiveness of the $\mathrm{B}_{4} \mathrm{C}$ layer is shown in $\mathrm{Fig}$. 45 , which is the result of a calculation done on a simplified reactor model consisting of a uniformly loaded UC-ZrC core ( $0.18 \mathrm{~m}$ in diameter) surrounded by $100 \mathrm{~mm}$ of $\mathrm{Be} 0$. 


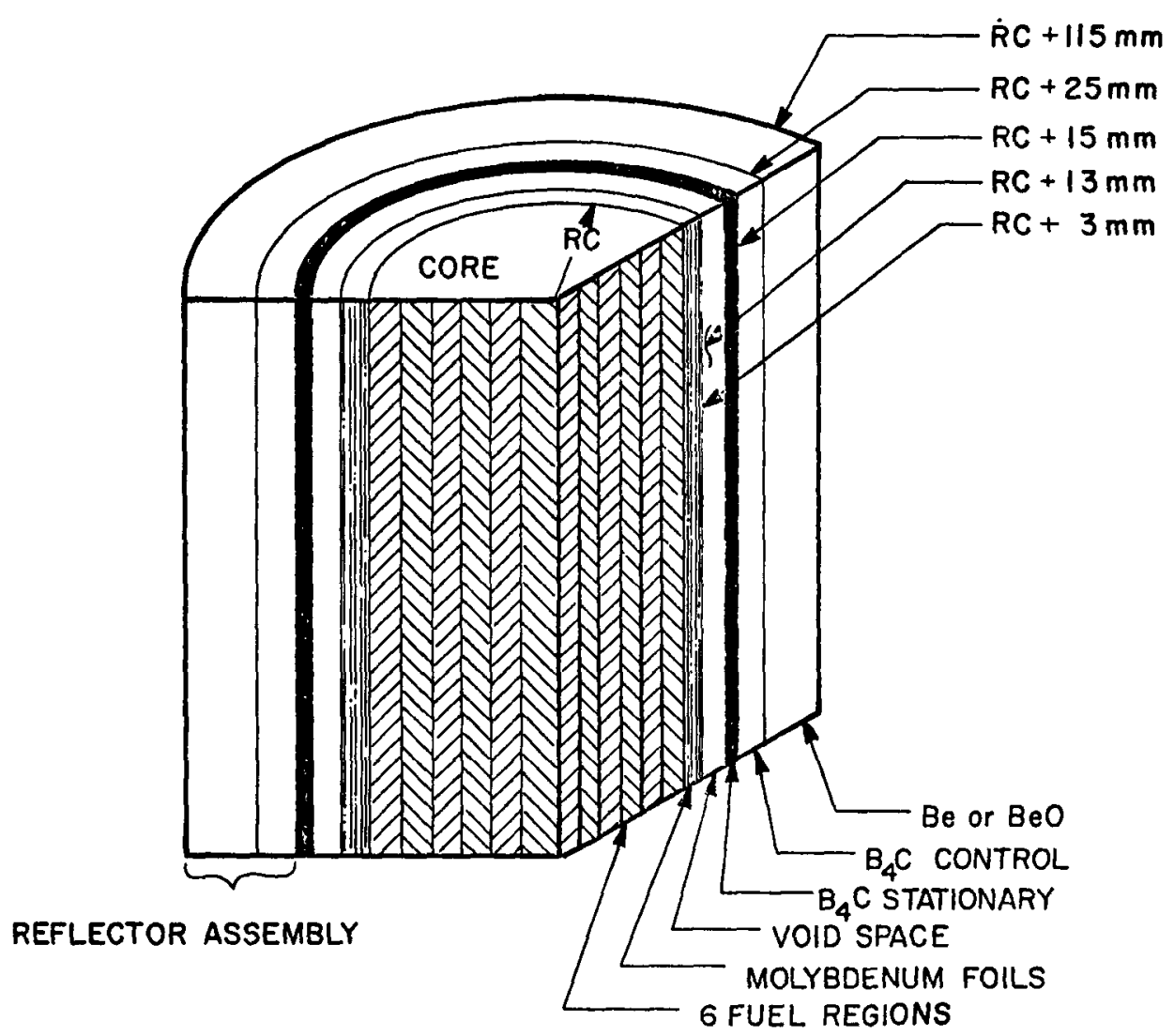

Fig. 43. One-dimensional model of reactor used in neutronic calculations.

In the absence of two-dimensional neutron transport calculations, it was estimated that a buckling-height to core-diameter ratio $(H / D)$ of 1.2 corresponds to a right cylinder core reflected on all sides by an equal thickness of reflector (all the system design calculations were performed for a right circular cylinder reactor). A summary of the neutron calculations shown in Fig. 46 indicates the variation of core diameter with the non-fuel volume fraction for different ratios of $H / D$. This volume fraction is defined as the volume fraction of the core that is not occupied by $100 \%$ dense fuel. It includes the heat pipe, fuel cladding, fuel porosity and expansion allowance, and voids in the core external to a fuel element (for example, in the absence of a central fuel element, or in gaps between elements).

b. Heat Removal. The heat transfer capability of heat pipes is a function of many parameters. Foremost is the operating temperature and the working fluid. Sodium is an ideal fluid for the temperature range $1200-1400 \mathrm{~K}$ because the pressure of the vapor is not too high (less than 10 


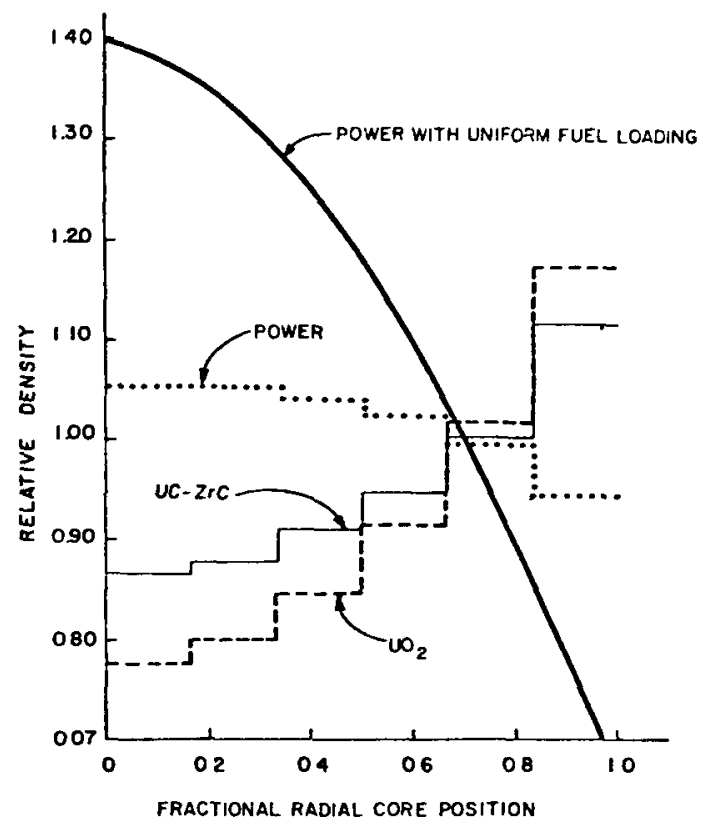

Fig. 44. Relative fuel concentration and power density vs radial position.

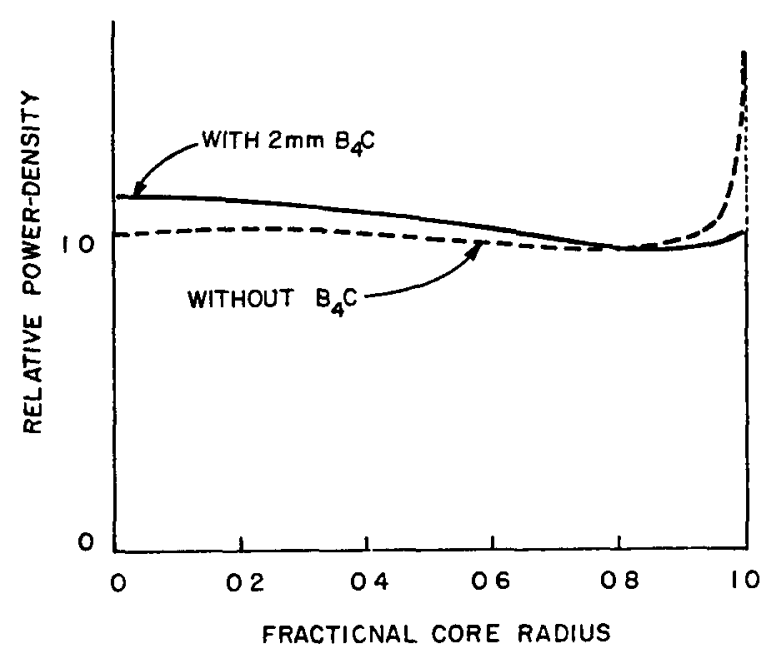

Fig. 45. Effect on radial power density of $2-\mathrm{mm} \mathrm{B}_{4} \mathrm{C}$ Tayer located on core periphery.

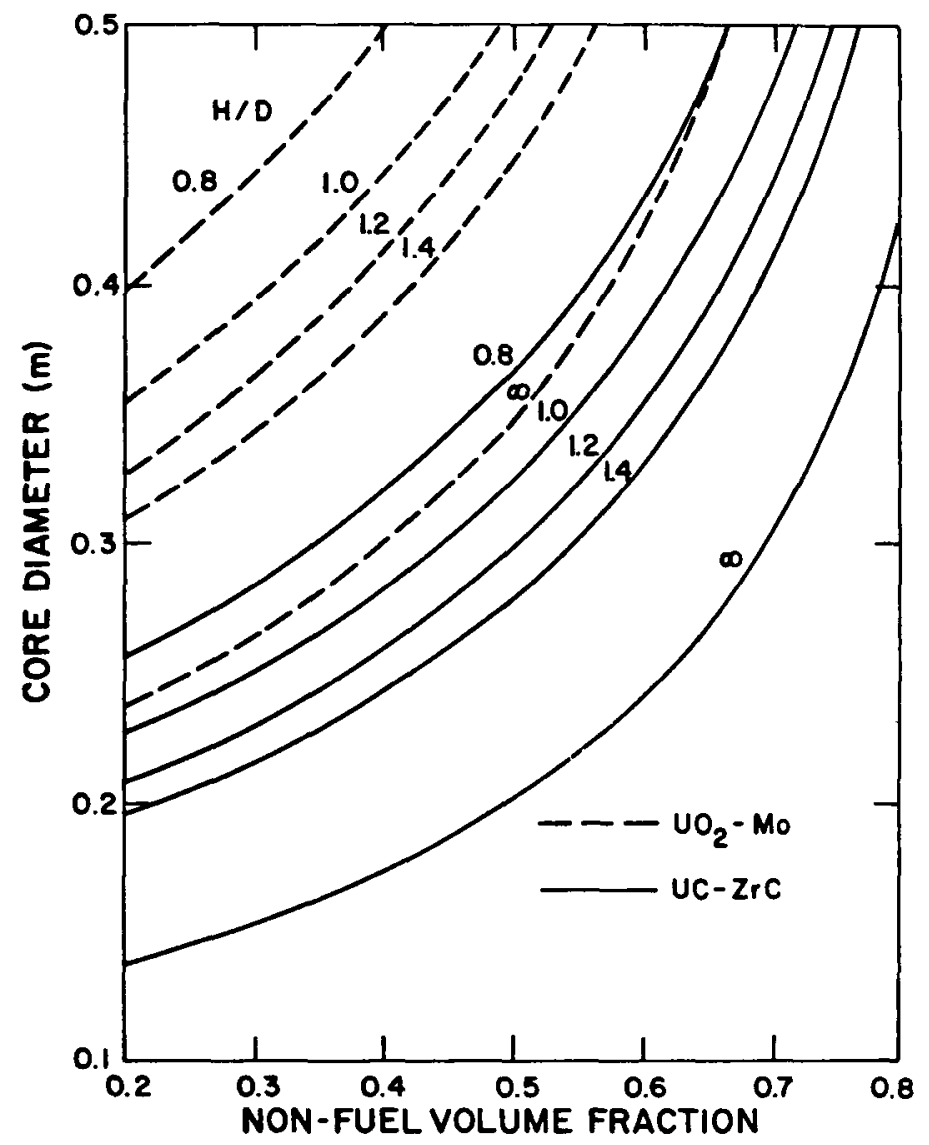

Fig. 46. Critical core diameter vs non-fuel volume fraction for UC-ZrC and $\mathrm{UO}_{2}$-Mo reactors with varying $\mathrm{H} / \mathrm{D}$. 
atmospheres) and its sonic limit is much higher than any practical heat transfer rate. (The sonic limit of a given working fluid is the axial heat transfer rate when the vapor is moving at sonic velocity.) At $1200 \mathrm{~K}$, this limit is $500 \mathrm{MW} / \mathrm{m}^{2}\left(50 \mathrm{~kW} / \mathrm{cm}^{2}\right)$. A practical limit of $100 \mathrm{MW} / \mathrm{m}^{2}\left(10 \mathrm{~kW} / \mathrm{cm}^{2}\right)$ was arbitrarily assumed for the system design calculations. Although this axial heat flux is quite high, it has nevertheless been demonstrated in the laboratory. ${ }^{4,5}$

The problem of determining how much power can be extracted from a core of a given size and non-fuel volume'fraction is simply that of calculating the total cross-section area available for the heat-pipe vapor space and multiplying that area by the assumed heat-pipe performance limit. Given a non-fuel volume fraction and a desired power level, one can compute the required core diameter, as shown in the heat removal curves of Fig. 47.

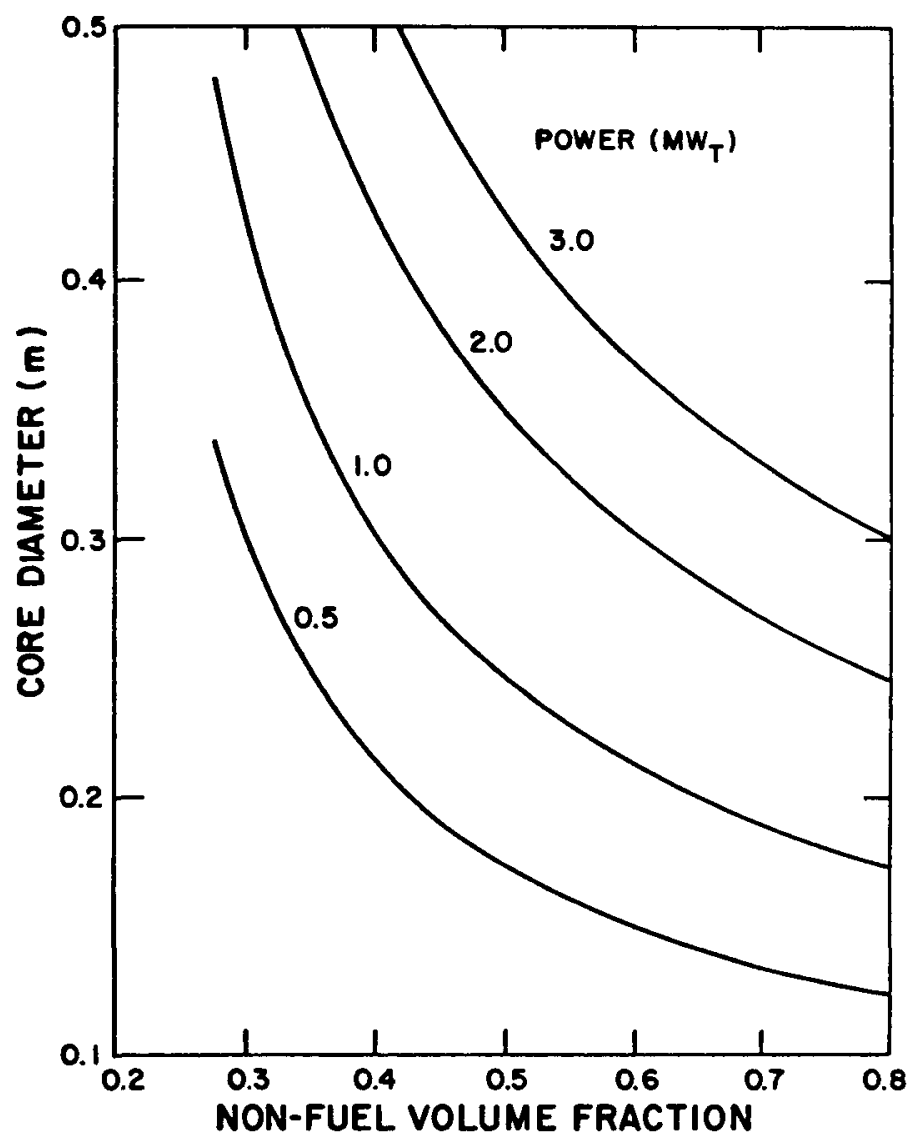

Fig. 47. Minimum UC-ZrC core diameter vs non-fuel volume fraction needed to remove thermal power. 
As part of an on-going effort in the NEP program, ${ }^{5}$ recent experiments have been carried out on high-temperature heat pipes having design characteristics quite similar to those being proposed for the $1-\mathrm{MW}_{\mathrm{t}}$ SPAR reactor. A 2-mm-long, 25-mm-diameter stainless steel sodium heat pipe having a wick structure consisting of five screen arteries was tested in the temperature range 900-1150 K. This heat pipe transferred $20 \mathrm{~kW}(7.2$ $\mathrm{kW} / \mathrm{cm}^{2}$ of vapor area) at $1150 \mathrm{~K}$. This rate was not a limit but a stable operating point near the expected limit. Extrapolation of the data to 1300 $K$ gives a heat transfer rate in excess of $11 \mathrm{~kW} / \mathrm{cm}^{2}(30 \mathrm{~kW})$. This compares very favorably with the limit of $10 \mathrm{~kW} / \mathrm{cm}^{2}$ currently assumed in the SPAR (Space Power Reactor) reactor system studies.

Another experiment was conducted with a molybdenum-lithium heat pipe of similar dimensions but having a corrugated screen ( 15 corrugations) wick structure. This test was performed in the temperature range $1200-1400 \mathrm{~K}$. The heat pipe performed very we11, departing from the sonic 1 imit at $1380 \mathrm{~K}$. A heat transfer 1 imit of $11.3 \mathrm{~kW} / \mathrm{cm}^{2}(27 \mathrm{~kW})$ was observed at $1405 \mathrm{~K}$, the maximum temperature reached in the test. Attempts to achieve higher power levels resulted in the destruction of the heat pipe caused by arcing between the heat pipe and the RF coil generating the power for the experiment. These two tests under realistic conditions demonstrate that the heat-pipe performance assumed in the SPAR reactor design studies is achievable.

The reactor core diameter in a heat-pipe reactor must be increased to maintain criticality as the power level is raised because more heat-pipe cross-section area must be provided. As power is increased, the capacity to extract more energy must be enlarged. Compare this with a gas-cooled reactor. The reactor cooling holes are sized for a given inlet temperature, temperature rise, and fractional pressure drop (delta $p / p$ ). The coolant mass-flow rate is determined by thermal power, temperature and temperature rise. If we increase the reactor power, holding inlet temperature, temperature rise, and delta $\mathrm{p} / \mathrm{p}$ constant, the coolant mass-flow rate must increase proportionally to the power. To maintain delta $p / p$ we must either increase the flow area (more or larger diameter cooling holes) or increase the pressure level. Increasing the pressure level proportionally to power maintains the flow velocity and holds delta $p / p$ constant. (Delta $\mathrm{p} / \mathrm{p}$ must be kept low, $\sim 2 \%$, for good thermodynamic cycle performance.) The 
performance of Brayton machinery improves when pressure increases with power, although not quite linearly. So, to optimize a gas-cooled design as power is increased, the pressure level must increase somewhat less and the hole size or number of holes must increase only slightly. Heat transfer film drop does notincrease much with increasing power, as the coefficient of heat transfer varies almost as the first power of mass flow for constant flow area.

c. Reactor Core Size Optimization. The minimum reactor core size is obtained by optimizing the conflicting requirements of heat removal and criticality as shown for a typical reactor in Fig. 48. The dashed curve shows how the core diameter increases with decreasing non-fuel volume fraction (which contains the volume fraction available to the heat pipes or to the coolant channels) to extract a specified power from the core, in this case $1 \mathrm{MW}_{\mathrm{t}}$. The point of intersection of the solid and dashed curves is the minimum core diameter that satisfies both criticality and heat removal requirements. Additional problems such as fuel swelling, burnup, thermal stresses and exceeding the maximum fuel temperature may raise the core diameter above the minimum value. These problems, except fuel swelling above $1400 \mathrm{~K}$, are alleviated by reducing the power density in the fuel region for example, by increasing the fuel porosity. The net effect is to shift the heat removal curve toward the right resulting in a higher value of the core diameter at the point of intersection.

Fuel swelling becomes a problem with the UC-ZrC fuel above $1400 \mathrm{~K}$ and with the $\mathrm{UO}_{2}$-Mo above $1700 \mathrm{~K}$. The fuel-swelling estimates are based on data summarized in Fig. $49 .^{6,7}$ The data show that fuel swelling increases exponentially with temperature and linearly with fission density (hence, linearly with power density and lifetime). Swelling data for $\mathrm{UO}_{2}-40$ vol\% Mo is not available and it was assumed, on the basis of equivalent strain in the molybdenum matrix, that this fuel has three times the swelling rate of $\mathrm{UO}_{2}-60$ vol\% Mo. The criterion for the design calculations is to limit fuel swelling to less than $10 \%$ of the fuel region, where the fuel region is defined as the volume occupied by $100 \%$ dense fuel plus the voids allotted for porosity and fuel expansion. Figure 50 shows reactor mass vs thermal power level for different heat-pipe operating temperatures. Deviations from 


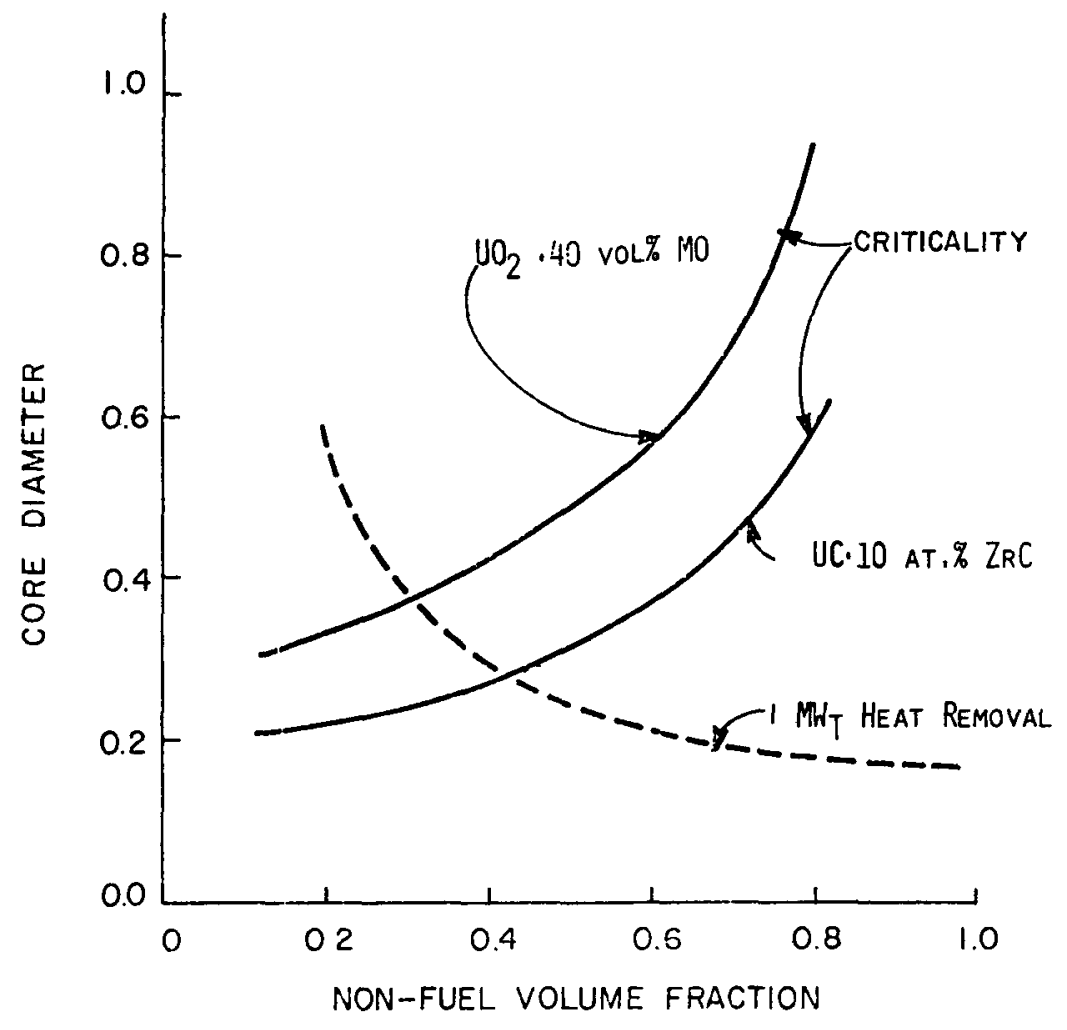

Fig. 48. Minimum core size of UC-ZrC reactor is smaller than that of $\mathrm{NO}_{2}$-Mo.

the lowest curve for each fuel type are due to the fuel swelling limitation. These curves were calculated for a 10-yr lifetime for right cylinder reactors reflected with $100 \mathrm{~mm}$ of $\mathrm{Be} 0$.

d. Thermal Analys is of Layered Fuel Heat-Pipe Reactors. We performed a preliminary thermal analys is of the layered $\mathrm{UO}_{2}-20$ vol\% Mo fuel heat-pipe reactor. Temperatures in the fuel were computed as a function of fuel thickness. The effects of varying the thermal coupling of $\mathrm{UO}_{2}$ to Mo were considered.

Space reactors with $\mathrm{UO}_{2}-40$ vol\% Mo fuel have been studied along with UC-10 at.\% $\mathrm{ZrC}$ fueled reactors. The former reactors have higher-temperature capabilities, less fuel swelling, and more predictable thermal characteristics, particularly for failed heat-pipe conditions. However, because the fuel is more dilute, these reactors are larger and heavier than the UC reactors at low power (under $\sim 2 \mathrm{MW}_{\mathrm{t}}$ ) where the core is criticality limited. A $1000-\mathrm{kW}_{\mathrm{t}}$ reactor with a layered $\mathrm{UO}_{2}-20$ vol\% Mo fue $\mathrm{l}$ and a mass of $477 \mathrm{~kg}$ was only $15 \%$ heavier than the corresponding UC-10 at.\% $\mathrm{ZrC}$ reactor. Some advantages of the layered core follow. 


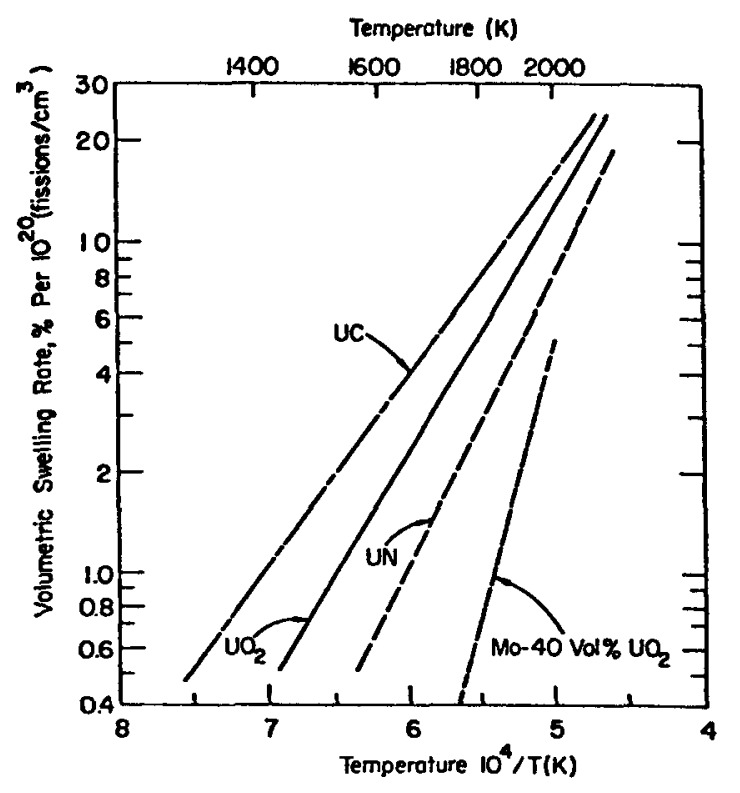

Fig. 49. Dependence of fuel swelling on fission density and temperature for $U C, U N, \mathrm{UO}_{2}$ and $\mathrm{UO}_{2}-60$ vol\% Mo.

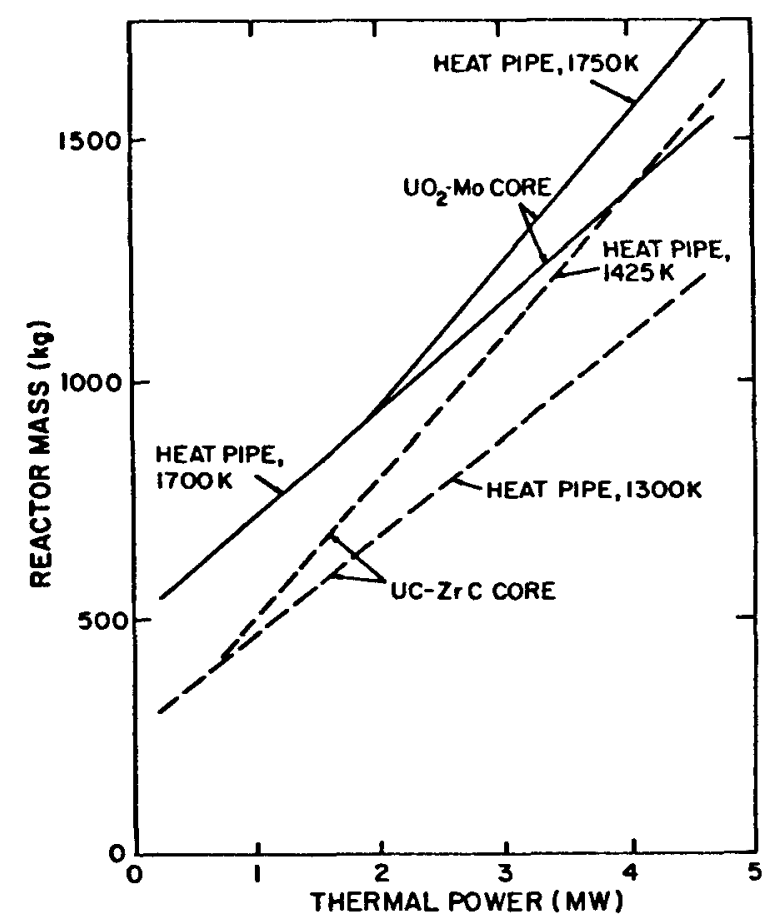

Fig. 50. Weight vs thermal power for $\mathrm{UO}_{2}-40$ vol\% Mo and UC- 10 at.\% ZrC reactors. The weights include a $1-m$ extension of heat pipes outside the reactor.

- The heat transfer structure is metallic so that

(1) the structure can be brazed together,

(2) the structure is analyzable and reliable, and

(3) heat removal is good in the failed heat-pipe situation.

- The fuel is $\mathrm{UO}_{2}$ so that

(1) fabrication technology and characterization is well developed,

(2) it can get very hot before melting (at $3000 \mathrm{~K}$ ) or cracking without changing the structure, and,

(3) although high temperatures increase the swelling and evaporation rate, the heat transfer to the molybdenum structure will improve with swelling and evaporation due to improved thermal contact.

- The modular design is easier and safer to assemble.

Design data are given in Table XI. The following are assumptions made in the thermal analysis of this reactor. 
TABLE XI

$\begin{array}{lr}\text { DESIGN DATA FOR UO }{ }_{2}-20 \text { vol\% MO HEAT-PIPE REACTOR } \\ \text { Reactor power (kWt) } & 1000 \\ \text { Number of heat pipes } & 90 \\ \text { Heat-pipe temperature }(\mathrm{K}) & 1400 \\ \text { Core diameter }(\mathrm{m}) & 0.30 \\ \text { Core height }(\mathrm{m}) & 0.30 \\ \text { Heat pipe o.d. }(\mathrm{mm}) & 15.4\end{array}$

- For calculations made for maximum power location, max/avg power is 1.5 .

- Molybdenum sheets are thermally bonded to molybdenum heat pipes.

- $\mathrm{UO}_{2}$ is not thermally bonded to molybdenum heat pipes.

- Heat flows in $\mathrm{UO}_{2}$ axially into molybdenum sheet (not directly radially into the neat pipes).

- The temperature of the molybdenum sheet at the junction with the heat pipe is $1400 \mathrm{~K}$.

- Thermal conductivity ${ }^{8}$ of $\mathrm{UO}_{2}(\mathrm{~W} / \mathrm{mK})$ is 2.5 .

- Thermal conductivity of Mo $(W / m K)$ is 85 .

- Emissivity, $\varepsilon$, of $\mathrm{UO}_{2}$ is 0.8 .

- Emissivity of bare molybdenum is 0.3 .

- Emissivity of coated molybdenum is 0.8 .

Temperatures were calculated for three thicknesses of $\mathrm{UO}_{2}(1.6,3.2$, and $6.4 \mathrm{~mm}$ ), for two locations (coldest molybdenum next to heat pipe and hottest molybdenum at the apex of the hexagon surrounding the heat pipe), and for three conditions of the interface with the molybdenum sheet, (perfect thermal contact, emissivities of 0.8 for both $\mathrm{UO}_{2}$ and coated molybdenum, and emissivities of 0.8 for $\mathrm{UO}_{2}$ and 0.3 for bare molybdenum). The molybdenum temperature is not dependent on thickness as long as the $80 / 20$ volume ratio of $\mathrm{UO}_{2}$ to $\mathrm{Mo}$ is maintained.

These temperatures are listed in Table XII, and plotted in Figs. 51 and 52 as a function of $\mathrm{UO}_{2}$ thickness. The lowest $\mathrm{UO}_{2}$ temperatures, obtained with perfect thermal contact with molybdenum, are at the interface or surface. The corresponding temperature rise in the midplane above the surface temperature ranges from $15 \mathrm{~K}$ for $1.6-\mathrm{mm} \mathrm{UO}_{2}$ to $235 \mathrm{~K}$ for $6.4-\mathrm{mm}$ $\mathrm{UO}_{2}$ (varying as the square of the thickness). This rise is the same for 
TABLE XII

CALCULATED $\mathrm{UO}_{2}$ TEMPERATURES

\begin{tabular}{|c|c|c|c|c|c|c|}
\hline \multirow{2}{*}{$\begin{array}{l}\mathrm{UO}_{2} \text { thickness, in. } \\
\mathrm{UO}_{2} \text { thickness, mm } \\
\text { Mo sheet location }\end{array}$} & \multicolumn{2}{|c|}{$\begin{array}{l}1 / 16 \\
1.6\end{array}$} & \multicolumn{2}{|c|}{$\begin{array}{l}1 / 8 \\
3.2\end{array}$} & \multicolumn{2}{|c|}{$\begin{array}{l}1 / 4 \\
6.4\end{array}$} \\
\hline & cold & not & cold & hot & cold & hot \\
\hline & \multicolumn{6}{|c|}{ Temperatures (K) } \\
\hline Mo sheet & 1400 & 1643 & 1400 & 1643 & 1400 & 1643 \\
\hline \multicolumn{7}{|c|}{ Perfect $\mathrm{UO}_{2}$-Mo Contact } \\
\hline $\mathrm{UO}_{2}$ surface & 1400 & 1643 & 1400 & 1643 & 1400 & 1643 \\
\hline $\begin{array}{l}U_{2} \text { midp } 7 \text { ane } \\
\varepsilon=0.8, \varepsilon_{M 0}=0.8\end{array}$ & 1415 & 1658 & 1459 & 1702 & 1635 & 1878 \\
\hline $\mathrm{UO}_{2}$ surface & 1583 & 1766 & 1718 & 1867 & 1919 & 2031 \\
\hline $\mathrm{UO}_{2}$ midplane & 1598 & 1781 & 1777 & 1926 & 2154 & 2266 \\
\hline$\varepsilon=0.8, \varepsilon_{M 0}=0.3$ & 1763 & 1903 & 1983 & 2085 & 2282 & 2351 \\
\hline $\mathrm{UO}_{2}$ surface & 1763 & 1903 & 1983 & 2085 & 2282 & 2351 \\
\hline $\mathrm{UO}_{2}$ midplane & 1778 & 1918 & 2042 & 2144 & 2517 & 2586 \\
\hline
\end{tabular}

both locations and for the two cases of radiation heat transfer because of the assumption of constant thermal conductivity. The $\mathrm{UO}_{2}$ temperature increases greatly as the contact is lost between the $\mathrm{UO}_{2}$ and molybdenum, and heat must be transferred by radiation. Temperature increases are roughly proportional to the $\mathrm{UO}_{2}$ thickness, and about double in going from molybdenum emissivity of 0.8 (coated) to 0.3 (bare).

Temperature distributions were also calculated for a layered core composition with an $85 / 15$ ratio of $\mathrm{UO}_{2}$ to molybdenum. The core site was assumed to be the same as for the $80 / 20$ case. A temperature increase occurs in the molybdenum as it carries more heat. The temperature drop from $\mathrm{UO}_{2}$ to molybdenum decreases when the heat radiates across the gap.

Figure 53 shows the temperature increase in the $85 / 15$ fuel as a function of $\mathrm{UO}_{2}$ thickness at the hottest molybdenum location. The molybdenum is $100 \mathrm{~K}$ hotter for $85 / 15$ than for $80 / 20$ fuel. With perfect contact, the $\mathrm{UO}_{2}$ will therefore also be $100 \mathrm{~K}$ hotter for $85 / 15$. With radiation heat transfer, the increase in $\mathrm{UO}_{2}$ temperature is less; only $40 \mathrm{~K}$ for a $6-\mathrm{mm}$ thickness and a lowmolybdenum emissivity.

In heat-pipe reactors with homogeneous fuel, the temperature rise of the fuel between heat pipes (maximum fuel temperature minus fuel temperature next 


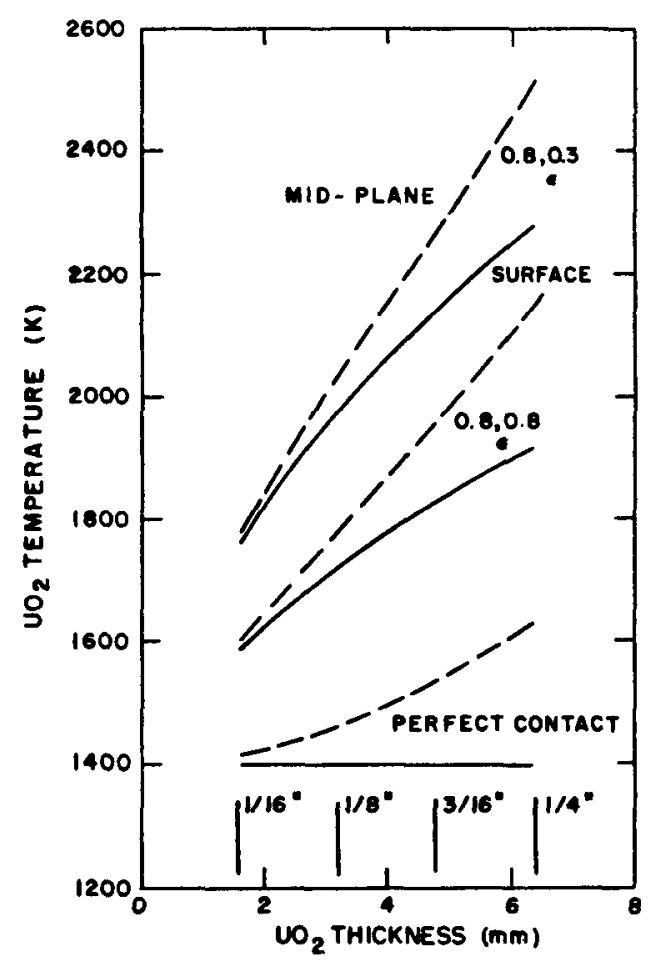

Fig. 51. $\mathrm{UO}_{2}$ temperatures vs thickness at the coldest molybdenum location.

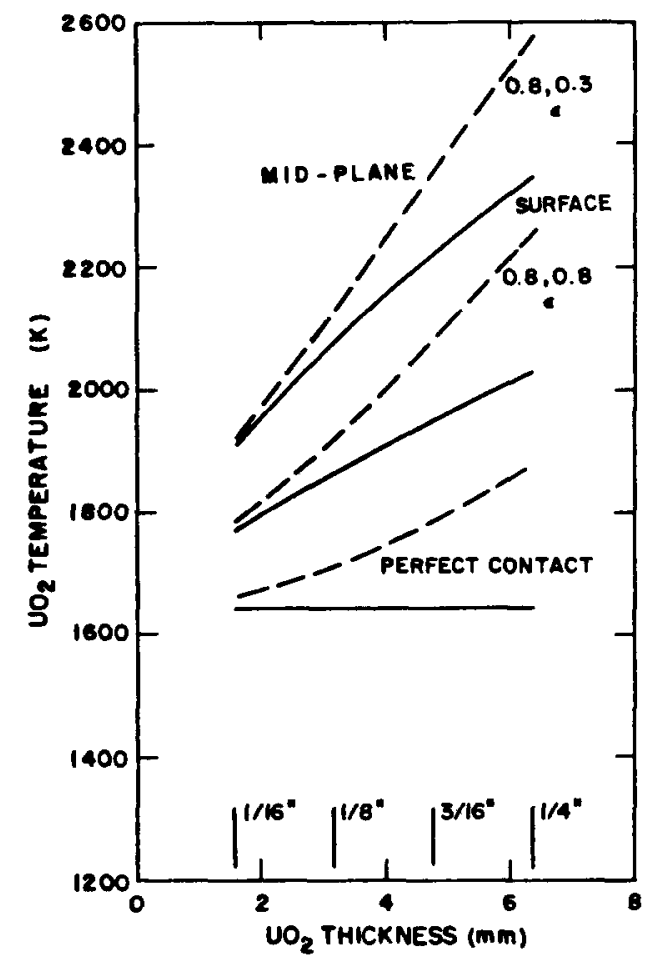

Fig. 52. $\mathrm{UO}_{2}$ temperatures vs thickness at the hottest molybdenum location.

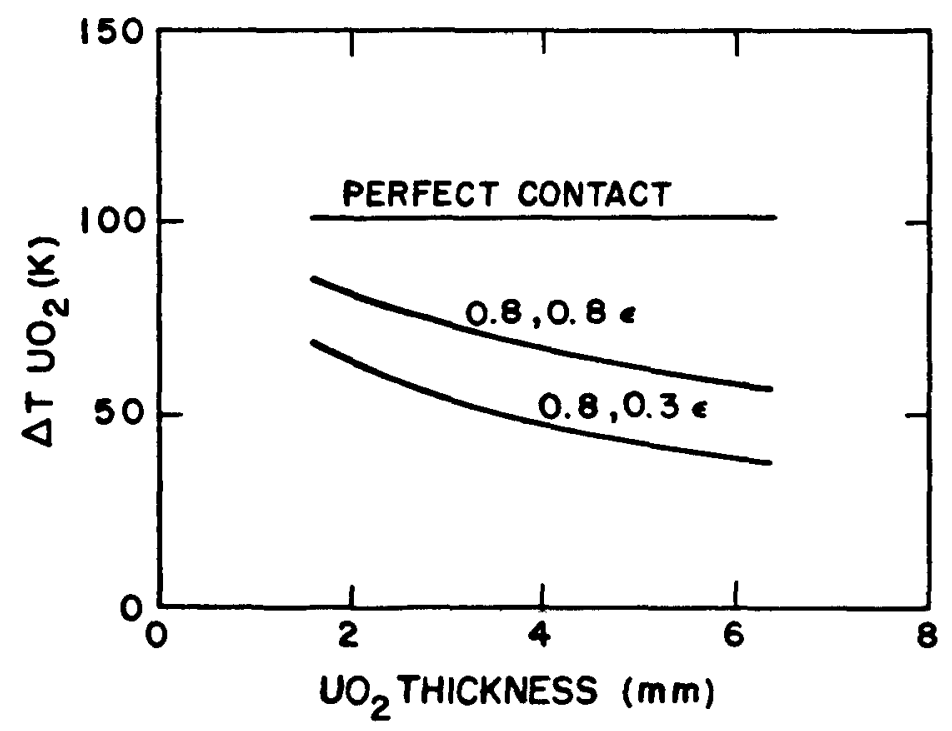

Fig. 53. Increase in $\mathrm{UO}_{2}$ temperature at the hottest molybdenum location from $80-20$ to $85-15 \mathrm{UO}_{2}-\mathrm{Mo}$. 
to the heat pipe) is inversely proportional to the number of heat pipes, assuming constant core size and void fraction. This proportionality also applies to the temperature rise in the molybdenum sheet in the layered-fuel reactor. The temperature rise in $\mathrm{UO}_{2}$ from surface to midplane is not affected, however, as the heat flux is axially directed in the $\mathrm{UO}_{2}$ and is not affected by the number or spacing of heat pipes. The temperature drop necessary to radiate heat across a gap between the $\mathrm{UO}_{2}$ and the molybdenum is affected slightly because of the $\mathrm{T}^{4}$ hot $-\mathrm{T}^{4}$ cold function. To a first approximation, the temperature of the $\mathrm{UO}_{2}$ is affected by the same amount as that of the molybdenum as the number of heat pipes is varied. For example, doubling the number of heat pipes from 90 to 180 decreases the maximum molybdenum temperature rise from 240 to $120 \mathrm{~K}$, and decrease $\mathrm{UO}_{2}$ temperatures at this location by somewhat less than $120 \mathrm{~K}$. e. Reflector Thickness. We studied the reflector materials Be0, beryllium, graphite, $\mathrm{B}_{4} \mathrm{C}$ (natural isotopic composition), and ${ }^{10} \mathrm{~B}_{4} \mathrm{C}$ and calculated one-dimensional neutron reactivity for a fixed core diameter, near the current $1-M W_{t}$ SPAR-reactor design point. Figure 54 shows the change in reactivity $k$ as a function of thickness for reflectors consisting entirely of one of the materials. These curves are not sensitive to core radius; that is, changing the radius displaces all the curves vertically by the same amount. The reactor used in the calculations was fueled with 90 UC-10 at.\% ZrC.

of the materials studied, $\mathrm{Be} 0$ is the best reflector and ${ }^{10} \mathrm{~B}_{4} \mathrm{C}$ is the worst. A rotating-drum reflector assembly based on these two materials should provide the largest reactivity control margin and the smallest reactor. $\mathrm{A} \mathrm{Be}-{ }^{10} \mathrm{~B}_{4} \mathrm{C}$ combination would be second best, followed by the $\mathrm{C}_{-}{ }^{10} \mathrm{~B}_{4} \mathrm{C}$ reflector.

The action of rotating control drums which contain sectors of ${ }^{10} \mathrm{~B}_{4} \mathrm{C}$ (or $B_{4} C$ ) was simulated in one dimension by moving the control annulus of $B_{4} C$ from the inside to the outside of the reflector region (see Fig. 55). The thickness of the control layer was varied to find, for a given reflector assembly thickness, the control layer thickness which produces the greatest swing in reactivity. Results of a typical case show the changes in reactivity that are obtained as the thickness of the control layer is varied, for the layer either on the inside or on the outside of the reflector assembly. The difference between these two curves is the reactivity swing that can be achieved with 


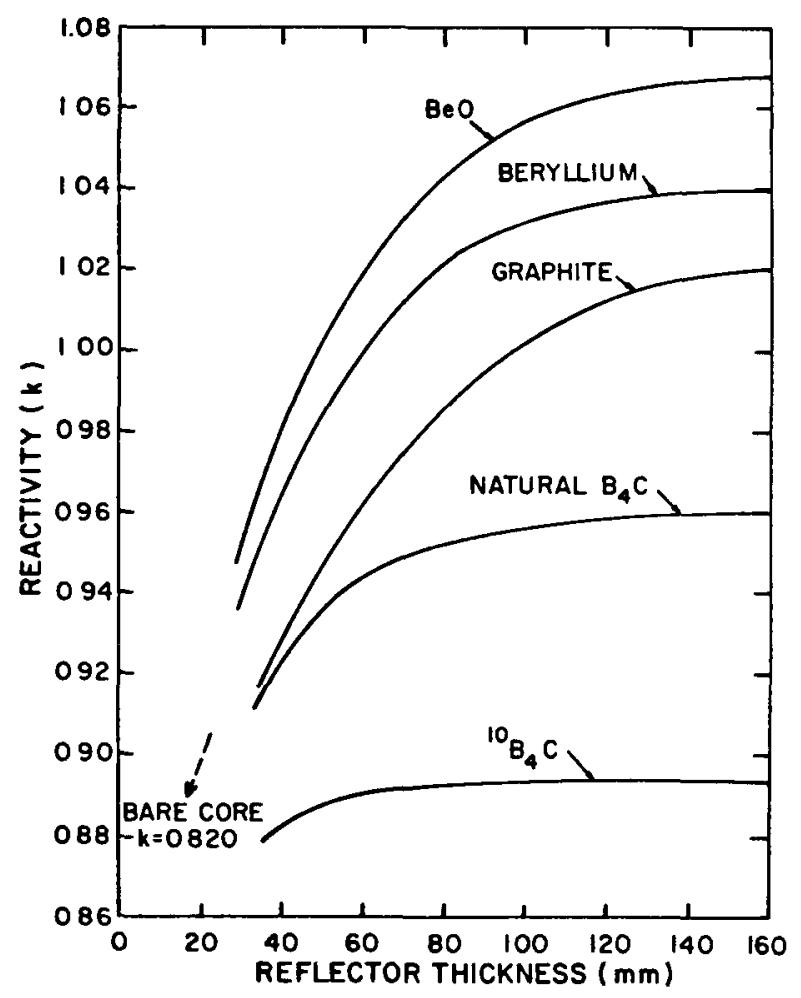

Fig. 54. Reactivity vs reflector thickness for reflector composed of pure material.

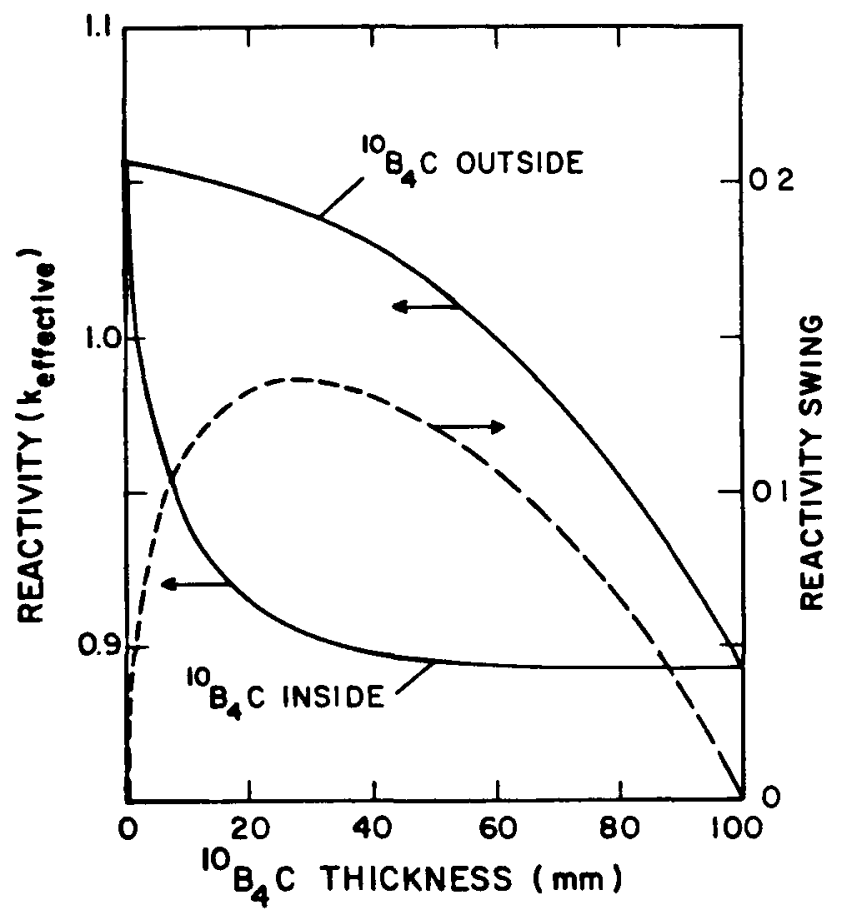

Fig. 55. Reactivity changes vs ${ }^{10} \mathrm{~B}_{4} \mathrm{C}$ layer thickness for a BeO reflector assembly having a fixed overall thickness of $100 \mathrm{~mm}$. 
that reflector control system. The optimum thickness lies in a rather broad peak, whose position was found to be relatively insensitive to the overall thickness of the reflector. For reflector assembly thicknesses in the range of $50-150 \mathrm{~mm}$, the maximum reactivity swing is obtained with a ${ }^{10} \mathrm{~B}_{4} \mathrm{C}$ thickness of $25 \mathrm{~mm}$. The maximum obtainable reactivity swing is plotted vs reflector assembly thickness in Fig. 56 for some of the reflector materials studied. Actually, real control drum systems would be less effective and, therefore, have smaller reactivity swings than the onedimensional model. Nevertheless, the calculated results provide a good indication of the relative effectivenesses of the reflector assemblies.

A comparison of reactor size was made between two reactors having either $\mathrm{BeO}$ or beryllium $100-\mathrm{mm}$ thick reflectors. The Be0-reflected reactor has a diameter of $505 \mathrm{~mm}$ and weighs $474 \mathrm{~kg}$. The beryllium-reflected reactor has a diameter of $510 \mathrm{~mm}$ and weighs $414 \mathrm{~kg}$. Although lighter, the beryllium-reflected reactor contains $4 \mathrm{~kg}$ more ${ }^{235} \mathrm{U}$ and is slightly larger. Therefore, its radiation shadow-shield will be heavier and the reactor will have a smaller reactivity control margin.

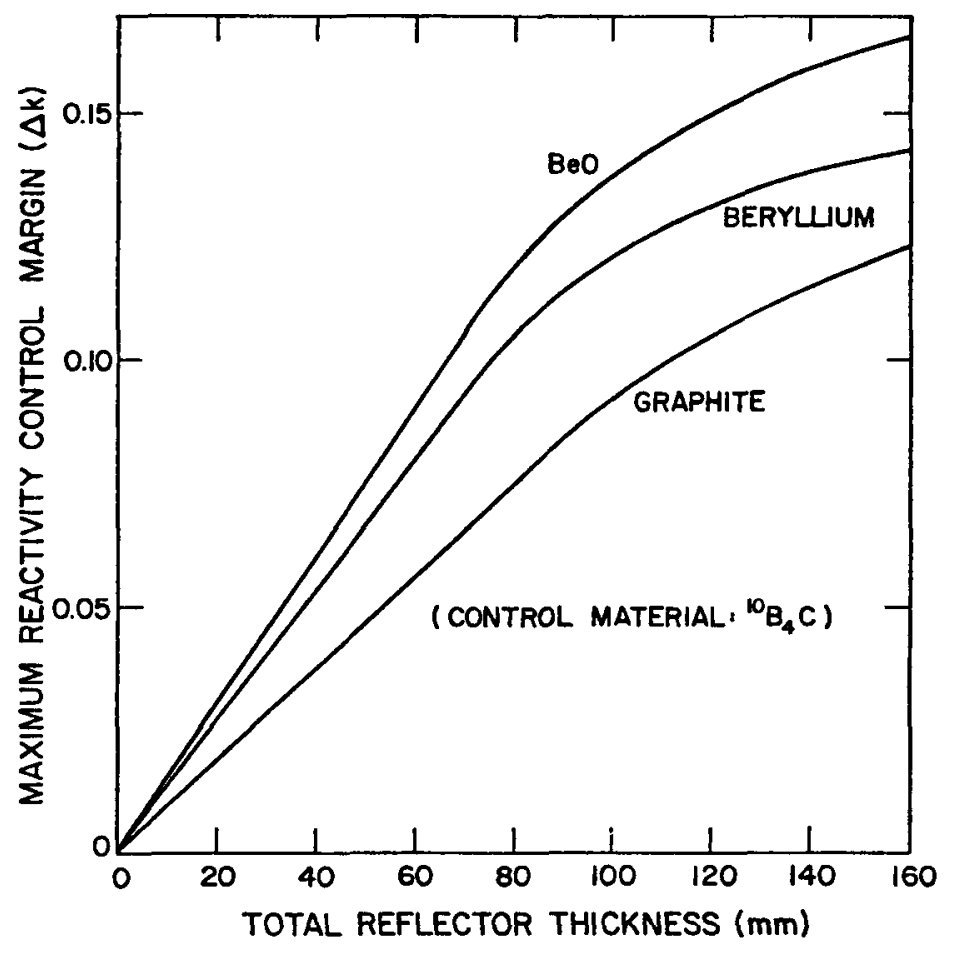

Fig. 56. Control effectiveness of several reflector assemblies. 
If a $100-\mathrm{mm}$ beryllium reflector provides a sufficient control margin then an $80-\mathrm{mm}$ BeO reflector would provide the same control margin with a smaller reactor. Such a reactor would have a diameter of $467 \mathrm{~mm}$ and weigh $410 \mathrm{~kg}$. Because "equivalent" Be0- and beryllium-reflected reactors weigh about the same, the selection of either reflector material will be governed by considerations of heat transfer, manufacturability, toxicity, safety, etc.

f. Effect of Heat-Pipe Failures. The number of heat pipes required to extract the power from the core is an important design parameter particularly if the core heat-pipes are coupled directly to thermoelectric or thermionic converters. For reliability and simplicity of assembly, one would like a small number of heat pipes. For redundancy and ease of heat transfer, a large number of heat pipes is desirable. Also less perturbation due to a heat-pipe failure occurs if the number of pipes is large.

To establish the number of heat pipes needed, the temperatures in the fuel module in the vicinity of a failed heat pipe, and the reactions that occur in the surrounding heat pipes must be determined. Molybdenum and free carbon will react near $1460 \mathrm{~K}$ to form $\mathrm{Mo}_{2} \mathrm{C}$ depending mainly on the availability of free carbon. At $1460 \mathrm{~K}, \mathrm{Mo}_{2} \mathrm{C}$ layer growth would be about $1.0 \mathrm{~mm}$ in $7 \mathrm{yr}$ if sufficient carbon were available. This should present no limitation to heat pipes operating normally at $1425 \mathrm{~K}$. Above $1813 \mathrm{~K}$, UC reacts with molybdenum to form $U_{M o C}$ and MoC, but this is acceptable. A ternary peritectic reaction $2 \mathrm{UC}+\mathrm{MO} \rightarrow \mathrm{UMOC}_{2}+\mathrm{U}$ ( 1 iquid) occurs near 2125 $k$. This reaction should be avoided because the uranium (liquid) will tend to migrate to cooler regions and dissolve adjacent heat pipes.

Figure 57 displays various temperatures in the normal and failed conditions. A reactor with 1 of 60 heat pipes failed might experience deleterious chemical reactions. Ninety or more heat pipes provide a large margin of safety and should stop progressive failures around a fuel module where an element has failed.

It was necessary to redesign the core periphery to remove heat generated around a failed heat pipe. Design changes to evaluate a possible periphery element failure include circumferential heat pipes around the core or a change in fuel loading for the peripheral elements. 


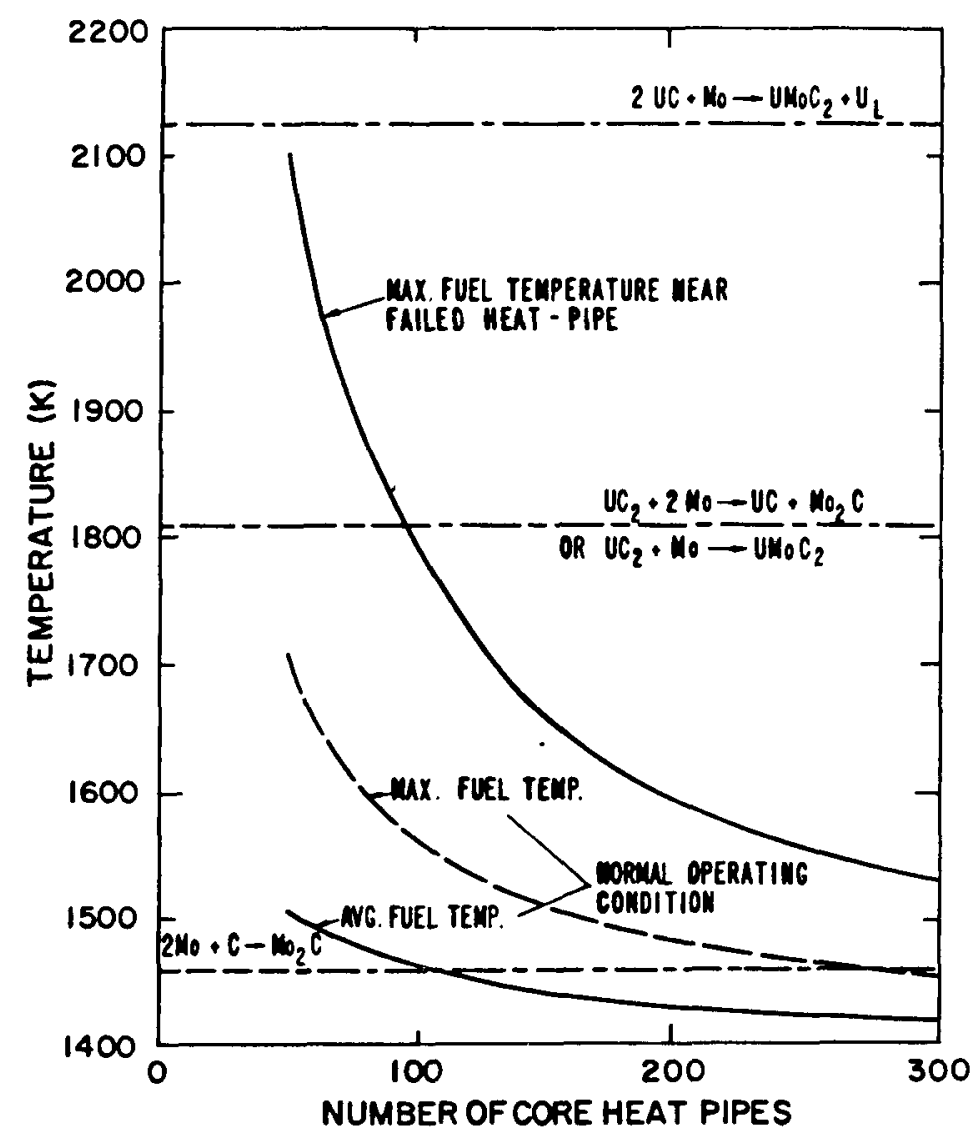

Fig. 57. Fuel temperature vs number of core heat-pipes for a $1-M W_{t}$ UC-10 at.\% ZrC reactor.

An important feature of the heat-pipe space reactor is redundancy. If a heat pipe fails, the heat generated in the fuel element containing this failed heat pipe simply flows out through neighboring fuel elements to the surrounding heat pipes. The increase in fuel temperature depends mainly on

- the number of heat pipes surrounding the failed heat pipe,

- the geometry of the fuel element and heat pipe,

- the type of fuel, which determines the thermal conductivity,

- the volumetric rate of heat production, and

- the inter-element heat transfer resistance.

Elevated temperatures in a reactor core can cause distress in the core. The temperature rise should be limited to a maximum dictated by the lowest melting temperature of the core materials. At temperatures below the melting point, thermal stresses induced in the core by temperature gradients and by uniform temperature rises with core restraint can 
cause damage to the core. Long-term thermai creep must also fall within acceptable limits.

Using Table XIII, we made calculations for different locations of failed heat pipes in a $3-\mathrm{MW}_{\mathrm{t}} \mathrm{UO}_{2}$-fueled reactor and in a $1-\mathrm{MW}_{\mathrm{t}} \mathrm{UC}$ fueled reactor. Both reactors contain hexagonal fuel elements with a central heat pipe. Cross sections of typical portions of the cores are shown to scale in Fig. 58. Heat-pipe failures were assumed to occur in the maximum heat production region of the reactor core and to be isolated (that is, there are no adjacent failures). Figure 59 shows locations of periphery and interior failed heat pipes.

The $1-M W_{t}$ reactor differ from the $3-M W_{t}$ reactor as follows:

- The outer boundary of the UC-ZrC element has a thin layer of cladding material.

- The size is smaller.

- The ratio of heat-pipe diameter/heat-pipe spacing is different.

- The fuel is different.

TABLE XIII

FUEL ELEMENT DATA

\begin{tabular}{|c|c|c|}
\hline Reactor Power $\left(M_{t}\right)$ & 3 & 1 \\
\hline Fue 1 & $\mathrm{UO}_{2}-\mathrm{Mo}$ & $U C-\operatorname{ZrC}$ \\
\hline Fuel element width across flats (mm) & 42.8 & 27.7 \\
\hline Heat-pipe o.d. (mm) & 26.8 & 15.3 \\
\hline Heat-pipe i.d. (mm) & 22.8 & 11.9 \\
\hline Fuel element length (mm) & 427.0 & 227.0 \\
\hline Number of fuel elements & 90 & 90 \\
\hline Max/av power density ratio & 1.5 & 1.5 \\
\hline Heat-pipe operating temperature $(K)$ & 1675 & 1425 \\
\hline Thermal conductivity in fuel $(W /(m K))$ & 27.5 & 25.0 \\
\hline Thermal conductivity in Mo heat-pipe wall (W/(mK)) & 105.0 & 105.0 \\
\hline Modulus of elasticity of Mo heat pipe (MPa) & 172000 & 172000 \\
\hline Poisson's ratio & 0.32 & 0.32 \\
\hline Coefficient of thermal expansion $\left(\mathrm{K}^{-1}\right)$ & $7.7 \times 10^{-6}$ & $7.7 \times 10^{-6}$ \\
\hline Melting point of fuer (K) & 2900 & $2100^{\mathrm{a}}$ \\
\hline
\end{tabular}

a Peritectic reaction between UC and Mo. 


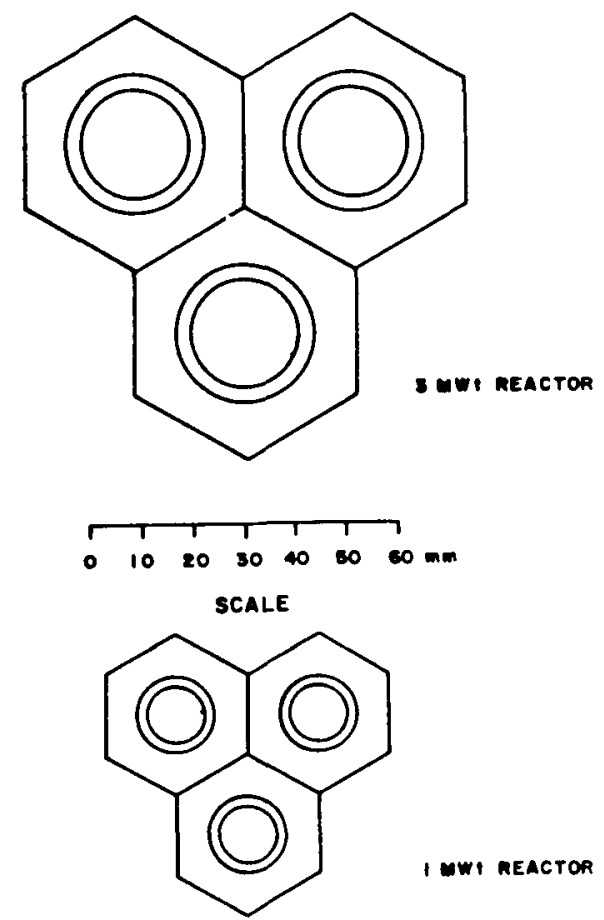

Fig. 58. Typical core partial configuration.

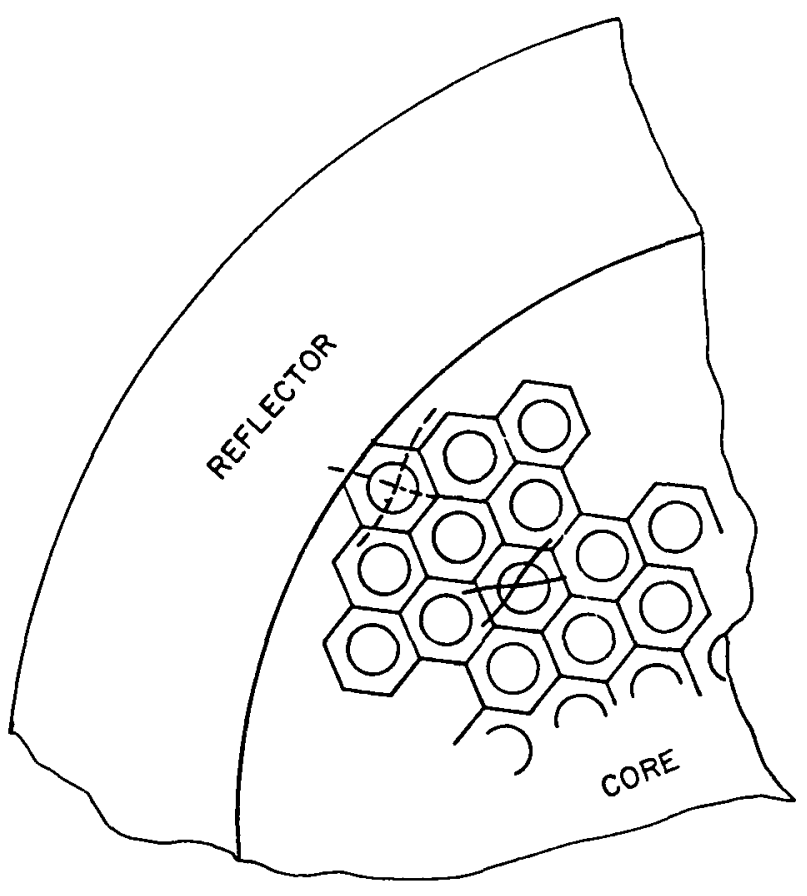

Fig. 59. Location of periphery $(\not i)$ and interior $(x)$ failed heat pipes.

The vapor temperature in the adjacent active heat pipes was assumed to remain at the design value. We realize that this is an optimistic assumption; unless the reactor heat pipes are cross-coupled, the converters attached to the heat pipes which have added heat flow will increase in temperature. The heat pipes will also increase in temperature, even though they could carry the extra heat load at the design temperature.

The thermal calculation used the AYER finite element code (Ref. 10) with the mesh shown in Fig. 60 for a periphery heat-pipe failure. Symmetry allows performing the calculation on a $30^{\circ}$ wedge with the apex at the center of the failed heat pipe for a central heat-pipe failure.

Calculations were made assuming perfect thermal contact between fuel elements, complete separation of fuel elements so that heat flow would be by radiation and incomplete contact between fuel elements with heat flow by a combination of radiation and conduction. Emissivities used in the calculation were: 


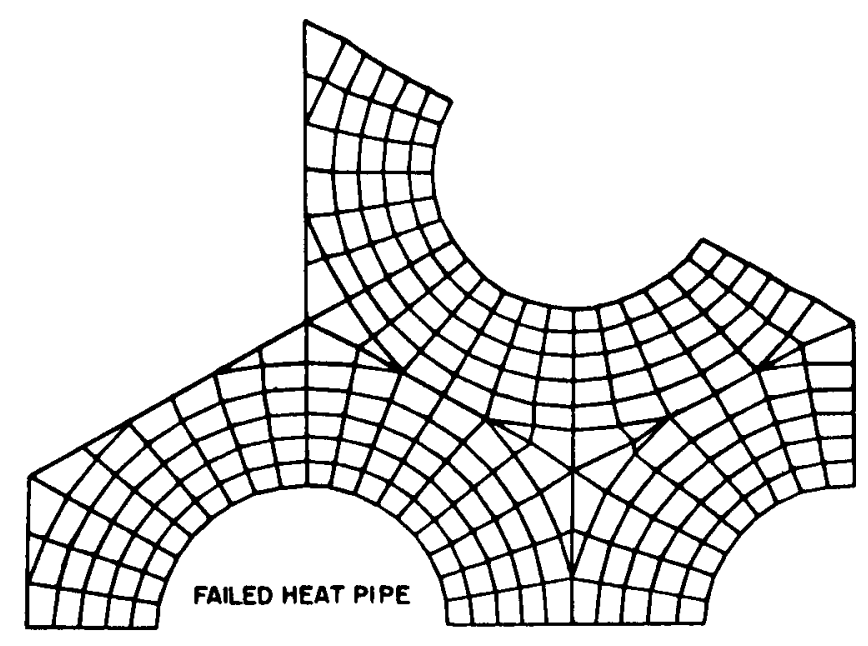

Fig. 60. AYER mesh for periphery heat-pipe failure.

- 1.0, the theoretical maximum (approached only by use of coatings or surface treatment),

- 0.5 , representative of rough surfaces, and

- 0.25 representative of polished surfaces.

Table XIV shows that a conductive interface can greatly reduce the temperature drop between separated fuel elements.

TABLE XIV

TEMPERATURE DROPS ACROSS FUEL ELEMENT INTERFACES AND RESULTING MAXIMUM FUEL TEMPERATURES (K) FOR 3-MW $t$ REACTOR

$\begin{array}{lrrr}\text { Emissivity } & 1.0 & \frac{0.5}{0} & \frac{0.25}{0} \\ \text { Delta T - perfect contact } & 280 & 660 & 1130 \\ \text { Delta T - pure radiation } & 200 & 350 & 450 \\ \text { Delta T - radiation + conduction (pessimistic) } & 120 & 160 & 180 \\ \text { Delta T - radiation + conduction (average) } & 60 & 70 & 80 \\ \text { Delta T - radiation + conduction (opt imistic) } & 2320 & 2320 & 2320 \\ \text { Max fuel T - perfect contact } & 2600 & 2980 & 3450 \\ \text { Max fuel T - pure radiation } & 2520 & 2670 & 2770 \\ \text { Max fuel T - radiation + conduction (pessimistic) } & 2440 & 2480 & 2500 \\ \text { Max fuel T - radiation + conduction (average) } & 2380 & 2390 & 2400 \\ \text { Max fuel T - radiation + conduction (optimistic) } & & & \end{array}$


The worst place for a failure is on the periphery, at one of the corners of the hexagonal core (Fig. 59). There are only thrte adjacent heat pipes, rather than six as in the central-failure case. The heat not only has fewer heat pipes to flow to, but because the path length is greater, the temperature difference is greater.

Isotherms from an AYER calculation of the periphery failure of a $3-M W_{t}$ reactor are as shown in Fig. 61. We again assumed that there was no thermal resistance between fuel elements. The isotherms are spaced 125 $\mathrm{K}$ apart; intervals of $750 \mathrm{~K}$ are labeled.

Figure 62 shows the calculated maximum fuel temperatures for no failure, central failure, and periphery failure, all assuming perfect thermal contact between fuel elements. It also shows the effect of imperfect contact on a failed central heat pipe for pure radiation transfer across the fuel element interface, a combination of radiation and pessimistically calculated conduction, and a combination of radiation and optimistically calculated conduction. Maximum fuel temperatures for the $1-$ and $3-\mathrm{MW}_{\mathrm{t}}$ reactors are shown. The lower temperatures for the $1-M W_{t} U C-Z r C$ reactor reflect a lower heat-pipe temperature, more favorable geometry, and lower heat production per unit volume. We conclue that

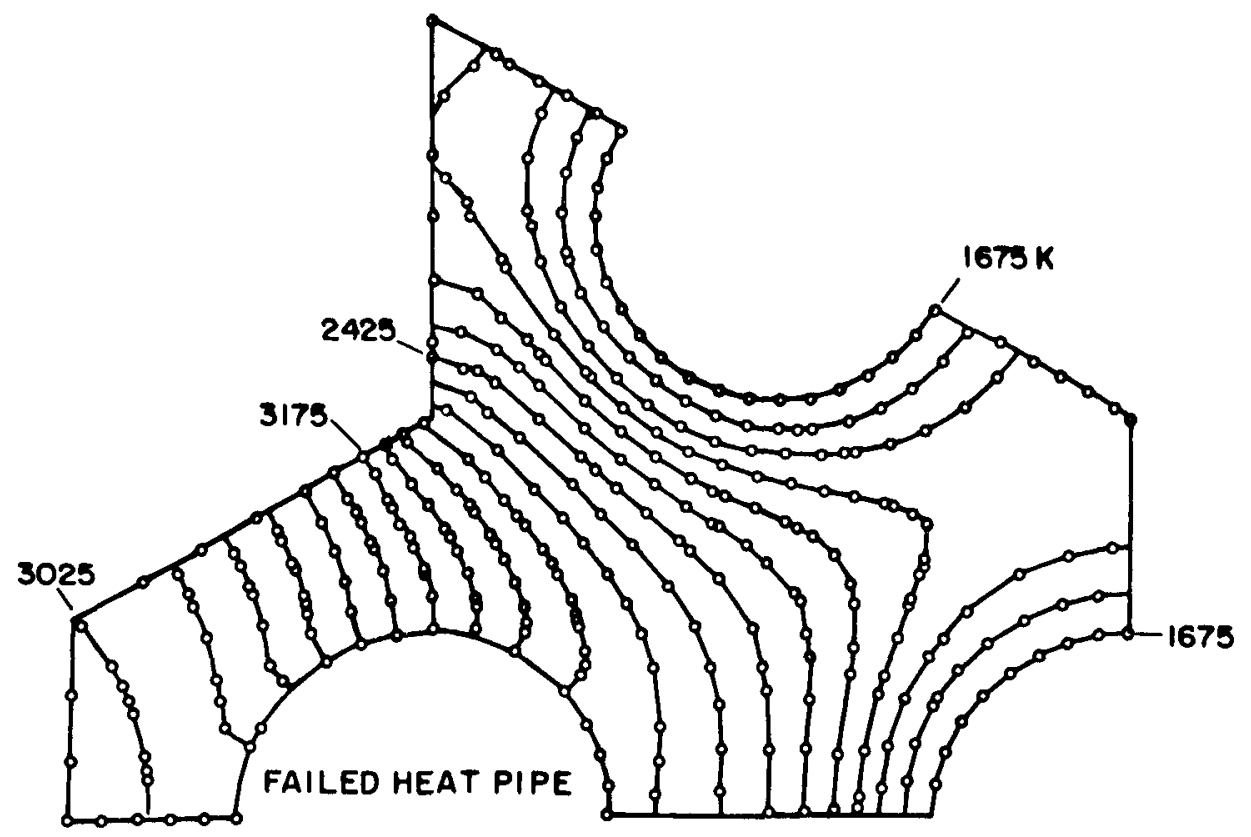

Fig. 61. AYER-generated isotherms for periphery failure for l- MW $\mathrm{t}$ reactor. 


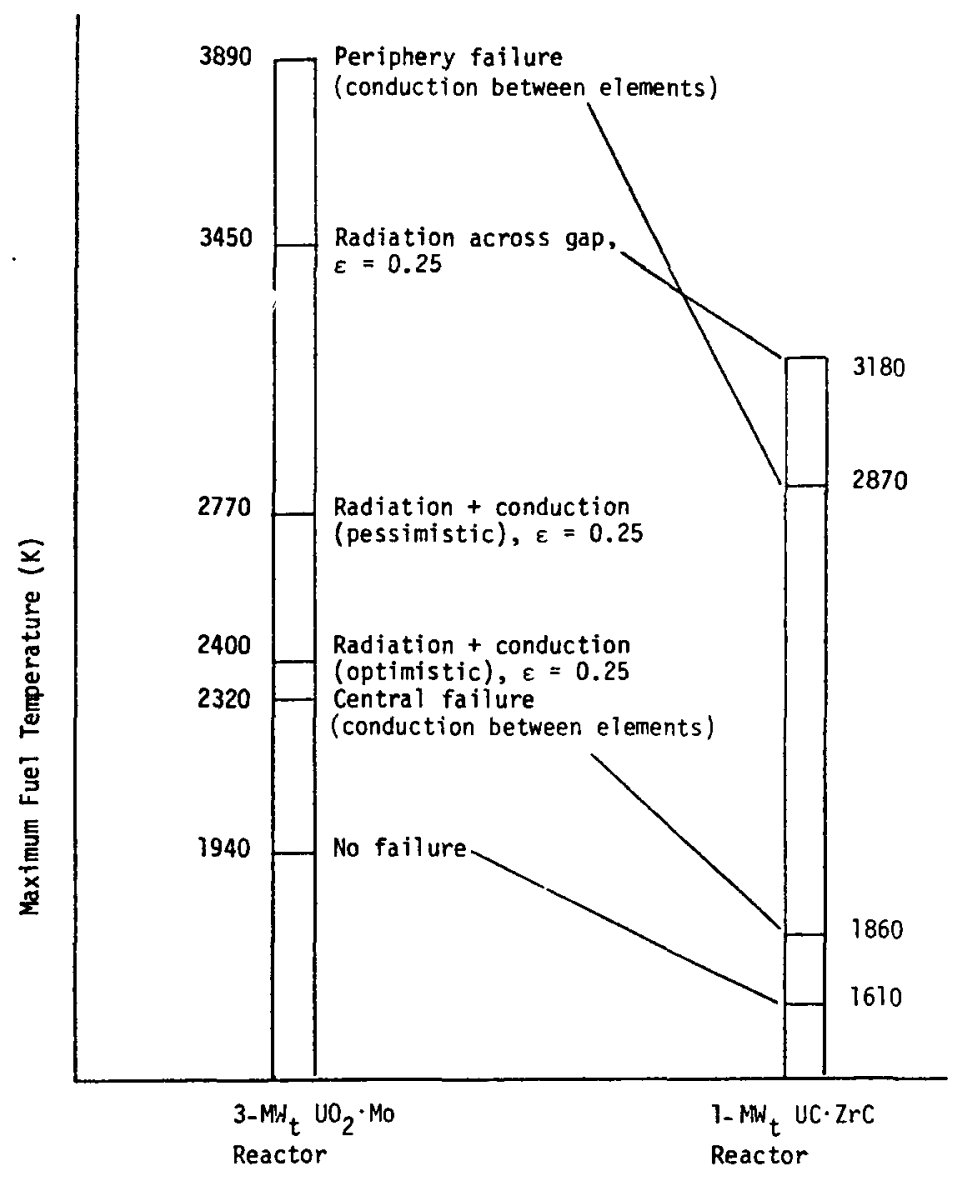

Fig. 62. Maximum fuel temperature.

- A central failure appears tolerable, with an increase in maximum fuel temperature from the unfailed case of $380 \mathrm{~K}$ for $3 \mathrm{MW}_{\mathrm{t}}$ and $250 \mathrm{~K}$ for $1 \mathrm{MW}_{\mathrm{t}}$.

- A periphery failure is not tolerable; the design must be modified for better cooling.

- Thermal bonding of adjacent fuel elements is necessary.

3. Reactor Design Characteristics.

a. Heat-Pipe Reactors. A computer code has been prepared to facilitate parametric studies of fast heat-pipe reactor systems. The code operates in a design mode and a specified mode. In the design option the user provides the materials, descriptions of the reactor, and operating parameters such as power level, heat-pipe temperature, lifetime, etc., and the code computes the minimum core diameter and the corresponding void 
fraction that will satisfy the conflicting constraints of criticality and heat removal. In the specified mode, the user specifies the desired core diameter and void fraction; the code then calculates all the operating characteristics of the reactor: dimensions, number of heat pipes, weights, temperatures, power densities, burnup, fuel swelling, and reactivity needs. System parameters and operating characteristics are listed in Table XV for reactors fueled with $U C-Z r C$ and $\mathrm{UO}_{2}-\mathrm{Mo}$. These reactors are designed to operate for $7 \mathrm{yr}$ at a thermal power level of $1 \mathrm{MW}$ and a heat-pipe temperature of $1400 \mathrm{~K}$. The reactors have beryllium reflector assemblies. The design calculations were done for an $H / D$ ratio of 1.0 and for a reflector assembly thickness of $100 \mathrm{~mm}$. Both of these parameters will be treated as variables in future analyses. As a consequence, the results presented in these tables, while representative and comparatively consistent, are not optimized.

b. Gas-Cooled Reactors. Sizes and weights of gas-cooled reactors were calculated for various Brayton-cycle temperature and pressure combinations. Both UC- $\mathrm{ZrC}$ and $\mathrm{UO}_{2}-\mathrm{Mo}$ fuels were considered. Boundary conditions as provided by AiResearch are listed in Table XVI. The He-Xe working fluid has a molecular weight of 39.94. For each of the combinations of temperature and pressure, reactor thermal powers of 400,700 , and 1000 $\mathrm{kW}_{t}$ in addition to the specified maximum power were used in the size and weight calculations. Also, a sensitivity analysis was made on the effect of varying reactor pressure drop.

(1) Power vs Weight. The reactor weight as a function of reactor power level for the four data combinations plotted in Fig. 63 shows that reactor weight increases with increasing power, is greater with $\mathrm{UO}_{2}-\mathrm{Mo}_{0}$ fuel than with UC-ZrC fuel, and generally decreases with increasing reactor exit temperature.

(a) Power. Increasing power requires increasing gas flow and flow area, thereby increasing core size and weight.

(b) Temperature. The four thermodynamic combinations are identified in Fig. 63 by the reactor exit temperatures. The general tendency for reactor weight to decrease with increasing temperature occurs partly because the temperature rise within the reactor increases with increasing exit temperature. This decreases the mass flow of gas at a given power, thereby reducing flow passage area, reactor diameter, and weight. 
TABLE XV

$1000-k W_{t}$ REACTOR COMPARISON

\begin{tabular}{|c|c|c|c|}
\hline Fuel & 0 at.\% ZrC & $\mathrm{UO}_{2}-20$ vol\% Mo & $\mathrm{UO}_{2}-40$ vol\% Mo \\
\hline Number of heat pipes & 90 & 90 & 90 \\
\hline Reflector material & $\mathrm{Be}$ & $\mathrm{Be}$ & $\mathrm{Be}$ \\
\hline Thermal conductivity $[\mathrm{W} /(\mathrm{mK})]$ & 25 & 20 & 28 \\
\hline (Fuel alone) & (22) & (3) & (3) \\
\hline Fuel form & Alloy & Washer or Cermet & Pellet or Cermet \\
\hline Heat-pipe temperature (K) & 1400 & 1400 & 1400 \\
\hline Maximum fuel delta $T(K)$ & 155 & 205 & 157 \\
\hline Average fuel temp (K) & 1469 & 1553 & 1466 \\
\hline Maximum fuel temp (K) & 1581 & 1621 & 1578 \\
\hline Fuel swelling, (vol \%) & 8 & 6 & 0.1 \\
\hline \multicolumn{4}{|l|}{ Dimensions (m) } \\
\hline Core diameter & 0.28 & 0.30 & 0.35 \\
\hline Core height & 0.28 & 0.30 & 0.35 \\
\hline Reflector thickness & 0.10 & 0.10 & 0.10 \\
\hline Reactor diameter & 0.51 & 0.53 & 0.58 \\
\hline Reactor he ight & $0.49^{\prime}$ & 0.51 & 0.55 \\
\hline Heat-Pipe o.d. & 0.0153 & 0.0154 & 0.0153 \\
\hline \multicolumn{4}{|l|}{ Mass (kg) } \\
\hline Fue 1 & 127 & 171 & 256 \\
\hline Reflector & 133 & 147 & 183 \\
\hline Heat pipes & 94 & 96 & 98 \\
\hline Control system & 33 & 33 & 33 \\
\hline Support & 27 & 30 & 40 \\
\hline Total & 414 & 477. & 610 \\
\hline
\end{tabular}

(c) Pressure. The reactor pressure specified in Table XVI generally increases with increasing temperature, augmenting the tendency of weight to decrease with temperature. This is because the flow area for a given mass flow decreases as the pressure (and, therefore, density) increases, for constant delta $\mathrm{p} / \mathrm{p}$. The anomalous appearing behavior of the $1650 \mathrm{~K}$ lines (Fig. 63 ) results from the fact that the initial specified pressure decreases from that of the $1500 \mathrm{~K}$ case. 


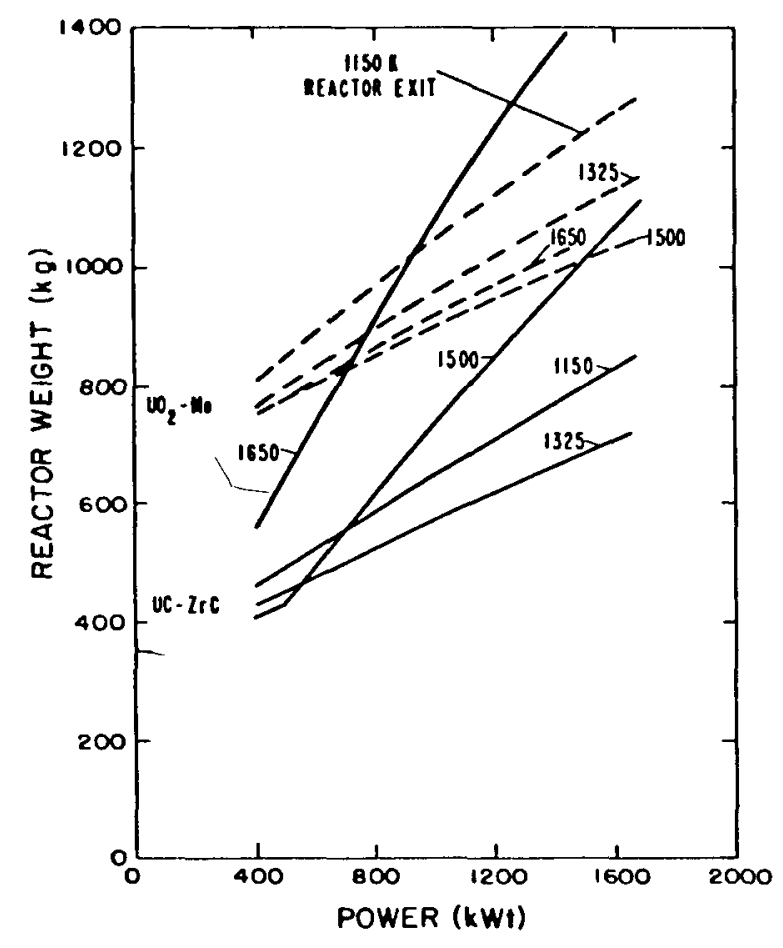

Fig. 63. Effect of power on reactor weight for gas-cooied reactors.

(d) $\mathrm{UO}_{2}-\mathrm{Mo}$ vs UC-ZrC. The $\mathrm{UO}_{2}$-fueled reactors are geirerally heavier than the UC reactors because the fuel is less concentrated and a greater size is required for nuclear criticality.

(e) Swelling. The maximum allowable irradiation swelling is $10 \%$ of the fuel volume. This limit was approached only for the UC-ZrC reactors at 1500 and $1650 \mathrm{~K}$. Weights for UC-ZrC reactors at these two temperatures show very rapid increases with power as the large amount of

TABLE XVI

THERMODYNAMIC BRAYTON CYCLE DATA

\begin{tabular}{|c|c|c|c|c|}
\hline Case & 1 & 2 & 3 & 4 \\
\hline Reactor exit temperature (K) & 1150 & 1325 & 1500 & 1650 \\
\hline Reactor inlet temperature (K) & 907 & 1007 & 1145 & 1266 \\
\hline Reactor inlet pressure (MPa) & 1.007 & 1.138 & 1.710 & 1.289 \\
\hline Reactor pressure drop $(\triangle P / P)$ & .015 & .015 & .015 & .015 \\
\hline Maximum power (kWt) & 1660 & 1660 & 1680 & 1435 \\
\hline
\end{tabular}




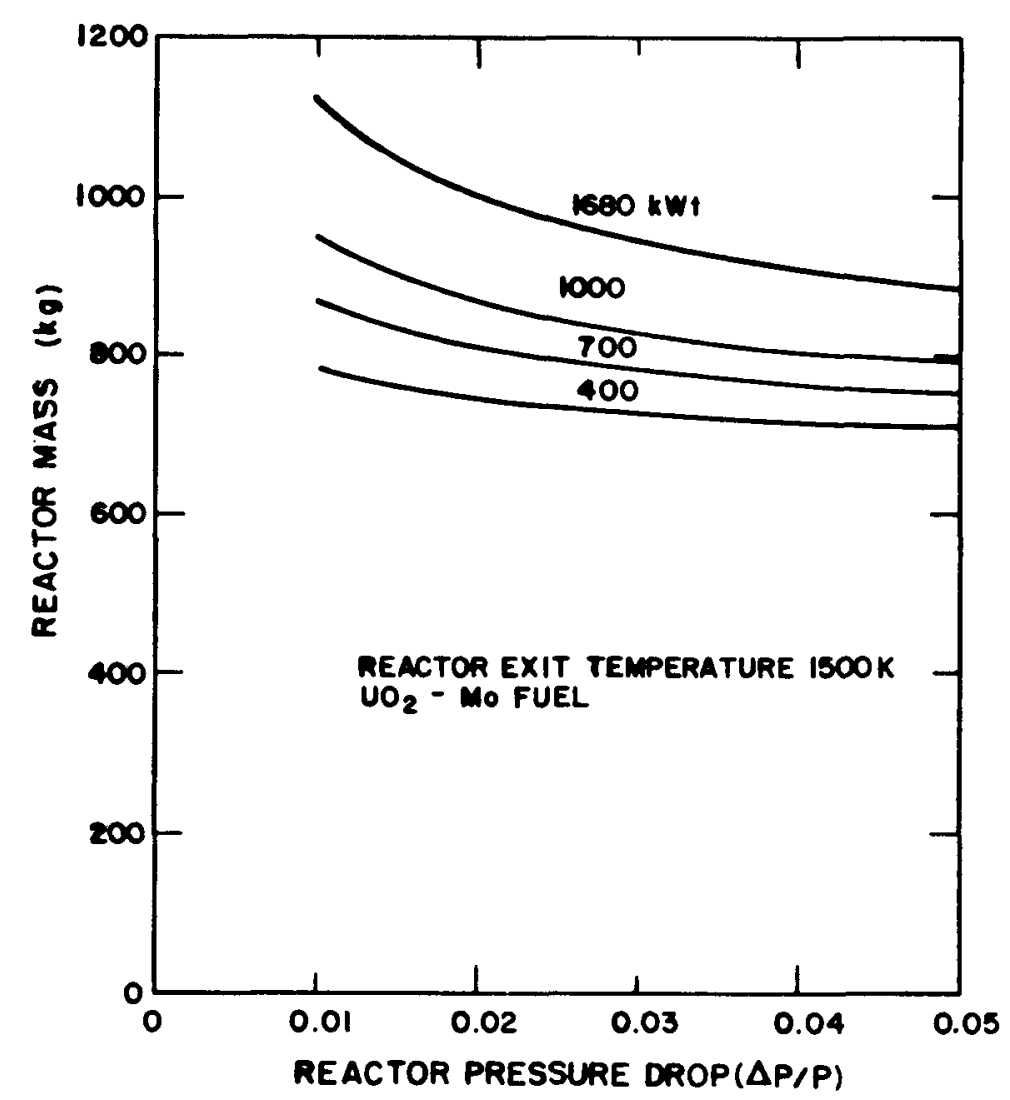

Fig. 64. Effect of reactor pressure drop on reactor weight.

Swelling requires large fuel volumes and, therefore, large and heavy reactors. High-power UC-ZrC reactors at high temperature can be ruled out because of this swelling effect.

(2) Pressure vs Weight. The sensitivity of reactor weight to delta $\mathrm{p} / \mathrm{p}$ is shown in Fig. 64. Only $\mathrm{UO}_{2}$-Mo fuel was considered at $1500 \mathrm{~K}$ because UC-ZrC fuel was ruled out.

The reactor weights are relatively flat above a delta $p / p$ of 0.02 . They do increase more sharply as delta $p / p$ decreases below 0.015 , the value specified for the basic calculations. Increasing pressure drop requires a smaller flow area and therefore leads to a smaller and lighter reactor.

The calculations were made with the computer program GASCL2 (Ref. 11). This program calculates heat transfer and pressure drop, sizing cooling hole diameter and reactor core diameter to satisfy specified pressure drop and criticality requirements. Reference 12 discusses geometry, the calculation procedure, and assumptions. For the present calculations, GASCL2 was revised and extended to include weight calculations. 
(a) Fuel Type. The computer program offers a choice of fuels, UC-10 at.\% $\mathrm{ZrC}$ or $\mathrm{UO}_{2}-40$ vol\% Mo. The relationships between solid fuel fraction ( $100 \%$ dense) and critical diameter $(k=1.05,100-\mathrm{mm}$ thick Be0 reflector) were obtained by fitting equations to heat-pipe reactor results. The heat-pipe reactor program assumes that non-fuel material in the reactor core (heat pipes, cladding) behaves as a void in the criticality calculations. The solid fuel fraction is a function of porosity, cladding fraction, and cooling hole fraction.

(b) Porosity and Fuel cladding. Porosity and fuel cladding fraction are specified as input variables. $\mathrm{UO}_{2}$-Mo is assumed to have no cladding. Porosity is used as a variable for the fuel-swelling limited cases.

(c) Weights. Total weight is the sum of fuel, pressure vessel, reflector, and control system weights. The ${ }^{235} U$ weight is calculated for each of the two fuel choices based on the correlations with solid fuel fraction and core diameter.

Pressure vessel weight is based on a design from (Ref. 12), and an allowable hoop stress of $55 \mathrm{MPa}$. This basic design weight was scaled by the (ratio of core diameter) ${ }^{3} \times$ (ratio of pressure).

Reflector weight was based on a 100-mm thick beryllium reflector. The i.d. of the reflector was taken as the core outer diameter plus $50 \mathrm{~mm}$ (allowing for annular flow passage and pressure vessel wall).

Control weight was assumed to be $33.0 \mathrm{~kg}$ for each reactor. (d) Swelling. A porosity of 0.15 of the fuel space was taken for all cases where fuel swelling was not limiting. An allowable fuel swelling due to irradiation of $10 \%$ of the fuel volume was assumed. Reactor exit temperatures of 1500 and $1650 \mathrm{~K}$ for the UC-ZrC reactor reached this fue 1 swelling limit. Numerical values of swelling were based on Fig. 50 of Ref. 13 which, for UC-ZrC is represented by the following equation:

$$
\text { SWELL }=10^{-18} * \text { FISSD *AF* } e^{B F / T}
$$

where

SWELL = volumetric fuel swelling $\%$ 


$$
=\frac{\text { swelling * } 100}{\text { fuel volume (including porosity) }} \text {, }
$$

FISSD = average fissions $/ \mathrm{cm}^{3}$ in fuel region for the reactor lifetime of $10 \mathrm{yr}$,

$$
\begin{aligned}
& A F=142.2, \\
& B F=-13545,
\end{aligned}
$$

and

$$
T=\max \text { fuel temperature in } \mathrm{K} \text {. }
$$

Iterative calculations, which required fuel porosity to give $10 \%$ swelling, were required to obtain T. The volumetric swelling is linear with fission density in the above expression. Therefore, if the calculated swelling is larger than the allowable 10\%, the fission density must be reduced by increasing the fuel volume. This is done by increasing the void fraction of the core, which increases the critical size. B. Materials

1. Fuel Element Materials. The nuclear fuels of interest follow are (1) uranium monocarbide (UC), (2) uranium zirconium carbide (UC- $\operatorname{ZrC}$ ), (3) uranium dioxide $\left(\mathrm{UO}_{2+x}+M_{1}\right)$, where $M_{1}$ may be molybdenum, tungsten, etc., and (5) uranium mononitride (UN). Uranium-zirconium hydride fuels were originally considered but dropped because of their limited temperature capability with respect to the electric converters of interest.

Critical to design and safety are melting point, density, phase relationships, modulus of elasticity, thermal conductivity, thermal expansion, creep strength, Poisson's ratio, heat capacity, specific heat, emissivity, vapor pressure and rate of vaporization, chemical compatibility with surrounding environment, and radiation effects.

The melting point, theoretical density and volume relationships are presented in Table XVII. The melting point of UN, $U C$, and $\mathrm{UO}_{2}$, the three basic fuels are nearly the same (near $2800 \mathrm{~K}$ ). Uranium mononitride has the highest uranium density $\left(13.50 \mathrm{~g} / \mathrm{cm}^{3}\right)$ of the five candidate fuels. Uranium monocarbide is next with a density of $12.97 \mathrm{~g} / \mathrm{cm}^{3}$. The strengthening and stabilizing influence of the addition of 10 mole \% zirconium 
TABLE XVII

MELTING POINT, THEORETICAL DENSITIES, AND VOLUMES OF CANDIDATE FUELS

\begin{tabular}{|c|c|c|c|c|c|c|}
\hline & UC & vC -10 at. $\%$ ZrC & $\mathrm{UO}_{2}$ & $\mathrm{vO}_{2}-40$ vol\% Mo & $\mathrm{UO}_{2}-20$ vo $1 \%$ Mo & UN \\
\hline Melting Point (K) & 2803 & 2900 & 2800 & -- & -- & 2800 \\
\hline $\begin{array}{l}\text { Theoretical Density } \\
\left(\mathrm{g} / \mathrm{cm}^{3}\right)\end{array}$ & 13.63 & 13.03 & 10.97 & 10.66 & 10.81 & 14.30 \\
\hline $\begin{array}{l}\text { Uranium Density } \\
\left(\mathrm{g} / \mathrm{cm}^{3}\right)\end{array}$ & 12.97 & 11.86 & 9.70 & 5.02 & 7.76 & 13.50 \\
\hline $\begin{array}{l}\text { Formula Weight } \\
(\mathrm{g} / \mathrm{mole})\end{array}$ & 250.08 & -- & 270.07 & -- & -- & 252.08 \\
\hline $\begin{array}{l}\text { Formula volume } \\
\left(\mathrm{cm}^{3} / \mathrm{mo} / \mathrm{e}\right)\end{array}$ & 18.4 & -- & 24.5 & -- & -- & 17.6 \\
\hline
\end{tabular}

carbide ( $\mathrm{ZrC}$ ) to form a solid solution carbide (UC-10 at.\% $\mathrm{ZrC}$ ) is far more significant than the lowering of the uranium density to 11.86 $\mathrm{g} / \mathrm{cm}^{3}$. Uranium dioxide has a uranium density of $9.70 \mathrm{~g} / \mathrm{cm}^{3}$, which is lowered to $5.82 \mathrm{~g} / \mathrm{cm}^{3}$ and $7.76 \mathrm{~g} / \mathrm{cm}^{3}$ for the $\mathrm{UO}_{2}-40$ vol\% Mo and $\mathrm{UO}_{2}-20$ vol\% Mo cermets, respectively.

The $\mathrm{UO}_{2}$ cermets are more compatible than the carbides with the environment (the environment being the fuel, clad, and heat pipes) and they can operate at higher reactor temperatures. Uranium mononitride has a high fuel density but is probably not a viable candidate because of its high vapor pressure at reactor temperatures. This problem would require the application of an overpressure of nitrogen, seriously complicating the design.

The phase diagrams for the UC, UC- $\mathrm{ZrC}, \mathrm{UO}_{2}$ and UN systems are presented in Figs. 65-68 (Refs. 14-16). Some mechanical property data trends are shown in Figs. 69-73. Figure 69 (Refs. 17-19) shows the variation of hardness with temperature. Uranium monocarbide and UN show a softening point at $1000 \mathrm{~K}$, whereas $\mathrm{U0}_{2}$ shows a softening point at $\sim 1200 \mathrm{~K}$. The UC-10 at.\% ZrC fuel shows no evidence of a softening point up to $\sim 1700 \mathrm{~K}$ and has the highest hardness of the fuels represented.

Flexure strength vs temperature is shown in Fig. 70 (Refs. 20-23) for $U C, U C-Z r C$ and UN. The UC fuel shows a linear relationship from room temperature to $\sim 1000 \mathrm{~K}$ of $\sim 105 \mathrm{MPa}$, where its strength rapidly increases to $\sim 160 \mathrm{MPa}$ at $1400 \mathrm{~K}$. The UC-ZrC fuel behaves in a similar manner starting at $\sim 110 \mathrm{MKPa}$ at room temperature and continuing out to $\sim 1800 \mathrm{~K}$, where 


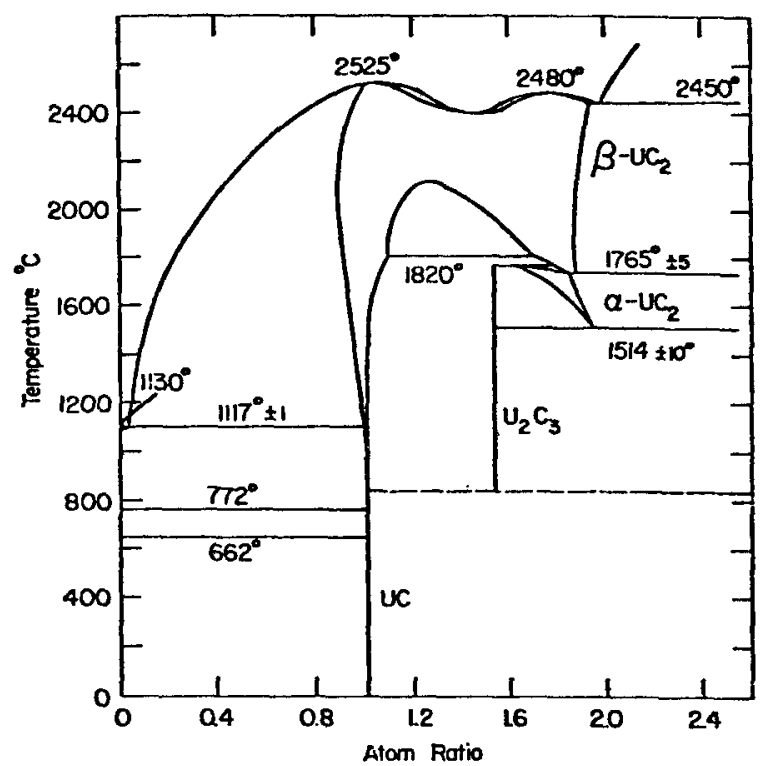

Fig. 65. Phase relationships for the UC system.

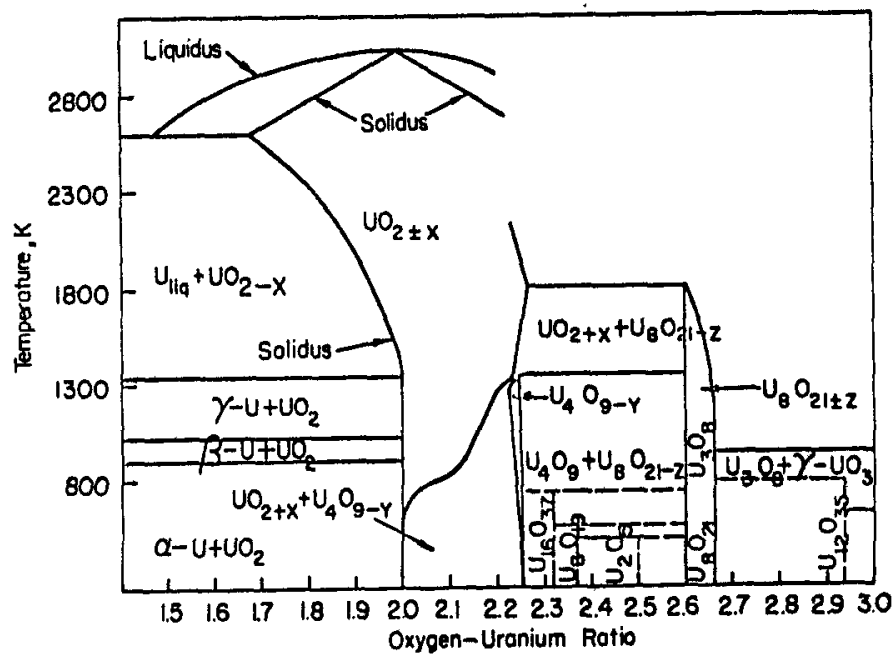

Fig. 67. Phase relationships for the uranium-oxygen system.

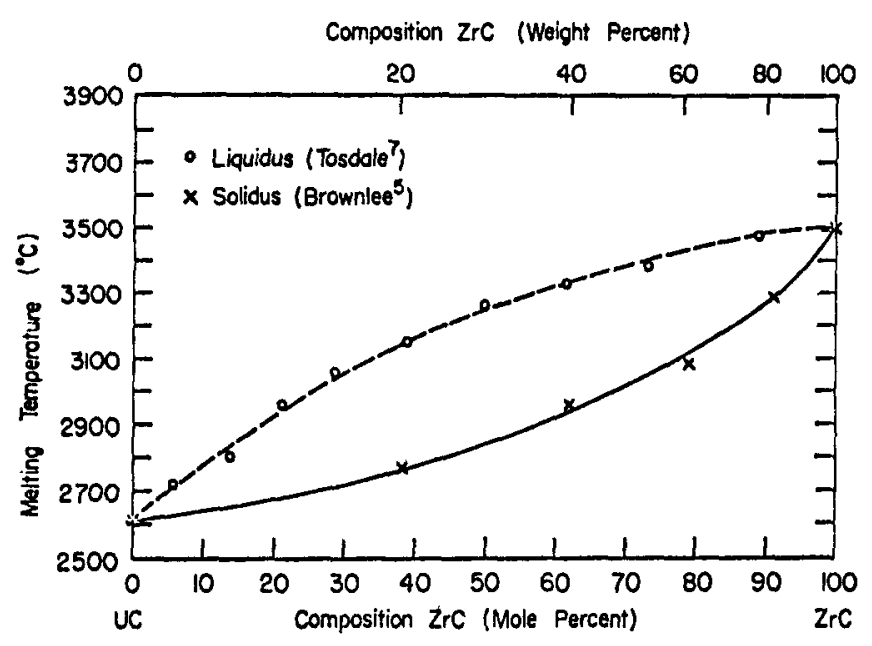

Fig. 66. Liquidus/solidus curves for the UC-ZrC pseudo-binary system.

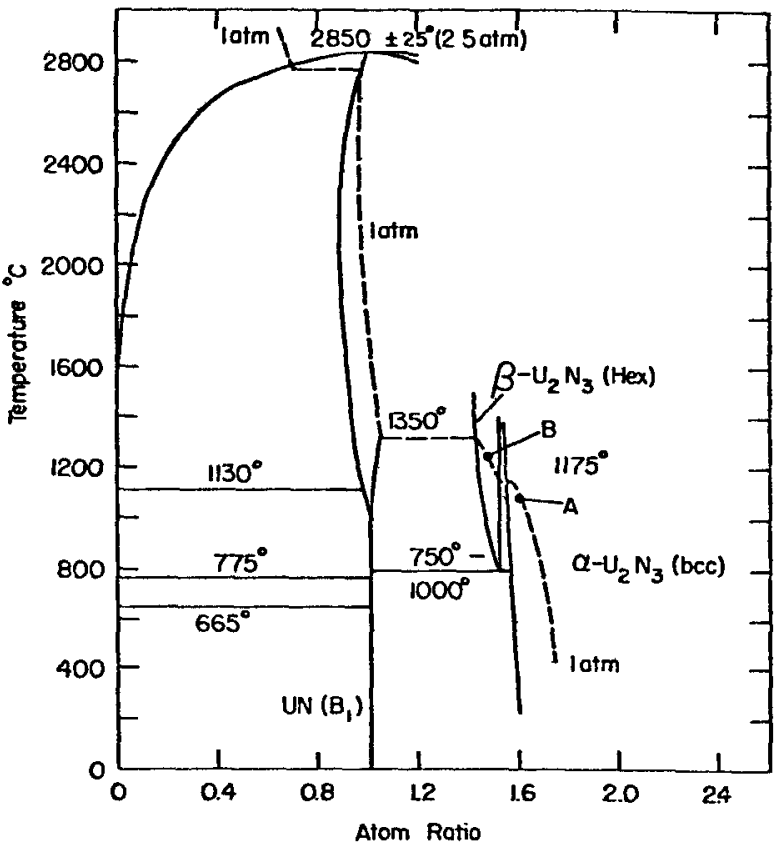

Fig. 68. Phase relationships for the UN system. 


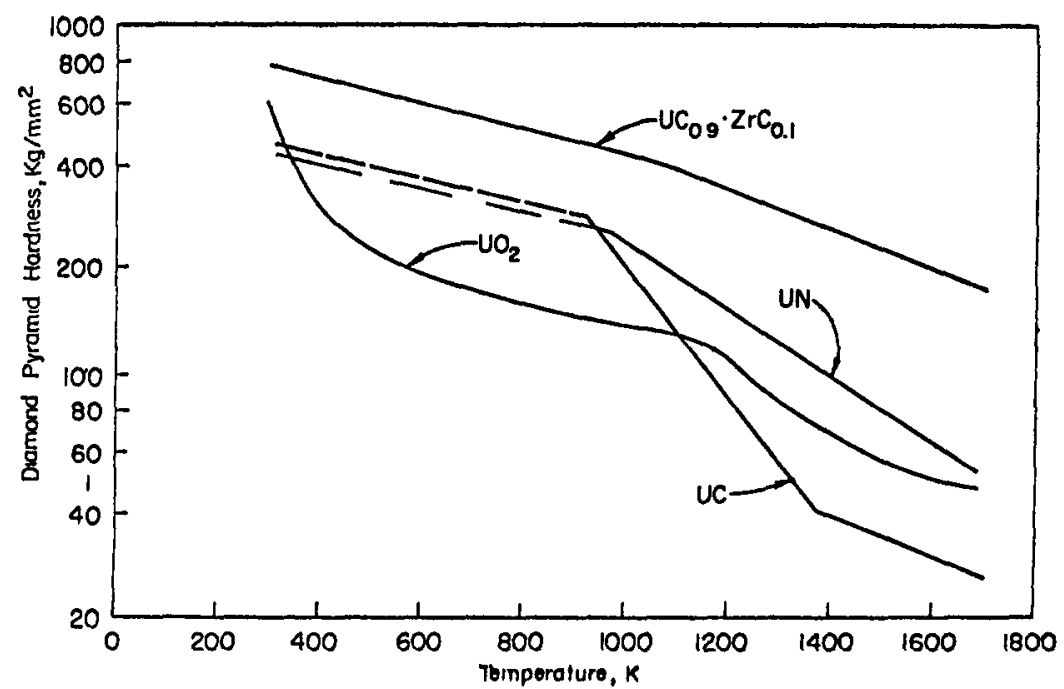

Fig. 69. Diamond pyramid hardness vs temperatures for various fuels.

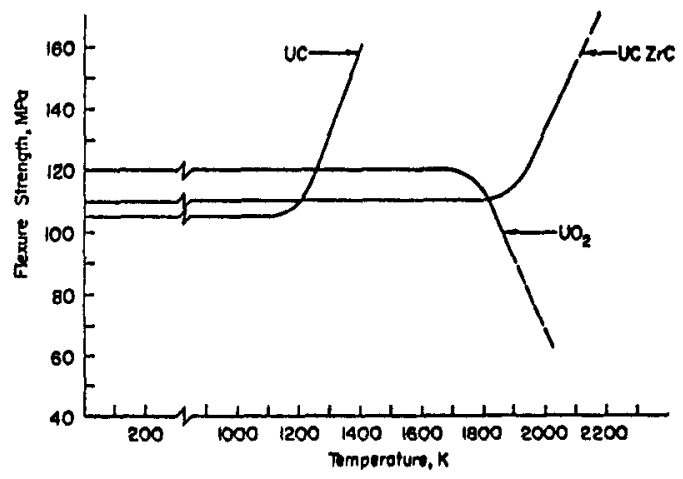

Fig. 70. Flexure strength vs temperature for $U C, U C-Z r C$, and $U_{2}$ fuels.

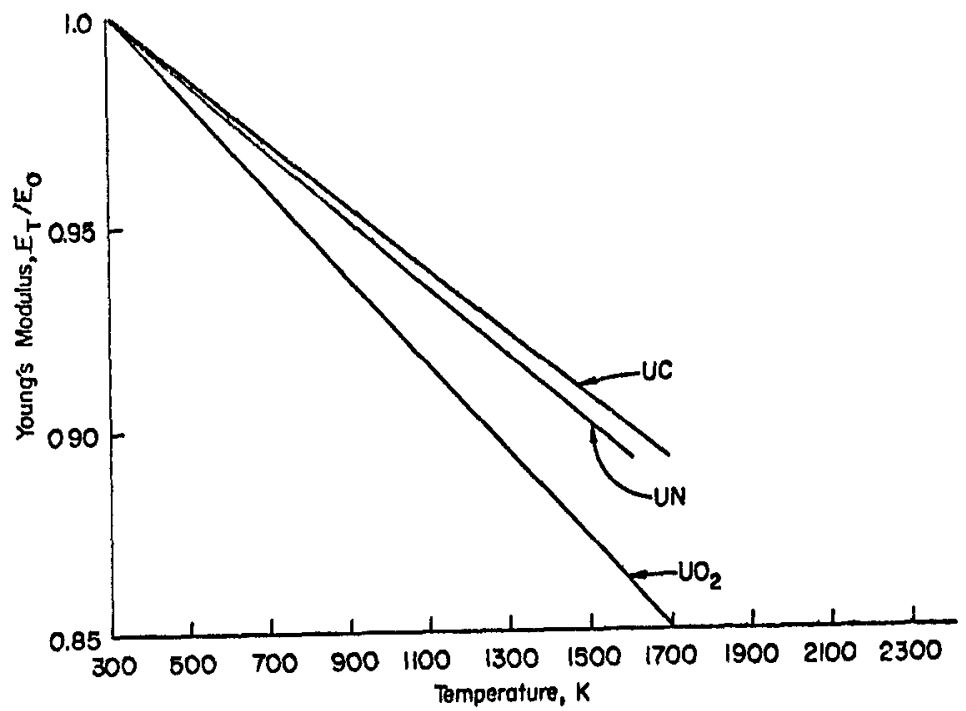

Fig. 71. Variation of Young's modulus with temperature. 


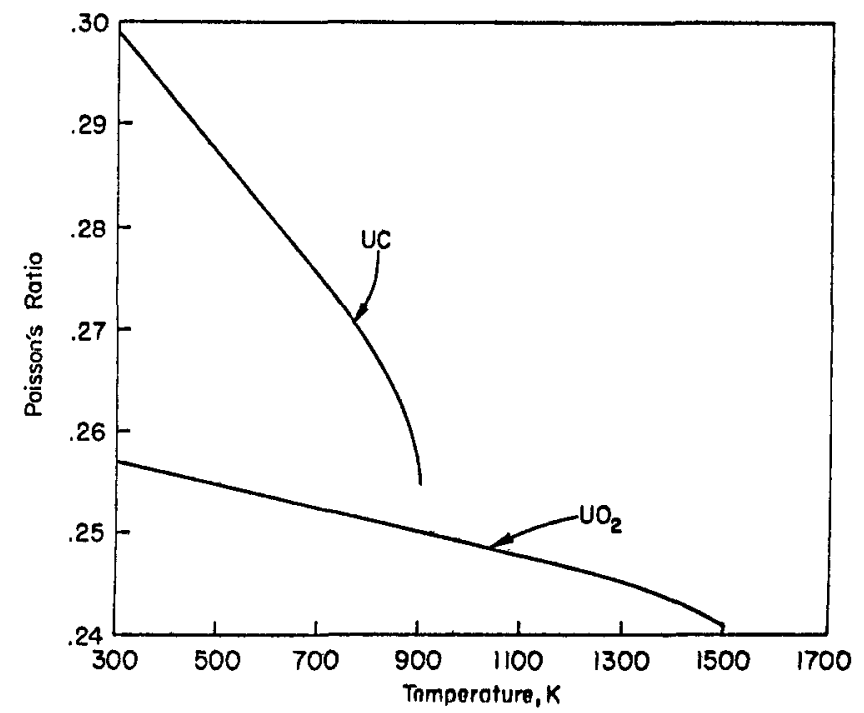

Fig. 72. Variation of Poisson's ratio with temperature for $\mathrm{UC}$ and $\mathrm{UO}_{2}$.

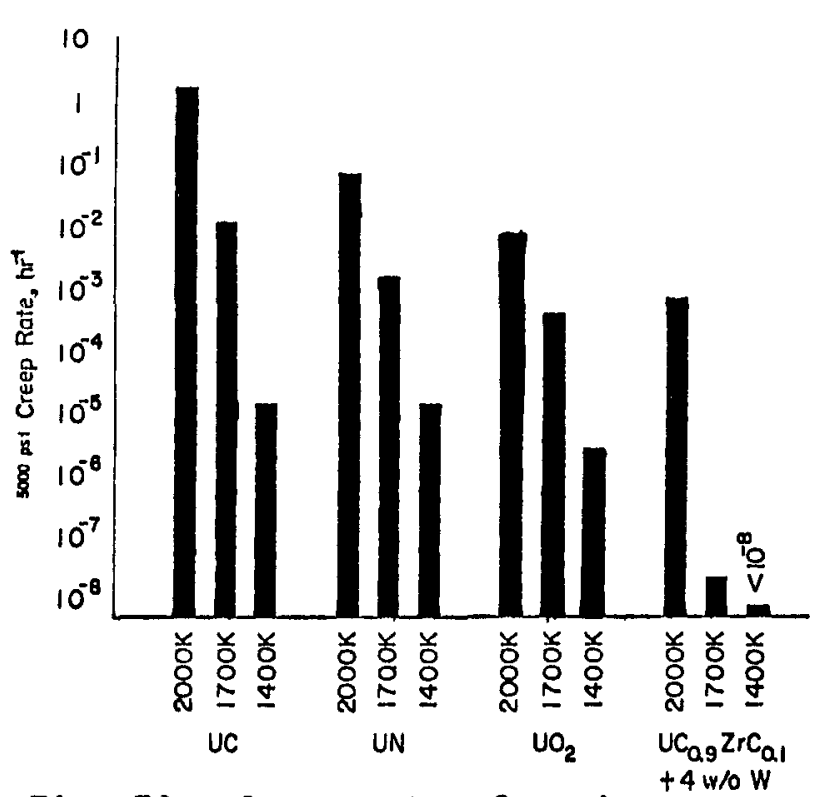

Fig. 73. Creep rate of various fuels.

the strength shows a rapid increase to $\sim 180 \mathrm{MPa}$ at $2100 \mathrm{~K}$. No data was found that showed where the two carbide fuels start to soften. Uranium dioxide has a higher starting strength ( $\sim 120 \mathrm{MPa}$ ) from room temperature to $\sim 1700 \mathrm{~K}$ at which point softening occurs and the strength drops very rapidly. No data was found for the UN fuel.

Young's modulus for the three basic fuels are shown in Fig. 71 (Refs. 24 and 25) as a function of temperature. These results are for near fully dense material. Poisson's ratio as a function of temperature for UC and $\mathrm{UO}_{2}$ are shown in Fig. $72^{26}$. The ratio of UC drops very rapidly from 0.30 at room temperature to 0.26 at $900 \mathrm{~K}$. $\mathrm{UO}_{2}$ drops gradually from 0.257 at room temperature to $\sim 0.242$ at $1500 \mathrm{~K}$. The results seen in Figs. 70 and 71 are for very dense material.

One of the most important properties to consider in designing a longlife high-temperature reactor is the creep rate. A highly condensed summary of creep rate at 2000,1700 , and $1400 \mathrm{~K}$ for $\mathrm{UC}, \mathrm{UN}, \mathrm{UO}_{2}$, and $\mathrm{UC}-\mathrm{ZrC}$ is presented in Fig. 73 (Refs. 6, 27-31). The creep rate is similar for $U C$, UN, and $\mathrm{UO}_{2}$, but the stabilizing influence of the $\mathrm{ZrC}$ and tungsten addition in the UC-ZrC lowers the creep rates, particularly at 1700 and $1400 \mathrm{~K}$. No usefur data was found for comparison with the $\mathrm{Mo}^{-\mathrm{UO}_{2}}$ cermet.

Figure 74 (Refs. 16, 32-36) shows thermal conductivity as a function of temperature. The $\mathrm{UO}_{2}$ fue 7 has the lowest thermal conductivity of all 


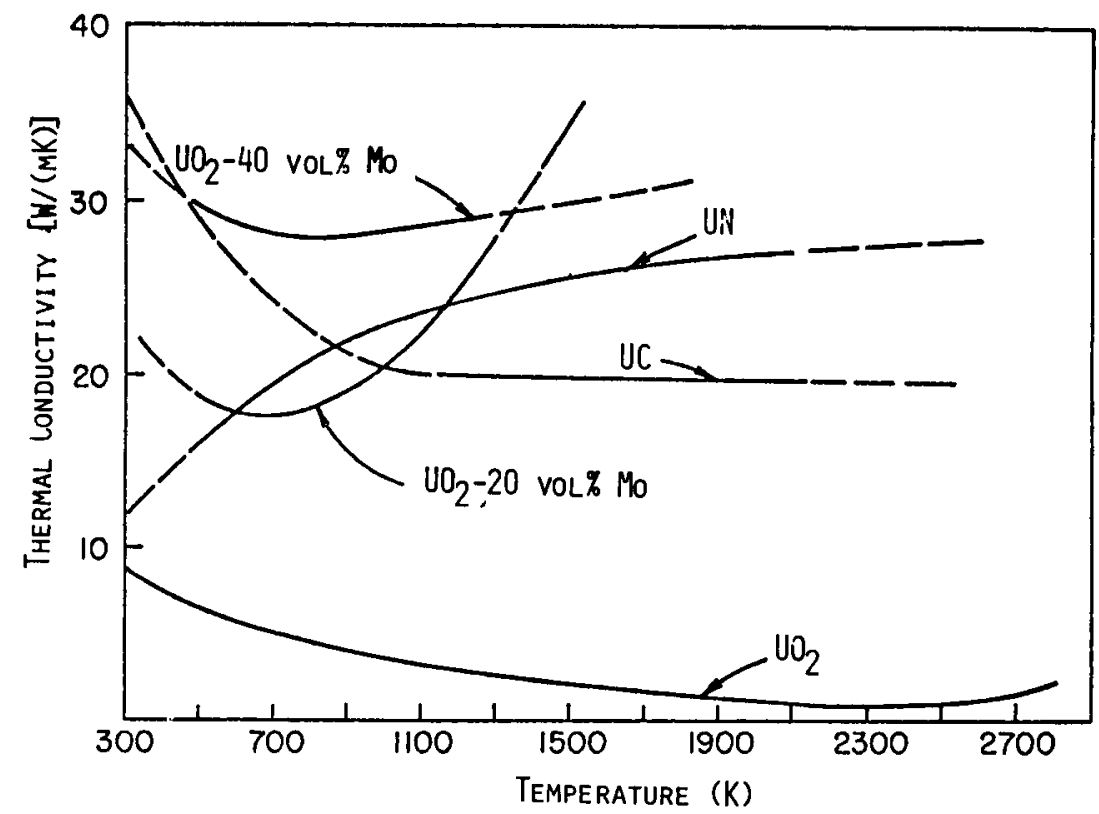

Fig. 74. Thermal conductivity vs temperature for various fuels.

fuels, $\sim 9 \mathrm{~W} /(\mathrm{m} . \mathrm{K})$ at room temperature, and decreasing gradually to $\sim 2$ $\mathrm{W} /(\mathrm{m} . \mathrm{K})$ at $2300 \mathrm{~K}$. Uranium mononitride starts at $\sim 12 \mathrm{~W} /(\mathrm{m} . \mathrm{K})$ at room temperature and increases parabolically to $\sim 28 \mathrm{~W} /(\mathrm{m} . \mathrm{K})$ at $2000 \mathrm{~K}$. Unconfirmed data for two Mo- $\mathrm{UO}_{2}$ cermets are also presented.

The thermal expansion data (Fig. 75, Refs. 16, 37-39) for UC, UN, $\mathrm{UO}_{2}$, and ${\mathrm{Mo}-\mathrm{UO}_{2}}_{2}$ cermets are quite similar over the temperature range from room temperature to $1500 \mathrm{~K}$. Figure 76 (Refs. 22, 32, 40-45) shows vapor pressure curves as a function of temperature for $U N, U_{2}, U C$ and $U C-\operatorname{ZrC}$ in decreasing order. The vaporization rate at 2000, 1700 and $1400 \mathrm{~K}$ for these fuels are shown in Fig. 77 (Refs. 22, 32, 40-45). Again there was insufficient data at this time to include clad $\mathrm{Mo}^{-\mathrm{UO}_{2}}$ cermets in these plots.

Temperature and chemistry have the greatest effect on swelling (radiation-induced) and the compatibility of any fuel with its environment, such as metal clad (or heat pipe in the case of the SPAR). A substoichiometric fuel in which the free uranium will react with any metal in its environment and undergo breakaway swelling at temperatures as low as $500 \mathrm{~K}$ cannot be used. An excess of oxygen, nitrogen, or carbon also interacts with metals in the environment and, therefore, cannot be used. For maximum 


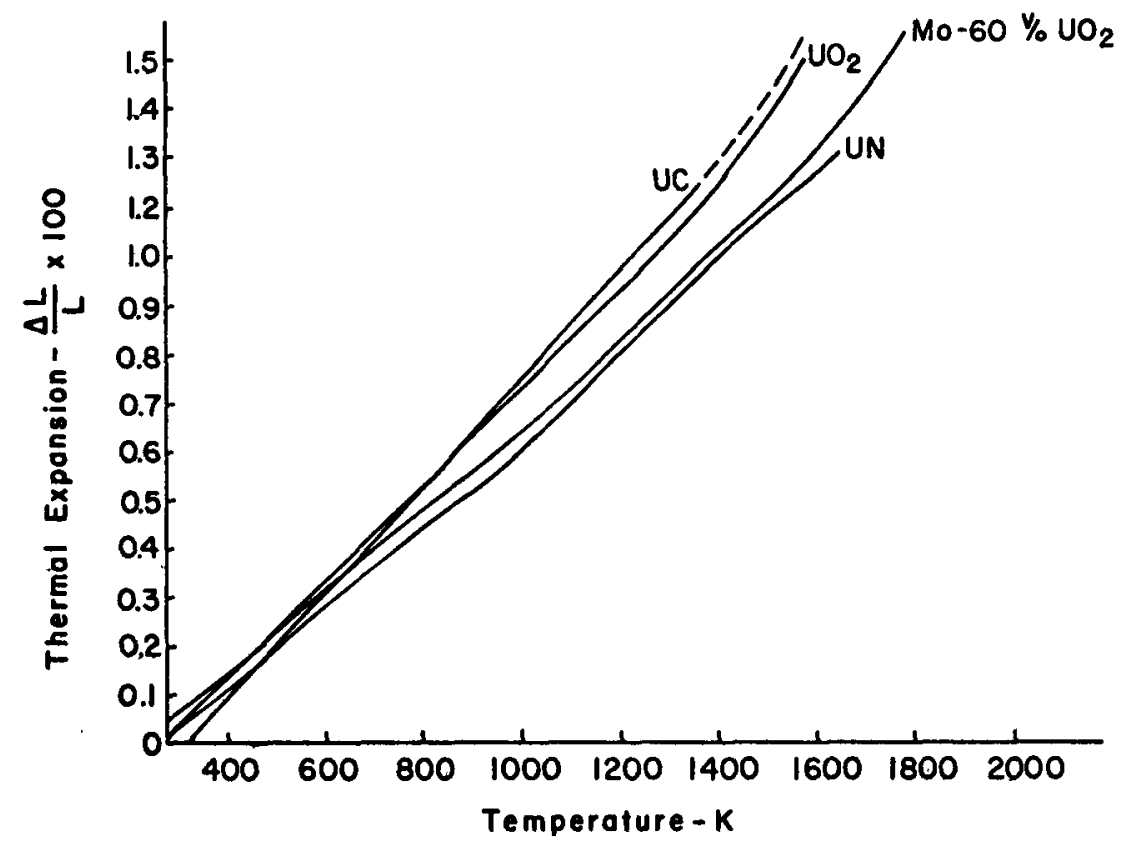

Fig. 75. Thermal expansion vs temperature for various fuels.

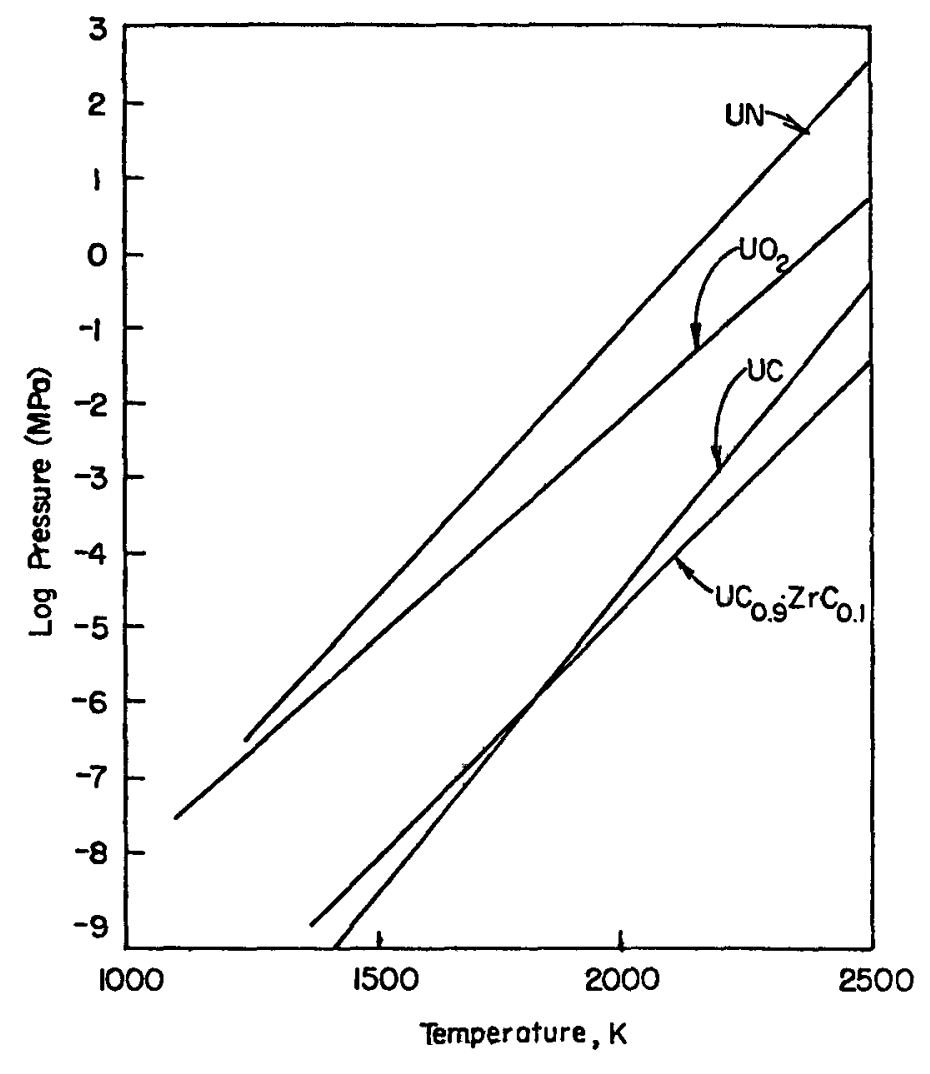

Fig. 76. Vapor pressure of various fuels. 


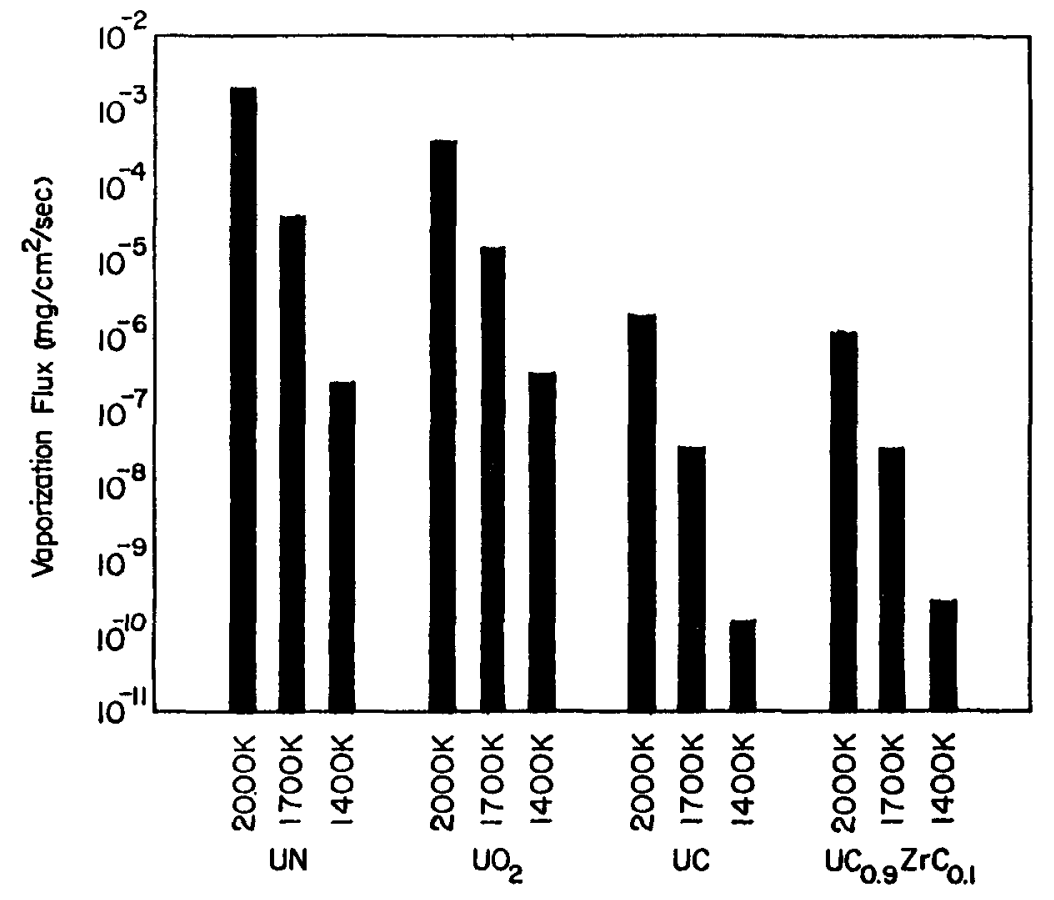

Fig. 77. Vaporization flux for various fuels.

stability and compatibility near absolute, stoichiometry of the fuel is essential.

Chemical compatibility of heat-pipe material with fuel material is sensitive to time and temperature-dependent diffusion rates. The compatibility with stoichiometric carbide fuels is limited to the temperature diffusion relationships shown in Table XVIII. Data in the literature indicates that stoichiometric $\mathrm{UO}_{2}$ is compatible with molybdenum to temperatures in excess of $2300 \mathrm{~K}$ for long periods of time.

Figure 49 is an Arrhenius plot of volumetric swelling as a function of temperature. ${ }^{29}, 46,47$ These data are used as the basis for the reactor design. Uranium carbide exhibits significantly higher swelling rates than the $\mathrm{UO}_{2}$ cermets. It appears that there is a relationship between the threshold temperature and fission gas release. A typical representation of this is shown for UC fuel in Fig. 78 (Refs. 48 and 52). The fuel data presented here represent trends in an early assessment of a partial compilation of the data and are subject to change.

2. Core Heat Pipes. Candidate materials for the core-cooling heat pipes are limited to the refractory metals and their alloys because of the 
TABLE XVIII

REACTION PRODUCTS OF UC AND REFRACTORY METALS

Temperature

\begin{tabular}{|c|c|c|c|c|}
\hline$\left(k \times 10^{2}\right)$ & $W$ & Mo & $\mathrm{Nb}$ & $\mathrm{Ta}$ \\
\hline 28 & $M P-U W C_{2}$ & & & \\
\hline 26 & & $M P-U_{M O C}$ & & \\
\hline 25 & Liquid & & & \\
\hline 23 & Liquida & & & \\
\hline 21 & & Liquid & & \\
\hline 20.5 & $\mathrm{UWC}_{2} \& \mathrm{~W}_{2} \mathrm{C}$ & Liquida & & \\
\hline 20 & $\mathrm{UWC}_{2}$ & & & \\
\hline 18.5 & $U_{W C} \& W_{2} C$ & $\mathrm{UMoC}_{2} \& \mathrm{Mo}_{2} \mathrm{C}$ & $\begin{array}{l}\mathrm{Nb}_{2}+\mathrm{NbC}+ \\
\text { Liquid }\end{array}$ & $\mathrm{TaC} \& \mathrm{Ta}{ }_{2} \mathrm{C}$ \\
\hline 16.5 & UE \& $\mathrm{H}_{2} \mathrm{C}$ & & & Liquid \\
\hline 16 & & & Liquid & \\
\hline 15.5 & $W C$ & & & \\
\hline 15 & $W C$ & $\mathrm{Mo}_{2} \mathrm{C}$ & $\mathrm{Nb}_{2} \mathrm{C \& NbC}$ & $\mathrm{TaC} \mathrm{Ta}_{2} \mathrm{C}$ \\
\hline 14 & & & & Liquida \\
\hline
\end{tabular}

atoichiometric UC, All others hyperstiochiometric.

high reactor operating. temperatures. The refractory metals that show promise include niobium, molybdenum, tantalum and tungsten.

Criteria for the heat-pipe materials are high temperature, long-term creep strength, durability, and light weight. To compare the strength aspects of candidate core heat-pipe materials, the $10^{5} \mathrm{~h}$ rupture strength to material-density ratios of selected refractory metals and alloys have been plotted in Fig. 79 as a function of temperature by extrapolating published vacuum data. 53,54 These materials were chosen for this figure primarily on the basis of availability of creep-rupture data. The dashec line indicates that data was not available. The alloy with the highest 


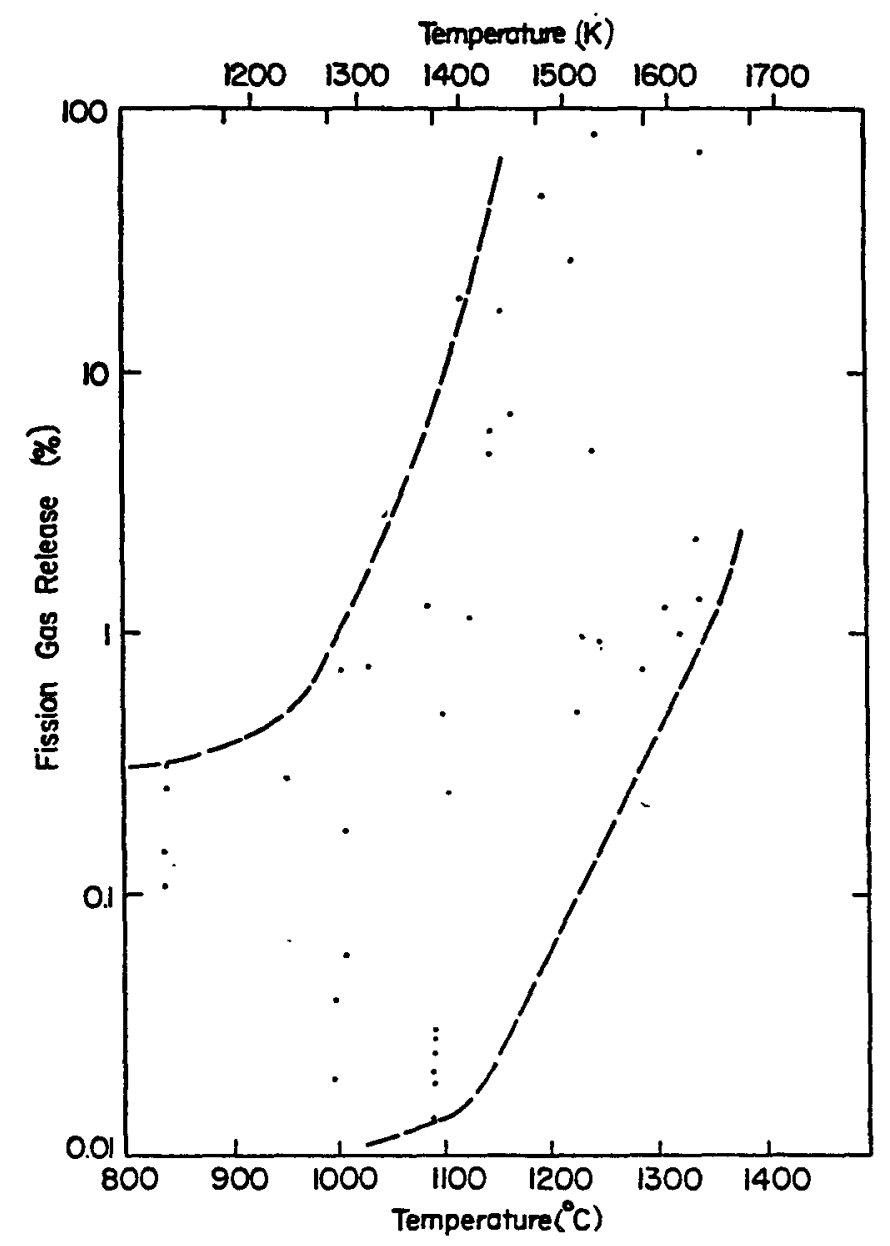

Fig. 78. Fission gas release from $U C_{1+x}$ as a function of centerline temperature.

strength/density ratio at all temperatures of interest is niobium-modified TZM (Nb-TZM) which is a precipitation-strengthened molybdenum-base alloy containing $1.5 \mathrm{wt} \% \mathrm{Nb}, 0.5 \mathrm{wt} \% \mathrm{Ti}, 0.08 \mathrm{wt} \% \mathrm{Zr}$, and $0.05 \mathrm{wt} \% \mathrm{C}$. (Ordinary TZM has no niobium and slightly less carbon.) T-222, which is the strongest commercially available tantalum-base alloy, contains 10 wt\% $\mathrm{W}$ and 2.5 wt\% Hf. F-48 which is one of the strongest commercially available niobium-base alloys contains 15 wt\% $\mathrm{w}, 5 \mathrm{wt} \%$ Mo, and 1 wt\% $\mathrm{Zr}$. The Nb-1Zr data was obtained from flowing lithium. These data are extrapolations of at least two orders of magnitude in time and may not accurately represent the creep performance of the material under the operating conditions. Even though arc-cast molybdenum does not have the highest strength/density ratio, its strength appears to be sufficient for the core heat pipes. 


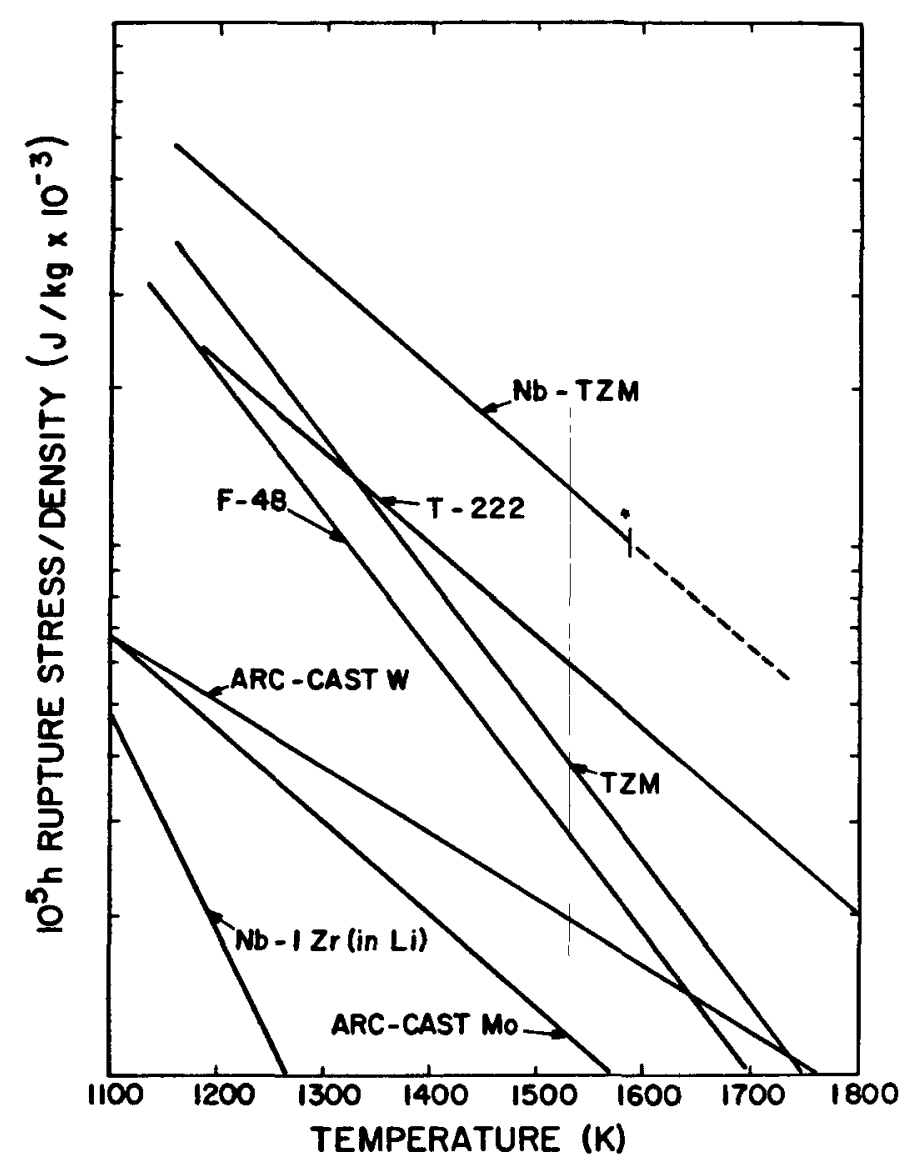

Fig. 79. $10^{5}-\mathrm{h}$ rupture stress/density ratios for selected refractory metals.

Additional creep tests in a core heat-pipe simulated environment are needed to confirm this estimate.

Because part of the heat pipe is located inside the core of the nuclear reactor, the material from which the heat pipes are made must not have a detrimental effect on the neutronics of the core. On the basis of neutron absorption cross section, niobium and molybdenum are the best (least absorbing), followed by tungsten and tantalum.

Neutron irradiation damage in the heat pipes manifests itself in alterations in the mechanical and physical properties of the material. Under certain combinations of temperature and neutron fluence, voids form in metals in such size and numbers that measurable swelling can be detected. In 1973 Brimhall et. al. ${ }^{55}$ developed a three-dimensional plot representing the temperature and fluence dependence of swelling in irradiated 
molybdenum. This plot predicts an irradiation swelling of about $1 \%$ at fast fluences (>0.1 MeV) of $10^{26} \mathrm{n} / \mathrm{m}^{2}$ and at temperatures between 1075 and $1475 \mathrm{~K}$. Bentley and Wiffen ${ }^{56}$ have recently published swelling data from high-temperature irradiation experiments that indicate that the swelling of molybdenum at $10^{26} \mathrm{n} / \mathrm{m}^{2}$ in the temperature range $858-1273 \mathrm{~K}$ is close to $0.5 \%$. Little data is available on the combined effects of high temperatures and high neutron fluences. Wiffen has studied the effects of fastneutron irradiation on the tensile properties of molybdenum, Mo-0.5\% Ti, and Mo-50\% Re after irradiating in EBR-II at temperatures between 663 and $1410 \mathrm{~K}$ and neutron fluences in the range $1.5-6.1 \times 10^{26} \mathrm{n} / \mathrm{m}^{2}$. The graphs in Fig. 80 illustrate the effects of high temperature irradiation on the tensile strength and total elongation of molybdenum. These curves indicate a significant increase in ultimate tensile strength and a significant decrease in total elongation due to irradiation. The tensile properties of Mo-0.5\% $\mathrm{Ti}$ respond to irradiation in a manner similar to that seen of pure molybdenum.

There is little information on the influence of the neutron irradiation environment on the creep behavior of molybdenum. So $f a r$, it appears that on ly three in-pile creep tests have been performed on molybdenum to as high as $1145 \mathrm{~K}$ (Ref. 58). These data are comparable with data obtained outside an irradiation environment. This is consistent with an estimate based on observations of effects of neutron irradiation on the microstructure of molybdenum. 59 Some post-irradiation creep experiments on molybdenum have been reviewed by $Z i l l i n s k i, 60$ but these data are generally inappropriate because the majority of the irradiations were performed at $1273 \mathrm{~K}$ or less. More data is needed on the effects of neutron irradiation on the mechanical properties of molybdenum.

There is also little data on the effects of high-temperature highfluence neutron irradiation on the thermal conductivity of molybdenum. Wiffen ${ }^{59}$ indicates this irradiation has little effect on the electric resistivity, which theoretically implies that there is a similar small effect on the thermal conductivity, but this prediction should be experimentally verified.

Besides being strong, the material chosen for the core heat pipes must be fabricable into tubular shapes several meters long, probably with 


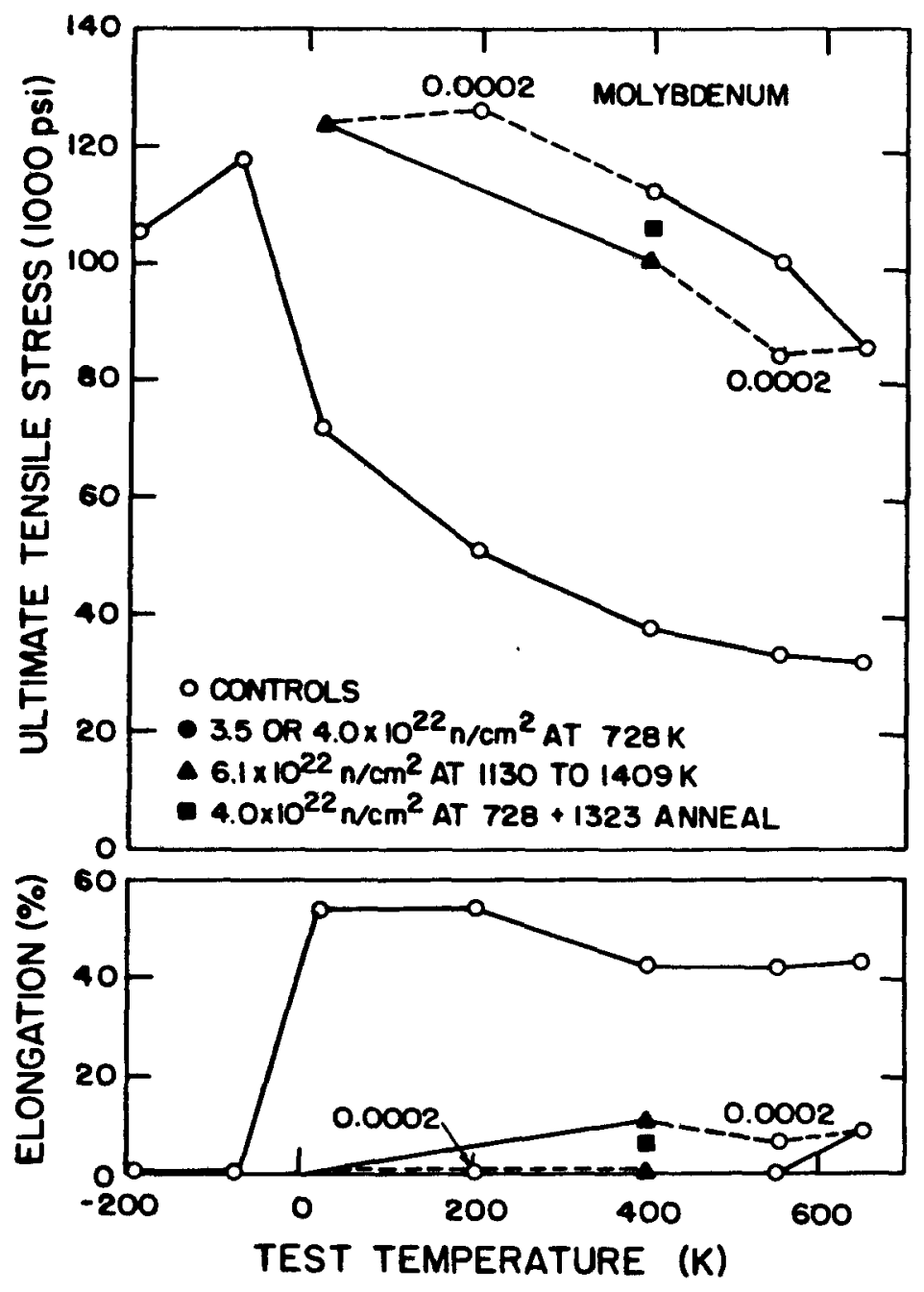

Fig. 80. The ultimate tensile strength and total tensile elongation for irradiated and control samples of molybdenum. Tensile strain rate was $0.03 \mathrm{~min}^{-1}$ except as shown. Solid lines connect results differing only in test temperature. Dashed lines connect results where irradiation conditions or strain rates are not held constant.

internal longitudinal grooves. The material must also be weldable by electron-beam methods. The fabrication of ductile, seamless molybdenum tubing in the sizes needed for core heat pipes has been demonstrated using extrusion and tube drawing methods. ${ }^{61}$ Niobium- and tantalum-base alloys have been fabricated into tubes using similar methods. Pure tungsten tubing has been fabricated by chemical vapor deposition methods. Tubing from high-strength alloys such as W-4 Re-HfC is not listed as being available in the Aerospace Structural Metals Handbook. ${ }^{62}$ So far, internally grooved refractory metal tubing appears to be unavailable so 
that a process development program will probably have to begin to obtain this type of product.

Because the core heat pipe's main function is heat transfer, the heatpipe walls must have high thermal conductivity. Figure 81 shows that tungsten and molybdenum have significantly better thermal conductance than either niobium or tantalum. Molybdenum with its $100 \mathrm{~W} /(\mathrm{m} . \mathrm{K})$ conductivity at $1375 \mathrm{~K}$ is a good choice for core heat-pipe material.

Sodium is the heat-pipe working fluid, therefore, the heat-pipe structural material must be able to withstand the severe corrosiveness of refluxing sodium. The mechanism of corrosion in heat pipes is basically a dissolution of the container and wick material in the solute-free liquid that is derived from the vapor in the condenser section and a precipitation of this dissolved material in the evaporator section. For the first approximation, the corrosion rate is proportional to the liquid-metal mass transfer rate and the solubility of the container material in the liquid metal. Contamination of the liquid metal by such things as oxygen and carbon can enhance the corrosion rate of the heat-pipe material. Tantalum and niobium are more susceptible to corrosion enhancement by contamination

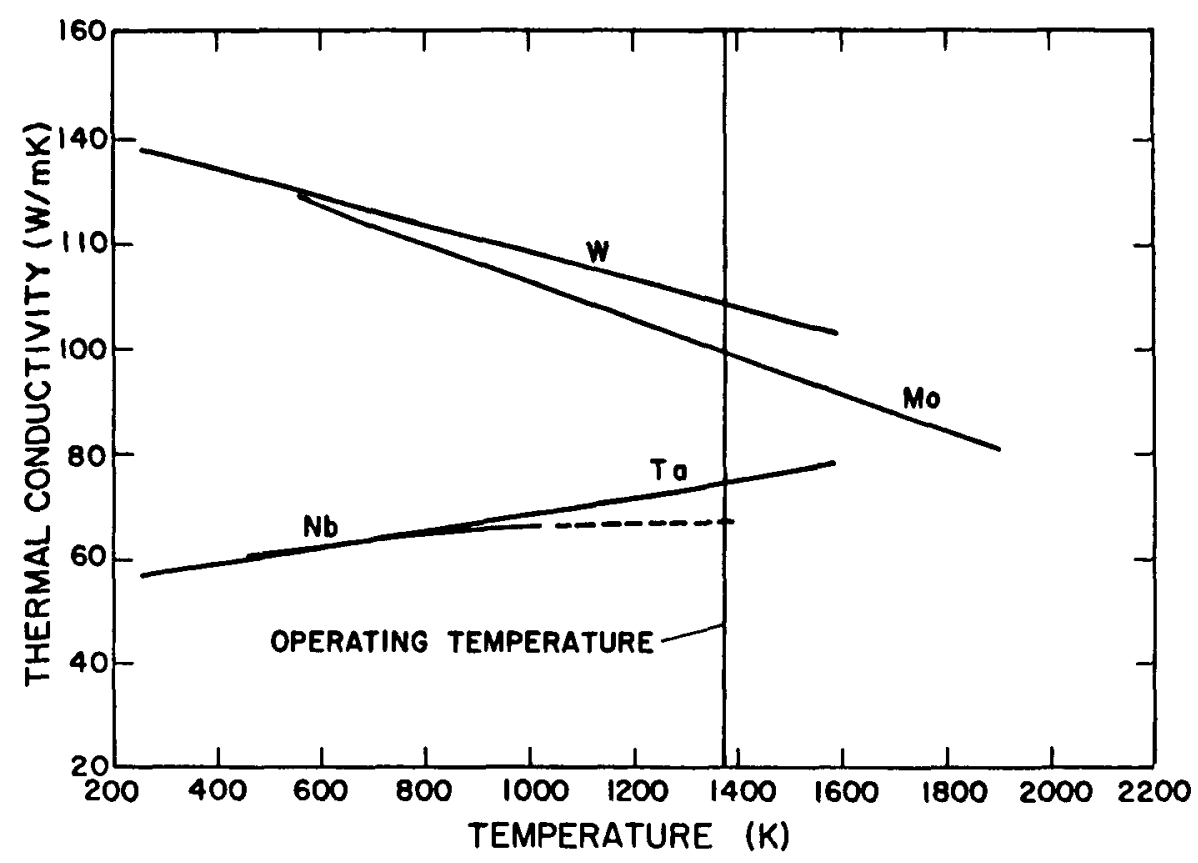

Fig. 81. Thermal conductivity of tungsten, molybdenum, tantalum, and niobium. 
than either tungsten or molybdenum. It has been shown, for example, that oxygen dissolved in either niobium or tantalum can cause severe intergranular attack of these metals in the 875-1275 $\mathrm{K}$ temperature range. ${ }^{63}$

Contaminants coming from sources external to the heat pipe also pose problems, especially if they enter the condenser section. Because the interstitial elements $(H, C, O, N$, and sometimes $S i)$ diffuse at a rapid rate through refractory metals, materials that contain these elements and that contact the outside of the heat pipes can cause rontamination. The contamination of the condenser section of the core heat pipes is totally dependent on the design and materials used in the electric conversion device. For example, if a Brayton converter made of niobium- or tantalum-base alloys is connected tọ the core heat pipes, the large amounts of residual, dissolved oxygen in the system heat exchanger and ducting materials will be absorbed into the heat-pipe condenser causing enhanced corrosion. A similar situation might occur with thermoelectric converters. The extent of this problem cannot be adequately assessed until converter designs and materials become better defined.

The UC-ZrC candidate fuel is a potential source of carbon to the heatpipe evaporator section by carbon diffusion through the wall. An estimate has been made of the amount of carbon expected to permeate through the heat-pipe walls during reactor operation. Using data for carbon diffusion in molybdenum, carbon solubility, and high temperature data, ${ }^{64-66}$ it was est imated that only $25 \times 10^{-4} \mathrm{gm}$ of carbon would permeate through a 1.8-mm-thick molybdenum heat-pipe wall after $10 \mathrm{y}$ at $1375 \mathrm{~K}$. This assumes that the thermodynamic driving force for a solution of carbon in molybdenum is stronger than the chemical binding force for carbon in UC-10 at.\% $\mathrm{ZrC}$. This estimate is coarse and should be verified experimentally.

Reactions between the carbide fuel and heat pipes that form refractory metal carbides are another possible mechanism for putting carbon in the heat pipe evaporator. Figure 82 indicates the potential for the reactions. Free energy curves for niobium and tantalum fall below those for the uranium carbides indicating that niobium and tantalum will react with the carbon in UC to form the refractory metal carbides and free uranium at high temperatures. On the other hand, these curves indicate that molybdenum will only react with $U \mathrm{C}_{2}$ forming $\mathrm{Mo}_{2} \mathrm{C}$, and this fact has been verified experimental7y $66,67^{2}$, with the added feature that $\mathrm{UMoC}_{2}$ is also formed at $1875 \mathrm{~K}$ 
and above. For molybdenum, the reaction with $U C_{7+x}$ yields a layer of $\mathrm{Mo}_{2} \mathrm{C}$ on the molybdenum which grows at approximately the same rate as the $\mathrm{Mo}_{2} \mathrm{C}$ layer derived from the reaction of molybdenum with carbon. ${ }^{68}$ Using a reaction-layer growth rate constant derived from the literature, ${ }^{66-73}$ one calculates that molybdenum in contact with $U C_{1+x}$ for $7 \mathrm{yr}$ at $1375 \mathrm{~K}$ will develop a $\mathrm{Mo}_{2} \mathrm{C}$ layer no more than $0.4 \mathrm{~mm}$ thick. If the interface temperature is increased to $1505 \mathrm{~K}$, the entire heat-pipe wall (1.8 mm) will be converted to $\mathrm{Mo}_{2} \mathrm{C}$ in $7 \mathrm{yr}$. The layer thicknesses will be reduced from these values if there is insufficient excess carbon in the UC. As shown Fig. 83 , the reaction between molybdenum and $U C_{1+x}$ is faster than for the other candidate refractory metals. However, the reactions between $U C_{1+x}$ and tantalum and $U C_{1+x}$ and niobium do not stop when $x=0$. As implied in Fig. 82 uranium metal is formed by this reaction.

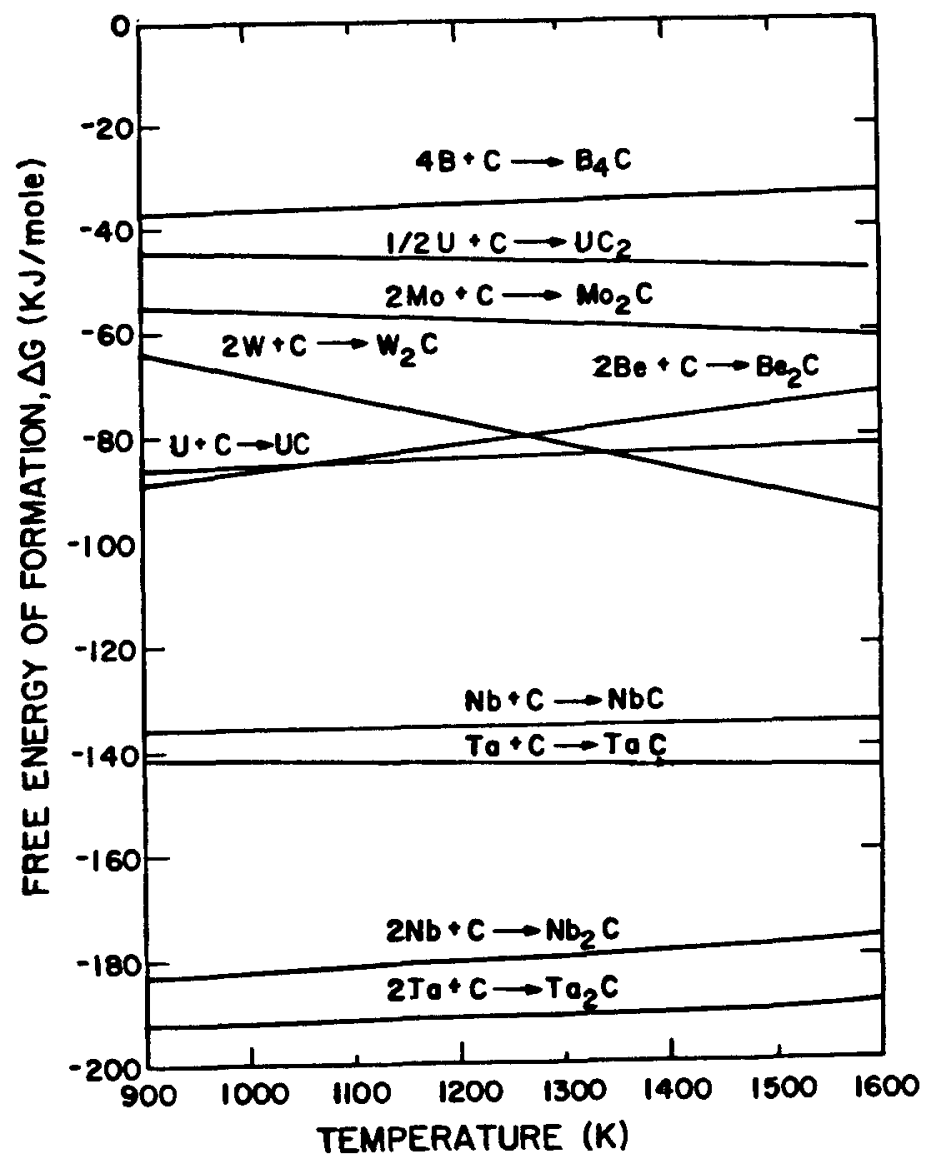

Fig. 82. Comparison of free energy of formation. 


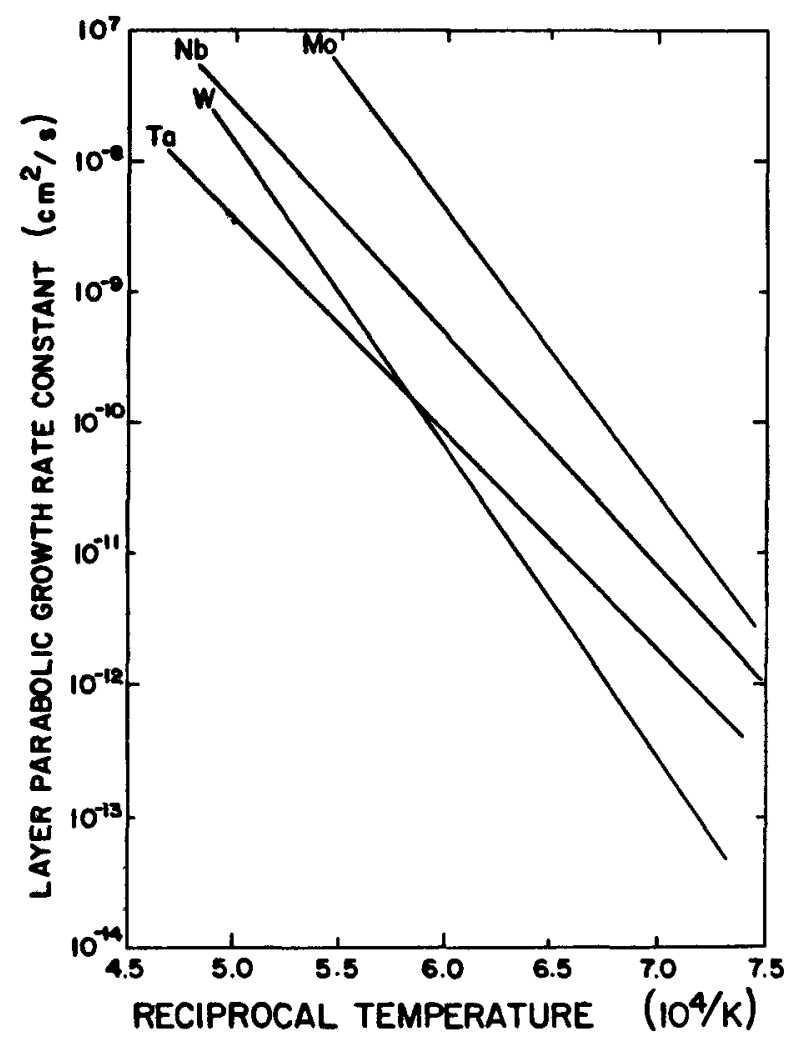

Fig. 83. Comparison of rates of growth of carbide layers on refractory metals heated in contact with hyperstoichiometric UC.

If the temperature of the molybdenum-fuel interface is allowed to exceed $\sim 2125 \mathrm{~K}$, a liquid is expected to form from a peritectic reaction of the type

$$
2 U \mathrm{UC}+\mathrm{Mo} \rightarrow \mathrm{UMoC}_{2}(\mathrm{sol})+U(1 \mathrm{iq})
$$

which has been shown experimentally to occur between molybdenum and UC-ZrC (Ref. 69). A similar reaction occurs between tungsten and UC above about $2325 \mathrm{~K}$ (Ref. 63). Experimental studies indicate that peritectic reactions between stoichiometric UC and tantalum and stoichiometric UC and niobium 1 imit the contact temperatures to below $1475 \mathrm{~K}$ (Ref. 66). This would give tantalum- or niobium-base alloy core heat pipes an overheat margin of only $100 \mathrm{~K}$.

3. Reflector Materials. Candidate materials for the core neutron reflector include beryllium, BeO and graphite. Neutronic calculations have indicated that a BeO reflector would yield the smallest $1-\mathrm{MW}_{\mathrm{t}}$ reactor 
core. 70 The maximum temperature of a 0.9 - emmissive Be0 radial reflector for this size reactor core would be $\sim 850 \mathrm{~K}$, while a 0.9-emissive beryllium radial reflector would be operating at $\sim 800 \mathrm{~K}$. The temperatures in the end reflector opposite the heat-pipe exit end (HPEE) are comparable to those in the radial reflectors. Both beryllium and BeO can be expected to have sufficient strength and stability at these temperatures, so that we need only be concerned with their irradiation stability. The operating temperatures of the reflector at the HPEE end of the core are close to the heat-pipe temperature which automatically precludes the use of beryllium at the HPEE.

of most concern is the swelling and loss of thermal conductance caused by neutron irradiation. The primary cause of the swelling in beryllium is the formation of helium by $(n, 2 n)$ and $(n, \alpha)$ reactions. At temperatures less than $373 \mathrm{~K}$ the helium enters into an enforced solid solution in the metal, no significant volume changes have been observed at doses up to $I \times$ $10^{25} \mathrm{n} / \mathrm{m}$ (Ref. 71). At higher temperatures the helium gas accummulates into bubbles and swelling proceeds as the bubbles grow. Hickman ${ }^{72}$ has summarized the available elevated temperature irradiation swelling data in Fig. 84 , where the swelling is normalized to a dose of $10^{20}$ nvt $\left(10^{24}\right.$ $\mathrm{n} / \mathrm{m}^{2}$ ) assuming a linear relation between dose and swelling. Most of the results were obtained over the $3-7 \times 10^{24} \mathrm{n} / \mathrm{m}^{2}$ dose range, so this normalization procedure should not introduce significant errors. As can be seen in Fig. 84, there is no significant swelling up to $\sim 825 \mathrm{~K}$. Above this temperature, the swelling data becomes quite scattered, and with the exception of the two anomalously high values reported by Weir, ${ }^{75}$ the swelling is not excessive. However, as a result of the projected high neutron fluence for the reflector $\left(4 \times 10^{25} \mathrm{n} / \mathrm{m}^{2}\right)$, the operating temperature would probably have to be limited to below $825 \mathrm{~K}$ to keep the swelling to an acceptable level $(1-2 \%)$.

As with most solids, neutron irradiation of beryllium significantly reduces stress-rupture times at elevated temperatures. Weir reports an order of magnitude reduction in the rupture time at $875 \mathrm{~K}$ in a fast flux of $3-9 \times 10^{17} \mathrm{n} / \mathrm{m}^{2} \mathrm{~s}$. A general loss of ductility results from neutron irradiation at elevated temperatures. This is due in part to the formation of helium bubbles at the grain boundaries.

Above room temperature, the thermal conductivity of beryllium is not significantly affected by atomic displacement produced defects resulting 


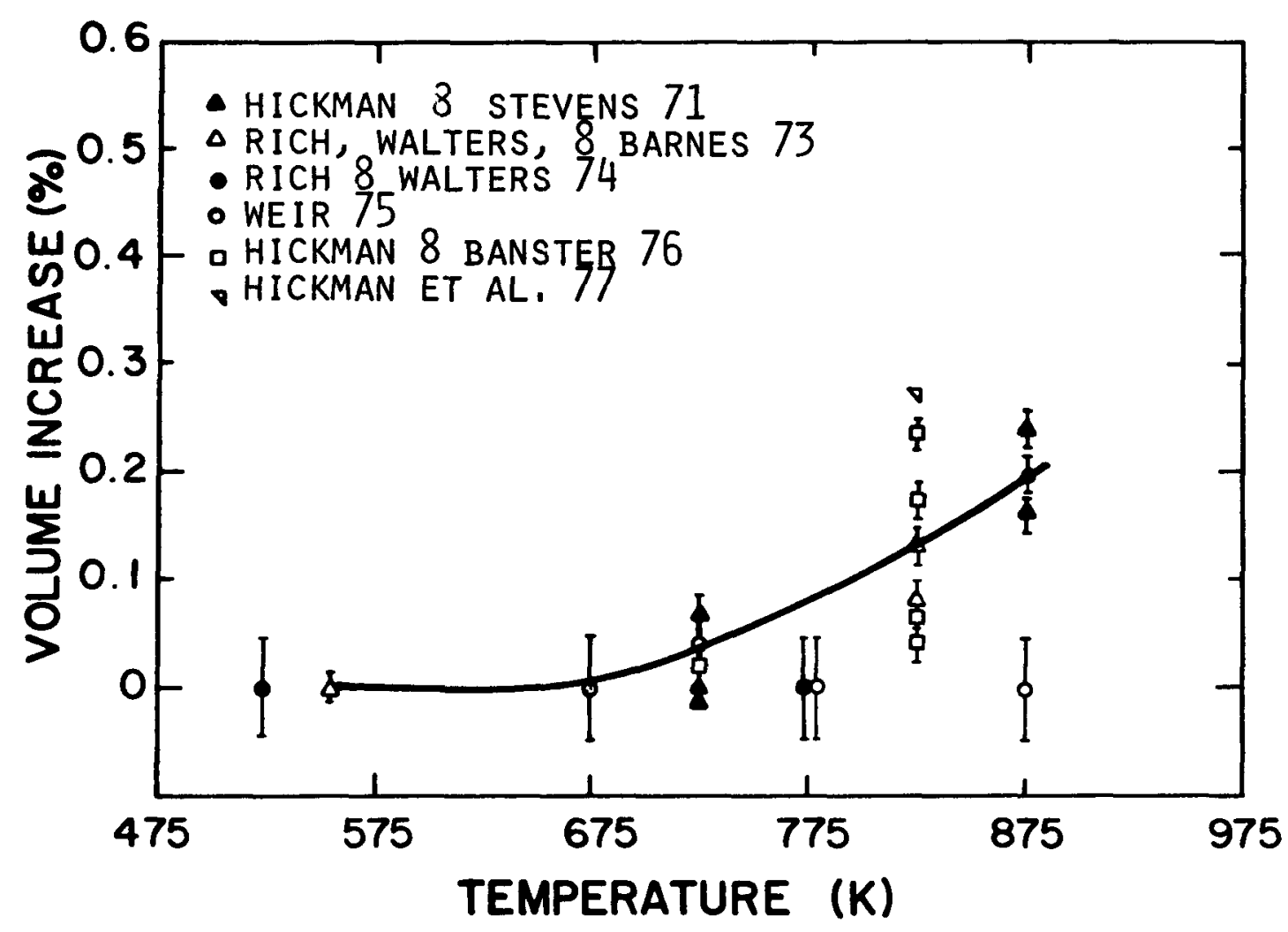

Fig. 84. Volume changes observed in irradiated beryllium as a function of temperature. The reported values have all been normalized to a dose of $10^{24} \mathrm{n} / \mathrm{m}^{2}$.

from the neutron flux. ${ }^{72}$ However, helium bubble formation at high fluences $\left(>10^{21} \mathrm{n} / \mathrm{m}^{2}\right)$ and high temperatures $(>825 \mathrm{~K})$ would be expected to reduce the thermal conductivity.

Irradiation studies on BeO (Ref. 78) show that a neutron reflector made from this material should be operated above $\sim 975 \mathrm{~K}$ to minimize irradiation swelling ( $2 \%$ for $4 \times 10^{25} \mathrm{n} / \mathrm{m}^{2}$ ) that results from microcracking.

This microcracking occurs in polycrystalline bodies due to the anisotropic growth of the BeO crystal lattice. The lattice still grows above $975 \mathrm{~K}$, but the macroscopic growth exceeds the lattice growth in this temperature regime. Helium bubbles start contributing to the irradiation swelling of Be0 above $1175 \mathrm{~K} .{ }^{72}$ Microcracking is a problem above $975 \mathrm{~K}$, especially for coarse-grained material $(20 \mu \mathrm{m})$. At these temperatures, the microcracking does not cause excessive swelling, but it significantly degrades both the strength and thermal conductivity. In-pile measurements around 
$1175 \mathrm{~K}$ showed large reductions in thermal conductivity that appeared to be caused by microcracking. ${ }^{79}$

Beryllium metal is the best choice for the radial and core closed-end reflector material from the standpoint of irradiation stability, and, furthermore, it can be relied upon as a self-supporting, structural member during the operating lifetime of the reactor. A structural container would undoubtedly be required to keep it properly located around the reactor.

Beryllium oxide is the best for the reflector at the HPEE of the core because this end will be operating close to $1375 \mathrm{~K}$. A refractory metal container will be required to keep this ceramic material in place in case it cracks or fragments during handling, transportation, launch, and reactor operation. Because this reflector section will be in contact with the core heat pipe and the fuel cladding, the $\mathrm{Be} 0$ whould be contained in molybdenum. Beryllium oxide has a higher thermal expansion coefficient than molybdenum, $10 \times 10^{-6}$ vs $6 \times 10^{-6} \mathrm{~K}^{-1}$, so that space will have to be provided in the container for the Be 0 to expand. Niobium has a better thermal expansion match with $\mathrm{BeO}$ and will probably be an adequate canning material.

For the HPEE reflector high density tiles of Be0 ( 95\% theoretical density) can be fabricated by cold pressing and sintering, and these pieces can be fitted into the core container. Negligible developmental activities are anticipated in this fabrication but new Occupational Safety and Health Act (OSHA) requirements on fabrication facilities may cause difficulty in finding a vendor to fabricate the required parts.

Beryllium reflector pieces could be fabricated by either vacuum hot pressing (VHP) or hot isostatic pressing (HIP) powdered metal to near final shape. The HIP process can typically provide large as-pressed parts closer to the final shape than the VHP technique. Some machining of the reflector pieces will be required regardless of the method used to make the rough shape. All parts will be fabricated from nuclear grade beryllium which is a commercially available product. A negligible developmental effort probably will be required to procure the desired reflector pieces but again new OSHA requirements could make procurement difficult.

A neutron absorber is required both for power flattening at the core periphery and for core reactivity control in the rotating control drums. The prime candidate for both cases is $B_{4} C$, because it is lightweight, has 
excellent neutron absorbing capabilities, and is a high-temperature refractory compound about which much is known. A good compilation of design data for $B_{4} C$ relevant to nuclear applications can be found in Ref. 80 .

Boron carbide is a nonstoichiometric carbide that melts $\sim 2725 \mathrm{~K}$. The theoretical density of $\mathrm{B}_{4} \mathrm{C}$ varies from $2.512 \mathrm{Mg} / \mathrm{m}^{3}$ for natural boron $\left(20\right.$ at. $\%{ }^{10} B$ ) to $2.367 \mathrm{Mg} / \mathrm{m}^{3}$ for $100 \%{ }^{10} \mathrm{~B}_{\text {in }} \mathrm{B}_{4} \mathrm{C}$. Much data has been obtained on the neutron irradiation stability of $\mathrm{B}_{4} \mathrm{C}$ at elevated temperatures. ${ }^{80,81}$ Using the irradiation swelling equation from Ref. 86 with a $B_{4} C$ temperature of $850 \mathrm{~K}$ and $20 \times 10^{20}$ captures $/ \mathrm{cm}^{3}$, one est imates that the $\mathrm{B}_{4} \mathrm{C}$ will have increased in volume about $2 \%$ after $7 \mathrm{yr}$ of reactor operation. At this temperature most of the helium is expected to be retained within the solid, and the material probably will be quite friable. Also, irradiation at this temperature and burnup is expected to cut the thermal conductivity of $\mathrm{B}_{4} \mathrm{C}$ in half. 80 The loss of mechanical integrity due to neutron irradiation strongly suggests a need for enclosing the $\mathrm{B}_{4} \mathrm{C}$ in some kind of structural container. As shown in Fig. $82 \mathrm{~B}_{4} \mathrm{C}$ is expected to react with all of the refractory metals but least with molybdenum. However, the temperatures are so low that a reaction would probably proceed at an insignificant rate. This will require experimental proof. If the temperature can be maintained below $850 \mathrm{~K}, 316$ stainless steel might also be a candidate material because of its known slow reaction rate with $\mathrm{B}_{4} \mathrm{C}$, both with ${ }^{82}$ and without ${ }^{80}$ neutron irradiation at this temperature.

As shown in Fig. 82, beryllium is expected to react with $B_{4} C$, so the $B_{4} C$ segments in the beryllium reflector drums will require a reaction barrier. Experiments are required to define the need for a barrier and to determine which barrier's will solve the problem.

The best alternate candidate material for the neutron absorber is $E_{4} B_{6} \cdot{ }^{83}$ This material has been considered for use in liquid-metal fast breeder reactors (LMFBRs). Europium hexaboride has slightly better neutronic properties and higher thermal conductivity than $B_{4} C$, but there is little data on its properties and neutron irradiation performance.

Boron carbide shapes are fabricated typically by either hot or cold pressing and sintering. Depending upon the dimensional tolerances required, diamond grinding may be used for final sizing and finishing of the parts. The container for the $B_{4} C$ would be made up from sheets using 
electron-beam welding or mechanical fastening. Because helium is released from $\mathrm{B}_{4} \mathrm{C}$ during irradiation, the container should be vented to space.

4. Other Reactor Materials. Materials have also been considered for those reactor core components that (1) bind and support the core, (2) thermally insulate the core, and (3) drive and support the control drums.

The temperatures outside the core are sufficiently low enough to allow the use of super alloys for the core support structures. A hightemperature, precipitation-strengthened, nickel-base alloy such as Inconel 718* has sufficient strength-to-weight properties at temperatures up to $\sim 780 \mathrm{~K}$, good room-temperature strength, and the toughness required for 1 aunch to make it a prime candidate for these structures. Inconel 718 is also a well characterized material. A higher-temperature material may be required wherever attachments are made directly to the core. Niobium alloys such as $\mathrm{F}-48$ and $\mathrm{Cb}-752$ ( $\mathrm{Nb}-10 \mathrm{~W}-25 \mathrm{Zr}$ ) might be considered for these structures if the temperatures are too high for super alloys.

These same materials may be considered for the control drum, driveshaft, and bearing support structures. If the reactor is well insulated, it might be possible to use a titanium or titanium-alloy drive shaft and bearing support structure as was demonstrated in the SNAP 1OA developmental activities. ${ }^{84}$ Because of the relatively high neutron fluence $\left(8 \times 10^{24} \mathrm{n} / \mathrm{m}^{2}\right)$ that these materials will be subjected to in service, a major consideration is the resistance to loss of strength and toughness resulting from neutron irradiation. If the operating temperature is $\sim 755 \mathrm{~K}$, titanium alloys such as Ti-5522 (Ti-5Al-5Sn-2Zr-2Mo-0.25Si) might be considered to save weight. Irradiation damage data will be required for each candidate material prior to final selection.

The requirements on the control drum, drive shaft, and bearing material demand that the shaft be operable (rotatable) for $7 \mathrm{yr}$ at moderately high temperatures $(\sim 800 \mathrm{~K}$ ) while being exposed to a neutron fluence of about $10^{26} \mathrm{n} / \mathrm{m}^{2}$. If this temperature is not exceeded, it is feasible to use the same bearing materials as used in the SNAP 10A reactor. ${ }^{85}$ The SNAP 10A used a self-aligning ball-and-socket with journal-and-sleeve bearing design. The socket and shaft were made of titanium which was flame-spray coated with $\mathrm{Al}_{2} \mathrm{O}_{3}$ and lubricated with sodium silicate bonded $\mathrm{MOS}_{2}$

*Trademark of an International Nickel Company $\mathrm{Ni}-\mathrm{Cr}-\mathrm{Fe}$ alloy. 
plus graphite. The ball was made of sintered nickel plus titanium carbide (Kennametal $\mathrm{K} \mathrm{162B).} \mathrm{Another} \mathrm{journal} \mathrm{bearing} \mathrm{material} \mathrm{combination} \mathrm{that} \mathrm{was}$ found to have excellent performance in the 535-785 $\mathrm{K}$ range was carbon graphite (Purebon P-5N, 40\% graphite $+60 \%$ carbon) in contact with alumina flame-sprayed onto titanium. ${ }^{85}$ The only data on the neutron irradiation stability of these material combinations comes from ground testing and flight experiences, which only indicate that no major problems were encountered. 96 Qualification testing of these material combinations in a high-temperature neutron flux environment simulating reactor operation is required.

The prime candidate for insulation between the reflector and the core is Multi-Foil*, which is a compact, highly insulating composite consisting of parallel layers of thin metal foils each separated by a thin layer of high-purity refractory oxide powder. Molybdenum foil was chosen for the foil material because it has sufficient refractory properties and is the same material as the fuel cladding it will contact. Zirconia powder was chosen for the oxide because of its high-temperature properties, its good (as compared to thoria) neutronic properties and its long-term, hightemperature compatibility with molybdenum. 87

The heat fluxes through typical layers of ${\mathrm{Mo}-\mathrm{ZrO}_{2}}_{2}$ Multi-Foil in a vacuum are plotted in Fig. 85 against the source temperature and referred to a sink temperature of $310 \mathrm{~K}$. Despite the excellent insulation in the perpendicular direction, the designer must remember that Multi-Foil insulation is a good conductor in the plane of the insulator. The compactness of Multi-Foil insulation is illustrated by the fact that typical foil- and oxide-layer thicknesses have densities of 20-40 layers/mm (Ref. 88). C. Comparison of Reactor Designs

Before comparing heat-pipe, gas-cooled, and liquid metal reactions we shall review the design characteristics for heat-pipe reactors with UC-10 at.\% $\mathrm{ZrC}, \mathrm{UO}_{2}-20$ vol\% Mo, and $\mathrm{UO}_{2}-40$ vol\% Mo fuels.

Table XV in Section $A$ above is a comparison of dimensions and mass for the three fuels. The more dense UC fuel results in a more compact and lighter reactor. However, a major design problem exists in maintaining good thermal bonds between the fuel and the heat pipe and good thermal

*Registered trademark of Thermo Electron Corporation. 


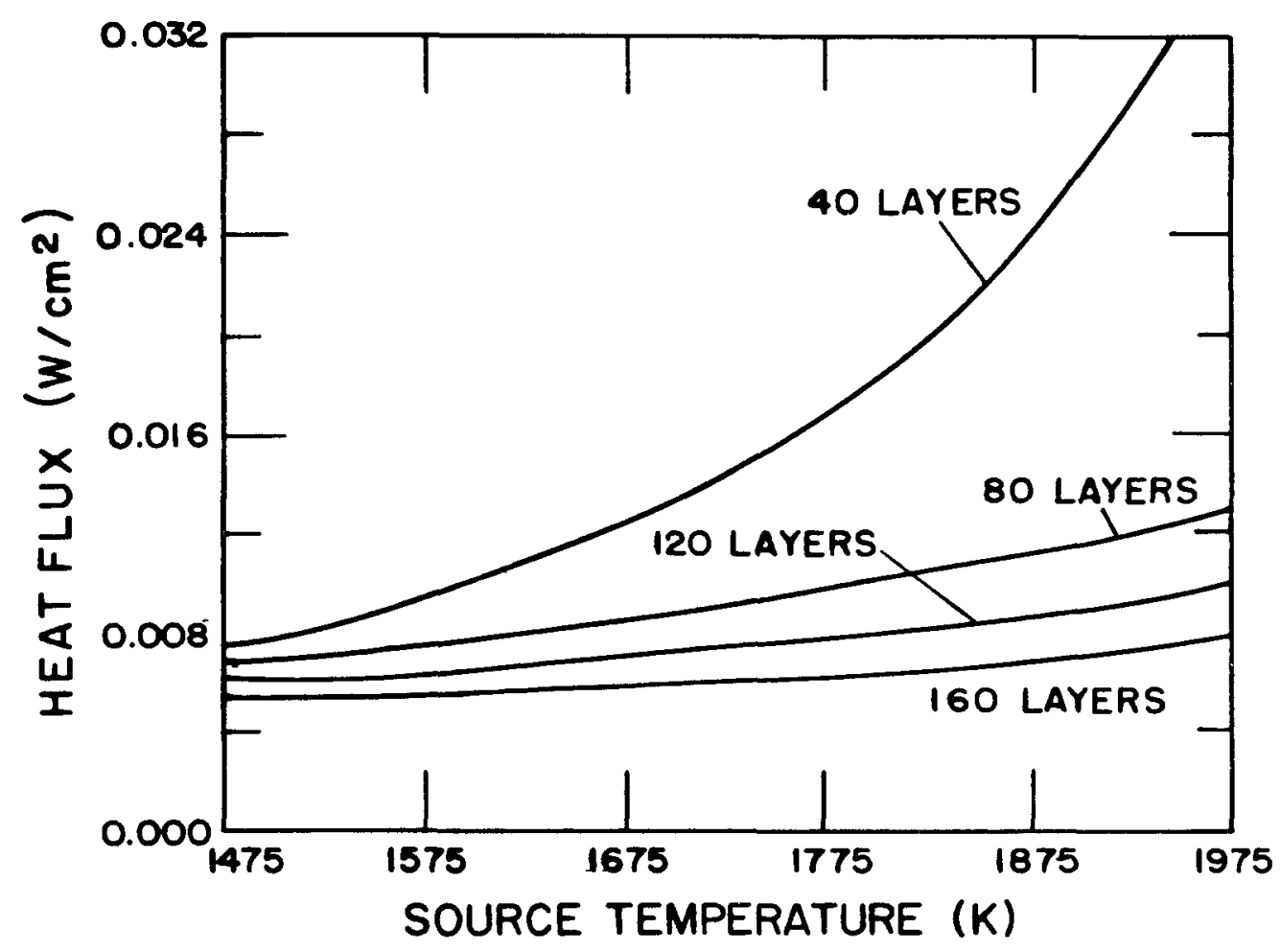

Fig. 85. Heat flux vs source temperature for a $\mathrm{Mo}^{-} \mathrm{ZrO}_{2}$ multi-foil insulator.

bonds between adjoining fuel modules for a $7 \mathrm{yr}$ period. The thermal expansion properties of the UC-ZrC fuel and molybdenum heat pipes are quite different. Fuel swelling appears to be a limitation on UC, though some data indicates that alloying UC with $\mathrm{ZrC}$ reduces this problem. Chemical stability is also much more of a problem, with temperatures limited to below $2125 \mathrm{~K}$, whereas $\mathrm{UO}_{2}$ is 1 imited to $2625 \mathrm{~K}$. The consequences of heat-pipe failures are quite sensitive to this temperature limit. Fabrication methods for UC are much less developed than $\mathrm{UO}_{2}$. Fabrication would need to be done in a glove box environment. The major disadvantage of $\mathrm{UO}_{2}$-Mo is the lower uranium density, as reflected in the higher reactor mass in Table XVI.

A comparison of heat-pipe and fluid-cooled (gas or liquid) reactors indicates that one would expect similar core diameters and lengths, reflector thickonesses, and U-235 mass because the neutronic parameters are similar. Fluid-cooled reactors require a fluid containment or pressure 
vessel so that they are slightly heavier than heat-pipe reactors. Fig. 86 compares reactor mass for gas-cooled and heat-pipe reactor designs for two Brayton operating temperatures. The temperatures were taken to correspond with Brayton inlet temperatures of 1325 and $1500 \mathrm{~K}$. The heat-pipe design is slightly less massive than the gas-cooled design.

The major problems with fluid reactors are that they are subject to single-failure points (a fluid leak would result in termination of power operation), the core design tends to be more complex, fuel properties must be better known, and the reactors lack the redundancy desirable for highly reliable long-life power plants.

Single failure points in fluid reactors can occur from fluid leakage either out of the pressure vessel or fluid lines, or from internal failures that result in excessive flow in some channels and a reduction of flow in others. Either way, excessive temperatures can occur in the core and result in a power plant shutdown. Also, fuel element corrosion or erosion can lead to loss of reactivity and premature shutdown as a result of fuel swelling, embrittlement, chemical reactions with impurities in the fluid and fluid flow forces. Heat-pipe reactors, on the other hand, have no

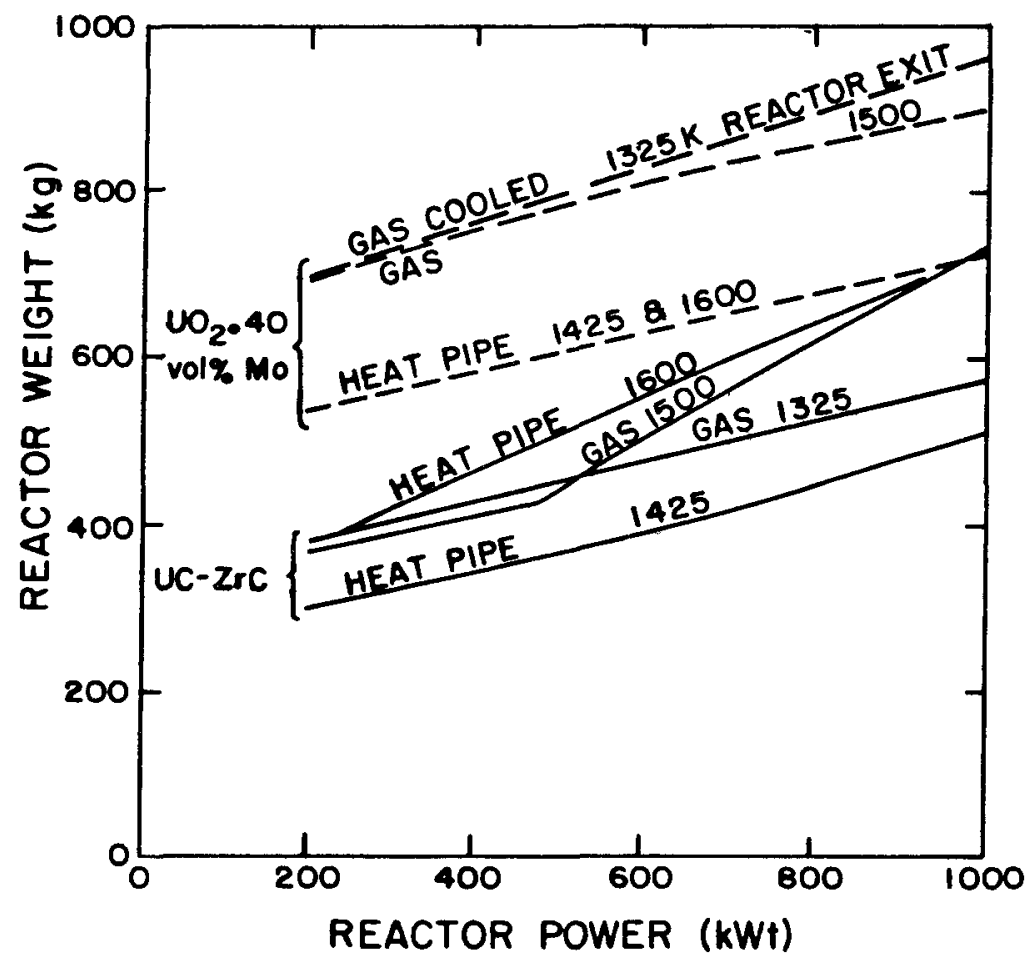

Fig. 86. Gas-cooled and heat-pipe reactor design mass comparison. 
flowing fluid in the sense of a fluid reactor. The heat pipe acts as an individual pressure containment vessel and provides a high degree of redundancy to the design by providing a large number $(\sim 90)$ of completely independent fluid coolant channels. The heat pipes are quite strong compared to the fuel claddings in fluid reactors, and, therefore, heat-pipe reactors can accept greater amounts of fuel swelling, cracking, and embrittlement. The fuel is confined to its immediate vicinity and, accordingly, potential loss of reactivity due to coolant transport of fuel is minimized. Also heat-pipe reactors have a small volume of fluid compared to fluid-cooled reactors. Problems associated with coolant activation are thereby greatly reduced.

Fluid-core designs are complicated by the need to control the flow into many parallel channels. This is usually done by orificing the fluid as it enters the core. Support structures, which have proven to be quite complex, usually in the form of plates, are needed for acceleration loads, thermal expansion, and to support the fuel elements. These complications are not present in the heat-pipe reactor design.

Fuel properties must be better known in a fluid-cooled core design because rupture of the fuel clad can be disasterous to the mission. Whereas in the heat-pipe reactor the fuel is confined outside the heat pipe, the fuel in the luid reactor is conversely freer to migrate. Thus, quality control is more stringent and the conditions that can lead to fuel corrosion must be well established.

The lack of redundancy in a fluid-cooled reactor has already been mentioned. The lifetime and reliability goals for the reactor will therefore be much more difficult and costly to achieve. Heat-pipe reactors el iminate the need for mechanical or electromagnetic pumps. These are complex developmen $i$ items and difficult to operate $7 \mathrm{yr}$ without maintenance.

\section{REFERENCES:}

1. H. J. Banach, "Preliminary Design of the 2 MWt Reactor and Shield (PWAR-20) for the SNAP-50 SPUR Powerplant," (Pratt and Whitney Aircraft, Middletown, Connecticut) report PWAC-445 (30 December 1964).

2. T. R. Hill, "ONETRAN: A Discrete Ordinates Finite Element Code for the Solution of the One-Dimensional Multigroup Transport Equation," Los Alamos Scientific Laboratory report LA-5990-MS (June 1975). 
3. K. D. Lathrop, "DTF-IV, a FORTRAN-IV Program for Solving the Multigroup Transport Equation with Anisotropic Scattering," Los Alamos Scientific Laboratory report LA-3373 (November 1965).

4. P. Vinz and C. A. Busse, "Axial Heat Transfer Limit of Cylindrical Sodium Heat Pipes Between $25 \mathrm{w} / \mathrm{cm}^{2}$ and $15.5 \mathrm{~kW} / \mathrm{cm}^{2}$," Proc. First Int. Heat Pipe Conf., Stuttgart, Germany, 1973.

5. J. E. Kemme, E. S. Keddy, and J. R. Phillips, "Performance Investigations of Liquid-Metal Heat Pipes for Space and Terrestrial Applications," Proc. 3rd Int. Heat Pipe Conf., Palo Alto, California, May 1978.

6. D. L. Keller, "Progress on Development of Fuels and Technology for Advanced Reactors During July 1970 through June 1971," Battelle Columbus Labs. report BMI-1918 (July 1971).

7. W. A. Ranken and W. H. Reichelt, "Behavior of Tungsten $\mathrm{Clad} \mathrm{Mo-UO_{2 }}$ Fuel under Neutron Irradiation at High Temperature," Proc. 3rd Int. Conf. on Thermionic Electrical Power Generation, Julich, Germany, 1972.

8. R. Brandt, G. Haufler, and G. Neuer, "Thermal Conductivity and Emittance of Solid $\mathrm{UO}_{2}, "$ Y. S. Touloukian, translation Ed. Center for Information and Numerical Data Analysis and Synthesis, Purdue University, West Lafayette, Indiana, (Apri) 1976).

9. "Engineering Data for Molybdenum Metal," (Climax Molybdenum Co., 1960).

10. R. G. Lawton, "The AYER Heat Conduction Computer Program," Los Alamos Scientific Laboratory report LA-5613-MS, (May 1974).

11. K. Cooper, "Space Power Reactors: GASCL2, A Fortran Program for Calculating Heat Transfer and Pressure Drop in a Gas-Cooled Reactor," Los Alamos Scientific Laboratory memo Q-13:77:507 to D. Buden, December $5,1977$.

12. K. Cooper, "Space Power Reactors: Comparison of Gas-Cooled and Heat-Pipe Reactors for Brayton Cycle Power Conversion," Los Alamos Scientific Laboratory memo Q-13:77:506 to D. Buden, December 5, 1977.

13. D. R. Koenig, W. A. Ranken, and E. W. Salmi, "Heat-Pipe Reactors for Space Power Applications," J. Energy, I No. 4, 237-234 (July-August 1977).

14. Melvin G. Bowman, "The High Temperature Chemistry of Refractory Carbides as Determined by High Temperature Technique," Los Alamos Scient if ic Laboratory report LADC-6391.

15. D. C. Fee and C. E. Johnson, "Phase Equilibria and Melting Point Data for Advanced Fuel Systems," Argonne National Laboratory, Argonne, Illino is report ANL-AFP-10 (June 1975). 
16. R. B. Holden, AEC Monography, United Nuclear Corporation, New Haven, Connecticut (Gordon and Breach Science Publishers, New York, 1957.

17. E. 0. Speidel and D. L. Keller, "Fabrication and Properties of Hot Pressed Uranium Mononitride," Battelle Memorial Institute, Columbus, Ohio, report BMI-1633 (May 30, 1963).

18. M. A. DeCrescente, "Advanced Materials Program for November-December 1962." Pratt and Whitney Aircraft, Middletown, Connecticut, report PWAC-1006 (January 31, 1963) (CANEL).

19. W. Chubb and R. F. Dickerson, "Research on Uranium Carbides at Battelle Memorial Institute," 4th Uranium Carbide Conf., East Hartford, Connecticut, May 20-21, 1963, TID-7676.

20. G. G. Bentle and R. M. Kniefel, "The Fracture Strength of Castuc," Atomics International, Canoga Park, California, report NAA-SR-9006, (September 1963).

21. Quarterly Report, Rover Program; Los Alamos Scientific Laboratory report LA-4468-MS, (May 31, 1970).

22. L. Yang et a1., "Investigation of Carbides as Cathodes for Thermionic Space Reactors," General Atomic, San Diego, California report GA-4769 (March 17, 1964).

23. Annual Progress Report, Argonne National Laboratory, Argonne, I1linois report ANL-7299 (1966).

24. A. Paden and C. DeNovion, "Elastic Constants of Uranium and Plutonium Carbides, Nitrides and Oxides," Argonne National Laboratory, Argonne, Illino is, report ANL-TRANS-803.

25. M. S. Farkas, "Mechanical and Physical Properties of Fuels and Cladding Materials With Potential for Use in Brookhavens Pulsed Fast Reactor," Oak Ridge National Laboratory, Oak Ridge, Tennessee, report ORNL-TR-2388 (July 1967).

26. A. R. Hall, "Elastic Moduli and Internal Friction of Some Uranium Carbides," J. Nuc. Mater.37, 318-319 (1970).

27. M. S. Seltzer, T. R. Wright, and D. P. Moak, "Creep Behavior of UC-Based Alloys," J. Am. Ceram. Soc., 58, (1975).

28. M. S. Seltzer, J. S. Perrin, A. H. Claver and G. H. Wilcox, "A Review of Creep Behavior of Ceramic Nuclear Fuels," React. Technology 14 (2), (1971).

29. A. A. Bauer, "Nitride Fuels: Properties and Potentials," React. Technology 15 (2), (1972). 
30. D. L. Keller, and W. Chubb, "Developments in the Technology of Nuclear Fuels During August 1967 thru July 1968," Annual Report, Ba.telle Columbus Labs, Columbus, Ohio, report BMI-1848 (August 1, 1968).

31. T. R. Wright et al., "Out-of-Pile Creep Behavior of Uranium Carbide," Summary Report 1 July 1972 - 30 June 1973, Battelle Columbus Labs. Columbus, Ohio, report N74-27177 (NASA-CR-134588) (July 1973).

32. S. C. Weaver and J. L. Scott, "Comparison of Reactor Fuels for High Temperature Application," Oak Ridge National Laboratory, Oak Ridge, Tennessee, report ORNL-TM-1360 (December 1965).

33. A. Sheth and L. Leib. wite, "Thermal Conductivity Values for Advanced Fuels," Inter im Report, Argonne National Laboratory, Argonne, I1linois, report ANL-AFP-3 (November 1974).

35. M. S. Farkas, Ed., "Mechanical and Physical Properties of Fuels and Cladding Materials with Potential Use in Brookhaven's Pulsed Fast Reactor," Battelle Memorial Institute, Columbus, Ohio, report BMI-X-455 (July, 1967).

35. "Advanced Materials Program Report, March-Apri1 1965," Pratt and Whitney Aircraft, Middletown, Connecticut, report PWAC-1020 (CANEL).

36. W. Chubb, and S. J. Paprocki, "Development of Advanced High-Temperature Nuclear Materials During November 1964 thru January 1965." Battelle Columbus Labs, Columbus, Ohio. report BMI-1716 (1 February 1965).

37. M. F. Lyons et al., "U0 2 : Properties Affecting Performance," Nucl. Eng. and Des. 21 (1972).

38. J. C. Rowley, C. R. Saunders, C. McInteer, C. P. Kemper, and R. E. Riley, "Elastic Moduli and Thermal Expansion of Porous MO- $\mathrm{UO}_{2}$ Cermets," Los Alamos Scient if ic Laboratory, report LA-4825 (November 1971).

39. M. A. DeCrescente, "Advanced Materials Program for November-December 1964," Pratt and Whitney Aircraft, Middletown, Connecticut, report PWAC- 1018 (January 1965) (CANEL).

40. D. L. Keller and W. Chubb, "Progress on High Temperature Fuels Technology During August 1968-July 1969," Battelle Memorial Institute, Columbus, Ohio, report BMI-1870, (August 1969).

41. M. Tetenbaum, A. Sheth, and W. 01son, "A Review of the Thermodynamics of UC, Pu-C and U-Pu-C Systems," Argonne National Laboratory, Argonne, Illino is, report ANL-AFP-8 (June 1975).

42. L. Yang et al., "Investigations of Carbides as Cathodes for Thermionic Space Reactors, Quarterly Progress Report for the Period Ending February 28, 1963." General Atomic Div., General Dynamics Corp., San Diego, CA, GA-4173. May 15, 1963. 
43. M. A. DeCrescente and A. D. Miller, "Advanced Materials Program for March-April 1964," Pratt and Whitney Aircraft Corporation, Middletown, Connecticut, report PWAC-1014 (June 1964) (CANEL).

44. M. A. DeCrescente and A. D. Miller, "Advanced Materials Program for November-December, 1963." Pratt and Whitney Aircraft Corporation Middletown, Connecticut, report PWAC-1012 (February, 1964) (CANEL).

45. "Present Status of Thermionic Fuel Element Materials," General Atomic Div., General Dynamics Corp., San Diego, California, report GA-5622, (August 1964).

46. "Quarterly Status Report on Space Electric R \& D Program for the Period Ending January 31, 1969," Los Alamos Scientific Laboratory, report LA-4110-MS, (February 1969).

47. W. Chubb, V. W. Storhok, and D. L. Keller, "Factors Affecting the Swellirg of Nuclear Fuels at High Temperature," Nuc. Techn., 18 (June 1973).

48. D. L. Keller and $W$. Chubb, "Progress on High Temperature Fuels Technology During February thru April 1969," Battelle Memorial Institute, Columbus, Ohio, reportBMI-1864 (May 1969).

49. J. A. L. Robertson, "AEC Monograph," Atomic Energy of Canada Ltd. for the American Nuclear Society, (Gordon and Breach, Science Publishers, New York, London and Paris, 1969).

50. D. G. Freas, P. B. Shumaker, J. H. Stang, and J. E. Gates, "High Temperature Irradiation of Úranium Carbide, Battelle Memorial Institute, Columbus, Onio, report BMI-1622 (March 1963).

51. J. B. Melehan, A. J. Markworth, J. S. Perrin, R. A. Wullaert, W. Chubb, J. E. Gates, "Irradiation Behavior of UC," Battelle Memorial Insitutue, Columbus, Ohio, report BMI-1806 (June 1967).

52. J. E. Frank, "Irradiation Behavior of Unalloyed Uranium Carbide," Atomics International Combustion Engineering Al-CE-MEM0-9 (Apri1 1966).

53. J. B. Conway and P. N. Flagella, Creep-Rupture Data for the Refractory Metals to High Temperatures (Gordon and Breach Science Publishers, New York, 1971).

54. R. L. Stephenson, "The Effect of Fabrication Variables on the Creep-Rupture Properties of Molybdenum-Base Alloys," in Trans. Met. Soc. of AIME 245 (1969) 997-1001.

55. J. L. Brimha17, E. P. Simonen, and H. E. Kissinger, "Fluence and Temperature Dependence of Swelling in Irradiated Molybdenum," J. Nucl. Mater., 48, 339-350 (1973). 
56. J. Bentley and F. W. Wiffen, "Neutron-Irradiation Effects in Molybdenum and Molybdenum Alloys," in Proceedings of the 2nd Topical Meeting on The Technology of Controlled Nuclear Fusion, Richland, Washington chland, Wash, Sept. 21-23, 1976.

57. F. W. Wiffen, "The Tensile Properties of Fast Reactor Neutron Irradiated B.C.C. Metals and Alloys," in Proc. Int. Conf. on Defects and Defect Clusters in B.C.C. Metals and Their Alloys, Gaithersburg, Maryland, August 1973, published in Nucl. Metal1. 18, 176 (1973).

58. R. W. Swindeman, Oak Ridge National Laboratory, personal communication, Apr $\div 1,1978$.

59. F. W. Wiffen, Oak Ridge National Laboratory, personal communication, Apri1, 1978.

60. R. E. Zielinski, "A Summary Report of the Compressive Creep Properties of Irradiated and Unirradiated Molybdenum," Mount Laboratory report MLM-24-6 (Apri1 1977).

61. A. J. Moorehead, J. R. DiStefano, and R. E. McDonald, "Fabrication Procedures for Unalloyed Molybdenum," Nucl. Technol., 24 50-63 (October 1974).

62. Aerospace Structural Metals Handbook, Mechanical Properties Data Center, Belfour Stulen, Inc. (1977).

63. R. L. Klueh, "Penetration of Refractory Metals by Alkali Metals," in Corrosion by Liquid Metals, J. E. Draley and J. R. Weelks, Eds. (Plenum Press, New York (1970), pp. 177-196.

64. L. N. Aleksondrov and V. Ya. Shchelkonogov, "The Diffusion of Carbon Concentrations," Poroshk. Metall, 4 (22), English Translation pp. 288-291, (1964).

65. E. From and V. Roy, "The High Temperature Terminal Solubility of Carbon in Molybdenum, Tungsten and Rhemium," Phys. Status Solidi 9, K83-K86 (1965).

66. V. Coen, H. Hausner, H. Kolbe, and D. Quataert, "Interaction between Uranium Carbide and Refractory Metals," in Ceramic Nuclear Fuels, $0 . \mathrm{L}$. Kruger and A. I. Kaznoff, Ed., American Ceramic So. Columbus, Ohio (1969).

67. J. M. Fackelmann and D. P. Moak, "Studies of the Compatibility of Uranium Carbide with Refractory Metals," Battelle Memorial Institute Report Number B-1818 (October 1967).

68. R. J. Fries, J. E. Cummings, C. G. Hoffman and S. A. Daily, "The Chemical Diffusion of Carbon in the Group VIb Metal Carbides," in High Temperature Materials, 6th Plansee Seminar, June 24-28, 1978, Metallwerke Plansee AG., Rentie, Tyrol (1969) pp. 568-607. 
69. C. A. Alexander, J. J. Ward, J. S. Ogden, and G. W. Cunningham, "Thermodynamics for Compatibility Studies of Metal Clad Uranium Carbide," in Carbides in Nuclear Energy, Vol. 1, (Macmillan and Company Ltds., London 1964).

70. J. L. Warren (compiler) "Reactor Technology, April-June 1977," Los Alamos Scientific Laboratory report LA-7316-PR (July 1978).

71. D. S. Hickman and G. T. Stevens, Australian Atomic Energy Commission report AAEC/E 109 (1963).

72. D. S. Hickman, "Radiation Effects in Beryllium and Beryllium 0xide," in Studies in Radiation Effects, Series A, Physical and Chemical, Vol. 1, G. J. Dienes (Ed.), (Gordon and Breach Science Publishers, New York, NY 1966).

73. J. B. Rich, G. D. Walters and R. S. Barnes, J. Nucl. Mat. 4 , 287 (1961).

74. J. B. Rich and G. D. Walters, The Metallurgy of Beryllium, (Chapman and Hal1, London 1961) p. 362.

75. J. Weir,

76. B. S. Hickman and G. Bannister, Australian Atomic Energy report AAEC/E115 (1964).

77. Hickman, Bannister, Chute, McCracken, Smith and Bell, United Kingdom Atomic Energy Authority report TRG-540 (S/X) (1962).

78. "Third Annual Report - High Temperature Materials and Reactor Complonent Development Programs, Vol. I - Materials," General

Electric-Nuclear Materials and Propulsion Operation report GEMP - $270 \mathrm{~A}$ 110 (February 1964).

79. G. W. Keilholtz, J. E. Lee, and K. E. Moore, J. Nucl. Mater. 11253 (1964).

80. "A Compilation of Boron Carbide Design Support Data for LMFBR Control Elements," Hanford Engineering Development Laboratory report. HELD-TME $75-19(1975)$.

81. A. L. Pitner, "Instrumented Fast Reactor Irradiation of Boron Carbide Pellets," Nucl. Tech. 30 77-85 (1976).

82. J. A. Basmajian, A. L. Pitner, D. E. Mahagin, H. C. F. Ripfel, and D. E. Baker, "Irradiation Effects in Boron Carbide Pellets Irradiated in Fast Neutron Spectra," Nucl. Tech. 16 238-248 (1972).

83. R. E. Roake and T. T. Claudson, "Breeder Reactor Reference Control Materials, Semi-Annual Report, January-June 1977," Hanford Engineering Development Laboratory report HELD-TME-77-58 (October 1977). 
84. W. J. Kurzeka, Ed., "SNAP 10A Component Development Summary, Vol. I Control Components," Atomics International report NAA-SR-9898, Vol. I (August 1964).

85. W. J. Kurzeka, Ed., "SNAP 10A Component Development Summary, Vol. III Shield, Ground Test Assembly, and Materials Applications," Atomic International report NAA-SR-9898, Vol. II (February 1965).

86. D. W. Staub, "SNAP IOA Summary Report," Atomics International report NAA-SR-12073 (March 1967).

87. "Multi-Foil Vacuum Insulations," Thermo Electron Corporation Sales Brochisre (undated).

88. S. J. Burnett, "Properties of Refractory Materials, "Atomic Energy Research Estab lishment, Harwe11, England, report AERE-R-4657 (June 1964). 


\section{SHIELD DESIGN}

Shield design and technology use work done on space reactor shields for SNAP 2, 8, and 10A, and ROVER. These reactors have features in common with current designs, namely, small physical size, unmanned space application with comparable allowance of neutron and gamma doses, and comparable radiation flux levels.

Only shadow shielding is required because

- only unmanned power-plant operation is considered;

- the reactor will be used only in high Earth orbit, where neutron and gamma scattering from air is negligible; and,

- the reactor can be located at one end of the assembly, followed by the shield, control actuators and radiator, and, finally, the payload.

Neutron attenuation is provided by $\mathrm{LiH}$ in the shape of a frustum. A heavy-metal gamma shield is added at the reactor end of the shield if needed.

A. Parametric Analys is

The shield is shown schematically in Fig. 87. The end of the reflector is rounded to reduce shield weight and the possibility of secondary scattering. The shield may be attached to the reactor as in some Brayton cycle configurations or separated from it to permit bending heat pipes around the shield to the converters as in layouts for thermoelectrics. The shield weight is a function of power level, cone half-angle, and distance between payload and reactor. Lithium-hydride neutron attenuation is shown in Fig. 88. Four decades of attenuation require a 570-mm-thick shield.

Figure 89 shows the shield mass for a typical Brayton converter design for $50 \mathrm{~kW}_{\mathrm{e}}\left(200 \mathrm{~kW}_{\mathrm{t}}\right)$ with no separation between reactor and shield. The effect of designing the reactor for $1000 \mathrm{~kW}_{\mathrm{t}}$, but operating at $200 \mathrm{~kW}_{\mathrm{t}}$ is shown in Fig. 90. Figure 91 shows the shield mass for a thermoelectric design. Figure 92 shows variation of shield thickness with separation distances. Figure 93 shows shield mass as a function of power level for a $12^{\circ}$ cone half-angle in Brayton and thermoelectric converters. The $1000-\mathrm{kW}_{\mathrm{t}}$ reactor assumes a single design for all electric power levels; the customized core design implies a different reactor design for each power level. The mass of any given shield will depend on the mission, and 


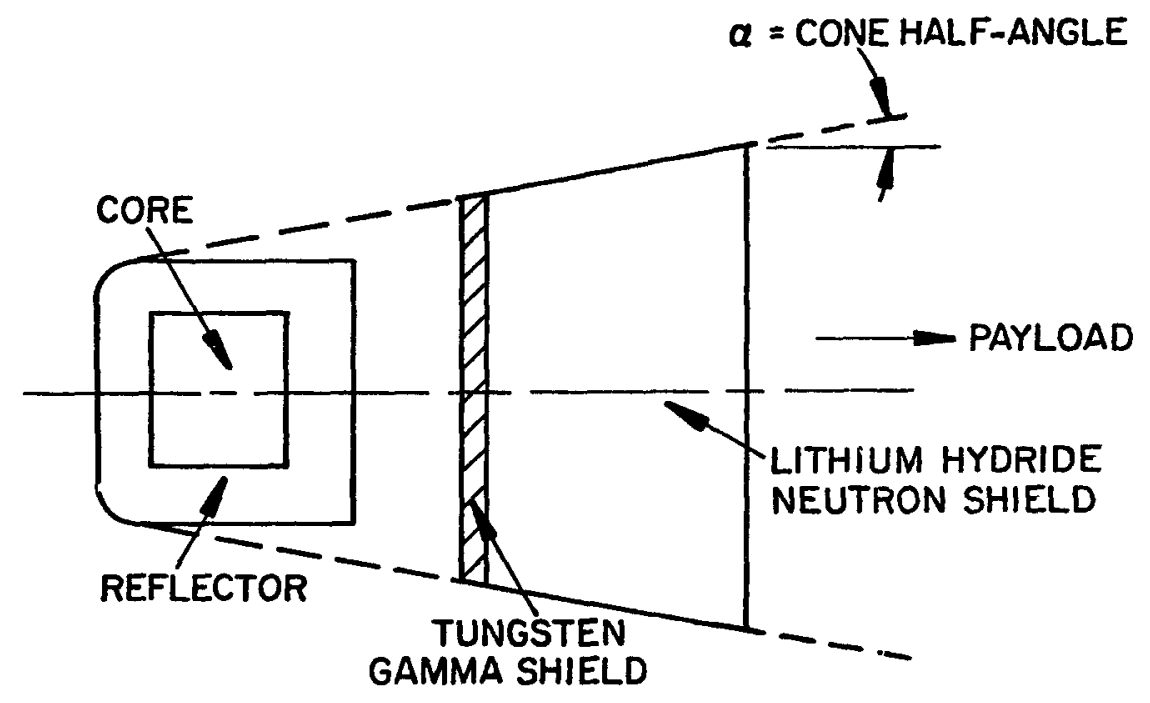

Fig. 87. Reactor shielding.

it may vary from a few kilograms to many hundred kilograms. Figure 94 shows the variation in shield mass with power level for various possible standard reactor designs.

More refined analysis was performed on a reference $550-\mathrm{mm}$-thick shield. This reference shield incorporates a $2.1 \%$ fraction of 316-stainless steel structure and a $6 \%$ void fraction to account for separation cracks or other deviations from the theoretical density of LiH. The resulting density of the $L i H$ is $0.733 \mathrm{~g} / \mathrm{cm}^{3}$. Figure 95 gives the distribution of the neutron fluence within the 550 -mm-thick shield out to a distance of 10 meters from the core center, normalized to the one neutron source strength.

In Fig. 96, an upper limit and a lower limit for the distribution of the energy fluence from secondary gamma rays are shown per source neutron for the 550-mm-thick shield. The lower limit curve is obtained by homogeneously distributing the structural steel within the LiH shield. This procedure takes the production of secondary gamma rays in the steel into account, but overestimates the attenuation of these gamma rays by the stee 1 structures because roughly half of the structural material (mainly canning) is oriented in such a way that it is not "seen" by the gamma rays emitted in the direction of a payload at a large distance. The upper limit curve is obtained by considering only half of the steel structure to be homogenized into the LiH, but doubling the resulting flux of secondary gamma 


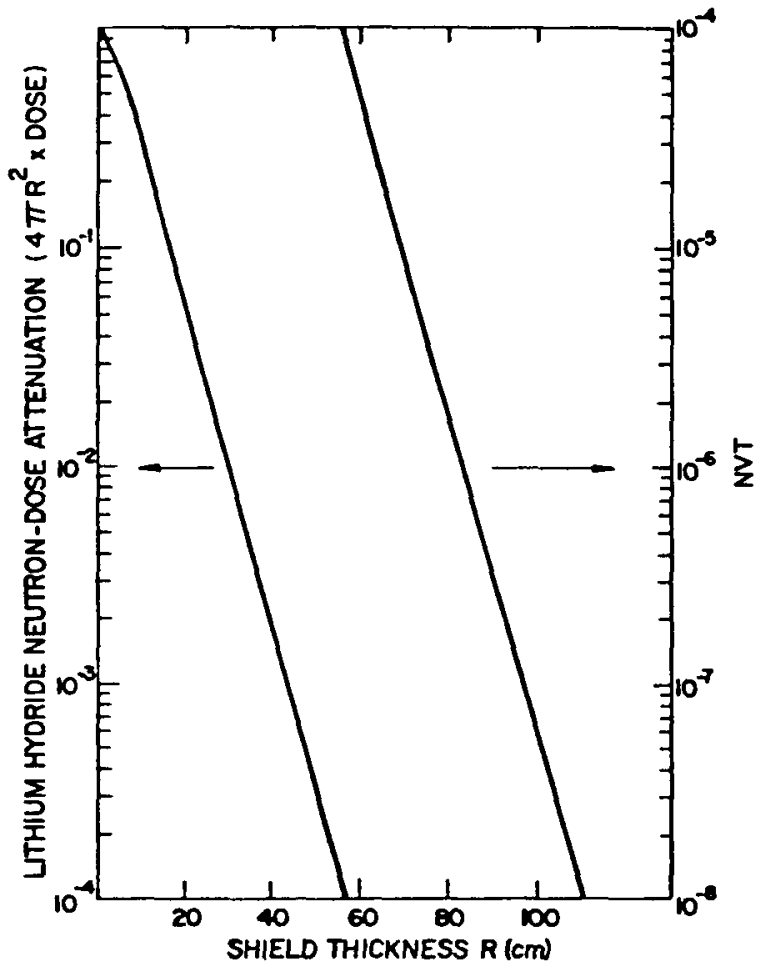

Fig. 88. Lithium-hydride neutron radiation attentuation.

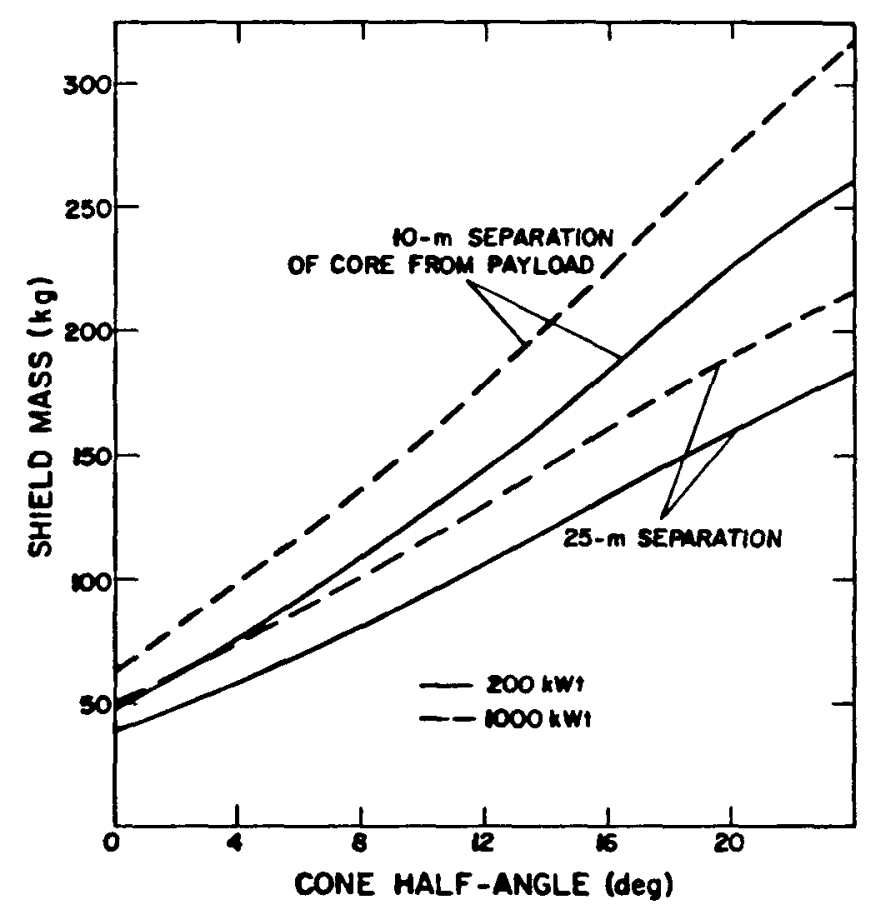

Fig. 90. Brayton cycle shield masses for 200- and 1000-kWt designs operating at $200 \mathrm{~kW}_{\mathrm{t}}$.

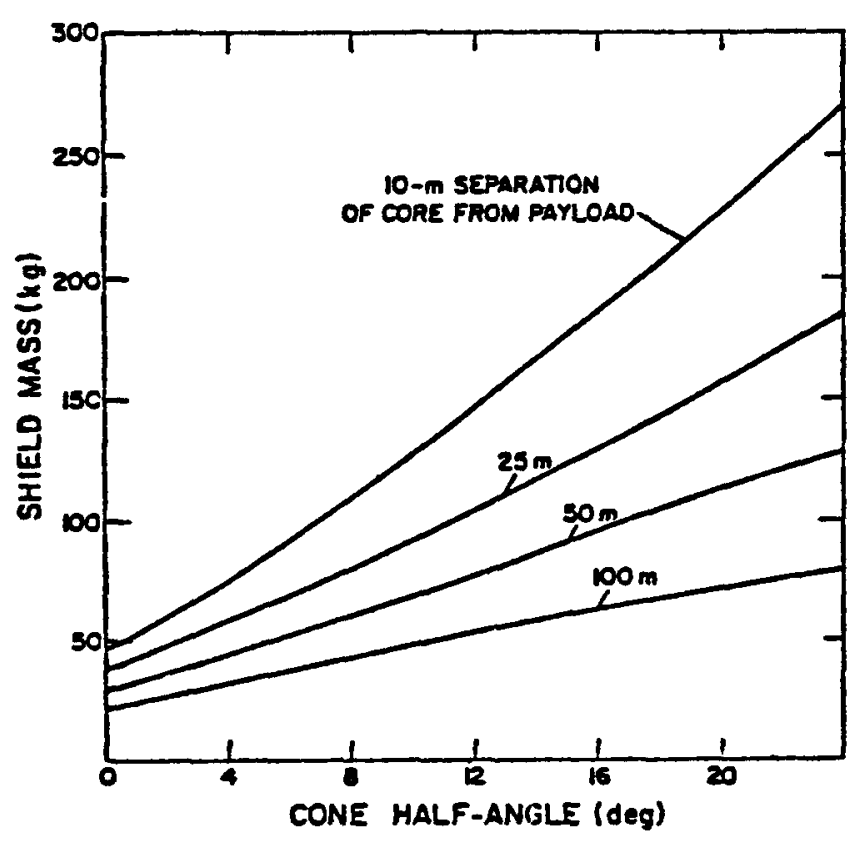

Fig. 89. Brayton cycle shield mass for $200-\mathrm{kW}_{\mathrm{t}}$ design operating at $200 \mathrm{~kW}_{\mathrm{t}}$.

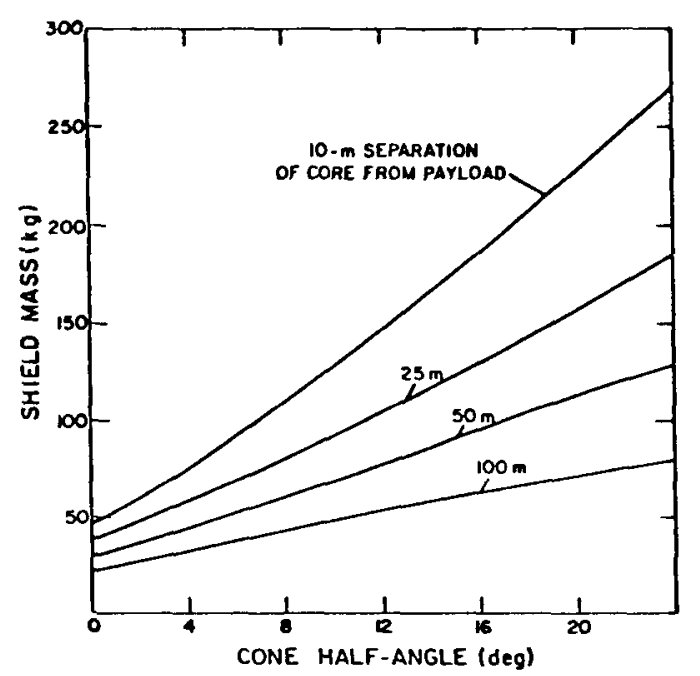

Fig. 91. Thermoelectric shield mass for $1000-\mathrm{kW}_{t}$ design operating at $200 \mathrm{~kW}_{\mathrm{t}}$. 


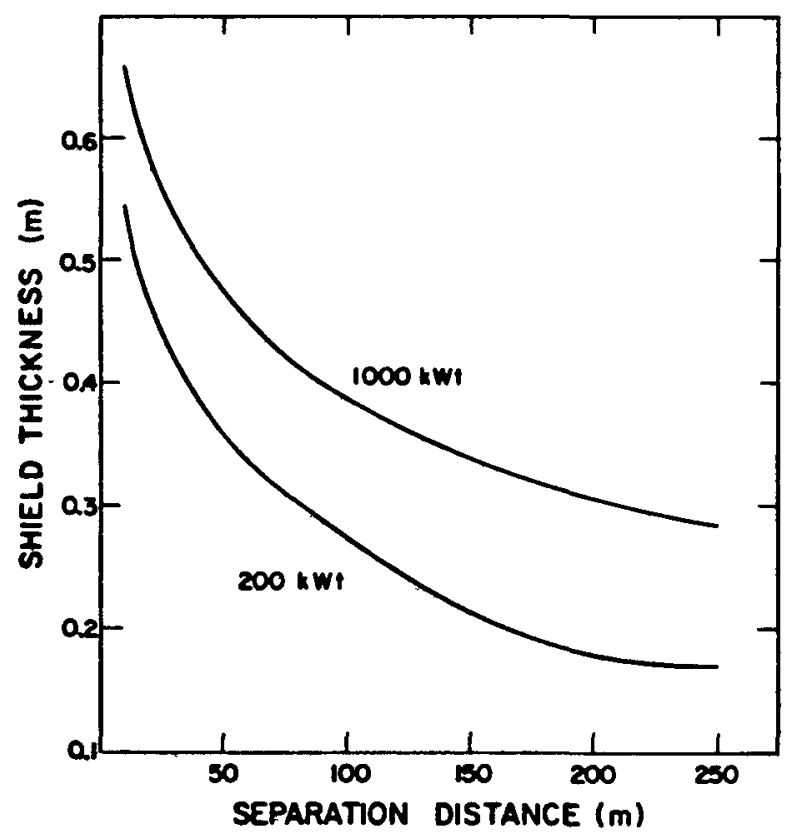

Fig. 92. Shield thickness vs separation distance.

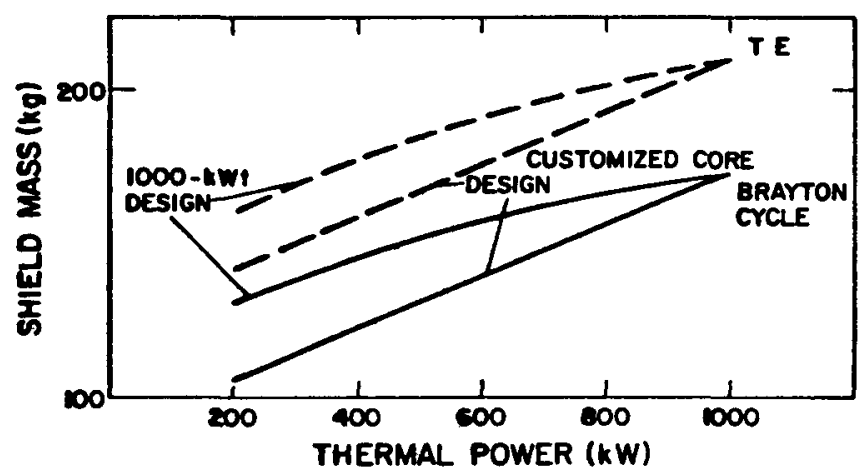

Fig. 93. Shield mass based on 25-m separation of core and payload.

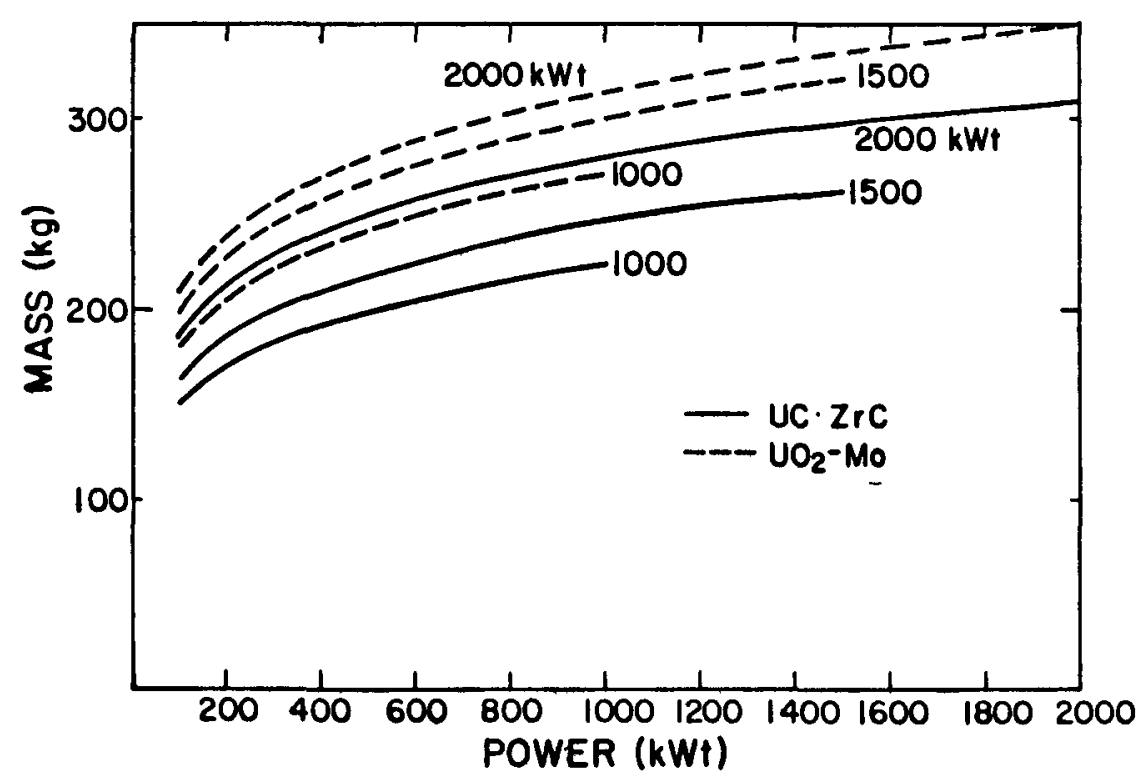

Fig. 94. Shield mass for thermoelectrics. 


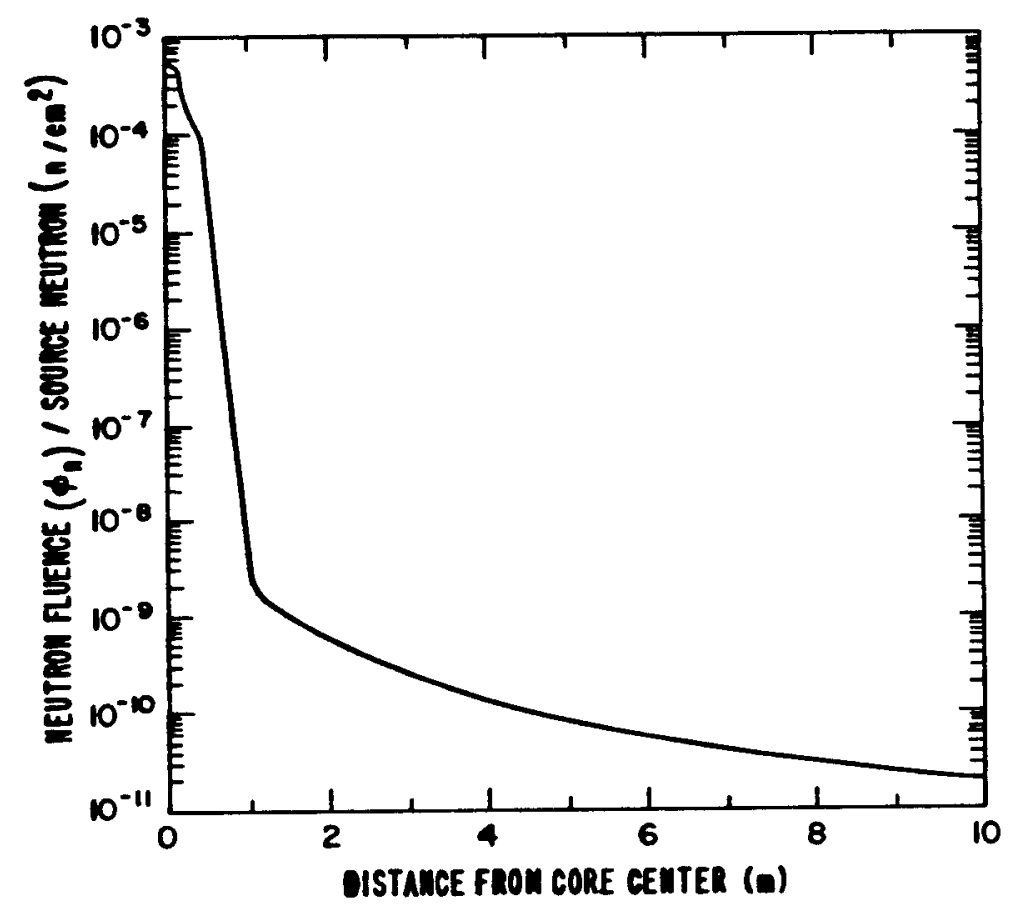

Fig. 95. Neutron fluence in shield.

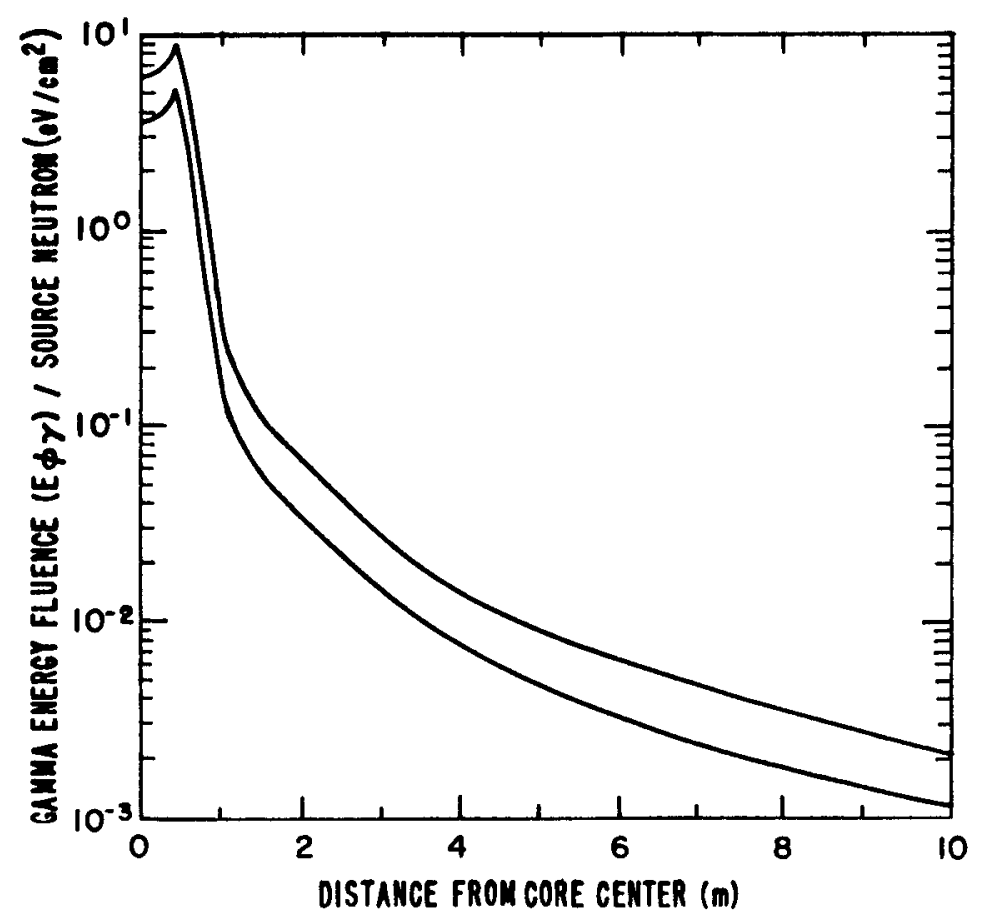

Fig. 96. Energy fluence band from secondary gamma rays. 
rays. This underestimates the attenuation effect of the steel structures. However, even the upper-1 imit estimate of the gamma energy fluence at $10 \mathrm{~m}$ is well below the established preliminary design criteria.

B. Radiator Analysis Including Scatter.

We performed a series of calculations using the MCNP Monte Carlo program to evaluate the neutron fluences at the payload of a typical SPAR geometry with a Brayton power plant. Although the results are specific to the system analyzed, conclusions regarding the magnitudes of the radiation scattering from radiators are generic to many nuclear space applications. Results indicated that fast neutron ( $E>1 \mathrm{keV}$ ) fluences at a payload $25 \mathrm{~m}$ from the $1200-\mathrm{kW}$ reactor would be $6 \times 10^{14} \mathrm{n} / \mathrm{cm}^{2}$ for constant operation over a $10 \mathrm{yr}$ lifetime. Essentially all of the effective neutrons were scattered around the shadow shield by radiators and headers outside of the shadow cone. The only ways to reduce the scattered radiation to the design level of $10^{13}$ nvt are to 1) place the radiators and headers behind the shield or 2) shield the radiators and headers at the source.

The geometry employed for the calculations is shown in Figs. 97-99 and associated masses and densities are shown in Table XIX. Where densities were a:ailable (for example, for the shield) they were used and masses were derived from the densities. Where total mass was defined (for example, for the headers), densities were derived from geometries to preserve total mass. Results for the Brayton unit (Fig. 96) arc quite insensitive to detail in this region.

Two source spectra were used. For the majority of calculations, an equivalent point source normalized to the net leakage of 0.456 neutrons/ fission was used with the spectrum shown in Table XX. For those calculations where a full description of the source was made, a standard fission spectrum was used.

The principal calculations employed an isotropic point source located within the core. Since results were normalized to an equivalent point source of leakage, the core and all reflectors were considered as void. A point detector was located $50 \mathrm{~cm}$ lateraliy off the symmetry axis and $25 \mathrm{~m}$ from the core center. The detector was offset $50 \mathrm{~cm}$ to prevent selfshielding within the radiators and headers from artificially reducing the detector response. Results for (1) the base case, (2) the base case with 


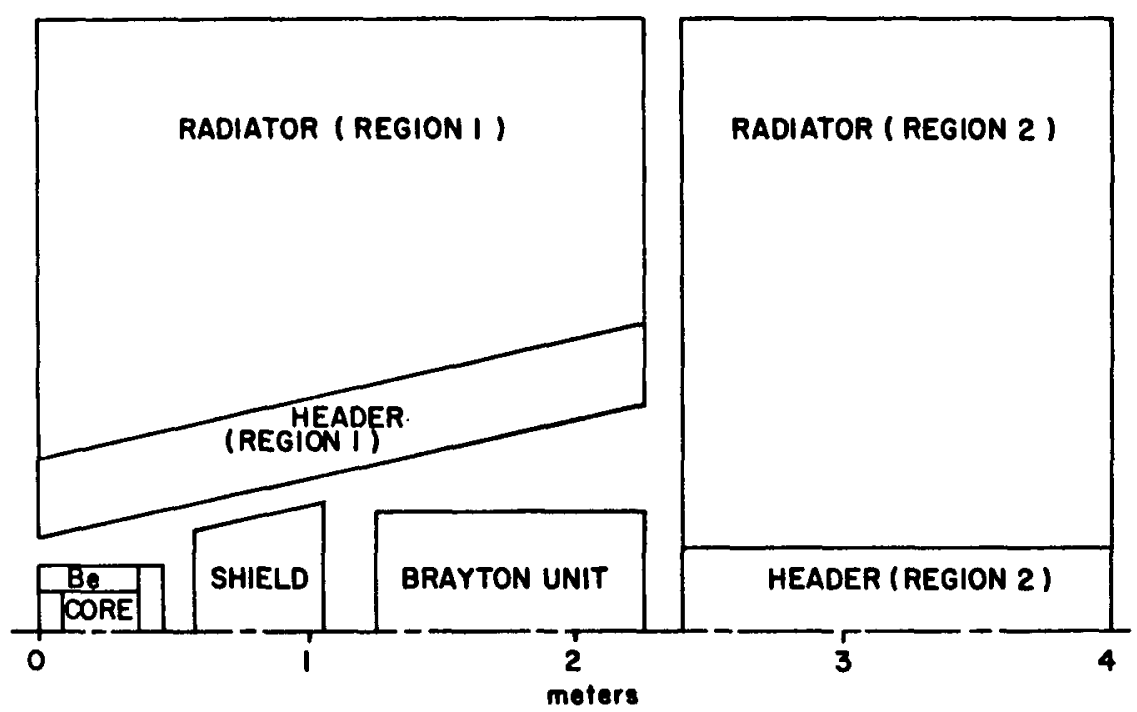

Fig. 97. Side cross section for Brayton power plant geometry.

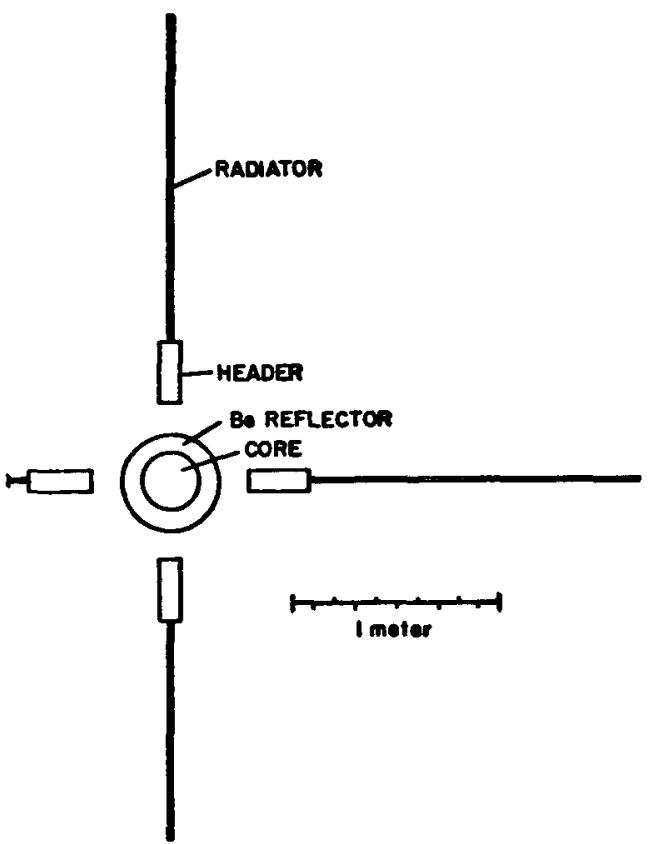

Fig. 98. Cross section through core for Brayton power plant.

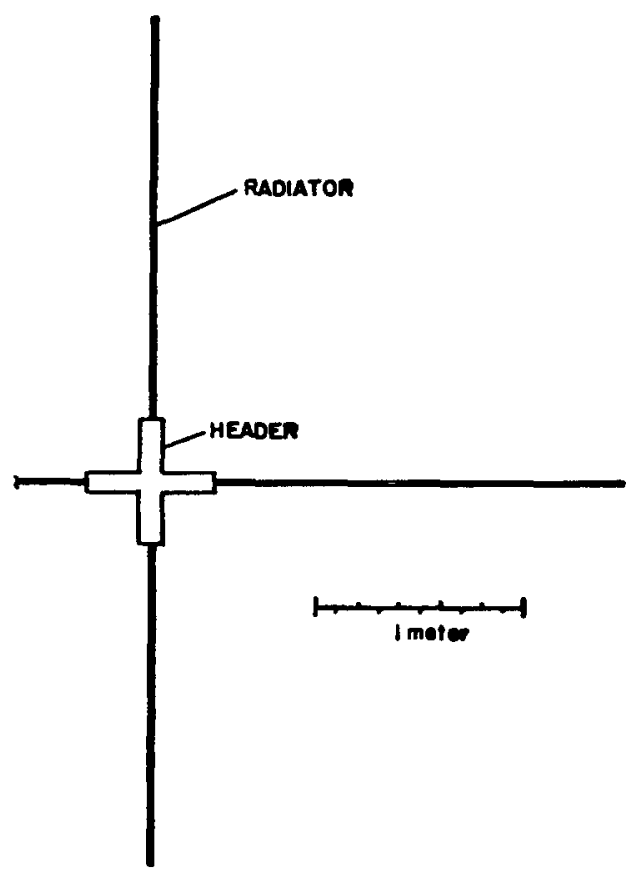

Fig. 99. Cross section through region 2 header and radiator for Brayton power plant. 
TABLE XIX

MATERIAL DESCRIPTIONS

\begin{tabular}{|c|c|c|c|c|c|}
\hline Region & Material & Atom Fraction & $\begin{array}{l}\text { Density } \\
\left(\mathrm{gm} / \mathrm{cm}^{2}\right)\end{array}$ & $\begin{array}{l}\text { Mass } \\
(\mathrm{kg})\end{array}$ & $\begin{array}{r}\text { Total } \\
(\mathrm{kg}) \\
\end{array}$ \\
\hline \multirow[t]{3}{*}{ Core } & c & 0.50 & 0.38 & 6.55 & \\
\hline & $\mathrm{Zr}$ & 0.05 & 0.29 & 5.00 & 127.24 \\
\hline & $U$ & 0.45 & 6.71 & 115.69 & \\
\hline Be Reflector & $\mathrm{Be}$ & 1.00 & 1.91 & & \\
\hline End & & & & 11.79 & 11.76 \\
\hline Side & & & & 86.65 & 86.65 \\
\hline \multirow[t]{2}{*}{ Be0 Reflector } & $\mathrm{Be}$ & 0.50 & 0.69 & 12.49 & \\
\hline & 0 & 0.50 & 1.22 & 22.08 & 34.57 \\
\hline \multirow[t]{2}{*}{ Shield } & Li & 0.50 & 0.45 & 110.60 & 126.66 \\
\hline & $H$ & 0.50 & 0.07 & 16.06 & \\
\hline Brayton Unit & $\mathrm{Fe}$ & 1.00 & 0.76 & 458.75 & 458.75 \\
\hline Header & Al & 1.00 & 0.52 & & \\
\hline \multicolumn{2}{|c|}{ Region 1 (4 units) } & & & 145.47 & 236.94 \\
\hline \multicolumn{2}{|c|}{ Region 2 (4 units) } & & & 91.47 & \\
\hline Radiator & Al & 1.00 & 0.11 & & \\
\hline \multicolumn{2}{|c|}{ Region 1 (4 units) } & & & 14.23 & 27.74 \\
\hline \multicolumn{2}{|c|}{ Region 2 (4 units) } & & & 13.51 & \\
\hline
\end{tabular}

radiators and headers voided (to eliminate scatters so only the direct beam is present), and (3) the base case with radiators and headers voided with shield increased in thickness from $47.86 \mathrm{~cm}$ to $60 \mathrm{~cm}$ are shown in Table XXI. In all cases, 20000 histories were run resulting in a calculated variance on the total flux of $\pm 5 \%$. Individual energy bins showed 
TABLE XX

LEAKAGE SPECTRUM

Group

Energy Range

Relative Intensity

$17.0-15.0 \quad \mathrm{MeV}$

- $13.5 \mathrm{MeV}$

$1.22 \times 10^{-6}$

2

- $12.0 \mathrm{MeV}$

$3.71 \times 10^{-6}$

3

- $10.0 \mathrm{MeV}$

$1.23 \times 10^{-5}$

4

- $7.79 \mathrm{MeV}$

$5.82 \times 10^{-5}$

5

6

- $6.07 \mathrm{MeV}$

$2.90 \times 10^{-5}$

- $3.68 \mathrm{MeV}$

$9.09 \times 10^{-4}$

7

8

9

10

11

12

13

14

15

16

17

18

19

20

21

22

23
- $2.865 \mathrm{MeV}$

- $2.232 \mathrm{MeV}$

- $1.738 \mathrm{MeV}$

- $1.353 \mathrm{MeV}$

- $0.823 \mathrm{MeV}$

- $0.5 \mathrm{MeV}$

- $0.303 \mathrm{MeV}$

- $0.184 \mathrm{MeV}$

- $67.6 \mathrm{keV}$

- $24.8 \mathrm{keV}$

- $9.12 \mathrm{keV}$

- $3.35 \mathrm{keV}$

- $1.235 \mathrm{keV}$

- $.454 \mathrm{keV}$

- $.167 \mathrm{keV}$

- $.0001 \mathrm{eV}$
$4.22 \times 10^{-3}$

$3.12 \times 10^{-3}$

$7.09 \times 10^{-3}$

$8.43 \times 10^{-3}$

$8.52 \times 10^{-3}$

$9.16 \times 10^{-3}$

$1.39 \times 10^{-2}$

$9.60 \times 10^{-3}$

$1.08 \times 10^{-2}$

$1.85 \times 10^{-2}$

$1.59 \times 10^{-2}$

$1.38 \times 10^{-2}$

$1.20 \times 10^{-2}$

$9.39 \times 10^{-3}$

$7.38 \times 10^{-3}$

$5.64 \times 10^{-3}$

$1.57 \times 10^{-2}$

variances of $\pm 20 \%$ for bins with significant responses. A characteristic spectrum at the detector is given in Table XXII.

The full geometry verified the normalization and use of an equivalent point source. Statistical difficulties (excessive contributions to the response from an occasional "lucky" neutron) and long running times generally negated the results for this stage of cons,deration. However, the tentative values supported the normalization through consideration of leakage tallies. 
TABLE XXI

SUMMARY OF RESULTS

Configuration
(1) Base case
(2) Base case
Shield $48 \mathrm{~cm}$ thick
Di 'ect only

(3) Shield $60 \mathrm{~cm}$ thick
Flux
(nvt)
Fluęnce
$\left(\mathrm{n} / \mathrm{cm}^{2} 10 \mathrm{yr}\right)$

$1.7 \times 10^{6}$

$5.5 \times 10^{14}$

$1.9 \times 10^{3}$

$5.9 \times 10^{11}$

$1.9 \times 10^{2}$

$6.1 \times 10^{10}$

TABLE XXII

NEUTRON SPECTRUM AT POINT DETECTOR

Er -gy Range (MeV)

$$
\begin{array}{cl}
0.0- & .001235 \\
- & .00335 \\
- & .00912 \\
- & .0248 \\
- & .0676 \\
- & .184 \\
- & .303 \\
- & .500 \\
- & .823 \\
- & 1.738 \\
- & 2.232 \\
- & 2.865 \\
- & 3.680 \\
- & 6.070 \\
- & 7.790 \\
- & 10.000 \\
- & 12.000 \\
- & 13.500 \\
- & 15.000
\end{array}
$$

Total

Flux

$$
\begin{aligned}
& \left(\mathrm{n} / \mathrm{am}^{2}-\mathrm{s}\right. \text { in the interval } \\
& 6.8 \times 10^{3} \\
& 1.7 \times 10^{5} \\
& 1.9 \times 10^{5} \\
& 2.1 \times 10^{5} \\
& 7.1 \times 10^{4} \\
& 1.8 \times 10^{5} \\
& 1.1 \times 10^{5} \\
& 1.6 \times 10^{5} \\
& 1.4 \times 10^{5} \\
& 1.8 \times 10^{5} \\
& 4.5 \times 10^{4} \\
& 6.8 \times 10^{4} \\
& 1.1 \times 10^{4} \\
& 2.0 \times 10^{4} \\
& 1.0 \times 10^{3} \\
& 7.1 \times 10^{0} \\
& 6.7 \times 10^{0} \\
& 3.5 \times 10^{1} \\
& \frac{5.4 \times 10}{1.7 \times 10^{6}}
\end{aligned}
$$


Sensitivity analyses were made with a restricted geometry (one quarter symmetry) and a biased source (emission angle restricted to illuminate the header and radiator). Results indicated the variation of flux as a function of off-axis position (Table XXIII). In addition, the futility of finessing the shielding problem by small changes in the header and radiator locations was demonstrated.

The analysis showed the fullowing

- The configuration considered results in neutron fluences 50 times the design level.

- There is no easy way to reduce the levels to tolerance.

- A redesign which places the radiators behind the shield could be the most effective approach.

C. Shield Penetrations

A detailed calculation of radiation streaming along heat-pipe penetrations through a shield using Monte Carlo techniques has been postponed pending a more specific definition of the plant configuration. Until then, the design criterion suggested for shield penetrations is a minimum of two-diameter offset from a straight line penetration (Fig. 100) with the penetrations angled to eliminate near line-of-sight paths. This recommendation is based on the fact that the shield is relatively thin and "streaming" becomes consequential only for optically thick shields where multiple scattering in the walls of directed voids (streaming) contributes substantially to the transmitted radiation. Shield penetrations with the two-diameter offset will not be ignored but will be treated by reducing the shield density to account for the introduction of voids. Streaming will not be explicitly considered, but when shield verification is called for, the design will be proof-calculated using Monte Carlo techniques. Until then, the shield will be treated as a homogeneous mass of reduced density.

D. Design Considerations

One shield design being considered is similar to the SNAP shield profiles (Fig. 101) with maximum thickness at the center line. Other mechanical designs have not yet been considered in detail. In the SNAP shields, the LiH is spring-loaded against the cone to improve heat iransfer and resist launch loadings. It is necessary to can the $L i H$ to maintain a hydrogen overpressure and prevent gradual loss of hydrogen. The LiH has to 
TABLE XXIII

RELATIVE DETECTOR RESPONSE AS A FUNCTION OF OFFSET

FROM THE SYMMETRY AXIS

$\frac{\text { Offset }}{0.0 \mathrm{~cm}}$

$50.0 \mathrm{~cm}$

$100.0 \mathrm{~cm}$
Relative Response

2.2

6.7

8.1

be maintained at a minimum temperature of $600 \mathrm{~K}$ during operation so that radiolytically decomposed hydrogen can be reabsorbed by the LiH, thereby preventing swelling. The heat generated by neutron and gamma absorption is sufficient to maintain this teniperature during operation. ${ }^{2}$

In keeping with the design goal of preventing single-failure points, the LiH will be encapsulated in a number of pancake-shaped cans, so that failure of the pressure containment by meteoroid penetration or a weld failure, for example, will lead to a depletion of hydrogen in only a part of the shield.

The shield weights are based on $\mathrm{LiH}$ being at $94 \%$ of theoretical density, with $20 \%$ added to the $\mathrm{LiH}$ weight to account for metal (such as structure, casing, loading springs, and reinforcing mesh).

The shield connects the reactor on one end of the radiator to the payload on the other end. The load will be carried by the outer conical she11, with appropriate end fittings.

A great deal of engineering data is available on LiH, and a variety of space nuclear shields of $L i H$ have been fabricated and used, such as on SNAP 2, 8, and 10A, which were built in the mid-1960s by Atomics International (AI). Lithium hydride can be used in either the cold-pressed-and-sintered form or in the cast form. Small bodies of LiH are most easily formed by cold pressing and sintering; large bodies, by casting. ${ }^{3}$ AI has developed facilities for casting very large pieces for reactor shielding. ${ }^{4}$

For long-term use at elevated temperatures, it is essential that LiH be hermetically sealed to prevent loss of hydrogen by dissociation. Permeation coefficients of cladding materials govern hydrogen loss. 5

Tight containment of the LiH presents a complication in high neutronflux fields if natural lithium is used. In natural lithium, about $7.5 \%$ of 


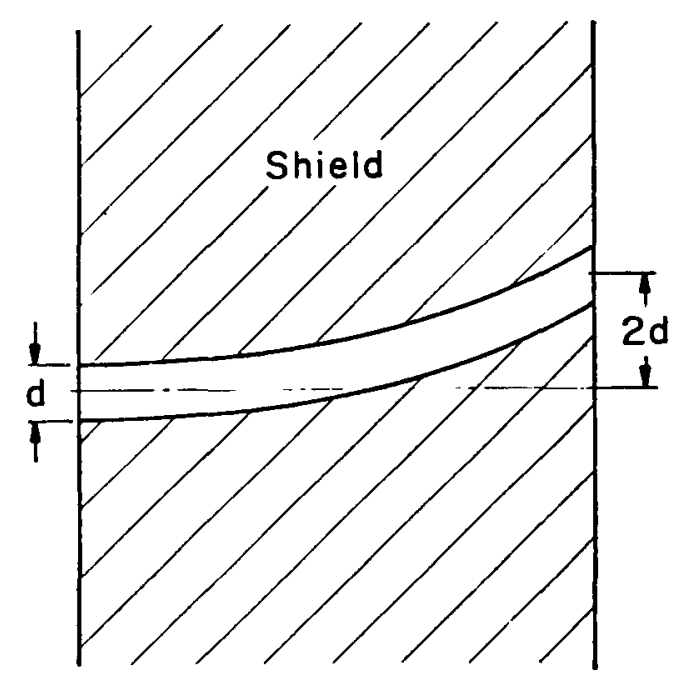

Fig. 100. Two-diameter offset shield penetration.

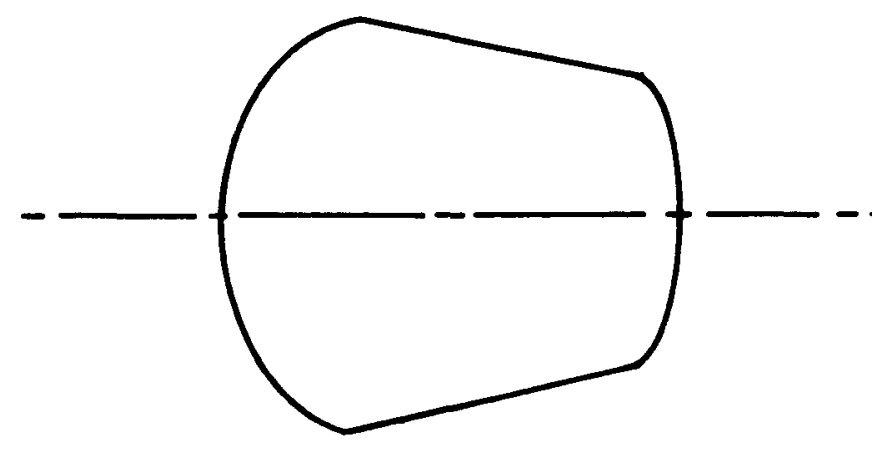

Fig. 101. SNAP shield shape.

the lithium has a very high thermal-neutron cross section ( 945 barns at $2200 \mathrm{~m} / \mathrm{s})$ for the reaction ${ }^{6} \mathrm{Li}(n, \alpha)^{3} \mathrm{H}$. The helium generated by this reaction would build up significant pressures in the containers during the lifetime of the system. Therefore, $\mathrm{LiH}^{\mathrm{i}}$ should be used ${ }^{6}$ in regions of the shield where the thermal-neutron fluence is expected to be high.

Lithium hydride has very little strength ( 2700-psi ultimate tensile strength at room temperature). It is brittle at room temperature and below, but exhibits plastic behavior above $\sim 530 \mathrm{~K}$ (Ref. 7). To compensate for its low strength, it will be reinforced with a metallic-foil web (probably a 300-series stainless steel). The web will prevent the LiH from rattling around in its containers during the shock and vibration of launch and will prevent large cracks from developing.

Fabrication of the shield is expected to follow closely the procedures developed by AI for the SNAP 2, 8, and $10 \mathrm{~A}$ reactor shields. 4 The metal parts of the shield are fabricated by conventional methods. The LiH requires special procedures. The LiH must be loaded, processed, and, when at room temperature, maintained in a dry atmosphere to prevent reaction with water or water vapor. At elevated temperature, a hydrogen overpressure must be maintained to prevent hydrogen loss. The fragile stainless steel foil honeycomb for reinforcing the LiH can be shaped by casting wax into an oversize block of honeycomb, machining the block to size conventionaliy, 
and then melting out the wax. The honeycomb is then placed in the shield casing or canning sections, and LiH powder is poured in and vibrated. The LiH can be cold- or hot-pressed, but casting is favored. In the casting process, the $\mathrm{LiH}$ powder, after being $\mathrm{placed}$ as described above, is brought up to melting temperature in a furnace and then cooled in a controlled manner.

\section{E. Neutron Shield Materials}

The primary function of the shield is to reduce the neutron and gamma dose rates to levels acceptable for payload and control instrumentation operation. As materials containing large amounts of hyd: ugen make the best shielding materials, one of the most important parameters for rating shielding materials for space applications is the number of hydrogen atoms per unit volume, $N_{H}$ (specifically, the number of hydrogen atoms per cubic centimeter). Water with an $\mathrm{N}_{H}$ of $\sim 6.7 \times 10^{22}$ is commonily used to moderate and shield low-temperature terrestrial nuclear reactors, but it is not suitable wi a shield above its critical point. Because of hightemperature stabilities and $N_{H}$ values, metal hydrides are the prime candidates for space reactor shielding.

Lithium hydride is an excellent choice primarily because it has a high hydrogen density $\left(\mathrm{N}_{\mathrm{H}}=5.9 \times 10^{22} \mathrm{H}\right.$ atoms $\left./ \mathrm{cm}^{3}\right)$, a low mass density $\left(0.775 \mathrm{Mg} / \mathrm{m}^{3}\right)$ and a moderately high melting point $(961 \mathrm{~K})$. It also produces a minimum amount of secondary radiation.

Other hydrogeneous materials suggested for elevated temperature shield applications include $\mathrm{TiH}_{2}$ and $\mathrm{ZrH}_{2}$ which possess $\mathrm{N}_{\mathrm{H}}$ values $\sim 9.5 \mathrm{x}$ $10^{22}$ and $6.5 \times 10^{22}$ respectively. Of these two hydrides, $\mathrm{TiH}_{2}$ is the least stable at elevated temperatures, and its hydrogen dissociation pressure exceeds $0.1 \mathrm{MPa}$ ( 1 atmosphere) above $775 \mathrm{~K}$. At least an order of magnitude reduction in hydrogen dissociation pressure can be achieved at the same temperature if the hydrogen content is reduced to give $\mathrm{TiH}_{1.5}$, but this pressure is still about an order of magnitude higher than for $\mathrm{ZrH}_{1.6}$. Neither of these two hydrides compare well with $\mathrm{LiH}$ when mass densities are compared. The $\mathrm{ZrH}_{1.6}$ has a density of $5.65 \mathrm{Mg} / \mathrm{m}^{3}$ and $\mathrm{TiH}_{1.5}$ has a density of $\sim 3.8 \mathrm{Mg} / \mathrm{m}^{3}$. Even though the titanium and zirconium hydrides have higher $N_{H}$ values than $L i H$, their higher hydrogen concentrations do not compensate for their significantly higher densities and consequently heavier shields. 
If additional gamma shielding is required one might consider a composite shield containing a mixture of $\mathrm{LiH}$ and tungsten or zirconium hydride. As indicated by an AI study, ${ }^{7}$ a shield of this type can be easily fabricated by surrounding granulated gamma shield material with molten LiH and casting in place. There were no materials compatibility problems observed in either the $\mathrm{LiH}-\mathrm{W}$ or $\mathrm{LiH}-\mathrm{ZrH} \mathrm{H}_{\mathrm{x}}$ systems after $4000 \mathrm{~h}$ at $810 \mathrm{~K}$.

Irradiation damage studies have been performed on LiH up to fluences of $\sim 10^{23} \mathrm{n} / \mathrm{m}^{2}$ and temperatures of $\sim 685 \mathrm{~K}$ with only small amounts of swelling observed. ${ }^{8}$ However, there are considerable inconsistencies in the data, and data at higher fluences are needed.

\section{REFERENCES:}

1. D. D. Cashwe 11, J. Neergaard, W. M. Taylor, and G. D. Turner, "MCN: A Neutron Monte Carlo Code," Los Alamos Scientific Laboratory report LA-475] (January, 1972).

2. J. H. Van Osdol, Ed., "Design and Integration of Zirconium Hydride Reactor Power Systems," Atomics International report AI-AEC-13072 (June 1973).

3. J. D. Sutherland, "Mechanical Design of the SNAP 10A Radiation Shield," Atomics International report NAA-SR-9901 (June 1964).

4. V. Keshishian, J. V. Focha, R. J. Thomson, and F. H. Welch, "Radiation Shielding for Zirconium Hydride Reactor Systems," Atomics International report AI-AEC-13081 (June 1973).

5. C. B. Magee, "Saline Hydrides," in Metal Hydrides, W. M. Mueller, J. P. B:ackledge, and G. G. Lib witz, Eds., (Academic Press, New York, 1968), Chapter 6, p. 165.

6. F. H. Welch, E. C. Phillips, J. G. Asquith, and N. F. Davies, "Lithium Hydride Technology I. Properties of Lithium Hydride and Corrosion Studies," Atomics International report NAA-SR-9400 (May 1964).

7. F. H. Welch, "'-ithium Hydride Technology: IV. A Novel Neutron-Gamma Material for SNAP Shielding Applications," Atomics International report NAA-SR-9400, (May 1967).

8. F. H. Welch, "Lithium Hydride Technolog: : III. Properties of Lithium Hydride for SNAP Shielding Applications," Atomics International report NAA-SR-9400 (May 1967). 
VI. ELECTRIC POWER CONVERTER DESIGN

A. Description of Converters

A number of systems have been considered for power conversion. These include both direct conversion and dynamic or rotating machinery systems. Figure 102 shows the systems considered. Principal candidates are SiGe and SiGe alloyed with GaP, semiconductor thermoelectric conversion, out-of-core thermionic conversion, inert-gas Brayton cycle, organic or potassium Rankine cycle, and free-piston stirling engine. Appendixes at the end of this section provide a mathematical description of thermoelectric, thermionic, and Brayton cycle converters.

After surveying the various technologies, we concentrated on thermoelectric direct conversion using SiGe semiconductor material and SiGe alloyed with GaP semiconductor, and on the inert-gas (He-Xe mixture) Brayton cycle. These represent the princtpal classes of electric conversion systems, that is, direct and dynamic. Also, these are the principal conversion systems that are $f$ ar enough advanced in technology development for use in the late 1980s and early 1990s flight programs.

For time periods in the mid 1990s, thermionic systems hold promise, with NASA supporting a technical feasibility program aimed at a converter demonstration in 1985. Higher-temperature thermoelectric and Brayton cycles also hold promise for this later time.

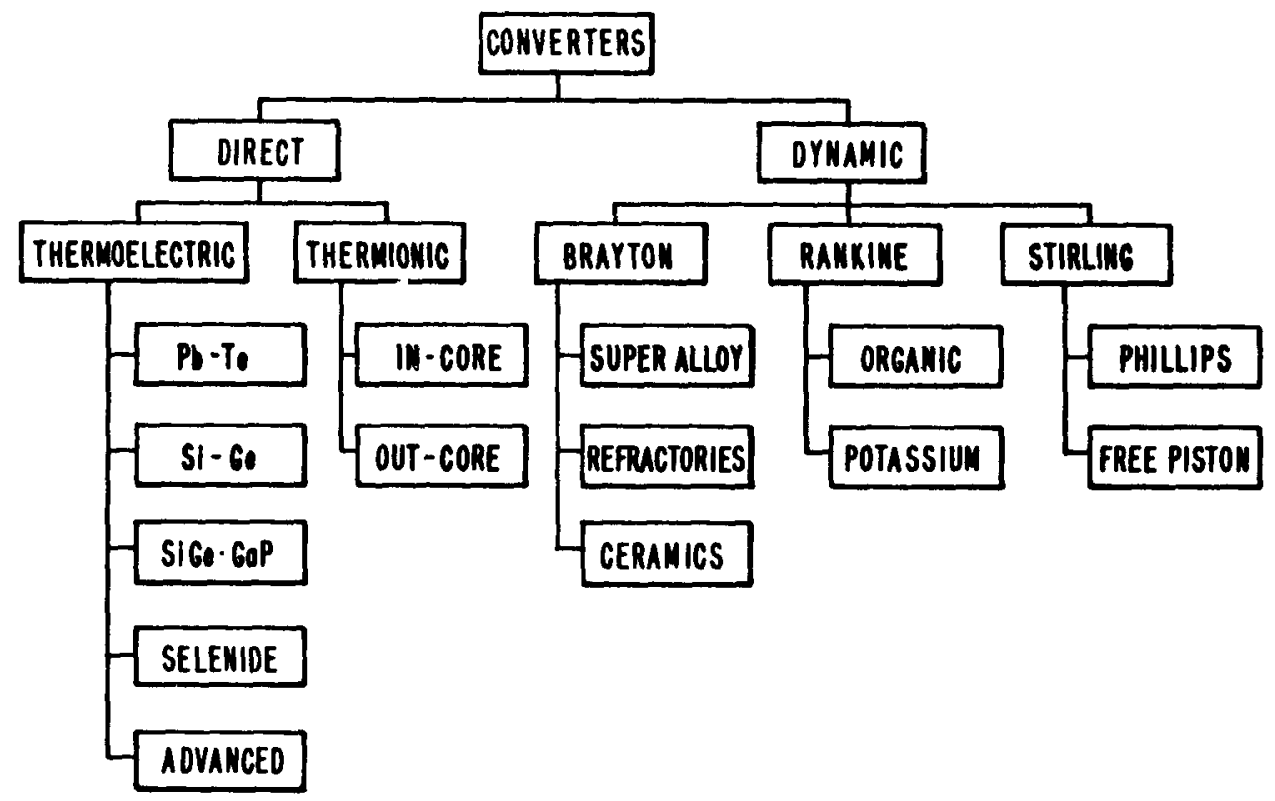

Fig. 102. Potential conversion systems. 
1. Thermoelectric Conversion. Direct conversion of heat-to-electric power in a thermoelectric device is based on the Seebeck effect in which an emf is developed when two dissimilar conductors, $p$ and $n$, are connected so that their junctions are at different temperatures. The most common practical application is the thermocouple for temperature measurement. With development of special semiconductor materials that combine a high Seebeck coefficient $\alpha$, relatively low electric resistance $\rho$, and high thermal resistance $k$, direct conversion of electric power in a thermoelectric converter is practical. These parameters define a figure-of-merit $Z$ for thermoelectric performance, $z=\alpha^{2} /(\rho k)$. Figure 103 is a simple schematic of a thermoelectric converter cell.

The output of the thermoelectric cell depends on the operating temperatures, properties of the $n$ and $p$ semiconductor materials, and specific design. In the cell, the induced voltage is equal to the product of overall Seebeck coefficient ( $n$ plus $p$ ) and temperature difference. Current flow is equal to the voltage divided by the sum of internal and external resistances. Resulting net output power is current squared divided by external (load) resistance. Maximum power occurs when load resistance is equal to internal resistance. The thermal heat transferred from the hot side to the cold side of the TE through the semiconductor material represents a loss. This heat conduction is essentially independent of the power removed. It is dependent only on the temperature difference, design, and thermal conductivity of the materials.

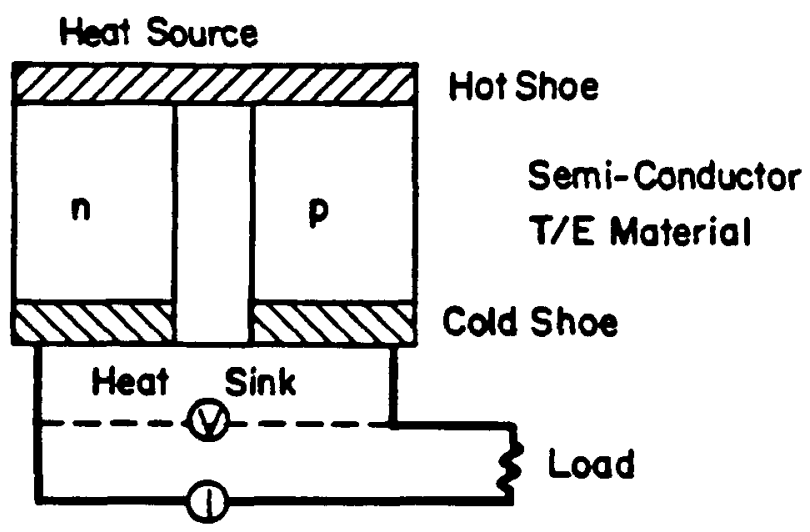

Fig. 103. Schematic of thermoelectric conversion cell. 
The overall efficiency is defined as the net electrical output divided by the heat conducted through the hot junction. As described in Appendix VI-A, the maximum efficiency for a temperature difference can be estimated for given $n$ and $p$ semiconductor materials assuming optimal design of the cell and ideal matching of the load resistance. Optimum design requires minimizing extraneous heat losses, reducing electric contact resistances as much as possible, and minimizing temperature drop across the hot and cold shoes.

a. Thermoelectric Materials. All space isotope power systems flown to date have had the thermoelectric heat-to-electric power conversion systems. The thermoelectric materials included PbTe, silver-antimony-germanium telluride (TAGS), and SiGe (Ref. 1). The tellurides are limited by material sublimation to $825 \mathrm{~K}$. For power plants operating at $10-100 \mathrm{~kW}_{\mathrm{e}}$, it is desirable to operate at $1275 \mathrm{~K}$ or higher. Silicon-germanium can operate at this temperature. Silicon-germanium alloys, besides having the highest temperature capability of any currently used materials, have reliable long term-operation at high temperatures, in almost any operating environment without deleterious effects on their performances. They can be metallurgically bonding even at their nighest operating temperatures and possess strength characteristics considerably greater than those of all other commonly used thermoelectric materials. They can be operated generally at much nigher hot-side temperatures than other thermoelectric materials. By operating the cold side at an elevated temperature, it is possible to reduce the size and weight of the radiator needed for rejecting waste heat without severely penalizing conversion efficiency.

The approximate relationship for conversion efficiency is $n=(1 / 4) Z \Delta T$, where $n$ is the conversion efficiency, $z$ is the figure-of-merit and $\Delta T$ is the temperature difference across which a thermoelectric material operates. Figure 104 shows that the SiGe alloy possesses the lowest figure-of-merit of any of the commonly used thermoelectric materials. Using the expression given for conversion efficiency, it is found that SiGe alloys are capable of as large conversion efficiencies as are the other materials; in fact, with the exception of the selenides, SiGe alloys exhibit better performance. But, as there are questions about the use of the selenides in practical thermoelectric devices, SiGe alloys permit the best overall combination of 


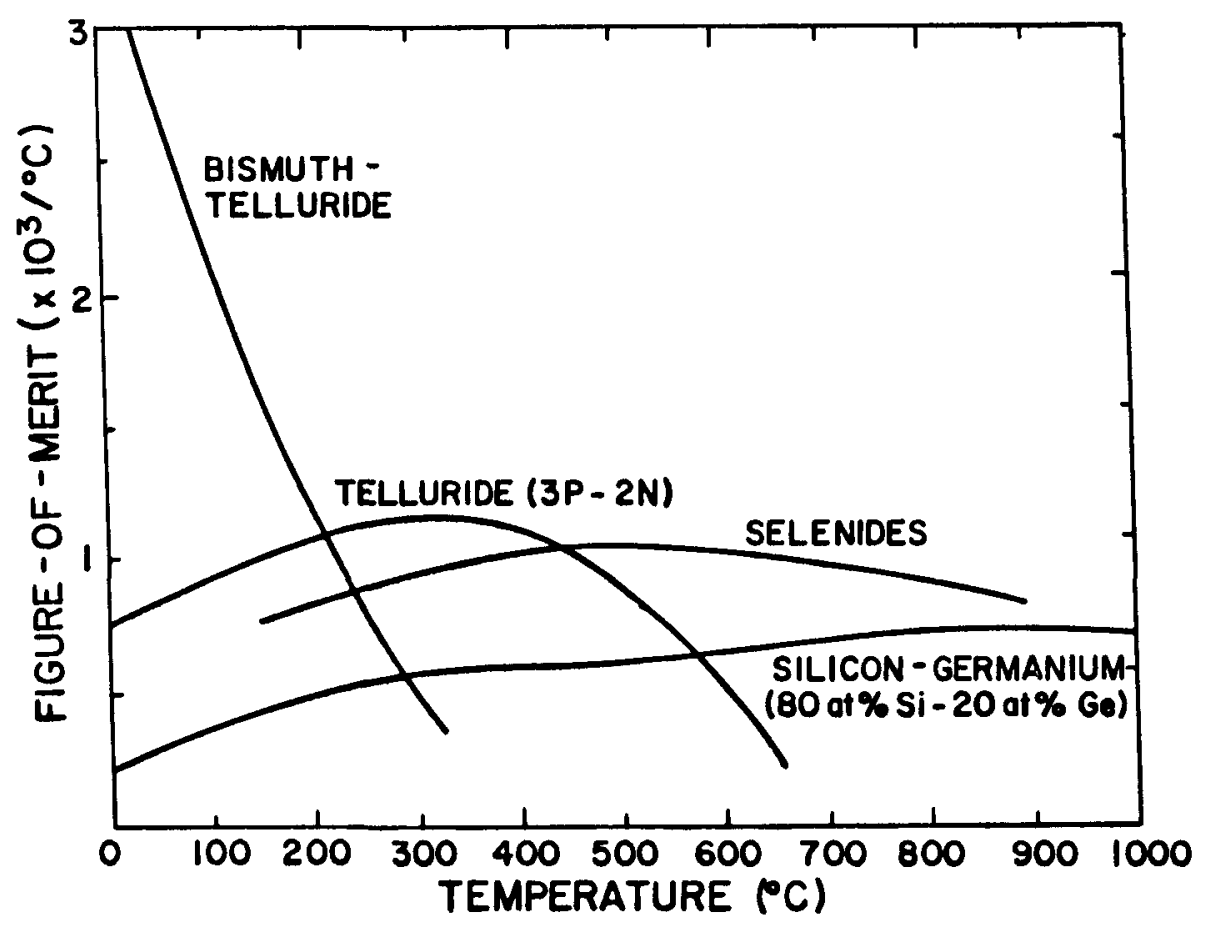

Fig. 104. Figures-of-merit of thermoelectric materials.

performance and reliability. This is especially true when the thermoelectric materials are considered for use in space applications with relatively elevated cold-side temperatures.

A consideration of the three thermoelectric properties that constitute the figure-of-merit of a material for each of the commonly used thermoelectric materials indicates that the electric properties, the Seebeck coefficient and the electric resistivity are quite similar for each material. This is not surprising because all of these materials are extrinsic semiconductors that obtain their electric properties from doping. The differences in the figures-of-merit materials are due to differences in the thermal conductivity. The tellurides and the selenides all have very low values of thermal conductivity, $\sim 0.005-0.015 \mathrm{~W}(\mathrm{~K}-\mathrm{cm})$. The SiGe alloys, on the other hand, have values in the range of 0.04-0.06 W(K-cm).

The SiGe alloys have a considerably simpler basic lattice structure. The scattering of heat waves is, therefore, considerably less, which results in the relatively higher thermal conductivity. Consequently if it were feasible to create greater complexity in the SiGe alloy lattice than normally exists, the thermal conductivity of these alloys might be reduced. If this can be done without unduly affecting the electric properties of the 
material, the result would be a considerably enhanced figure-of-merit. These considerations several years ago led to a NASA-sponsored study to attempt to improve the figure-of-merit of SiGe alloys, while retaining all of the attractive mechanical and physical characteristics of the material.

Syncal Corporation ${ }^{2}$ performed this study on SiGe alloyed with GaP. Samples of $n$ - and p-type $\mathrm{Si}-20$ at.\% Ge alloy and GaP were pulverized to a particle size of less than 44 microns. The two materials were intermixed and further pulverized in an orbital ball mill using agate containers and balls. The powders were mixed to yield a final material with a composition having five mol\% GaP and 95 mol\% SiGe alloy. The mixed powder was placed in a graphite-lined TZM die and placed in an RF-heated vacuum hot press. Prior to the application of any pressure, the powders were outgassed at $575 \mathrm{~K}$ over a 24 hour period, then slowly heated to a temperature of $875 \mathrm{~K}$, and further outgassed for a short period of time. A pressure of 30000 psi was then applied to compact the powder into a pellet. This pressure was maintained while the pellet was heated relatively rapidly to $1475 \mathrm{~K}$ and held at a temperature of $1475 \mathrm{~K}$ for $1 \mathrm{~h}$. Pressure was then released and the pellet rapidly cooled to room temperature. Following this procedure, it was found that material densities of the order of $98-99 \%$ had been obtained. Also, it was found that both $n$ - and p-type materials retained their original conductivity characteristics, and that they exhibited approximately the same magnitude of Seebeck coefficient originally associated with the SiGe alloy itself. This means that no phosphorus was lost during the pressing operation; otherwise the additional doping with pure gallium would have had an effect on the Seebeck coefficient. The reason that no noticeable phosphorus was lost is due to the compaction at temperatures significantly below those at which GaP dissociates and the continued compaction throughout the heating of the pellet. The GaP was not able to dissociate because it was contained within the compacted SiGe alloy matrix. Very likely small quantities of GaP on the surface of the pellet did dissociate, with a consequent loss of phosphorus. This, however, is a surface phenomenon and its extension into the sample is based on the diffusion rate of GaP to the surface. Such diffusion rates, however, are extremely low and practically no loss of internal GaP is to be expected. The results bear this out.

Comparison of the results of the measurements of SiGe alloys with GaP additions and data for plain SiGe alloys are made in Figs. 105-107 in terms 
of the three individual thermoelectric properties. The data in for the plain SiGe alloy pertain to those generated at Syncal Corporation on the alloy. These data are the so-called beginning-of-life data and are used here because the corresponding data on the SiGe alloy with GaP additions also pertains to the beginning-of-life.

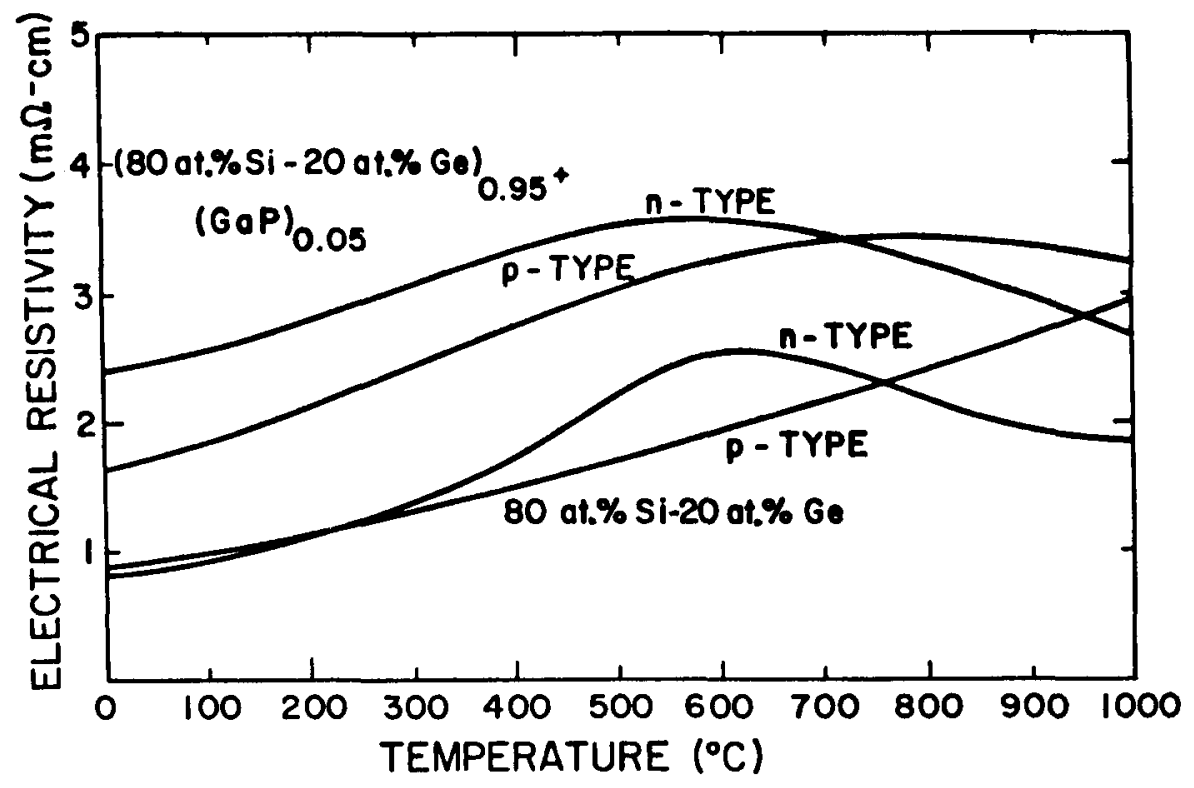

Fig. 105. Thermoelectric material resistivity curves.

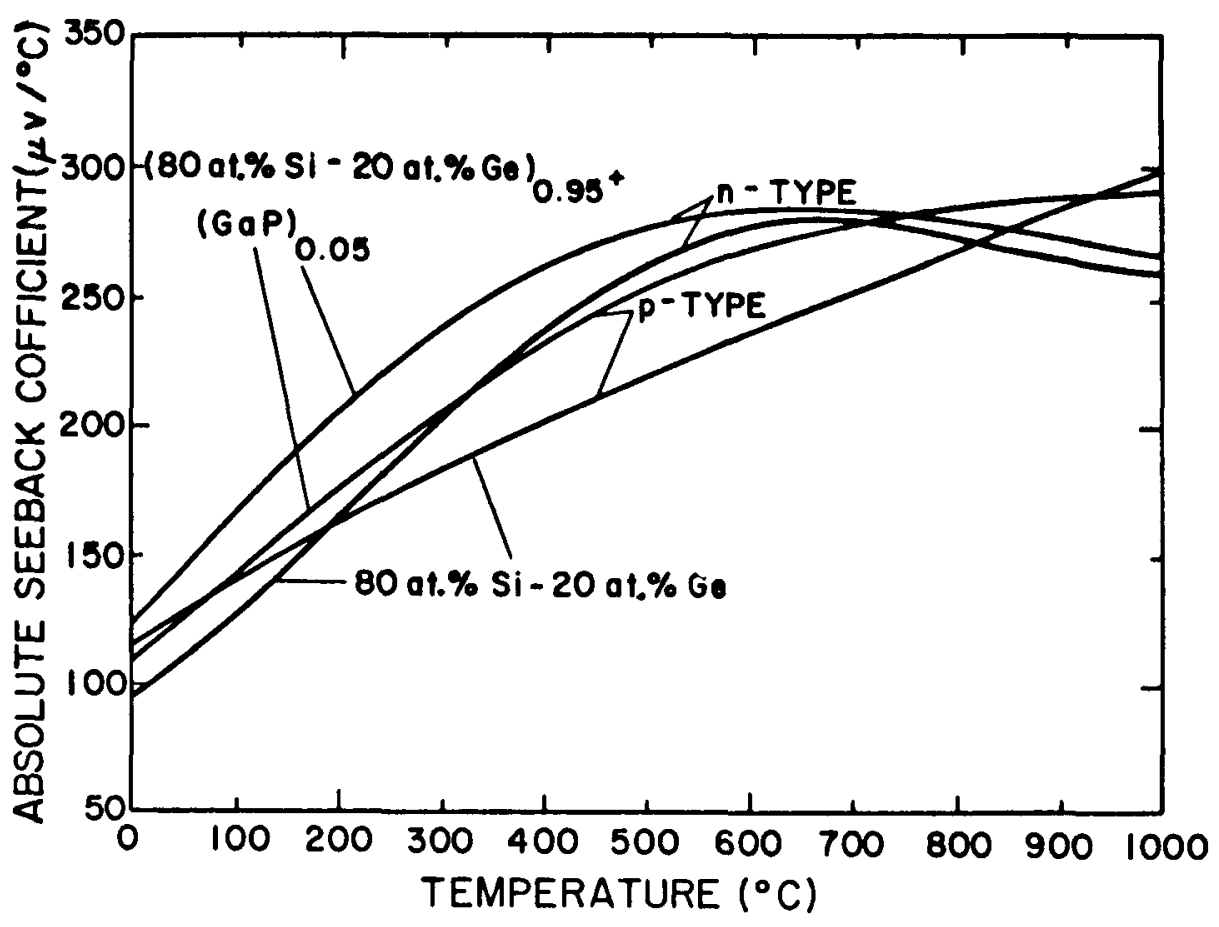

Fig. 106. Seebeck coefficient curves. 


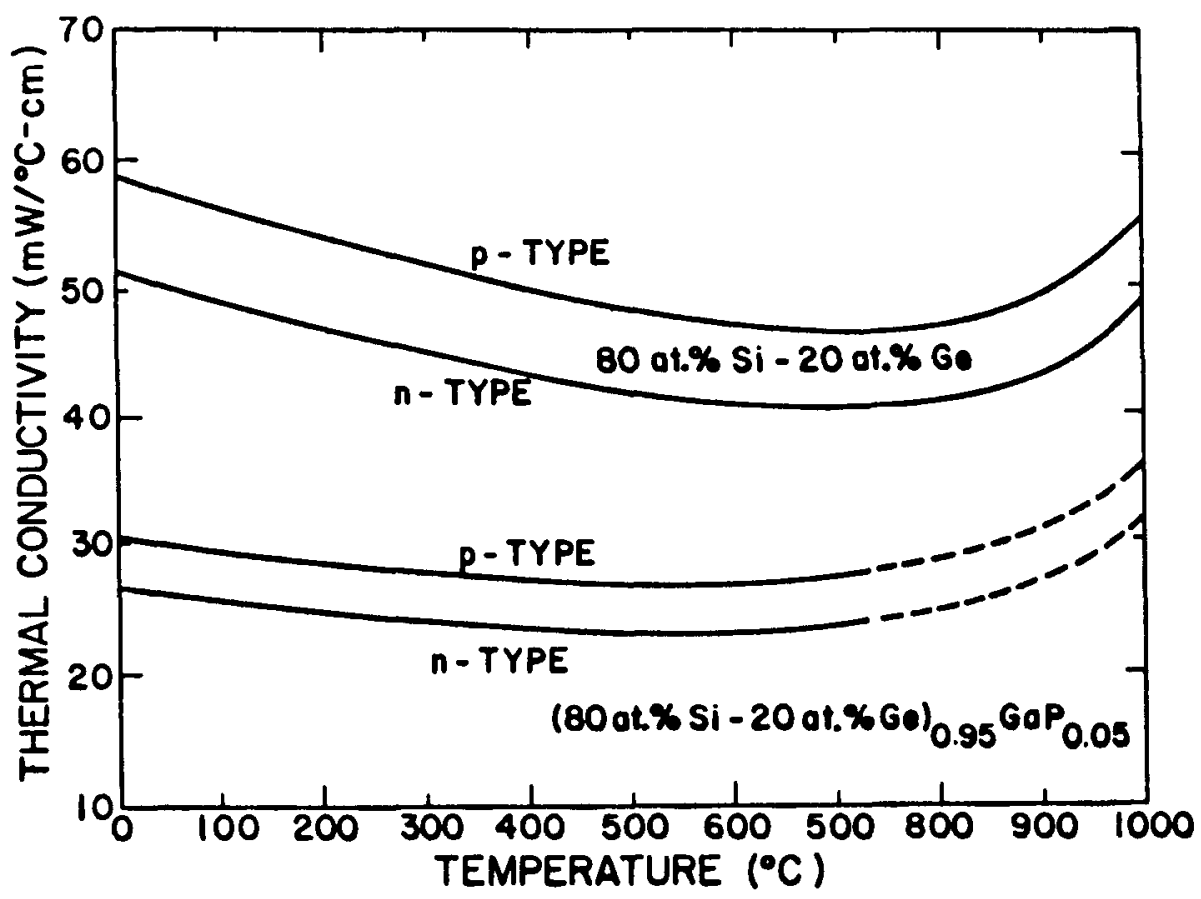

Fig. 107. Thermal conductivity curves.

An inspection of the relative thermoelectric properties of the plain SiGe alloy and the alloy containing a GaP addition shows that, al though the Seebeck coefficient of both materials is fairly similar, differences exist in the electric resistivity and the thermal conductivity. The desired effect of the GaP addition has been obtained in the lowered values of thermal conductivity, but the intent of keeping the other two properties unchanged has not been totally realized. The Seebeck coefficient has remained essentially the same, but the electric resistivity exhibits higher values for the material containing GaP. As the Seebeck coefficient is inversely proportional to the carrier concentration of a material, the GaP addition to SiGe alloys must not result in gross changes in carrier concentration. Therefore, no noticeable decomposition of GaP should occur during the material preparation process. If this were to happen, changed values of Seebeck coefficient would be expected because the loss of the relatively volatile phosphorus from the material would result in excess p-type doping by gallium. In the case of the n-type material, this would result in increased values of Seebeck coefficient and in the case of the p-type alloy, the result would be decreased values of Seebeck coefficient. 
The higher values of electric resistivity of the resultant material are due to carrier mobility changes. Th ' follows because electric resistivity is inversely proportional to the product of carrier concentration (which was unchanged) and mobility. There are several explanations for the decrease in mobility by the GaP addition. First, it is possible that some oxidation of the constituent materials occurs during the material preparation process. Second, the introduction of GaP into SiGe alloys may enhance carrier scattering. Third, any inhomogeneity or less than theoretical density can also be responsible for reduced carrier mobility. It was found in the previous NASA sponsored program that high-temperature annealing generally results in reduced values of electric resistivity without noticeable changes in the other thermoelectric properties. Even though the data given here pertain to the material in its as-prepared state, the values of electric resistivity are lower than the corresponding values obtained in the previous NASA program. The reason for the this effect is the higher material preparation temperature used in the present program; such temperatures result in a more homogeneous and denser material. Further annealing of the material may result in further reducing the values of electric resistivity making it conceivable that the resultant material will possess nearly double the performance capability of plain SiGe alloys because appropriate GaP additions to SiGe alloys reduce thermal conductivity by nearly two.

To make a one-to-one comparison between plain SiGe alloy and the corresponding alloy with GaP additions, the results of the individual thermoelectric property data have been combined into the figure-of-merit for each polarity type of materials. The data in Fig. 108 pertain to the n-type material and those in Fig. 109 pertain to the p-type material. For comparison, each figure also includes data on the corresponding SiGe alloy without GaP addition. Over a large temperature range, the prepared samples exhibit figure-of-merit values some $30 \%$ higher than the plain SiGe alloy. The data shown pertain essentially to the materials as prepared. It is not known how the properties of the materials behave as a function of time. Assuming that the GaP addition has no effect on the time behavior of the material, a slight adjustment in the properties may occur with time as a result of adjustments in dopant concentrations that reflect the temperature dependence of dopant solid solubility. Although the results are based on very limited data and represent only a cursory investigation of SiGe alloys with GaP 
additions, an enhanced figure-of-merit seems possible with the addition of GaP to SiGe alloys. Considerable work will have to be done before these materials can be considered for use in practical devices.

Other materials identified in the literature that may be potential thermoelectric materials are NbSiGe, refractory metal silicides ( $\mathrm{NbTaSi}_{4}$ ), carbides (SiC), and rare-earth sulfides $\left(\mathrm{Ln}_{2} \mathrm{~S}_{3}\right)$. Figures-of-merit and converter efficiencies for these materials are shown in Figs. 110 and 111 .

Among the advanced thermoelectric materials are the selenides. The p-type material is a copper-silver-selenide with an atom composition ratio of 1.97:0.03:1.0045. The n-type is GdSe with an atom proportion of 1.00:1.49. These materials, designated TPM-217, were developed by the 3M Company. They are currently being tested by the Jet Propulsion Laboratory (JPL). The selenides have from 1.4 to 1.8 times better efficiency than SiGe. However, based on current testing programs, selenides have proven to be difficult thermoelectric material to work with. They are fragile, their properties change with time and temperature, there are composition changes due to diffusion of materials, and they have higher vapor pressure than SiGe. It appears that the current selenide materials will be limited to $1125-1175 \mathrm{~K}$ because of sublimitation and sensitivity to oxygen.

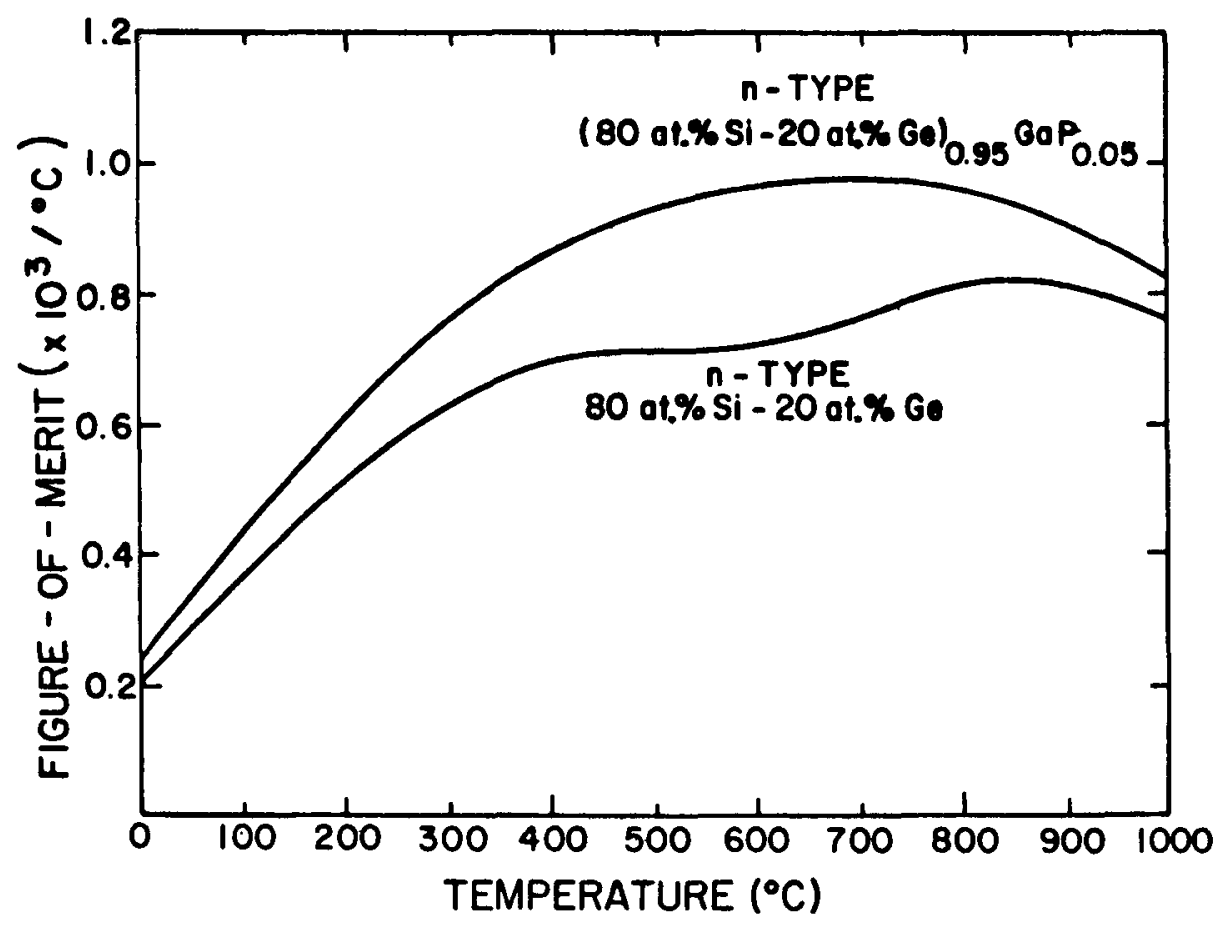

Fig. 108. Figure-of-merit as a function of temperature, n-type material. 


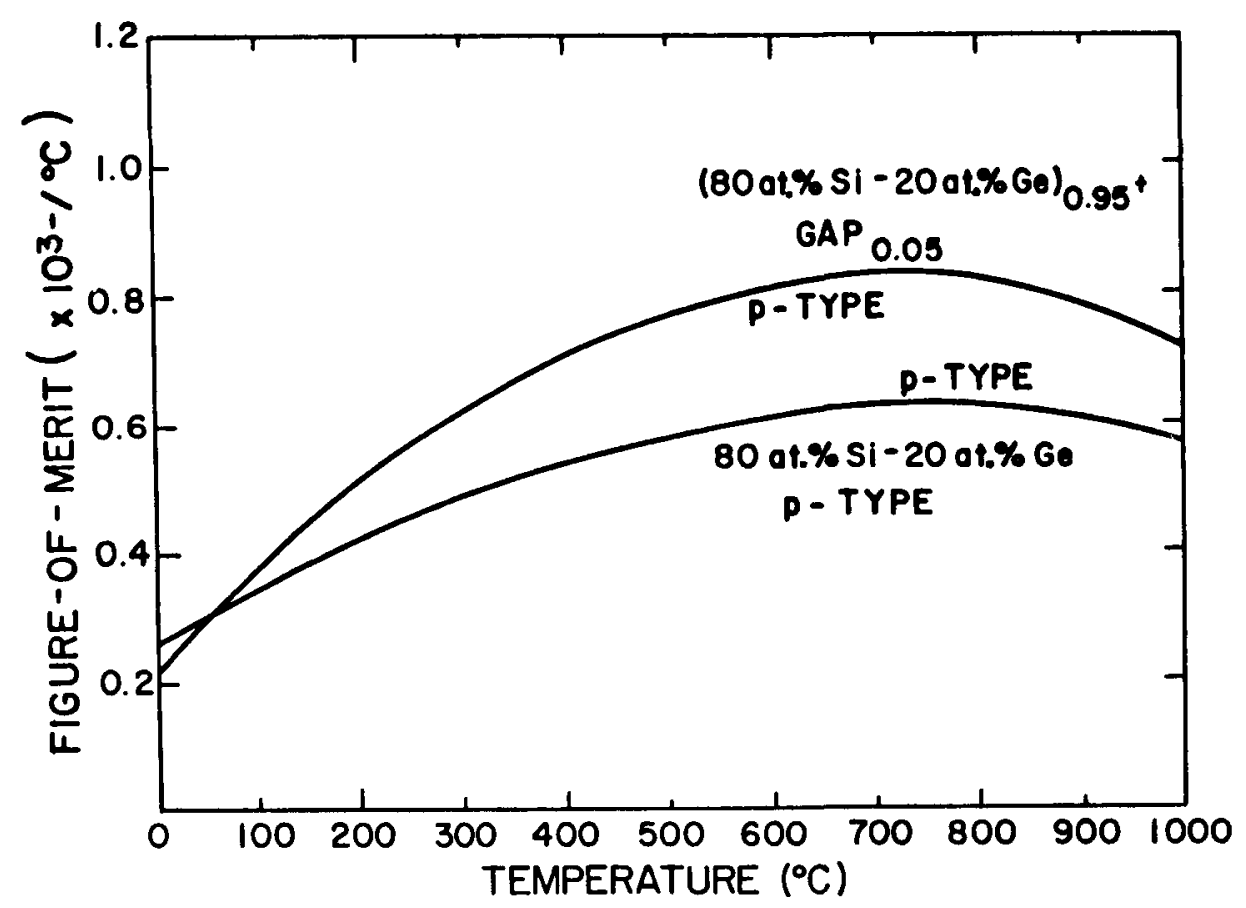

Fig. 109. Figure-of-merit as a function of temperature, p-type material.

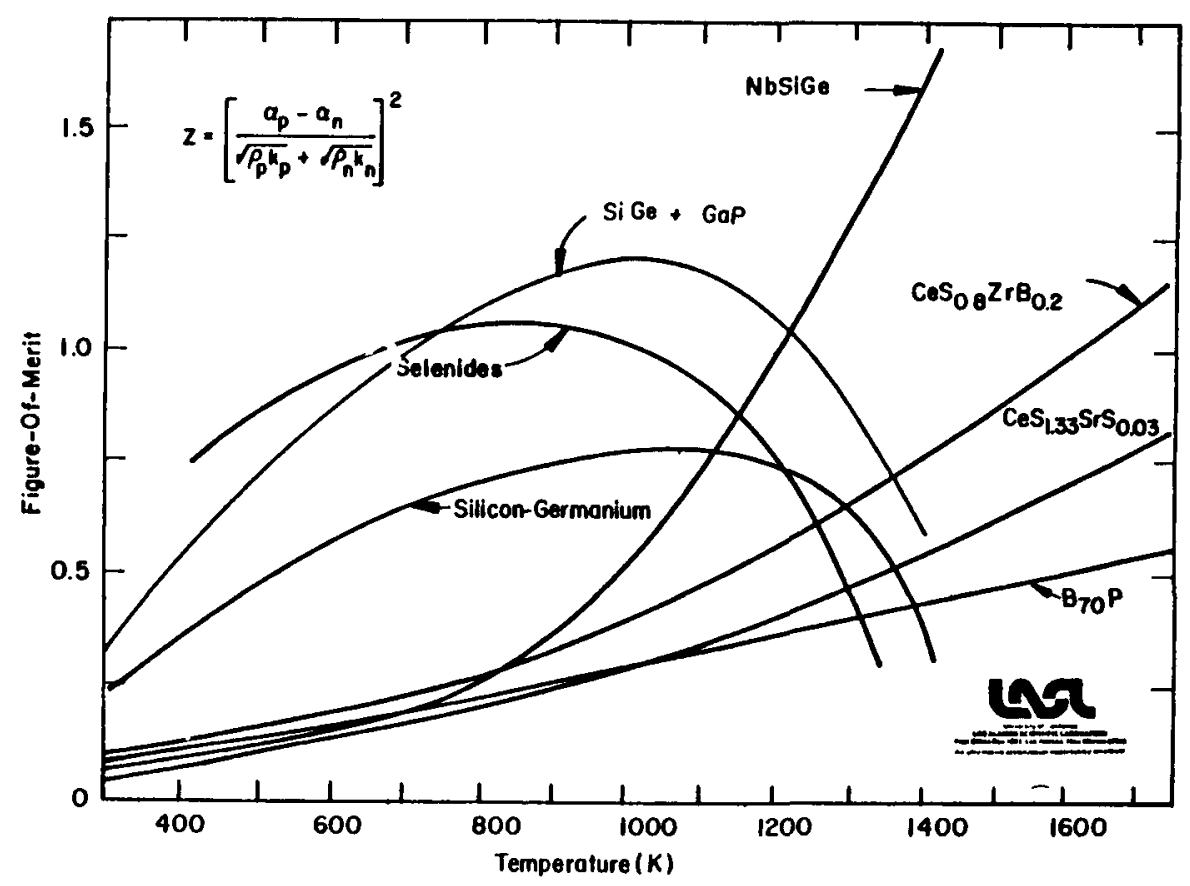

Fig. 110. Figure-of-merit for thermoelectric materials. 


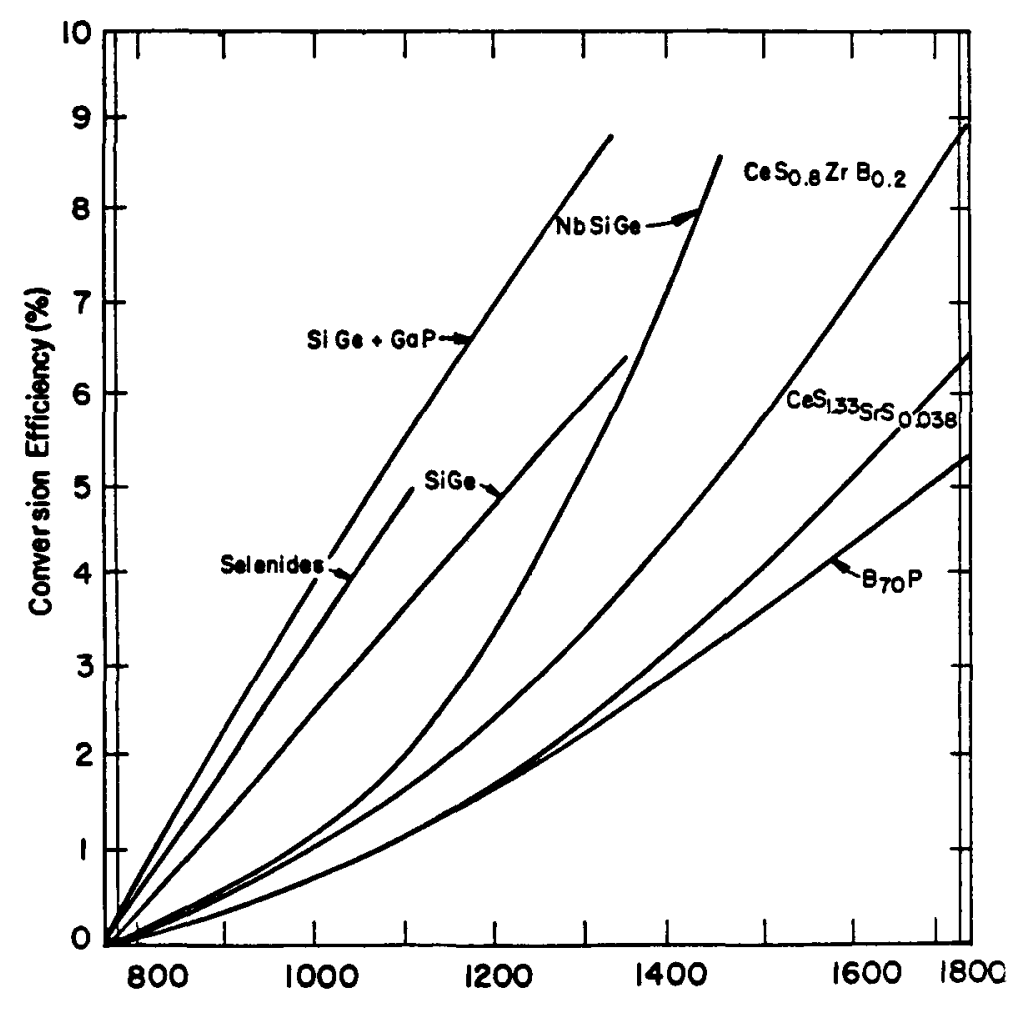

Hot Side Temperature (K)

Fig. 111. Conversion efficiency for thermoelectric materials.

b. Module Design. A first iteration of a high power-density module was completed. The module includes thermoelectric material, electric connectors and electric insulators segmented and maintained in compression between the core heat pipes and the outer sleeve. The compression is maintained by the relative expansion of the various module components. The study addressed the selection of materials and component configuration based on electric and mechanical performance.

Figure 112 is a drawing of the module. The initial thermoelectric material will be SiGe. Then SiGe-GaP will be substituted after material processes have been perfected. The electrical insulator is beryllia with BN an alternate material for the cold-side shoe. Molybdenum is proposed for the current conductor between the individual thermoelectric elements. The outer sleeve is niobium. The ends of the module are insulated with layers of Mini-K 2020 (silicon dioxide foam) thermal insulator and then sealed with refractory metal baffles made of niobium. 


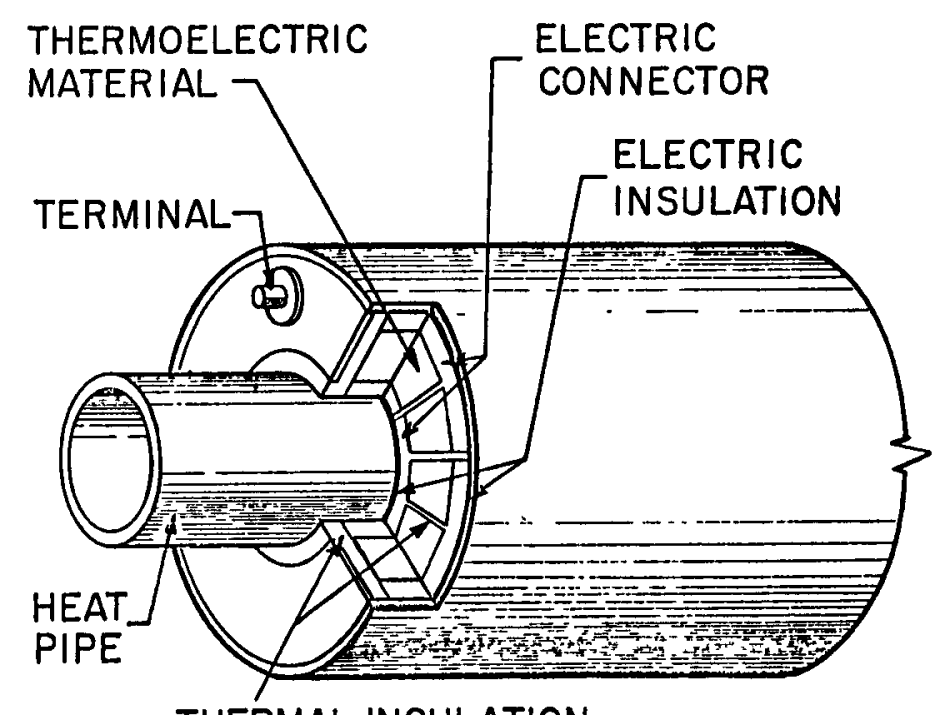

THERMAL INSULATION

Fig. 112. Thermoelectric module.

Table XXIV provides information on the physical dimensions of the module. A typical module is $40 \mathrm{~mm}$ diam and $330 \mathrm{~mm}$ long, weighing $1.9 \mathrm{~kg}$. Table XXV describes the temperature distribution between a hot side of 1375 $K$ and cold junction of $775 \mathrm{~K}$. The thermoelectric element operates between 1310 and $804 \mathrm{~K}$. Computed conversion efficiencies are shown in Fig. 113. Operating between 1375 and $775 \mathrm{~K}$ provides $6.3 \%$ efficiency. With SiGe-GaP, we hope to obtain over $9 \%$ efficiency.

TABLE XXIV

PHYSICAL DIMENSIONS OF MODULE

Module diameter - $\mathrm{mm}$

Module length - mm 330

Heat pipe diameter - $\mathrm{mm}$

Number of thermocouple rings 28

Number of thermocouples per ring 6

Total number of thermocouples 336

Thermoelement height - mm 7.5

Thermoe lement top width - $\mathrm{mm}$ 8.8

Thermoelement bottom width - mm 4.8

Thermoe lement length - fim

10.7

Module weight - $\mathrm{kg}$ 
TEMPERATURE PROFILE OF MODULE IN OPERATION BETWEEN 1375 AND $775 \mathrm{~K}$

Component Interface

Heat Pipe - hot side insulator

Hot side insulator - hot side conductor

Hot side conductor - thermoelement

Thermoelement - cold side conductor

Cold side conductor - cold side insulator

Cold side insulator - outer cylinder
Average Temperature - K

1375

1323

1310

804

798

775

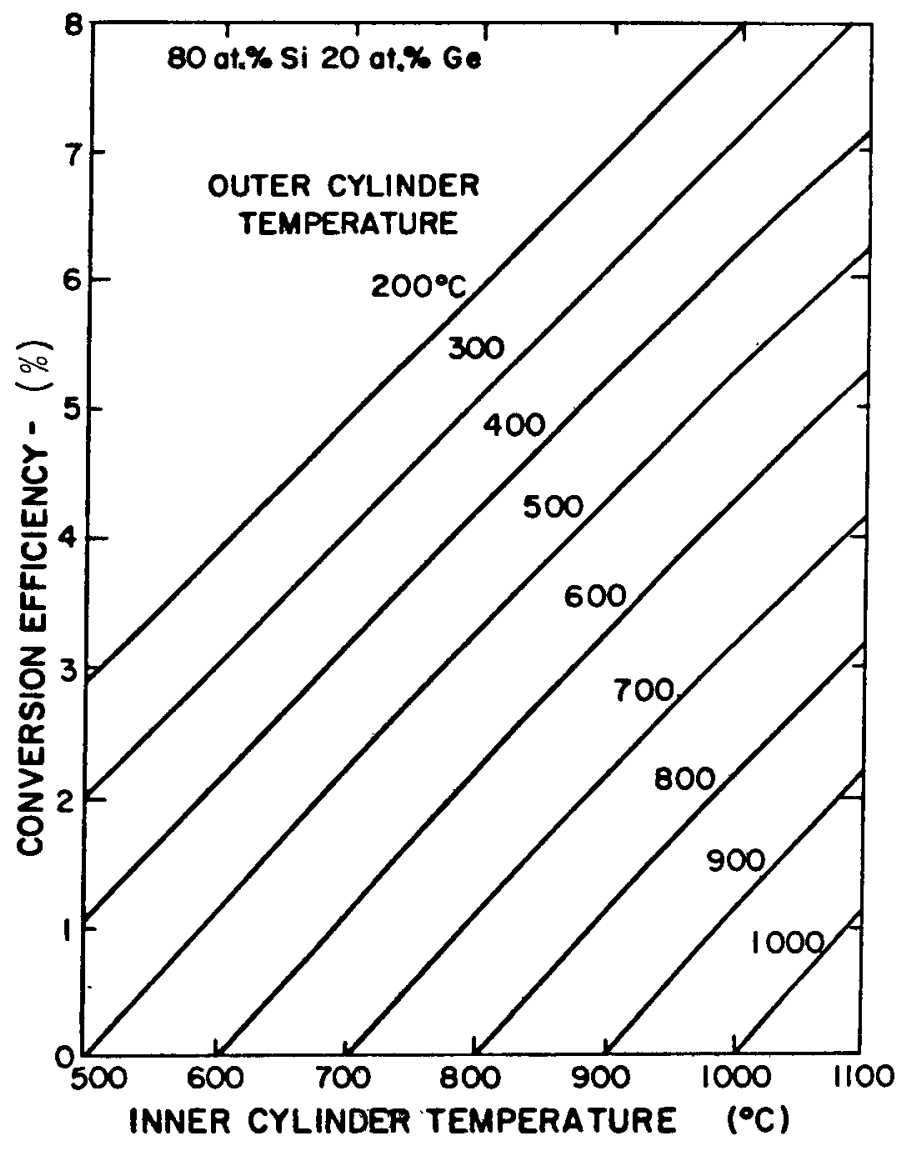

Fig. 113. Computed modular conversion efficiencies.

c. Current Status. Thermoelectric conversion has been extensively used in nuclear space power system (Ref. 3). The SiGe type has been well characterized and demonstrated as a TE material. Converter design is essentially a state-of-the-art technology. 
Space applications of thermoelectric converters are summarized in Table XXVI. With the exception of the SNAP-10A all applications have used a radioisotope heat source. These radioisotope thermoelectric generators (RTGs) are low power, less than 100 We and low temperature. Current programs emphasize higher temperatures and higher powers using SiGe.

Telluride-based thermoelectric converters have been used for many years, and their performances have been excellent as demonstrated by the SNAP-27 radioisotope generators that were left on the moon during the Apollo program. However, tellurides are limited to relatively low operating temperatures because of material sublimation. For this same reason, they and the TAGS (silver-antimony germanium telluride) systems were eliminated from this study.

Silicon-germanium semiconductor material has been studied extensively and has been used in a variety of applications, including high-temperature operation in RTGs (Ref. 4). Operation at temperatures in the range of 1300-1400 $\mathrm{K}$ has been demonstrated. The reference design has been based on $1375 \mathrm{~K}$ hot-shoe temperature. The SiGe RTGs have been tested at temperatures of $1375 \mathrm{~K}$ or higher for $2.5 \times 10^{6} \mathrm{~h}$ and individual elements as long as $30000 \mathrm{~h}$ (Ref. 5). The test program has been essentially failure free, leading to confidence that there is sufficient knowledge to design a thermoelectric module. A higher temperature may be possible. Compression modules will need to be designed and tested to establish temperature limits as well as actual performance.

\section{TABLE XXVI}

THERMOELECTRIC CONVERTER APPLICATIONS IN SPACE

Semiconductor Material

Tellurides

Silicon-German ium
Satellite

SNAP-3A

Nimbus III

Pioneer

Viking

Transit

SNAP-27

MHW-LES $8 / 9 a$

Mariner

SNAP-10A
Application

Navigation

Weather

Jupiter Fly-by

Mars Lander

Navigation

Moon Landing

Communications

Jupiter-Saturn

U-ZrH Reactor

a Multi-Hundred Watt Generator - Lincoln Experimental Satellite 
The converter uncertainties are with design, fabrication, and demonstration of the compression module having the predicted efficiency, power density, and specific mass. The design uncertainty is in finding the best way to couple (package) the large number of modules with the reactor heat pipes and radiator. A functional and reliable method to uniformly cool the module cold-shoe and cross-link cooling between radiator stringers needs to be demonstrated.

Improved performance seems likely. A near-term material currently under investigation is SiGe alloying with GaP. Significant improvements in the figure-of-merit have been measured. It is believed that the SiGe-GaP can be directly substituted for SiGe in the compressor module design.

Many alternate advanced materials show promise. A study of other materials to exploit the high-temperature and high power density available with a heat-pipe-cooled reactor is justified. Although SiGe has been well characterized and could be used in early designs, and although SiGe alloyed with GaP can provide efficiency improvements of $40 \%$, we expect that even better performance could be achieved with other advanced materials.

2. Thermionic Conversion. Thermionic energy conversion is another method of converting heat directly to electricity. A metal electrode, the emitter, is heated sufficiently to emit electrons. The electrons cross a narrow interelectrode gap and are collected by another electrode, the collector. The flow of electrons constitutes an electric current which delivers power to the load. ${ }^{6}$ (Fig. 114). Appendix II-B explains more fully how thermionic conversion works.

Thermionic converters have been undergoing continuing improvement in performance. First generation converters tested under the in-core thermion ic program in the early 1970 's produced power densities of $6 \mathrm{~W} / \mathrm{cm}^{2}$ at $1850 \mathrm{~K}$. Continuing development of thermionic converters has maintained this performance level, but at lower emitter temperatures.

\section{a. Converter Design. The operating characteristics for thermi-}

on ic converters currently under development by NASA are

- efficiency - $15 \%$,

- emitter temperature - $1650 \mathrm{~K}$,

- collecter temperature - $950 \mathrm{~K}$,

- power density - $6 \mathrm{~W} / \mathrm{cm}^{2}$, and

- current density - $10 \mathrm{~A} / \mathrm{cm}^{2}$. 


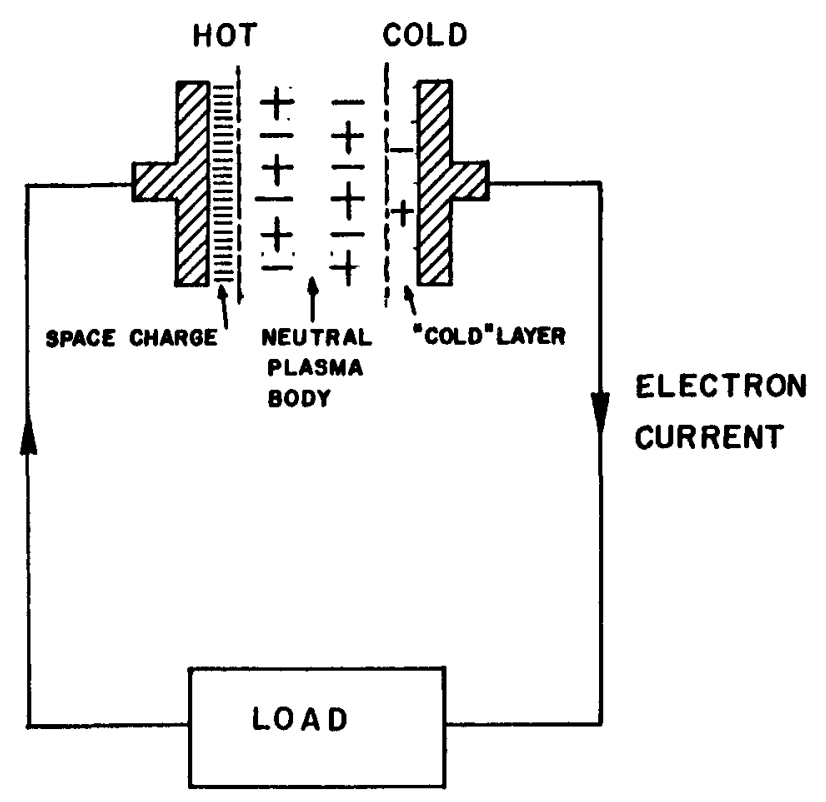

Fig. 114. Schematic of basic thermionic converter.

The diameter of each converter is goverened essentially by the diameter of the heat pipe supplying the heat. The total length of the system is determined by the area needed to produce the power within the converters. The length of each converter is limited by $I^{2} R$ losses as a result of conduction of the generated power along each electrode to the electric leads at each end of the converter.

Heat pipes are connected with their converters into a matrix array to minimize power losses in the electric circuit and avoid single-failure points in the system. The converter array illustrated in Fig. 114 for a 400-kW $\mathrm{e}$ NEP power supply contains 540 converters in a 90 by 6 series parallel array. The converter system theoretically will produce 54 volts total $\left(0.6 \mathrm{~V}\right.$ per diode). However, some of the voltage is lost in an $I^{2} R$ drop in electric leads, resulting in an input to the power processors of $\sim 45$ volts $\pm 22.5 \mathrm{~V}$ from ground. Present data indicate that the thermionic converter may optimize at higher current density and lower voltage. The 90 heat pipe system may be connected also in a $5 \times 108$ or $4 \times 135$ matrix and still maintain the overall current and voltage output from the system. 


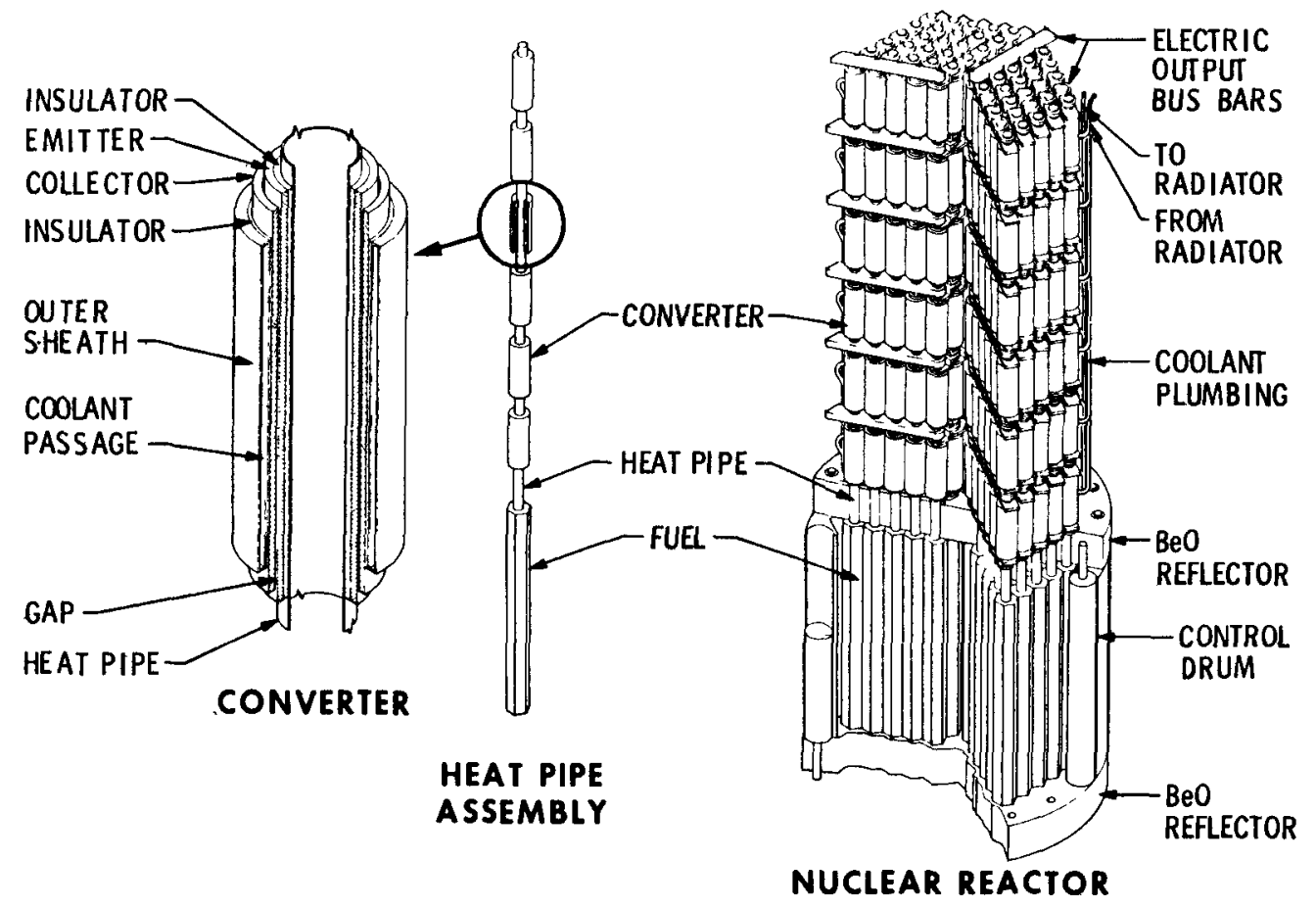

Fig. 115. NEP system with thermionic power conversion on reactor side of the neutron shield.

b. Current Status. Thermionic technology development has been ongoing since the 1960s at varying levels of support. The initial research efforts had developed converters which provided performance levels at 1800 to $2000 \mathrm{~K}$ which justified development of a system. A Joint NASA-AEC Space Nuclear Power Systems Office was set up to develop the in-core thermionic power system as well as other space nuclear power systems. This effort resulted in both continuing research and development as well as in-core testing of prototypical elements in core using nuclear heat.

The design was directed toward the $120-\mathrm{kW}_{\mathrm{e}}$ power level with probable lifetimes of 10,000 to 20,000 hours because of materials and nuclear fuel problems as a result of the high operating temperatures. This effort was cancelled in 1972, when the nuclear space power effort was cancelled.

Thermionic conversion was continued on a research basis with NASA and ERDA support resulting in lower operating temperatures. This allows the system to become an out-of-core design, which separates the reactor from the power conversion system and results in much more effective optimization of both the reactor and the thermionic power conversion system. The current 
program has been aimed at reducing the uncertainties associated with hightemperature insulator stability and thermionic performance. Current sialon technology is limited to $1700 \mathrm{~K}$. A 1000-h test under electric load at 1675 $K$ is presently in progress. Fabrication techniques of both explosive forming and diffusion bonding have given indications of success. The explosive forming method has made possible alternative material selection for the insulator, specifically Be0. Further testing is planned.

The major concern on thermionic conversion is performance. Theoretical efficiency projections are in disagreement and operating data of good quality are not available. A dual approach to reducing collector work function and reducing arc drop are required (Appendix VI-B). How much collector work function can be reduced at the 900- to 950-K collector temperature is uncertain. The interaction between arc-drop reduction methods and collector work-function reduction techniques must be evaluated. Present system designs have reduced specific weights, so that some reduction in desired converter efficiency can be tolerated.

The current thermionic program is aimed at demonstration of converters by 1985. This would lead to flight systems in the early to mid 1990s.

3. Brayton Cycle. An inert-gas (helium-xenon) closed Brayton cycle power converter has been studied by NASA (Ref. 7) since the mid 1960. We used information mainly supplied by the AiResearch Company, a Division of Garrett Company, Phoenix, Arizona. The general conceptual design is patterned after work on the Brayton Isotope Power System (BIPS) conducted by AiResearch for DOE.

The principal components of a Brayton cycle system are a turbinecompressor-alternator rotating unit, high-temperature heat-source heat exchanger, low-temperature heat-sink heat exchanger, heat recuperator, ducting, controls, and gas system. The rotating unit consists of a singlestage radial turbine, single-stage radial compressor, and an alternator, all mounted on a single shaft. Foil-type gas bearings are used throughout, effectively eliminating all bearing wear. Alternator cooling is provided either by bypass of gas or a secondary organic or NaK coolant loop. The rotating unit is a very compact unit on which considerable development has been done. including over $30000 \mathrm{~h}$ of testing at NASA-Lewis.

$$
\text { a. Cycle Description. The Brayton cycle (see Appendix IV-C), }
$$
shown in Fig. 116, uses a non-condensing, inert gas as the working fluid. 
Output power is the power extracted as the compressed gas undergoes adiabatic expansion in the turbine at high temperature, minus the power required to recompress the gas adiabatically at low temperature. The working fluid, starting at the heat-source outlet, is expanded through the turbine and into the high-temperature pass of the recuperator where it is cooled by gas returning to the heat source. The working fluid is then further cooled in the heat-sink heat-exchanger. This is accomplished by exchange with a secondary fluid that goes through the radiator. (As an alternative, the working fluid could be cooled directly by flowing through the radiator.) At the low temperature in the cycle the working fluid is compressed, recovers heat in the low-temperature pass of the recuperator, and is reheated in the heat-source heat exchange to complete the cycle.

A mixture of helium and xenon is used as the working fluid. This gas is noncorrosive, and by changing the mixture the effective molecular weight can be varied from 4 to 131. As molecular weight is increased for a given power the turbo machinery and ducting can be made smaller. However, heat exchange is better at the lower molecular weight. Thus, an optimum to balance turbo-machinery and heat exchanger sizes is chosen. A mixture having a molecular weight of 40 is assumed to be near the optimum.
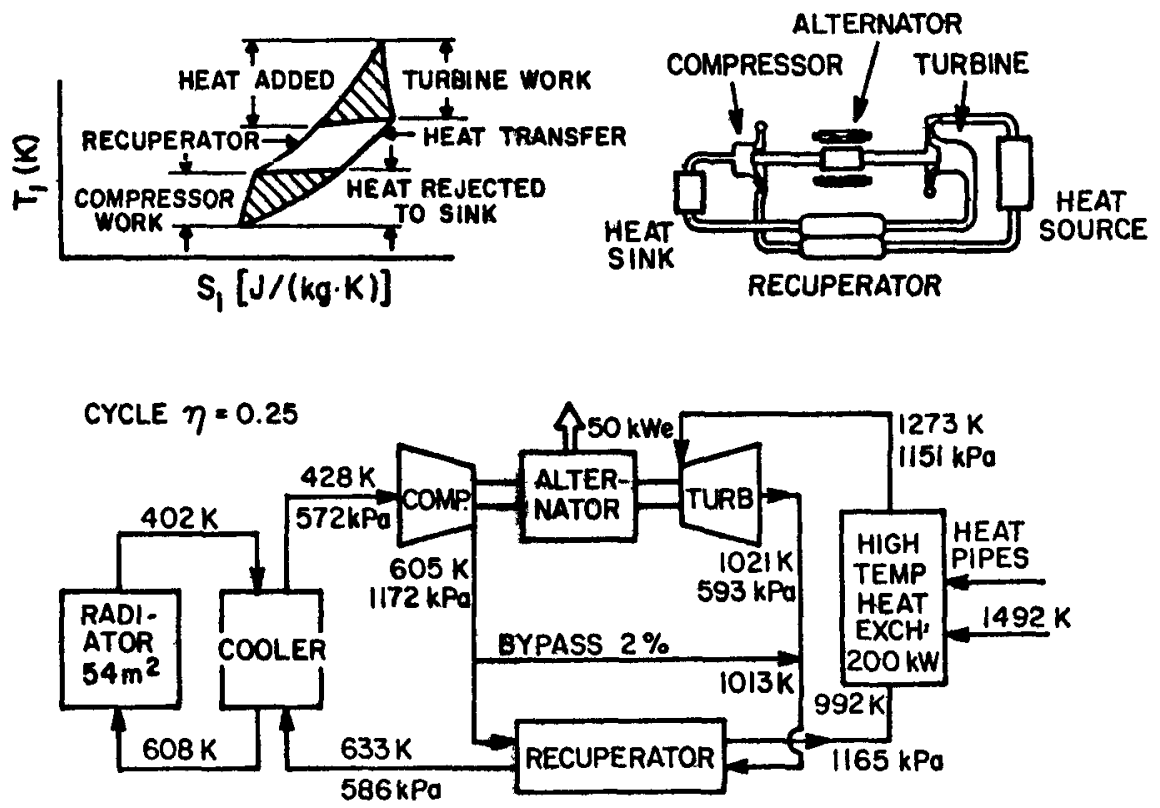

Fig. 116. Brayton cycle schematic. 
b. Design. A compact arrangement of the Brayton rotating unit and recuperator follows the design layouts developed for NASA by AiResearch in various Brayton cycle studies. The rotating unit with gas bearings is essentially free of wear. The exceptions are the pivot points of the tilting pad gas bearings. Testing has shown that this wear is small, predictable, and can be controlled for a 7-yr mission. Long-term creep of the turbine blades and other structural materials is also a problem that can be controlled by correct design. The control of creep sets the limit on design stress and temperature of components, particularly the turbine blades and inlet ducting. Materials that meet the operating temperatures assumed for this study are being developed.

The alternator requires cooling to $\sim 475 \mathrm{~K}$. This is assumed to be accomplished with a small secondary cooling loop. Bypass of some of the primary working fluid is also a possibility. The thermodynamic calculations were made assuming $2 \%$ bypass to compensate for the energy used in alternator cooling.

The recuperator is an extended-surface plate-type countercurrent-flow heat exchanger. An extremely large number of very small flow passages are used to develop a high heat exchange per unit mass. A small interpass leakage in the recuperator will reduce efficiency, but will not result in system failure, as would occur from a leak of the working fluid to space.

To provide the redundancy required for reliability, two completely independent Brayton systems are used. Each system is rated for full power. At the beginning of the mission, it is assumed that each unit operates at half power. As a first-order approximation, half power is produced if each unit runs at half of full pressure $(586 \mathrm{kPa})$ and at design temperature. In this case, each unit is running at design efficiency; the radiator is rejecting its normal heat at normal temperature and the reactor is operating at normal power and temperature. Minor deviations are noted in the heat exchanger because the heat transfer coefficient change is not quite linear with mass flow. Also, friction pressure losses in the system are reduced, leading to improvement in overall efficiency. These effects, however, are secondary and power is assumed proportional to pressure.

Should one of the Brayton systems fail the pressure in the second loop would be increased to compensate. 
c. Predicted Performance. The expected performance of a Brayton cycle as a function of turbine inlet temperature is shown in Fig. 117. At an inlet temperature of $1275 \mathrm{~K}$ the efficiency is predicted to be $25 \%$ with a compressor inlet temperature of $425 \mathrm{~K}$. These performance estimates use $85 \%$ turbine efficiency, $80 \%$ compressor efficiency, 0.95 heat recuperation, and a loop pressure drop of 0.05 of the turbine inlet pressure. For 1arge, welldeveloped machines, higher turbine and compressor efficiency may be achieved.

The effect of pressure drop in the system and recuperator effectiveness is shown in Figs. 118 and 119. It is shown that efficiency drops rapidly as pressure drop increases or as recuperator effectiveness is lowered.

d. Design Considerations. Brayton cycle units have been tested extensively by NASA and considerable experience has been gained from commercial units used in the aircraft industry. The technology is being extended in terms of operating temperatures, lifetimes, and the special environmental problems of space application.

Two Brayton cycle systems are used for redundancy. The rotating units and recuperators are totally independent, their designs are not influenced by this. Redundant Brayton systems have a significant impact on the designs for the heat-source heat exchanger, the radiator cooler (if used), the electric system, and the controls.

With a single heat-pipe cooled reactor, two independent heat-pipe to working-fluid heat exchangers are required, one for each 10op, with no possibility of a common mode failure. Failure of one heat exchanger must not increase the probability of failure of the second.

For the combination of heat-pipe reactor and Brayton cycle power converter, two types of heat exchangers are the most promising, the finned muff and the helical coil. Both types have good thermal and pressure drop characteristics, and moderate space requirements. They are fabricated of molybdenum for thermal expansion compatibility with the molybdenum heat pipes. They can be fabricated and leak-tested before brazing to the heat pipes. Figures 120 and 121 show these exchangers.

Table XXVII compares parameters of the muff and helix heat exchangers. The heat exchanger lengths and weights are for the heat exchange portion of a single Brayton circuit only (rather than the two 


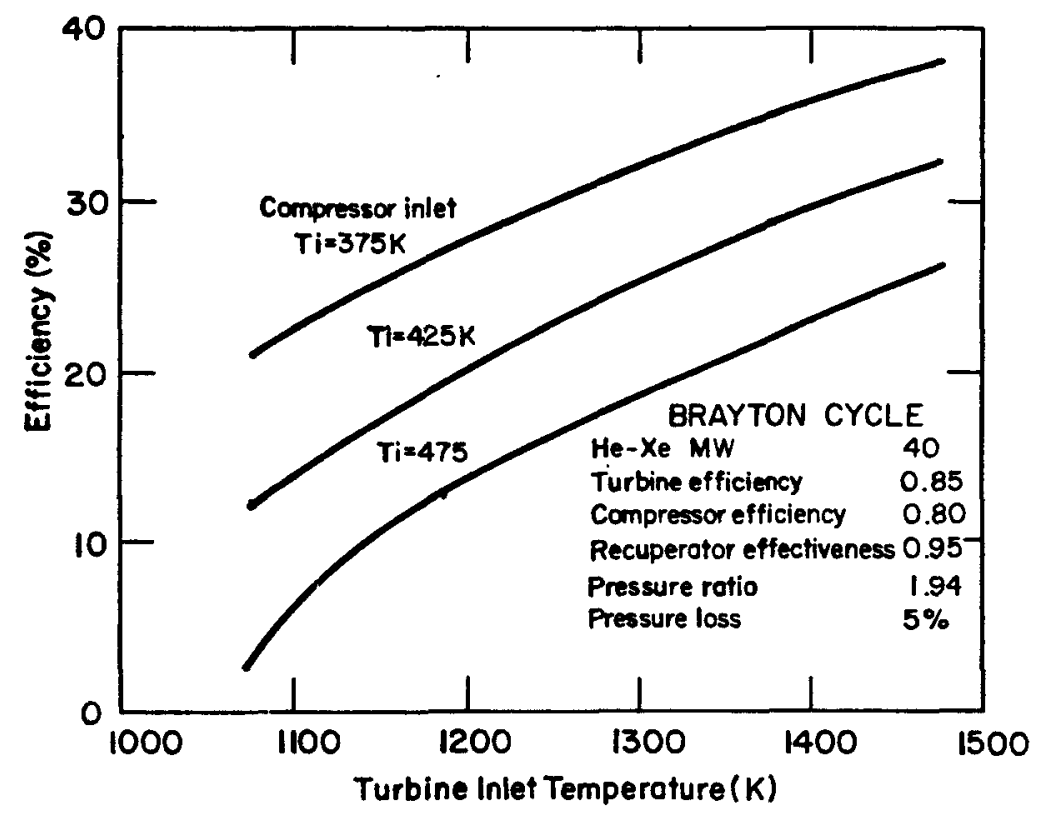

Fig. 117. Predicted Brayton cycle efficiency.

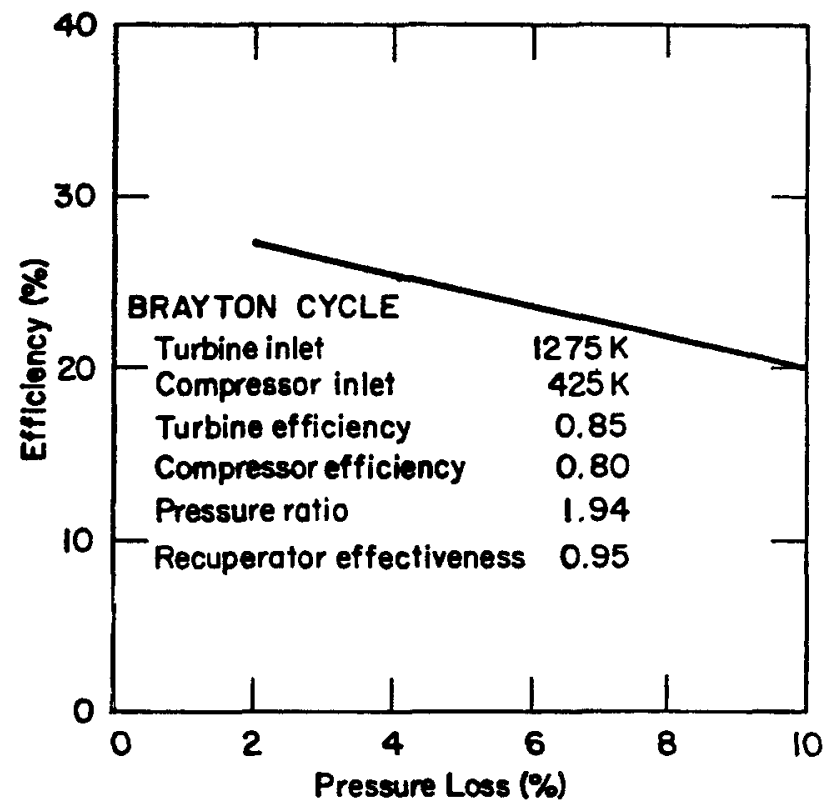

Fig. 118. Effect of loop flow pressure loss on Brayton cycle efficiency.

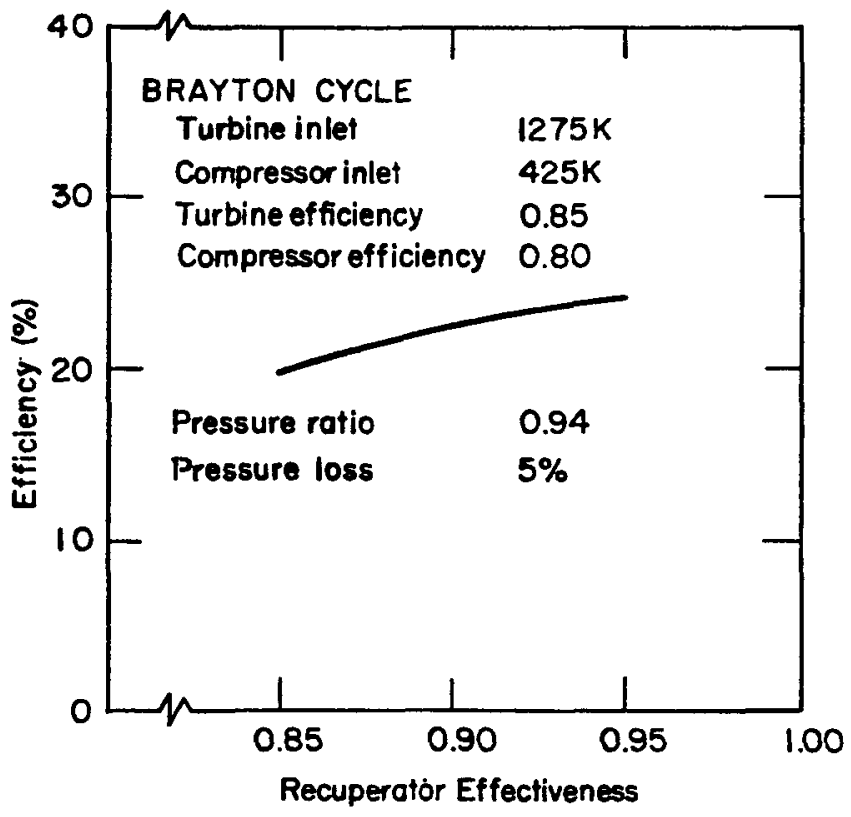

Fig. 119. Effect of recuperator effectiveness on Brayton cycle efficiency. 
actually planned) and do not include inlet and outlet pipes and plenums, or heat-pipe weights. The major difference is in the length of the heat exchanger, the helix being $40 \%$ longer than the muff.

A major design problem for the heat exchanger is ducting. Figure 122 shows a muff exchanger with inlet- and exit-pipe flow areas equal to the heat exchanger flow areas. The heat exchanger is dwarfed by the piping and ducts.

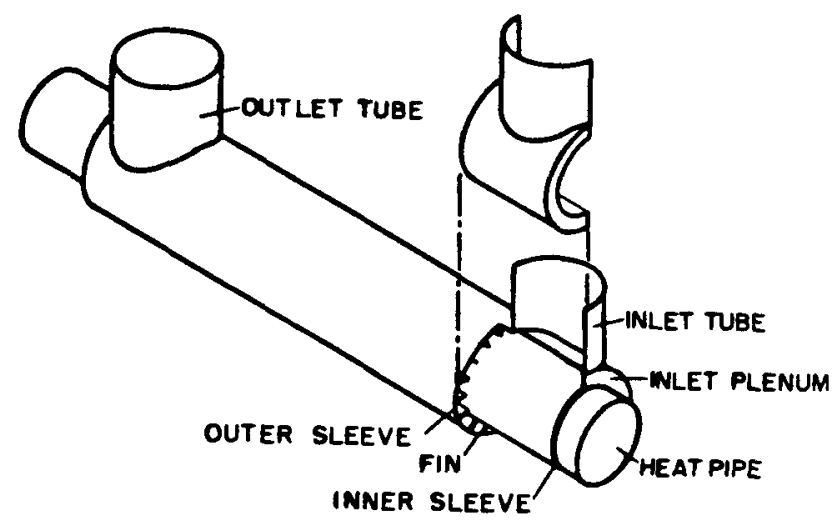

Fig. 120. Muff heat exchanger design.

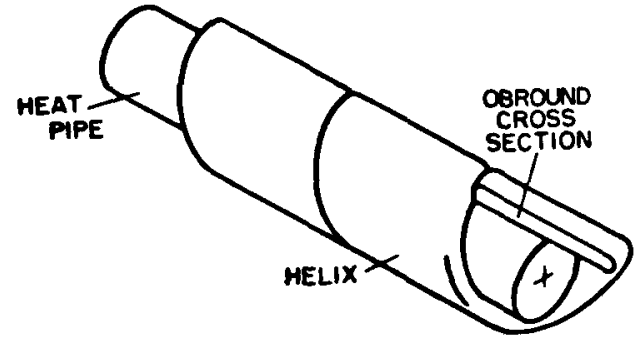

Fig. 121. Helix heat exchanger design.

TABLE XXVII

COMPARISON OF MUFF AND HELIX HEAT EXCHANGERS

\begin{tabular}{llll}
$200^{-k W_{t}}$ & Reactor & \multicolumn{1}{c}{$1000-k W_{t}$} & Reactor \\
Muff & Helix & Muff & Helix
\end{tabular}

Number of heat pipes

o.d. of heat pipe (mm)

Centerline spacing of heat pipes (mm)

Inlet pressure (MPa)

Heat-pipe temperature (K)

o.d. of exchanger $(\mathrm{mm})$

Length of exchanger ( $\mathrm{mm}$ )

Weight of one exchanger set $(\mathrm{kg})$
91

15.3

24.8

1.15

1375

$20.0 \quad 20.1$

$51 \quad 72$

3.13 .8
91

15.3

24.8

2.30

1375 

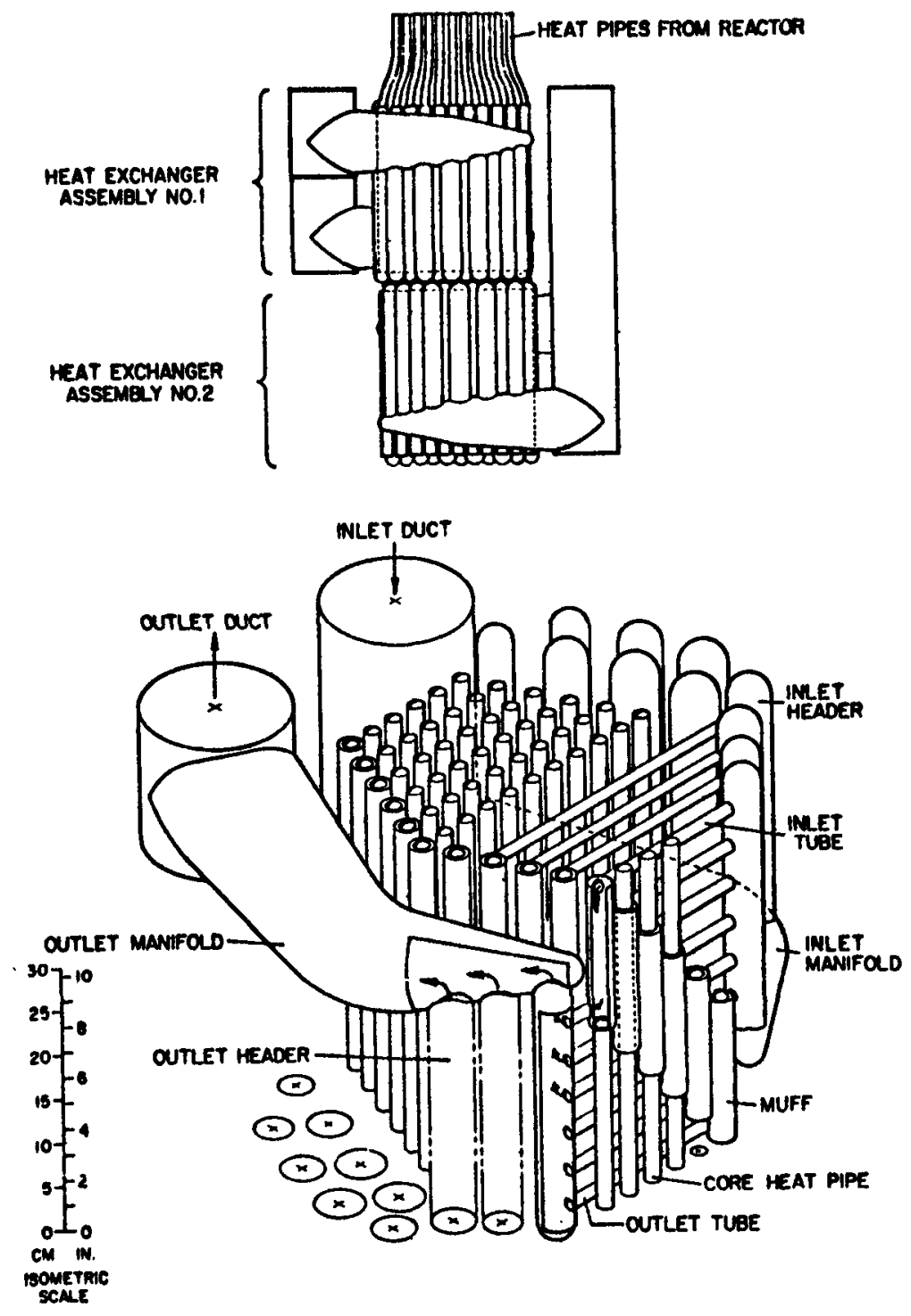

Fig. 122. Muff exchanger.

The two alternators run independently for power conversion, potentially delivering power at different frequency and voltage if the two loops are not running at identical rotating speed. The electric system should be designed to use either or both systems. Failure of one system should not lead to failure of the other.

e. Mass and Dimensions. The mass of a Brayton cycle converter has been extrapolated from preliminary estimates by the AiResearch Company. Detailed designs have not been made. The estimates are, therefore, made on 
the basis of experience with other systems and do not include unique features of our proposed SPAR system.

A system operating at $25 \%$ efficiency, 1275-K turbine inlet, and $425-\mathrm{K}$ compressor inlet is used as the reference case for mass estimates (see Fig. 123). Figure 124 shows the mass as a function of power and number of converters for these operating conditions. The mass includes the rotating units, high temperature heat exchangers, recuperators, and a compact duct system.

The 1275-K turbine inlet temperature corresponds to the use of columbium as the turbine inlet material. Higher turbine temperatures such as $1500 \mathrm{~K}$ could be achieved with molybdenum; this would lead to $\sim 40 \%$ saving in mass. If superalloys were used for turbine material, the turbine inlet temperature would be reduced to $1150 \mathrm{~K}$ and specific mass increased to $30 \%$. The higher turbine inlet temperature results in reduced radiator area. Raising the temperature from 1275 to $1500 \mathrm{~K}$ results in a $40 \%$ decrease in area.

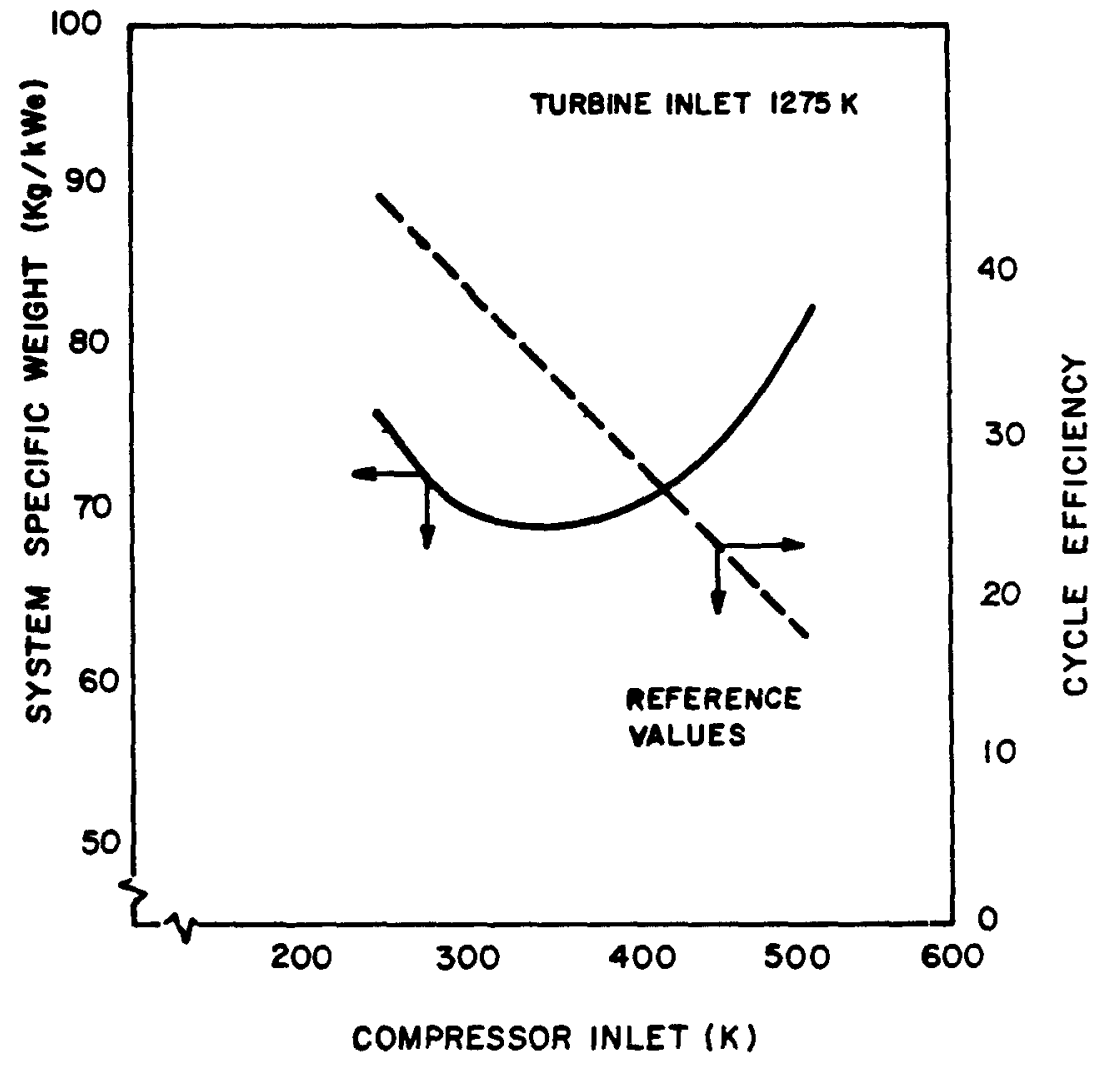

Fig. 123. Brayton cycle at $50 \mathrm{~kW}_{\mathrm{e}}$. 


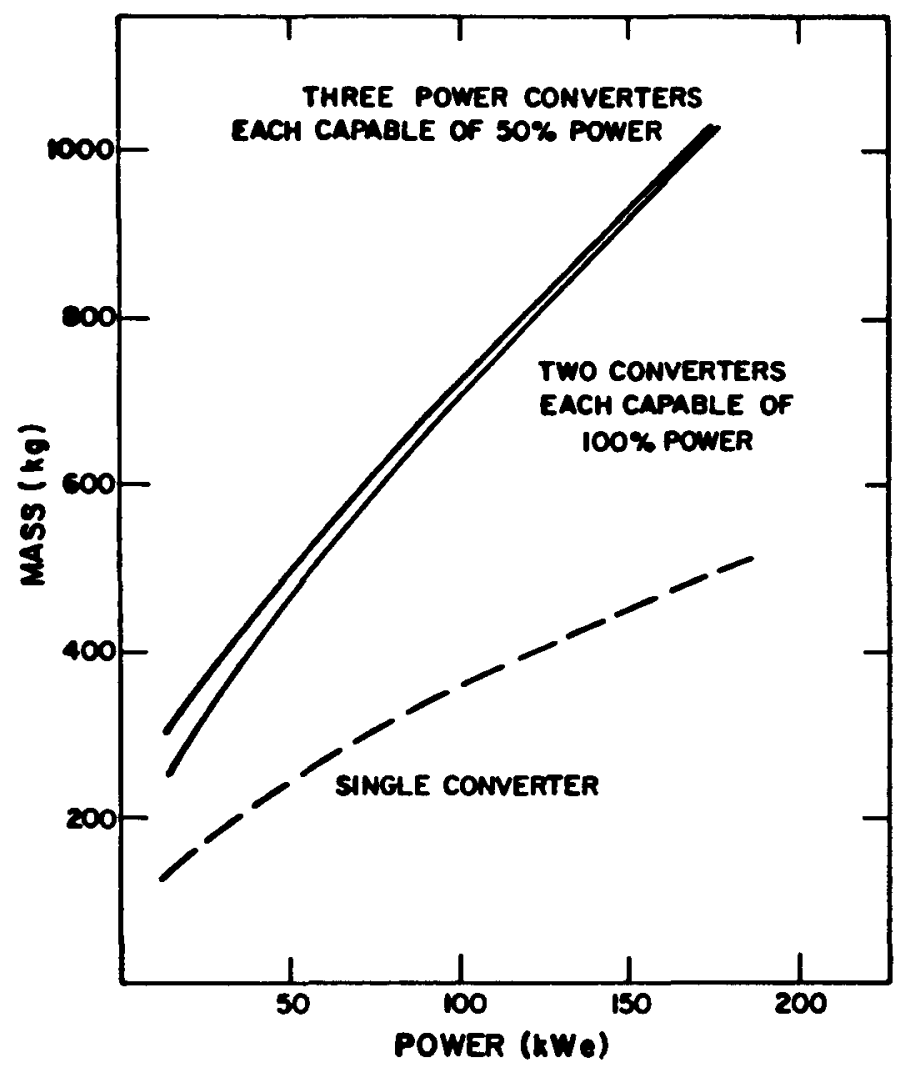

Fig. 124. Brayton converter mass vs power.

Table XXVIII provides typical dimensions for Brayton cycle components. f. Start up. Start up is accomplished by using the alternator as a motor to circulate the He-Xe working fluid. The reactor is slowly brought critical and then the temperature is raised to the point at which the sodium-filled heat pipes will function, $\sim 1000 \mathrm{~K}$. At this temperature the

TABLE XXVIII

DIMENSIONS OF BRAYTON CONVERTER COMPONENTS

Power

$12.5 \mathrm{~kW}_{\mathrm{e}}$

$25 \mathrm{~kW}_{\mathrm{e}}$

$37.5 \mathrm{~kW}_{\mathrm{e}}$

$50 \mathrm{~kW}_{\mathrm{e}}$

Rotating machinery (m) $0.3 \times 0.6$

$0.3 \times 0.7$

$0.3 \times 0.7$

$0.3 \times 0.7$

Recuperator ( $m$ )

$0.4 \times 0 \times 2 \times 0.5$

$0.5 \times 0.1 \times 0.5$

$0.6 \times 0.1 \times 0.5$

$0.7 \times 0.1 \times 0.5$

High-temperature heat exchanger

length (m)

$0.3-0.4$

$0.3-0.4$

$0.4-0.5$

$0.4-0.5$ 
alternator powers the rotating unit to about $50 \%$ of its normal operating speed. A battery-powered system is needed for this start up, which takes a few seconds. The Brayton unit is selfsustaining at this speed and temperature and will accelerate further under its own power.

Speed control is sustained by an auxiliary or parasitic load. Stable operation temperature throughout the loop will take up to an hour to read, during which time reactor power and temperature increases to the design points.

Starting is assumed to take place with the system in its operating orbit. Start up in the shuttle or on the launch pad for checkout would result in increased radiation background that may not be tolerated.

g. Control. The independent and controllable variables of the system are the reactor control drum positions, the electric load demand (impedance.), loop pressure, and possibly flow rates in the radiator cooling loops. It is not obvious that control of flow through the radiator is feasible or necessary. Start up and, if required, restart capabilities are special procedures that will need to be carefully evaluated.

The reactor control drums regulate reactivity and are essential for start up of the reactor. Start up and restart of the reactor requires a special strategy and instrumentation. During operation, however, a drum position can be regulated on the basis of either a temperature, a flux (nuclear power) level, or a load demand. Presumably, the system could operate at a controlled temperature, with power seeking an equilibrium depending on the vagaries of the radiator and rotating unit performance or controlled by load demand. Use of a parasitic electric load provides a simple control measure.

There is considerable merit, at least in concept, in establishing of a constant reactor temperature and, because the turbine inlet is closely coupled to the reactor temperature, the turbine inlet essentially would be constant during the mission. With a constant-temperature reactor there are at least two variables, the load impedance and loop pressure. To achieve a preselected temperature distribution, load or pressure must be controlled. If the load impedance is high (low power demand) at constant source temperature, the turbine will speed up until the internal resistances of flow friction, windage losses, turbine and compressor inefficiency, and aiternator internal losses increase to a balance point. We can slow the turbine down by demanding more 
power or by reducing loop pressure. If start up was at full loop pressure in both systems, the beginning of mission would be at double power which is undesirable.

Presumably, the starting procedure can be controlled to get a proper balance of pressure and load to meet design turbine speed. During the mission some loss of radiator effectiveness is expected. As the radiator degrades, the obvious consequence is an increase in compressor inlet temperature leading to lower efficiency. To hold load power, a pressure increase is needed that, in turn, will demand more reactor power. Alternately, demand load could be decreased. If a failure occurred during a mission, there could be a loss of working fluid or a failure in one of the Brayton systems. As pressure is lost, gas from storage can be added to hold steady-state conditions. If all the gas from one system is lost, the pressure in the other would be doubled, which would produce full pressure. Control of loop pressure requires sensors, controllers, gas storage, and valves. The beginning-of-life equilibrium condition has not been predicted in this study. Presumably, it would involve somewhat lower temperatures, lower turbine speed (alternator frequency), and lower efficiency than the design condition.

In summary, dual units may present some control problems, the nature and consequence of which are speculative until systems studies are performed.

h. High-Temperature Materials. A considerable reduction in system weight can be obtained for the Brayton conversion system if higher-temperature materials could be used. Higher radiator temperatures are desirable and, in order to increase the radiator temperature without loss of efficiency, it is necessary to increase the turbine inlet temperature. Using Brayton cycle efficiency curves, one estimates that to increase the radiator temperature $100 \mathrm{~K}$, it will be necessary to increase the turbine inlet temperature $\sim 300 \mathrm{~K}$.

Materials capable of operating in Brayton turbines and inlet ducts at 1500-K temperature and above have been investigated. ${ }^{8}$ The prime consideration in choosing a high-temperature turbine material is the creep-rupture to density ratio. The plot of this ratio vs temperature is shown in Fig. 125 for some of the candidate materials. The precipitation-strengthened molybdenum alloy Nb-TZM rates highest. The second most attractive alloy is the tantalum alloy, T-222. These materials require further development before being used in this application. 


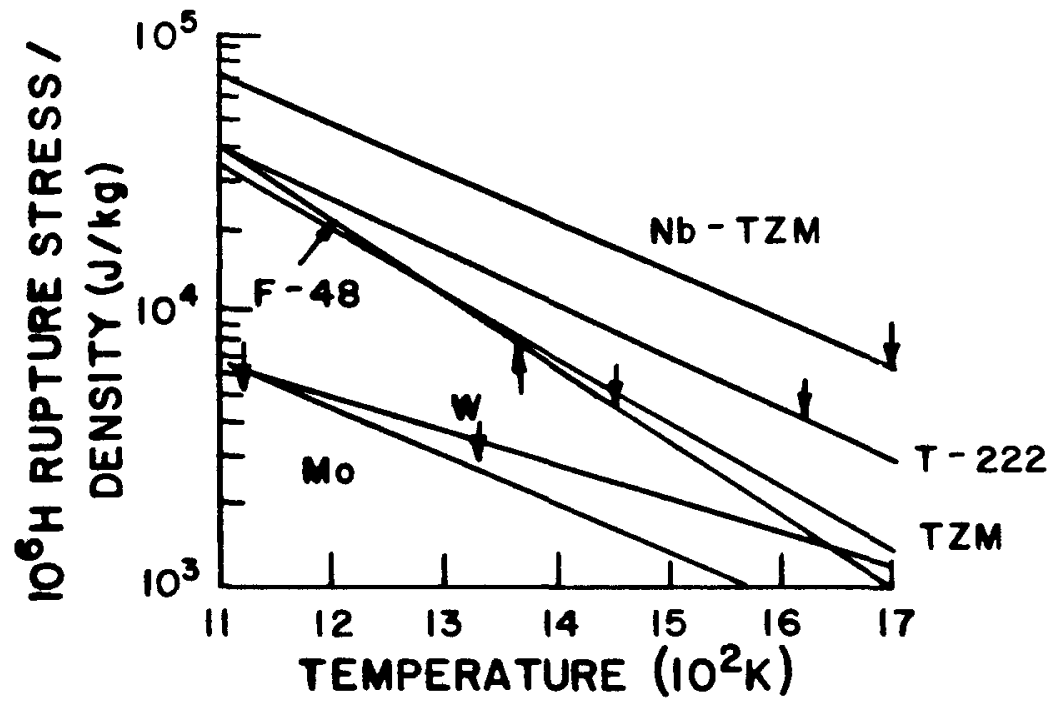

Fig. 125. High-temperature converter materials limited by rupture weight.

Niobium- and tantalum-base alloys in Brayton systems can be sources of oxygen contamination of the core heat pipes. This problem can be alleviated if the oxygen content of the alloy is kept below a few 10s per million. Contamination of these alloys from outside sources, such as insulation, must be kept to a minimum because they are known to be degraded by being exposed to small amounts of oxygen. ${ }^{8,9}$ Because ordinary TZM is degraded by Small amounts of oxygen at high temperatures, ${ }^{10}$ it is expected that Nb-TZM will be degraded also if the Brayton fluid becomes contaminated with oxygen.

i. Current Status. The rotating machinery of a Brayton unit with superalloy inlet scroll and turbines is essentially state-of-the art. However, an inlet temperature of $1275 \mathrm{~K}$ is pushing these materials beyond current capabilities. Therefore, development of materials is required to meet the predicted performance. There is considerable confidence that such materials advancement is practical and could be accomplished.

Advanced systems using refractory materials and/or ceramics have shown promise. This development is being pursued for aircraft and other applications. Such materials readily extend to space systems.

The engineering of foil-type gas bearings for the turbine, compressor, and alternator is well developed. A space version of the major components of the Brayton cycle including the rotating machinery has been run for over $30000 \mathrm{~h}$ by NASA-Lewis to demonstrate the life and long-term reliability of 
the converter (Ref. 11). Gas bearings have been developed that eliminate frictional surfaces from the rotating machinery. Test results provide a high level of confidence that the Brayton converter can meet space requirements. The heat exchanger equipment, and to some extent the recuperator, have not been designed or demonstrated. Significant problems probably will be met in fabrication of the heat exchangers. There are also uncertainties in the duct designs and required bellows joints. But, these seem to be solvable problems.

The control system tends to be complicated but appears feasible. Thorough systems studies would be required to evaluate off-normal operation and long-term degradation. There are a number of unresolved issues

- The reproducibility, reliability, and durability of the turboalternator bearings are questionable. Difficulties were experienced with the BIPS foil bearing. The tilting-pad bearing operated without difficulty in the NASA-Lewis Brayton program, but efficiency and specific power were reduced.

- Higher-temperature materials such as molybdenum or even ceramics lead to lower-weight systems, but will require extensive development. Superalloy components limited to a turbine inlet temperature of $1150 \mathrm{~K}$ are the only ones that can be considered demonstrated components.

- The Brayton system contains many unique components leading to a more costly development program than a passive converter that has fewer and simpler components duplicated many times.

4. Rankine Cycle. Rankine cycles using mercury, potassium, and organic working fluids have been studied for potential space power systems. The SNAP-8 mercury cycle was studied extensively by NASA for use with a NaK-cooled $\mathrm{U}-\mathrm{ZrH}$ reactor operating at $933 \mathrm{~K}$. The potassium cycle was studied for a nigh-temperature ( $1400 \mathrm{~K}$ turbine inlet) system that has a very small radiator. Component tests were conducted to demonstrate material compatibility and performance. Unfortunately, this work has been terminated, making the evaluation of a potassium cycle highly speculative.

An organic Rankine cycle is being developed for the Kilowatt Isotope Power System (KIPS) program by Sundstrand Corporation. We are following the development. The cycle is a low-temperature system that would not fully utilize the high-temperature capability of the heat-pipe reactor. The cycle peak temperature is limited to $600-650 \mathrm{~K}$ to prevent thermal decomposition of 
the organic working fluid. Consequently, low rejection temperatures and relatively low efficiency are characteristics of the this cycle.

The interface between an organic Rankine cycle and a heat-pipe-cooled reactor would be simple. The easy interface, possible high reliability, and minimal development problems expected might be used to advantage as a nearterm, low-power system. Further consideration of an organic Rankine system will be given only if the KIPS system shows promise and it is desired to upgrade the system to a higher power heat source. The low temperatures are basically incompatible, conceptually, with a high-temperature, highperformance, heat-pipe fast reactor.

The use of a Rankine cycle with potassium as the working fluid, however, is an interesting candidate for space electric power conversion. Potassium has the potential for high-temperature operation leading to small radiator size and, because of its excellent heat transfer characteristics, to smallheat exchanger sizes.

The potassium Rankine cycle was investigated by the NASA-Lewis Research Center as part of NASA's advanced space power technology research program during the 1960s. An experimental program was conducted on materials and components, and systems studies were made. A reference 300 - to $375-\mathrm{kW}_{\mathrm{e}}$ Rankine cycle power system, incorporating the results of the experimental test programs and studies, was prepared and presented by J. A. Heller et al., (Ref. 12).

a. Cycle Description. The basic Rankine cycle is shown schematically in Fig. 126. This system uses a heat-pipe reactor whereas the NASA system used a liquid-metal (lithium) reactor.

The major components of the conversion system are the heat-pipe to potassium boiler, multistage turbine with potassium reheat and condensate removal, alternator, potassium to liquid-metal ( $N a K$ ) condenser, NaK space radiator, and electromagnetic pumps (EMP) for liquid potassium and NaK circulation. Small secondary loops are proposed for cooling the potassium turbine bearing coolant, the potassium alternator bearing lubricant, and an organic coolant for electronics.

Potassium working fluid is vaporized and superheated in a heat-pipe heated boiler. The potassium vapor expands through the turbine, driving the alternator to produce both net electric power and current to drive the liquid-metal EMPs. At low pressure the potassium working fluid is condensed. 


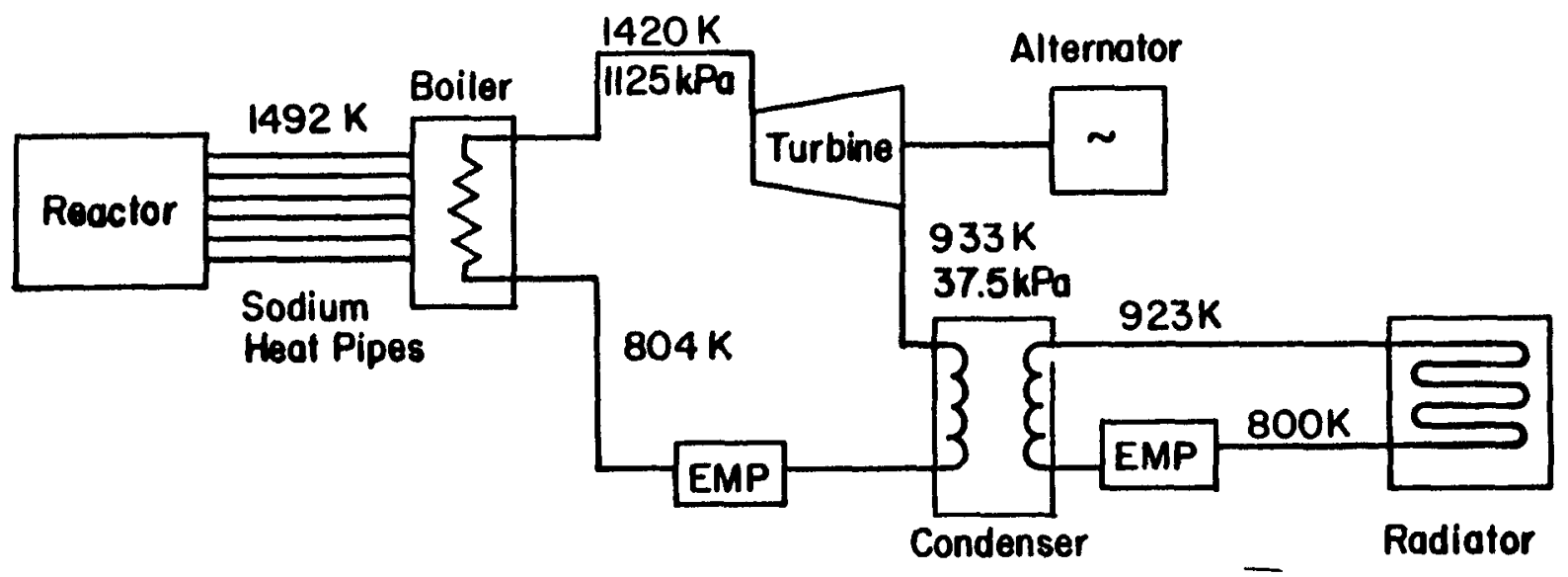

Fig. 126. Schematic of a potassium Rankine cycle.

Several condensers in parallel are proposed, each of which is cooled by an independent section of a liquid-metal ( $N a K$ ) cooled radiator. The proposed condensers are shell- and tube-type with the potassium condensing in the tubes. Design for zero gravity operation has not been developed. The addition of flow deflectors, such as spiral inserts, may be needed. The condensed potassium is pumped back to the boiler by an EMP.

b. Performance. At the proposed turbine inlet temperature of $1420 \mathrm{~K}$ and a condensing temperature of $933 \mathrm{~K}$ the overall efficiency is estimated to be 19 percent. The condensate pressure, turbine back pressure, at $933 \mathrm{~K}$ is $38 \mathrm{kPa}$ (5.44 psia). Turbine inlet pressure is $1125 \mathrm{kPa}$ (162 psia).

The radiator is assumed to be liquid-metal ( $\mathrm{NaK}$ ) cooled operating over the temperature range of $800-923 \mathrm{~K}$, as compared to the range of 428-633 $\mathrm{K}$ projected for the Brayton system.

The flow schematic, Fig. 126, is considerably simplified. It does not indicate interstage condensate removal, interstage reheat loops, auxiliary turbine alternator, or electronic cooling loops.

c. Mass. The estimated mass of the conversion system including the boiler, turbine-alternator, condensers, and pumps; but not including radiator, reactor, shielding, structure, and electronics is $1450 \mathrm{~kg}$. This weight was extracted from the data presented in the NASA report. With an estimated output power of $375 \mathrm{~kW}_{\mathrm{e}}$ (referred to as a nominal $300 \mathrm{~kW}$ system), the specific weight on the derated basis is $5 \mathrm{~kg} / \mathrm{kW}_{\mathrm{e}}$. This is for a single unit. d. Turbine Design Considerations. One problem with potassium as a Rankine cycle working fluid is that the turbine operates in the condensing 
region of the potassium phase diagram. Material temperature limits force the design into this region. Large enough superheat to avoid entry into the liquid part of the phase diagram during expansion is not practical. A reheat cycle helps, but does not completely prevent condensation. Both reheat and condensate removal are required.

For the conditions shown in the schematic, the exit quality of the turbine would be $80 \%$ if the design did not include condensate removal. This type of problem also occurs in steam turbines for central power station light-water cooled nuclear reactors. If condensation is permitted, it has been shown historically to result in turbine blade erosion and consequent shortening of life. The technology that has been developed for alleviating condensation in central power station turbines can also be applied to potassium turbines. Tests run by the General Electric Company (Ref. 13) have demonstrated that erosion will occur with potassium if condensate is not removed. Tests have also shown that rotor condensate removal and interstage removal devices are effective at protecting the turbine blading. In addition to condensate removal, reheat of the potassium vapor is proposed to reduce condensation and improve efficiency. The added complication is partially compensated by improved efficiency and reduced boiler size. ${ }^{14}$

The high-temperature materials that showed promise for potassium use were hot-worked TZM (Mo-0.6Ti-0.035C), Cb-1Zr, T-111 (Ta-8W-2Hf), and ASTAR 811C (Ref. 15). Corrosion and creep tests of 2 000-10 000 h were conducted on these materials. T-111 was recommended for the turbine disks and blading. $\mathrm{Cb}-1 \mathrm{Zr}$ was recommended for low-temperature turbine parts and stainless steel was to be used for the radiator tubing and condensers.

The potassium cycle is considered advanced technology because of the high temperature, material unknowns, and lack of demonstrated long-term turbine performance. The studies indicate considerable potential, especialiy for larger size systems where the small radiator size would be especially important and where the added turbine complication necessitated by the reheat cycles and condensate removal become relatively less significant. The work done by NASA is encouraging.

e. High-Temperature Materials. The same materials mentioned in Fig. 125 could be considered also for turbines and high-temperature piping in potassium Rankine systems. Ordinary TZM has been found to resist corrosion by $1370 \mathrm{~K}$ potassium vapor at an impingement velocity of $343 \mathrm{~m} / \mathrm{s}$ for up to $5000 \mathrm{~h}$ 
(Ref. 16), so that turbine corrosion at nigher temperatures does not appear to be a problem. It is expected that the higher-strength Nb-TZM is equally potassium-vapor corrosion resistant. It has also been found that $\mathrm{Nb}-\mathrm{IZr}$ has sufficient potassium corrosion resistance to be usable as piping material. ${ }^{15}$ It appears that with some additional development, the turbine inlet temperature of a nuclear-heated potassium Rankine power conversion system can be raised to at least $13 / 0 \mathrm{~K}$.

f. Current Status. A potassium Rankine system has potential advantage because it could operáte with a high heat rejection temperature. Active study of this system by NASA was terminated in the early 1970s. The research did not show any technological barriers, but it did show that the system is complex and would require sophisticated engineering.

Materials studies with TZM, Cb-12Zr, T111, and ASTAR $811 \mathrm{C}$ were encouraging. But, continued study that is costly and time consuming would be required. Turbine problems appear manageable, but complex and expensive. Turbine blade erosion will occur if design measures are not take to eliminate condensate. A combination of interstage reheat and condensate removal is required. Such systems were demonstrated. The general conclusion is that a potassium Rankine cycle would be practical only at high power where the added complexity of the turbine could be justified.

Because no systems demonstration loops have been or are being run on the potassium Rankine cycle, potential problem areas may not have been identified. Some problem areas in the design follow:

- Demonstration of the jet condenser in zero gravity cannot be performed in a ground demonstration test.

- Potential problems exist with the seals in the rotating unit.

- A high degree of uncertainty exists on development time and cost because of the lack of activity on the program.

5. Stirling Engine. The Stirling cycle engine has the potential for high conversion efficiency. It is expected that the Stirling engine will not drop off in efficiency as rapidly as the Brayton cycle as the heat-rejection temperature is increased.

The concept being evaluated for space power is based on the free-piston Stirling engine invented by William Beale. The output power of the engine is delivered directly to a linear alternator. The linear alternator induces an alternating voltage by the linear reciprocating motion of the "rotor" through 
the stator magnetic field, in contrast to the commonly used rotary motion. This design does not require any mechanical linkages, all bearings are hydrodynamic gas bearings with a single vessel enclosing the working fluid. Sliding piston seals are not required. Piston leakage of working fluid from one side of the piston to the other, although undesirable since it represents a loss in efficiency, is in no way harmful. The engine can be dynamically balanced with pairs of pistons acting directly opposed to each other.

a. Cycle Description. The Stirling cycle is thermodynamically characterized by a constant-volume heating resulting in compression of the working fluid, constant high-temperature (not adiabatic) expansion, constantvolume cooling expansion, and then constant low-temperature compression (see Fig. 127). The constant-volume heating uses the heat stored in a regenerator during the constant-volume cooling. The difference in work done during the high and constant-temperature expansion and low and constant-temperature compression is the net output of the cycle. It is all done with pistons.

The ideal cycle is approximated with two pistons, a displacer piston and a power piston. The constant-volume part of the cycle is approximated by a displacer piston moving gas from the hot end to cold end or from cold end to

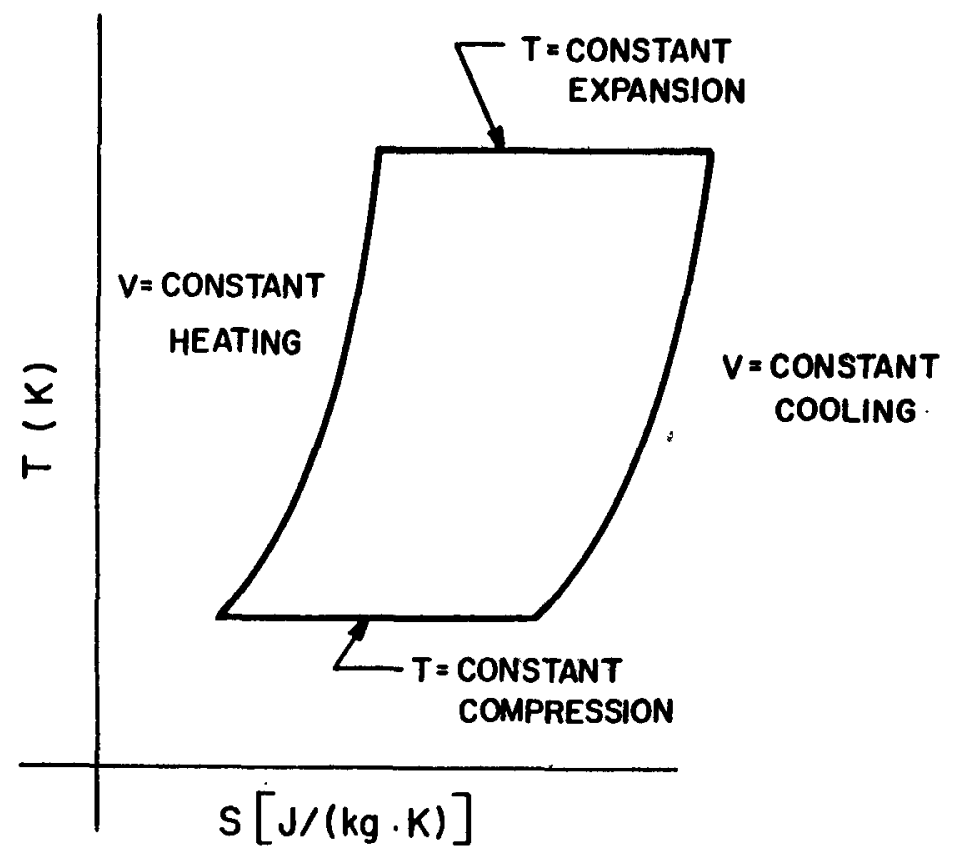

HEATER

REGENERATOR

COOLER

Fig. 127. Ideal Stirling cycle. 
hot end through the heat exchangers. This is done while the power piston is out of phase; i.e., in its top or bottom center. The power piston moves away from the displacer piston in the expansion or power mode and toward the displacer in the compression mode. The two pistons, in the same cylindrical space, are essentially 90 degrees out of phase.

The heat exchanger consists of a heater section, storage or regenerator section, and cooling section, all in series. The gas moves back and forth, heater to regenerator to cooler or vice versa, during each cycle. When the gas is expanded and hot the displacer forces the gas through the heater, where little heat transfer occurs because the gas is hot. The gas then goes through the regenerator, being cooled as it heats the regenerator, further cooled in the cooler, and into the cold volume. At this point, the displacer has occupied the hot space. The returning power piston compresses the gas and the displacer piston moves the gas, still cool, through the cooler, through the regenerator where it is heated by cooling the regenerator, and then through the heater.

The Phillips engines proposed for terrestrial application, such as for an automobile engine, use a double-crank system to synchronize the displacer and power pistons. The Beale free-piston engine does not have a crank to the displacer. It uses the dynamic "bounce" of the pistons on compressed gas. The spring-mass inertial dynamics control the operating frequency of the system and the piston phase relationships. A massive power piston coupled to a linear alternator works with a light displacer piston. This system works and has been found easy to start.

b. Performance. DOE is sponsoring a development effort of the Beale free-piston stirling engine at Mechanical Technology Incorporated (MTI), Latham, New York. WE are following the MTI development on the Stirling engine and currently basing the evaluation of the engine on data developed by MTI and on systems studies prepared by Mr. Goldwater of MTI (Ref. 16).

The reference point being used is a $50-\mathrm{kW}_{\mathrm{e}}$ system. The conversion system consists of a four-cylinder opposed configuration, four alternators, with a common bumper space between the opposed power pistons. The performance characteristics for the reference design are given in Table XXIX. A schematic of the Stirling system is shown in Fig. 128. 
TABLE XXIX

STIRLING CYCLE POWER-CONVERSION SYSTEM

$\begin{array}{lc}\text { System power (kWe) } & 50 \\ \text { Engine gross power (kWe) } & 58 \\ \text { Net electric power (kWe) } & 51 \\ \text { Working fluid } & \text { Hel ium } \\ \text { Heat source fluid } & \text { NaK } \\ \text { Temperature heater fluid (K) } & 1500 \\ \text { Coolant temperature (K) } & 700 \\ \text { Efficiency (net)(\%) } & 30 \\ \text { Weight (kg) } & \\ \text { Alternator } & 347 \\ \text { Pressure Vessel } & 39 \\ \text { Piston and Displacer } & 5 \\ \text { Heater } & 6 \\ \text { Cooler } & 3 \\ & 400 \\ \text { Size (m) Total } & \\ \text { Length } & 1.76 \\ \text { Width } & 0.55 \\ \text { Height } & 0.27 \\ \text { Materials } & \\ \text { All hot components } & \\ \text { Pressure enclosure } & 316 \text { ss } \\ \text { Piston } & \text { Titanium } \\ \text { Displacer } & \text { Aluminum } \\ \text { Titan } & \end{array}$

Configuration

Four cylinder opposed

Four alternators

Cooler - counterflow tube

Heater - tube bundle, parallel flow

Regenerator - spiral coil type

A Stirling engine combined with a high-temperature heat-pipe reactor provides the option of higher efficiency at higher heat rejection temperatures. The system efficiency is extrapolated from the MTI data on the simplistic assumption that the ratio of Stirling cycle efficiency to the theoretical maximum, the Carnot cycle efficiency, is a constant. This ratio is estimated to be 0.60 . At lower temperatures, ratios of 0.60 and higher have been demonstrated and, from thermodynamic considerations, there is no reason to expect that this high an efficiency cannot be achieved at high 


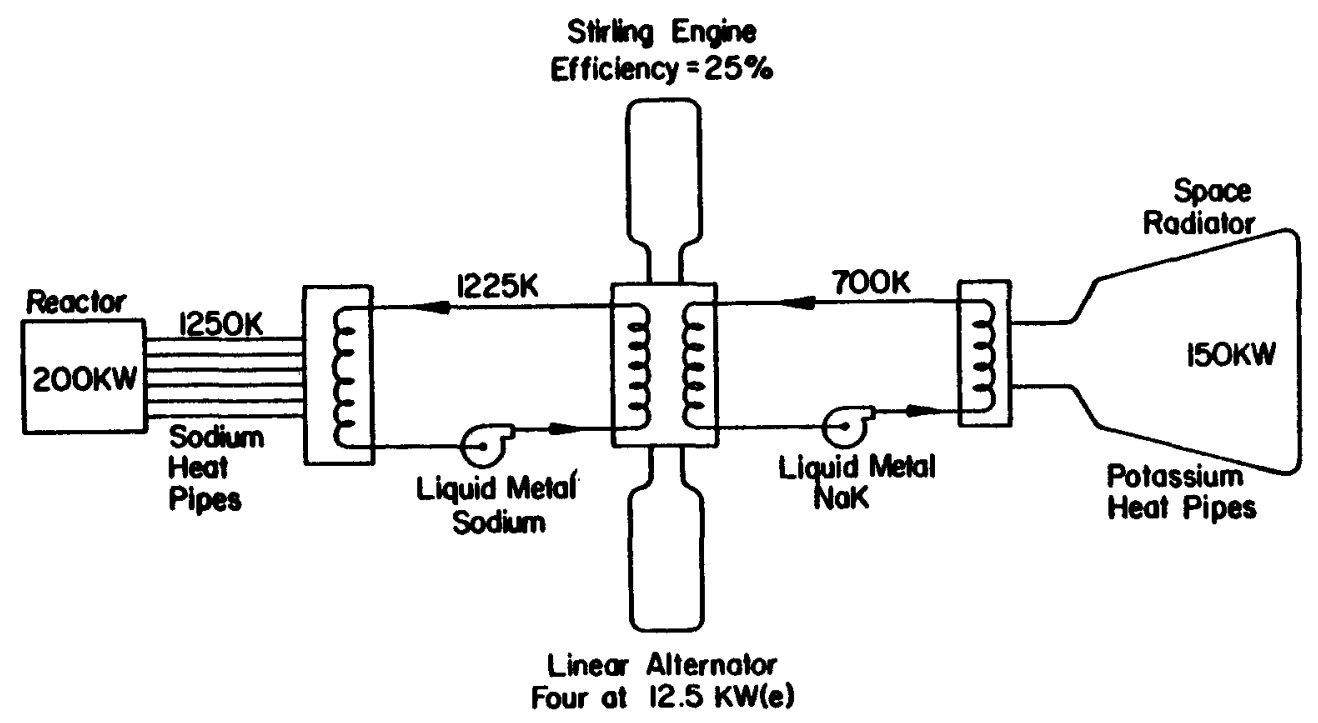

Fig. 128. Stirling cycle power-conversion free-piston linear alternator.

temperatures. It is assumed, of course, that the materials problems associated with a higher temperature can be solved. Estimated engine efficiency as a function of heater and cooler temperature is shown in Fig. 129.

It is desirable to heat the helium working fluid directly with the core heat pipes. However, since it is important to minimize the working fluid volume external to the swept volume of the piston and displacer, such an arrangement is not considered rikely. It is assumed that the heat source will be a liquid metal, such as sodium or Nak, depending on temperature. A liquid metal core heat-pipe heat exchanger and circulating pump will be required. Also, a coolant loop and coolant-to-radiator heat-pipe heat exchanger will be required. The fluid in the cooler depends on rejection temperature.

The question of redundancy has not been evaluated. The engines are modular and some types of failure would reduce total output proportional to the loss of a piston-alternator unit. Some excess capacity, proportional to the number of units is assumed. Redundancy in the liquid-metal core heat exchangers and cold-side radiator heat exchangers needs to be evaluated.

Most of the converter weight is concentrated in the alternator. Scaling of weight to powers other than $50 \mathrm{~kW}_{\mathrm{e}}$ is presumed to be linear with output. Converter weight is weakly dependent on efficiencies and can be assumed independent of efficiency as a first-order approximation. At higher power, more units would be used. 


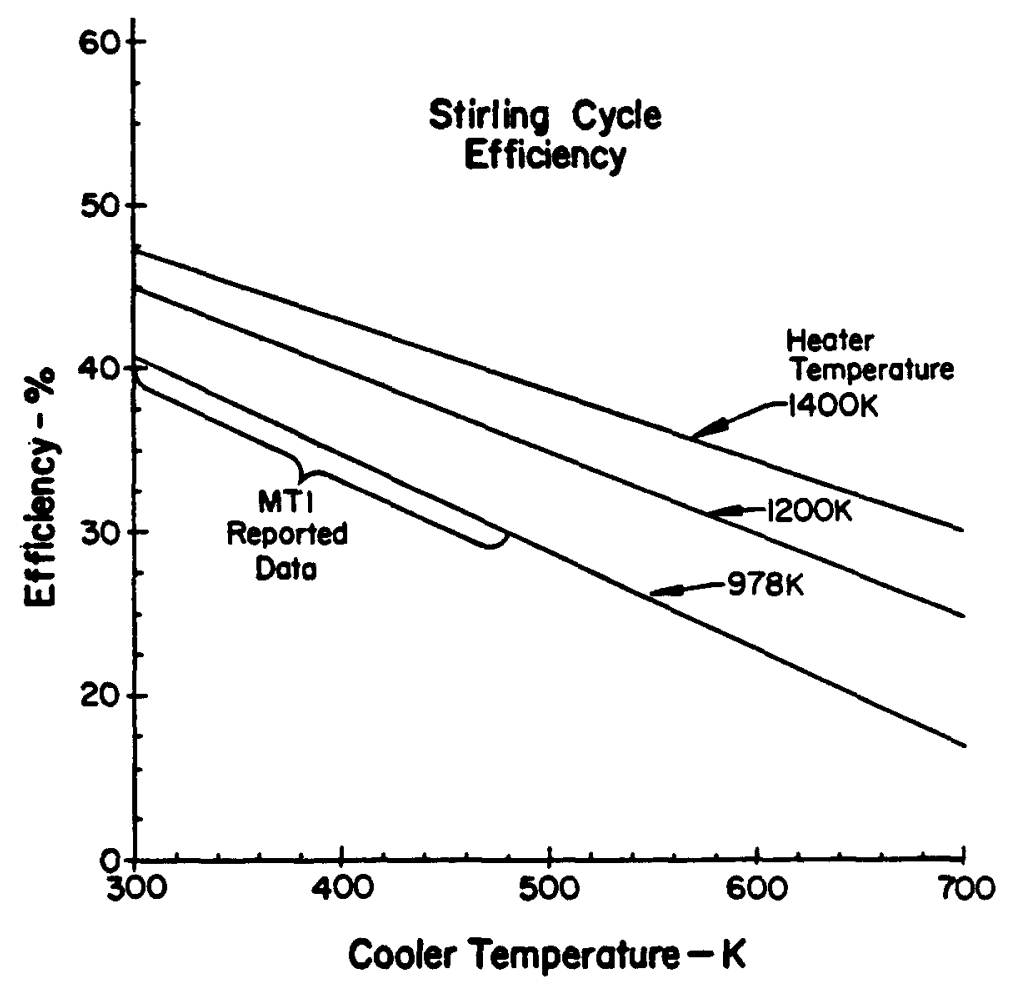

Fig. 129. Stirling cycle efficiency.

c. Current Status. The Stirling cycle is interesting because of its potential for high efficiency and for high heat rejection temperature. The development of space hardware is in the early stage. A Beale free-piston linear alternator converter is being tested by MTI.

The Stirling cycle engine is being developed for a number of terrestrial applications, including transportation. Phillips and the Ford Motor Company have a cooperative program for development of an automotive or truck engine. These systems show promise, but are not directly applicable to a space power system because the mechanical, lubricated crank mechanism to convert the piston motion to rotary motion is not believed to be sufficiently reliable for a long-term space mission.

MTI has a DOE-sponsored program to demonstrate a Stirling engine for space applications. The objective is to develop a $2-\mathrm{kW}_{e}$ free-piston Stirling-engine linear alternator powered by a radioisotopic heat source (Ref. 16). The free-piston linear engine alternator eliminates the need for crank mechanisms, simplifies sliding seal problems, and makes use of gas bearings to reduce wear and friction. Such a system may meet the life and reliability demands of a space system. 
The problems of scaling into to the range of $50-200 \mathrm{~kW}_{\mathrm{e}}$ have not been studied. Simple scaling of the MTI low-power demonstration leads to a machine of excessive mass. Consequently, the ultimate potential of the Stirling engine is speculative and can only be answered by further development efforts. In particular, the linear alternator is very heavy. Stirling engines must be considered advanced technology requiring extensive development before they are applicable to a high-power space electric power system. B. Relative Characteristics

1. Performance. Thermoelectric and thermionic converters are passive in nature; that is, there are no mechanical moving parts. Essentially, they are built up using multiples of small modules until the desired power output is achieved. Thus, scaling the power output between 10 and $100 \mathrm{~kW}$ is achieved in a straightforward manner. Dynamic systems, on the other hand, require new hardware for each power level even though the basic design is not changed. This can lead to additional fabrication difficulties and result in higher costs.

Thermoelectrics converters are low-efficiency systems (currently $6 \%$ with the potential for twice this in the next few years). Thermionic converters are expected to have system efficiency of $15-20 \%$, but not demonstrable until 1985. Dynamic converters are relatively high-efficiency devices: Brayton at 25\%, Rankine at 19\%, and Stirling at 30\%. A comparison of efficiencies as a function of heater and reject heat temperatures (Fig. 130) indicates that Brayton cycle efficiency decreases quickly as the reject heat temperature increases, whereas the Stirling cycle has relatively high reject heat temperatures for a given efficiency. The Rankine cycle is between the two. The Brayton cycle is the only dynamic converter that can be considered developed for early 1980's power plant design.

Reject heat radiator area requirements are a function of converter efficiency and more importantly, a function of reject heat temperature. Thermoelectric converters operate with a radiator temperature $\sim 775 \mathrm{~K}$, thermionics at $925 \mathrm{~K}$, Brayton cycle $\sim 475 \mathrm{~K}$, Rankine cycle $\sim 800 \mathrm{~K}$, and Stirling $700 \mathrm{~K}$. Radiator temperatures below $700 \mathrm{~K}$ tend to lead to bulky radiators that must be folded to fit into the Space Shuttle. This leads to definite design and shuttle storage complexities with the Brayton cycle.

Dynamic converters introduce vibration and torque modes into the spacecraft. These are absent from passive electric power conversion systems. 


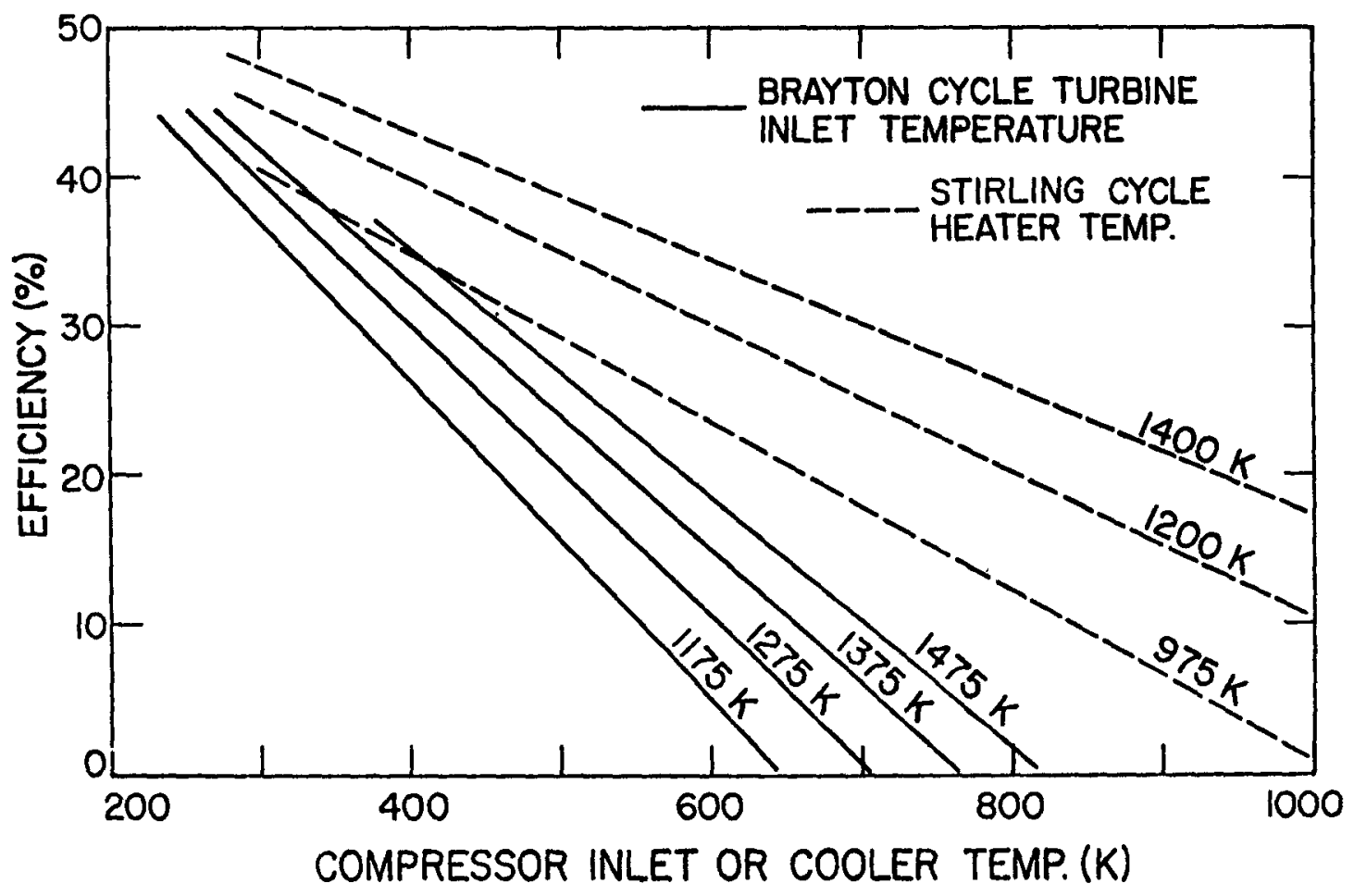

Fig. 130. Comparison of efficiencies as a function of heater and reject heat temperatures.

Table XXX provides a list of relative weights for the various converters. The thermionic is potentially the lowest weight converter and the Stirling is estimated as the highest weight (a significant amount of the Stirling mass is in the linear alternator).

Thermoelectric features include

- the best short-term candidate for up to $50 \mathrm{~kW}_{\mathrm{e}}$ with SiGe and to 100 $k W_{e}$ with SiGe-Gap,

- well developed and proven SiGe semiconductor material,

- proven conversion reliability,

- compression module with a high probability of success,

- efficiency of $6 \%$ almost guaranteed and high efficiency with advanced materials very probable,

- interface to heat-pipe reactor conceptually clean,

- built-in redundancy allows gradual degradation, and

- $\quad$ specific mass estimated at $5 . \mathrm{kg} / \mathrm{kW}$ with SiGe and less with improved materials. 
TABLE XXX

RELATIVE SPECIFIC WEIGHTS (100-kW $\mathrm{e}$ Base)

Specific Weight

Thermoe lectrics

$(\mathrm{kg} / \mathrm{kW})$

Thermi on ics

$5^{\mathrm{a}}$

Brayton cycle

Rankine cycle

Stirling cycle

\footnotetext{
${ }^{a}$ Assumes $6.4 \%$ efficiency plus cold junction converter ring.

${ }^{b}$ Assumes $15 \%$ efficiency.

C Two-unit Brayton for redundancy.

d Based on redundant potassium Rankine units.

e Based on three $50-\mathrm{kW}_{\mathrm{e}}$ Stirling engines.
}

Thermionic features include

- principles demonstrated with system demonstration planned by 1985 ,

- efficiency of 15-20\% projected,

- requires high reactor temperatures, like $1675 \mathrm{~K}$,

- specific mass estimated at $2 \mathrm{~kg} / \mathrm{kW}$

- interface with heat-pipe reactor conceptually clean, and

- built-in redundancy provides gradual degradation.

Brayton cycle features include:

- rotating machinery well developed and demonstrated,

- requires large radiator,

- efficiency of $25 \%$ at $1275-K$ turbine inlet, $425-K$ compressor inlet,

- two converter loops needed to el iminate single-failure points and for reliability,

- problems associated with bearings, heat exchanger design, and radiator design, and

- $\quad$ specific mass estimated at $10 \mathrm{~kg} / \mathrm{kW}_{\mathrm{e}}$ at $50 \mathrm{~kW}$ end $7 \mathrm{~kg} / \mathrm{kW}_{\mathrm{e}}$ at $100 \mathrm{~kW}$ levels in a dual-converter system configuration. 
Rankine cycle features include,

- potassium Rankine cycle has good thermodynamic characteristics

(organic Rankine temperature 1 imited; not a viable candidate);

- high heat rejection temperature;

- experience with potassium as a working fluid is good,

- turbine and cycle is complex,

- turbine, boiler, and condenser demonstrated as components, but considerable development remains, especially on system level,

- interesting only at high power where development and complexity is justified, and

- no current development programs.

Stirling cycle features include

- Beàle free-piston possibly meeting reliability and lifetime requirement (Phillips engine rejected on basis of mechanical requirement for lubrication and seals),

- MTI testing small engine,

- specific mass of $12 \mathrm{~kg} / \mathrm{kW}_{\mathrm{e}}$ with 3 half-power engines at $100 \mathrm{~kW}_{\mathrm{e}}$,

- mass dominated by alternator (low velocity), and

- efficiency of $30 \%$ at $1400 \mathrm{~K}$ heater, $700 \mathrm{~K}$ cooler.

2. Development. The most straightforward development activity would be for the thermoelectric converter with SiGe or SiGe-GaP. This is taken as a base for estimating the relative development effort required with each type of converter. Figure 131 shows the near-term candidates for an early 1980s ground demonstration power plant (GDS), while Fig. 132 indicates the candidates for a late 1980's GDS. The numbers in Figs. 131 and 132 indicate an estimate of the relative expense of developing various types of converters. Near-term candidates are mainly thermoelectric including SiGe, SiGe-GaP, and some advanced thermoelectric material and Brayton cycle with superalloy or refractory metals. These have all had sufficient work to generate a high degree of confidence in their availability. The longer term systems probably must consider thermionic conversion the leading candidate, both because there is an active development program and its potentially high performance. Another serious candidate is higher-temperature thermoelectric converters. 


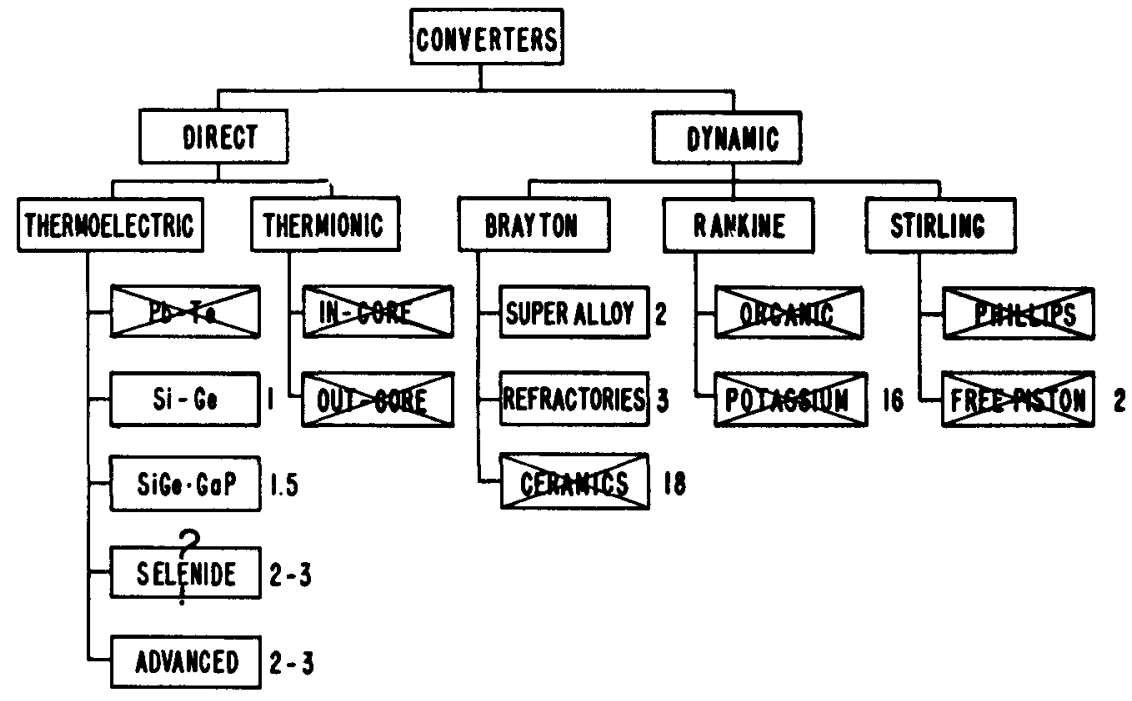

Fig. 131. Near-term potential conversion systems.

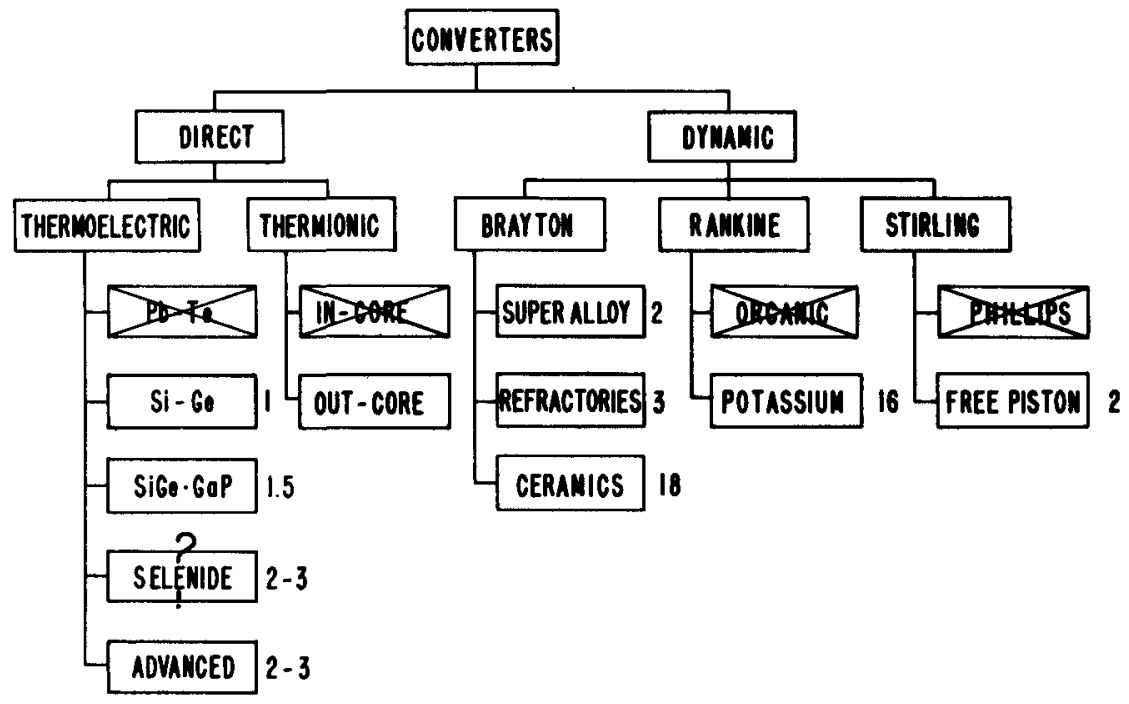

Fig. 132. Longer-term potential conversion systems. 


\section{APPENDIX VI-A}

\section{THERMOELECTRIC CONVERTER}

The idealized relationships describing the design characteristics of a thermoelectric power generation unit are summarized. (See Fig. A-1.) These equations are abstracted from the presentation by S. L. Soo, "Direct Energy Conversion." Consider a simple thermoelectric circuit consisting of a heat source, a heat sink, and two semiconductor legs, one $n$ - and one p-type, which are connected electrically in series with an external load. Nomenclature is given in Table A-l.

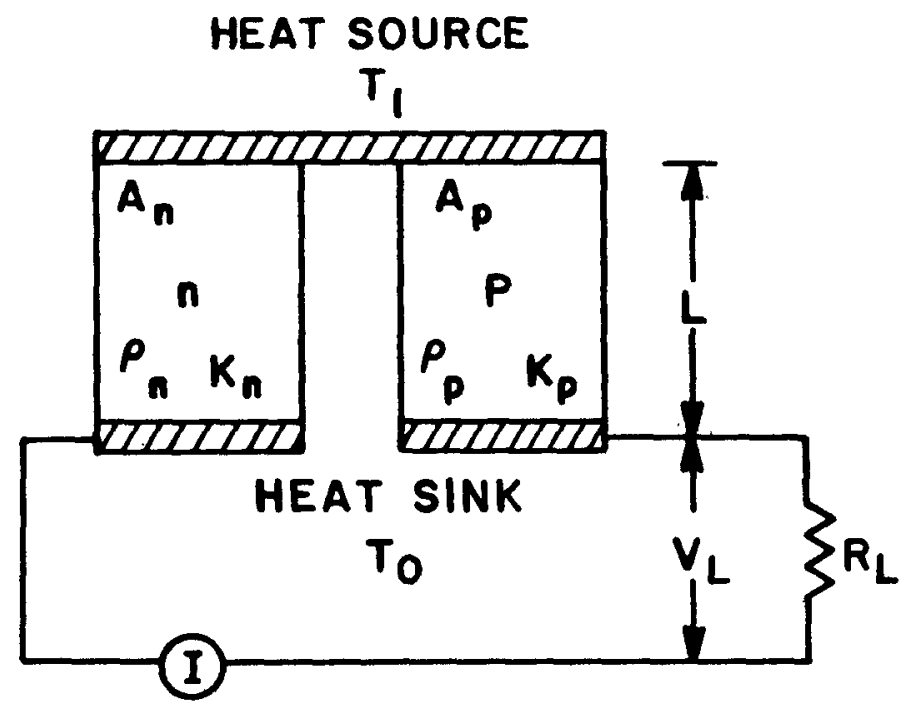

Fig. A-1. Thermoelectric, converter schematic.

TABLE A-1

\section{LIST AF VARIABLES FOR THERMOELECTRIC CONVERTER EQUATIONS}

$T_{i}$

n

p

$A_{n}, A_{p}$

$L_{n}, L_{p}$

$k_{n}, k_{p}$

$\rho_{n}, \rho_{p}$

$\alpha_{n}, \alpha_{p}$
$=$ moerature of heat source (K)

$=$ temperature of heat sink (K)

$=n$-type semiconductor

$=p$-type semiconductor

$=$ cross-section area of semiconductor $\left(\mathrm{cm}^{2}\right)$

$=$ length of semiconductor $(\mathrm{cm})$

$=$ thermal conductivity of semiconductor $(w / \mathrm{cm}-K)$

$=$ electrical resistivity of semiconductor $(-\mathrm{cm})$

= Seebeck coefficient (V/K) 
With the imposed temperature difference between the hot and cold junctions of the unit, $T_{1}-T_{0}$, the induced voltage is equal to the algebraic sum of the Seebeck coefficients multiplied by the temperature difference.

$V_{I=0}=\alpha_{n p}\left(T_{1}-T_{0}\right)$,

where

$$
\alpha_{n p}=\left|\alpha_{n}\right|+\left|\alpha_{p}\right|
$$

When the external load $R_{L}$ is connected into the circuit a current I will flow. The voltage across the load is equal to the induced voltage less the internal voltage losses.

$$
V_{L}=\alpha_{n p}\left(T_{1}-T_{0}\right)-\left(R_{n}+R_{p}\right) I
$$

where

$$
R_{n}=\frac{\rho_{n} L_{n}}{A_{n}}
$$

and

$$
R_{p}=\frac{\rho_{p} L_{p}}{A_{p}}
$$

$R_{n}$ and $R_{p}$ are the total electric resistances in the two semiconductor elements. It is assumed that contact resistances and other external resistances are zero.

The total work done is

$$
W_{L}=R_{L} I^{2}
$$

The current can be found by Kirchhoff's law as the total induced voltage divided by the sum of the resistances in the circuit 


$$
I=\frac{\alpha_{n p}\left(T_{1}-T_{0}\right)}{R_{L}+R_{p}+R_{n}}
$$

Thus, the power is found by substitution of Eq. (6) into Eq. (5), as:

$$
W_{L}=\left[\frac{R_{L}}{\left(R_{L}+R_{p}+R_{n}\right)^{2}}\right]\left[\begin{array}{cc}
\alpha_{n p}^{2} & \left(T_{1}-T_{0}\right)^{2}
\end{array}\right]
$$

The efficiency of the unit is defined as the electric output of the unit $W_{L}$ divided by the thermal energy input $Q$. The thermal energy input is made up of three components, the direct conduction heat transferred across the elements, plus the heat required to compensate for Peltier cooling at the hot junction, less the contribution of the Joule, $I^{2} R$, internal heating to the hotjunction temperature.

Assuming half of the Joule heat appears at each junction, the heat input is

$$
\begin{aligned}
Q & =\left(\frac{k_{p} A_{p}}{L_{p}}+\frac{k_{n} A_{n}}{L_{n}}\right)\left(T_{1}-T_{0}\right)+\alpha_{n p} I T_{1} \\
& -\frac{1}{2}\left(\frac{\rho_{p} L_{p}}{A_{p}}+\frac{\rho_{n} L_{n}}{A_{n}}\right) I^{2} \\
& =\left(K_{p}+K_{n}\right)\left(T_{1}-T_{0}\right)+\alpha_{n p} I_{1}-\frac{1}{2}\left(R_{p}+R_{n}\right) I^{2} .
\end{aligned}
$$

We define the ratio of load resistance to internal resistance

$$
m=\frac{R_{L}}{R_{p}+R_{n}}
$$

Using this and

$$
\eta=\frac{W_{L}}{Q} \text {, }
$$


by substitution and algebraic manipulation, the efficiency is found to be $n=\left(\frac{T_{1}-T_{0}}{T_{1}}\right) m\left[(m+1)-\frac{1}{2} \frac{\left(T_{1}-T_{0}\right)}{T_{1}}+\frac{(m+1)^{2}\left(K_{p}+K_{n}\right)\left(R_{p}+R_{n}\right)}{\alpha_{n p}^{2} T_{1}}\right]^{-1} \cdot(A-12)$

The first term of Eq. $(A-12)$ is the Carnot efficiency $n_{c}$. The second term may be considered a material efficiency $n_{m}$, which is a function of materials properties, geometry, ratios of resistances, and the operating temperatures. The material efficiency can be optimized with regard to geometry and load resistance in terms of a material figure-of-merit $z$. For the optimized geometry and load, the efficiency can be calculated in terms of the figure-of-merit and temperature.

The figure-of-merit $Z$ is defined as

$$
Z=\left[\frac{\alpha_{p}-\alpha_{n}}{\sqrt{\rho_{p} k_{p}}+\sqrt{\rho_{n} k_{m}}}\right]^{2}
$$

The geometric restraint to maximize $m$ is

$$
\frac{A_{n} L_{p}}{A_{p} L_{n}}=\sqrt{\frac{\rho_{n} k_{p}}{\rho_{p} k_{p}}}
$$

The corresponding optimum load resistance ratio is,

$$
m_{c}=\frac{R_{L}}{R_{n}+R_{p}}=\sqrt{1+\frac{Z}{2}\left(T_{1}+T_{0}\right)} \text {. }
$$

The figure-of-merit, at optimum, is shown by substitution of Eq. (A-14) into $\mathrm{Eq} .(\mathrm{A}-13)$ to be

$$
z^{*}=\frac{\alpha_{n p}^{2}}{\left(K_{n}+K_{p}\right)\left(R_{n}+R_{p}\right)}
$$


By substitution of $m_{0}$ for $m$, and using $E q \cdot(A-16)$, Eq. (A-12) may be reduced to

$$
\eta_{\text {opt }}=\left(\frac{T_{1}-T_{0}}{T_{1}}\right)\left(\frac{m_{0}-1}{m_{0}+\frac{T_{0}}{T_{1}}}\right)=n_{c} \cdot \eta_{m} \text {. }
$$

The requirements for high efficiency according to the above relations are

- high Carnot efficiency, $1-T_{0} / T_{1}$,

- large figure-of-merit, $Z$ *,

- area ratio optimized,

$$
\frac{A_{n}}{A_{p}}=\frac{L_{n}}{L_{p}} \sqrt{\frac{\rho_{n} k_{p}}{\rho_{p} k_{p}}},
$$

- load resistance optimized by equation (A-15),

- no heat losses or extraneous heat conduction from source-to-sink, and - no contact resistances. 


\section{APPENDIX VI-B \\ THERMIONIC ENERGY CONVERSION PROCESS}

A simple analytical mode $1^{6}$ of thermionic converter performance uses the ideal thermionic diode as its basis. Motive diagrams and converter current voltage characteristics for an ideal diode are shown in Fig. B-l. In the motive diagram $\phi_{E}$ and $\phi_{C}$, are the emitter and collector work functions respectively. They represent the potential barrier which must be overcome by electrons leaving either electrode. The output voltage of the converter is the difference between the emitter and collector Fermi levels, $V$.

Assuming no space charge or other such phenomena between the electrodes, the current flow from the emitter to the collector, J, will be determined by the emitter temperature $T_{E}$, the potential barrier the electrons must overcome $\phi$, and the Richardson-Dushman equation

$$
J\left(A / \mathrm{cm}^{2}\right)=A T_{E}^{2} e^{-\phi / k T_{E}}
$$

Clearly there are two distinct regions of operation. As long as the sum of the collector work function $\phi_{C}$ and the output voltage $V$ is less than the emitter work function $\phi_{E}$ the barrier to electron flow is $\phi=\phi_{E}$ J is independent of output voltage. This is the "saturation region" of the IV curve and the current density is

$$
J_{S}=A T_{E}^{2} e^{-\phi} \phi_{E} / k T_{E}
$$

As soon as the output voltage is increased to the point where $\phi_{C}+V$ $=\phi_{E}$, the barrier becomes $\phi_{C}+V$, and the converter current falls exponentially with further increases in output voltage, according to

$$
J=A T^{2} e^{-\left(\phi_{C}+V\right) / k T_{E}} .
$$

Two problems with this simple picture appear. First, typical refractory metals have work functions exceeding $4 \mathrm{ev}$. Polycrystalline tungsten, for example, has a work function of $\sim 4.6 \mathrm{ev}$. To obtain a current density of $1 \mathrm{~A} / \mathrm{cm}^{2}$ with this material would require an operating temperature of $2600 \mathrm{~K}$. 

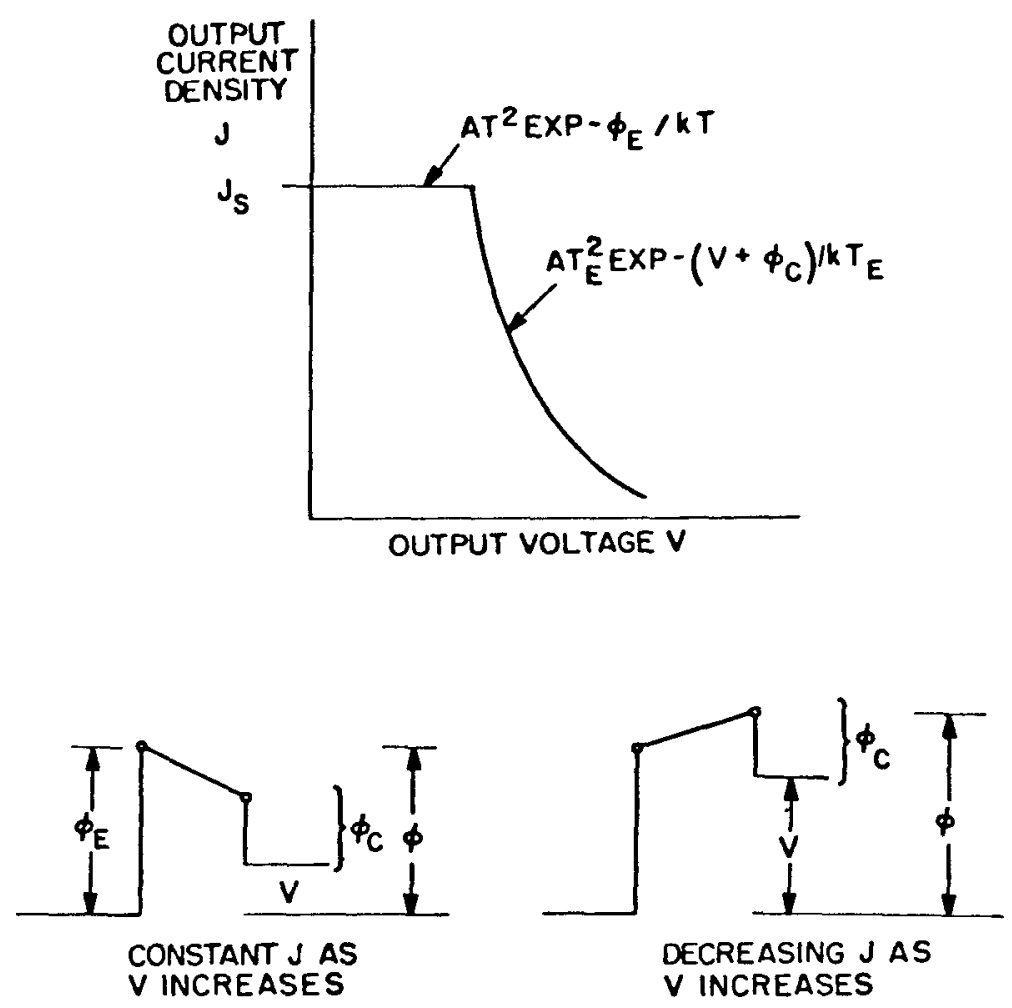

Fig. B-1. Ideal thermionic diode characteristics.

Even tungsten has a significant evaporation rate at such temperatures. Second, electron space charge effects would limit current flow in a vacuum diode to less than $1 \mathrm{~mA}$ with an interelectrode gap of $10 \mathrm{mils}$.

Both of these problems are solved by adding a low pressure of cesium vapor (0.1-10 torr) in the interelectrode space. Such a pressure can be established by connecting the device to a reservoir of liquid cesium at a suitable temperature $T_{R}$, which is typically between 500 and $600 \mathrm{~K}$. In the presence of the cesium vapor a partial monolayer of cesium will form on both the emitter and collector. The work functions of both electrodes will fall in the manner shown in Fig. B-2. By varying the cesium temperature (pressure) a range of work functions may be obtained at given emitter temperatures. The collector is operated at a low work function in order to obtain maximum output voltage, and its work function is thus insensitive to cesium pressure changes. In this way any desired $\mathrm{J}_{S}$, shown in Fig. B-I, can be obtained.

The electron space charge barrier to current flow can be neutralized by providing heavy cesium ions. Cesium is a particularly good choice because it 
has the lowest ionization potential of any element. In the converter the ions are generated in two ways. At high emitter temperatures sufficient ions are generated thermally simply by contact ionization with the emitter surface. At low temperatures the ions are produced electrically in a low-voltage arc between the electrodes. In this case the power to produce the ions is reflected in a voltage drop between the emitter and collector which is called the arc drop. It typically is $\sim 0.5 \mathrm{~V}$.

Since losses such as the arc drop and electron scattering are incurred when cesium is added to the converter, its performance is no longer accurately represented by the ideal diode. It has been found, however, that a converter can be well characterized simply by adding another voltage loss term in the ideal diode equation. As shown in Fig. B-3 the sum of these losses, including the collector work function, is called the Barrier Index, $V_{B}$. Actual converter performance is then represented by the equation:

$$
J=A T_{E}^{2} e^{-\left(V+V_{B}\right) / k T_{E}}
$$

An effort to reduce the barrier index $V_{B}$ with consequent improvements in converter performance, is one of the primary goals of the current NASA, DOE, and National Science Foundation thermionic program. Converters built in the past have had $V_{B} \sim 2.1 \mathrm{ev}$. Currently laboratory converters can be built with $V_{B} \sim 1.9 \mathrm{ev}$. Our goal is to achieve $\sim 1.5$ ev by 1982 and $\sim 1.0$ ev by 1987 .

While the actual output power of the converter is the product of current and voltage, as defined by Eq. (B-4), only about $90 \%$ of this power is available at the load due to voltage drops in the converter,s electrical leads. Consequently, the useful output power density of a practical converter is

$$
P_{L}\left(w / \mathrm{cm}^{2}\right)=0.9 \mathrm{~J}\left[k T_{E} \ln \left(A T_{E}^{2} / J\right)-V_{B}\right]
$$

\section{COLLECTOR TEMPERATURE}

The collector temperature, or heat rejection temperature $T_{C}$ of the thermionic converter is of crucial importance to the performance of the system. The highest possible heat rejection temperature is desired in space, since all waste heat must be radiated and the size of the radiator is inversely proportional to $T_{C}^{4}$. 


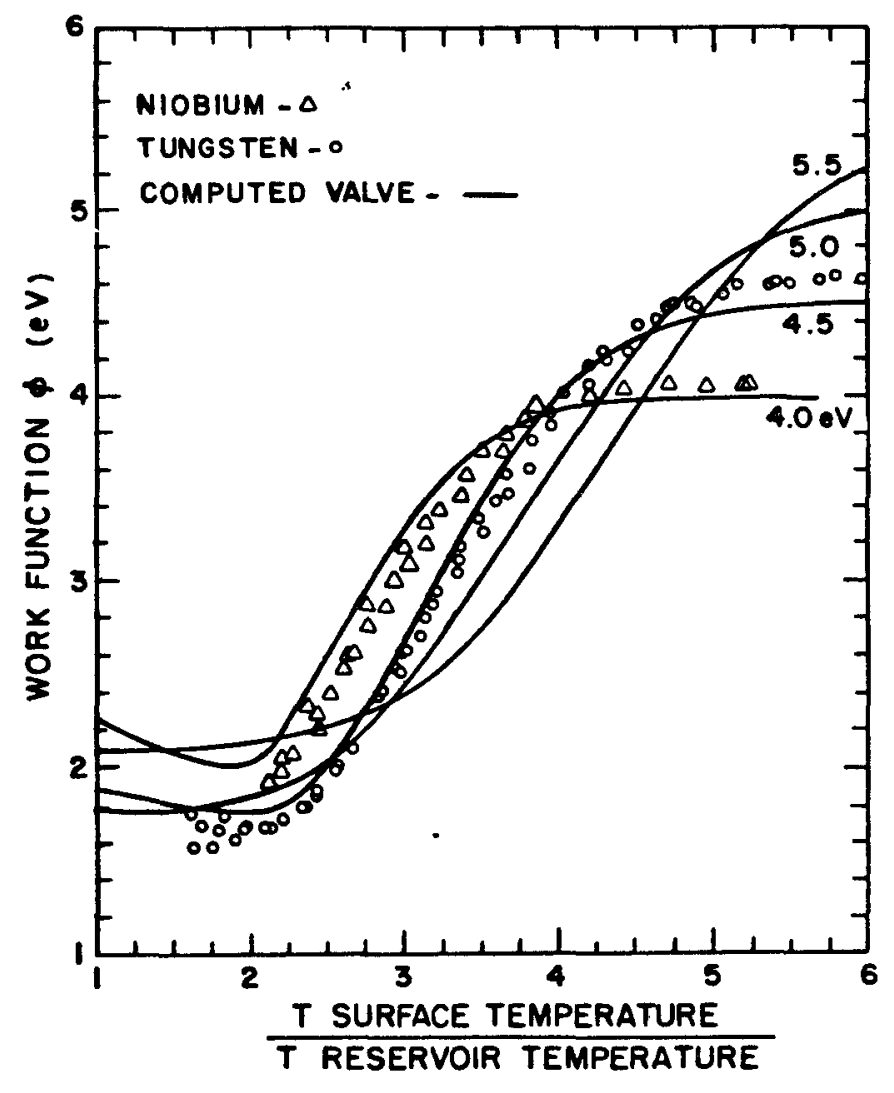

Fig. B-2. The work function characteristics of tungsten and niobium cesium vapor.

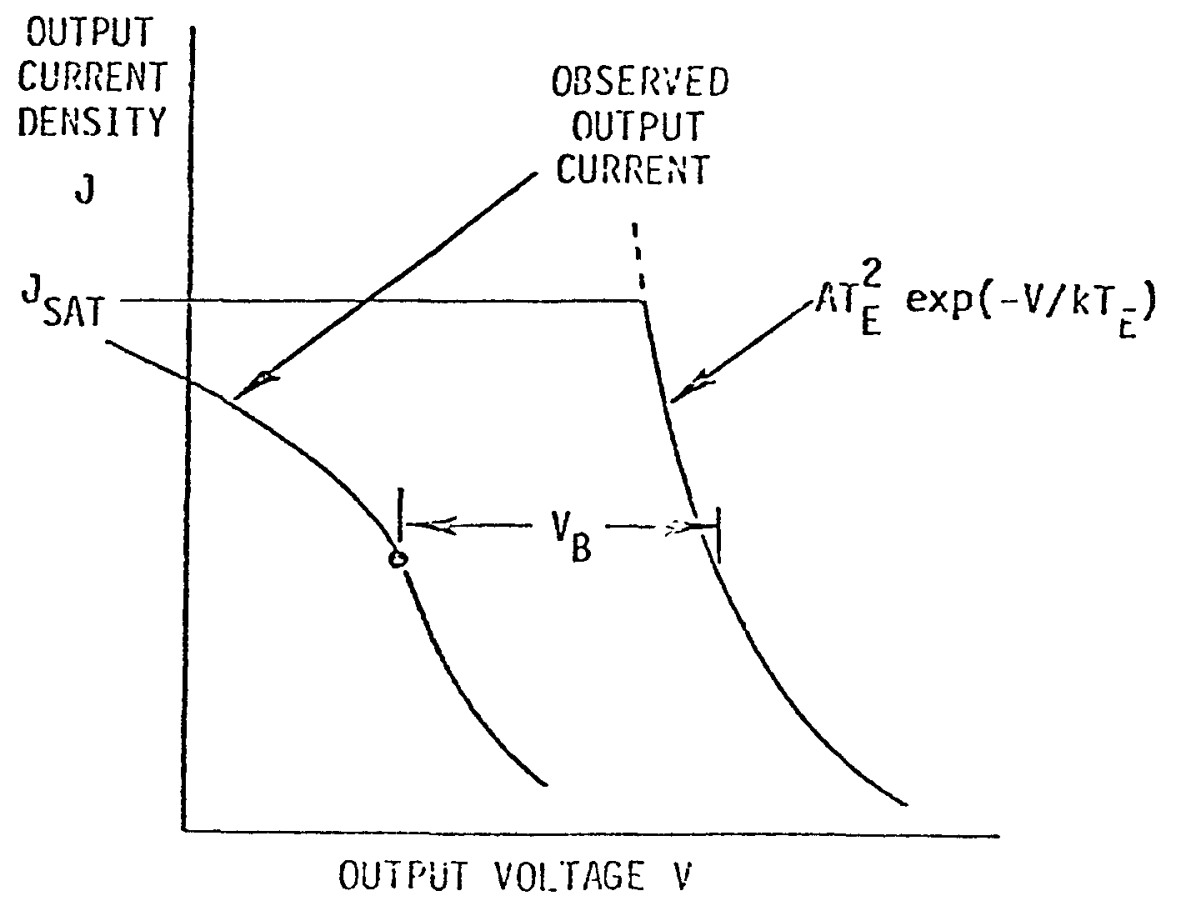

Fig. B-3. The relationship between barrier index and ideal and observed 
The upper temperature limit on $T_{C}$ is set by the emission of electrons from the collector surface back into the interelectrode gap. In most converters this back emission must be 1 imited to $10 \%$ or less of the emitter current J. Thus,

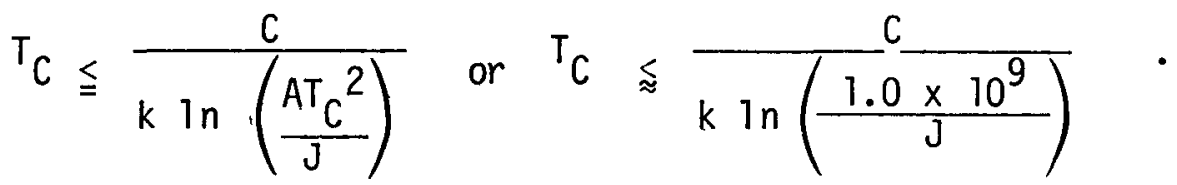

\section{INPUT PWOER REQUIREMENTS AND EFFICIENCY}

The input power required at the emitter is determined by emitter radiative heat transfer, cesium thermal conduction, conductive losses through the electric leads, and electron cooling of the emitter. Electron cooling and radiative heat transfer are the dominant mechanisms. A good fit to most converters in the region of interest is provided by the equation

$$
Q_{i n}\left(W / \mathrm{cm}^{2}\right)=1.8 \times 10^{-3} \mathrm{~J} \mathrm{~T}_{E}+1.2 \times 10^{-12}\left(\mathrm{~T}_{E}^{4}-\mathrm{T}_{C}^{4}\right) .
$$

Input power as a function of both emitter temperature and current density is shown in Fig. B-4.

Combining Eqs. (B-5) and (B-7) the efficiency of the converter at its leads, $n_{L}$, can be estimated:

$$
\eta_{L}=\frac{\left.0.9 \mathrm{~J}\left[k T_{E} \ln \left(A T_{E}^{2} / J\right)-V_{B}\right)\right]}{1.8 \times 10^{-3} J T_{E}+1.2 \times 10^{-12}\left(T_{E}^{4}-T_{C}{ }^{4}\right)}
$$

As shown in Fig. B-5, the efficiency of a thermionic converter is relatively insensitive to current density. As a result, the performance of the converter remains near its design level under part load conditions. The output power density of the converter, like the required input power density is almost directly proportional to current density. Thus, the design current 
density must be carefully chosen to optimally match the heat flux from the heat source, the requirement of the electric load, and system size and mass constraints.

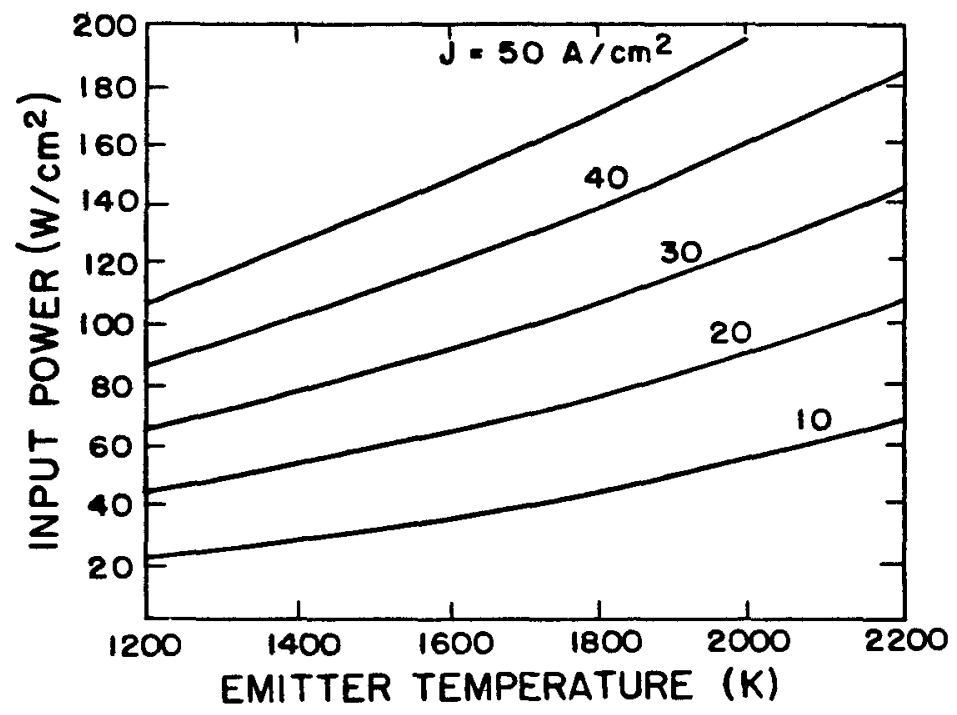

Fig. B-4. Converter input power requirements.

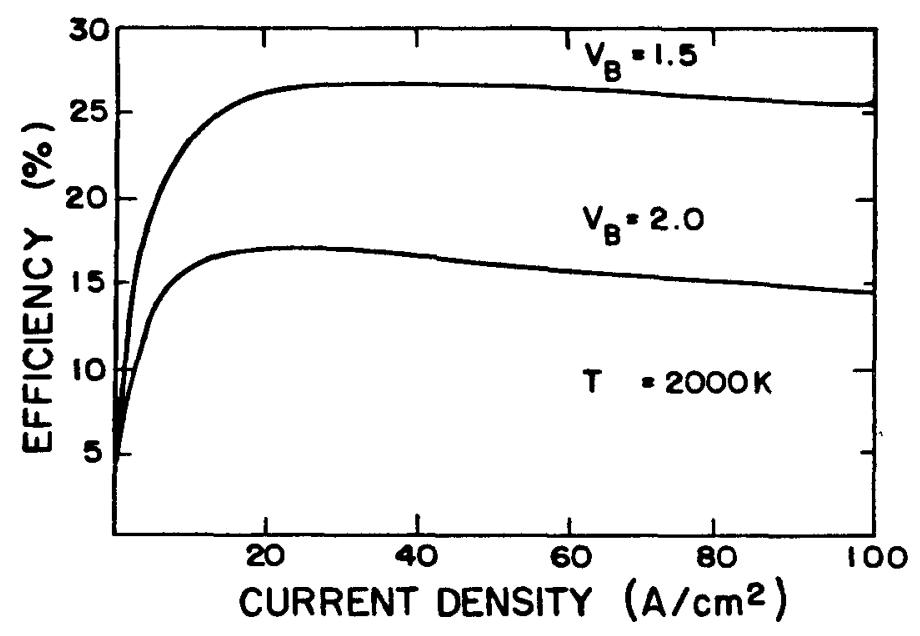

Fig. B-5. Converter efficiency as a function of current density and barrier index. 


\section{APPENDIX VI-C \\ BRAYTON CYCLE THERMODYNAMIC ANALYSIS}

Figure $\mathrm{C}-1$ is a schematic of the cycle defining state points. The numbering of points corresponds to that used by the Garrett Corporation for ease of comparison. Table C-l contains definitions for the Brayton cycle thermodynamic analys is equations.

\section{TABLE C- 1}

\section{LIST OF VARIABLES FOR BRAYTON CYCLE THERMODYNAMIC ANALYSIS}

\begin{tabular}{|c|c|c|}
\hline$T_{0}$ & $=$ & radiation sink temperature $(K)$ \\
\hline $\mathrm{T}_{1}$ & $=$ & compressor inlet temperature $(K)$ \\
\hline $\mathrm{T}_{2}$ & $=$ & compressor outlet temperature (K) \\
\hline$T_{5}$ & $=$ & recuperator outlet, cold pass (K) \\
\hline$T_{6}$ & $=$ & turbine in1et temperature $(\mathrm{K})$ \\
\hline$T_{9}$ & $=$ & turbine outlet temperature $(K)$ \\
\hline$T_{9}$ & $=$ & turbine outlet temperature, mixed (K) \\
\hline $\mathrm{T}_{10}$ & $=$ & recuperator out let, not pass $(K)$ \\
\hline$T_{\text {in }}$ & $=$ & radiator coolant inlet temperature $(K)$ \\
\hline$T_{\text {out }}$ & $=$ & radiator coolant outlet temperature $(K)$ \\
\hline$P_{1}$ & $=$ & compressor inlet pressure (kPa) \\
\hline$P_{2}$ & $=$ & compressor outlet pressure (kPa) \\
\hline$P_{5}$ & $=$ & heat pipe $H X$ inlet pressure $(\mathrm{kPa})$ \\
\hline$P_{6}$ & $=$ & turbine inlet pressure ( $\mathrm{kPa})$ \\
\hline$P_{9}$ & $=$ & turbine outlet pressure $(\mathrm{kPa})$ \\
\hline$P_{10}$ & $=$ & cooler inlet pressure $(\mathrm{KPa})$ \\
\hline$n_{T}$ & $=$ & efficiency of turbine \\
\hline$n_{c}$ & $=$ & efficiency of compressor \\
\hline$n_{R}$ & $=$ & recuperator effectiveness \\
\hline$c_{p}$ & $=$ & specific heat of working fluid (w/kg K) \\
\hline$\gamma$ & $=$ & ratio of specific heat \\
\hline BP & $=$ & fraction of turbine By-Pass \\
\hline W & $=$ & flow rate of working fluid $(\mathrm{kg} / \mathrm{s})$ \\
\hline$\Delta \mathrm{P}_{\mathrm{H}}$ & $=$ & pressure drop in heater $(\mathrm{kPa})$ \\
\hline$\Delta \mathrm{P}_{C}$ & $=$ & pressure drop in cooler $(\mathrm{kPa})$ \\
\hline
\end{tabular}


Table $C-1$ (continued)

$$
\begin{array}{ll}
\Delta P_{K C C} & =\text { pressure drop per pass in recuperator }(\mathrm{kPa}) \\
\mathrm{Q} & =\text { input heat }(\mathrm{KW}) \\
\mathrm{P} & =\text { output power }(\mathrm{kW}) \\
\Delta \mathrm{T}_{\mathrm{C}} & =\text { cooler temperature driving force }(K)
\end{array}
$$

The cycle efficiency is calculated for assumed $T_{6}, T_{1}, P_{6} / P_{9}$, and component performance, and for efficiency. Once hardware. is selected or designed, more detailed calculations can be made, considering specific performance. These equations are used to show the relative importance of various parameters.

For an assumed $T_{6}, T_{6} / T_{9}, n_{T} T_{9}$ is calculated by

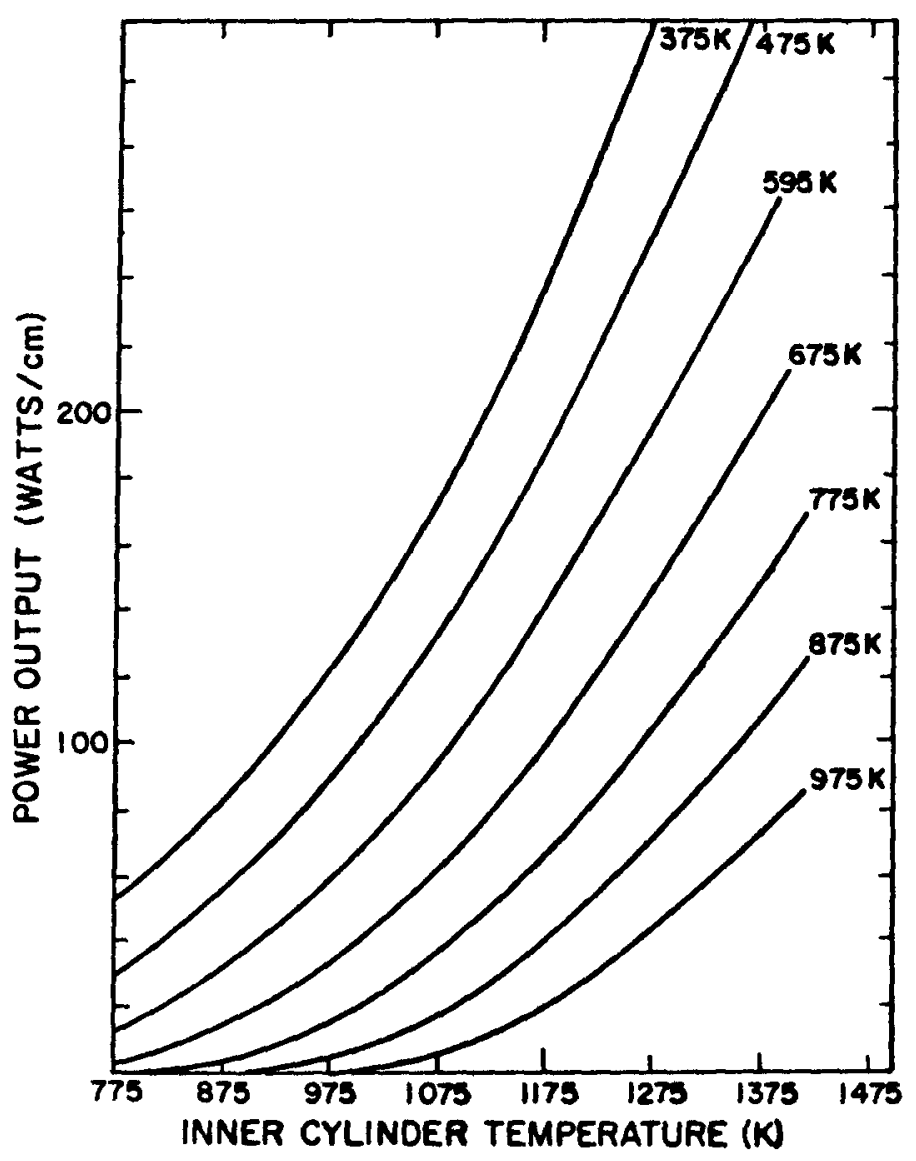

Fig. C-1. Cycle defining state points. 


$$
\frac{T_{9}^{\prime}}{T_{6}}=\left(1-n_{T}\right)+n_{t}\left(\frac{P_{6}}{P_{9}}\right)-\frac{\gamma-1}{\gamma} .
$$

The inlet temperature is a design parameter limited by the heat source, heat exchange materials, and turbine materials. The pressure ratio must be optimized on the basis of the turbine design.

For an assumed $T_{1}$ and $n_{c}, T_{2}$, is calculated by

$$
\frac{T_{2}}{T_{1}}=\left(1-\frac{1}{n_{c}}\right)+\frac{1}{n_{c}}\left(\frac{P_{2}}{P_{1}}\right)^{\frac{\gamma-1}{\gamma}} \text {. }
$$

The compressor pressure ratio is larger than the turbine ratio to compensate for pressure loss in heat exchangers and ducts. Thus,

$$
P_{2}=P_{6}+\Delta P_{H}+\Delta P_{K C C}
$$

and

$$
P_{1}=P_{9}-\Delta P_{C}-\Delta P_{K C C} \text {, }
$$

where duct loss is included in the heat-exchanger losses.

The by-pass mixed temperature, $\mathrm{T}_{9}$, is:

$$
T_{9}=(1-B P) T_{9}^{\prime}+B P\left(T_{2}\right)
$$

Some designs do not include bypass flow, in which case this correction to turbine outlet is not used.

Recuperator temperatures are

$$
\begin{aligned}
& T_{5}=T_{2}+n_{R}\left(T_{9}-T_{2}\right) \\
& T_{10}=T_{9}-(1-B P)\left(T_{5}-T_{2}\right) .
\end{aligned}
$$

The flow rate is calculated from the input power as 


$$
W=Q /\left[C_{P}(1-B P)\left(T_{6}-T_{5}\right) \cdot 1000\right]^{-1} \text {. }
$$

The output power is

$$
P=C_{P} W\left[\left(\dot{T}_{6}-T_{9}\right)(1-B P)-\left(T_{2}-T_{1}\right)\right] 1000,
$$

and efficiency is:

$$
\text { Eff }=P / Q \text {. }
$$

\section{REFERENCES:}

1. V. Raag, "The Time and Temperature Behavior of the Thermoelectric Properties of 78 a/O Si-22 a/O Ge," 11 th Intersociety Energy Engineering Conf., Lake Tahoe, California, September 12-17, 197.6, pp.

2. "Technical Report on High Power Density Thermoelectric Module Design and SiGe/GaP Thermoelectric Material Work," Syncal Corporation, Sunnyvale, Cal if ornia (October 25, 1978).

3. P. A. O'Riordan, "Thermoelectricity Executive Summary," 11th Intersociety Energy Conversion Engineering Conf., Lake Tahoe, California, September 12-17, 1976, pp. 1525-26.

4. A. R. Leberman, W. E. Osmeyer, and T. E. Hammel, "The Low Cost High Performance Generator (LCHPG)," 11th Intersociety Energy Conversion Engineering Conf., Lake Tahoe, California, September 12-17, 1976, pp. $1525-26$.

5. "Final Reliability Assessment for the M55 77 Multi-Hundred Watt Radioisotope Thermoelectric Generator," General Electric, Philadelphis, Pennsylvania, report GESP-7131, (Aprii 12, 1977).

6. G. 0. Fitzpatrick and E. J. Britt, "Thermionics and Its Application to the SPS," NASA Conf. on Radiation Energy Conversion, January 26-28, 1978, Razor Assn., Inc., Sunnyvale, California:

7. J. L. $\mathrm{Kl}$ ann and W. T. Wintucky, "Status of the 2 to $15 \mathrm{~kW}_{\mathrm{e}}$ Brayton Power System and Potential Gains from Component Improvements," Intersociety Energy Conversion Engineering Conf., Boston, Massachusetts, August 3-5, 1971, pp. 195-200. 
8. D. R. Stoner, "Determination of Weldability and Elevated Temperature Stability of Refractory Metal Alloys. III - Effect of Contamination Level on Weldability of Refractory Metal Alloys," National Aeronautics and Space Agency Report NASA-CR-1609 (September 1970).

9. L. B. Lundberg and K. A. Johnson, "Effect of Oxygen Content on the Impact Behavior of the Tantalum-Based Alloy T-111 at 2400\%F," Metallurgical Rev. 1, 32-36 (1972).

10. C. T. Liu, S. H. Anderson and H. Inonye, "Effect of Oxidizing Environment on Mechanical Properties of Molybdenum and TZM," Oak Ridge National Laboratory, Oak Ridge, Tennessee, report ORNL-5431, (October 1973).

11. Lewis News, NASA-Lewis Research Center, Vo1. 14, No. 15.

12. Jack A. Heller, Thomas A. Moss, and Gerald J. Barna, "Study of a 300-Kilowatt Rankine-Cycle Advanced Nuclear-Electric Space-Power System," Lewis Research Center, National Aeronautics and Space Administration report NASA TM X-1919 (November 1969).

13. R. J. Bossbach and G. M. Kaplan, "Potassium Testing of Condensate Removal Devices for Rankine Space Power Turbines, "Proc. of 1971 Intersociety Energy Conversion Engineering Conf., Boston, Massachusetts, August 3-5, 1971, Paper No. 719059, pp. 409-421.

14. "Third Annual Report-High-Temperature Materials and Reactor Component Development Programs, Vol. I - Materials," General Electric report GEMP-270A (February 1976).

15. E. E. Hoffman and R. W. Harrison, "The Compatibility of Refractory Metals with Liquid Metals," in Refractory Metals and Alloys, Metallurgy and Technology, I. Machlin, R. T. Begley, and E. D. Weisert (Eds.), Plenum Press, NY (1960) 251-287.

16. Personal Communication, Bruce Goldwater, Mechanical Technology Corporation, Latham, New York, March 1977. 


\section{RADIATOR DESIGN}

The radiator design depends on operating temperature and power level. The amount of waste heat that can be radiated to space by a given surface area is proportional to the fourth power of the radiating surface temperature. The STS shuttle bay has limited packaging volume for the radiator. If $30 \%$ of the bay can be allocated to the power supply, then the power plant should use less than $5.5 \mathrm{~m}$ of length. Other components can be packaged in or around the radiator, which cannot exceed the shuttle bay length of 18.3 m. Power plants with thermoelectric converters have minimum weight with 775-875 $\mathrm{K}$ heat rejection temperature. Power plants with Brayton converters have minimum weight for radiator temperatures $\sim 475 \mathrm{~K}$. This leads to large-area radiators that require folding to fit the constraints of the shuttle bay. The temperature range and area differences lead to different configurations for thermoelectric and Brayton converter radiators.

The useful range of various potential radiator materials is shown in Fig. 133. The area and mass as a function of temperature is given in Fig. 134, which shows that a high radiator temperature is desirable.

\section{A. High-Temperature Radiators ( $>650 \mathrm{~K}$ )}

A conceptual design of a waste-heat radiator has been developed for a thermoelectric or other high-temperature reject heat converter system for space nuclear power. The most important constraint was a survival standard of $99 \%$ probability that the radiator be functional at full power at the end of a 7-yr mission. The basic shape of the heat-pipe radiator is a frustum of a right circular cone. The design includes stringer heat pipes to carry reject heat from the thermoelectric modules to the radiator skin that is composed of small-diameter, thin-walled cross heat pipes. The stringer heat pipes are armored to resist puncture by a meteoroid. The cross heat pipes are designed to provide the necessary unpunctured radiating area at the mission end with a minimum initial system mass. Several design cases were developed in which the individual stringer survival probabilities were varied and the radiator system mass was calculated. These radiator studies will be used in the evaluation of several candidate electric power conversion systems for space electric power.

Results are presented for system mass as a function of individual stringer survival probability for six candidate container materials, three candidate heat-pipe fluids, three radiator operating temperatures, two 


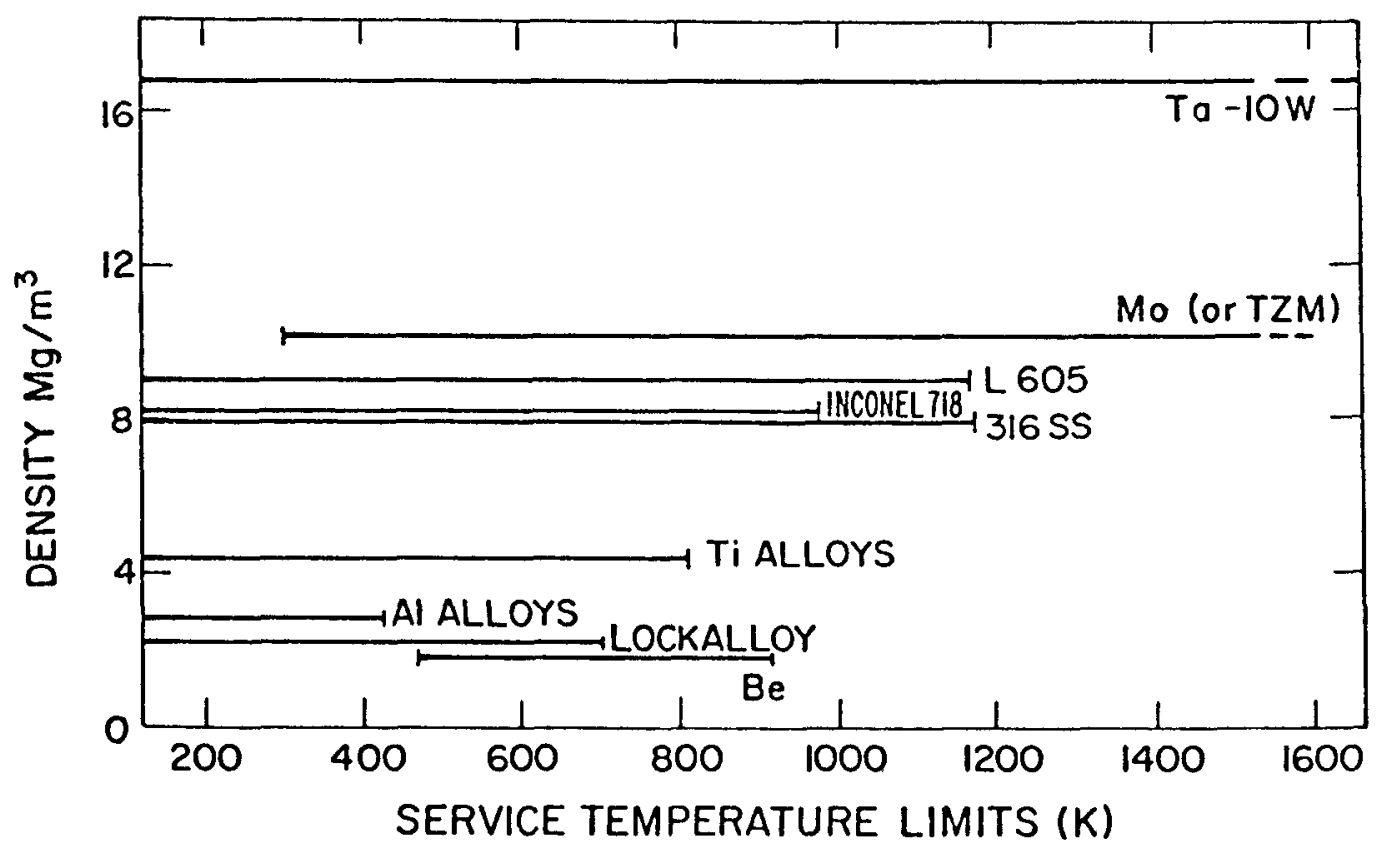

Fig. 133. Space power radiator materials.

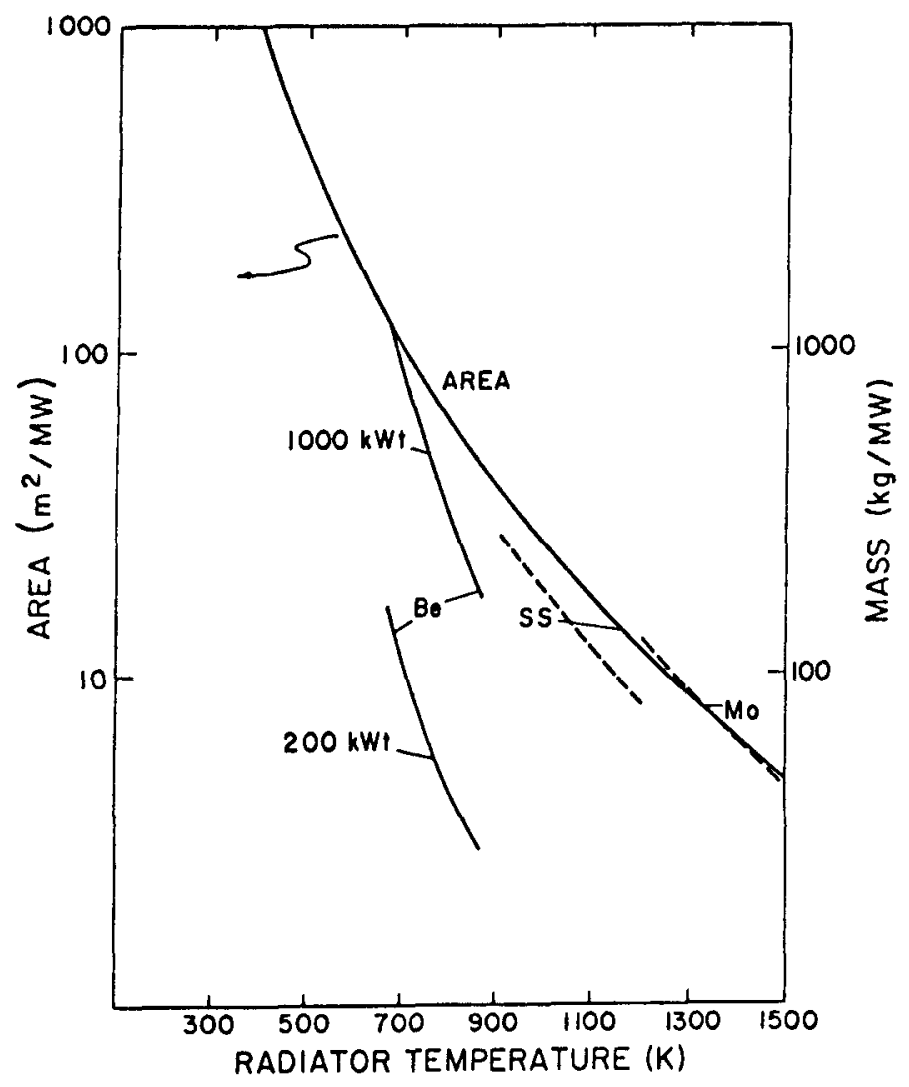

Fig. 134. Area and mass as function of temperature. 
meteoroid shields, and two radiating surface cases. Results are also presented for radiator reject heat as a function of system mass, area, and length.

A heat-pipe cooled system was chosen for study because it is believed to be lighter and more reliable than a conventional pumped-fluid system. The study objectives were to provide the size and weight estimates for use in power plant parametric studies, to clarify potential problems, and to evaluate technical feasibility of the heat-pipe concept.

The only failure mechanism considered, was micrometeoroid puncture of heat pipes. The overall reliability is provided by selecting sufficiently thick heat-pipe material to provide a selected probability that a prescribed number of heat pipes would survive the mission. Results from previous studies $^{l}$ on radiator segmenting were used in optimizing between material thickness and redundant heat pipes to minimize the initial system mass.

1. Radiator Design. The radiator configuration chosen for study was the frustum of a right circular cone. The design includes 91 thermoelectric modules arranged in a 1.18-m-diam circle at the small base of the frustum. The radiator was designed to use two systems of heat pipes in series, rather than the conventional pumped-fluid system. Ninety-one axial stringer heat pipes, arranged on the cone slant surface, uniformly transfer heat from the thermoelectric modules to the radiator skin. The radiating surface is composed of many small-diameter thin-walled heat pipes laid side by side at right angles to the stringers around the radiator circumference. Heat is conducted from the stringers to cross heat pipes and then radiated to space. The design is shown in Fig. 135. The cross heat pipes are assumed to be brazed to the stringer heat pipes to provide the heat transfer. They may also be brazed to each other, but that has not been assumed in the thermal analysis.

2. System Reliability. The heat rejection system is composed of the cross and stringer heat-pipe systems. The radiator must have a $99 \%$ survival probability that both systems will remain functional for a 7-yr mission. Functional is defined as capable of rejecting the design heat load at the design temperature. The probability of failure from means other than meteoroid penetration is not considered here, but must be reduced to a very small value. Because the heat pipe systems are statistically independent, the total system survival probability is given by ${ }^{2}$ 


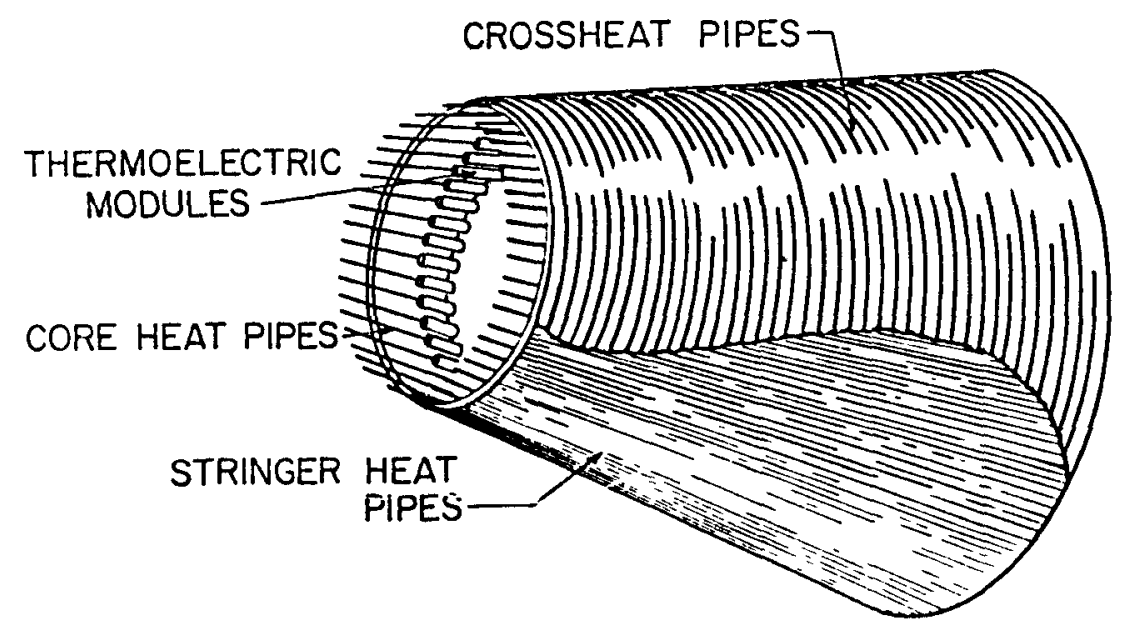

Fig. 135. Ninety-one heat-pipe thermoelectric system radiator.

$$
p(S \cap C)=p(S) \times p(C) \text {, }
$$

where $p(S)=$ probability of stringer system survival, and $p(C)=$ probability of cross heat-pipe system survival.

The system survival probability must be equal to 0.99 , which is the product of 0.995 and 0.995 . Thus, the survival probability of each system must be at least $99.5 \%$.

Two failure modes from hypervelocity impact were considered. A dimple failure mode is assumed for the stringers and a perforation failure mode is assumed for the cross heat pipes. The difference in beryllium wall thickness as a function of individual survival probability for a vulnerable area of $0.1 \mathrm{~m}^{2}$ is shown in Fig. 136 for both failure modes.

The reference design of the 91 heat-pipe thermoelectric system radiator assumes a $200-\mathrm{kW}$ reactor, $5 \%$ efficient SiGe thermoelectric modiles, and a radiator operating temperature of $775 \mathrm{~K}$. The stringer and cross heat-pipe container material is beryllium and the working fluid is potassium.

a. Stringer Heat-Pipe System. The stringer heat-pipe system is composed of 91 heat pipes. The evaporator section of each pipe is thermally linked to the cold junction of a single thermoelectric module. (The evaporator section design is not covered in this report.) The assumption is made that there will be thermal coupling between modules so that failure of a stringer heat pipe does not result in failure to cool a module. 


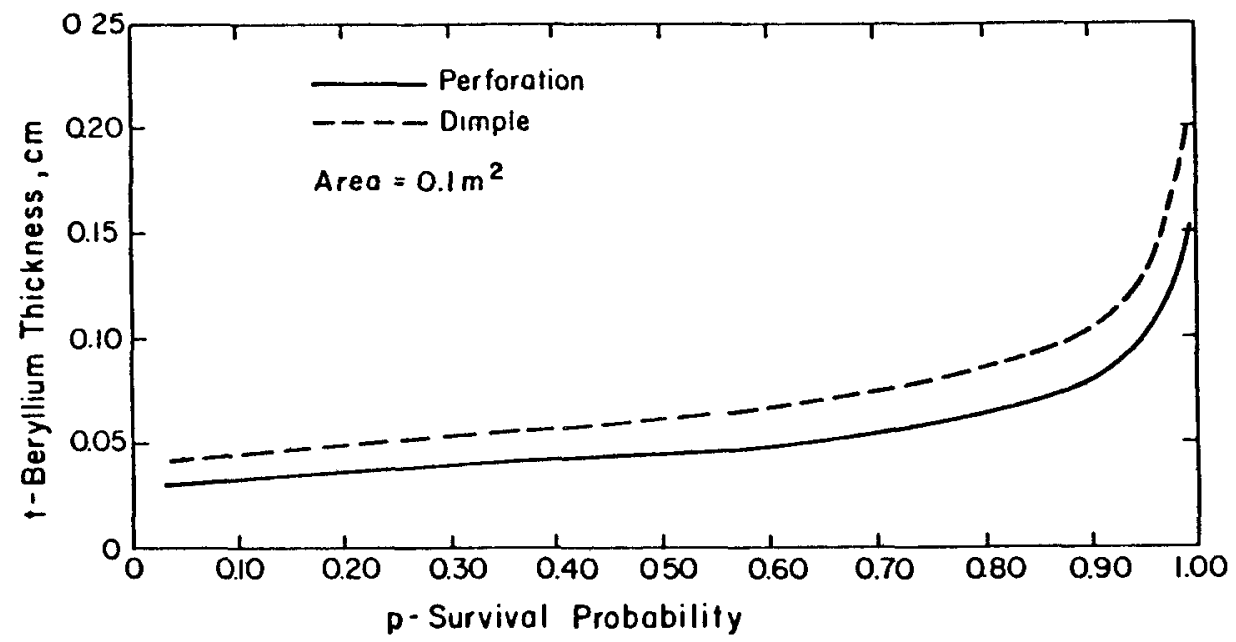

Fig. 136. Beryllium thickness for perforation and dimple failure modes.

It was necessary to develop several design cases based on different stringer survival probabilities. The system mass determined for each survival probability was used to choose a reference design case. Because the condenser sections of each stringer heat pipe are statistically independent of all the other stringers, the system survival probability can be calculated using the cumulative binomial distribution ${ }^{1}$

$$
S=\sum_{n=N}^{N} \frac{N !}{(N-n) ! n !}(1-p)^{N-n} p^{n},
$$

where $p=$ individual stringer survival probability, $N=$ total number of segments, $N_{S}=$ number of surviving segments, and $S=$ probability that $N_{S}$ segments are not punctured during the mission.

Figure 137 illustrates the calculated system survival probability as a function of $\mathrm{N}_{\mathrm{S}}$ for four survival probabilities. The calculations show, for example, that of 91 heat pipes, each having a 0.89 survival probability, there is a $99.5 \%$ probability that 73 will survive.

These calculations are used to determine the end-of-life number of stringers from which the resulting heat load per stringer can be determined. The end-of-life heat load per stringer is 


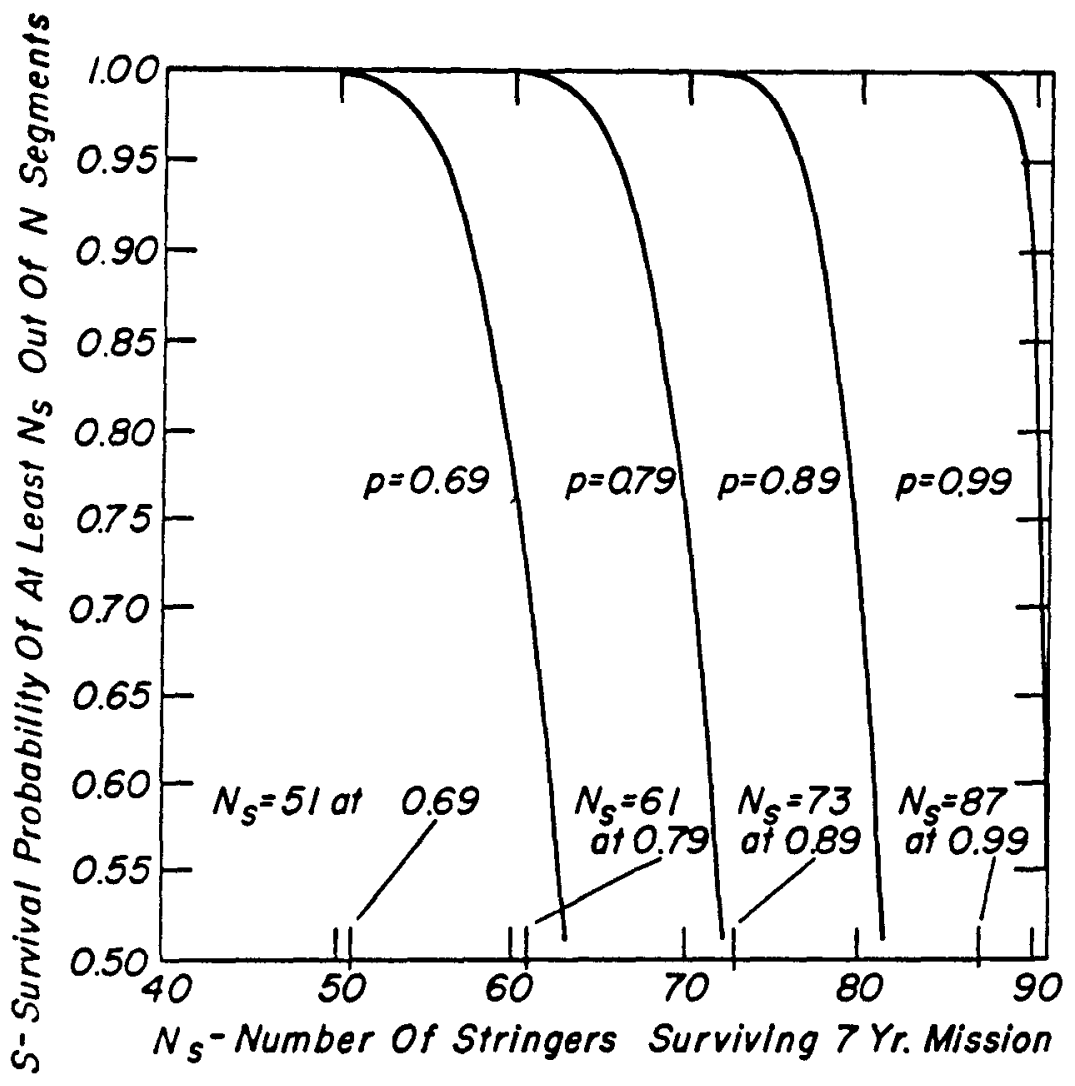

Fig. 137. System survival probability vs number of surviving stringers.

$$
q_{\max }=\frac{Q_{r e j}}{N_{s}}
$$

where $Q_{r e j}=$ total heat to be rejected. This was used to size the stringer. The cross-section area of the heat pipe was calculated using the sonic limit of the heat-pipe fluid at the operating temperature, ${ }^{3}$ multiplied by a safety factor of 2 .

The minimum length of the condenser section is assumed to be the slant height of the conical radiator. Pressure drop calculations for the given stringer lengths were done by J. E. Kemme ${ }^{4}$ and show favorable pressure and temperature profiles.

b. Cross Heat-Pipe System. The cross heat-pipe system is composed of many thin-walled heat-pipe segments that operate independently. The cross heat pipes were assumed to be the only surface that radiates waste heat to 
space and are the most vulnerable radiator parts. If the cross heat pipes were circumferentially segmented, then only the punctured segments would be sacrificed as useful radiating surface. In Ref. 1, it was shown that the mass per unit area decreased with increasing numbers of segments. For many segments and minimum initial mass, the individual segment survival probability

$$
p=\frac{N_{S}}{N_{\text {min }}}=0.78 \text {. }
$$

Figure 138 illustrates the heat-pipe thickness required as a function of segment survival probability for five exposed vulnerable areas. Thickness begins to increase rapidly for survival probabilities greater than 0.85 . The exposed area requires significant increases in thickness, which means that a weight savings can be achieved by dividing a heat pipe into shorter sections. (Segmenting is feasible with cross heat pipes, but is not necessarily feasible with the stringers.)

For the reference design radiator, the cross heat pipes are segmented into approximately 3200 segments on the radiator surface. Using the cumulative binominal distribution, Eq. (2), the required individual segment survival probability can be calculated so that there is a 0.995 probability of

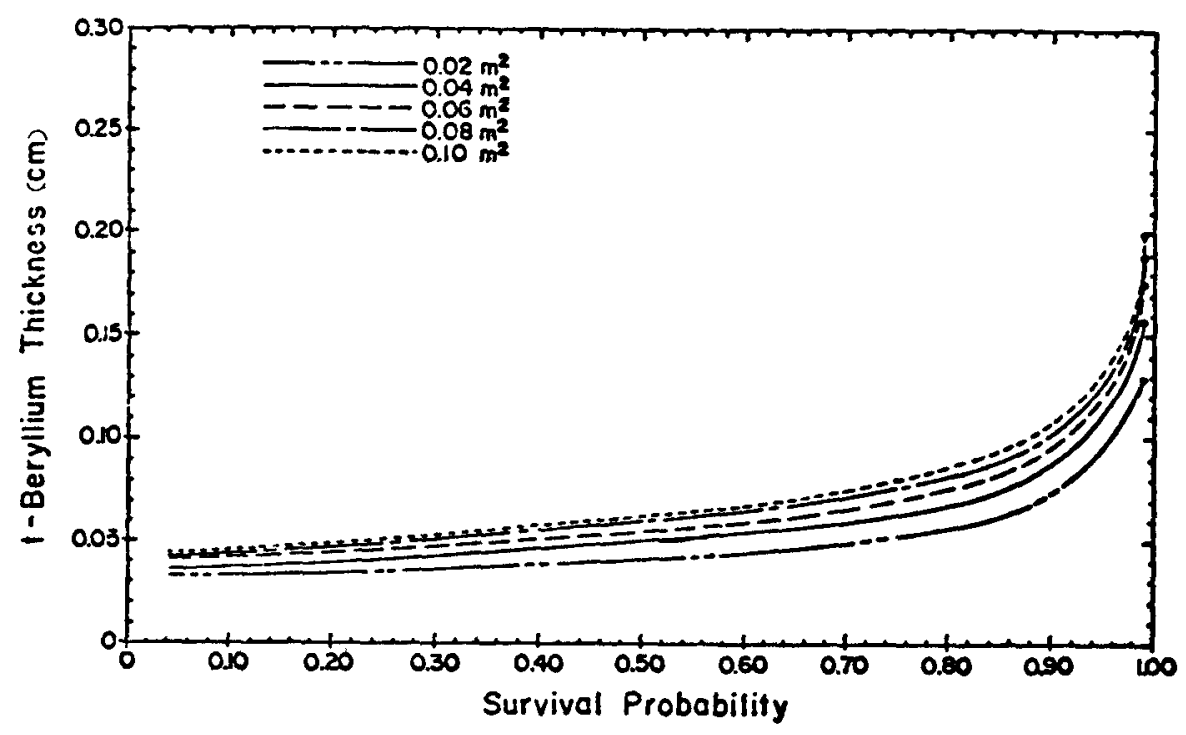

Fig. 138. Beryllium thickness vs survival probability. 
0.78 fraction of the cross heat pipes surviving the mission. Then, using the individual survival probability and the exposed vulnerable area of each segment, the required thickness of the cross heat pipes can be calculated. The cross heat pipes outside the stringers act as a meteoroid shield or bumper, and must be considered when calculating the wall thickness of the stringers. The bumper effect of the cross heat pipes was estimated by the methods described in Ref. 5 .

3. Thermal Design. The thermal environment assumed for the radiator 6 includes solar radiation $\left(1399 \mathrm{~W} / \mathrm{m}^{2}\right)$, Earth radiation $\left(243 \mathrm{~W} / \mathrm{m}^{2}\right)$, and space sink temperature $(0 \mathrm{~K})$.

The heat balance consists of inputs of direct solar radiation, Earthemitted radiation, reflection of solar radiation from Earth, and the internally generated heat load to be rejected, all of which must be radiated to space. The controlling equation is given by ${ }^{7}$

$$
a_{s} \bar{F}_{s} G_{s}+a_{r} \bar{F}_{r} \bar{A}_{p} G_{s}+a_{e} \bar{F}_{e} E_{e}+\bar{P}_{i}=\sigma e \bar{T}^{4}
$$

where

$$
\begin{aligned}
& a_{S}= \text { solar absorptivity }=0.21, \\
& F_{s}= \text { cosine of angle between the unit surface normal vector } \\
& \text { and the direction to the sun }(0 \text { to } 1 .), \\
& G_{S}=\text { solar irradiation on a plane normal to the sun } \\
&=1398.76 \mathrm{~W} / \mathrm{m}^{2}, \\
& a_{r}=\text { absorptivity to radiation reflected from } \mathrm{planet}=0.21, \\
& F_{r}=\text { shape factor for reflected planetary radiation }=0.015 \text { for } \\
& A_{p}=\text { fraction of incoming solar radiation to Earth that is } \\
& a_{e}=\text { absorptivity to radiation emitted by } \mathrm{planet}=0.90 ;, \\
& F_{e}=\text { shape factor from planet to surface }=0.3, \\
& E_{e}=\text { Earth-emitted radiation }=243 \mathrm{~W} / \mathrm{m}^{2}, \\
& P_{j}=\text { internal waste heat load, } \\
& \sigma=\text { Stefan-Boltzmann constant }=5.67 \times 10^{-8} \mathrm{~W} /\left(\mathrm{m}^{2}-\mathrm{K}^{4}\right), \\
& e=\text { radiator surface emissivity }=0.9 \text { assumed, and } \\
& T=\text { radiator operating temperature }=775 \mathrm{~K} .
\end{aligned}
$$


The maximum shape factor values were used to get the worst case solar and earth heat inputs as follows

- Input from solar radiation $=0.21 \times 1 \times 1399=294 \mathrm{~W} / \mathrm{m}^{2}$.

- Input from Earth-emitted radiation $=0.90 \times 1.0 \times 243=219 \mathrm{~W} / \mathrm{m}^{2}$.

- Input from Earth-reflected solar radiation $=0.21 \times 0.3 \times 1399$ $=88 \mathrm{~W} / \mathrm{m}^{2}$.

It was assumed that the base looks directly at the payload so that Earthemitted and Earth-reflected radiation would be shielded from the radiator; therefore, the total environmental input is $294 \mathrm{~W} / \mathrm{m}^{2}$.

The average radiator temperature is assumed to be constant and equal to the cross heat-pipe temperature. The radiator temperature for the reference thermoelectric/design case is $775 \mathrm{~K}$, at which temperature the heat rejected per unit area is

$\frac{\text { Solar input }}{\text { Projected area }}+\frac{\text { Waste heat load }}{\text { Effective area }}=\frac{\text { Heat radiated to space }}{\text { Effective area }}$, $294 \mathrm{~W} / \mathrm{m}^{2}+\frac{P_{i}}{A_{\text {eff } m^{2}}}=5.67 \times 10^{-8}(0.9)(775 \mathrm{~K})^{4} \mathrm{~W} / \mathrm{m}^{2}$.

The solar input is very small compared to the heat rejected, so that only small errors result from using the worst-case solar input values applied to the effective radiator area. The resultant safety factor SF applied to solar input is given by

$$
\begin{aligned}
S F & =\frac{\text { effectice radiator area }}{\text { projected radiator area }} \\
& =\frac{\pi\left(R_{1}+R_{2}\right) \mathrm{s}}{\left(R_{1}+R_{2}\right) S \cos \phi}
\end{aligned}
$$

where $R_{1}=$ cone small radius, $R_{2}=$ cone large radius, $s=$ cone slant height, and $\phi=$ cone half angle.

The effective area required to reject the total heat load at the design temperature is given by 


$$
A_{\text {eff }}=\frac{\bar{P}_{1}}{\sigma e T^{4}-I} \text {, }
$$

where $I=$ solar input $=294 \mathrm{~W} / \mathrm{m}^{2}$. The effective area represents the radiating area available and functioning at the end of the mission (EOM). The radiating area at the beginning of the mission (BOM) must be larger to compensate for the loss of cross heat pipes during the mission.

The radiator is assumed to be a frustum of a right circular cone, Fig. 139. The overall radiator size must be compatible with or the Space Shuttle whose diameter is approximately $4.57 \mathrm{~m}$. The effective radiator area is assumed to be the outer slant surface of the cone, plus, in some cases, the fraction of area visible through the cone base. The slant surface area ${ }^{8}$ is

$$
A=\pi\left(R_{1}+R_{2}\right) s
$$

where $A=$ area of slant surface, $s=$ slant height of cone, $R_{1}=$ small radius $=0.59 \mathrm{~m}$ in reference design, $R_{2}=1$ arge radius, and $\phi=$ half angle of cone $=12^{\circ}$ in reference design. For cases that allow radiation to shine through the base of the cone

$$
A_{\text {eff }}=A+F_{1-2} A=A\left(1+F_{1-2}\right) \text {, }
$$

where $\mathrm{F}_{1-2}$ = shape factor.

In both cases, the cone slant height is calculated in terms of $R_{1}, \phi$, and $A_{\text {eff }}$ as

$$
S=\left(\frac{-2 \pi R_{1}+\left[\left(2 \pi R_{1}\right)^{2}-4 \pi \sin A_{e f f}\right]^{l / 2}}{2 \pi \sin \phi}\right) \text {. }
$$

Whether or not this base shine-through occurs depends on the mission and payload. The expectation is that the void space inside the radiator will have instrumentation, controls, or equipment that must be protected from the high-temperature radiator. Consequently, it was assumed for the reference design that the backside of the radiator base, which would be looking directly at the payload, would need protection. Without base shine-through the radiator is larger and heavier. 


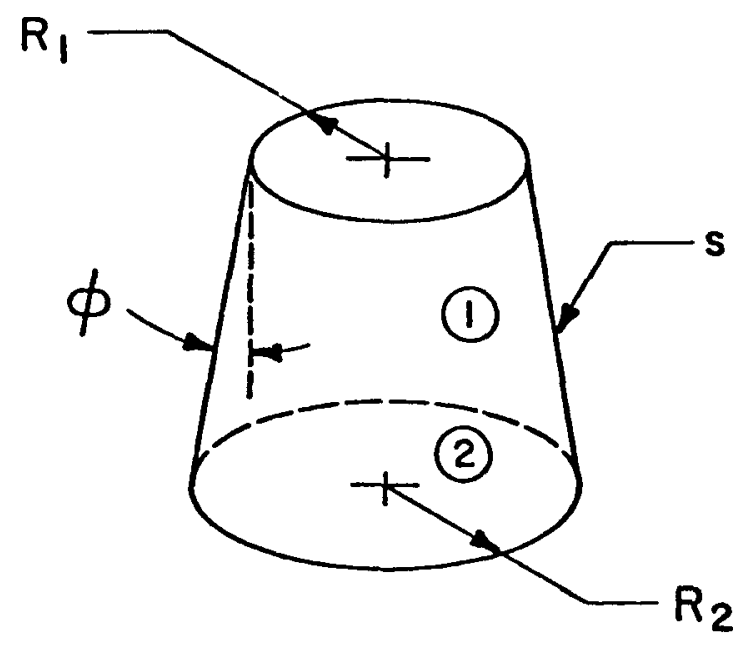

Fig. 139. Cone frustum.

4. Micrometeoroid Criteria. The radiator must be designed to minimize failure because of damage from micrometeoroids. The only radiator parts that require thick walls are the stringer heat pipes from the converters to the cross heat pipes on the cone surface. The cross heat pipes were assumed to be significantly segmented to avoid the necessity for thick armor. The dimple failure mode was assumed for the stringers. Perforation failures were assumed for the cross heat pipes. The meteoroid model used for these calculations ${ }^{6}$ includes comet particles having masses between 1 and $10^{-12} \mathrm{~g}$ for sporadic meteoroids and between 1 and $10^{-6} \mathrm{~g}$ for stream meteoroids. The average total environment has a particle density of $0.5 \mathrm{~g} / \mathrm{cm}^{3}$ and a particle velocity of $20 \mathrm{~km} / \mathrm{s}$. Flux mass models:

$$
\begin{aligned}
& \text { For } 10^{-6} \leq M \leq 1, \log N t=-14.37-1.213 \log M \\
& \text { For } 10^{-12} \leq M \leq 10^{-6}, \log N t=-14.339-1.584 \log M-0.063(\log M)
\end{aligned}
$$

$N t=$ number of particles $/ \mathrm{m}^{2} / \mathrm{s}$ of mass $M$ or greater, and $M=$ mass in grams.

The equation used to determine the material thickness was developed by Haller and Lieblein ${ }^{5}$ 


$$
\begin{aligned}
\delta= & \gamma_{R} a\left(\frac{\rho_{p}}{\rho_{a}}\right)^{1 / 2}\left(\frac{V_{p}}{C_{a}}\right)^{2 / 3}\left(\frac{6}{\pi \rho_{p}}\right)^{1 / 3}\left(\frac{E \alpha A_{v} t}{-\ell n P_{0}}\right)^{1 / 3 \beta} \\
& \left(\frac{2}{3 n \theta \beta+2}\right)^{1 / 3 \beta}\left(\frac{T}{T_{R}}\right)^{1 / 6},
\end{aligned}
$$

where

$\delta=$ armor thickness $(\mathrm{cm})$,

$\mathrm{Y}_{\mathrm{R}}=$ room temperature cratering coefficient,

$\mathrm{a}=$ rear surface damage thickness factor,

$\rho_{p}=$ meteoroid average density $\left(0.5 \mathrm{~g} / \mathrm{cm}^{3}\right)$,

$\rho_{\mathrm{a}}=\operatorname{armor}$ density $\left(\mathrm{g} / \mathrm{cm}^{3}\right)$,

$v_{p}=$ meteoroid average velocity $(20 \mathrm{~km} / \mathrm{s})$,

$c_{a}=$ sonic velocity in $\operatorname{armor}(\mathrm{km} / \mathrm{s})$,

$\mathrm{E}=$ armor Earth shielding factor $=0$. yy3 for geosynchronous orbit,

$\alpha=$ meteoroid flux constant $\left(10^{-14.37} \mathrm{~g} / \mathrm{m}^{2}-\mathrm{s}=4.2658 \mathrm{E}-15 \mathrm{~g} / \mathrm{m}^{2}-\mathrm{s}\right)$,

$A_{v}=$ vulnerable area $\left(\mathrm{m}^{2}\right)$,

$t=$ mission time, $(t=7 \mathrm{yrs}=2.20752 \mathrm{E}+8 \mathrm{~s})$,

$P_{0}=$ design probability of no critical damage $(p=0.69-0.99)$,

$\mathrm{n}=$ damage factor for oblique impact $(1.0)$,

$\theta=$ penetration constant (0.667),

$\beta=$ meteoroid flux constant (1.213),

$\mathrm{T}=$ armor temperature $(\mathrm{K})$, and

$T_{R}=$ room temperature $(K)$. 
The data on cratering coefficients came from Refs. 9, 10, and 11. The data on rear surface damage thickness factors came from Refs. 11 and 12. The remaining material properties came from Ref. 13.

The earth shielding factor depends on orbit altitude and is defined as the ratio of shielded to unshielded flux. Figure 140 illustrates the geometry for calculating the earth shielding factor $E$ (Ref. 5).

$$
E=\frac{1+\cos \theta}{2}
$$

The vulnerable area is calculated based on the area of the condenser section of one stringer heat pipe as

$$
A_{v u 1}=\pi D_{i} s\left(m^{2}\right)
$$

The mission time is assumed to be $7 \mathrm{yr}, \mathrm{t}=2.20752 \times 10^{8} \mathrm{~s}$. The design probability for critical damage was varied in four steps from $p=0.69$ to $p=0.99$.

Six candidate radiator materials were considered. Table XXXI lists the properties used in the calculation of required thickness. The validity of the data is difficult to judge. The beryllium data, in particular, are questionable because significant improvement has been made in the fabrication of beryllium to improve its ductility. ${ }^{14}$

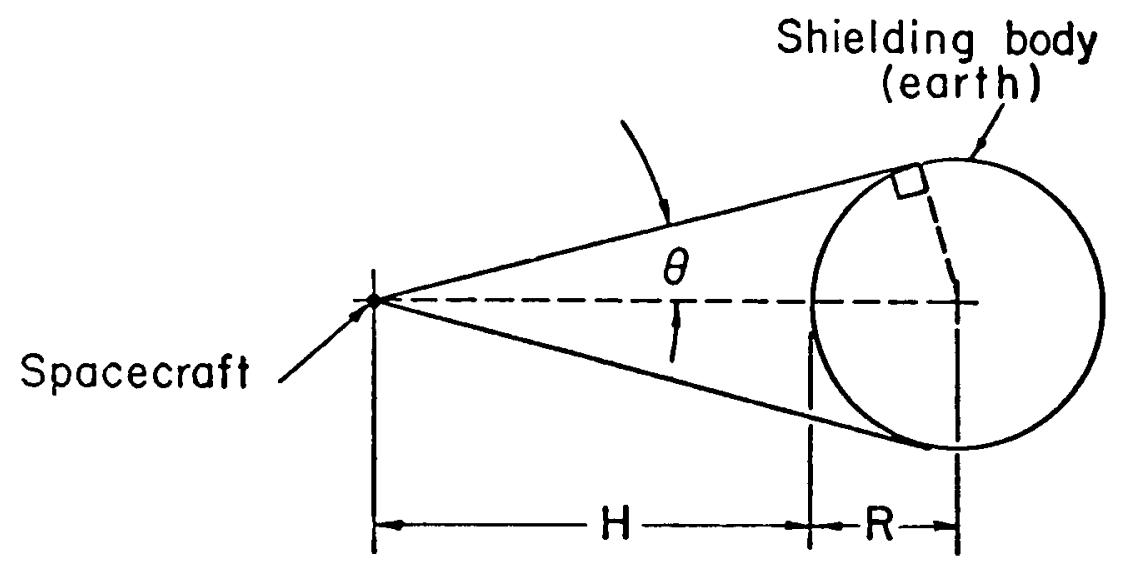

Fig. 140. Geometry for earth shielding factor. 
TABLE XXXI

PROPERTIES OF CANDIDATE RADIATOR MATERIALS

\begin{tabular}{|c|c|c|c|c|c|c|}
\hline Material Property & Beryllium & $T i-6 A]-4 V$ & Steel 315 & Inconel 718 & TZM Molybdenum & Tant a lum \\
\hline Density $\left(\mathrm{g} / \mathrm{cm}^{3}\right)$ & 1.85 & 4.43 & 7.76 & 8.0 & 10.21 & 16.6 \\
\hline Young's modulus $\left(\mathrm{Pa} \times 10^{11}\right)$ & 2.76 & 1.09 & 1.93 & 2.0 & 2.76 & 1.79 \\
\hline Conductivity (W/m K at $775 \mathrm{~K}$ ) & 100 & 13. & 19.8 & 19.03 & 121. & 64.7 \\
\hline Sound speed $(\mathrm{km} / \mathrm{s})$ & 12.22 & 4.97 & 4.99 & 4.99 & 5.64 & 3.35 \\
\hline Cratering coefficient & 2.28 & 1.75 & 2.19 & 1.85 & 2.0 & 1.77 \\
\hline Temperature coeff lcient $\left(T / T_{R}\right)^{6}$ & 1.175 & 1.02 & 1.175 & 1.175 & 0.91 & 1.0 \\
\hline \multicolumn{7}{|l|}{ Rear surface damage factors } \\
\hline Dimple & 2.0 & 3.1 & 3.1 & 3.0 & 3.25 & 4.5 \\
\hline Spall & 1.75 & 2.6 & 2.6 & 2.5 & 3.0 & 3.7 \\
\hline Perforation & 1.5 & 1.65 & 1.85 & 1.75 & 1.85 & 2.6 \\
\hline
\end{tabular}

Some new materials have not been tested. The material data are used with the expectation that future testing and development of materials, if done, will show that these values are very conservative.

5. Results. Results from this study fall into two categories. The first set of results shows the effects of changes in design parameters on the reference radiator system mass for four different stringer survival probabilities. The second set of results illustrates changes in the heat pipe radiator as a function of system size for the selected survival probability of $p=0.89$.

a. Effect of Design Parameters on System Mass. The thermal input to the radiator in a $3.22 \times 10^{7} \mathrm{~m}$ geosynchronous orbit is $294 \mathrm{~W} / \mathrm{m}^{2}$ from direct solar radiation. The reference configuration is for no shine through the radiator cone base and use of the cross heat pipes as bumpers for the stringer heat pipes. Potassium was selected as the reference heat-pipe fluid and pure beryllium as the container and wicking material.

Figure 141 shows the radiator mass as a function of stringer survival probability for the reference radiator and a radiator with the calculated thickness of heat-pipe container material. The reference radiator takes credit for the bumpering effect and protection that the cross heat pipes provide for the stringers by using only $40 \%$ of the calculated material thickness. Neglecting to take advantage of the protection afforded by the cross heat pipes results in $43-73 \%$ heavier radiator mass. 


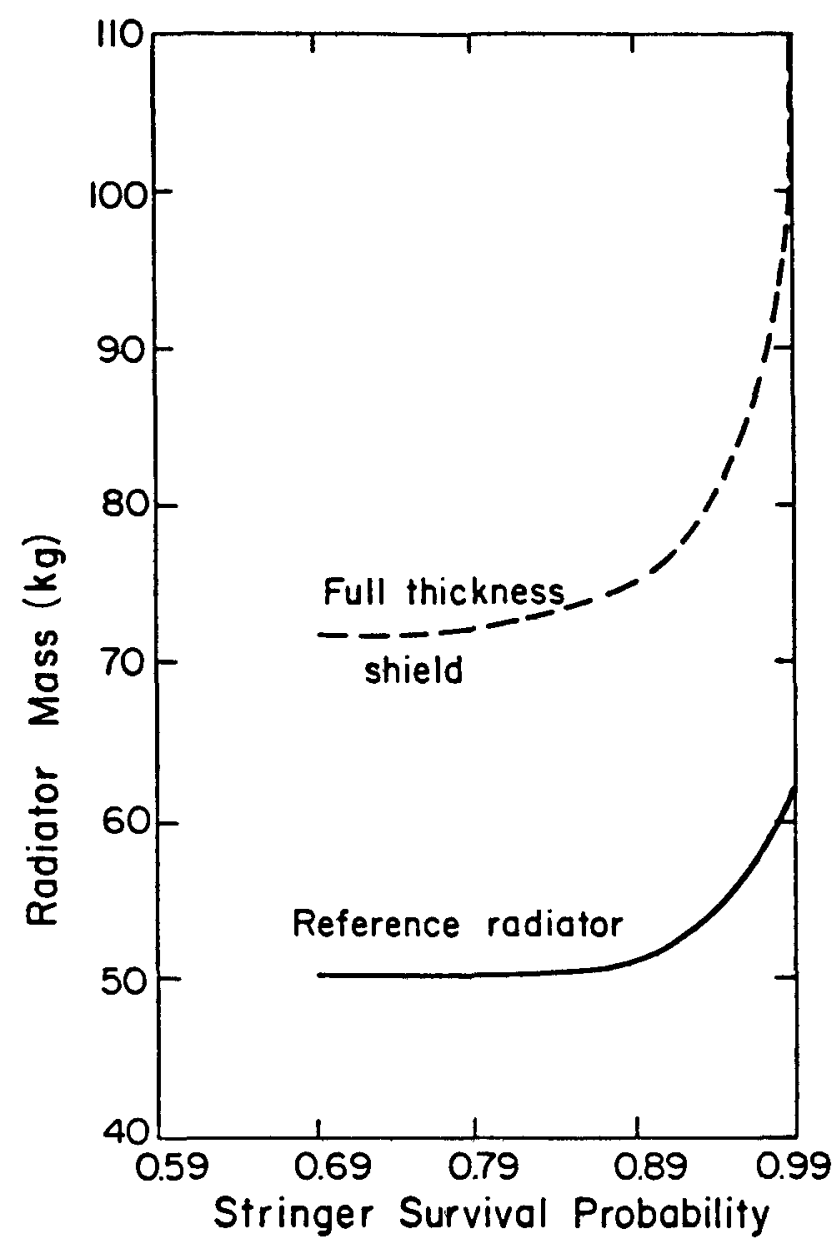

Fig 141. Radiator mass with and without bumper effect.

Figure 142 illustrates the radiator mass for the six candidate container materials considered. The materials were selected for their usefulness at elevated temperatures over long periods and for the availability of data from hypervelocity impact experiments. The hypervelocity impact data used for all the materials are from Refs. 9, 10, 11, and 12 except beryllium and titanium which were estimated. The rear surface damage factors for beryllium and tantalum were patterned after titanium. The cratering coefficient for Ti-6Al-4V and the temperature coefficient for tantalum were estimated. Results show that pure beryllium yields the lightest radiator, with Ti-6A1-4V giving the next lightest.

Figure 143 illustrates the effect of changes in heat-pipe fluid on the radiator mass. The cesium and potassium curves are similar because of the 
similar densities and sonic limits at the operating temperature. The mass of a radiator with mercury heat-pipe fluid is significantly larger, primarily because of the density of mercury. Potassium was chosen as the reference heat-pipe fluid because it has a higher latent heat of vaporization and a higher 1 iquid transport factor than cesium ${ }^{3}$ and yields the lightest radiators.

Figure 144 shows radiator mass as a function of stringer survival probability for the two assumed radiator surface configurations. Since allowance for shine through the base of the radiator cone is mission- and payload-dependent, the reference design is the conservative choice. The

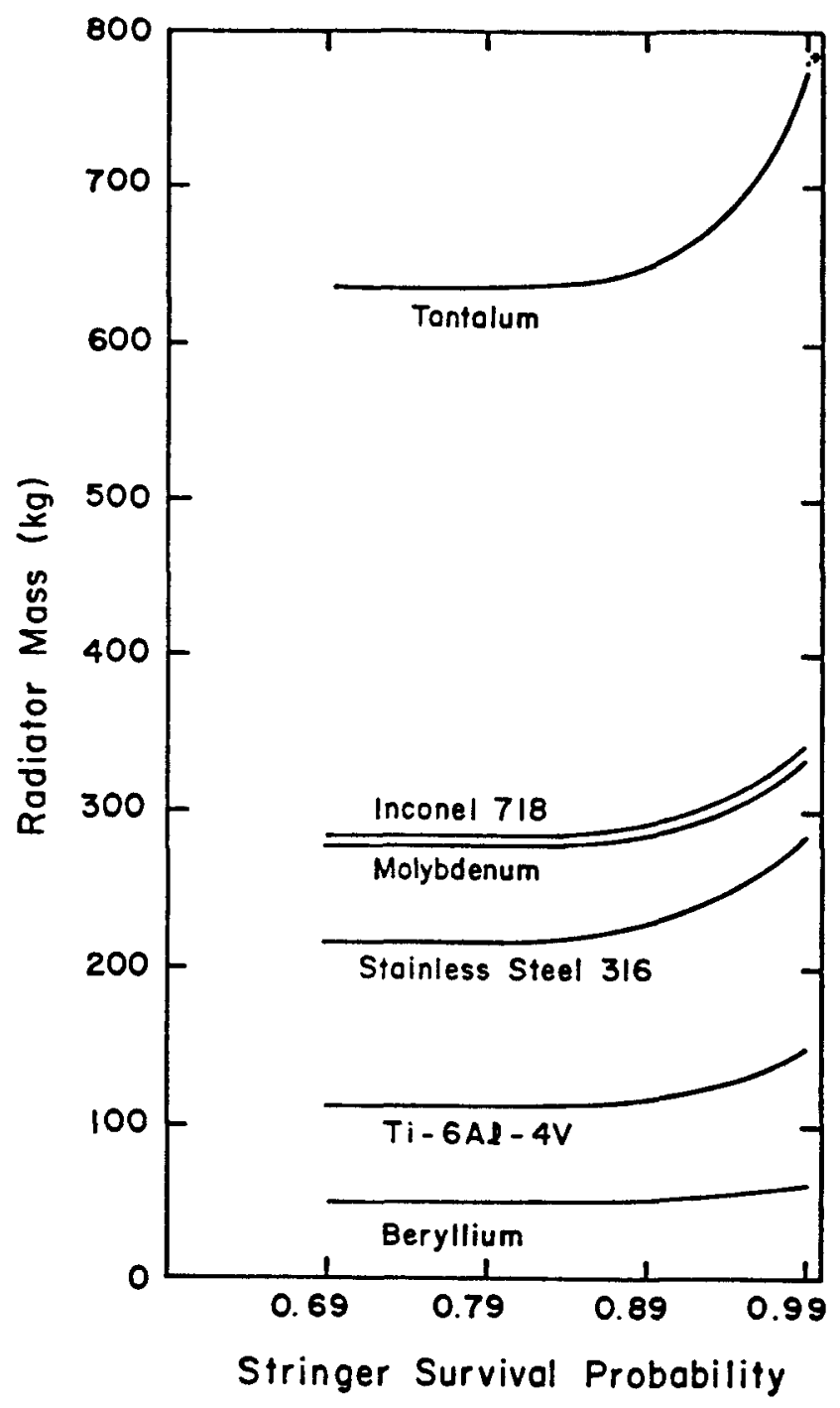

Fig. 142. Radiator mass for six candidate container materials. 


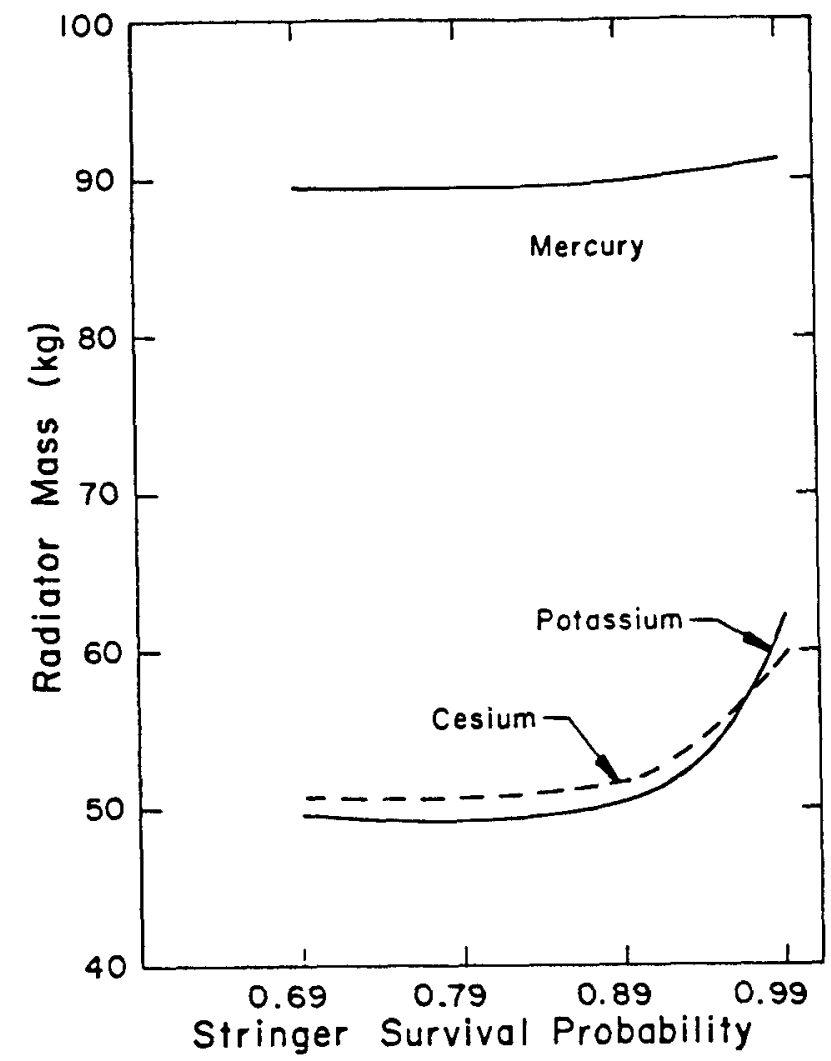

Fig. 143. Radiator mass for three candidate heat-pipe fluids.

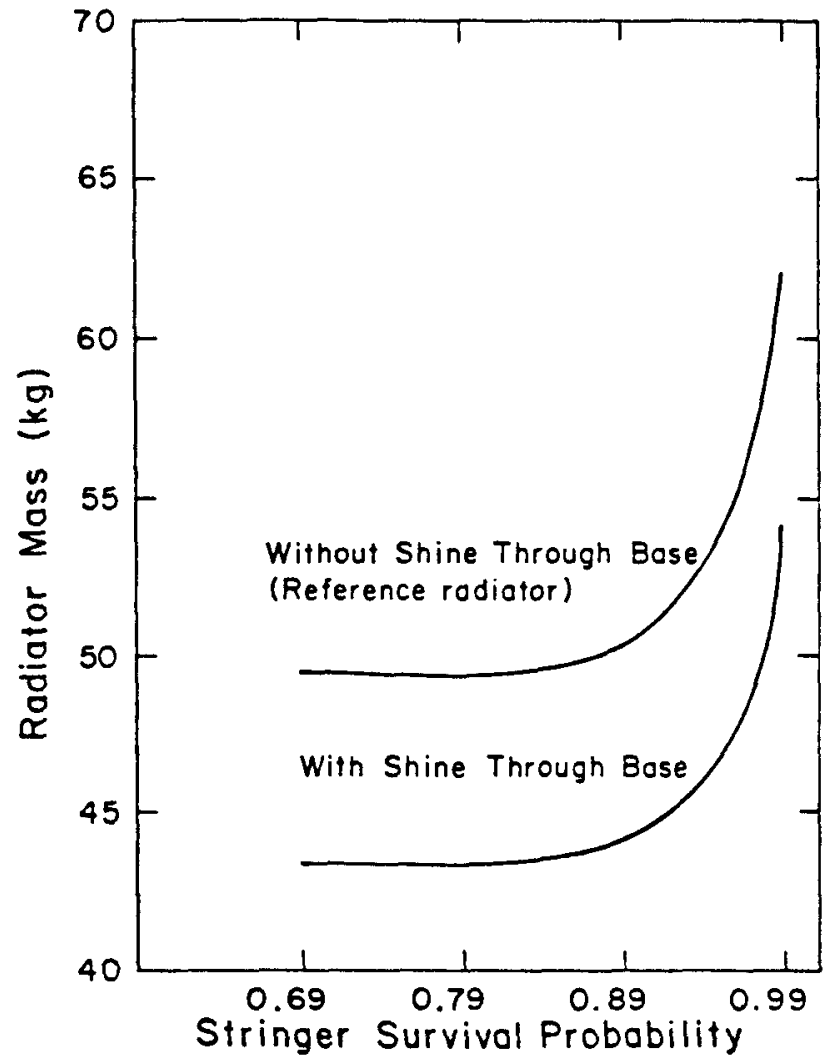

Fig. 144. Radiator mass with and without shine through base. 
mass of a radiator that allows shine through the base would be approximately $87 \%$ of the reference design mass.

Figure 145 illustrates the effect of operating temperature on the radiator mass. When the operating temperature was lowered from 775 to $675 \mathrm{~K}$, the radiator mass increased from $185-235 \%$ of the reference radiator mass.

With only one exception, all changes in the reference design assumptions or parameters increased the radiator system mass. The choice of a heat-pipe container material has the most significant effect on system mass. The material properties and empirical coefficients used to determine meteoroid shell thickness at the design temperatures should be well established for the selected container material.

b. Effect of System Size on Heat Pipe Radiator. Figure 146 is a plot of reject heat as a function of radiator systems mass for a stringer survival probability of 0.89 . Figures 147 and 148 are plots of reject heat as a function of radiator area and slant height, respectively. The curves indicate that the radiator mass, at a given stringer survival probability,

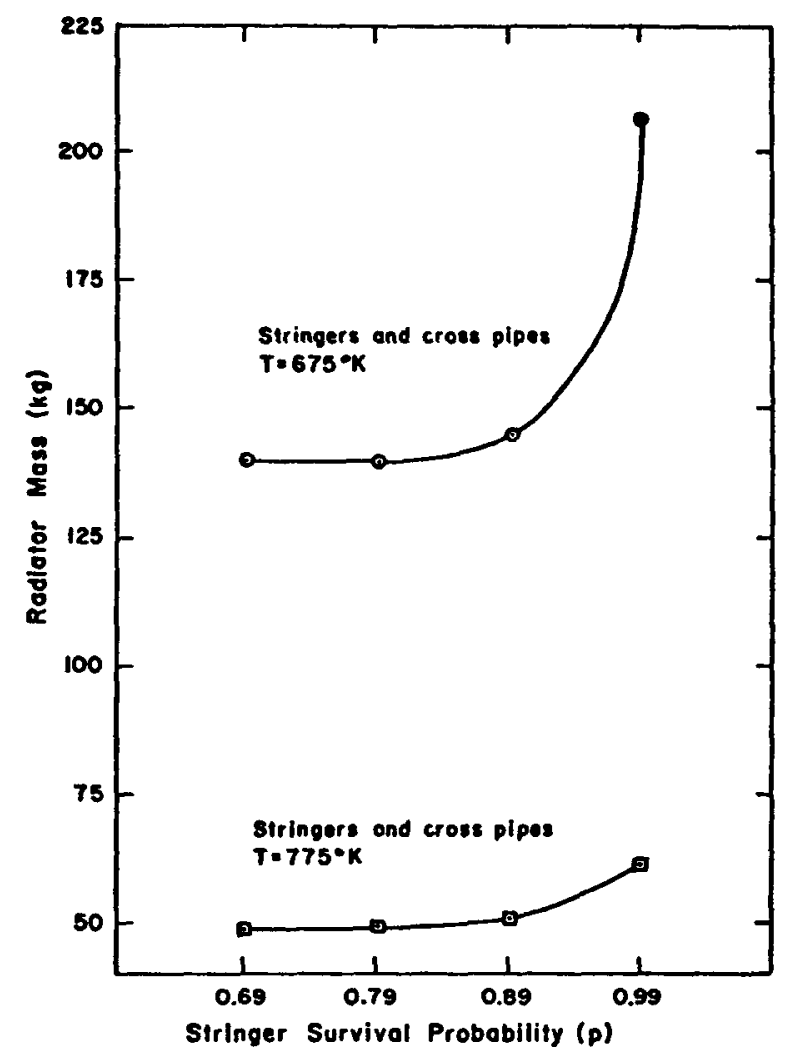

Fig. 145. Radiator mass for two operating temperatures. 


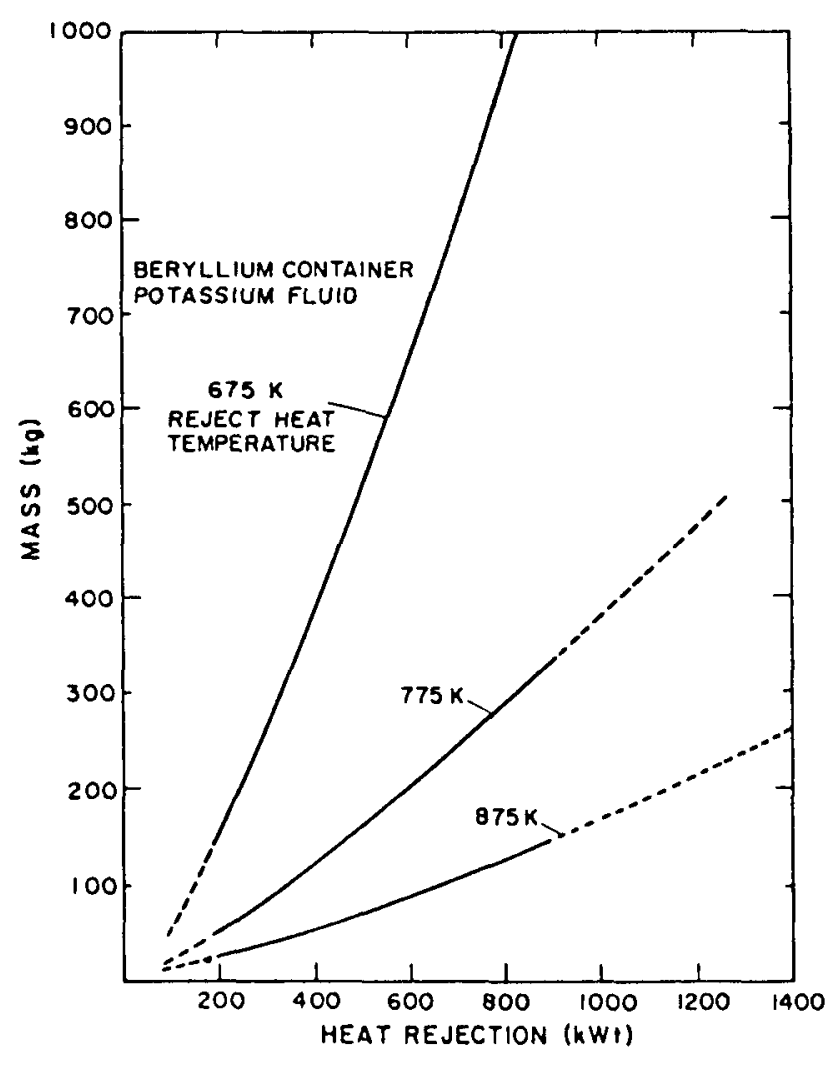

Fig. 146. Radiator mass vs reject heat.

increases nearly linearly with reject heat. Table XXXII lists size and mass information for the three different systems.

B. Low-Temperature Radiators (<650 K)

A reject heat system for the Brayton cycle was analyzed as a basis for understanding and evaluating power plants with lower-temperature radiators and fluid heat transfer systems. The study objectives were (1) to provide reliable estimates of the size and mass of the reject heat system for use in power plant parametric studies, (2) to identify potential problems associated with the design, and (3) to evaluate the technical feasibility of building the system. The reference case used in the study is a $200-\mathrm{kW}$ thermal reactor heat source, a $25 \%$ efficient Brayton closed-cycle converter and a 150-kW thermal heat rejection system. The mass goal established for the reject heat system for the reference case is $150 \mathrm{~kg}$ based on meeting the overall power plant mass goal. 


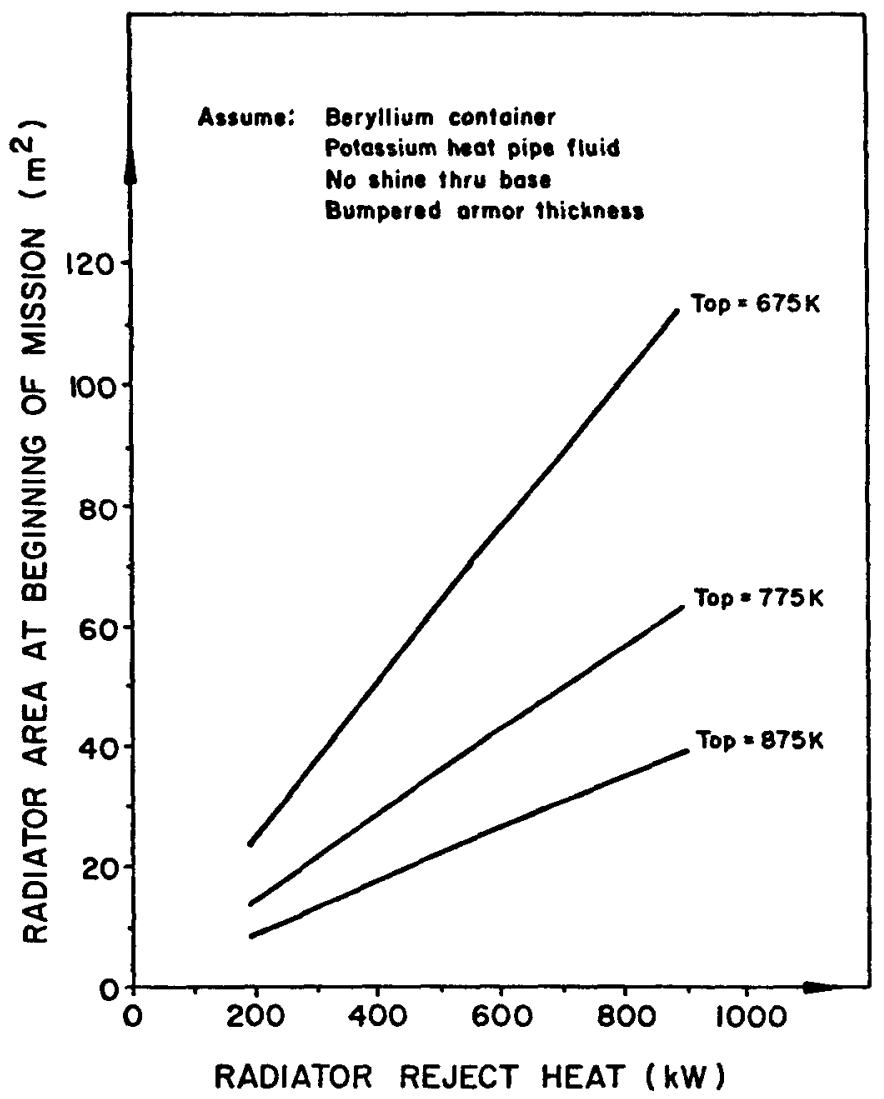

Fig. 147. Radiator area vs reject heat.

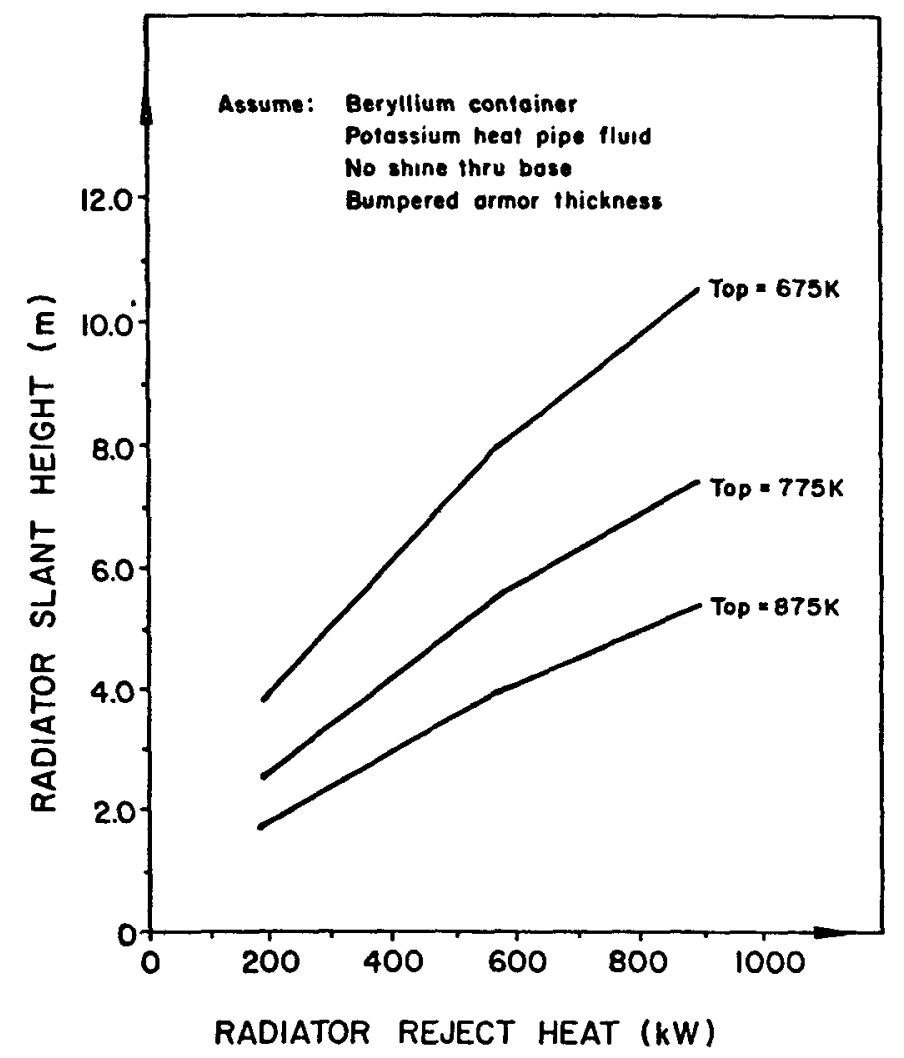

Fig. 148. Radiator slant height vs reject heat. 
TABLE XXXII

RADIATOR SYSTEM SIZE AND MASS DATA

$\begin{array}{lccr}\text { Reactor reject power (kW) } & 190 & 570 & 900 \\ \text { Qmax/stringer (W) } & 2645 & 7935 & 12549 \\ \text { Stringer i.d. (cm) } & 2.28 & 3.94 & 4.95 \\ \text { Armor thickness (cm) } & 0.12 & 0.174 & 0.20 \\ \text { Radiator small diameter (m) } & 1.18 & 1.18 & 1.18 \\ \text { Radiator large diameter (m) } & 2.23 & 3.47 & 4.27 \\ \text { Radiator slant height (m) } & 2.51 & 5.52 & 7.44 \\ \text { Radiating area at BOM (m) } & 13.45 & 40.34 & 63.7 \\ \text { Number of cross heat pipes } & 3263 & 7176 & 9672 \\ \text { Specific mass (kg/kW) } & 0.263 & 0.332 & 0.369 \\ \text { Stringer heat-pipe mass (kg) } & 15 & 82 & 160 \\ \text { Cross heat-pipe mass (kg) } & 23 & 75 & 123 \\ \text { Fluid and wick mass (kg) } & 12 & 32 & 49 \\ \text { Total radiator mass (kg) } & 50 & 189 & 332\end{array}$

The following constraints were imposed on the reject heat system for compatibility with the other parts of the power plant.

- The system is required to have a $99 \%$ probability of functioning at full-design heat load at the end of a 7-yr mission.

- The design must provide enough redundancy to insure against a single-failure point.

- The location of the system is confined to the region behind the shield and inside the shield shadow cone to avoid scattering radiation toward the payload.

- the power plant must be lightweight and fit inside the shuttle cargo bay.

To provide redundancy, it was decided to use two independent Brayton systems sharing a common heat source (the reactor) and common radiating elements. The only failure mechanism considered was puncture by micrometeoroids.

Two basic design ideas were investigated. The first introduces a heat exchanger between the Brayton converters and the radiating surfaces. Heat is extracted in the heat exchanger from the Brayton loops and distributed around the radiator by a tertiary fluid heat transfer system. The design 
incorporates two Brayton converters, a redundant cooler heat exchanger and several secondary, independent radiator coolant loops as shown in Fig. 149. The cooler heat exchanger is required to operate at full load with either or both Brayton units functioning and with at least three out of four radiator panels functioning. The heat exchanger is constructed in a shell and tube configuration, but the tubes are independent full-length heat pipes. Each heat pipe has two evaporator and four condenser sections and is specifically designed for its unique operating range of temperatures and heat flux levels. The radiator is a pumped-fluid design with a fin and armored tube arranged in four rectangular panels at right angles to each other.

The second design, Fig. 150, pumps the Xe-He Brayton converters working fluid directly through the radiator and then back to the converters. Heat pipes in the radiator extract heat from the Brayton converter fluid being pumped through the radiator in manifold heat exchangers. The radiating surfaces are the condenser sections of finned heat pipes which are arranged in four rectangular panels at right angles to each other.

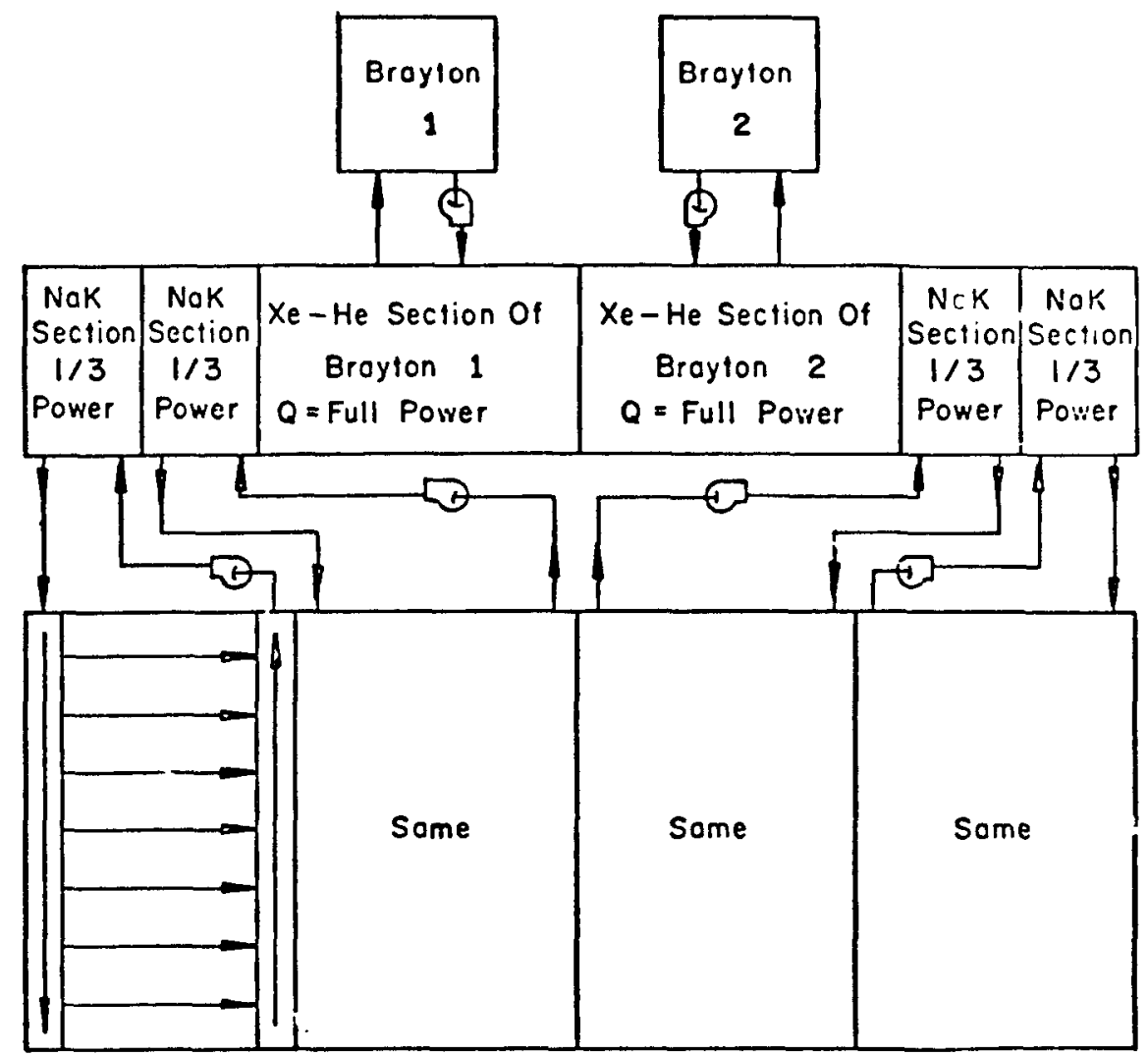

Fig. 149. Brayton cycle with tertiary heat rejection loop. 


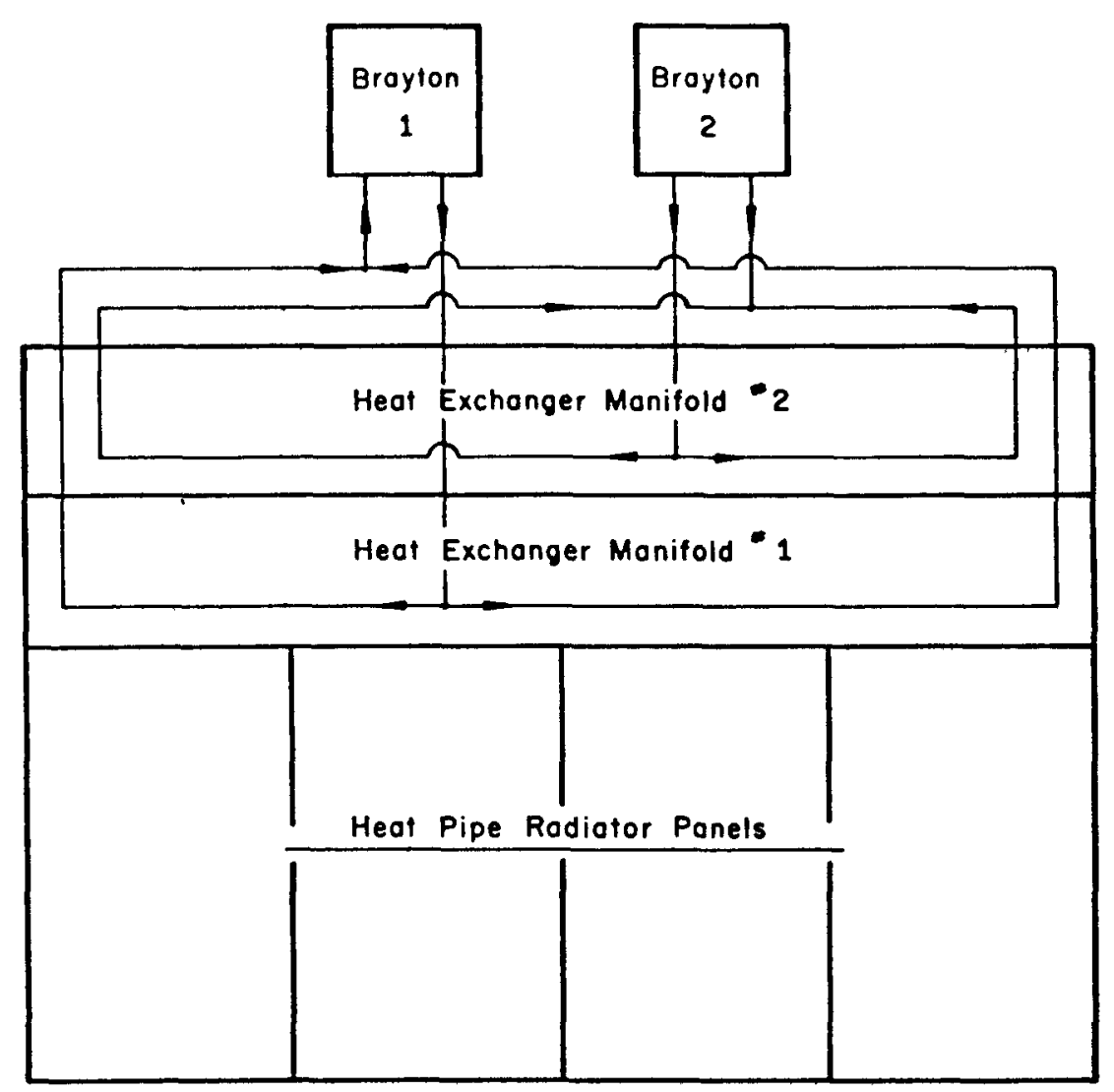

Fig. 150. Brayton cycle direct pumped heat rejection system.

\section{Tertiary Heat Rejection Loop Concept.}

a. Cooler Heat Exchanger Design. The Brayton system cooler heat exchanger is a modification of the general liquid-coupled, indirect-transfer type of heat exchanger. The modification entails the use of a system of heat pipes instead of a pumped-heat transfer medium between the direct transfer sections and eliminates the need for valves within the heat exchanger. The analysis was formulated from conservation principles and used experimental data where it could be applied.

The cooler looks like several shell and tube heat exchangers placed side by side, with the hot and cold fluids flowing in single-pass counter-current fashion. The cross flow of the heat exchanger refers to the exchange between each fluid circuit and the row of heat pipes that absorb or release heat between circuits. Figure 151 is a schematic of the proposed cooler heat exchanger.

To achieve the required redundancy, the shell must be divided so that each fluid circuit is independent and separately contained. The sizing was 


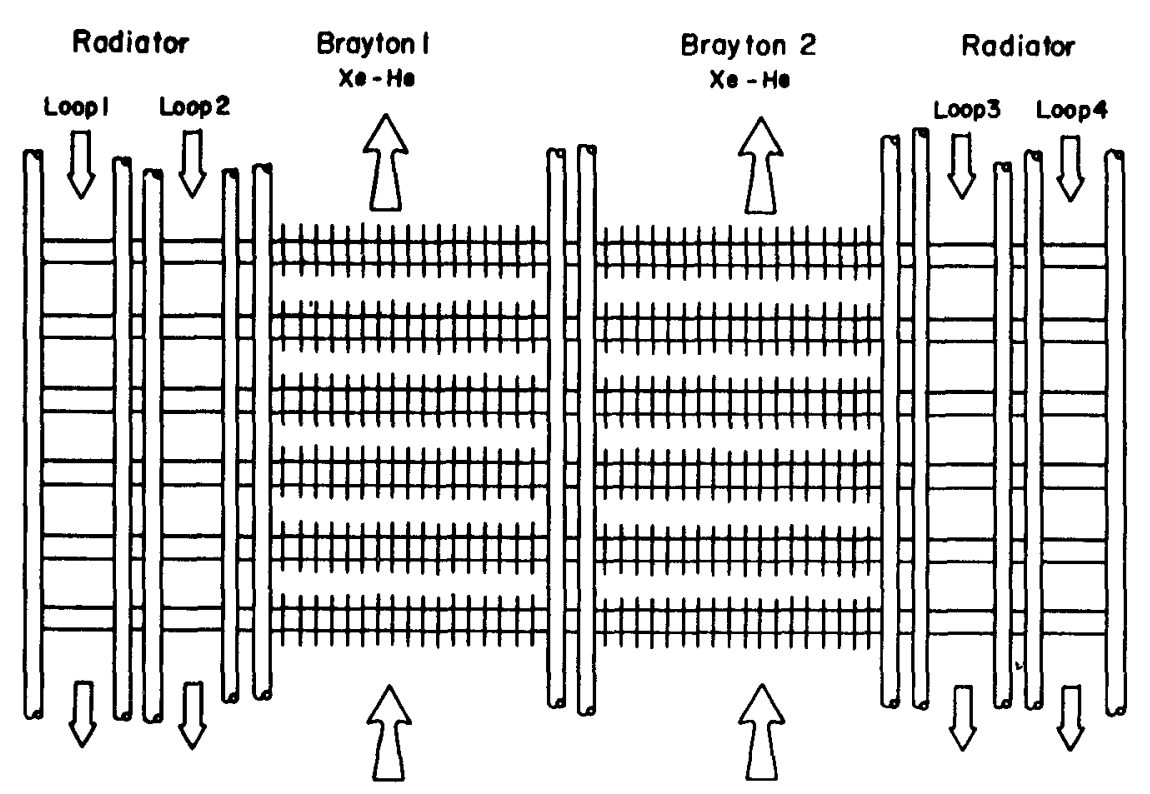

Fig. 151. Cooler heat-exchanger schematic.

done by assuming the worst-case conditions for operation, that is, one Brayton unit and three of the four radiator circuits functioning. The failed components have the effect of producing an adiabatic section in each heat pipe and of changing the pressure level at which the converter operates.

Fluids considered for the reject heat system must have an operating range of 400-650 $\mathrm{K}$ for either the working fluid for the heat pipes or the fluid for the pumped circuits to the radiator. The desirable properties for the heat-pipe working fluid are good thermal stability, high latent heat, high thermal conductivity and surface tension, low viscosity, and compatibility with wick and container materials. Thermex, a biphenyl organic fluid, is the only fluid that spans the entire temperature range. Water and mercury were considered for the upper and lower ends. Table XXXIII lists some of the relevant properties of water, Thermex, and mercury ${ }^{15-17}$.

The desirable fluid properties for the pumped radiator loops are low density and viscosity, high thermal conductivity, acceptable pour points, and constant properties over extended time periods. The high-temperature organic fluids and the liquid metals were considered. Table XXXIV lists some of the pertinent properties of Therminol 88, sodium, NaK, and the Xe-He Brayton working fluid. 
TABLE XXXIII

PROPERTIES OF CANDIDATE HEAT-PIPE WORKING FLUIDS

Thermex

\begin{tabular}{|c|c|c|c|}
\hline Properties a & Water & (Dowtherm A) & Mercury \\
\hline $\begin{array}{l}\text { Operating temperature } \\
\text { range }(K)\end{array}$ & $303-473$ & $423-668$ & $523-923$ \\
\hline Melting point $(K)$ & 273 & 285 & 234 \\
\hline $\begin{array}{l}\text { Boiling point at atmospheric } \\
\text { pressure }(K)\end{array}$ & 373 & 530 & 634 \\
\hline Average latent heat $(\mathrm{kJ} / \mathrm{kg})$ & 2216 & 278 & 294 \\
\hline $\begin{array}{l}\text { Vapor pressure range } \\
\left(\mathrm{Pa} \times 10^{-5}\right)\end{array}$ & $0.02-16.2$ & $0.01-19.0$ & $0.01-63.0$ \\
\hline $\begin{array}{l}\text { Average liquid conductivity } \\
(W /(m-K))\end{array}$ & 0.66 & 0.11 & 12.8 \\
\hline $\begin{array}{l}\text { Figure of merit at boiling } \\
\text { point }\left(\mathrm{kW} / \mathrm{m}^{2} \times 10^{-8}\right)\end{array}$ & 4.55 & 0.19 & 16.4 \\
\hline Container compatibility & $\begin{array}{c}\text { copper } \\
\text { stainless steel } \\
\text { monel }\end{array}$ & $\begin{array}{l}\text { copper } \\
\text { stainless steel } \\
\text { nickel }\end{array}$ & $\begin{array}{l}\text { stainless } \\
\text { steel }\end{array}$ \\
\hline
\end{tabular}

व The values for these properties come from Ref. 14.

Scoping calculations were performed to identify feasible alternatives. One calculation was based on $90^{\circ}$ cross flow over bare staggered tubes using the correlation for turbulent flow of a gas over exterior surfaces. 18 This correlation was checked with experimental data from Kays and London ${ }^{19}$ for the same spacing and tube sizes and yielded the same heat transfer coefficients. The assumed geometry was for a $0.20 \times 0.18 \mathrm{~m}$ frontal area with 0.013-m-diam tubes and yielded a 5.7-m-long heat exchanger. It was concluded that finned tubes would be required for the Xe-He fluid circuits.

A calculation done for finned, staggered tubes based on the Kays and London CF-8.72 geometry ${ }^{19}$ with the same frontal area yielded a 0.94-mlong heat exchanger with $8960 \mathrm{~Pa}$ pressure drop which is less than the 13790 $\mathrm{Pa}$ limit. A worst case calculation of the pressure drop was done using Kern's correlations ${ }^{20}$ that yielded a $25500 \mathrm{~Pa}$ pressure drop. These results were assumed to bracket the pressure drop expected in the core. It 
TABLE XXXIV

PROPERTIES OF PUMPED WORKING FLUIDS

Properties

\begin{tabular}{|c|c|c|c|}
\hline $\begin{array}{c}\text { Xe-He } \\
{ }^{2} \\
\text { (Mol.wt }=39.94)\end{array}$ & Therminol $88^{\mathrm{b}}$ & Sodium $^{\mathrm{C}}$ & $\mathrm{NaK}^{\mathrm{C}}$ \\
\hline any & $422-672$ & $400-1450$ & $400-1450$ \\
\hline 1 & 418 & 371 & 261 \\
\hline 520.4 & 2279 & 1330 & 946 \\
\hline
\end{tabular}

Fluid density $\left(\mathrm{kg} / \mathrm{m}^{3}\right)$

4.4-6.4

900

895

820

Fluid conductivity

$0.08-0.11$

0.12

80

25 $(W /(m-K)$

Container compatibility

$$
\begin{aligned}
& \text { aluminum } \\
& \text { steel } \\
& \text { copper } \\
& \text { beryllium }
\end{aligned}
$$

stainless stee 1

nickel stainless

steel nickel brass bronze

\footnotetext{
a See Ref. 15.

b See Ref. 16 .

c See Ref. 17 .
}

was found that a $0.35-\mathrm{m}$ cube on a side, yielded the smallest volume, transferred the required amount of heat, and was still inside the core friction drop limits.

Organic fluids were the first choice for the radiator fluid because of the ease of handling, high specific heat, and numerous compatible container materials available. A calculation assuming the same 0.35 -m-cube heat exchanger and correlations for cross flow of light oils across tube banks $^{21}$ shows that the organic circuit can deliver only $13 \%$ of the required heat load. The low conductivity and high Prandtl numbers typical of the organic fluids result in heat exchangers larger than is acceptable. 
The calculations were repeated using sodium and eutectic NaK properties and heat-transfer correlations. Data for the $90^{\circ}$ cross flow of liquid metals through rod and tube banks ${ }^{22}$ was located for the uniform wall temperature and uniform heat-flux boundary conditions. The uniform wall temperature was considered to be the most realistic boundary condition for short heat pipes. Results show that the required amount of heat can be transferred in a very small volume, $0.35 \mathrm{~m} \times 0.05 \mathrm{~m} \times 0.35 \mathrm{~m}$. Since sodium would be solid at launch temperatures, it was decided to use $\mathrm{NaK}$ as the heat-transfer fluid for the radiator circuits.

The heat-pipe performance was checked by assuming that each heat pipe would transfer a $1 / n$ fraction of the total heat load. The radial flux is in the range of $9-65$ watts $/ \mathrm{cm}^{2}$, which is acceptable for the water and mercury heat pipes. A check of several references on the operation of organic heat pipes shows that the critical flux is $\sim 26-30$ watts $/ \mathrm{cm}^{2}$ (Ref. 23) for heat pipes with Refrasil 96-100 and sintered fiber wicks, and about $0.8-2.5$ watts $/ \mathrm{cm}^{2}$ (Ref. 24) for heat pipes with fine wire mesh wicks in several polygon shapes. Since the average radial flux calculated for each heat pipe was much higher than the data reported, it was concluded the heat-pipe performance must be included in the calculations to size the direct heat exchangers for the gas and liquid circuits. Later in the study, calculations were done assuming grooved wicks for water and mercury heat pipes. The results showed that both fluids could be stretched to cover the organic fluid temperature range without encountering radial flux, sonic limit, or viscous problems.

Appendix III-A provides a description of the computer program used to analyze the heat exchanger. Figure 152 shows an illustration of the proposed cylindrical Brayton system reject heat exchanger. The pressure vessel thickness was determined from ASME code ${ }^{25}$ which is somewhat more conservative than the thickness calculated from the thin wall cylindrical vessel assumptions. The heat exchanger mass vs drum diameter is plotted in Fig. 153 and shows a minimum mass of $290 \mathrm{~kg}$ at $0.95 \mathrm{~m}$.

b. Pumped-Liquid Radiator Design. Since NaK was selected as the working fluid for the radiator circuits, the conceptual design of the pumped-liquid radiator was limited to materials compatible with liquid metals at moderately high temperatures. The structure and general shape of the folding plate "accordion" design is illustrated in Fig. 154 in the 


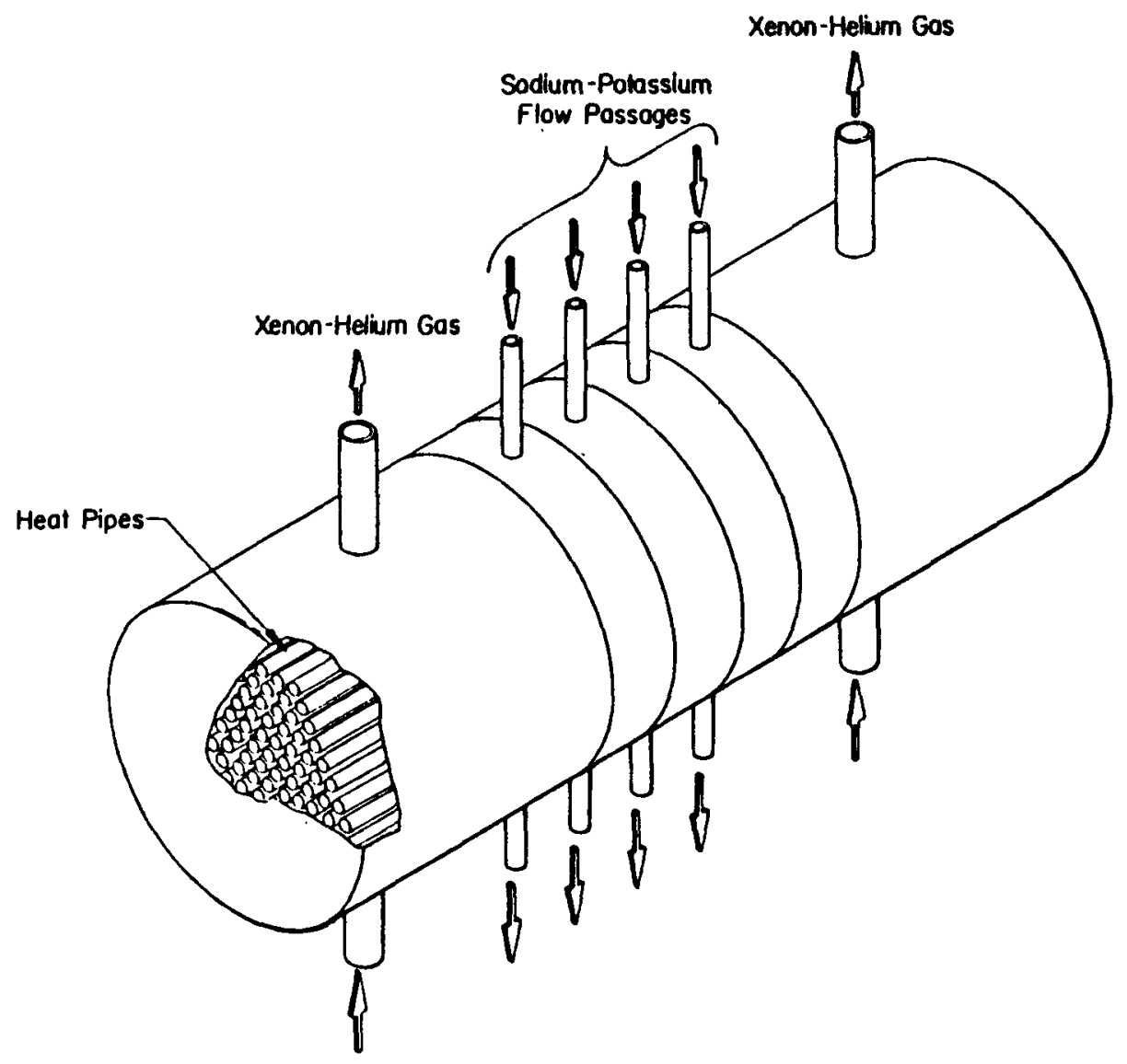

Fig. 152. Brayton system reject heat exchanger.

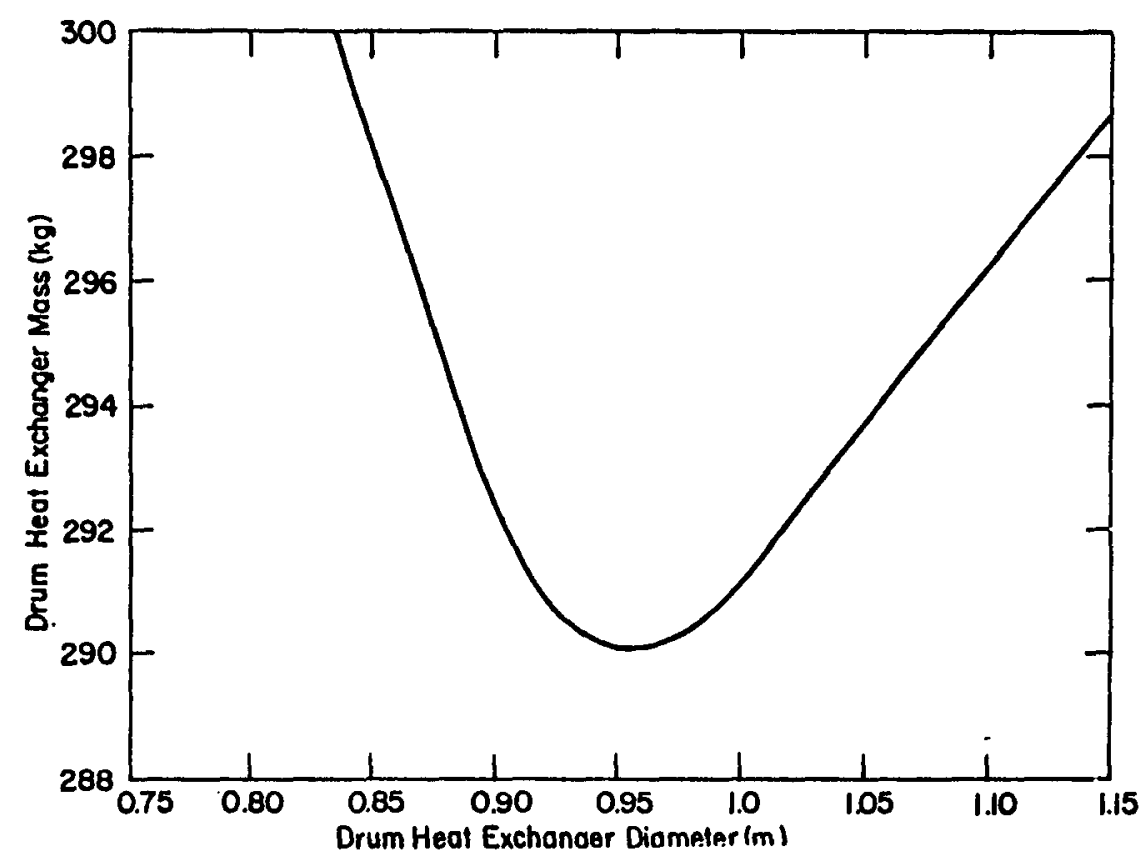

Fig. 153. Drum heat exchanger mass vs diameter. 


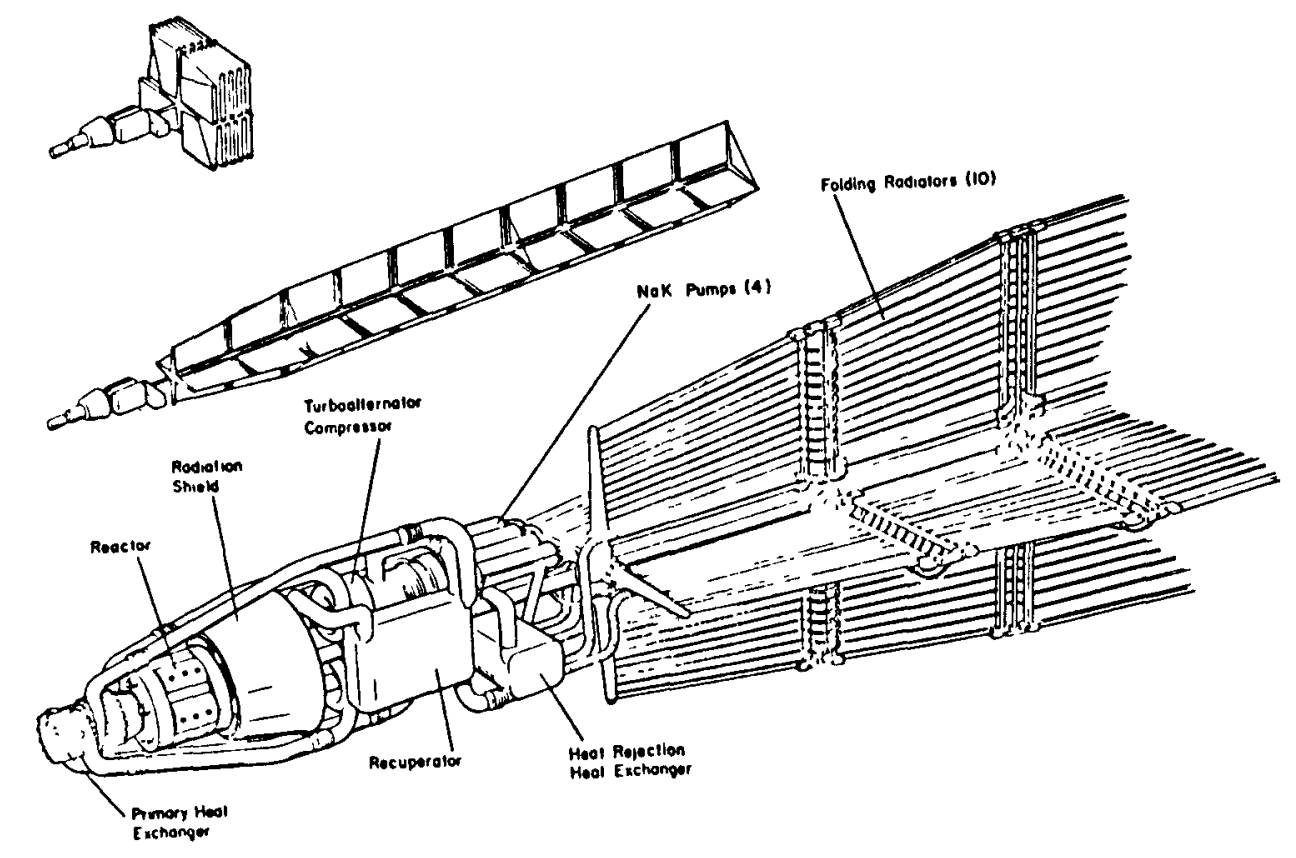

Fig. 154. Brayton cycle pumped-liquid radiator design.

folded and extended modes. The design of the radiator assumes the use of four independent panel arrays to fulfill the requirement that three out of four arrays have a $99 \%$ probability of surviving a 7-yr mission.

The forward section uses trapezoidal panels with asymmetric fins and coolant flow tubes nearly parallel to the axis of the system. The trapezoidal section allows the radiator to be situated directly behind the reject heat exchanger and the electromagnetic pumps and still fit inside the shadow shield cone. The second section of the radiator is composed of an even number of rectangular panels sized so that the folded radiator fits into the cargo bay of the Space Shuttle.

The formulation of the heat transfer problem is based on the incremental section of radiator shown in Fig. 155. The fin and armored tube geometry is illustrated in Fig. 156. The equations are included in Appendix II I-B.

The three candidate materials were pure beryllium, titanium-6Al-4V, and aluminum-2024-T6 for the flow tubes, manifolds, and fins. Titanium radiators are considerably heavier than either aluminum or bervllium and were not considered further. Because the corrosion resistance of aluminum 


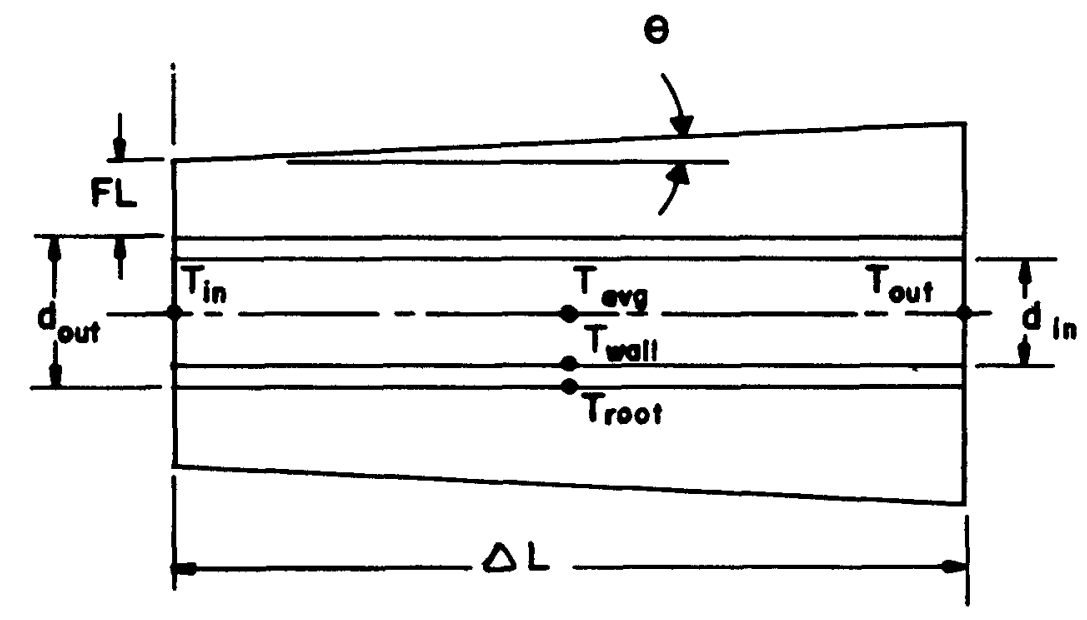

Fig. 155. Incremental section of radiator.

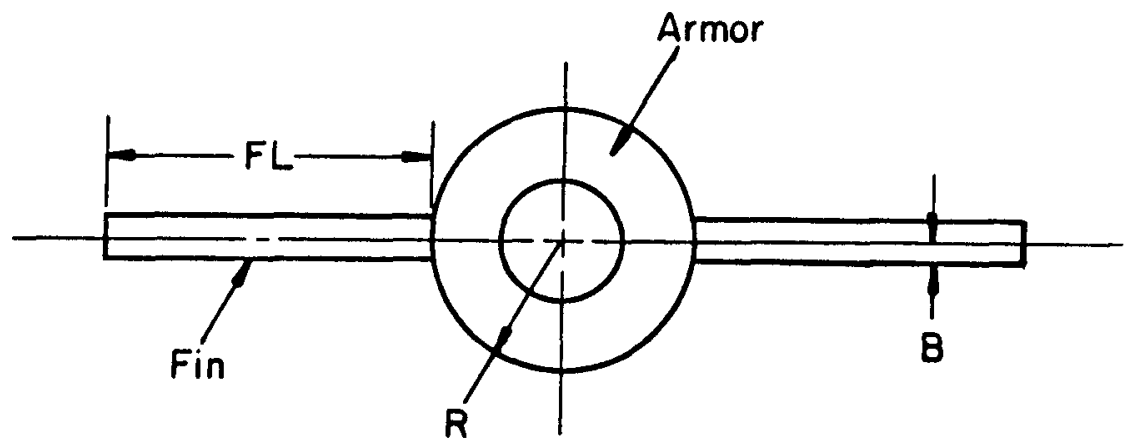

Fig. 156. Fin and armored tube geometry.

to NaK at the hot end of the radiator is unknown ${ }^{26}$, aluminum was el iminated.

A parameter study was done to identify a minimum-mass design point. Plots were made of the radiator mass and length as a function of two dimensionless ratios $F L / R$, the fin half-length over the flow tube outer radius, and $F L / B$, the fin half length over the fin half thickness. Figure 161 shows a clear local minimum mass at $F L / R$ of about 12. Using this $F L / R$ ratio, the calculations were repeated for various ratios of FL/B. Figure 162 shows that radiator mass seems to reach an asymptote and provides a minimum practical choice of fin thickness. The radiator length, and consequentiy, the frictional pressure drop increase sharply with increasing $F L / R$ as shown in Fig. 163. It was found that the pressure drop developed 
in the NaK flow tubes was about five to ten times greater than current designs of NaK electromagnetic (EM) pumps were capable of producing. The helical induction types of pumps developed for potassium were the only category that fulfilled the flow rate and pressure drop criteria but had a mass of $113 \mathrm{~kg}$ each. ${ }^{27}$

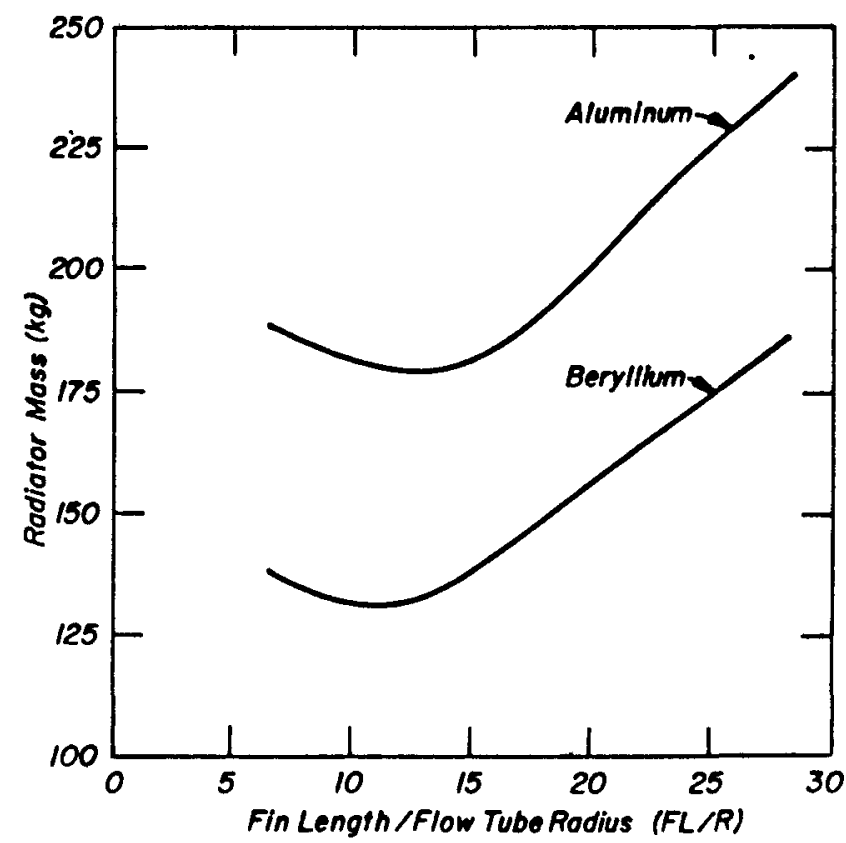

Fig. 157. Radiator mass as function $F L / R$ at $R=5 \times 10^{-3} \mathrm{~m}$ and $B=3.3 \times 10^{-4} \mathrm{~m}$.

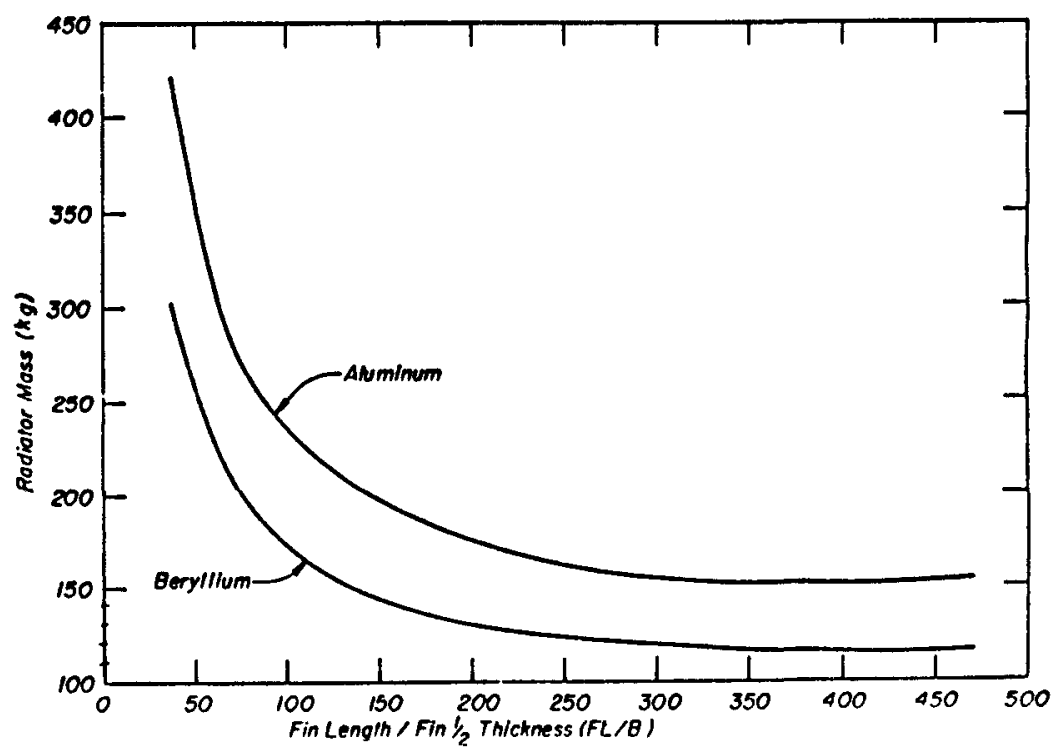

Fig. 158. Radiator mass as a function of $F L / B$ at $R=5 \times 10^{-3} \mathrm{~m}$ and $F L / B=12.2$. 


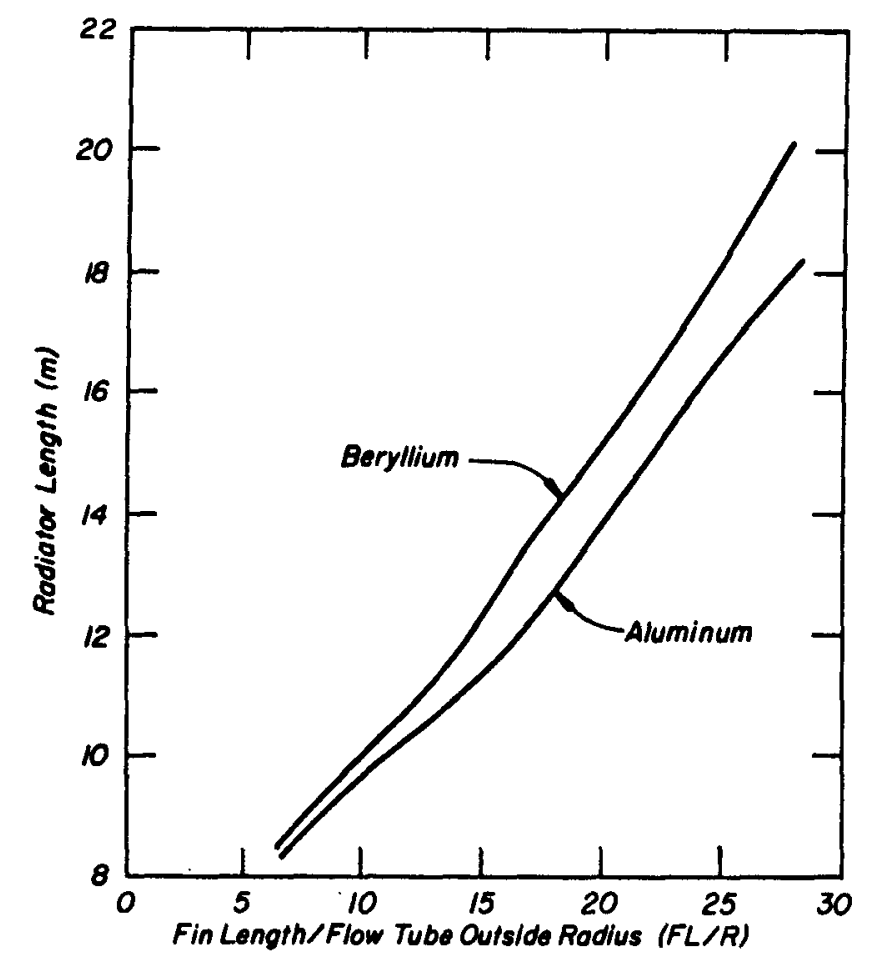

Fig. 159. Radiator length as a function of $F L / R$ at $R=5 \times 10^{-3}$ and $B=3.3 \times 10^{-4} \mathrm{~m}$.

The sum of the mass of the reject heat exchanger, NaK radiator, and four electromagnetic pumps is $872 \mathrm{~kg}$. This total does not include the mass of any support structure or mechanism to unfold the radiator. The total is still almost six times heavier than the mass goal set for the entire reject heat system. It was concluded that the omission of the NaK loop should be investigated in an effort (1) to avoid electromagnetic pump development programs and to (2) find a lighter design.

2. Direct Pumped Gas Heat Rejection System. The omission of the NaK loop requires that the $\mathrm{Xe}$-He working fluid be pumped by the compresser through an armored manifold heat exchanger on the radiator surface. This system design had initially been avoided because of the increased vulnerability of the Brayton converter loops. One puncture in a heat exchanger flow tube would disable a Brayton converter, one loop of the heat-source heat exchanger, and one loop of the reject heat exchanger. This system must still satisfy the criteria that it have a $99 \%$ probability of functioning at full load for a 7-yr mission. The component survival probabilities were chosen as $p=0.9975$ for each of the manifold heat exchangers and as 
$0.69 \leq p \leq 0.99$ for the numerous heat pipes based on the cumulative binomial survival probability of 0.995 .

This concept has the advantage of simpler mechanical and thermal design because of the (1) omission of the intermediate heat transfer fluid, tubing, and pumping equipment, (2) omission of several series thermal resistances, and (3) the possibility of using aluminum as well as beryllium for the container material. The availability of aluminum tubing and extruded shapes is large and varied and would be much less costly to fabricate than beryllium. A major disadvantage, besides the low redundancy, is also a result of the simpler mechanical design, poor heat transfer methods as compared to those used in the extended-surface, heat-pipe heat exchanger.

The pumped-gas radiator is composed of four panels arranged at right angles to each other and placed directly behind the Brayton converters as illustrated in Fig. 160. To simplify the calculations, the panels were assumed to be rectangular with a height small enough to fit inside the Space Shuttle. Neutronics calculations on a similar design have shown that

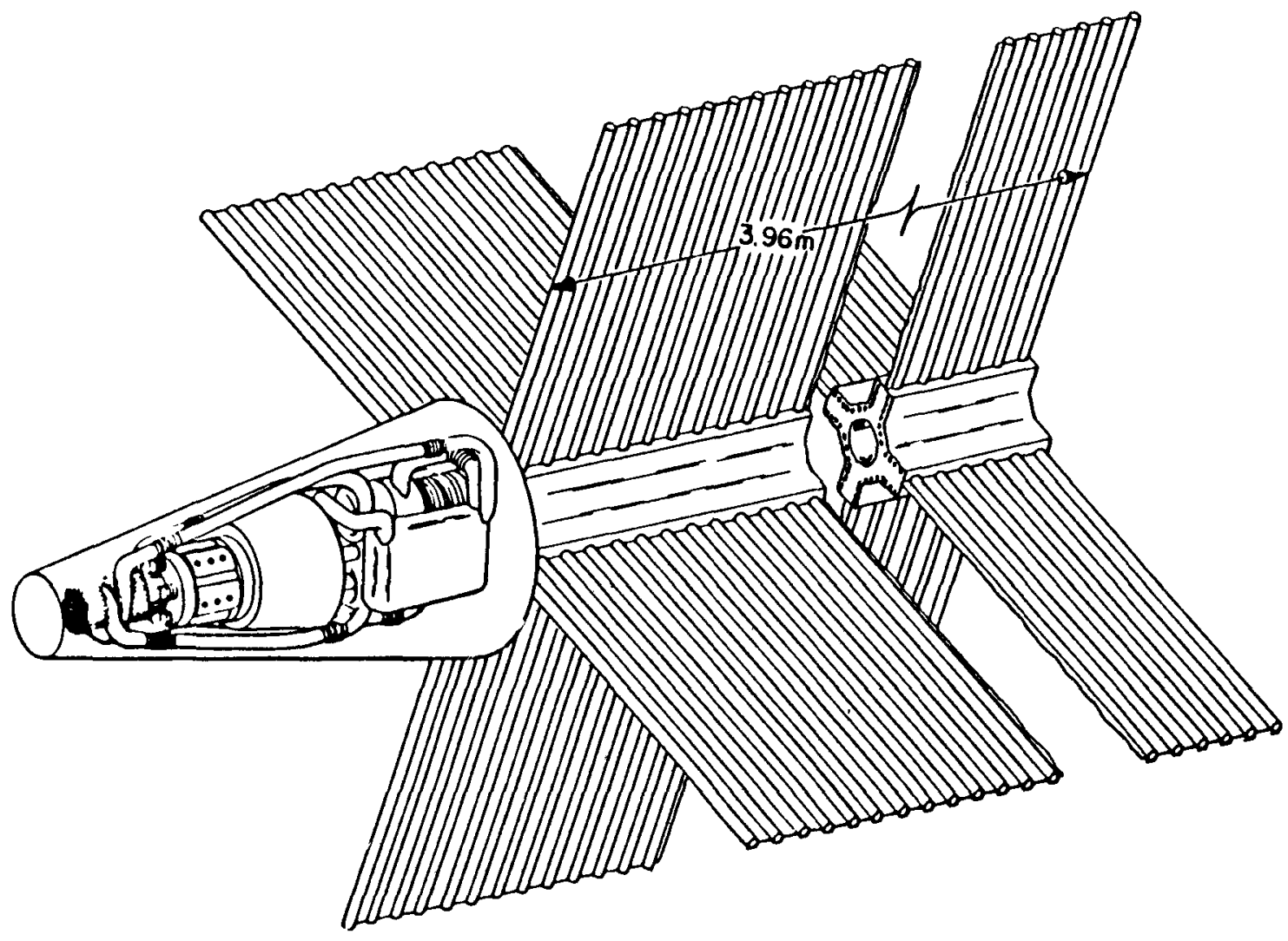

Fig. 160. Pumped-gas Brayton cycle and reject heat system. 
the radiator and manifolds must be behind the shield, but not necessarily inside the shadow cone, to obtain an acceptable level of neutron fluence at the payload. The manifold heat exchanger consists of many parallel gas flow tubes placed at the evaporator end of the radiator heat pipes as shown in Fig. 161. Gas flow in the manifold is single-pass from the converter to the end of the radiator on one panel and then back to the converter via the adjacent panel as shown in Fig. 162. This arrangement allows each heat pipe to receive energy from both converters at the same temperature, pressure, and heat flux. Puncture of a'heat pipe sacrifices only that pipe and not an entire radiator panel.

Formulation of the heat transfer for this system allows for the simultaneous solution of the heat exchanger equations, heat-pipe performance and radiation to space. Figure 163 illustrates an incremental radiator section with a heat-pipe and tube heat exchanger on which the formulation is based. Each section consists of one radiator heat pipe, adjoining fins, the cruciform structural support, and the multitube heat exchanger from both converters. The equations to describe the system are given in Appendix III-C.

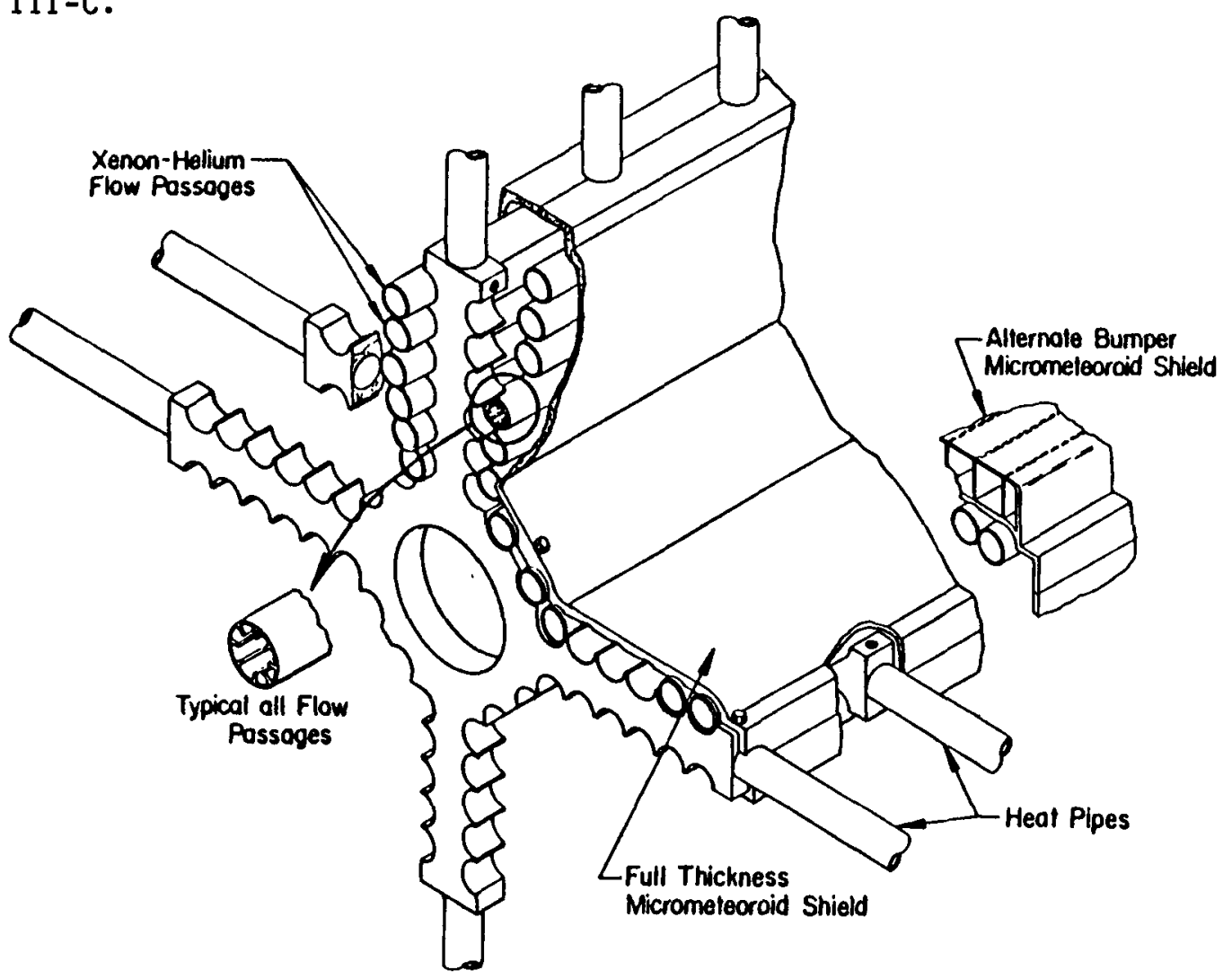

Fig. 161. Brayton system reject heat exchange manifold. 


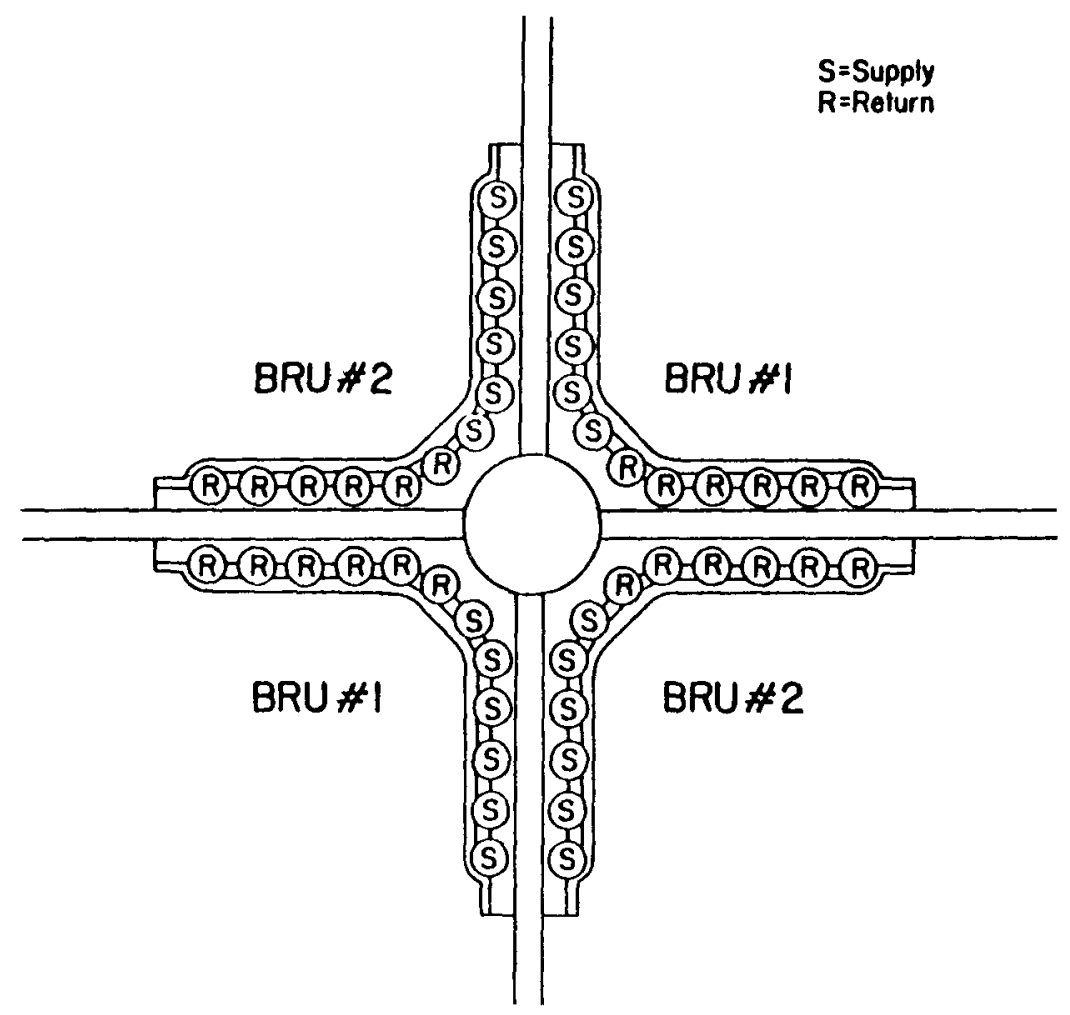

Fig. 162. Gas flow pattern in manifold.

A parameter study was done to identify a minimum-mass design point. Plots were made of the radiator mass as a function of gas flow tube diameter of the radiator $f$ in half-length. A minimum practical fin thickness of $0.76 \mathrm{~mm}$ was assumed for all calculations. Figure 164 shows that reject heat system mass seems to reach an asymptote for small numbers of 1 arger diameter flow tubes. The reject heat system mass at a flow tube diameter of $0.05 \mathrm{~m}$ is $436 \mathrm{~kg}$ for the radiator, $91 \mathrm{~kg}$ for the heat exchanger and 882 $\mathrm{kg}$ for full thickness armor which gives $1409 \mathrm{~kg}$ total. A large flow-tube diameter and the minimum fin thickness were used in the calculations of various fin half-lengths. Figure 165 illustrates that the mass is smallest for the short high-efficiency fins.

The minimum mass is a combination of several large-diameter smoothsurface flow tubes and many independent heat pipes with short fins. The poor heat transfer dictated by the smooth tubes results in larger temperature drops across the gas film than had been anticipated. Figure 166 


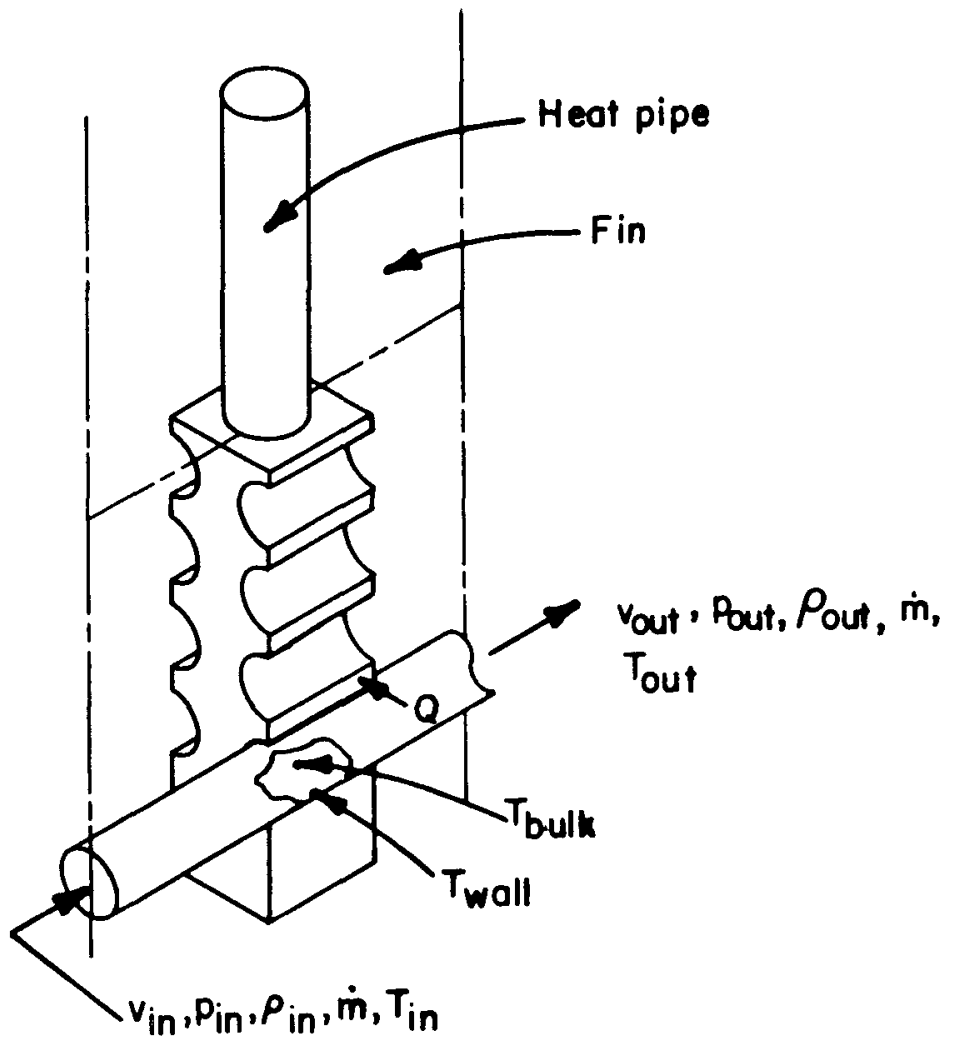

Fig. 163. Incremental heat pipes and heat exchanger manifold.

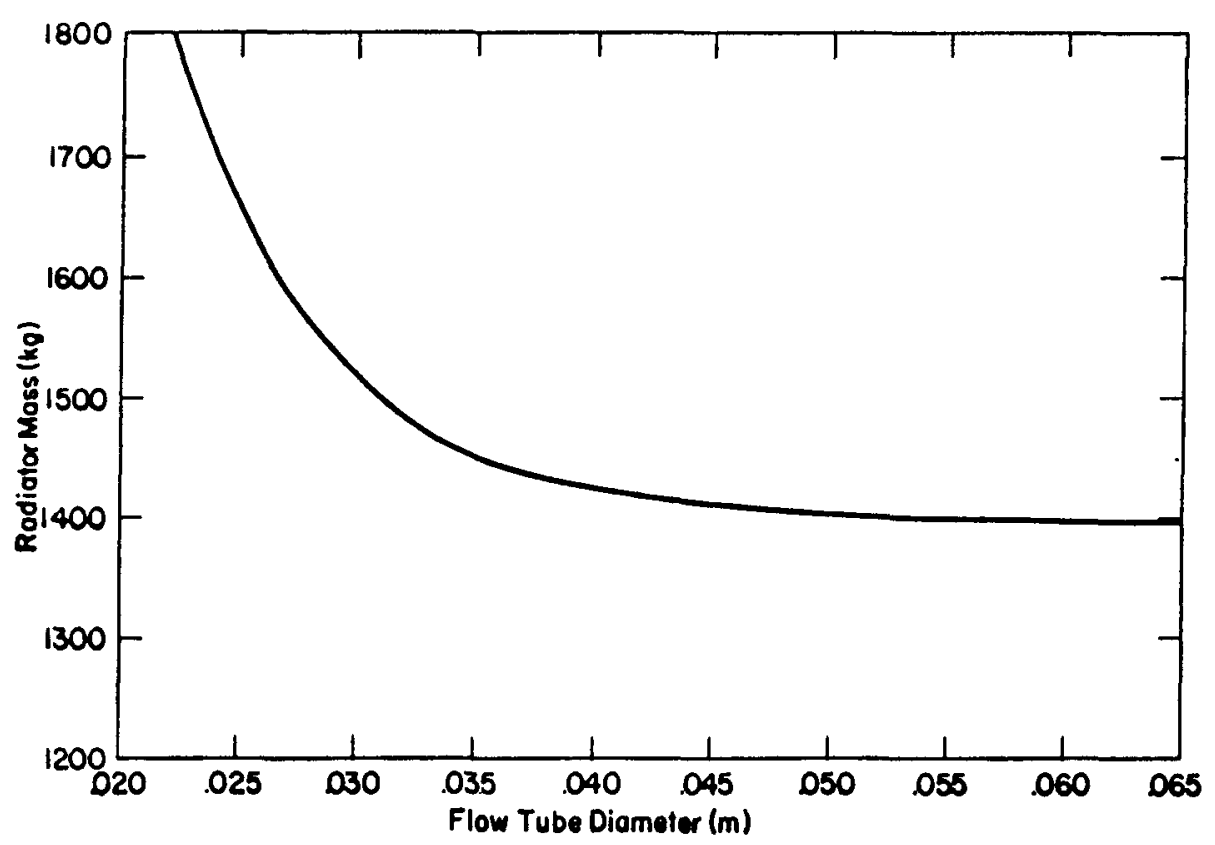

Fig. 164. Radiator mass vs flow tube diameter. 


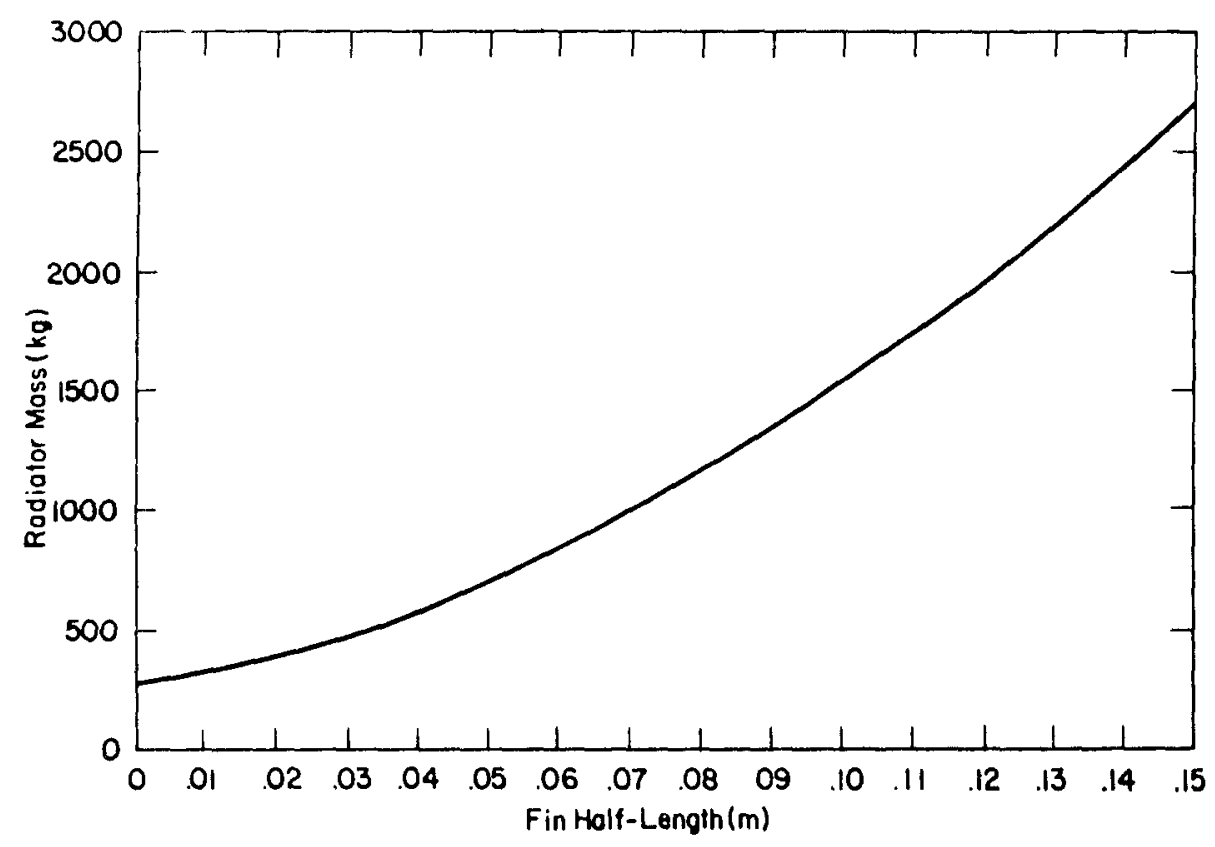

Fig. 165. Radiator mass vs fin half-length.

illustrates the gas and heat-pipe operating temperatures as a function of distance along the flow passage. The heat-pipe temperatures are low enough to permit the use of water for the working fluid throughout.

The mass of this design is

(1) radiator (heat pipes, working fluid, wick, and fins) $=198 \mathrm{~kg}$,

(2) heat exchanger (flow tubes, cruciform, and circle structure)

$=50 \mathrm{~kg}$, and

(3) shield $=316 \mathrm{~kg}$.

Use of the bumpered armor technique ${ }^{5}$ would reduce the shield to 158 $\mathrm{kg}$, with a resulting radiator mass of $406 \mathrm{~kg}$. This result is two to seven times larger than the $150-\mathrm{kg}$ goal set for the reject heat system, but is the lightest design found in this study.

Further reductions in reject heat system mass are obtainable by allowing the frictional pressure drop through the heat exchanger manifold to increase. This alternative must be considered if there are increases in the mass of the compressor or other machiriery in the system.

C. Summary

A conceptual design was prepared for both of the basic concepts shown schematically in Figs. 149 and 150. The intermediate Nak loop with a cylindrical-vessel heat-pipe heat exchanger has a mass of $872 \mathrm{~kg}$ for the 234 


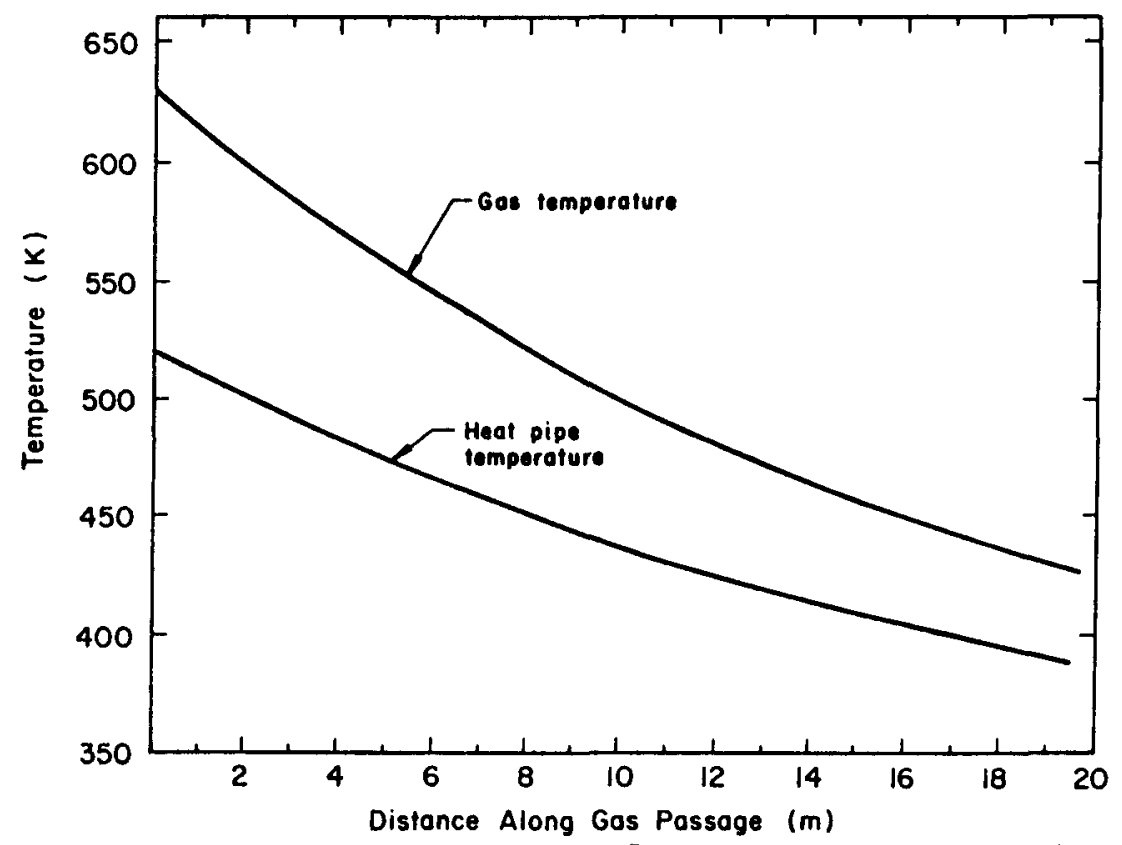

Fig. 166. Direct pumped Brayton cycle heat exchanger and radiator, $200 \mathrm{~kW}_{\mathrm{t}}, \mathrm{n}=25 \%$, Xe-He gas $\mathrm{mol} \mathrm{wt}=39.94$.

electromagnetic pumps, heat exchanger, and radiator alone. This is 5.8 times larger than the $150-\mathrm{kg}$ goal.

The direct pumped-gas design has a minimum mass of $406 \mathrm{~kg}$, which is 2.7 times larger than the goal, but is the lightest obtained in the study. It was concluded that the direct pumped-gas design is the better candidate for a low-temperature heat rejection system because of lower mass, simpler design, fewer components, and fewer size constraints.

D. Materials

The materials for the waste-heat radiator depend upon the selected power conversion system because of the temperature of the reject heat. As previously noted, the reference heat rejection temperature of the thermoelectric system is $775 \mathrm{~K}$, whereas the reference heat rejection temperature for the Brayton system ranges from 400 to $600 \mathrm{~K}$. Because of the resultant design differences, the materials for each power conversion system will be discussed separately.

The factors that must be considered when selecting materials for heatpipe radiators include heat transfer capability (this includes thermal emissivity, solar absorptivity, and thermal conductivity), strength-toweight resistance to meteoroid impact damage, and heat-pipe working fluid compatibility and fabricability. 
1. High-Temperature Materials (>650 K). Because of its elevatedtemperature heat transfer capability and density considerations, potassium has been chosen as the reference heat-pipe working fluid for the thermoelectric radiator, which limits the heat-pipe materials to those metals and alloys that are not corroded significantiy by potassium. The corrosion mechanism is one of dissolution into the pure liquid-metal condensate followed by transport to and precipitation at the evaporator. Both ferritic and austenitic steels, nickel-base alloys, and refractory metals are known to have good potassium corrosion resistance and so are considered for radiator heat pipes. Among the lightweight metals, beryllium and titanium are reported ${ }^{28}$ to have good resistance to corrosion by potassium up to $875 \mathrm{~K}$, so they are also candidate materials. As we shall see, only a few specific titanium alloys have sufficient high-temperature strength and stability to be considered, but their resistance to potassium corrosion is not known. Consequently, these alloys plus any other prime-candidate heat-pipe materials must be evaluated on the basis of long-term potassium corrosion resistance at temperatures close to the expected operating temperature.

Thermal conductance of the radiator heat-pipe wall is an important consideration. The thermal conductivity density ratios of several candidate heat-pipe materials are compared in Fig. 167. Note that beryllium possesses the highest conductivity relative to its density, with the molybdenum alloy TZM coming next. Nickel, low-carbon steel (Fe-0.2 C), vanadium, and the titanium alloy Ti-8Al-1Mo-IV are closely grouped together after TZM, and 304 stainless steel and Inconel 718 (IN-718) have the poorest thermal conductivity density ratio.

Because most metals have low thermal emittances, which is contrary to the requirements of a waste-heat radiator, high emissivity coatings must be applied to the radiator heat pipes. Another requirement for an Earthorbiting power system is that the waste-heat radiator surfaces have a low solar absorptance $\alpha_{s}$. (Most bare metals have high values of $\alpha_{s}$.) However, because the solar input is small compared to the energy output, solar absorptance is not as important as high emissivity. Criteria for selecting an emissivity coating include its thermal conductivity, specific heat, and thermal diffusivity. A thorough discussion of the selection 


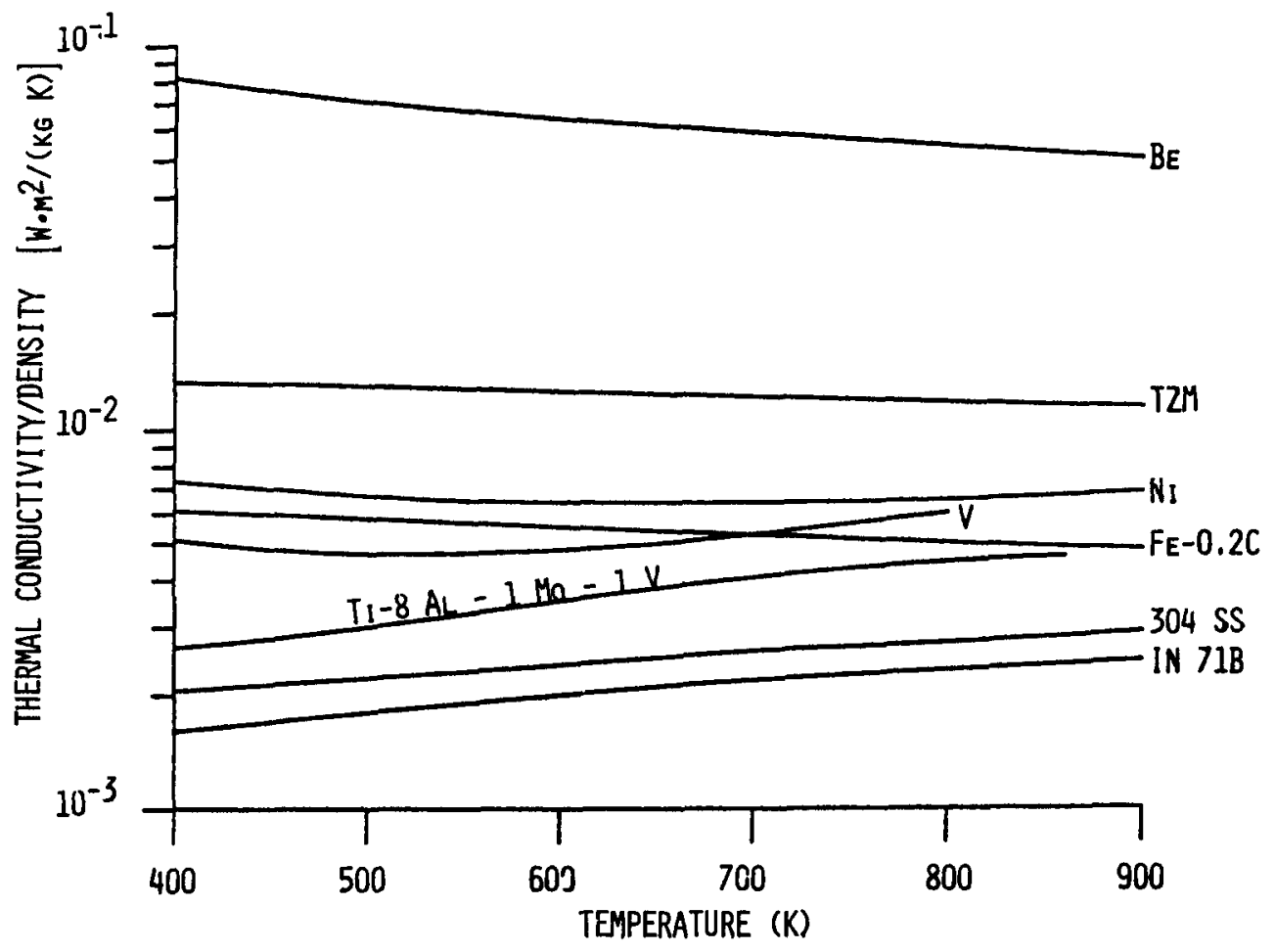

Fig. 167. Thermal conductivity/density ratios of candidate thermoelectric radiator materials.

procedures for "thermal control" materials can be found in the Space Materials Handbook ${ }^{29}$ along with data on a variety of coating materials. Many inorganic coatings listed possess good emissivity, but most are not stable in the vacuum of space at the operating temperature of the TE radiator. $A$ ceramic coating with an emissivity of 0.85, SP-40MA-I, developed by Solar Turbines International, has been applied to the beryllium radiators on SNAP-27 thermoelectric space power systems located on the moon, 30 but it is 1 imited to $<700 \mathrm{~K}$ for continuous operation.

Anodized coatings on beryllium appear to provide a high enough emissivity surface to make them viable candidates. Zhorov et al. 31 report emissivities as high as 0.88 for anodized beryllium with. the highest values being seen at $700 \mathrm{~K} \pm 100^{\circ}$. Zinc orthotitanate has been suggested ${ }^{32}$ as a possible candidate for an emissivity coating for the TE radiator heat pipes. Its emissivity is $\sim 0.94$, and its solar absorptance is $\sim 0.11$. Best of all, its melting point is $1750 \mathrm{~K}$ and it appears to resist degradation by ultra-violet radiation. A detailed study is required to determine 
which of the candidate emissivity coatings will provide the best performance over the 7-yr lifetime of the nuclear power system.

While in space, the waste-heat radiator along with the rest of the spacecraft will probably be struck occasionally by extraterrestrial solid debris or meteoroids. These meteoroids are quite sulal1, ranging mostly from $10^{-12}-1 \mathrm{~g}$ with an average density of $\sim 0.5 \mathrm{Mg} / \mathrm{m}^{3}$. They move at quite high velocities, averaging $\sim 20 \mathrm{~km} / \mathrm{s}$. The response of material to high-velocity impact has been studied for many years $10,11,32,33$ but as pointed out by Gehring, 33 "there is no detailed mathematical formulation with which to predict damage to a complex target by a hypervelocity fragment." Consequently, several empirical relationships have been proposed to approximate the meteoroid impact damage which might occur under limited conditions. However, these empirical relationships are based on simulation experiments where impact particle velocities and densities differ significantly from those of the average meteoroid, and thus the accuracy of the resultant performance predictions is questionable. Light-gas gun impact experiments using flat-plate material samples have provided most of the data from which our predictions have been made; however, it has been shown experimentally for some materials that flat plate impact data is slightly conservative when applied to tubular shapes. 11

Beryllium tubular-shapes hypervelocity impact tested in the past 10 has indicated a propensity to crack outward from the impact crater both circumferentially and longitudinally. This occurred as well in elevatedtemperature (up to $980 \mathrm{~K}$ ) tests. The beryllium tube was lined with a 316 stainless steel tube that remained intact after impact, though dimpled. This work plus later experiments ${ }^{11}$ demonstrates the advantages of using an optimum-thickness dissimilar metal liner inside a tubular shape to reduce the amount of armor material needed to prevent perforation of a tube. Clough et al. 11 found, for example, that a 316 stainless steel liner inside of cast 356-T51 aluminum armor had an optimum thickness of between 0.38 and $0.71 \mathrm{~mm}$ for prevention of 1 iner perforation.

We searched for the optimum liner material for a beryllium radiator heat pipe because of the desirable properties of beryllium, namely the low density and high thermal conductivity, and because certain laminate combinations appear to have better impact resistance than either of the component materials standing alone. ${ }^{33}$ One of the most important criteria 
that must be met in order to sustain a good bond between a beryllium tube and its liner is that the liner material must possess thermal expansion behavior close to that of beryllium. Figure 168 is a plot of the thermal expansion of a variety of metals and alloys. Nickel and nickel-base alloys possess thermal expansion properties closest to beryllium. Because pure nickel has much higher thermal conductivity than its alloys, it is probably the best choice as the liner material. Note that pure vanadium would make the best liner material for the candidate titanium alloy, Ti-8AL-1Mo-1V. $\mathrm{Ti}-6 \mathrm{Al}-2 \mathrm{Sn}-4 \mathrm{Zr}-2 \mathrm{Mo}-0.095 \mathrm{Si}(\mathrm{Ti}-6242-\mathrm{Si})$. None of these are routinely fabricated into tubing, so the fabrication even of single-material tubes of these titanium alloys would have to be developed.

The fabricability of the laminated tubular structures has not been demonstrated, but at least the fabrication of a beryllium nickel-laminated tube appears to be feasible because of past experiences in the beryllium industry of extruding beryllium with iron (low-carbon steel) containers and

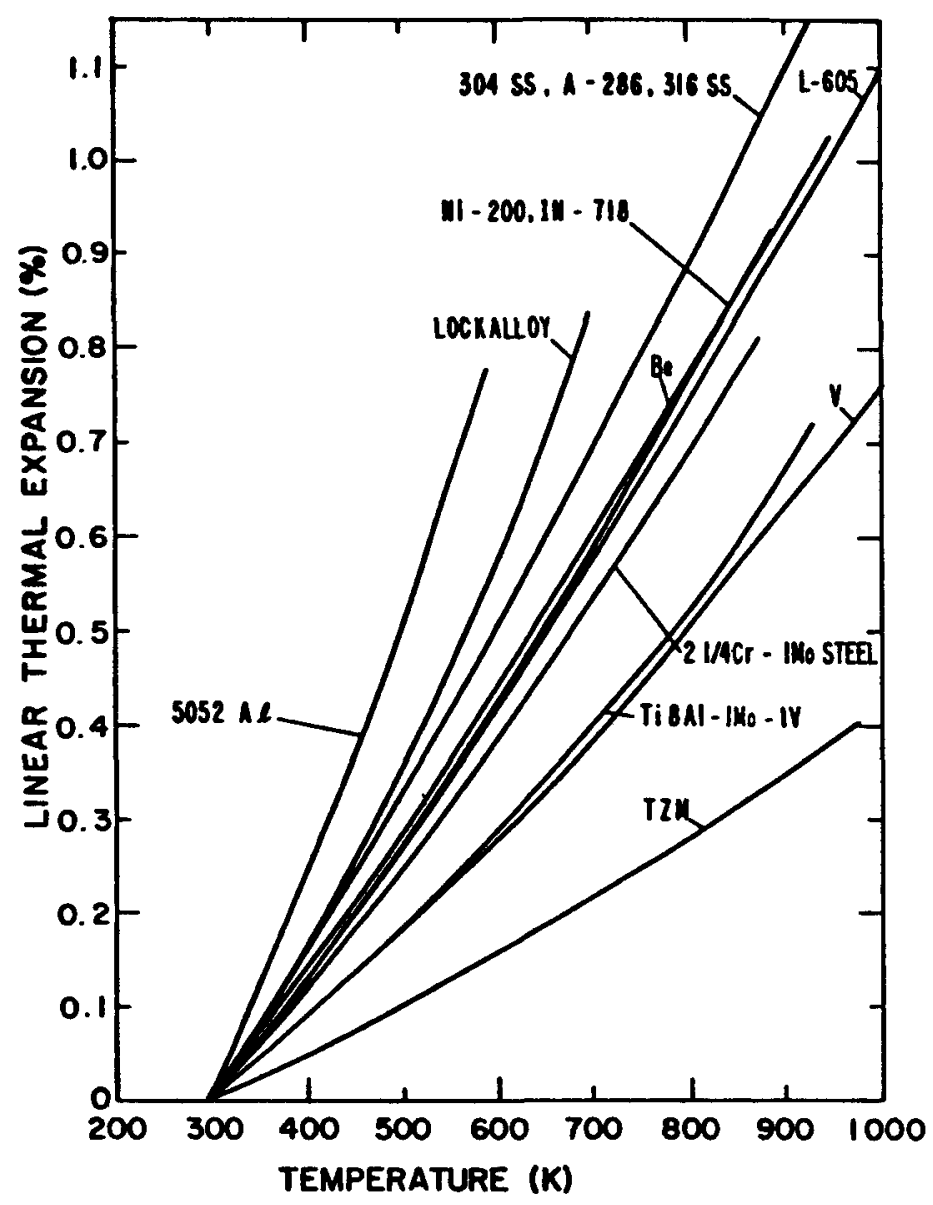

Fig. 168. Thermal expansion. 
obtaining good metal-metal bonds. It is thus felt that beryllium-nickel tubes could be fabricated by coextrusion. The nickel liner would also simplify the heat-pipe closure problem by eliminating the need for welding beryllium. A nickel end-cap welded to the nickel liner would probably be used. The fabrication of the titanium-alloy vanadium-laminated tube is possible also by coextrusion, but at this time we have no feel for the difficulties that might be encountered in developing the process.

The use of a beryllium nickel-laminated radiator heat pipe will also provide better structural reliability under the spacecraft launch conditions. Because beryllium has little ductility ( $<10 \%$ total elongation) below $\sim 500 \mathrm{~K}, 34$ the radiator heat pipes would have a tendency to crack during launch. But the nickel liner will have little tendency to crack during launch, and the Be-Ni bond should remain intact. If the heat pipe armor cracks the performance of the radiator during its operating lifetime should not be compromised.

Beryllium and nickel are known to react with each other at elevated temperatures to form intermetallic compounds, ${ }^{35,36}$ but there is considerable disagreement over the kinetics of the reaction. Also, there does not appear to be any kinetic data below $875 \mathrm{~K}$. Using reaction kinetics data reported by Vickers, ${ }^{36}$ one predicts a reaction layer $0.38-\mathrm{mm}$ thick to form after $7 \mathrm{yr}$ at $875 \mathrm{~K}$. One might expect about one-fourth this reaction layer thickness at $775 \mathrm{~K}$ during the same time period. A study is required to accurately establish the rates of reaction between beryllium and nickel as a function of temperature. It will also be important to determine the effects of any reaction layer on the impact resistance of the laminated tube.

2. Low-Temperature Materials $(<650 \mathrm{~K})$. Because of the additional components required in the Brayton cycle converter, the weight of its waste-heat radiator must be kept to an absolute minimum, and it appears that an acceptable system weight can be achieved only with beryllium nickel-laminated heat pipes and heat exchanger. Thus, all of the previous discussion of thermoelectric converter radiator materials applies equally to the Brayton cycle converter radiator. 


\section{APPENDIX VII-A \\ SIZING CALCULATIONS FOR COOLER HEAT EXCHANGER}

The conceptual design of the side-by-side direct heat exchangers with an intermediate heat-pipe circuit was formulated and programmed. The formulation allowed for the simultaneous solution of heat transfer on the Xe-He and NaK circuits. Figure $A-1$ is a plot of the fluid and heat-pipe temperature profile assumed at each tube bank. The nomenclature is given in Table A-1. The temperature differences noted in the figure are

$$
\begin{aligned}
& D_{\text {DTA }}=\text { THIN }- \text { TPIPE } \\
& D_{\text {DTB }}=\text { THOUT }- \text { TPIPE } \\
& D_{\text {DTA }}^{\text {cold }}=\text { TPIPE }- \text { TCOUT } \\
& \text { DTB }_{\text {cold }}=\text { TPIPE }- \text { TCIN. }
\end{aligned}
$$

The system of equations used in the solution is as follows. The energy balances on the Xe-He and NaK-fluid streams are

and

$$
\left.Q_{i}=m_{x} C P_{X} \text { (THIN }- \text { THOUT }\right)
$$

$$
Q_{i}=m_{N} * C P_{N} *(\text { TCOUT }- \text { TCIN })
$$

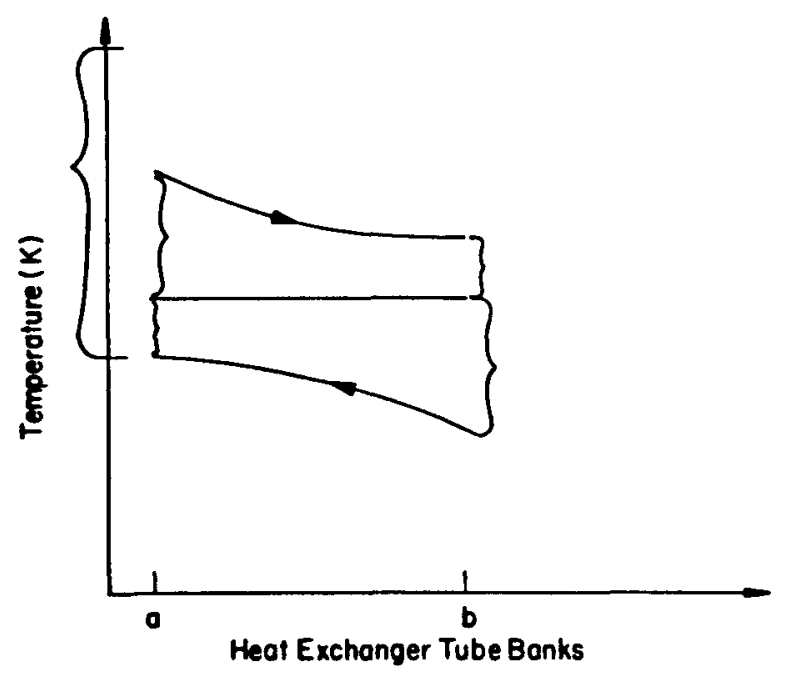

Fig. A-1. Fluid and heat-pipe temperature profiles. 
The heat absorbed and released by the evaporator and condenser sections of the heat pipes are

$$
Q_{i}=H_{X} \quad H_{X} A_{X} \frac{\left(\text { DTA }_{\text {hot }}-\text { DTB }_{\text {hot }}\right)}{\ln \frac{\text { DTA }_{\text {hot }}}{\text { DTB }_{\text {cold }}}}
$$

and

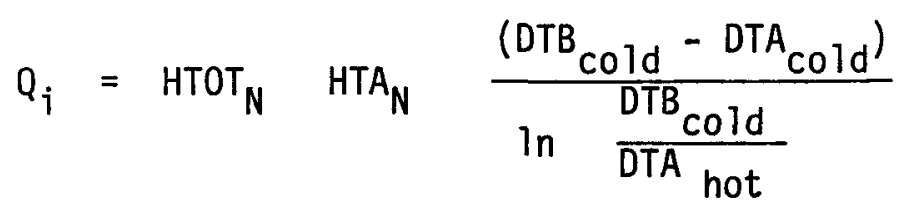

The heat transfer area relationship for both the gas and liquid-metal sides takes the form

$$
\text { HTA }=\alpha \text { VOLHX. }
$$

Data from Kays and London ${ }^{19}$ for extended surfaces was used to calculate the Colburn factor in the form

$$
X J=\frac{a}{R_{e}} \frac{a}{0.8}
$$

and then substituted into

$$
H_{X}=X J C P \frac{G}{P^{2 / 3}}
$$

to calculate a film coefficient on the XE-He side. ${ }^{19}$ The relationships used to calculate the Peclet and Nusselt numbers in the NaK circuits are 22

$$
P_{e}=\frac{D V_{\text {max }}{ }^{R H O} 0_{N} C P_{N}}{K_{N}}
$$

and 


$$
N_{u}=0.718\left(\frac{\phi}{D}\right)^{1 / 2}\left(\frac{P-D}{P}\right)^{1 / 2} P_{e} e^{1 / 2} .
$$

The film coefficient is then given by

$$
H_{N}=\frac{N_{U} K_{N}}{D} \text {. }
$$

The fin efficiency, surface efficiency, total resistance, and total conductance for both circuits are calculated as follows:

$$
\begin{aligned}
& X M=\left(\frac{H(2)(12)}{\text { COND }_{\text {fin }} \text { THICK }_{\text {fin }}}\right)^{1 / 2} \\
& \text { EFF }=\frac{\operatorname{Tanh}(X M B)}{(X M B)} \cdot \\
& \text { EFTOT }=\frac{\text { ATUBE }+ \text { EFF }}{\text { ATOT }} \text { AFIN } \\
& \text { RTOT }=\frac{1}{\text { EFTOT *H }}+\frac{\text { WALL }}{12 . \times \frac{\text { ATUBE }}{\text { ATOT }} * \text { COND }_{\text {Wal1 }}}+\frac{0.060}{12 \cdot \times 6.94} . \\
& \text { HTOT }=\frac{1}{\text { RTOT }} .
\end{aligned}
$$

The approach temperature constraint between fluid circuits is

$$
\text { DTHX }=\text { DTA }_{\text {hot }}+\text { DTA }_{\text {cold }}=25 \mathrm{~K} \text {. }
$$

The above equations and constraints were algebraically manipulated into a smaller set of simultaneous equations that were used for the numerical solution. 
The numerical solution scheme assumes that the geometry and conductance calculations for both circuits are done prior to entering the iteration loop at each tube bank. The iteration loop starts by using a guessed value for TCIN to calculate $Q_{j}$, THOUT, TPIPE, and TCIN. The guessed and calculated values of TCIN are compared and adjusted and the iterations continue until a preset convergence criteria is reached. The solution at each tube bank yields the heat transferred at that bank, the fluid temperatures, and the heat-pipe operating temperature. This procedure is repeated for the next tube bank until the sum of all heat transferred equals the total heat load required. The length of the heat exchanger is determined by the number of tube banks required to transfer the total heat load.

A subroutine at the end of the sizing loop calculates the mass of the heat exchanger using the size data generated. The mass calculated for a box-shaped heat-pipe heat exchanger is primarily the mass of the rectangular pressure vessel. The flat-plate equation used to calculate the required thickness of the vessel yields masses seven times greater than the mass of the material required for a cylindrical pressure vessel. It was concluded that a single-pass, $90^{\circ}$ cross flow, counter-current heat exchanger housed in a cylindrical pressure vessel would be the most realistic design approach that fulfills the requirements of the study.

The cylindrical heat exchanger design formulation and calculations were the same with the exception that the geometry and flow variables change and must be recalculated at each tube bank. 
TABLE A-1

LIST OF VARIABLES USED IN THE HEAT EXCHANGER DESIGN

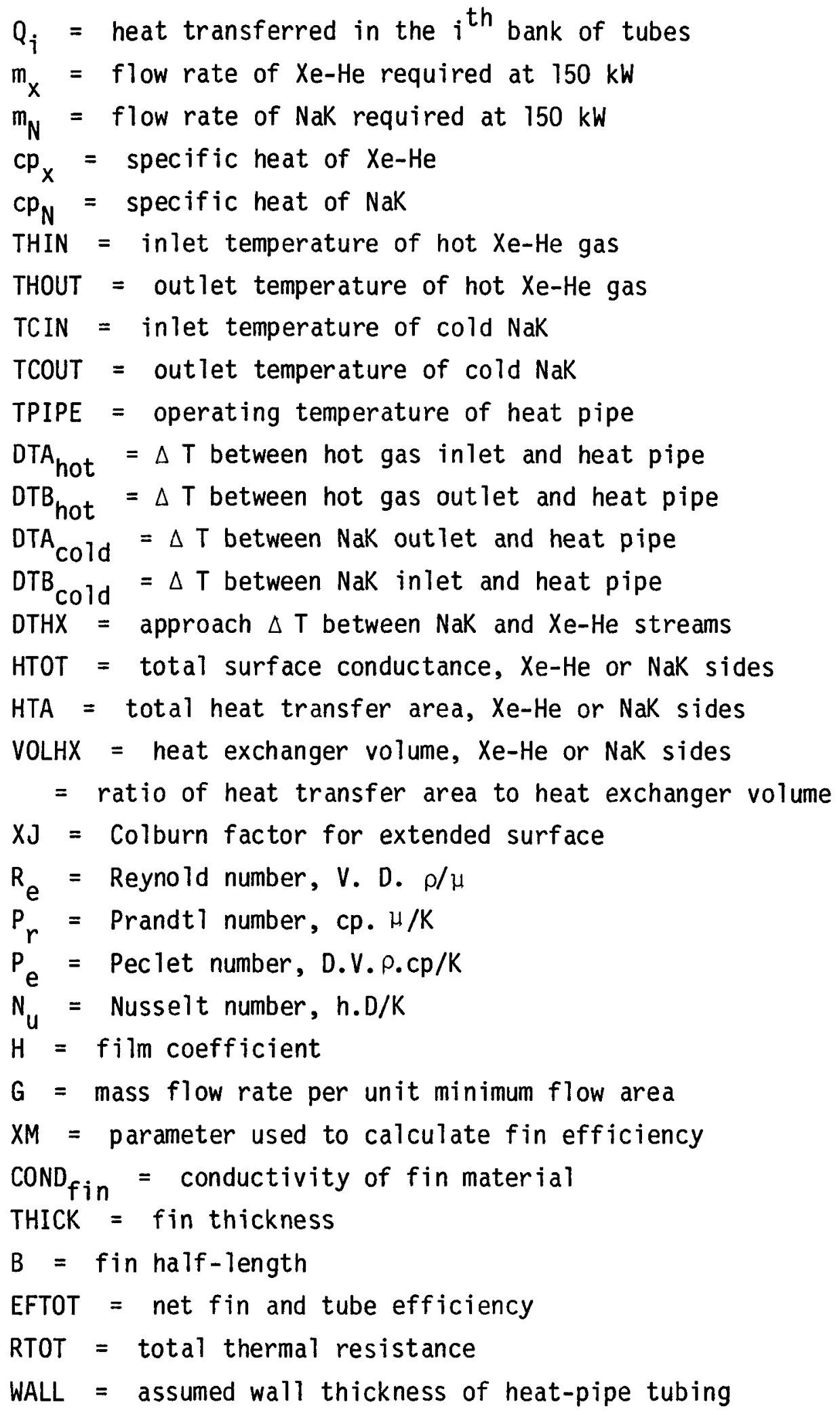


TABLE A-1 (Cont)

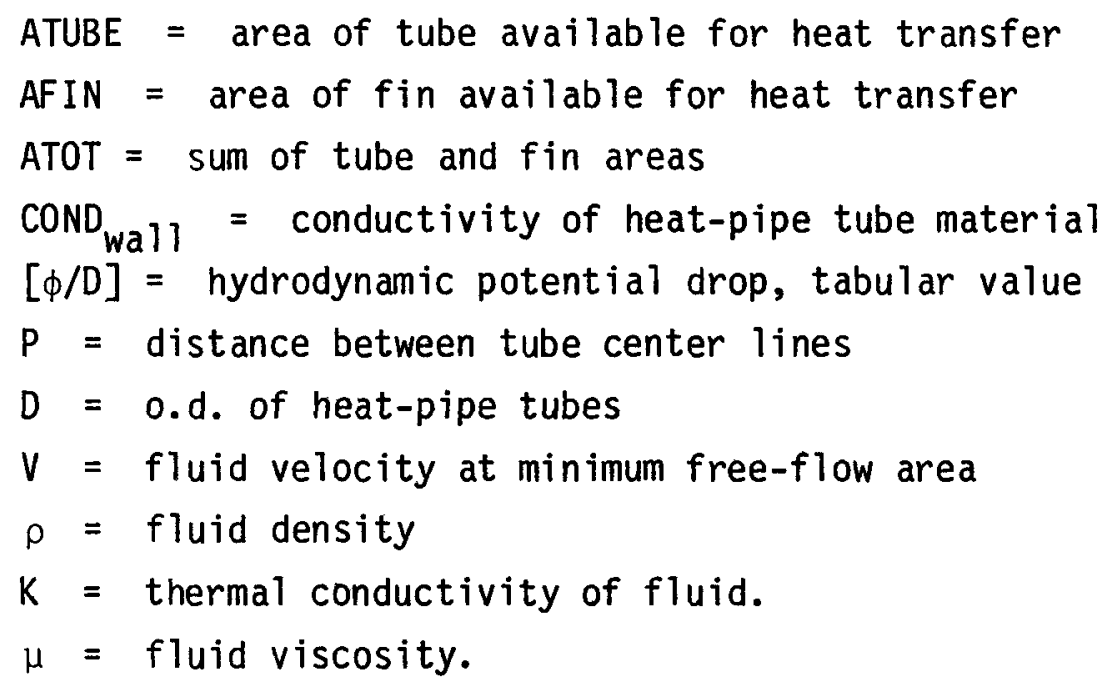




\section{APPENDIX VII-B \\ PUMPED-LIQUID RADIATOR DESIGN EQUATIONS}

The equations used to size the pumped NaK radiator are as follows. The nomenclature is given in Table B-1. The heat balance on the coolant fluid in a segment is given by the first law as

$$
\Delta Q=\dot{m} c p\left(T_{a}-T_{b}\right)
$$

The heat transferred across the liquid film is given by

$$
\Delta Q=\bar{h}_{c} A_{\text {conv }}\left(T_{\text {avg }}-T_{\text {wall }}\right),
$$

where $T_{a v g}=\left(T_{a}+T_{b}\right) / 2$

and $\bar{h}_{c}$ is calculated using the correlations for liquid metals flowing inside tubes and ducts. ${ }^{22}$

The heat transferred across the armored tube wall is

$$
\Delta Q=\frac{2 \pi K \Delta L}{(\mathrm{ID})} \quad\left(\mathrm{T}_{\text {wall }}-\mathrm{T}_{\text {root }}\right) .
$$

A heat balance on the incremental surface radiating to space is

$$
\Delta Q+\text { solar input }=\sigma \varepsilon F_{\text {space }} A T_{\text {root }}^{4} \text {, }
$$

where the solar input is assumed for the worst-case orientation. The quadratic expression that accounts for the area of the trapezoidal and rectangular fin shapes is

$$
\left(2 \eta_{f i n} \tan \phi\right) \Delta L^{2}+\left(\pi 0 D+4 \eta_{f i n} F L\right) \Delta L-F_{\text {space }} \Delta A=0 .
$$

The radiation fin effectiveness and the inlet section fin length are calculated at each segment and used in the calculation of incremental radiator area and length. The incremental radiator length, area, and heat transferred are summed so that 


$$
\begin{aligned}
& \text { radiator length }=\Sigma \Delta L, \\
& \text { radiator area }=\Sigma \Delta A,
\end{aligned}
$$

and

$$
\text { total radiator reject heat }=\text { QTOT }=\Sigma \Delta Q \text {. }
$$

The solution method is based on dividing the total radiator reject heat load into $\mathrm{N}$ increments and then calculating the area required to radiate the given incremental heat load at its particular root temperature. The QTOT was divided into several increasing numbers of increments until the radiator size and mass reached an asymptote. That number of increments was used then to calculate $Q$ and all remaining variables. An iterative numerical solution was used for the following reasons

- The tube armor thickness, which depends on radiator size, is unknown on the first iteration so that the o.d./i.d. ratio is a guess.

- The expression for temperature drop across the tube wall contains a natural logarithm term that prevents a closed form solution.

- A small change in root temperature causes big changes in the other variables.

The thermal, survival, and mass equations were programmed to provide an efficient way to change input variables. The program calculates radiator lengths (excluding folding joints), radiator area, coolant flow passage diameter, the convection film coefficient, outside tube diameter, fin effectiveness, manifold size, tube and manifold armor thicknesses, and the resulting radiator mass. The mass calculations are all done for previously calculated component survival probabilities that satisfy the $99 \%$ system survival probability requirement. 
TABLE B-I

LIST OF VARIABLES USED IN THE PUMPED-NaK RADIATOR DESIGN

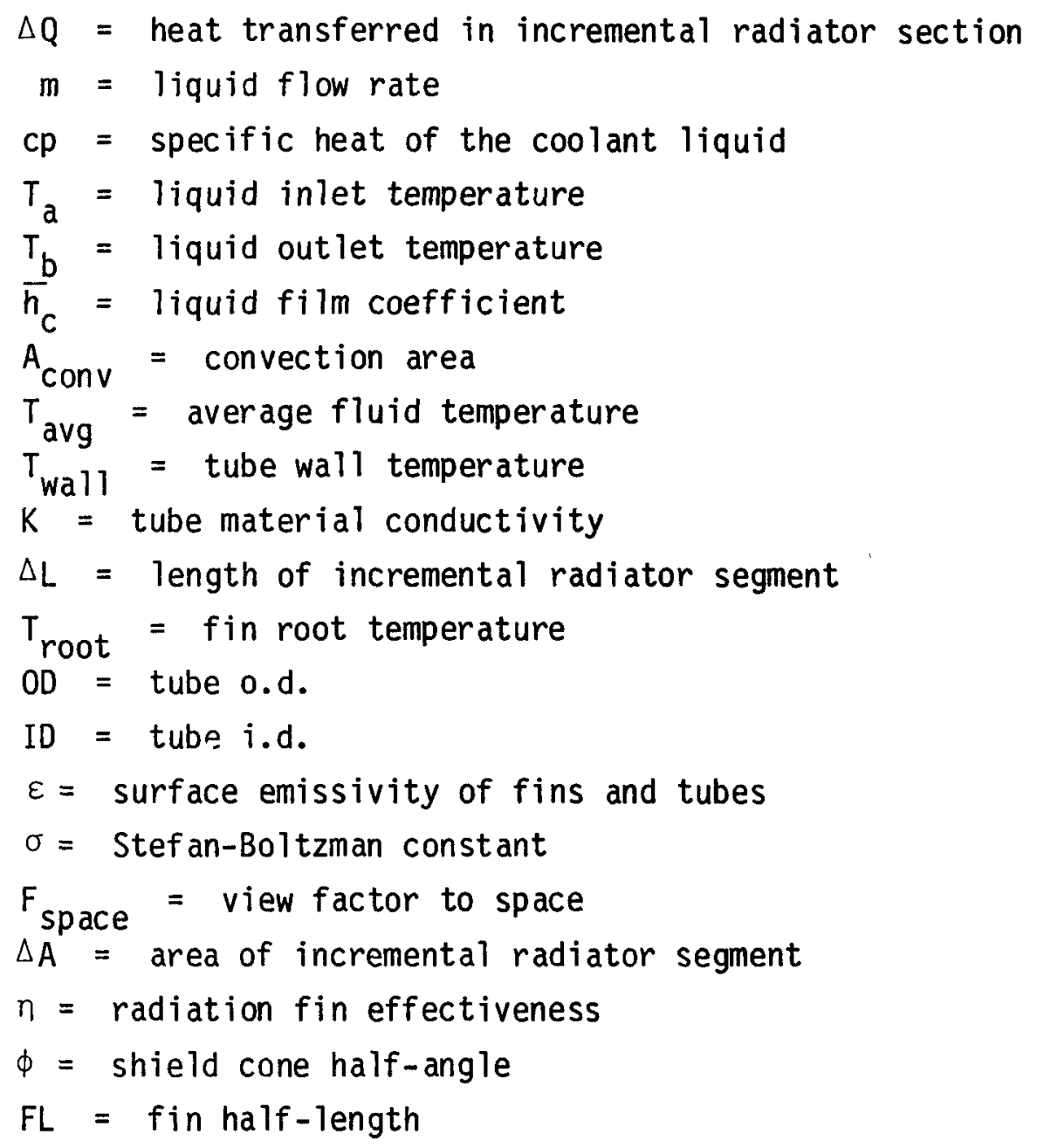




\section{APPENDIX VII-C \\ DIRECT PUMPED HEAT REJECTION SYSTEM CONCEPT EQUATIONS}

The conservation and heat transfer equations used to size the panels are applied at each incremental section and are as follows. The nomenclature is given in Table $\mathrm{C}-\mathrm{l}$. It was assumed that the Xe-He gas mixture behaves as a perfect gas over the temperatures and pressures encountered so that

$$
p=\rho R T \text {. }
$$

Application of conservation of momentum at each section assumes that the significant pressure drops are a result of viscous friction and is given by

$$
P_{1}-P_{2}=f \frac{\Delta L}{D H} \rho \frac{v^{2}}{2 g_{c}}
$$

where the velocity and density are for the inlet section. Since the tubes are all constant-area cross sections, the conservation of mass is simply

$$
\rho_{1} v_{1}=\rho_{2} v_{2}
$$

It was assumed that the kinetic energy change at a section is negligible so that the conservation of energy is given by

$$
\mathrm{J}_{\mathrm{cpT}}=\mathrm{J}\left[\mathrm{cpT} \mathrm{T}_{2}+\frac{\mathrm{Q}_{\mathrm{sec}}}{\mathrm{m}}\right] \text {. }
$$

The heat transfer across the gas film to the flow tube wall is given by

$$
Q_{\text {sec }}=\bar{h}_{c} A_{\text {conv }}\left(\frac{T_{1}+T_{2}}{2}-T_{\text {wall }}\right)
$$


where $h_{c}$ is calculated based on correlations for transitional or turbulent gas flow in tubes. 18 Since this gas has a Prandt 1 number of about 0.2 , it was also assumed that the correlations that apply to the range $0.5<P_{r}<$ 100 also apply to this case as opposed to the liquid-metal correlations. One-dimensional conduction across the flow tube wall, the cruciform materia1, and the heat-pipe tubing is given by

$$
Q_{\text {sec }}=\frac{K \cdot A_{\text {cond }}}{\text { th }}\left(T_{\text {wall }}-T_{\text {pipe }}\right) \text {. }
$$

Heat radiated to space from the fins and the heat pipe is

$$
Q_{\text {sec }}=A_{\text {rad }}\left(\sigma \varepsilon F_{\text {space }} T_{\text {pipe }}{ }^{4} \text { - solar input }\right) \text {, }
$$

where the solar input assumed is for a worst-case orientation and $T_{p}$ ipe is the temperature on the inner surface of the heat pipe at the evaporator exit. Each heat pipe is assumed to be isothermal at a slightly different temperature. The radiation area is calculated as discussed previously with additional shape factors for the tubes and fins. 37

The solution method is based on using an assumed size of the incremental section or radiator and heat exchanger and then calculating the amount of heat transferred and radiated at each section. The velocity, density, pressure, and temperature are known at the inlet. Using this velocity, the friction factor is calculated from the Colebrook equation. 38 The energy and heat transfer, Eqs. C-4-C-7, are an independent subset that are solved for the temperatures. The out let temperature and pressure are then used to solve for the velocity and density at the section outlet, which are used as the inlet conditions for the next section. The calculations are repeated at each succeeding section and the heat rejected is summed until it equals or just exceeds the total reject heat load. The length of the radiator as determined by summing the total number of increments, multiplying by 0.5 for path length and then multiplying by the section size. 
A subroutine at the end of the sizing loop calculates the armor thickness for both the heat pipes and each manifold. These thicknesses are used by another subroutine to calculate the mass of the entire heat rejection system.

TABLE C-I

LIST OF VARIABLES USED IN THE PUMPED GAS RADIATOR DESIGN

$p=$ absolute pressure of the gas

$\rho=$ gas density

$R=$ gas constant for Xe-He, mol wt $=39.944$

$T_{1,2}=$ absolute gas temperature at inlet and outlet

$f=$ gas flow friction factor

$\Delta L=$ incremental segment length

$\mathrm{DH}=$ hydraulic diameter of gas flow passage

$v=$ gas velocity

$g_{c}=$ gravitational constant

$J=$ conversion constant

$\mathrm{cp}=$ gas specific heat at constant pressure

$Q_{\text {sec }}=$ heat transferred and radiated at an incremental section

$m=$ gas flow rate

$\bar{h}_{c}=$ gas film coefficient

$A_{\text {conv }}=$ area available for convection

$T_{\text {wall }}=$ tube wall temperature

$K=$ tube material conductivity

$A_{\text {cond }}=$ projected area available for conduction

th = thickness of conduction material

$T_{\text {pipe }}=$ temperature at heat-pipe evaporator exit

$A_{\text {rad }}=$ area available for radiation to space

$\sigma=$ Stefan-Boltzman constant

$\varepsilon=$ emissivity of heat pipes and fins

$F_{\text {space }}=$ shape factor to space 


\section{REFERENCES}

1. R. E. English and D. E. Guentert, "Segmenting of Radiators for Meteorite Protection," Am. Rocket Soc. Pap. 31, 1162-1164 (1961).

2. Irwin Miller and John E. Freund, Probability and Statistics for Engineers (Prentice Hall, Inc., Englewood Cliffs, 1965), pp. 19-32.

3. "Heat Pipe Design Handbook," National Aeronautics and Space Administration report DRD SE-354 T (August 1972).

4. J. E. Kemme, Los Alamos Scientific Laboratory, personal communication, 1977.

5. W. H. Dauterman and L. D. Montgomery, "Design and Analysis of the Radiator Structure for Space Power Systems, "Atomics International Division Rockewl1 International report Ai-AEC-13093 (June 22, 1973).

6. "Space Shuttle Program-Space Shuttle System Payload Accommodations, Level II Program Definition and Requirements, Vol. XIV," National Aeronautics and Space Administration report JSC-07700 (November 26 , 1975).

7. Frank Kreith, Radiation Heat Transfer for Spacecraft and Solar Power Plant Design (International Textbook Co., Scranton, 1962), pp. 80-82.

8. CRC Standard Mathematical Tables (CRC Press, Inc., Cleveland, 1974), p. 17 .

9. Nestor Clough and Seymour Lieblein, "Crater Characteristics of 11 Metal Alloys Under Hypervelocity Impact Including Effects of Projectile Density and Target Temperatures," General Motors Corporation, Warren Research Laboratories report NASA-TN-D-5135 (April 1969).

10. James H. Diedrich and Irvin J. Loeffler, "Hypervelocity Impact Damage Characteristics in Beryllium and Graphite Plates and Tubes," General Motors Corporation, Defense Research Laboratories report NASA-TN-D-3018 (1965).

11. Nestor Clough, J. H. Diedrich, and Seymour Lieblein, "Results of Hypervelocity Impacts into Space Radiator Materials," Proc. Ist Rankine Cycle Space Power Systems Specialists Conf. Cleveland, Onio, October 26-28, 1965.

12. Nestor Clough, Seymour Lieblein, and Allen R. McMillan, "Dimple, Spall, and Perforation Characteristics of Thin Plates of Nine Materials Under Hypervelocity Impact," Lewis Research Center report NASA-TN-D-5625 (January 1970).

13. Taylor Lyman, Ed., Meta1s Handbook 8th Edition, Vo1. 1, Properties and Selection of Metals (American Society for Metals, Metals Park, Ohio, 1967).

14. P. D. Dunn and D. A. Reay, Heat Pipes (Pergamon Press, Oxford, 1978), pp. $100,299,300$. 
15. T. L. Ashe, Airesearch Manufacturing Company, personal communication, Juty 16, 1969.

16. "A Guide to the Selection of Therminol Heat Transfer Fluids," Monsanto Industrial Chemicals Co. Brochure IC-/FF-58.

17. "Physical Properties," in Sodium-NaK Engineering Handbook, Volume 1, 0. J. Foust, Ed., (Gordon and Breach, Science Publishers, Inc., New York, 1972), pp. 1-46.

18. Frank Kreith, Principles of Heat Transfer, Third Edition (Intext Educational Pub7ishers, New York, 1976), pp. 481.

19. W. M. Kays and A. L. London, Compact Heat Exchangers (McGraw-Hill Book Company, Inc., New York, 1958), pp. 60-61.

20. D. Q. Kern, Process Heat Transfer (McGraw-Hill Book Company, Inc., New York, 1950), p. 555.

21. 0. P. Bergalin et al., "Heat Transfer and Fluid Friction During Flow Acrass Tube Banks - IV, A Study of the Transition Zone Between Viscous and Turbulent Flow," Trans. ASME 74, 953-959 (1952).

22. "Liquid-Metal Heat Transfer," in Sodium-NaK Engineering Handbood, Volume 2, 0. J. Foust, Ed., (Gordon and Breach, Science Publishers, Inc., New York, 1976), pp. 139-144.

23. A. Basiulis and M. Filler, "Operating Characteristics and Long Life Capabilities of Organic Fluid Heat Pipes," American Institute of Aeronautics and Astronautics paper No. 71-408 (Apri1 1971).

24. A. Brown, "Boiling Limited Heat Pipes in a Mid-Temperature Range (150 to $300 \mathrm{C}$ ), "American Society of Mechanical Engineers publication 77-HT-39 (August 1977).

25. "American Society of Mechanical Engineers Boiler and Pressure Vessel Code," Section VIII, Rules for Construction of Pressure Vessels, (American Society of Mechanical Engineers, New York, 1974), pp. 14, 21.

26. R. N. Lyon, "Liquid Metals," in Reactor Handbook, Volume I, Materials, C. R. Tipton, Ed. (Interscience Publishers, Inc., New York, 1960), Chap. 49, pp. 994-1020.

27. J. P. Verkamp and R. G. Rhudy, "Electromagnetic Alkali Metal Pump Research Program," National Aeronautics and Space Administration report NASA-CR-380 (February 1966), pp. 5, 140.

28. Reactor Handbook, Vol. I, Materials, 2nd Ed., C. R. Tipton, Jr., Ed., (Interscience Publishers, Inc., New York, 1960) p. 995.

29. J. B. Rittenhouse and J. B. Singletary, "Space Materials Handbook, Third Edition," Air Force Material Laboratory report AFML-TR-68-205 (July 1968). 
30. A. R. Setson, Solar Turbine International, San Diego, California, personal communication, June 1978.

31. G. A. Zhorov, R. M. Al'moskii, M. I. Vrazbaev, and D. S. Gornyi, "Emissivity and Structure of Anodized Beryllium," Teplofiz. Vys. Temp., 14, 1 (1976), pp. 37-40 in English Transiation.

32. J. E. Gilligan, Illinois Institute of Technology, Chicago, Illinois, personal communication, June 1978.

33. J. W. Gehring, Jr., "Engineering Considerations in Hypervelocity Impact," in High-Velocity Impact Phenomena, R. Kinslow Ed. (Academic Press, New York, 1970), pp. 463-514.

34. Beryllium: Its Metallurgy and Properties, H. H. Hausner. Ed., (University of California Press, Berkeley and Los Angeles, 1965).

35. J. H. Kittel, Argonne National Laboratory Report ANL-4937 (1949).

36. W. Vickers, "The Compatibility of Beryllium with Various Reactor Materials," in The Metallurgy of Beryllium (Chapman \& Hall Ltd. for the Institute of Metals, 1963), pp. 335-349.

37. J. P. Callinan and W. P. Berggren, "Some Radiator Design Criteria for Space Vehicles," J. Heat Transfer 237-244 (August 1959).

38. Lewis F. Moody, "An Approximate Formula for Pipe Friction Factors," Mech. Eng., 69, Number 12, 1005-1006 (December 1947). 
VIII. SAFETY

Safety considerations establish certain design criteria and influence the modes of operation. The major safety-related design features are

- Operation in fail-safe orbits only (no operation during launch or until selected orbit is reached),

- Fission product built up during acceptance test restricted to safe level for ground and flight crews,

- Reactor subcritical immersed in water,

- Reactor subcritical from any single failure point, and

- Reactor designed to meet re-enetry safety criteria.

Recently, questions have been raised by the COSMOS 954 incident concerning the safe use of nuclear reactors as electric power plants in Earth orbit. Safety has been and continues to be a major concern of US scientists involved in using reactors in space. Before operation, the reactor and its uranium fuel are perfectly safe to handle and touch. There is absolutely no possibility that a nuclear electric power plant can explode.

The key to safe operation before and during launch is to keep the reactor in a nonoperative mode. This is accomplished by adding built-in safety features, such as redundant control elements (where only one element is allowed to be unlocked at a time) brakes on the control element actuating mechanisms to prevent movement without two independent signals; and a reactor designed to remain non-operative even with environmental changes, such as immersion in water.

Analyses and tests will continue to be used as with SNAP IOA to show safe launch operation in case of launch pad fires, propellant fires, impact at terminal velocity (if a launch aborts or fails to reach orbit), and water impact. Again, the major requirement for safety is not to operate the reactor until the prescribed orbit is reached.

Most applications considered for nuclear reactors are in high orbits, such as geosynchronous. The higher the orbit, the longer a satellite will remain in orbit. A 300-yr orbital lifetime is believed to be a sufficient time for radioactive products to decay to a level that will not exceed the whole-body radiation exposure standards established by the US government for reactor sites. A minimum orbit altitude of $\sim$ 400-500 nautical miles will 
provide for over a 1000-yr orbit life* (Fig. 169) and, thus, provide a margin of conservatism in meeting this safety criterion. The altitude depends on power level, operating time, and spacecraft configuration. Doubling the orbit to $800-900$ nautical miles increases the orbital lifetime

*The ballistic parameter $W /\left(C_{D} A\right)$ depends on

- The weight $W$ of the re-enetry body,

- The drag area A which is a function of the flight altitude with respect to the orbital path and

- The drag coefficient $C_{D}$ which is influenced by the geometric characteristics of the body.

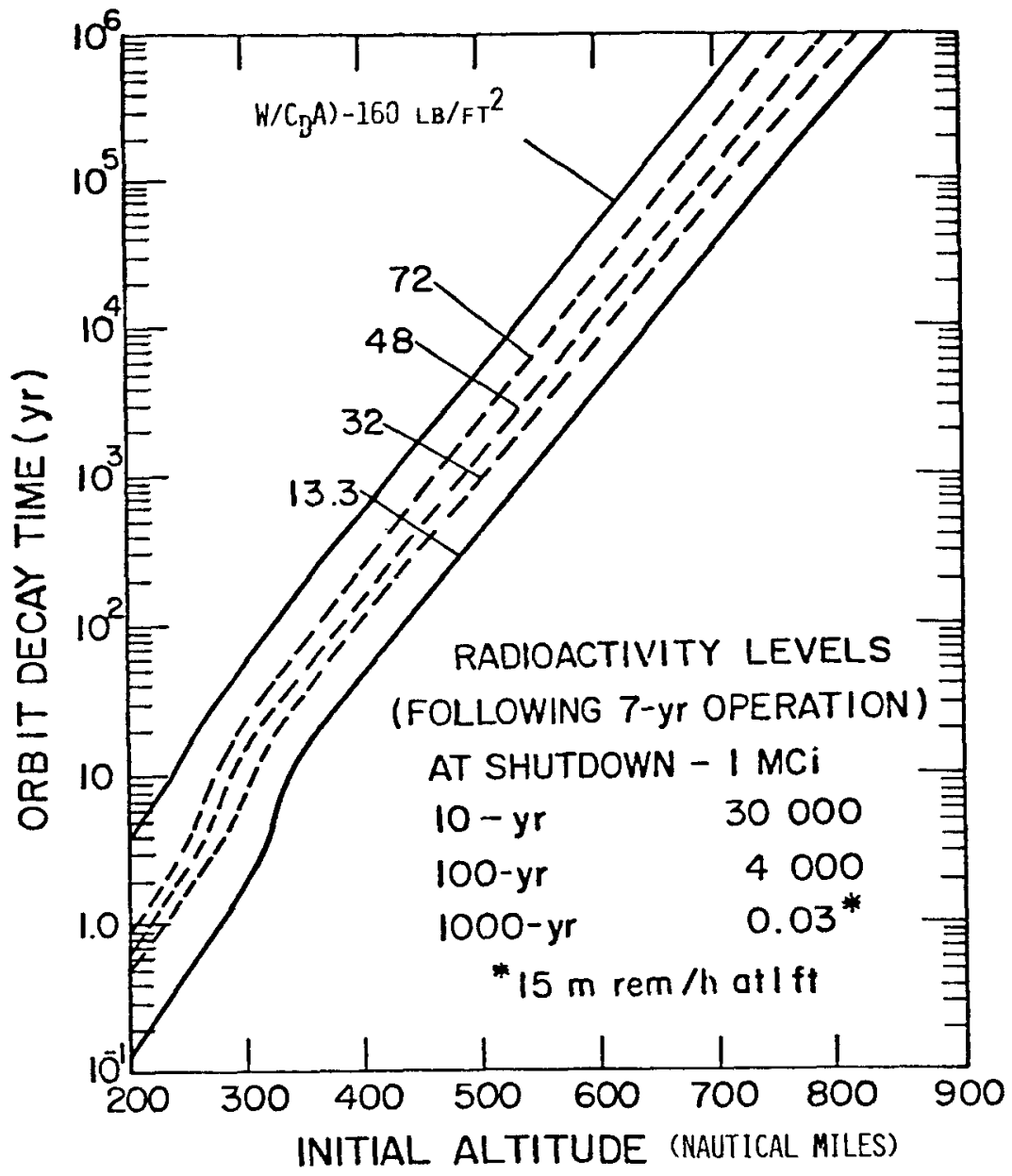

Fig. 169. Minimum orbit decay time. 
to $\sim 1$ million years. Satellites in geosynchronous orbit (19 300 nautical miles), the proposed location of most reactor-powered US satellites, will, for all practical purposes, never re-enter the earth's atmosphere.

If one considers using a nuclear reactor at an orbit lower than 400-500 nautical miles, then disposal becomes a safety issue unless the reactor is designed to disperse on re-entry into the Earth's atmosphere. The contamination through release of radioactive material in the atmosphere would be limited in quantity and widely dispersed. Potential direct radiation, ingestion, and inhalation exposure would be well below environmental guidelines by many orders of magnitude. The only. U. S. reactor flown in space, SNAP 10A in 1965, was not operated until its 700 nautical miles orbit was achieved. It is estimated that its orbital lifetime is $3800 \mathrm{yr}$. COSMOS 954 was scheduled for disposal by injection into a higher orbit but apparently something went wrong.

Detailed investigations were performed in SNAP 10A and the Atlas-Agena Rocket; future investigations will be pursued on SPAR and the Space Shuttle. A. Characteristics of the Reactor.

- What is the fuel? Will plutonium be used for such reactors?

The fuel is highly enriched uranium-235. Current designs are considering $\mathrm{UC}-\mathrm{ZrC}$ and $\mathrm{UO}_{2}$-molybdenum, depending on the power level. These fuels provide a lightweight, compact reactor design. Plutonium could be developed for use as a fuel, and if it was, a more compact reactor could be designed. However, plutonium is more 1 imited in operating temperature and thus would lead to a heavier overall power plant weight.

- How much fuel is needed? What size is the reactor?

A $1000-\mathrm{kW}_{\mathrm{t}}$ reactor, the size proposed for Earth-orbit missions, uses approximately $100 \mathrm{~kg}$ of uranium-235. A 3-MW reactor proposed for planetary exploration missions uses approximately twice the uranium-235. The reactors are right circular cylinders in shape, about a half meter long and a half-meter in diameter.

- How radioactive does the reactor become?

The reactor will be operated in orbits many thousands of years long, so the concern should be on the radioactivity at the time of reentry. At shutdown, following 7-yr full-power operation, fission product accumulation is $~ 1 \mathrm{MCi}$; after $10 \mathrm{yr}$, this reduces to $30000 \mathrm{Ci}$; at $100 \mathrm{yr}, 4000 \mathrm{Ci}$; and 
$1000 \mathrm{yr}, 0.03 \mathrm{Ci}$. The $0.03-\mathrm{C}$ s source delivers approximately the exposure of $15 \mathrm{~m} \mathrm{rem} / \mathrm{hr}^{\star}$ at $0.3 \mathrm{~m}$.

- How is the reactor cooled? Is there any possibility of coolant or cooling mechanism failures with subsequent meltdown or vaporization of fuel and fission product inventory?

Heat pipes without moving parts are used for transferring heat to cool the core. The fluid is either sodium or lithium depending on the reactor operating temperature. The core is built with many of these heat pipes to remove heat from different sections. Current designs use 90 separate heat pipes. If a single pipe is fractured, the surrounding pipes will remove the heat without melting the fuel. If several pipes are fractured in the same vicinity, fuel could melt; however, meltdown could only occur during orbital operation. The expected effect would be migration of fuel to a cold part of the reactor with a subsequent inherent shutdown of the reactor.

- What is the mechanism for converting heat to electricity?

Thermoelectric and Brayton converters are the prime candidates in the 1980 s and thermionic converters in the 1990s. The thermoelectric and thermionic converters have a high degree of redundancy built into the design. Brayton converter systems will include several parallel, independent converters.

- How is it used? The Russian satellite has been quoted as a laser-armed killer-satellite. Is this the purpose of the US satellites?

The exact uses of reactors for defense involves some areas that are classified. However, national defense could benefit from improved communication and surveillance systems. With the reusable Space Shuttle becoming a reality, larger satellites can be placed in orbit around the earth at a low cost compared with present-day disposable rockets used in the space program. These larger satellites wi.ll require significantiy increased quantities of power to perform their missions. Other missions of the future may include such things as national television systems that can reach remote areas with small antennas, voice communication by using wristwatch-size devices, image teleconferencing to permit appearance of absent participants,

\footnotetext{
*rem is a measure of equivalent radiation doses. A $m$ rem is one onethous andth of a rem.
} 
vehicle monitors and package locators to monitor articles during shipping, emergency communications from remote sites, energy and pollution monitoring, and space manufacturing of special materials such as high-performance magnets and improved quality silicon crystals.

- Why bother with reactors in space when solar arrays are available?

Solar arrays for higher-power levels are heavy, costly, and less flexible than nuclear power sources. At the higher-power requirements forecast for the future, reactors appear to be significantly lighter per kilowatt of electric output for unmanned missions. In fact, for missions in geosynchronous orbit, reactor power plants appear to be the only economical way to meet electric power levels of $50 \mathrm{~kW}$ or more. The main reason for not using solar energy is the high cost for large weights of material needed in geosynchronous orbits for electric power above $50 \mathrm{~kW}$. This is true even considering new developments in solar-cell technology which is expected to double the power per kilogram of solar collectors by 1985 and redouble again by the end of the century. (Significant improvements in batteries may decrease the solar-powered weight to about one-fifth of today's weight by T985 and one-fourteenth by the year 2000). Reactors also have the added advantage of eliminating mechanical devices needed to always keep the solar arrangements facing the sun.

- What about previous launches?

The US has launched one reactor, SNAP 10A, into space. The reactor was launched in April, 1965 aboard an Atlas/Agena rocket vehicle. SNAP 10A achieved a 700-nautical mile orbit with a projected 3800-yr lifetime. The reactor operated in that orbit for 43 days before being shut down. While safely orbiting for $3800 \mathrm{yr}$, the reactor fuel will decay at such a rate that in $100 \mathrm{yr}$, less than $0.1 \mathrm{Ci}$ of fission products will remain.

- How is this different than COSMOS 954 ?

The COSMOS 954 was reported to operate in a low near-circular 150nautical miles orbit. It was designed to be boosted to a long-life parking orbit of 500-nautical miles (500-years) on completion of its mission.

- Will US reactors have the explosive power of COSMOS 954, which was put

at 100000 tons of TNT by Time Magazine?

To get 100000 tons equivalent of TNT explosive would require a nuclear explosion which is impossible under present core designs. To design a nuclear explosive requires great care in configuration and assembly is 
entirely different than a reactor, and thus would require reprocessing the fuel into a different shape.

- What does the space reactor cost the US tax payer?

In Fiscal 1978, $\$ 300,000$ was spent on evaluating the need and technology for space reactors. In President Carter's FY-1979 budget, \$2 million is earmarked for experimental work related to space power reactors. When the decision is made to build a ground demonstration power plant, cost will increase to $\$ 15$ million per year.

- Which US agency funds development?

DOE will do the funding.

B. Safety Before Launch.

- How is the reactor shipped around the country?

Special vehicles are used to ship fissionable material around the country. These vehicles are licensed by the Nuclear Regulatory Commission. Great care is taken to assure that accidental criticality is a negligible risk and that the reactor is protected against loss or theft. These vehicles are designed to prevent spillage in the worst conceivable accident.

- Can it be stolen by terrorists to make a bomb?

Nuclear material is a vital ingredient of weapons. Recognizing this, the government takes extensive precautions to protect the material. In addition, there would be a large technical effort required to reprocess the fuel into a form that could be used as a weapon. The fuel would be useless as a dispersal weapon because of the low levels of inherent radioactivity. - How safe is the reactor for the ground crew? Is the reactor operated before launch?

It's very safe. In the SNAP program, the nuclear acceptance tests resulted in a fission product inventory of less than $0.01 \mathrm{Ci}$, producing a dose rate of less than $5 \mathrm{mrem} / \mathrm{h}$ at $1 \mathrm{ft}$ from the reactor vessei. This rate is low enough to permit personnel to work in the vicinity of the reactor and to allow shipment of the system by land or sea. Except for acceptance tests, the reactor is not operated before launch.

- Who approves the launch?

The Interagency Safety Review Panel (NASA, DOD, and DOE) reviews the system and evaluates its safety. The heads of the three agencies reviews the evaluation and request permission for the flight. The President's 
National Security and National Science Advisors review the request and make a recommendation to the President, who then makes the final decision.

- If the reactor is dropped accidentally, what will happen?

The reactor could be damaged, depending on the severity of the drop. There would be no nuclear problem. Accidental nuclear criticality is precluded by multiple control actuators armed with key locks and brakes. The heat transfer material in the heat pipes (sodium or lithium) is in the solid state so that cracking some of the heat pipes does not result in fluid spillage. Cracking the beryllium reflector at room temperatures does not pose safety problems.

C. Accidents at Launch

- What are the launch vehicles?

The Space Shuttle is the prime launch vehicle for late 1980s and 1990s missions.

- What happens if the launch vehicle explodes?

The reactor might be damaged but it could not explode and there would be no nuclear problem. The nonoperated reactor has little fission product inventory at this time; the consequences would be very slight.

- Is the shuttle crew protected?

Yes. The ground crew will be more exposed than the shuttle crew and, as they are safe, the shuttle crew is safe.

- If the shuttie fails to achieve orbit, what happens on water impact?

Land impact?

The shuttle is designed to "fly" in case of a failure to achieve orbit. The pilot could land it at Kennedy Space Center or one of the emergency landing sites now being identified. The probability of a crash is lower than in unmanned missions. But if the reactor should 1 and in water, current designs show the reactor to be subcritical. Thus, nothing would happen, $A$ 1 and impact, beyond the potential hazards of any launch vehicle returning in an abort situation, would be concerned with the scattering of reactor materials, mainly enriched uranium, beryllium, and Be0. Fission products would not be a problem because the reactor would not have been operated. Operation will not occur until a safe space orbit is achieved.

- Is the reactor operating during launch?

No. 
- Can the reactor explode?

No.

- How can accidental criticality be prevented?

Accidental criticality is prevented by built-in features such as redundant controls and brakes installed on the mechanisms that control the reactor power level. These cannot be released until two independent signals are given. The reactor is designed to be nonfunctional unless several independent commands are given. Even environmental change, such a immersion in water, will not cause the reactor to go critical.

D. Orbital Operation

- How is the shuttle crew protected in orbit?

The reactor will not be operated at power until the shuttle crew has moved a safe distance away from the satellite.

- What about an explosion in orbit? Will parts be propelled back to earth?

The reactor cannot explode. If all control drums did place the reactor on a fast power excursion, the reactor would disassemble itself by mechanical disintegration. If this happens at high orbits like geosynchronous orbit, no parts would return to earth. Even at relatively low orbits, say 300 nautical miles, the parts propelled in the direction of the Earth's surface would burn-up in the atmosphere.

- What orbits are being considered?

The main orbit, geosynchronous, is 19300 nautical miles above the earth. At this altitude, a satellite probably will never reenter the atmosphere. Some spacecraft designers are considering using electrically powered ion thrusters to transport the spacecraft to higher orbits or on planetary exploration missions. Nuclear operations might be initiated around 300 nautical miles. By the time any appreciable fission product inventory develops, the orbit will be very high. A failure at the 300 nautical miles after a short operating time results in a sufficiently long orbit for radioactive decay prior to re-entry.

- How long will the reactor stay in orbit?

A 1000-yr orbit is achieved between 400-500 nautical miles and a million-yr orbit between 730-850 nautical miles.

- Wi11 the reactor be recovered?

No. Plans call for high orbital disposal having long orbital lifetimes. 
- How can you be sure the reactor is shut down after operation?

Separate independent controllers can be used to shut down the reactor. The reactor will have inherent shutdown characteristics. If the temperature increases, the reactor will shut itself off (negative temperature coefficient) and will swell with increased temperature and mechanically destroy itself. If the reactor is not shut down by the controller, it will continue to operate until fuel burnup is sufficient to render it subcritical and lead to an inherent shutdown.

- Will the reactor be boosted into a higher orbit after operation, like the USSR intended to do?

The current US plans for reactor use are in high orbits where this is not necessary. If at some time there might arise an application that justifies low orbits, the most likely disposal method would be to boost the used reactor to a long-life orbit using on-board booster rockets. If the onboard system should fail, the US could use the Space Shuttle. Also, with the reactor being designed to disperse on re-entry to the earth's atmosphere, low orbits would not create safety problems. Thus, future hazards of using reactors in low orbits can be eliminated, although no need is seen for this mode of operation.

- What is meant by radioactive decay? Why is this important?

Radioactive decay is the spontaneous disintegration of the nucleus of an unstable atom. This is accompanied by the release of charged particles and/or photons (electromagnetic energy). It is important because it determines the time necessary to maintain the reactor in long-life orbits.

Will natural phenomena (radiation fields, solar flares, high magnetic fields, etc.) adversely affect operation?

Natural phenomena are not expected to affect operations. Lifetimes in low orbits are effected by atmospheric drag and the shape of the satellite or particles. In high orbits, these factors are insignificant.

- According to Newsweek Magazine, the USSR could possibly destroy US satellites. If a reactor-powered satellite is destroyed in a manner that significantly increases the surface area, will the small particles stay in orbit long enough to permit sufficient decay?

Military applications that might be subjected to disruptive attacks would be in high orbits. 
- How will this affect the weather around the globe?

No effect. The amount of debris from a satellite re-entering the earth's atmosphere is insignificant.

- Are there any dangers to future astronauts, that is, will everyone know what satellites contain dangerous radioactivity?

The US Air Force continually tracks all objects circling the earth. If at any future time an astronaut should want to determine if a satellite contained hazardous levels of ratioactive material, simple instruments are available.

E. Accidental Return to Earth After Operation

- What is the effect on the atmosphere if the reactor burns on re-entry?

If the radioactive material re-enters the atmosphere, how long will it stay there?

Depending on the design configuration, aerodynamic heating may cause the reactor to burn on re-entry, dispersing fission products in the upper atmosphere. Small particle fission fragments will slowly settle to earth over several years with the half residence time in the stratosphere (from 8 miles to 70 or 80 nautical miles above the earth's surface) $\sim 2$ years and troposphere (low atmosphere to an altitude of slightly more than 7 miles) about 21 days. The exposure of the general population after a few hundred years orbit following full 1000-kW power operation for $7 \mathrm{yr}$ would be one millionth of the maximum permissible concentrations for the general population.

Although the radiation could be detected with highly sensitive instruments, the amount is much less than natural radiation from space.

Large particle fission fragments (particles greater than the thickness of a sheet of paper in size), would be dispersed over a limited area (on the order of 500 square kilometers or less). The largest concentration of fallout is found to be $1 \%$ of the reactor inventory per square kilometer, which again means that a long orbit is desirable to minimize radioactive material exposure.

- What happens if the reactor lands in water (oceans)?

The major chance of re-entry is on launch before the reactor has operated. The physical condition of the reactor at the time of impact depends on the response during re-entry. Design features can be incorporated to enhance either disassembly or survival of the reactor core. If designed to remain intact, calculations indicate that the core will not go critical. 
- Can the reactor explode on impact?

A nuclear explosion will not occur on impact. This was demonstrated during testing of SNAP IOA.

- How many people will be killed or injured if the reactor lands on New

York City, instead of a remote site in Canada?

The major possibility of being killed or injured is from being hit with a piece of an assembly rather than radioactive material. This possibility is the same for any satellite from space, whether it contains a reactor or not, and the risk approaches that of being hit by a meteorite - very slim. The probability of being hit by either a satellite or meteorite is the same if one lives in New York City or a remote site in Canada. However, if it 1 ands in New York City there is a greater probability of some injury because of greater population density.

- What happens if the reactor lands in the countryside?

The secret of reducing reactor hazards to a negligible amount is the long orbital lifetimes prior to re-entry. The reactor can be designed to reenter and remain essentially intact. Impact with a hard surface will cause the reactor to disassemble with parts scattered over a limited area. The low levels of radiation will not cause safety problems. If the soil is soft, the reactor could stay intact. This again is a safe condition if the reactor is designed to be subcritical, even immersed in water.

- What is the expected dispersion area for radioactive material?

Large particles (greater than the thickness of a sheet of paper) will tend to settle over a limited area. Peak concentrations depend on the wind direction. The highest concentration is $1 \%$ of the total activity inventory per square kilometer (see chart below). If the original inventory is kept low no health hazard is present.

- What would be the expected effect (i.e., number of cancers induced) from human inhalation of this material.

Space reactors with long orbital times before re-entry add a negligible amount of radiation to the troposphere and would not increase the incidence of radiation-induced cancer in the general public. "The Effects on Populations of Exposure to Low Levels of Ionizing Radiation," by the National Academy of Sciences (November 1972) evaluated possible cancer induction. Below is a summary of estimated annual whole-body dose rates in the US from al1 sources $(1970)$. 

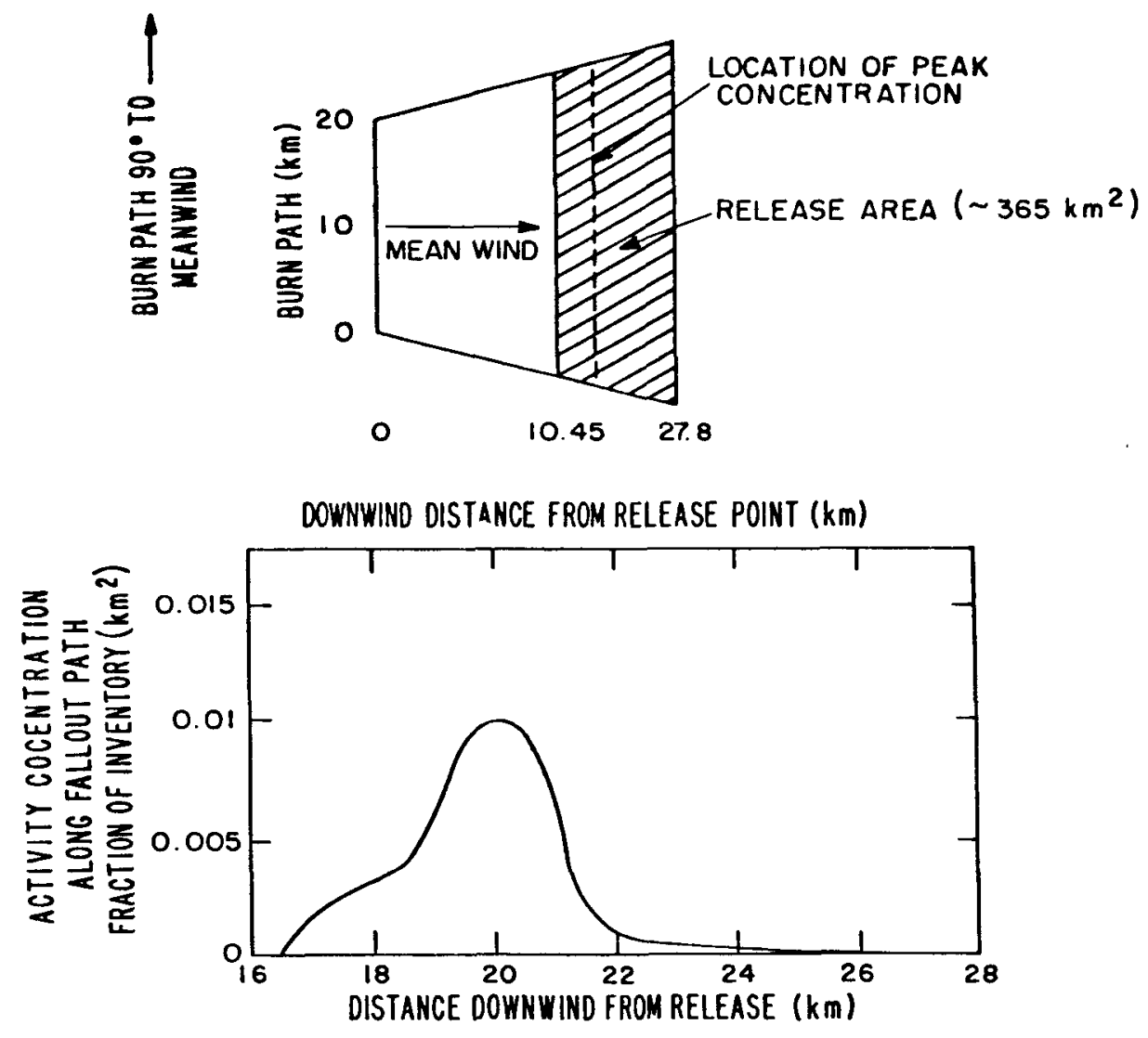

Fig. 170. Dispersion of particles after atmospheric re-entry.

Source

Environmental

Natural

Global fallout

Nuc lear power

Subtotal

Medical

Diagnostic

Radiopharmaceuticals

Subtotal

Occupational

Misce 11 aneous

TOTAL
Average Dose Rate

(mrem/yr) 


\section{RELIABILITY ANALYSES}

A power plant reliability goal of 0.95 for a $7-y$ r lifetime is based on the expected performance of spacecraft components. This goal has been allocated for the principle subassemblies for design purposes as follows:

$\begin{array}{ll}\text { Reactor } & 0.985 \\ \text { Shield } & 0.995 \\ \text { Converter } & 0.99 \\ \text { Radiator } & 0.99 \\ \text { Controls and instrumentation } & \underline{0.99} \\ \quad \text { OVERALL } & 0.95\end{array}$

Based on the preliminary analysis that follows, it is expected that with proper use of redundancy the subassembly and overall system reliabilities can be met.

Preliminary assessments were made on power plant designs with gas-cooled and heat-pipe reactors coupled to Brayton power conversion equipment and heat-pipe reactors with thermoelectric power conversion equipment. It was found that

- reactors, whether using gas or heat pipes, with only a single electric converter have a projected overall system reliability of 0.91-0.92;

- reactors with gas or heat pipes, with redundant Brayton converters have a projected overall system reliability of 0.94-0.96; and

- heat-pipe reactors with thermoelectric converters have a projected reliability of 0.96-0.98.

\section{A. Power Plants with Brayton Converters}

A number of alternatives were evaluated with Brayton converters including gas-cooled and heat-pipe reactors, single and dual converters, 6 and 12 drum actuators, and single- and double-ducting welds. Following is a list of items used in the analysis.

- Heat-pipe reactors would operate without degradation with $2 \%$ of the heat pipes failed ( 2 out of 90 failed). Individual heat-pipe fuel modules have a reliability of 0.999 for a subassembly reliability of 0.9999 .

- Gas-cooled reactors were assumed to have the same reliability as heat-pipe reactors. The $\mathrm{Xe}-\mathrm{He}$ gas is not reactive with the fuel. The 
pressure vessel at the pressures and temperatures of interest should have a high reliability.

- The reflector and shields are static components for which a mature science exist. Therefore, for our purposes, the reliability is 1.0.

- The high-temperature heat exchanger will have a constant failure rate with time. Based on extrapolation of BIPS information, of $0.11 \mathrm{x}$ $10^{-6}$ failures/h can be expected for a projected EOM reliability of 0.993 .

- The radiator contains about 100 welds with a potential failure rate of $2 \times 10^{-10}$ failures/weld-h. The radiator could also suffer meteoroid puncture of $0.49 \times 10^{-6} \mathrm{failure} / \mathrm{h}$, based on KIPS information. This leads to a reliability of 0.97 . With redundancy, the reliability could be increased to 0.98 or 0.99 . The analys is used 0.98 .

- Ducting reliability depends on single- or double-weld containment. Table XXXV shows the projected reliabilities for various power plant configurations. These figures were extrapolated from BIPS calculations.

- Overall drum actuator movement reliability depends on the number of drums and number of actuators in the design and how many must survive intact throughout the mission. The reliability of the actuators is based on the IEEE Handbook data for stepper motor failure rates and was taken as 0.99 . Three combinations are considered: 6 drums and 6 actuators with 5 of 6 intact resulting in a reliability of $0.990,12$ drums with 6 actuators with 5 of 6 intact resulting in a reliability of 0.995 , and 12 drums and 12 actuators with 10 of 12 intact resulting in a reliability of 0.997 .

- The control system permits adding redundancy at a minimum cost in weight. Based on KIPS projections, a single-control system has a reliability of 0.978 and a redundant, 0.9995 .

TABLE XXXV

PROJECTED DUCTING RELIABILITY FOR SINGLE- OR DOUBLE-CONTAINMENT WELDS Welds

Configuration

Gas-cooled

Heat-pipe, single converter

Heat pipe, two converters

\begin{tabular}{cc}
\hline Single Containment & Double Containment \\
\cline { 2 - 2 } 0.983 & 0.991 \\
0.986 & 0.993 \\
0.972 & 0.986
\end{tabular}


- The recuperator with a double-containment design based on BIPS source has a reliability of 0.983 .

The heat exchanger to the radiator would have a failure rate half that for the high-temperature heat exchanger, for a reliability of 0.997 .

- The turbine based on BIPS projections has a reliability of 0.994 . - The alternator based on BIPS projections has a reliability of 0.986 . - The compressor based on BIPS projections has a reliability of 0.994 . The overall system reliability is given in Table XXXVI. With a single converter loop the reliability of the power plant is about 0.9l-0.92. With dual converters the projected reliability can meet a 0.95 design goal with either a gas-cooled or heat-pipe reactor.

\section{TABLE XXXVI}

\section{OVERALL PROJECTED SYSTEM RELIABILITY FOR SEVERAL ALTERNATIVE} GAS-COOLED AND HEAT-PIPE BRAYTON POWER CONVERSION SYSTEM DESIGNS

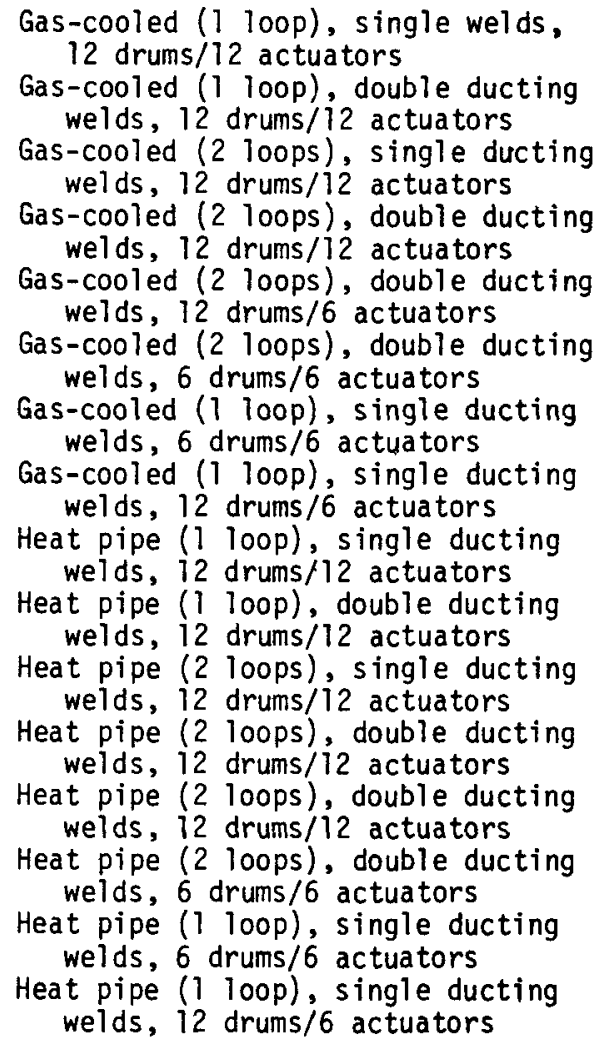

\begin{tabular}{|c|c|c|}
\hline $\begin{array}{l}\text { EOM Reliabi } \\
\text { Brayton Power } \\
\text { Conversion System }\end{array}$ & Other & $\begin{array}{r}\text { Total } \\
\text { System }\end{array}$ \\
\hline 0.995 & 0.960 & 0.917 \\
\hline 0.995 & 0.967 & 0.923 \\
\hline 0.988 & 0.960 & 0.958 \\
\hline 0.998 & 0.967 & 0.965 \\
\hline 0.998 & 0.949 & 0.947 \\
\hline 0.998 & 0.944 & 0.942 \\
\hline 0.955 & 0.946 & 0.906 \\
\hline 0.955 & 0.951 & 0.908 \\
\hline 0.955 & 0.956 & 0.913 \\
\hline 0.955 & 0.962 & 0.919 \\
\hline 0.998 & 0.943 & 0.941 \\
\hline 0.998 & 0.956 & 0.954 \\
\hline 0.998 & 0.954 & 0.952 \\
\hline 0.998 & 0,949 & 0.947 \\
\hline 0.955 & 0.949 & 0.906 \\
\hline 0.955 & 0.954 & 0.911 \\
\hline
\end{tabular}




\section{B. Power Plants with Thermoelectric Converters}

The reliability block diagram for a heat-pipe reactor with thermoelectric conversion system is shown in Fig. 171. Preliminary calculations were made for each functional block and then combined to produce the overall projected reliability. The reliability of each block was estimated as follows

- Heat-pipe reactor is based on a fuel element module having a reliability of 0.999 . The sensitivity to this assumption will be considered later.

- Thermoelectric module reliability is based on General Electric Company data for SiGe from MUS MHW-RTG and LES $8 / 9$ experiments. Almost 18 million $\left(17.7 \times 10^{6}\right)$ unicouple hours in unicouple modules and Test Bed Converters were tested without a single open circuit failure. In addition, $35 \times 10^{6}$ additional unicouple-hours have been accumulated on fueled RTG's.* A failure rate of $1.9 \times 10^{-8}$ failure/h are calculated from the data for a seven year mission reliability of 0.999 .

*Final Reliability Assessment for the MJS77 Multi-Hundred Watt RTG (MJS MHW-RTG), GESP-7B1, Apri1 12, 1977, General Electric Space Division, P. 0. Box 866 1, Philadelphia, PA 19101.

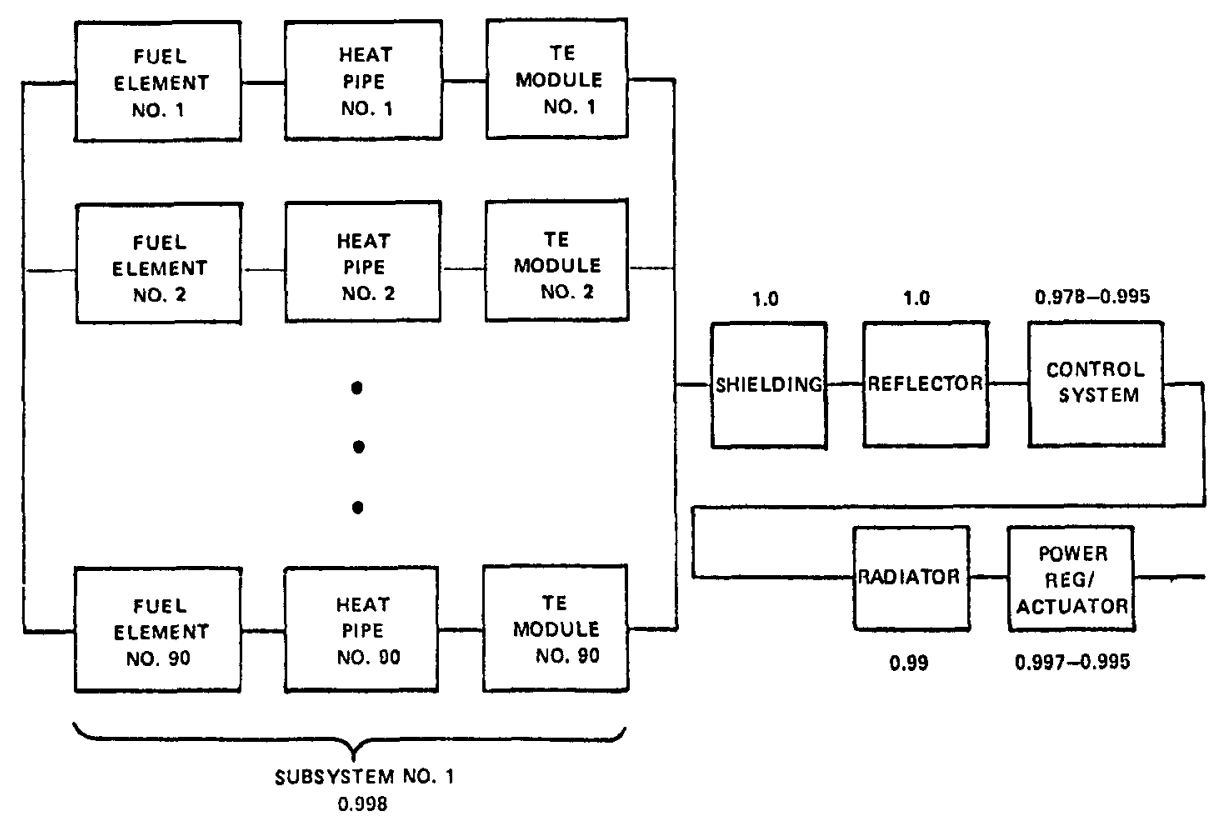

Fig. 171. Reliability block diagram of a heat-pipe reactor with thermoelectric power conversion system. 
- Shield and reflector are static elements and state-of-the-art. A reliability of 1.0 is expected.

- Control system will have a single-loop reliability of 0.978 and with redundancy will have a reliability of 0.9995 .

- Radiator with heat pipes is being designed with redundancy to provide for $20 \%$ failures mainly from meteoroid punctures and still be 0.99 .

- Power regular and actuators used similar assumptions as for the Brayton cycle. Thus, 12 drums with 12 actuators have a reliability of 0.997 and 12 drums with 6 actuators have a reliability of 0.995 .

Table XXXVII provides the projected EOM reliability for several combinations of elements. With redundant control system loops, the potential exists for a 0.98 power plant. This is a result of the high degree of redundancy that is inherently part of this design.

Now let us examine the sensitivity of the projected system EOM reliability to the heat-pipe reliability and percentage path failures allowed in Subsystem No. 1 in Fig. 171. Table XXXVIII presents the system reliability for combinations of heat-pipe reliability and percentage path failures for a design with 12 drums, 12 actuators and one redundant control system (the third case in Table $X X X V I)$. Two percent path failure is taken to mean 2 path failures out of $90,5 \%$ as 5 path failures out of 90 , and $10 \%$ path failures as 9 out of 90 . The system reliability is quite sensitive to the

\section{TABLE XXXVII}

PRELIMINARY EOM RELIABILITY FOR SEVERAL ALTERNATIVE DESIGNS FOR A HEAT-PIPE THERMOELECTRIC SPACE NUCLEAR REACTOR

\section{Design}

12 drums/12 actuators; one control system loop

12 drums/6 actuators; one control system loop

12 drums/12 actuators; redundant control system

12 drums/6 actuators; redundant control system
EOM Reliability

0.964

0.962

0.985

0.984 
heat-pipe reliability when only $2 \%$ path failure is allowed, particularly for a heat-pipe reliability as low as 0.99 .

A minimum requirement on core heat pipes is to design the individual heat pipe for 0.995 reliability and allow for $2 \%$ failure or to design the individual heat pipe for 0.990 and allow for $5 \%$ failures. Similar results would be obtained for the other designs in Table XXXVII.

\section{TABLE XXXVIII}

PROJECTED EOM HEAT-PIPE THERMOELECTRIC SYSTEM RELIABILITY FOR SELECTED COMBINATIONS OF HEAT-PIPE RELIABILITY AND PERCENTAGE PATH FAILURE IN SUBSYSTEM NO. 1

Percentage Path Failures

$2 \%$

$5 \%$

$10 \%$

\begin{tabular}{lccc} 
& Heat Pipe Reliability \\
\hline$\underline{0.990}$ & $\underline{0.995}$ & $\underline{0.999}$ \\
0.894 & 0.961 & 0.985 \\
0.986 & 0.986 & 0.987 \\
0.987 & 0.987 & 0.987
\end{tabular}




\section{$X$. SYSTEM CONSIDERATIONS}

Interactions between components and the power plant and the payload were evaluated.

The reactor design temperature is determined by converter performance and program emphasis. If the program emphasizes the $100-\mathrm{kW}_{\mathrm{e}}$ region, then higher converter performance is needed. Thermoelectrics converters that operate $\sim 1400 \mathrm{~K}$ are required, based on projected converter efficiencies. Reactor temperatures for the Brayton cycle must also be $\sim 1400 \mathrm{~K}$. At lower power levels, converter performance is less important and, thus, lower reactor temperatures might be accepted.

- A standard reactor design will save significant development cost and time over customized reactor designs. However, there is less peak power for single-shuttle spacecraft; $53-42 \mathrm{~kW}_{\mathrm{e}}$ with a $1-\mathrm{MW}_{\mathrm{t}}$ reactor, $35 \mathrm{MW}_{\mathrm{e}}$ for a $1.1 \mathrm{MW}_{\mathrm{t}}$-reactor, and $23 \mathrm{~kW}_{\mathrm{e}}$ for a $1.5 \mathrm{MW}_{\mathrm{t}}$-reactor. This is mainiy the result of the weight penalty of using a standard design reactor compared to building a customized reactor for each power level.

- The best means to package various power plant configurations into the Space Shuttle bay depends on the particular spacecraft. The radiator is the dominant power plant packaging element and it can be packaged in conical, flat-plate, or multiple-panel arrangements. For a $50-\mathrm{kW}_{\mathrm{e}}$ power $\mathrm{plant}$ containing a conical-shaped radiator behind the radiation shield, the thermoelectric power plant would be $6.3 \mathrm{~m}$ long; the thermionic power plant, $3.3 \mathrm{~m}$ long; Brayton, $10 \mathrm{~m}$ long; potassium Rankine, $3.8 \mathrm{~m}$ long; and Stirling, $4.5 \mathrm{~m}$ long. The Brayton requires a foldable design and flexible lines between radiator segments for storage within the spacecraft.

- Single failure point analysis conclusions are that a heat-pipe reactor with thermoelectric power conversion inherently avoids singlefailure points. If Brayton converters are used with a heat pipe reactor, dual converter loops can be used to eliminate single failure points. This will require the addition of accumulators or other means for regulation of pressure in the two loops between half and full power. The valves from the accumulators can be small and have slow reaction times. Gas-cooled reactor power plants can also eliminate single failure points by adding dual converters. However, a matrix of 16 valves needed for loop isolation in the inlet and outlet of the reactor means high temperature and large flow areas leading to additional complex development items. Liquid-cooled power plant 
designs are the most difficult for the elimination of single failure points. In fact, single failure points from core corrosion with lithium cannot be eliminated. Again, a matrix of 16 high temperature valves would be needed around the reactor for isolation of redundant flow loops.

- Combined cycles where thermionic converters are used on the hightemperature end and a Brayton converter on the low end, even though more efficient, lead to heavier-weight power plants.

- A heat-pipe reactor provides a means to include an emergency cool down system in the design without large stored fluid systems. Gas-cooled or liquid-cooled reactors would require large fluid storage systems if emergency cool down is to be provided in a manned spacecraft.

\section{A. Power Plant Design Temperatures}

Let us assume a standard $1000-\mathrm{kW}_{\mathrm{t}}$ reactor design. Optimizing the electric power output per unit mass depends strongly on the converter and radiator temperatures. For UC-ZrC fueled reactors operation is 1 imited to $1425 \mathrm{~K}$; $\mathrm{UO}_{2}$-Mo fueled reactors can be designed to operate to $\sim 1750 \mathrm{~K}$. The heatto-electric converter candidates for a ground demonstration system in the early 1980s are thermoelectric converters and Brayton turbogenerator cycles.

The reactor design temperature can determine the fuel and will determine the converter material development program. If the program emphasis is at power levels approaching $100 \mathrm{~kW}_{\mathrm{e}}$, then $\sim 1400-\mathrm{K}$ reactor operating temperature is required to obtain desired performance with either thermoelectric or Brayton converters. Slightly lower temperatures could be acceptable at lower power levels.

1. Thermoelectric Converters. Silicon germanium is the best deve1oped high-temperature thermoelectric material. Converters using SiGe could operate at $1425 \mathrm{~K}$. System operating temperatures are reduced to provide a margin for design and manufacturing uncertainties and to provide a temperature margin in case failures occur in parts of the system. The radiator mass is dependent on operating temperatures, the required radiator area changes with the fourth power of temperature. Using performance data from the converter (Figs. 172 and 173), shield (Fig. 174), and radiator section (Fig. 175), the variations in mass as a function of power for various hot junction thermoelectric temperatures and radiator temperatures has been calculated (Table IXL). A plot of this in Fig. 176 shows that system mass is generally at a minimum for a radiator temperature between 775 and $875 \mathrm{~K}$. 


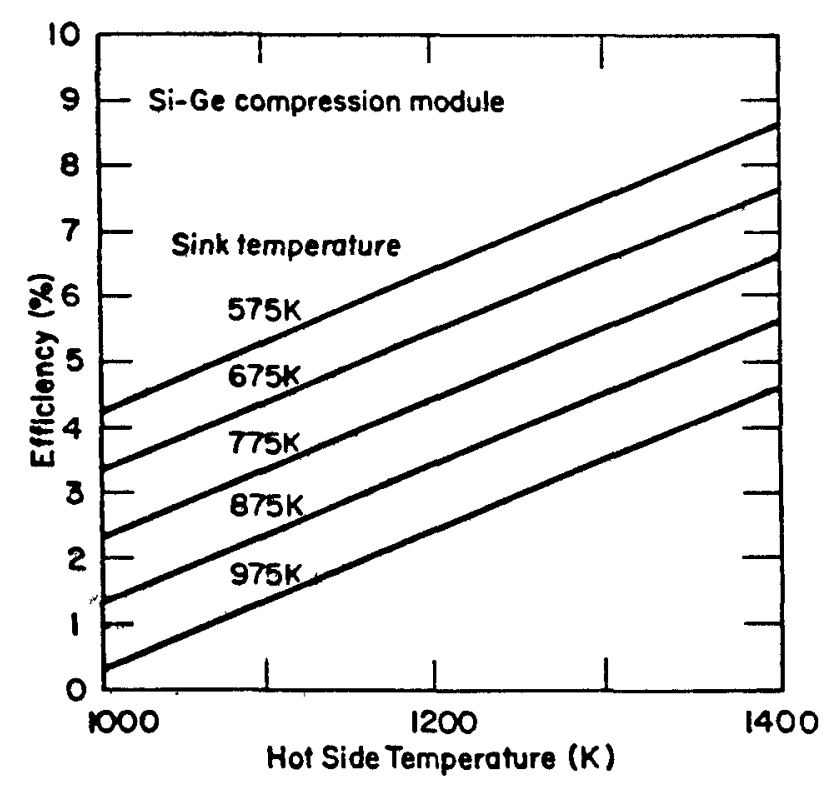

Fig. 172. Thermoelectric efficiency as a function of hot-side temperature for various sink temperatures based on SiGe compression module.

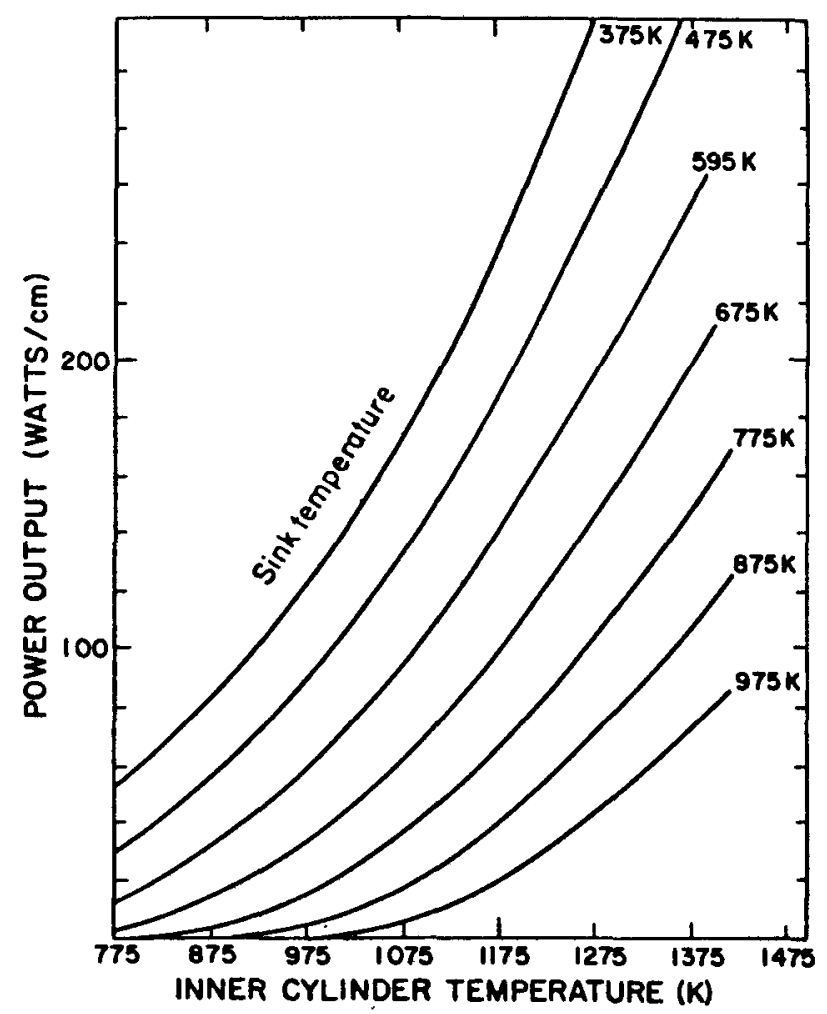

Fig. 173. Thermoelectric converter (SiGe) performance data.

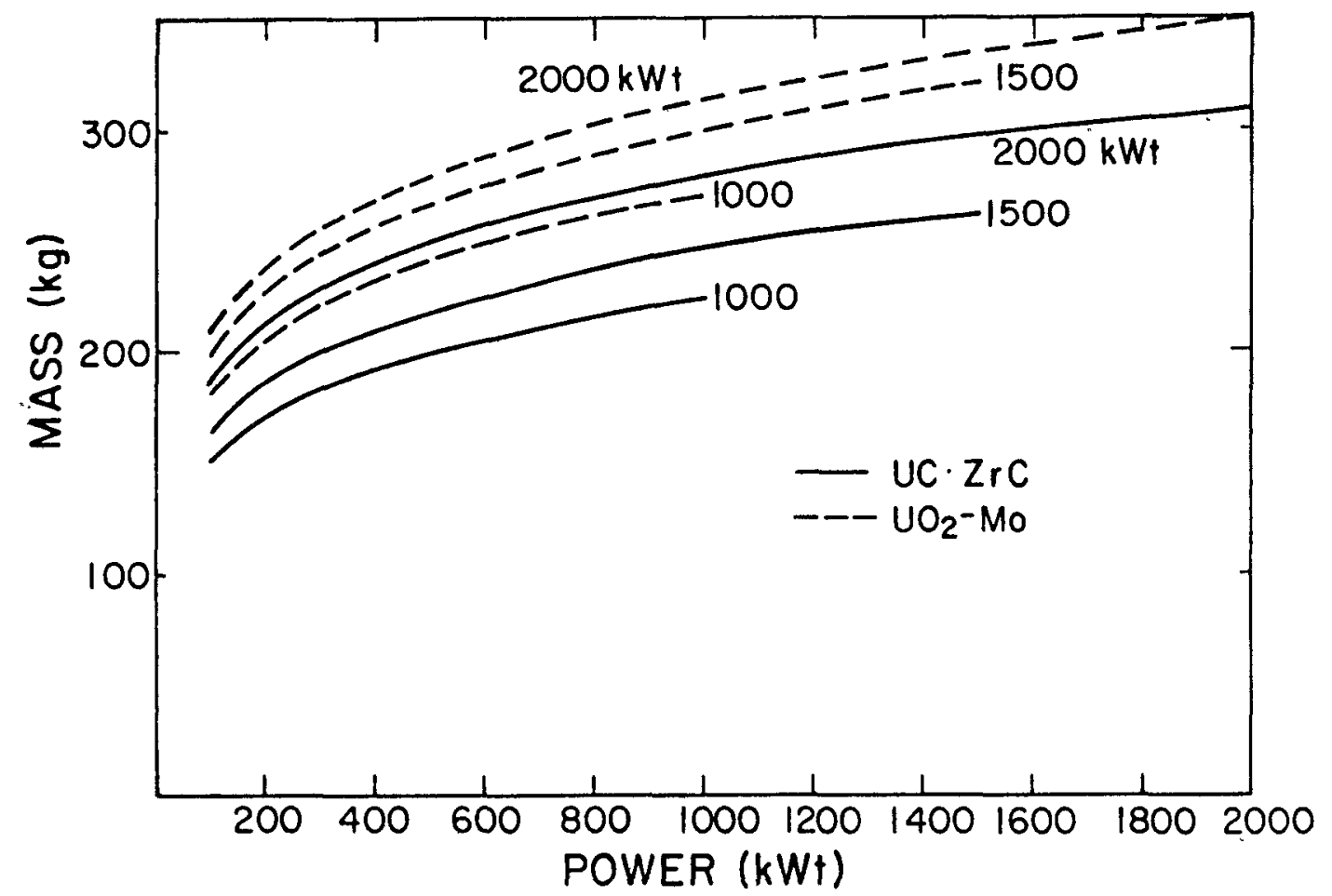

Fig. 174. Shield behavior (separation to payload $25 \mathrm{~m}$, cone half-angle $12^{\circ}$ ). 
TABLE IXL

THERMOELECTRIC PERFORMANCE WITH UC-10 at.\% ZrC

\begin{tabular}{|c|c|c|c|c|c|c|c|c|c|c|c|c|c|c|c|c|c|c|}
\hline Power $\left(k W_{e}\right)$ & & 10 & & & 50 & & & 10 & & 42 & & 50 & & 10 & & 32 & 43 & 54 \\
\hline TE Temp (K) & 1175 & 1275 & 1375 & 1175 & 1275 & 1375 & 1175 & 1275 & 1375 & 1175 & 1275 & 1375 & 1175 & 1275 & 1375 & 1175 & 1275 & 1375 \\
\hline Efficiency $(q)$ & 5.2 & 6.3 & 7.4 & 5.2 & 6.3 & 7.4 & 4.2 & 5.3 & 6.4 & 4.2 & 5.3 & 6.4 & 3.2 & 4.3 & 5.4 & 3.2 & 4.3 & 5.4 \\
\hline Thermal Power $\left(k H_{t}\right)$ & 192 & 159 & 135 & 961 & 794 & 676 & 238 & 189 & 156 & 1000 & 953 & 781 & 312 & 232 & 185 & 1000 & 1000 & 1000 \\
\hline Radiator Temp (K) & 675 & 675 & 675 & 675 & 675 & 675 & 775 & 775 & 775 & 775 & 775 & 775 & 875 & 875 & 875 & 875 & 875 & 875 \\
\hline Radiator Power $\left(\mathrm{kW}_{\mathrm{t}}\right)$ & 182 & 149 & 125 & 911 & 744 & 626 & 228 & 179 & 146 & 958 & 893 & 731 & 302 & 222 & 175 & 968 & 957 & 946 \\
\hline $\begin{array}{l}\text { Power Output }(\mathrm{w} / \mathrm{cm}) \\
\text { Mass, } \mathrm{kg}\end{array}$ & 15 & 23 & 31 & 15 & 23 & 31 & 11 & 16 & 23 & 11 & 16 & 23 & 6 & 11 & 17 & 6 & 11 & 17 \\
\hline Reactor & 415 & 415 & 415 & 415 & 415 & 415 & 415 & 415 & 415 & 415 & 415 & 415 & 415 & 415 & 415 & 415 & 415 & 415 \\
\hline Shield $\mathrm{d}^{\mathrm{a}}$ & 170 & 165 & 160 & 220 & 215 & 210 & 175 & 170 & 165 & 225 & 220 & 215 & 185 & 175 & 170 & 225 & 225 & 225 \\
\hline Converter & 70 & 45 & 35 & 360 & 235 & 175 & 105 & 70 & 45 & 435 & 340 & 235 & 175 & 95 & 65 & 560 & 415 & 350 \\
\hline Radiator & 140 & 110 & 80 & 1120 & 850 & 685 & 60 & 45 & 35 & 360 & 325 & 255 & 40 & 30 & 25 & 160 & 160 & 150 \\
\hline Structure (10\%) & 80 & 75 & 70 & 210 & 170 & 150 & 75 & 70 & $\underline{65}$ & 145 & 130 & 110 & 80 & 70 & 65 & 135 & 120 & 115 \\
\hline Total & 875 & 810 & 760 & 2325 & 1885 & 1635 & 830 & 770 & 725 & 1580 & 1430 & 1230 & 895 & 785 & 740 & 1495 & 1335 & 1255 \\
\hline
\end{tabular}

$a_{25-m}$ separation between core and payload, half-cone angle $12^{\circ}$ 
The peak power obtainable for a given hot-junction temperature is less for higher radiator temperatures. The radiator area is significantly reduced at higher radiator temperatures; $42 \%$ less at $775 \mathrm{~K}$ than at $675 \mathrm{~K}$ and $38 \% 1$ ess at $875 \mathrm{~K}$ than at $775 \mathrm{~K}$.

The peak output from SiGe converters using a hot-junction temperature of $1375 \mathrm{~K}$ and radiator temperature of $775 \mathrm{~K}$ for a $1000-\mathrm{kW}_{\mathrm{t}}$ reactor is $53 \mathrm{~kW}_{\mathrm{e}}$. The failure mechanism that could limit the hot-junction temperature is the evaporation of the SiGe material. The limit appears to be around $1425 \mathrm{~K}$, but may be higher in a highly compact design of the type we contemplate here. This needs experimental verification.

Another series of systems investigated assumed that the SiGe efficiency was improved $40 \%$ by reducing the thermal conductivity of SiGe by alloying with GaP. Table XL and Fig. 177 show power plant mass for various power levels with the improved efficiency. Similar trends are seen. For clarity, the improvement in performance for just one set of data is plotted in Fig. 178. At $50 \mathrm{~kW}_{e}$, a $16 \%$ power plant weight savings is forecasted with a $40 \%$ improvement in thermoelectric efficiency. The peak obtainable power for these conditions increased to $90 \mathrm{~kW}_{\mathrm{e}}$ from $64 \mathrm{~kW}_{\mathrm{e}}$ - a gain of $26 \mathrm{~kW}_{\mathrm{e}}$.

Analysis of configurations to achieve a $100-\mathrm{kW}_{e}$ power plant that weighs less than $19.1 \mathrm{~kg} / \mathrm{kW}_{\mathrm{e}}$ using thermoelectric converters included a choice of UC-ZrC or $\mathrm{UO}_{2}$-Mo fuels. Electric converter materials included a selection between SiGe, SiGe-GaP, advanced thermoelectric material and segmenting of these materials. Where necessary, the reactor size was increased from $1 \mathrm{MW}_{\mathrm{t}}$ to $1.5 \mathrm{MW}_{\mathrm{t}}$ or $2.0 \mathrm{MW}_{\mathrm{t}}$ to achieve an output power of $100 \mathrm{~kW}_{\mathrm{e}}$. Radiator materials choices included stainless steel, titanium, and nickel laminated with beryllium.

If one were to pick the most straightforward design approach possible, then $\mathrm{UO}_{2}-40$ vol\% Mo for the fuel operating at $1275 \mathrm{~K}$, SiGe thermoelectric power conversion, and a stainless steel heat-pipe radiator would probably be chosen (the first bar on Fig. 179). However, the mass is over $6000 \mathrm{~kg}$ and far exceeds our goal. The radiator must be significantly reduced in mass. Titanium and beryllium each reduce power plant mass in half, but it is still too heavy. Raising reactor temperatures will increase conversion efficiency and reduce the mass to $2500 \mathrm{~kg}$. Lowering the radiator temperature will also increase conversion efficiency, but the radiator size increases and adversely effects mass. Improved thermoelectric converters result in a lower 
TABLE XL

THERMOELECTRIC CONVERTER EFFICIENCY IMPROVED BY $40 \%$

\begin{tabular}{|c|c|c|c|c|c|c|c|c|c|c|c|c|c|c|c|c|c|c|c|c|c|c|c|c|c|c|}
\hline Power Level $\left(\mathrm{kw}_{\mathrm{e}}\right)$ & \multicolumn{9}{|c|}{10} & \multicolumn{8}{|c|}{50} & 73 & 88 & 1104 & 59 & 74 & 90 & 45 & 60 & 76 \\
\hline TE Temp (K) & 1175 & 1275 & 1375 & 1175 & 1275 & 1375 & 1175 & 1275 & 1375 & 1175 & 51275 & 1375 & 1175 & 1275 & 1375 & 1275 & 1375 & 1175 & 1275 & $|1375|$ & 1175 & 1275 & $|1375|$ & 1175 & 1275 & 1375 \\
\hline Efficiency (\%) & 3 & 8.8 & 10.4 & 5.9 & 7.4 & 9.0 & 4.5 & 6.0 & 7.6 & 7.3 & 8.8 & 10.4 & 5.9 & 7.4 & 9.0 & 6.0 & 7.6 & 7.3 & 8.8 & 10.4 & 5.9 & 7.4 & 9.0 & 4.5 & 6.0 & 7.6 \\
\hline Thermal Power $\left(\mathrm{kW}_{\mathrm{t}}\right)$ & 137 & 114 & 96 & 169 & 135 & ו1ו & 222 & 167 & 132 & 685 & 568 & 481 & 847 & 676 & 556 & 833 & 658 & 1000 & 1000 & 1000 & 1000 & 1000 & 1000 & 1000 & 1000 & 1000 \\
\hline Radiator Temp (K) & 675 & 675 & 675 & 775 & 775 & 775 & 875 & 875 & 875 & 675 & 675 & 675 & 775 & 775 & 775 & 875 & 875 & 675 & 675 & 675 & 775 & 775 & 775 & 875 & 875 & 875 \\
\hline Radiator Power $\left(\mathrm{kW}_{\mathrm{t}}\right)$ & 127 & 104 & 86 & 159 & 125 & 101 & 212 & 157 & 122 & 635 & 518 & 518 & 797 & 626 & 506 & 784 & 608 & 927 & 912 & 896 & 941 & 926 & 910 & 955 & 940 & 924 \\
\hline Power Output (w/in.) & 39 & 59 & 79 & 27 & 41 & 59 & 16 & 29 & 70 & & & & & & & & & & & & & & & & & \\
\hline $5 s(\mathrm{~kg})$ & & & & & & & & & & & & & & & & & & & & & & & & & & \\
\hline Reactor & 415 & 415 & 415 & 415 & 415 & 415 & 415 & 415 & 415 & 415 & 415 & 415 & 415 & 415 & 415 & 415 & 415 & 415 & 415 & 415 & 415 & 415 & 415 & 415 & 415 & 415 \\
\hline Shield ${ }^{a}$ & 160 & 155 & 150 & 165 & 160 & 150 & 175 & 165 & 155 & 210 & 205 & 200 & 220 & 210 & 205 & 215 & 210 & 225 & 225 & 225 & 225 & 225 & 225 & 225 & 225 & 225 \\
\hline Converter & 50 & 30 & 25 & 75 & 50 & 30 & 125 & 70 & 45 & 250 & 150 & 125 & 375 & 250 & 150 & 350 & 225 & 365 & 265 & 260 & 440 & 370 & 270 & 560 & 420 & 340 \\
\hline Radiator & 80 & 55 & 50 & 40 & 30 & 20 & 30 & 25 & 20 & 700 & 540 & 420 & 290 & 215 & 165 & 120 & 90 & 1150 & 1130 & 1125 & 350 & 345 & 335 & 160 & 155 & 150 \\
\hline Structure $(10 \%)$ & 70 & 65 & 65 & 70 & 65 & 60 & 75 & 65 & 65 & 155 & 130 & 115 & 130 & 110 & 95 & 110 & 95 & 215 & 205 & 200 & 145 & 135 & 125 & 135 & 120 & 115 \\
\hline Total & 775 & 720 & 705 & 765 & 720 & 675 & 820 & 740 & 700 & 1730 & 1440 & 1275 & 1430 & 1200 & 1030 & 12110 & 1035 & $|2370|$ & 2240 & 2225 & 1575 & $|1490|$ & $|1370|$ & 1495 & 1335 & 1245 \\
\hline
\end{tabular}

${ }^{a}$ Separation from core to payload $25 \mathrm{~m}$, cone half angle $12^{\circ}$. 


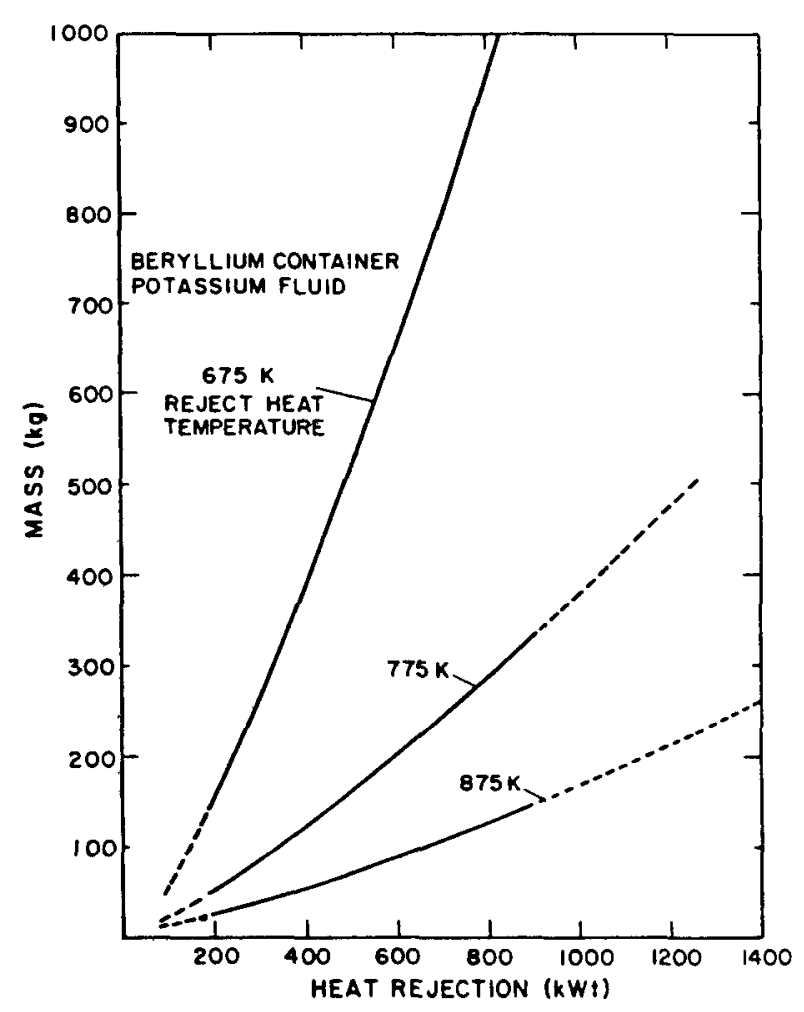

Fig. 175. Radiator weights.

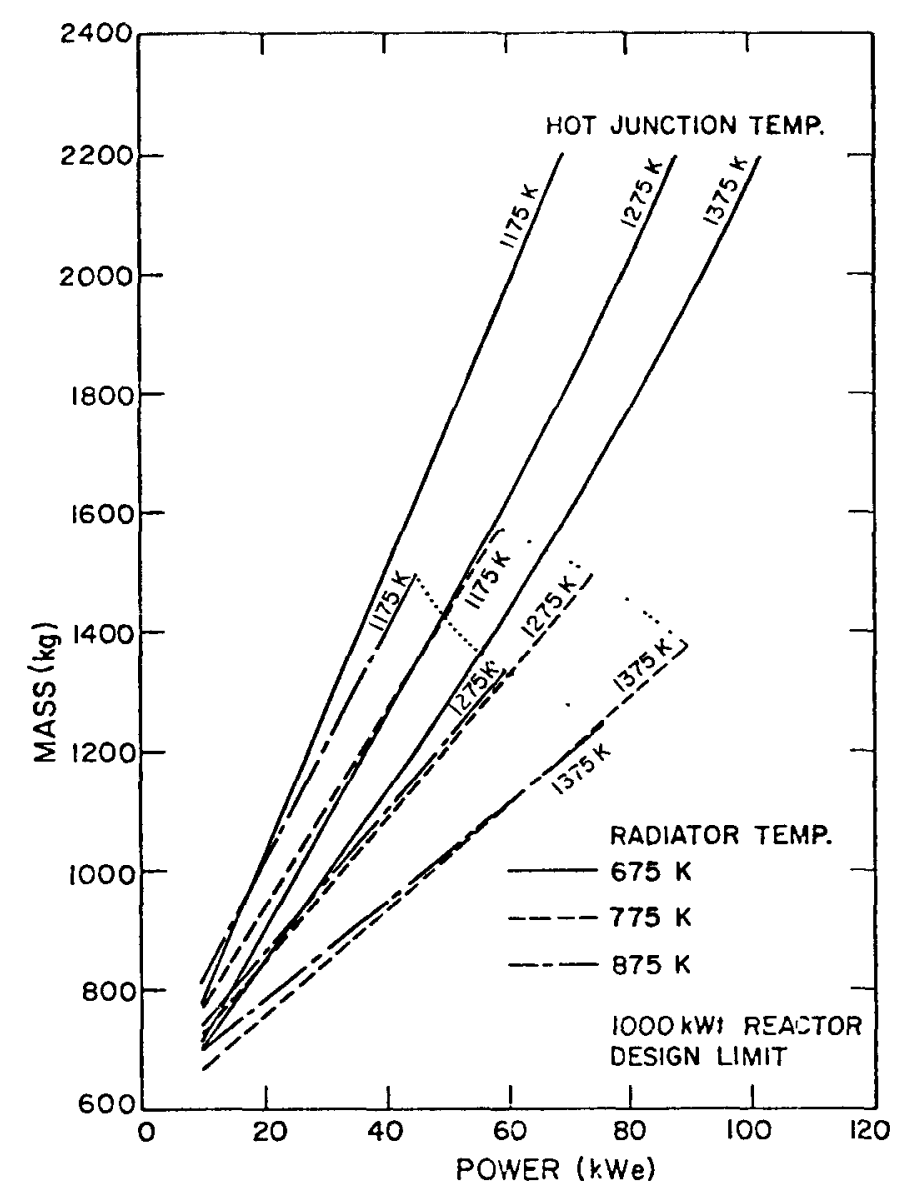

Fig. 176. Effect of thermoelectric temperature variations on power plant mass.

reactor, shield, converter, and radiator mass of $1965 \mathrm{~kg}$, which is quite close to our goal of $1910 \mathrm{~kg}$. This improved converter would use SiGe-GaP in place of SiGe. With a more concentrated fuel $\left(\mathrm{UO}_{2}-20\right.$ vol\% Mo), we could achieve our goal with a mass of $1745 \mathrm{~kg}$. An even more concentrated fuel, UC-10 at.\% ZrC would further decrease the mass to $1640 \mathrm{~kg}$. The UC-10 at.\% $\mathrm{ZrC}$ fuel has a more limited temperature range, whereas $\mathrm{UO}_{2}-20$ vol\% Mo can go to higher temperatures. Thus, higher efficiency converters are possible with the latter and could lead to a mass of $\sim 1500 \mathrm{~kg}$. The selected system is the $\mathrm{UO}_{2}-20$ vol\% Mo for fuel, SiGe-GaP thermoelectric material for the converter, and beryllium or nickel-laminated beryllium for the radiator. This meets the goal at $100 \mathrm{~kW}_{\mathrm{e}}$ and still allows further reductions in mass as thermoelectric technology advances. 


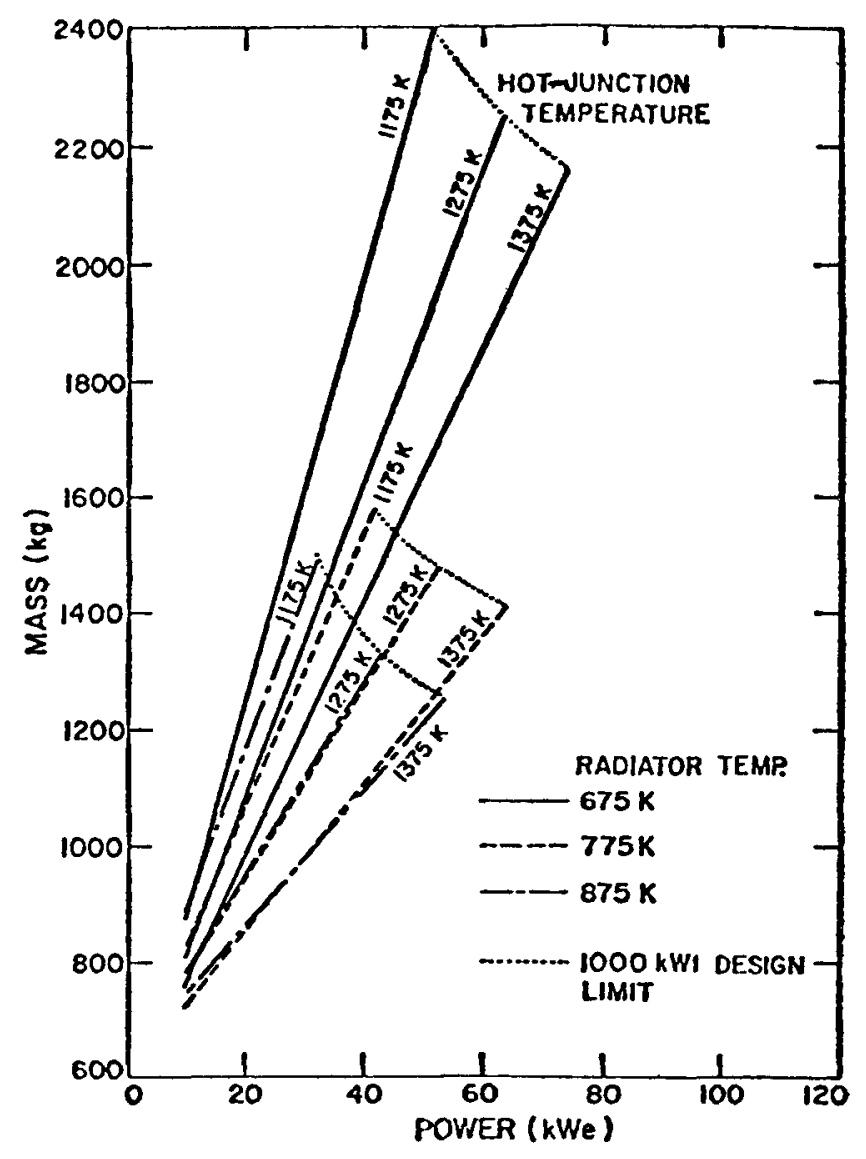

Fig. 177. Effect of thermoelectric temperature variations on power plant mass (efficiencies improved $40 \%)$.

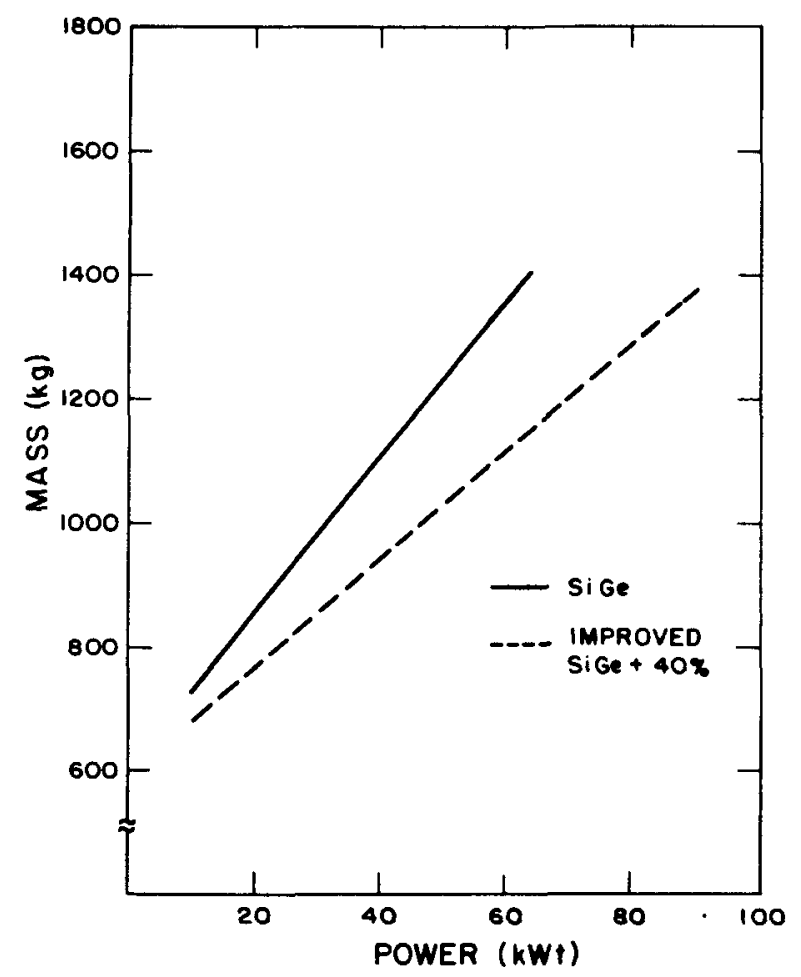

Fig. 178. Effect of thermoelectric efficiency on power plant mass.

A comparison of fuels and improved thermoelectric converter materials for 10, 50 and $100 \mathrm{~kW}_{\mathrm{e}}$ is shown in Table XLI and Fig. 180. In the 10- to $50-\mathrm{kW}_{\mathrm{e}}$ range, the reactor and shield weights dominate, so the improved converter efficiency that might be achieved by higher temperatures does not offset the higher nuclear subassembly weights. Thus, a UC fuel will provide the lowest-mass power plant, even if temperature-limited. In the range around $100 \mathrm{~kW}_{\mathrm{e}}$, the converter and radiator become an appreciably greater part of the total. Higher converter efficiency from higher temperature is now more significant, and a lighter-weight system results with a $\mathrm{UO}_{2}$ core and a $10 \%$ converter using advanced thermoelectric material. Growth to 
TABLE XLI

POWER PLANT PERFORMANCE WITH THERMOELECTRIC CONYERTER EFFICIENCY IMPROVED BY $40 \%$

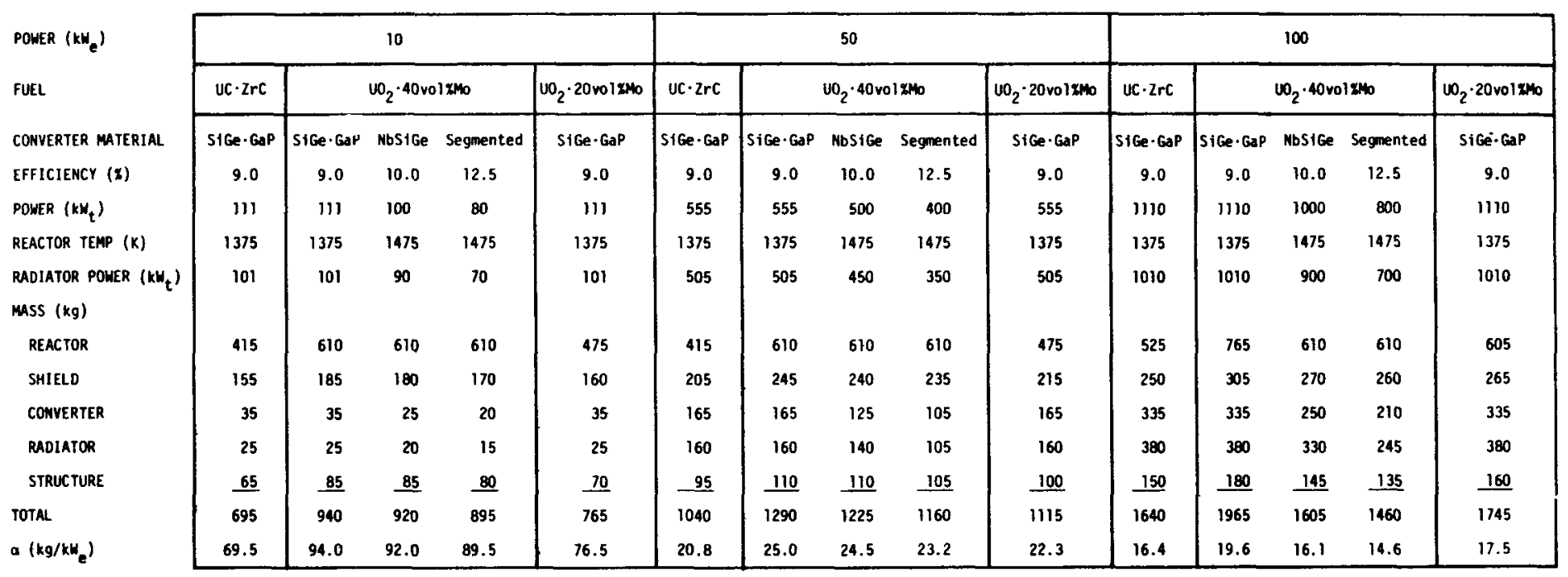


MASS (kg)

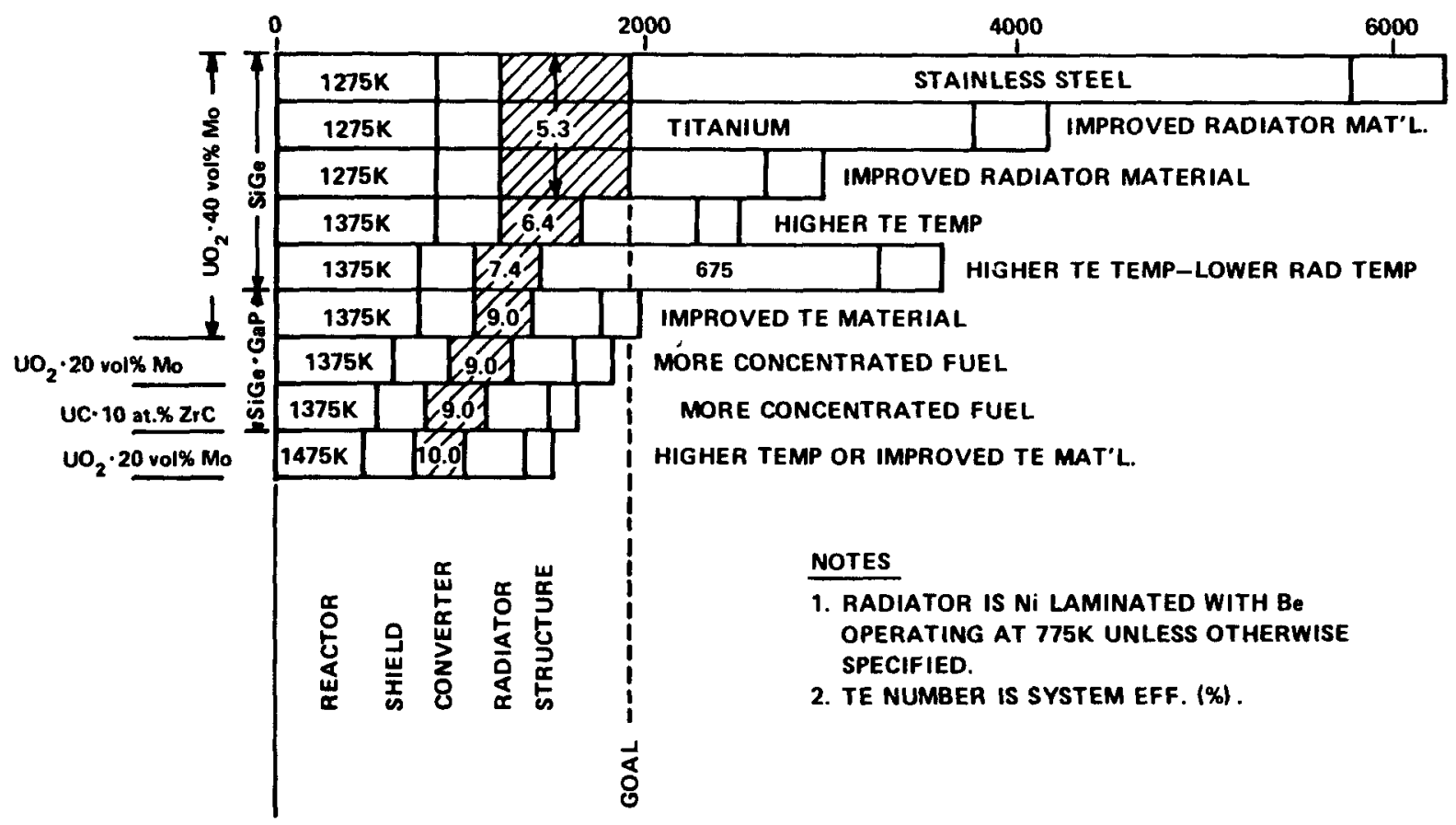

Fig. 179. Thermoelectric power plant options for $100 \mathrm{~kW}$.

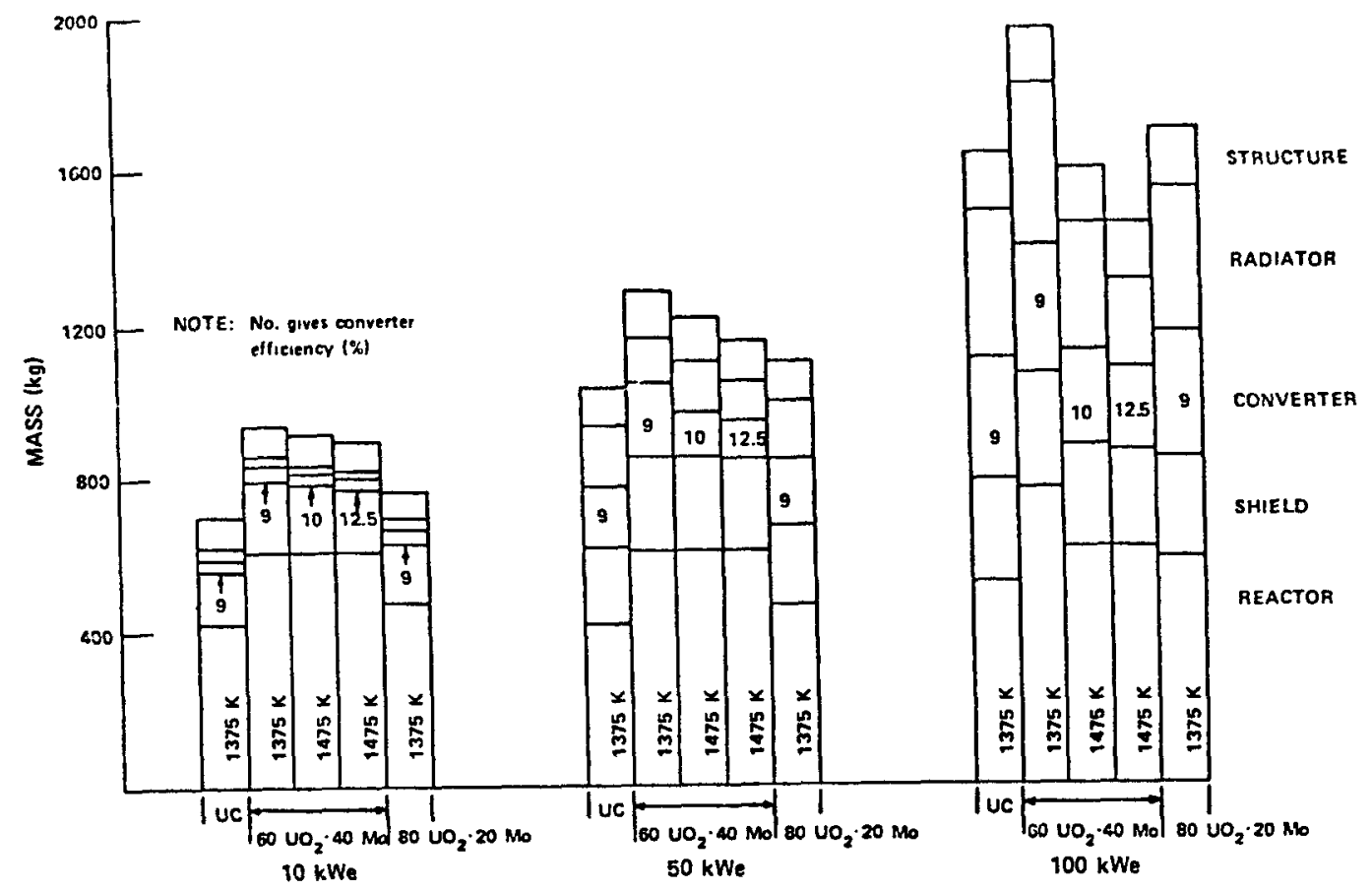

Fig. 180. Thermoelectric power plant comparisons. 
higher powers by even more advanced thermoelectric material development or lighter weight is possible with the $\mathrm{UO}_{2}$ fuel.

In conclusion, with thermoelectric converters, the selection of the fuel and temperature range depends on the emphasis one gives to power level and future growth potential. A minimum temperature of $1375 \mathrm{~K}$ is recommended based on thermoelectric materials performance.

2. Brayton Converter. Brayton converters show significant mass and packaging improvements with increased turbine outlet temperatures. (See Table XLII). A turbine inlet temperature of $7275 \mathrm{~K}$ is needed to meet the mass goal.* Because of the high temperature heat exchanger, the reactor will need to operate about $100 \mathrm{~K}$ higher than the turbine inlet temperature. B. Reactor Design Power Level

DoD established a potential requirement for $10-100 \mathrm{~kW}$. NASA missions could extend the desired power level to $200 \mathrm{~kW}_{e}$, but NASA has not indicated any inclination toward using reactors in geosynchronous orbit. The power plant based on a three-stage IUS should be able to deliver $100 \mathrm{~kW}_{\mathrm{e}}$ in a package weighing less than $1910 \mathrm{~kg}$.

* In this section we used an earlier projection of radiator weight for the Brayton cycle of $1 \mathrm{~kg} / \mathrm{kW}$. As discussed under Brayton radiator design, we have not been able to achieve this goal in our design efforts to date.

TABLE XLII

BRAYTON CYCLE PERFORMANCE AS A FUNCTION OF TURBINE INLET TEMPERATURE

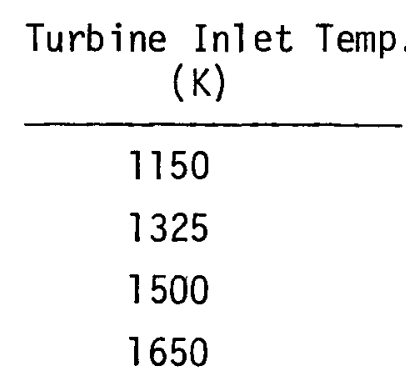

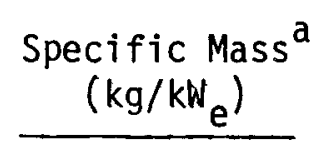

9

7

5

4
Specific Radiator

Area $\eta=28 \%$

$\left[\mathrm{m}^{2} /\left(\mathrm{kW}_{\mathrm{e}}\right)\right]$

1.9

1.1

0.7

0.4

a single converter and radiator only. Quantities taken from "Study of Space Nuclear Power System for a Nuclear Electric Spacecraft," AiResearch Progress Mid-Term Review, AiResearch, Phoenix, Arizona, Oct. 19, 1978. 
A ground'demonstration power plant will be needed for each unique reactor design to verify that modifications in the design did not change any parameters in an unanticipated manner. Each ground demonstration power plant will cost \$50-60 million. (This is based on the use of existing facilities). Each additional power plant will also involve a 2- to 3-yr development time for design, fabrication, and testing. Thus, if a single reactor can be developed to satisfy the range of projected missions, both cost and time would be saved. In addition, flexibility in meeting the spacecraft power needs can be very important. As the spacecraft design proceeds, the power requirements tend to change. The power plant development should proceed as indepentently of the spacecraft as possible.

If a single reactor design is selected, the shield, electric converter, and radiator can be tailored to a given mission. The basic configurations for each component could be designed and qualified separate from the reactor. At least one total configuration would be operated with the reactor in a ground demonstration system and another using flight qualified hardware.

Thermoelectric converters using SiGe-GaP with an anticipated efficiency of $9 \%$ should be available for use in power plants in the early 1980s. Brayton converters with efficiencies of 20-45\% are also achievable for early 1980 power plants with indications that power plant weight is minimized around a 25\% efficient converter. A fixed reactor design could be used to satisfy the power range from $10-200 \mathrm{~kW}_{\mathrm{e}}$ with some margin to account for uncertainties, but the question is whether the mass penalty at lower powers is acceptable.

The reactor mass vs power level is plotted in Fig. 181. A 200-kW reactor weighs about $40 \%$ less than a $1000-\mathrm{kW}_{\mathrm{t}}$ design. The lower power level designs are constrained by criticality considerations while the higher power levels are constrained by heat transfer rates and fuel swelling considerations. The reactor designs are for UC-10 at.\% $\mathrm{ZrC}$ cores with $10 \mathrm{~cm}$ of beryllium reflector. Substituting $\mathrm{Be} 0$ for beryllium in the reflector with the same reactivity control would require only an $8-\mathrm{cm}$ thickness. Reactor mass would be virtually the same with BeO as with beryllium. Also shown is the use of $\mathrm{UO}_{2}-40$ vol\% Mo as the reactor fuel. This increases reactor mass at $1000 \mathrm{~kW}_{t}$ by about $50 \%$. Unless the higher temperature potential of such a core can be utilized by the converters, this leads to a significant mass penalty. 


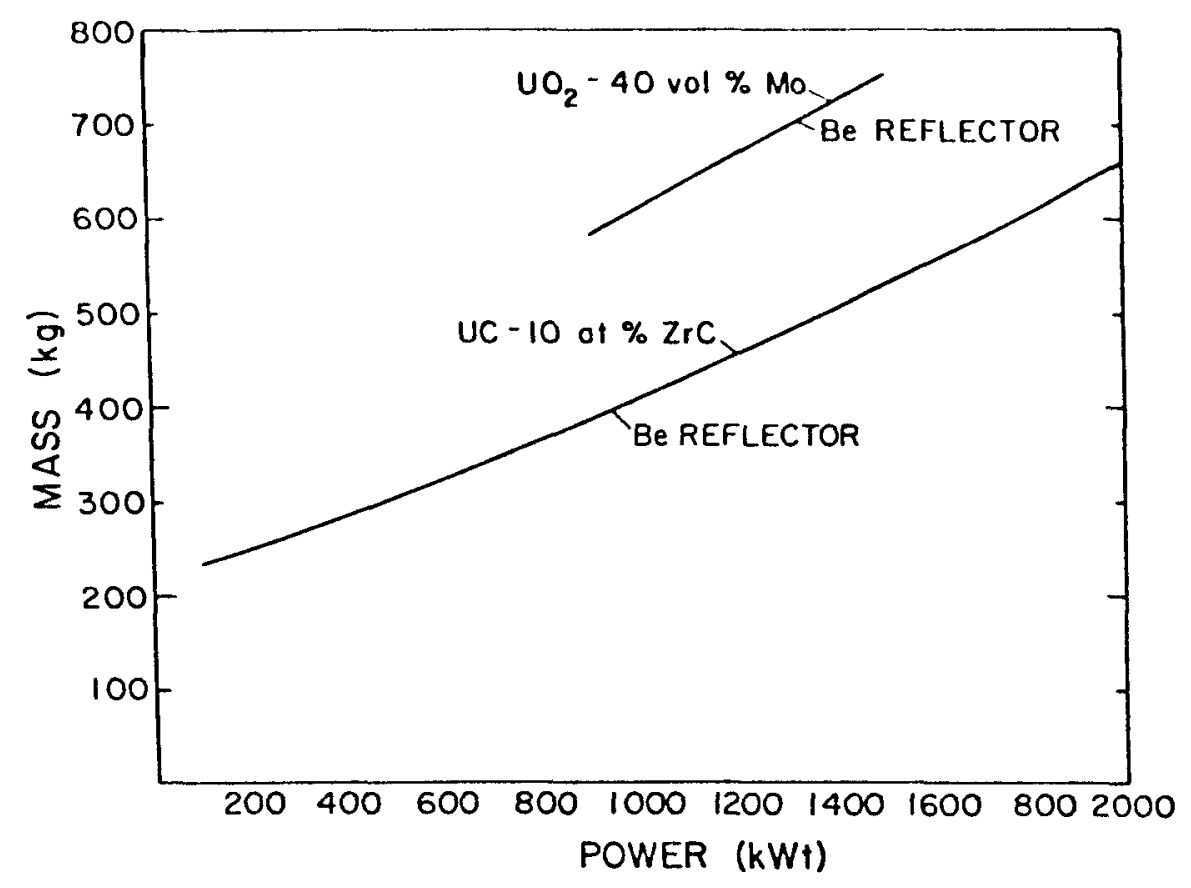

Fig. 181. Reactor mass vs power level.

Figure 182 shows that fuel swelling at a given power level is less with a standardized core design than with to a customized core design. The difference is not considered significant between the curves at each temperature because the reactor designs will accommodate the swelling amounts for the $1000-k W_{t}$ design.

Though the reactor weight is higher at low power levels for a standardized design than for a customized design, the overall power plant difference is what is important. The shield is a function of reactor dimensions, but the converter and radiator are virtually independent of the reactor size. Figure 183 is a plot of overall power plant weights. The thermoelectric curves are based on improved thermoelectric material (SiGe-GaP) operating at a 1375-K hot-junction temperature and a 775-K cold-junction temperature. A $1000-\mathrm{kW}_{t}$ reactor will not be sufficient to provide $100-\mathrm{kW}_{e}$ output using thermoelectric converters unless conversion efficiency can be improved to $10 \%$. Another way to get $100 \mathrm{~kW}_{\mathrm{e}}$ is to increase the standard reactor power level to perhaps 1500 or $2000 \mathrm{~kW}_{\mathrm{t}}$. The reactor core size will have to increase to accommodate these higher power levels while keeping the fuel swelling less than $10 \%$. The thermoelectric curves show that $42 \cdot \mathrm{kW}_{\mathrm{e}} \mathrm{can}$ be delivered by a single shuttle spacecraft with a standard $1-\mathrm{MW}_{\mathrm{t}}$ core vs $53 \mathrm{~kW}_{\mathrm{e}}$ with individual customized cores. If the standard core is 
$1.1 \mathrm{MW}_{\mathrm{t}}$, then $35 \mathrm{~kW}_{\mathrm{e}}$ is possible and if $1.5 \mathrm{MW}_{\mathrm{t}}$ then $23 \mathrm{~kW}_{\mathrm{e}}$. For a $\mathrm{UO}_{2}-\mathrm{Mo}$ core, $16 \mathrm{~kW}_{\mathrm{e}}$ at $1 \mathrm{MW}_{\mathrm{t}}$ core design could be delivered. The biggest penalty is at $10 \mathrm{~kW}_{\mathrm{e}}$, where the mass is increased from $50-100 \%$ depending on the selection for a standardized core.

C. Power Plant Configuration.

1. Thermoelectric. A thermoelectric system is logically a heat-pipecooled reactor, redundant thermoelectric modules, and heat-pipe radiator. The converter system is characterized by a large number of independent modules, one module per reactor-cooling heat pipe. The size of the module is dictated by design power level plus some margin to account for random failures. The heat rejection temperature is selected to be in the operating range of potassium-filled heat pipes.

To take advantage of the inherent redundancy provided by multiple heat pipes and thermoelectric modules, thermal cross-linking of the module heat sink is incorporated. If a radiator stringer heat pipe fails, its corresponding thermoelectric module should not lose its cooling.

The thermoelectric modules must be shielded from radiation. Therefore, they must be placed between the shield and payload. Reactor heat pipes can be routed around the shield, or can penetrate the shield. Controls, power

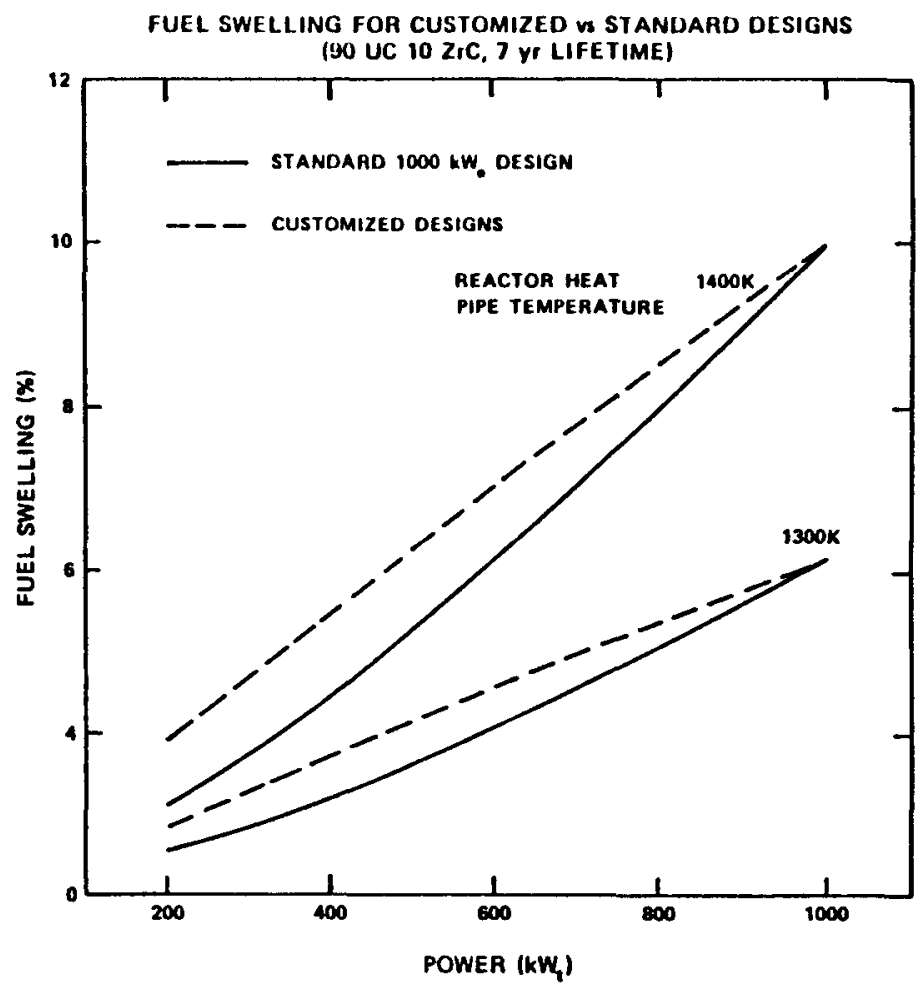

Fig. 182. Fuel swelling for customized vs standard designs. 


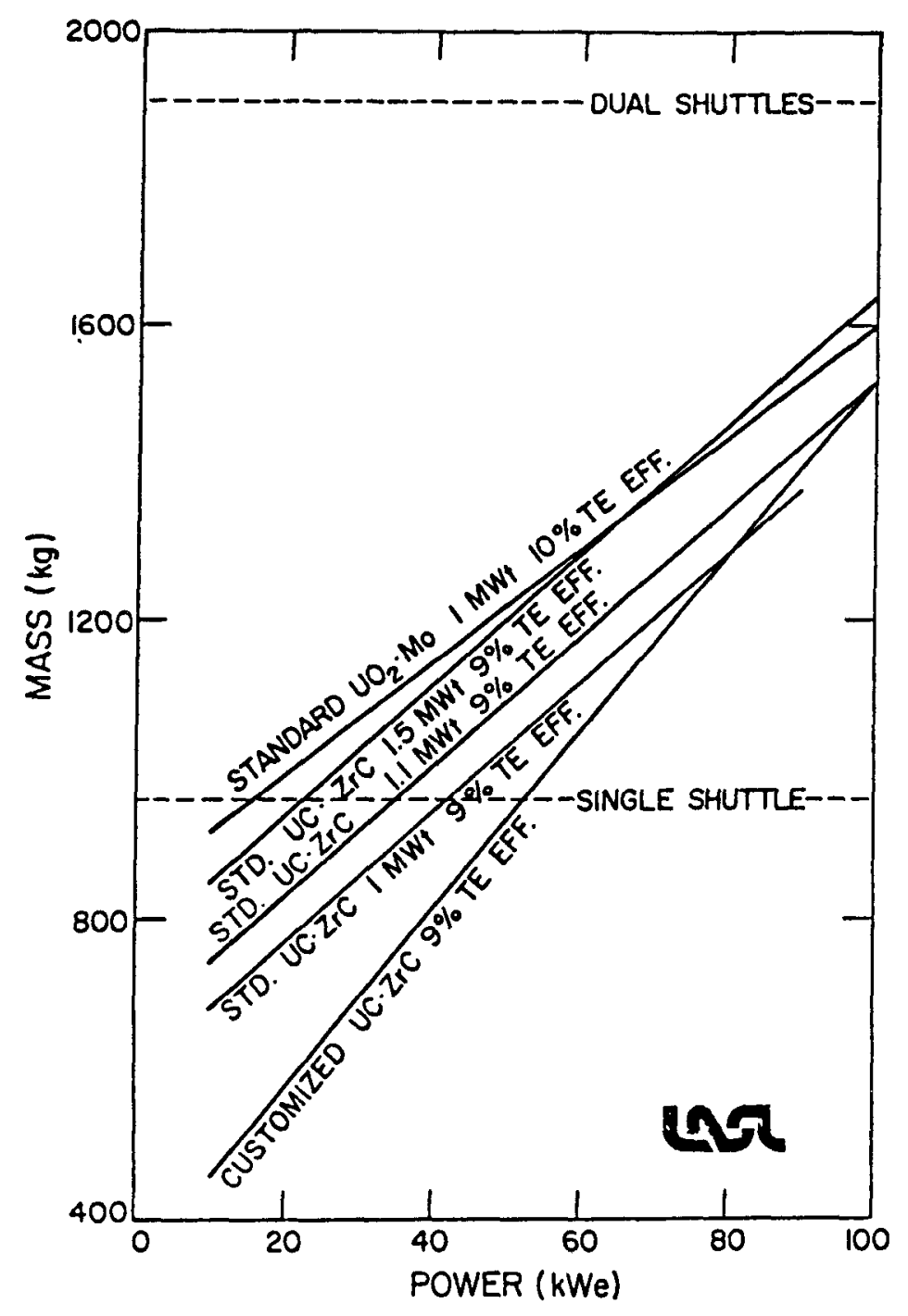

Fig. 183. Customized vs standard reactor design.

conditioning, and other components must be thermally protected since the thermoelectric sink temperature and radiator operate at temperatures above that which would be acceptable for electronic components.

Figure 184 is a layout for a $50-\mathrm{kW}_{\mathrm{e}}$ thermoelectric power plant. The power plant has a fixed geometry so that the shuttle stowed or orbit deployed configurations are the same. The overall power plant length is about $6.5 \mathrm{~m}$. In the Space Shuttle bay, components can be packaged in and around the radiator. The layout shows heat pipes being bent around the radiation attenuation shield. The core is divided into six symmetrical 
sections to minimize the number of variations in heat pipe bends. The layout shows the degree of bends necessary. It is desirable to minimize shield weight by placing the shield and reactor as close together as possible; however, to minimize heat-pipe development, it is desirable to reduce the number and degree of bends. The layout is a compromise between shieldweight and heat-pipe development complexity. A number of alternate arrangements were considered (see Table XLIII). These include having the heat pipes come out of the aft end of the reactor and around the reactor and shield, heat pipes bent through the shield with the core turned sideways, and adding a heat exchanger between the core and shield. The selected configuration is superior because the bends could accommodate thermal stress and there is a minimum of interface problems with the shield.

TABLE XLII I

\section{HEAT-PIPE ARRANGEMENTS}

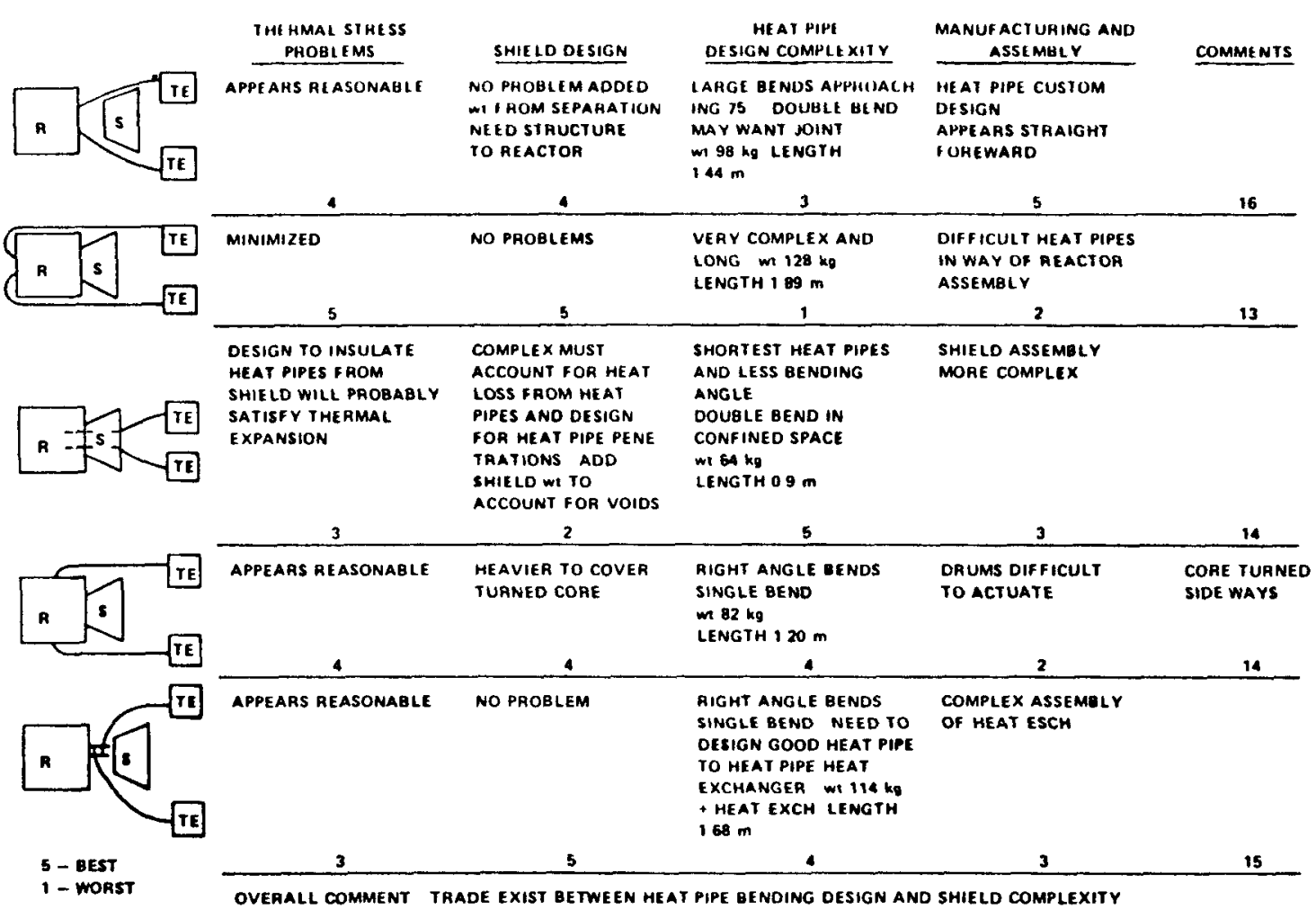




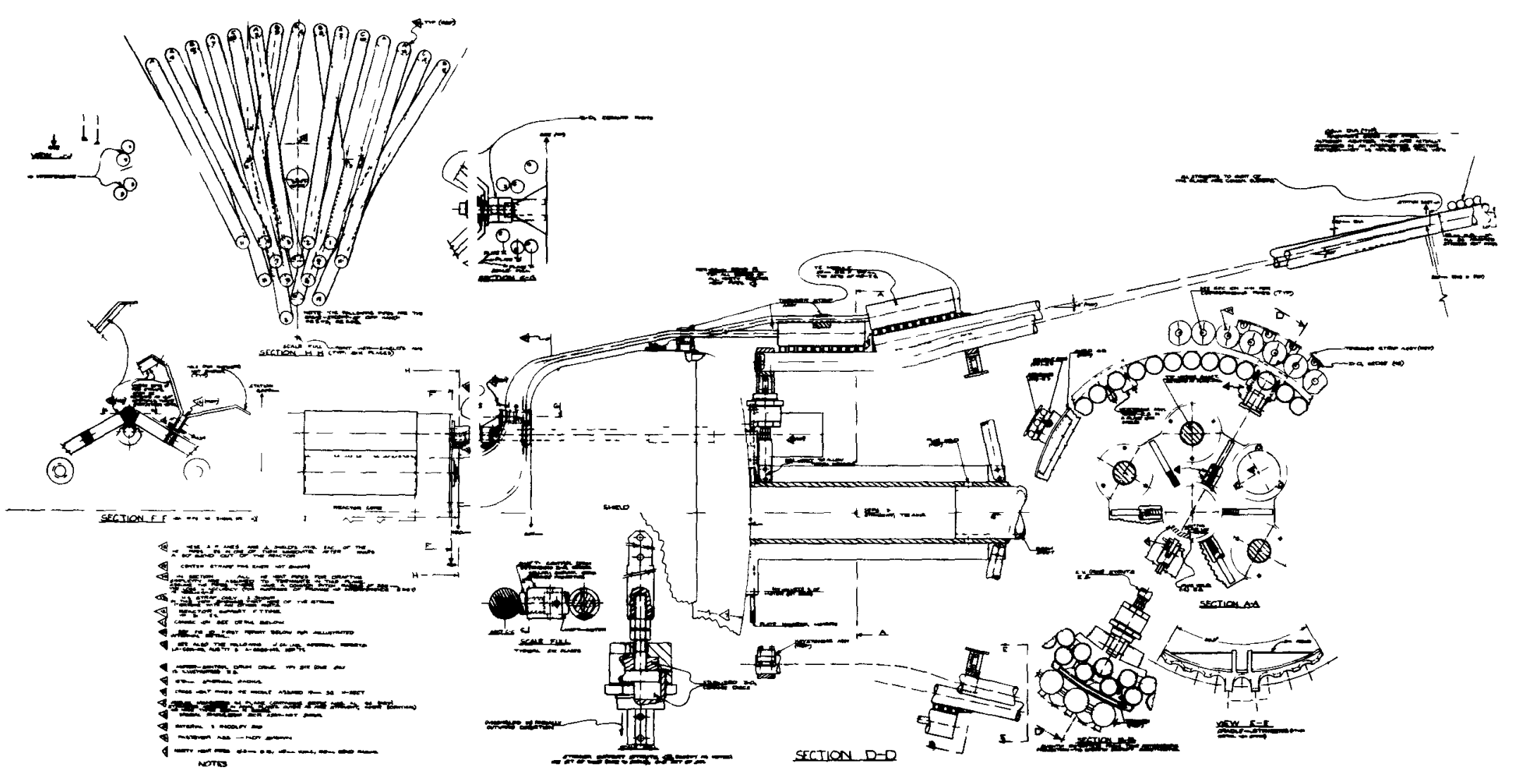

Fig. 184. Space electric power system. 
The dimensions for the thermoelectric elements are estimated. Two rows may be needed. The cold junctions are coupled together to ensure a common temperature and to provide redundancy. The radiator stringers from the converters are sufficiently close together to be used as a radiating surface for $2.7 \mathrm{~m}$ (circumferential heat pipes may be added here for their meteoroid bumper effect). Then, circumferential heat pipes are added to provide additional radiating surface.

The drawing indicates that an arrangement can be found that provides sufficient room for the various power plant components.

An alternative design to reduce weight is a flat-plate radiator in place of the conical-shaped radiator. Current design calculations on the conical radiator do not take advantage of shine through the base although it could reduce radiator weight $\sim 15 \%$, because a meteoroid or thermal shield may be desirable. However, a flat radiator could reduce radiator weight about $40 \%$ because heat can then be rejected from both sides of the radiator. The stringers would need to be made heavier because of the loss of bumper protection by the cross heat pipes on one side and the longer length. A flat radiator layout was made with thermoelectric converters (Figs. 185 and 186) at a power level of $100 \mathrm{~kW}_{\mathrm{e}}$. The core heat pipes bend around the shield to two rings of converters. The cold junction is then routed to the radiator, which consists of two panels around a central boom. The overall power plant is $9.5 \mathrm{~m}$ in length. The advantage of the flat radiators is weight and space reduction, and other components of the payload can be more convenientiy packaged around it.

One might consider routing the heat pipes through the shield by converging the heat pipes between the reactor and shield into six planes. For the radiator, two thermoelectric groups from two planes can be combined into a single radiator panel. Thus, a three-panel radiator configuration would result. This radiator would be significantly lighter than the conical radiator and shorter than the flat-plate radiator.

2. Thermionic. Thermionic conversion is a passive system similar in many respects to the thermoelectrics for spacecraft integration. However, it operates at a higher reject temperature leading to a significant reduction in overall length. A thermionic power plant with a conical radiator is about half the length of a thermoelectric power plant with a similarily 


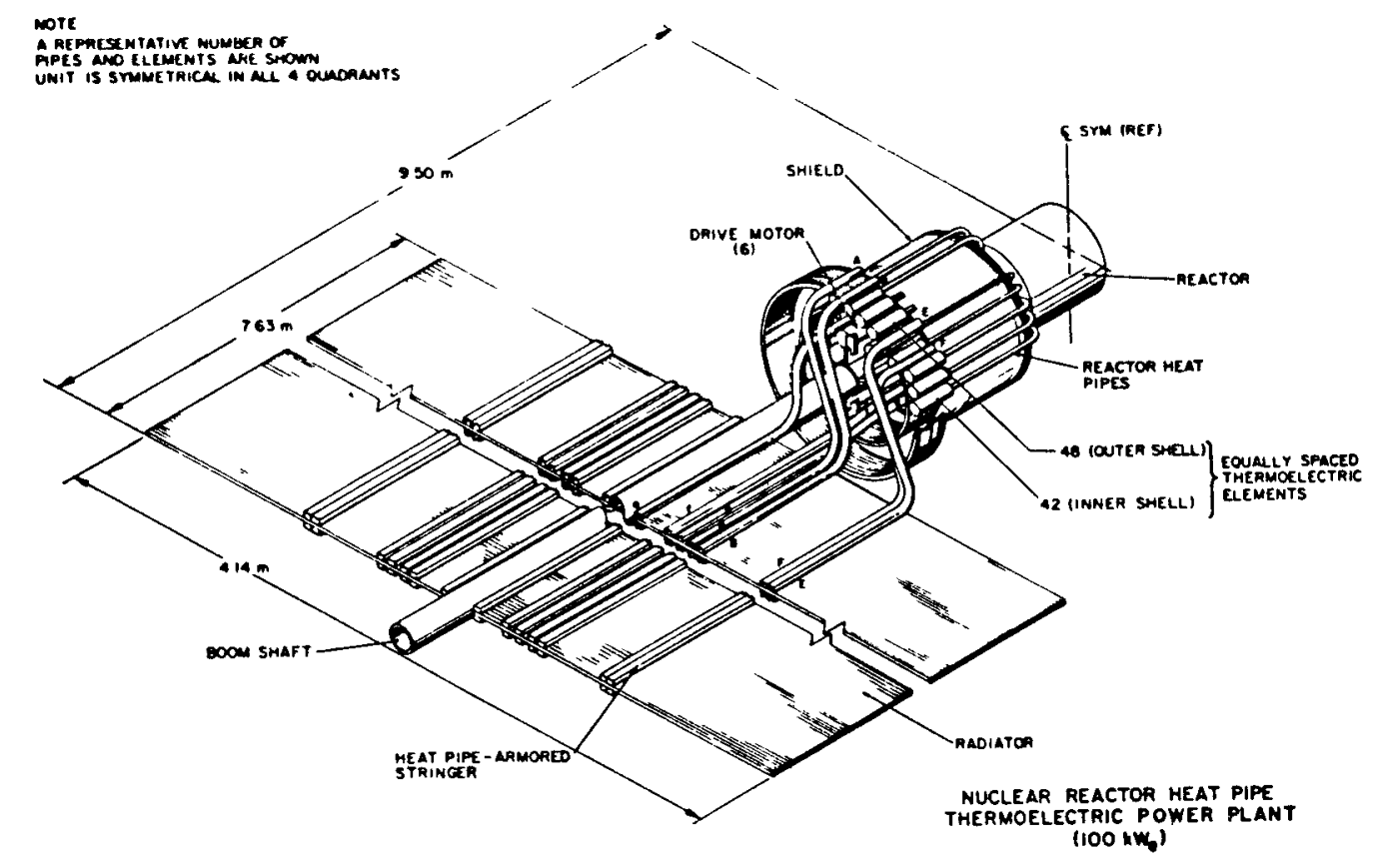

Fig. 185. Nuclear reactor heat-pipe thermoelectric power plant (100 kW).

designed radiator. The higher operating temperature does not lead to significant differences in reactor size; that is, for a $1000-\mathrm{kW}_{t}$ design, the reactor increases from 0.51 to $0.58 \mathrm{~m}$ in diameter and from 0.49 to $0.55 \mathrm{~m}$ in height. The larger reactor results from the higher operating temperatures needed with the less dense $\mathrm{UO}_{2}-40$ vol\% Mo fuel. Shield thickness also does not vary much with power level. A thermionic power plant is more efficient and thus requires a lower operating power. Power plant length significantly decreases when the radiator temperature is increased from $775 \mathrm{~K}$ for thermoelectric to $910 \mathrm{~K}$ for thermionic conversion. All factors combined lead to the need for one-fourth the radiating surface with thermionic as with thermoelectric conversion.

3. Brayton cycle. A Brayton-cycle spacecraft needs a large, lowtemperature radiator. The efficiency depends on a large temperature difference between turbine inlet and compressor inlet. Turbine inlet is limited by available materials to $\sim 1300 \mathrm{~K}$. To achieve an efficiency of $25 \%$, the radiator must operate in the range of $400-600 \mathrm{~K}$ so that the compressor inlet will be $425 \mathrm{~K}$. 


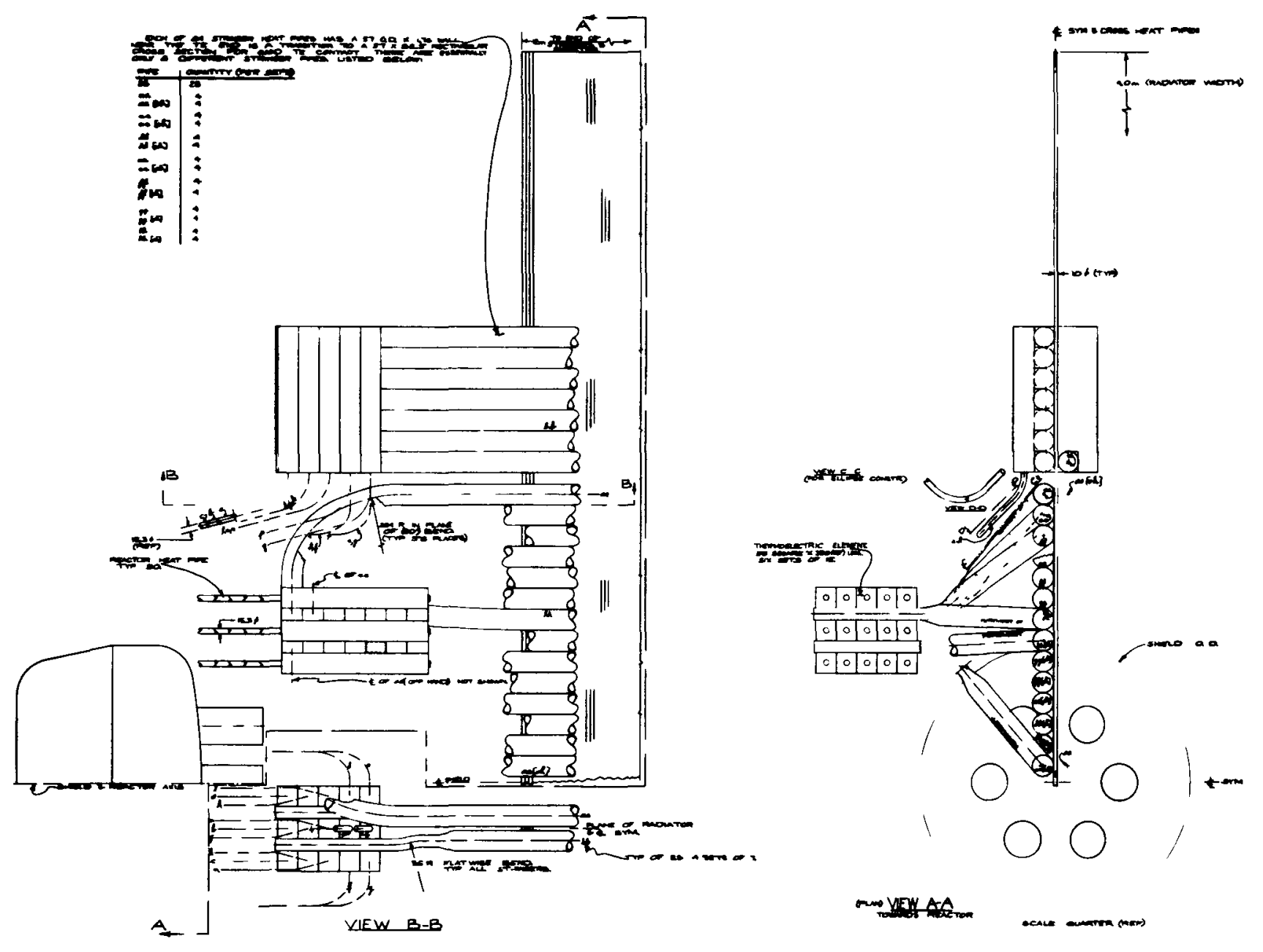


The Brayton cycle can he coupled to either a heat-pipe cooled reactor or a direct-cooled reactor. If redundancy is to be provided, a heat-pipe cooled reactor is the best choice. The location of the heat exchangers does not need to be outside the radiation field, which allows for more flexibility in spacecraft layout. The selected location is next to the reactor on the side away from the shield. This minimizes the heat-pipe design problems. It is easier to route the gas lines around the shield than heat pipes around or through the shield.

Two approaches to heat rejection were considered. One is to manifold and flow the working fluid directly to the heat rejection radiator, analogous to the designs proposed for the BIPS system. The second is to use a secondary radiator fluid, such as a liquid metal, with heat exchangers between the Brayton loop working fluid and radiator fluid. Direct cooling of the working fluid in the radiator has the advantage of simplicity as it eliminates a heat exchanger and a secondary fluid loop. However, it is believed to be more vulnerable to failure because of the long exposed piping and may result in a higher pressure drop in the system. A secondary fluid system may be more reliable, but the heat exchange design has proven to be difficult and heavy. The shuttle bay volume limitations result in using a folded configuration during transport to space. Several configurations were considered, including a four-panel foldable configuration (Figs. 187-189), sliding concentric cylinders (Fig. 190), and a flat-plate foldable arrangement around the reactor and converter (Fig. 191). Detailed layouts were made of the first configurations. It includes two independent Brayton gas loops. Heat exchangers at the forward end of the reactor are used to extract the thermal energy. Lines around the reactor and shield are used to bring the energy to the turbines. The Brayton converters are located aft of the shield. The gas flow is distributed to the heat-pipe radiating panels in a manner that loss of one converter will not degrade the other.

The telescoping cylinder design (Fig. 190) was sized to fit into the Space Shuttle. It expands when deployed in space. The smallest cylinder is $1.5 \mathrm{~m}$ in diameter and fits snugly around the power supply. Additional cylinders, $3.6 \mathrm{~m}$ long and each $0.2 \mathrm{~m}$ larger in diameter than the previous one are added until the required surface area is obtained. 


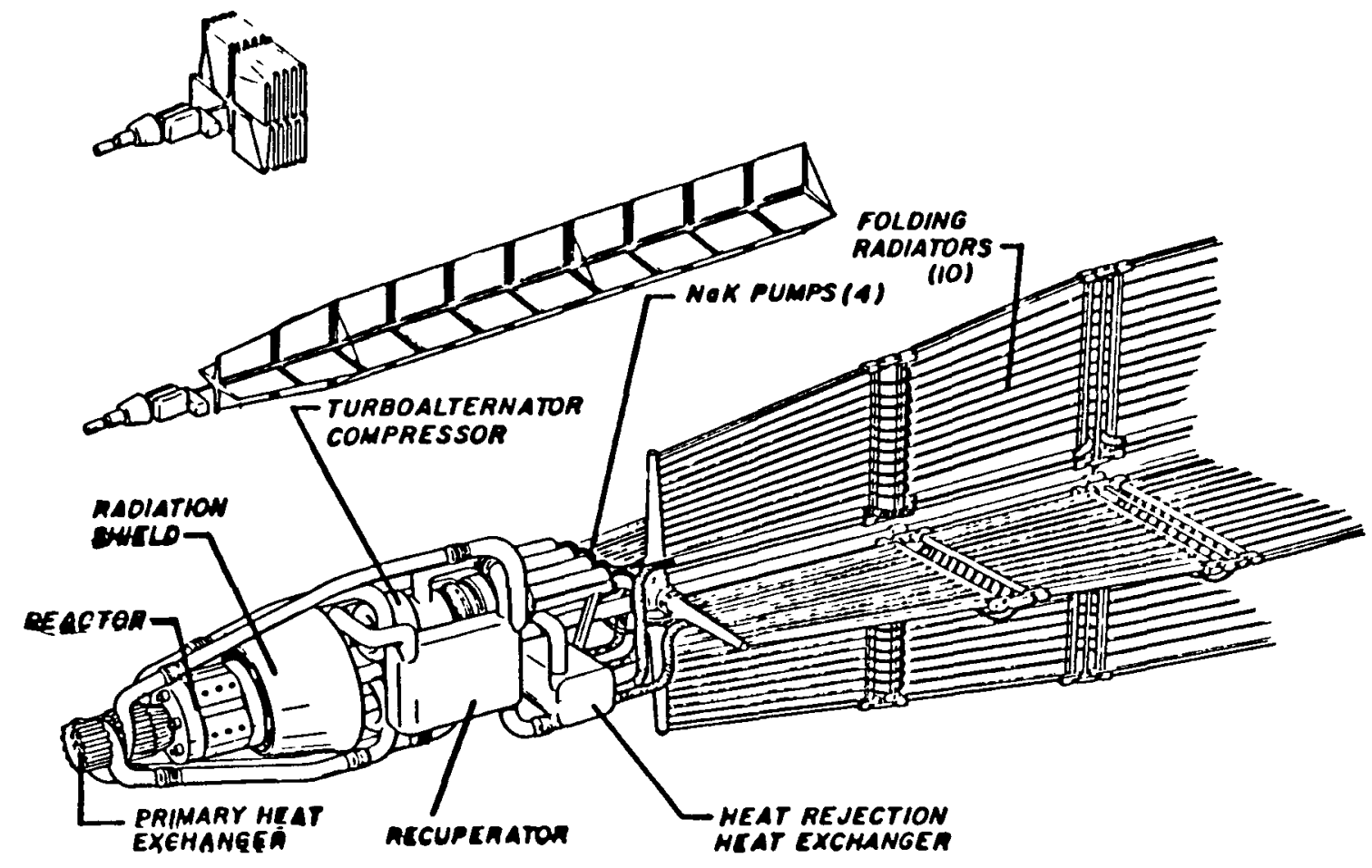

Fig. 187. Brayton cycle space electric power supply.

4. Rankine cycle. To obtain good efficiency and high heat reject temperatures, the Rankine cycle would operate at a turbine inlet temperature at $\sim 1500 \mathrm{~K}$. This implies a $\mathrm{UO}_{2}$-fueled reactor. The radiator is smaller than a Brayton, requiring about one-sixth the area for a given power level.

The Rankine cycle involves more components. There are liquid metal pumps, interstage coolers, condensers, and bearing coolant loops. The spacecraft would be a more complex unit. One advantage is that ducts and components for the liquid potassium are smaller and at lower pressures.

Design for redundant systems would be analogous to the Brayton cycle. However, advantage may be made of the better heat transfer characteristics of the liquid potassium. The radiator temperature is in the region of good liquid-metal heat-pipe operation, which is also an advantage.

The Rankine cycle requires about the same radiator area and is the same length as the thermionic power plant configuration.

5. Stirling cycle. A good design for a high-power Stirling system has not been found. It is assumed that scale-up would be accomplished by the addition of more modules, which is unsatisfactory. 


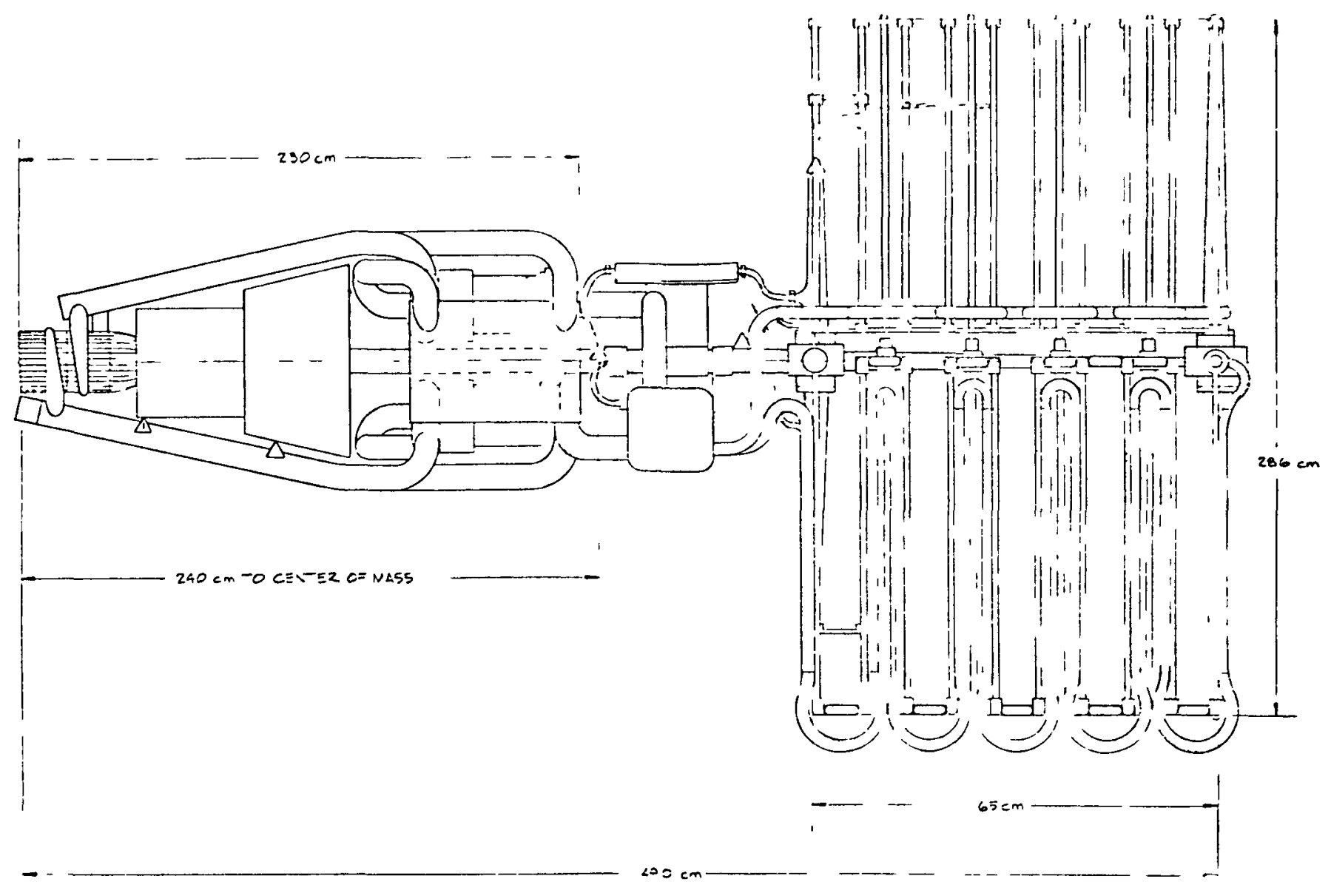

Fig. 188. 50-kW Brayton space nuclear electric power system.

For $50 \mathrm{~kW}_{e}$, four engines would be arranged as two pairs of linearly opposed, free-piston engines. There would be a liquid-metal heating loop per pair and a liquid-metal cooling loop per pair.

The Stirling cycle with its high efficiency, but 700-K reject heat temperature, is comparable in size to thermionic or Rankine cycle power plants.

D. Spacecraft Integration

1. Weights. A table of weights was constructed for each power plant to determine what could be delivered in single and dual-shuttle spacecraft (Table XLIV). The following assumptions were used

- Thermoelectric power plants with UC-ZrC fuel would use SiGe-GaP material with a $9 \%$ converter efficiency. Operating temperature would be $1375 \mathrm{~K}$. 


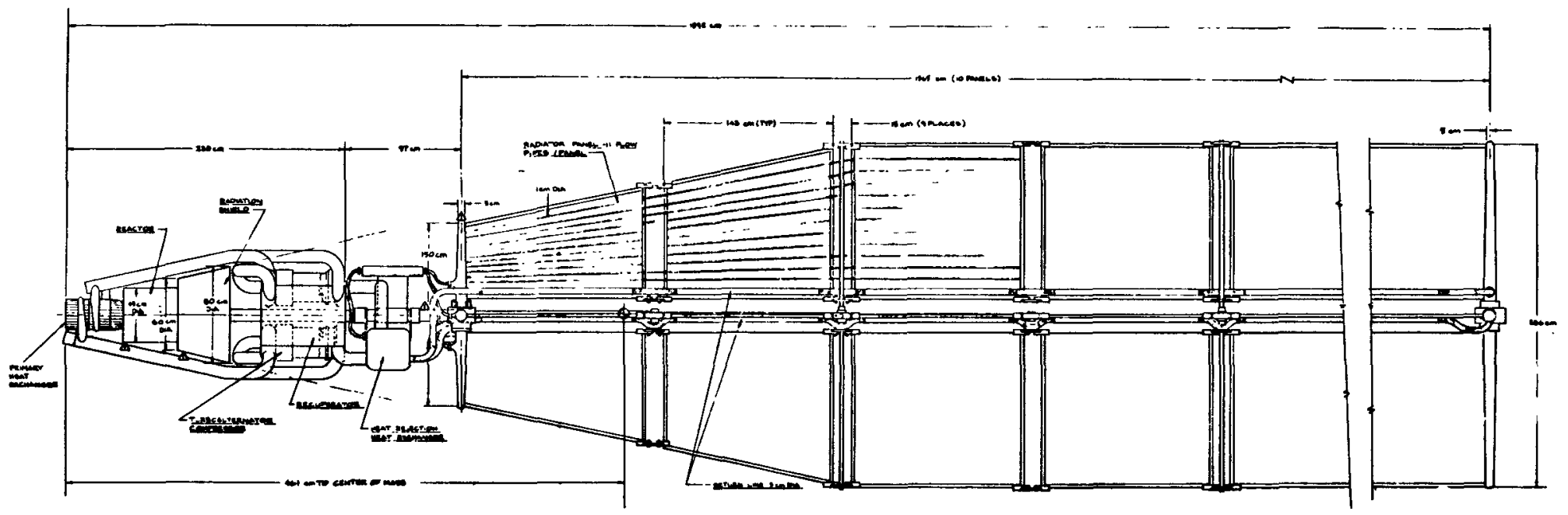




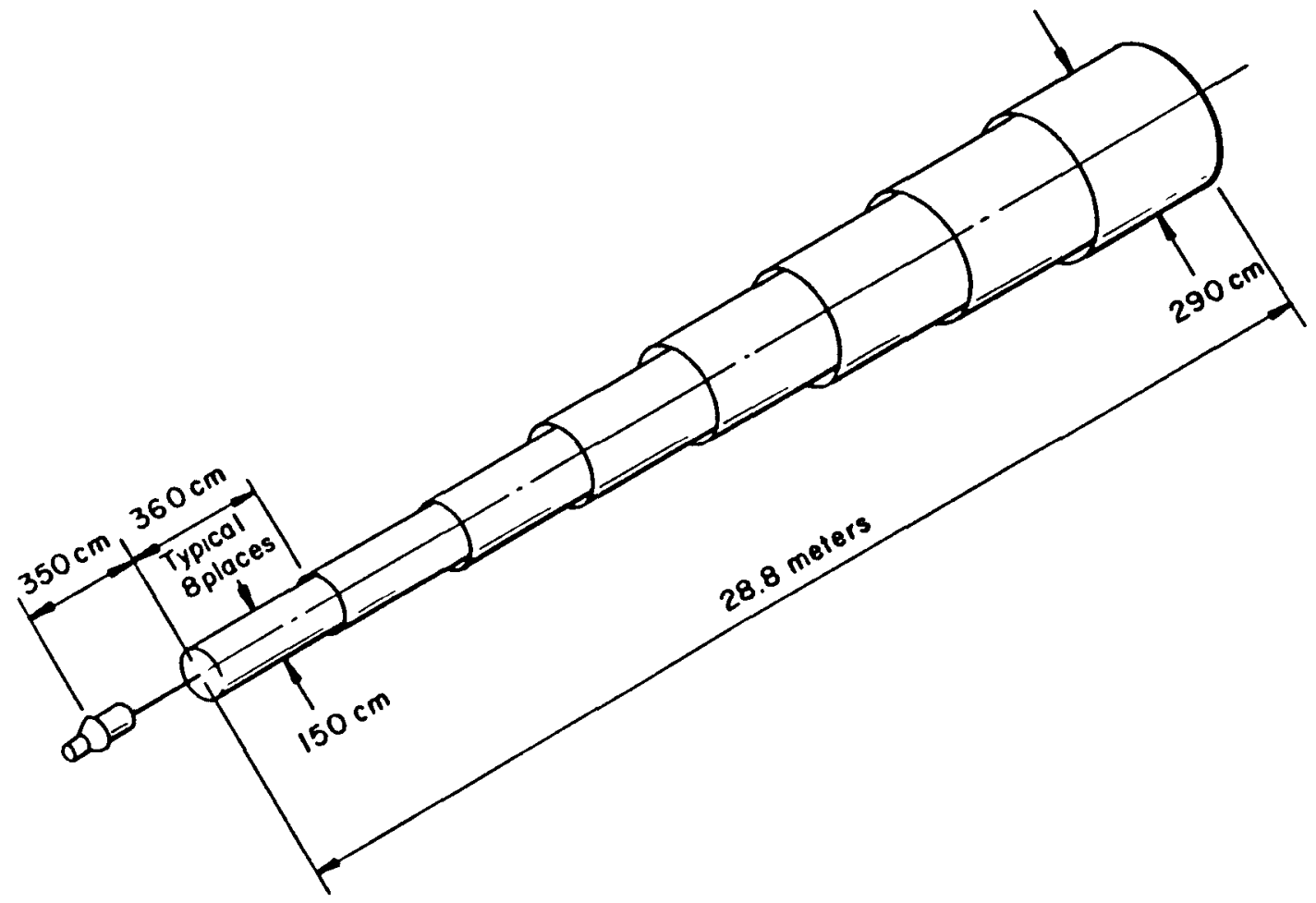

Fig. 190. Telescoping cylinder for 100-kW electric Brayton system.

- Thermoelectric power plants with $\mathrm{UO}_{2}$-Mo fuel would use NbSiGe or some other advanced thermoelectric material with $10 \%$ converter efficiency. Operating temperature would be $1475 \mathrm{~K}$.

- Thermionic power plants would use $\mathrm{UO}_{2}$-Mo fuel and operate at $1675 \mathrm{~K}$. Converter efficiency is $15 \%$.

- Brayton power plants would use UC-ZrC fuel and operate at a 1275 $K$-turbine inlet temperature (1375-K core exit temperature). Dual converters would be used with a four-panel radiator manifolded directly to the Brayton loop.

- Potassium Rankine cycle power plants would use $\mathrm{UO}_{2}$-Mo fuel and operate at $1500 \mathrm{~K}$ at the turbine. The reactor outlet temperature would be $1600 \mathrm{~K}$. Cycle efficiency would be $19 \%$.

- Stirling cycle power plants would use UC-ZrC fuel and operate at a temperature of $1400 \mathrm{~K}$. Efficiency would be $30 \%$.

Figure 192 is a plot of Table XLIV. It shows that a $1-M W_{t}$ UC-fueled reactor with SiGe-GaP could deliver $40 \mathrm{~kW}_{e}$ in one shuttle with a peak of 


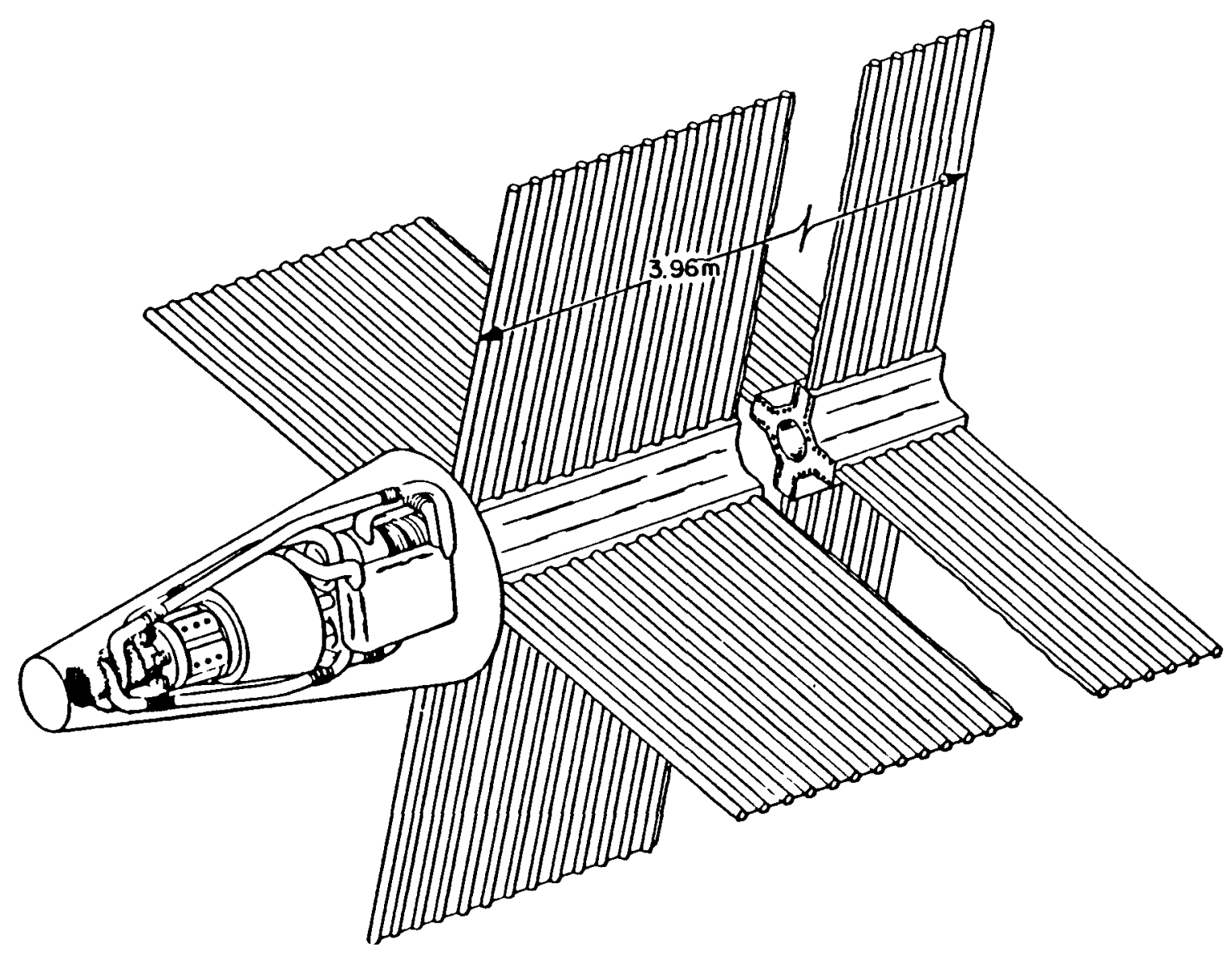

Fig. 191. Brayton cycle power plant with direct-coupled radiator.

only $90 \mathrm{~kW}_{\mathrm{e}}$ (curve A). If the reactor is increased to $1.5 \mathrm{MW}_{t}$, then the one-shuttle capability drops to $24 \mathrm{~kW}_{e}$, but a $100-\mathrm{kW}_{e}$ power plant weight is only $1640 \mathrm{~kg}$ (curve B). Higher-temperature thermoelectric power plants (curve $C$ ) could deliver $15 \mathrm{~kW}_{\mathrm{e}}$ with one shuttle but weigh only $1605 \mathrm{~kg}$ at $100 \mathrm{~kW}_{\mathrm{e}} \cdot$. Thermionic power plants (curve $\mathrm{D}$ ) are lightest in weight at 100 $\mathrm{kW}_{\mathrm{e}}$ at $1225 \mathrm{~kg}$, but can deliver only $24 \mathrm{~kW}_{\mathrm{e}}$ with one shuttle. Brayton power plants (Curve E) can deliver $20 \mathrm{~kW}_{\mathrm{e}}$ with one shuttle and weigh 1800 $\mathrm{kg}$ at $100 \mathrm{~kW}_{\mathrm{e}}$. Potassium Rankine power plants (curve $\mathrm{F}$ ) could deliver 10 $\mathrm{kW}_{\mathrm{e}}$ with one shuttle and $85 \mathrm{~kW}_{\mathrm{e}}$ with two. At $100 \mathrm{~kW}_{\mathrm{e}}$, the power plant missed the weight goal by $220 \mathrm{~kg}$. Stirling cycle power plants are also very heavy (curve G). They could deliver $24 \mathrm{~kW}_{\mathrm{e}}$ with one shuttle but only 84 $\mathrm{kW}_{\mathrm{e}}$ with two. At $100 \mathrm{~kW}_{\mathrm{e}}$, they exceed the weight goal by $250 \mathrm{~kg}$.

Figure 193 shows schematic layouts at $50 \mathrm{~kW}$ for each type of converter. All used conical radiators except the Brayton, which had foldable 
TABLE XLIV

COMPARISON OF POWER PLANT WEIGHTS

\begin{tabular}{|c|c|c|c|c|c|c|c|c|c|c|c|c|c|c|c|c|c|c|}
\hline & \multicolumn{6}{|c|}{$10 \mathrm{~kW} W_{E}$} & \multicolumn{6}{|c|}{$50 \mathrm{~kW}$} & \multicolumn{6}{|c|}{$100 \mathrm{~kW} W_{E}$} \\
\hline & 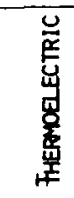 & 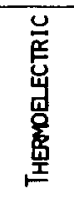 & 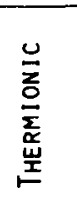 & 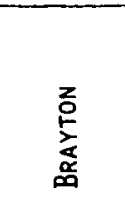 & 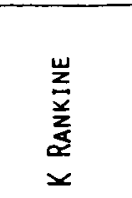 & $\begin{array}{l}\stackrel{0}{\underline{\underline{a}}} \\
\stackrel{\overrightarrow{\underline{\alpha}}}{\underline{\omega}}\end{array}$ & 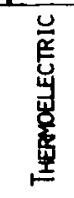 & 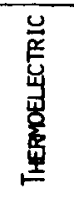 & 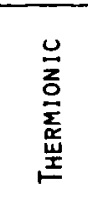 & 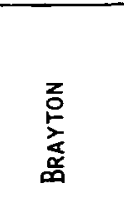 & 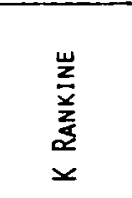 & $\begin{array}{l}\stackrel{o}{\underline{\underline{u}}} \\
\stackrel{\underline{\underline{w}}}{\underline{n}}\end{array}$ & 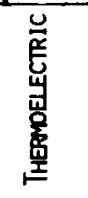 & 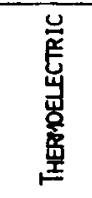 & 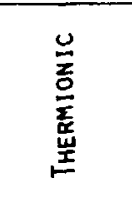 & 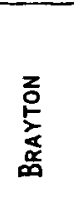 & 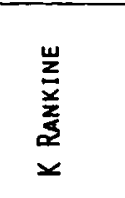 & 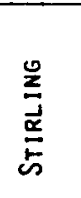 \\
\hline FUEL & UC & $\mathrm{UO}_{2}$ & $\mathrm{UO}_{2}$ & $U C$ & $\mathrm{UO}_{2}$ & $u C$ & $U C$ & $\mathrm{UO}_{2}$ & $\mathrm{UO}_{2}$ & $U C$ & $\mathrm{UO}_{2}$ & UC & $U C$ & $\mathrm{UO}_{2}$ & $\mathrm{wO}_{2}$ & $\overline{U C}$ & $\mathrm{UO}_{2}$ & $\mathrm{UO}_{2}$ \\
\hline POWER $\left(K W_{T}\right)$ & 111 & 100 & 67 & 40 & 53 & 33 & 556 & 500 & 333 & 200 & 263 & 167 & 1111 & 1000 & 400 & 667 & 526 & 333 \\
\hline EFFICIENCY (') & 9 & 10 & 15 & 25 & 19 & 30 & 9 & 10 & 15 & 25 & 19 & 30 & 9 & 10 & 25 & 15 & 19 & 30 \\
\hline $\begin{array}{l}\text { RADIATOR POWER } \\
\left(K W_{T}\right)\end{array}$ & 101 & 90 & 57 & 30 & 43 & 23 & 506 & 450 & 283 & 150 & 213 & 117 & 1011 & 450 & 300 & 567 & 426 & 233 \\
\hline $\begin{array}{l}\text { RADIATOR TEMP } \\
(\mathrm{K})\end{array}$ & 775 & 700 & 910 & $630-430$ & $925-800$ & 700 & 775 & 775 & 910 & $630-430$ & $925-800$ & 700 & 775 & 775 & $630-430$ & 910 & $925-800$ & 700 \\
\hline
\end{tabular}

RADIATOR AREA

$\left(M^{2}\right)$

$\begin{array}{llllllllllllllllll}7 & 7 & 2 & 12 & 2 & 2 & 36 & 31 & 9 & 58 & 10 & 12 & 72 & 63 & 116 & 18 & 20 & 24\end{array}$

MASS (KG)

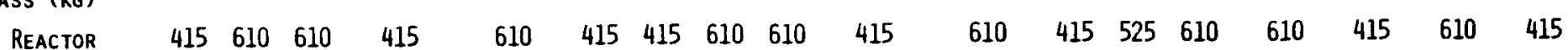

$\begin{array}{lllllllllllllllllllll}\text { SHIELD A } & 155 & 180 & 165 & 120 & 155 & 120 & 205 & 240 & 225 & 170 & 215 & 170 & 250 & 270 & 255 & 210 & 245 & 185\end{array}$

$\begin{array}{lllllllllllllllllllll}\text { CONVERTER } & 35 & 25 & 20 & 250 & 100 & 120 & 165 & 125 & 105 & 460 & 500 & 600 & 335 & 250 & 210 & 710 & 1000 & 1200\end{array}$

$\begin{array}{lllllllllllllllllllll}\text { BADIATOR } & 25 & 20 & 10 & 30 & 10 & 15 & 160 & 140 & 40 & 150 & 40 & 75 & 380 & 330 & 80 & 300 & 80 & 165\end{array}$

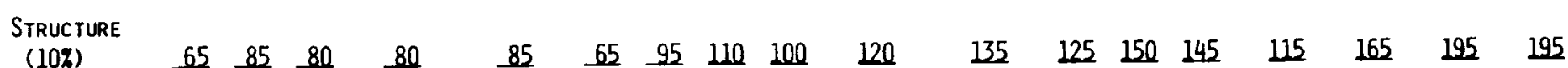

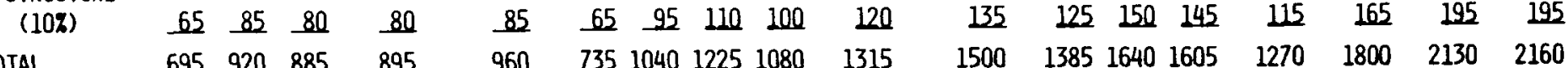

\footnotetext{
A Assume $12^{\circ}$ cone half-angle at 25 m.
} 


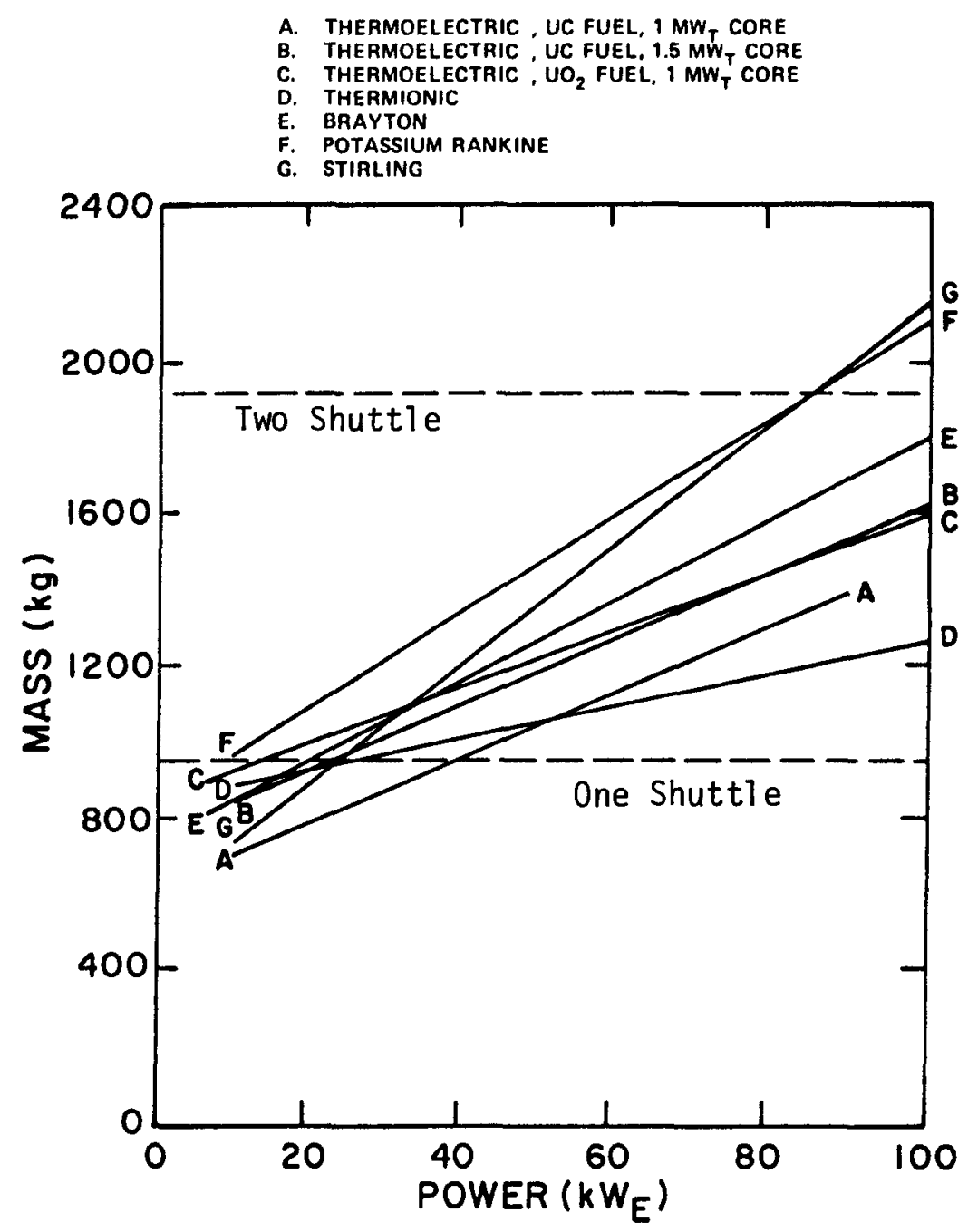

Fig. 192. Power plant weight comparison.

cylinders. In preparing Fig. 193, the converter elements and radiator were maintained in the shadow of the shield and all fit the shuttle bay. For near-term power plants, thermoelectric systems will be shorter than Brayton systems. Far-term power plants could be significantly reduced in overall lengths.

2. Volumes. In-orbit assembly spacecraft are being studied by General Dynamics and Martin Marietta for the Air Force Space and Missile Systems Organization. The system being analyzed is a SBR. One option under consideration is a nuclear power plant for electric power. A major part of the effort is in the packaging of the components to fit within the shuttle bay of the STS. One concept by General Dynamics packaged the feed mast and Brayton reactor power plant in a single shuttle with a chemical upper stage 


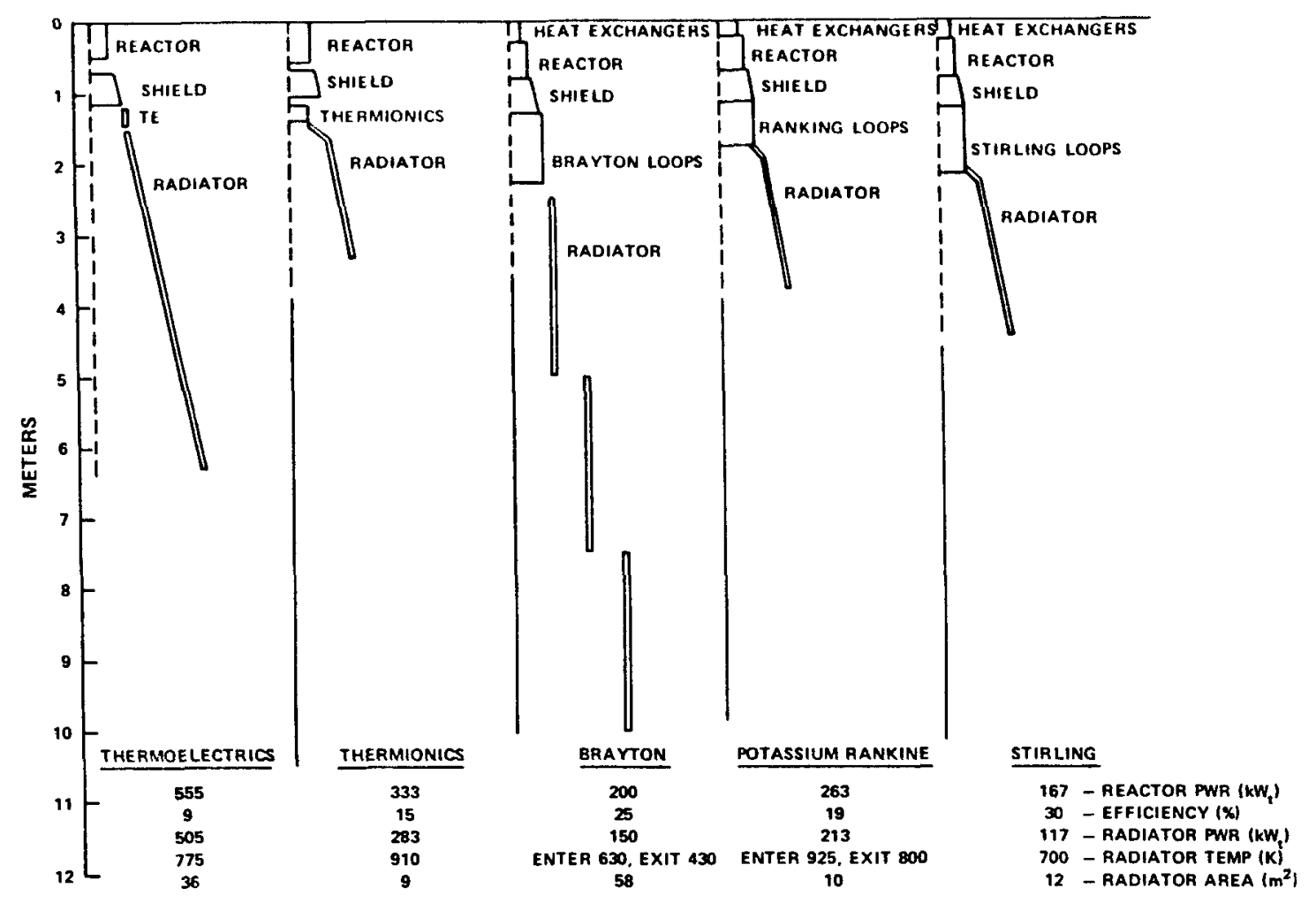

Fig. 193. Schematic layouts for each type of converter.

for orbit transfer (Fig. 194). The particular packaging shown in Fig. 196 is not recommended; however, it can be seen that a radiator could be packaged inside the stowed feed mast. With coordination between the spacecraft and reactor power $\mathrm{plant}$ designers, a $100-\mathrm{kW}_{\mathrm{e}}$ nuclear power $\mathrm{plant}$ could be incorporated into the design package.

E. Single-Failure Point Analysis

After the most careful design, component and system development and testing, meeting strict quality control standards, etc., the probability of unpredicted or random-type failures still exists. The purpose of identifying single-failure points is to either eliminate them by changes in the design or to reduce their probability of occurrence to an acceptable level. Randon multiple failures that are additive in nature should have a low enough probability of occurrence that mission life is not jeopardized.

A number of common assumptions are included throughout the analysis 


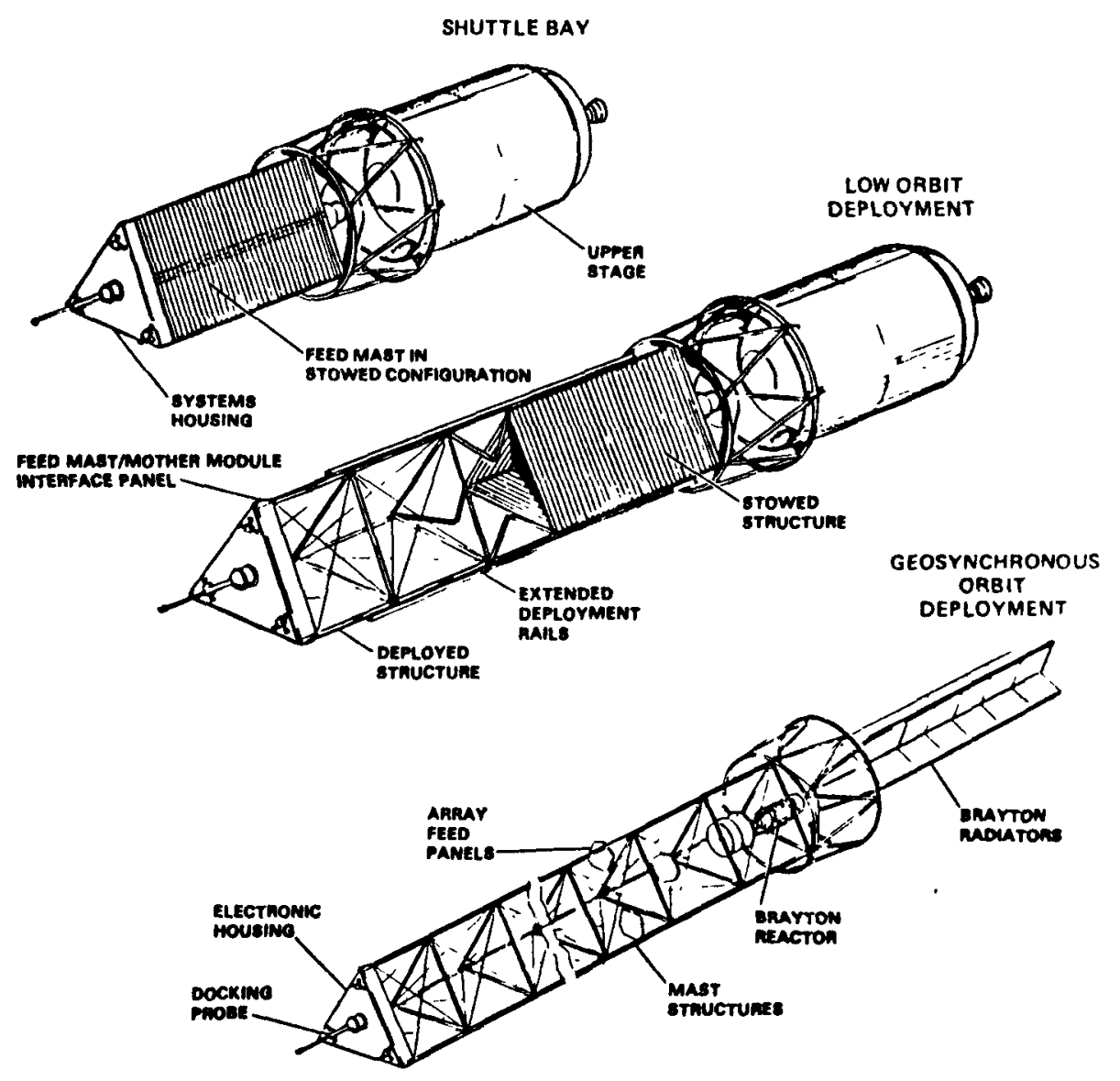

Fig. 194. In-orbit assembly configuration with Brayton reactor power plant (General Dynamics concept).

- Drum reactivity control will be used for each reactor configuration. The reflectors will be segmented so that one warped segment will not result in common failures in other segments.

- The control system components (electronics, power supplies, sensors, and wiring) will be sufficiently redundant that singlefailure points will be eliminated.

- Electric voltage regulators will incorporate sufficient redundant elements for each type of converter to eliminate single-failure points.

- Common mode failures for independent redundant elements such as material defects, welding defects, and wrong materials will be avoided in all configurations with an effective quality assurance program. 
The following is a summary of the single-failure point analysis conclusions.

(1) A heat-pipe reactor with thermoelectric power conversion inherently avoids of single-failure points.

(2) If Brayton converters are used with a heat-pipe reactor, dual converter loops can be used to eliminate single-failure points. This would require the addition of accumulators or other means for regulation of pressure in the two loops between half and full power. The valves from the accumulators can be small and have slow reaction times.

(3) Gas-cooled reactor power plants can also eliminate single failure points by adding dual converters. However, a matrix of 16 valves is needed for loop isolation with these valves in the inlet and outlet of the reactor. This means high temperature and large flow areas leading to additional complex development items.

(4) Liquid-cooled power plant designs have the most difficulties in the elimination of single failure points. In fact, single-failure points from core corrosion with lithium cannot be eliminated. Again, a matrix of 16 high-temperature valves would be needed around the reactor for isolation of redundant flow loops.

In summary, single-failure points are best avoided with a heat-pipe reactor and thermoelectric converters.

1. Gas-Cooled Reactor Power Plants. Reactor power plants using gas such as Xe-He basically consist of a reactor, a turbine, a compressor, an alternator, and heat exchangers (Fig. 195). The turbine is on a common shaft with the electric alternator and the compressor. Gas is heated in parallel flow passages in the reactor, flows through the turbine and exchanges heat through recuperator and radiator heat exchangers before entering the compressor. It is then recirculated back through the recuperator and the reactor. The power plant is controlled by varying the reactor power by movement of the control drums in the reflector. No valves are needed in this arrangement. Table XLV summarizes the major components, potential failure modes and the effects on system performance.

Three major modes of single-failure points have been identified: loss of fluid containment, loss of pumping power, and loss of power conversion equipment (Fig. 196 and Table XLVI). 


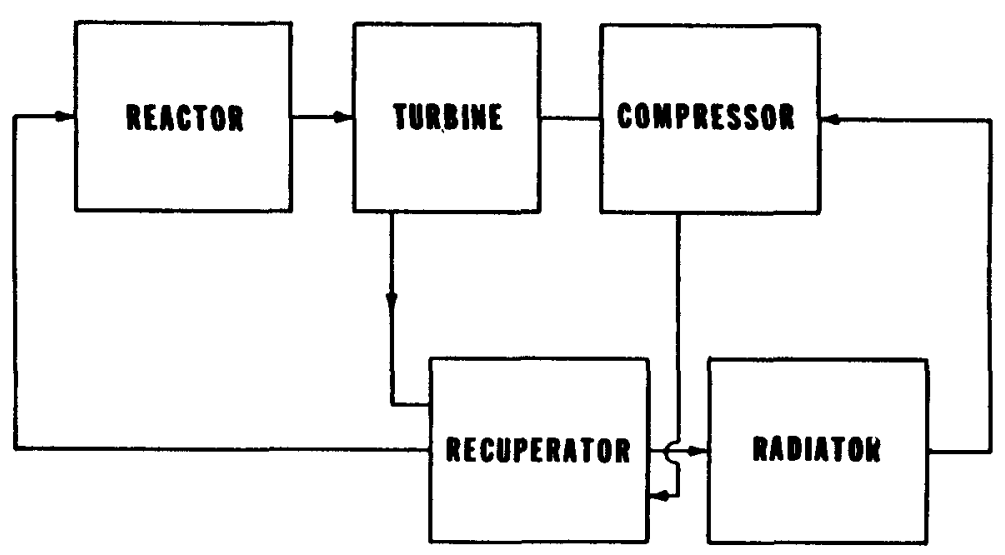

Fig. 195. Gas-cooled reactor with dynamic converter.

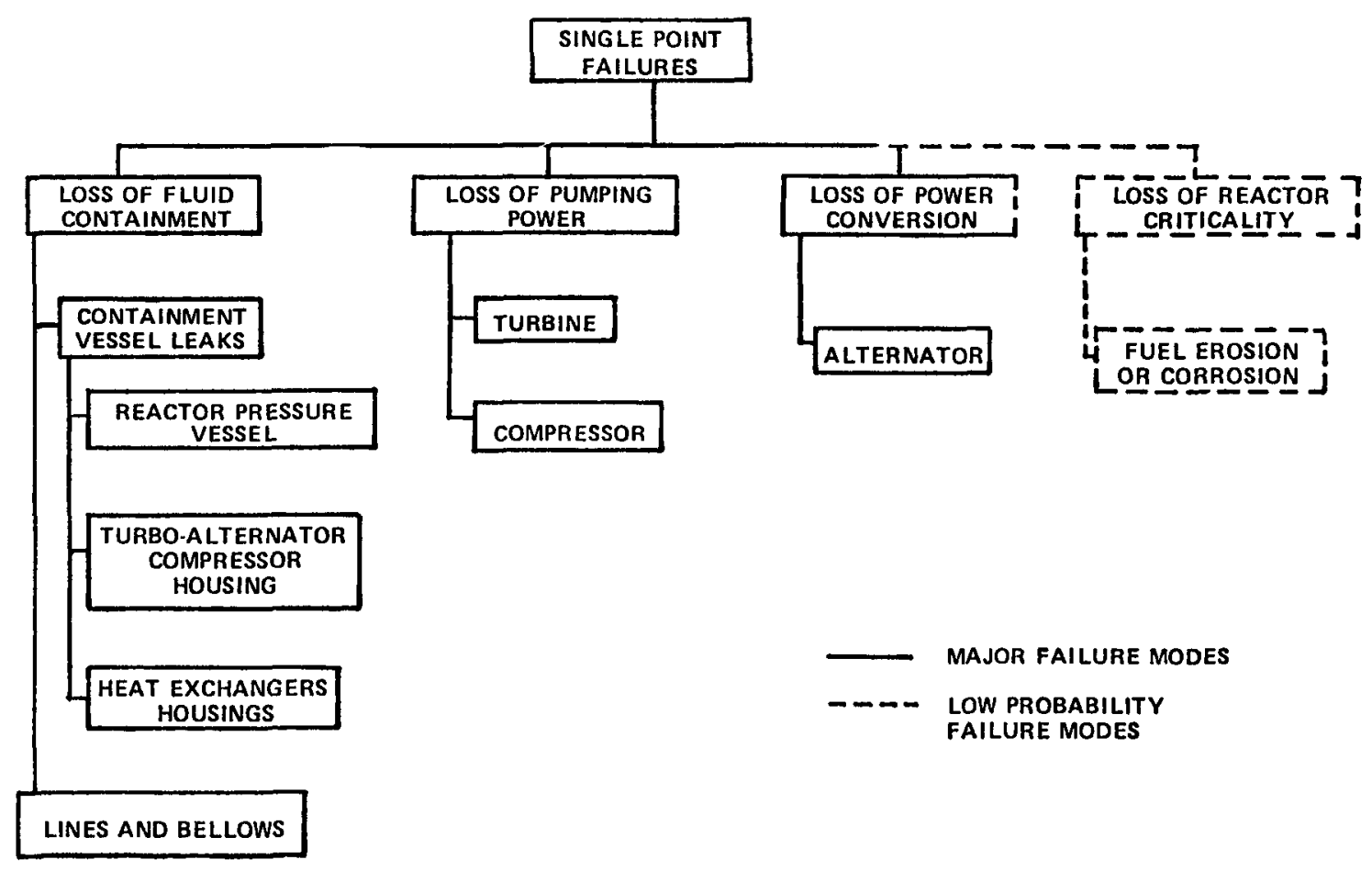

Fig. 196. Gas-cooled reactors with dyanmic converters.

The loss of fluid containment can occur in lines and bellows and in component housings such as the reactor pressure vessel, the turboalternatorcompressor housing, and the recuperator and radiator heat exchangers. The major potential contributors to such failures are micrometeoroid penetrations, weld or braze failures, and creep rupture. The turboalternator 


\section{GAS-COOLED REACTOR SINGLE-FAILURE POINTS}

Component and Function

Potential Failure Modes

Failure Effect

FUEL ELEMENT

Acts as heat source for power plant.

Xe-He gas not reactive with fuel but could react with fuel impurities.

CORE SUPPORT STRUCTURE

Maintains core integrity

Radiation-induced material damage, flow

induced vibration, wear, weld, or fastening failure.

PRESSURE VESSEL

Provides containment for Xe-He gas.

\section{Rupture of vessel from weld failure}

or radiation-induced material damage.

REFLECTOR

Improves reactor power distribution, with conduction and radiation cooling, lower critical mass.

no foreseen failure modes.

CONTROL DRUMS

Establishs power level by varying their positions.

TURBO-ALTERNATOR-COMPRESSOR Turbine spins alternator and compressor. Al ternator provides electrical power and acts as starting motor. Compressor provides pressurized working gas to converter loop.
Multiple failures of redundant elements. Warped reflectors could bind drums or failure of mechanical linkage.

Turbine wheel rubs due to mechanical interference.

Bearing fallure due to loss of gas film or mechanical fallure.
Loss of criticality. Pre-

mature shutdown of system.

(Low probability of

occurrence).

Premature shutdown, reactor dis integration.

Loss of coolant to reactor terminating operation.

None for single element.

Several drums failing would cause reactor shutdown; fall out would cause supercritical condition leading to reactor mechanical disintegration; fail in place would lead to premature shutdown.

Possible damage to rotating hardware and bearings and loss or decrease in power output.

Loss of decrease in power output. 
TABLE XLV (Cont.)

Turbine housing cracks due to thermal

stresses, material defect.

Compressor rubs due to misalignment

or out-of-tolerance.

Alternator shorts or opens.

Alternator fails to operate as start motor.

Turbine seal fails.

Blade fallures in turbinc or compressor.

\section{RECUPERATOR}

Heat exchanger to utilize part of reject heat to increase cycle efficiency.

RADIATOR HEAT EXCHANGER

Heat exchanger to radiator to el iminate reject heat.

RADIATOR PUMPS (4)

Circulate NaK in radiator loops.

RADIATOR LINES AND MANIFOLDS Transfer heat to radiating surfaces.
External leakage caused by manufacturing defect, meteoroid puncture, or structural failure.

External leakage caused by manufacturing defect, meteoroid puncture.

Electric motors open circuit or closed circuit, structural failure.

External leakage caused by manufacturing defect, meteoroid puncture, or structural failure.
External leakage results in

loss of gas, loss of power output and over-temperature shutdown.

Decrease system flow resulting in reduced power output.

Loss of power, shutdown.

No start.

Loss of efficiency and performance.

Shutdown.

External leakage results in loss of working fluid, loss of power output and overtemperature shutdown.

External leakage results in loss of working fluid, loss of power output and overtemperature shutdown.

Single failure would result in loss of redundant part of radiator. Multiple failures would result in reduced power output.

Single failure would result in loss of redundant part of radiator. Multiple failures would result in reduced power output. 
SINGLE-FAILURE POINT SUMMARY FOR SINGLE-LOOP GAS-COOLED SYSTEMS

\begin{tabular}{|c|c|c|c|}
\hline FAILURE MODE & COMPONFNI & MECHANISM & $\begin{array}{l}\text { PERFORMANCE } \\
\text { SIGNIFICANCE } \\
\end{array}$ \\
\hline LOSS OF FLUID CONTAINMENT & $\begin{array}{l}\text { REACTOR PRISSURE VESSEL } \\
\text { TURBOALTERNATOR } \\
\text { COMPHESOR HOUSING } \\
\text { RECUPERATOR } \\
\text { RADIATOR HEAT EXCHANGER } \\
\text { LINES AND BELLOWS }\end{array}$ & $\begin{array}{l}\text { MICROMETCOROID PENCTRATION } \\
\text { WELD ANO BRAZE FAILURE } \\
\text { CREEP RUPTURE } \\
\text { FRACTURE OF THE BOLTS IN } \\
\text { TURBO MACHINERY } \\
\text { TURBO MACHINERY HUB BUASTS } \\
\text { RADIATION INDUCED MATERIAL } \\
\text { DAMAGE } \\
\text { MANUUFACTURING DEFECTS } \\
\text { BELLOWS SEAL LEAKS }\end{array}$ & MAJOR \\
\hline LOSS OF PUMPING POWER & $\begin{array}{l}\text { TURBINE } \\
\text { COMPRESSOR }\end{array}$ & $\begin{array}{l}\text { STRUCTURAL FATIGUE } \\
\text { TURBINE WHEEL RUBS } \\
\text { COMPRESSOR IMPELLER RUBS } \\
\text { FROM MISALIGNMENT OR } \\
\text { VIBRATION } \\
\text { BEARING FAILURES FROM } \\
\text { FRICTION DURING } \\
\text { STARTUP AND SHUTDOWN } \\
\text { FLOW INDUCED VIBRATION } \\
\text { EROSION PRODUCTS } \\
\text { SEAL LEAKS }\end{array}$ & MAJOR \\
\hline $\begin{array}{l}\text { LOSS OF CONVERSION } \\
\text { EOUIPMENT }\end{array}$ & ALTERNATOR & $\begin{array}{l}\text { LOSS OF INSULATION CAUSING } \\
\text { SHORT } \\
\text { OPEN CIRCUIT FROM LOSS OF } \\
\text { LOAD }\end{array}$ & MAJOR \\
\hline LOSS OF CRITICALITY & REACTOR FUEL & $\begin{array}{l}\text { CORROSION OF FUEL } \\
\text { BY IMPURITIES }\end{array}$ & MINOR \\
\hline
\end{tabular}

housing is also exposed to rupture by hub bursts. Since some of the components are in a high-temperature and high-radiation environment, material failures can occur after long exposures.

Loss of pumping power can result from structural difficulties. Load switching that might unload the machinery and cause overspeeds must be avoided. Mechanical interference causing turbine wheel and compressor blades to rub the housing is avoided by using fluid-type bearings without frictional surfaces. The major bearing difficulties should be in startup and shutdown. Thermal stress in the housing is avoided by carefully designing for the operation environment.

Loss of power conversion equipment could result from insulation short or open circuits caused by load interruptions or by fission-product corrosion. Also, the wearing out of equipment and aging of materials can lead to eventual power conversion failure.

Loss of reactor criticality can occur from erosion or corrosion of the reactor fuel with deposition of fuel outside the core. Helium-xenon as a working fluid is not reactive and thus will have low probabilities of failure. Fission product contamiration of the gas stream could result in corrosion or radiation problems elsewhere in the system. 
In a gas-cooled system redundancy to eliminate single-failure points is possible but complicated. In the reactor, a double-containment vessel would be necessary. The converter would require dual independent loops. The radiator $c$ an be made redundant through the use of heat-pipe heat exchangers similar to those proposed for the heat-pipe reactor. A complex valveswitching system is introduced consisting of 16 valves in 4 modules - one in each turbine inlet line and one in each compressor line (Fig. 197). The four valve module is needed to provide redundancy if a valve fails to open or close. The valves must fit a $10 \mathrm{~cm}$ line. The control system componen.s and logic increase significantly. Besides the added control circuitry to operate each valve, sensors are needed to detect loss of flow accidents and a redundant logic system is needed for the switching function. The reactor containment vessel redundancy would need to be extended to cover the lines to the isolation valve modules.

Also shown in Fig. 197 is an emergency cooldown accumulator. Its function is to $c 001$ the reactor after termination of flow by some malfunction (such as a turbine disintegration through the housing) until the stand by converter loop can take over.

Redundancy in a gas-cooled system is possible but adds complexity, weight, and new components to be developed.

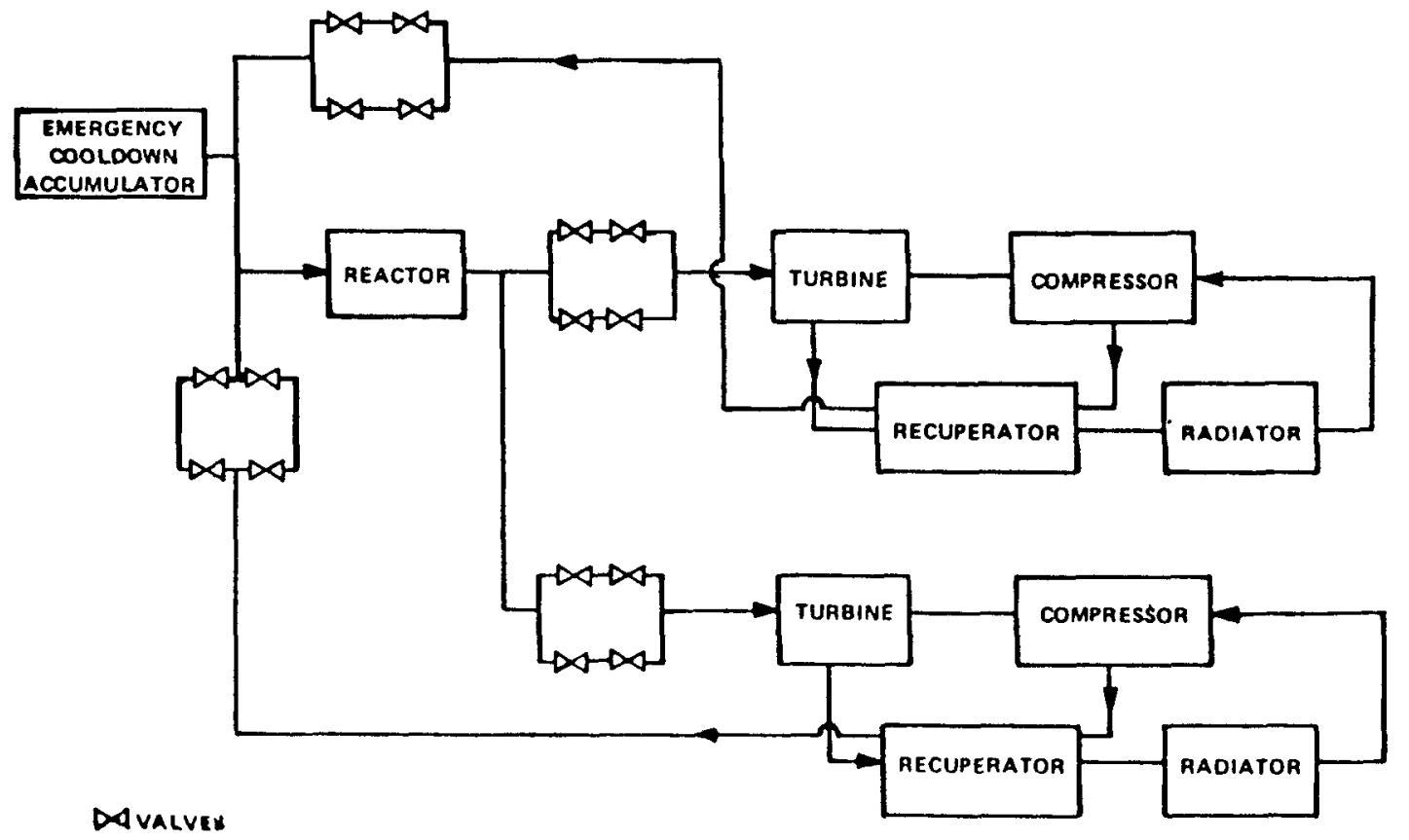

Fig. 197. Redundant elements in gas-cooled reactor with dynamic converters. 
2. Liquid-Cooled Reactor Power PIants. The SNAP-50 (Fig. 198) represents a liquid-cooled reactor power plant. The converter uses a potassium Rankine loop. A number of separate loops occur in the system. The primary loop is the reactor cooled by liquid lithium, a boiler to transfer heat to the power conversion loop, a lithium motor pump to maintain fluid flow and an accumulator for startup. The secondary loop is the power conversion equipment including a turboalternator, condensing radiator, jet pump, motor pump, and the boiler to extract heat from the primary loop. In addition, there are some auxiliary cooling loops for the motor pumps and turboalternator. Table XLVII summarizes the major components, potential failure modes and the effect on system performance.

Four modes of single-failure points have been identified: loss of fluid containment, loss of pumping power, loss of power conversion equipment and loss of reactor criticality (Fig. 199 and Table XLVIII).

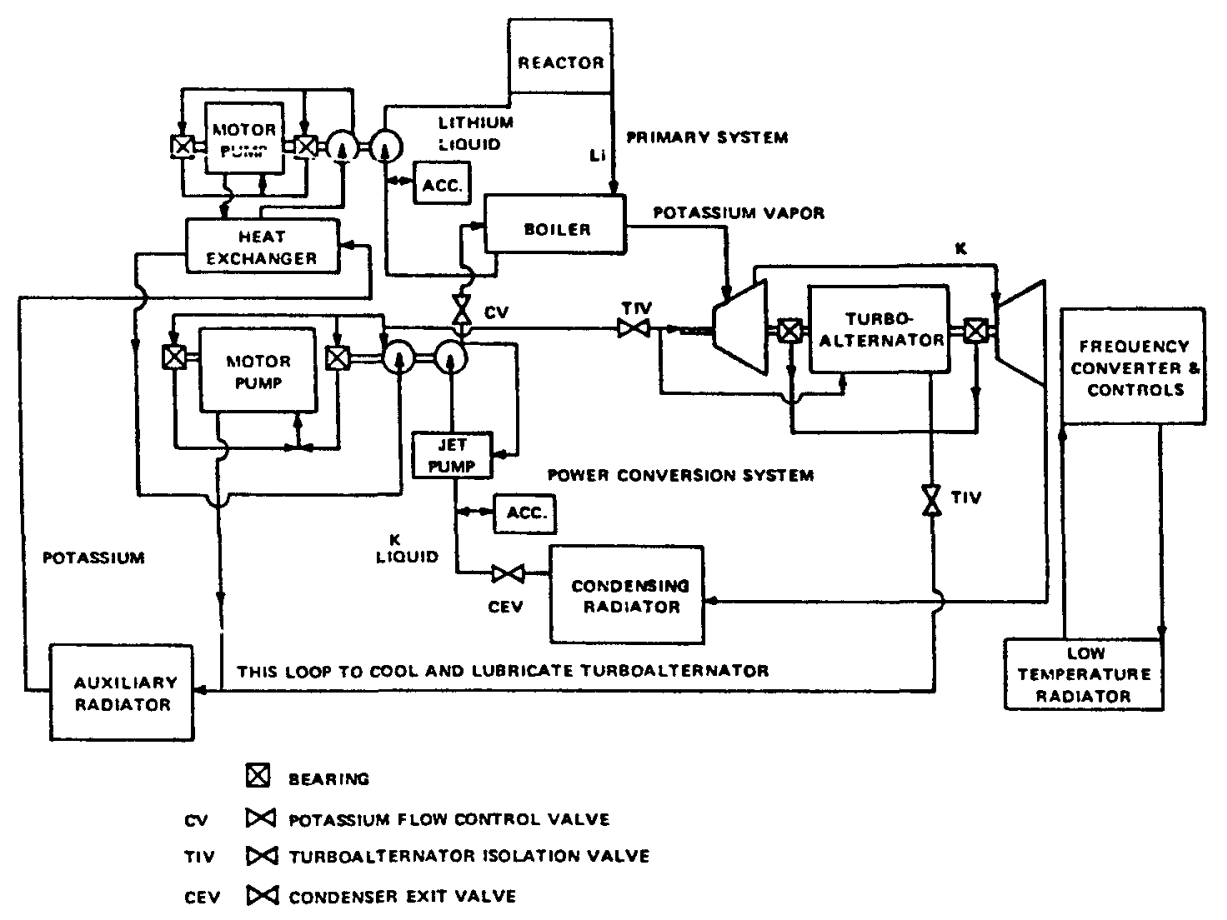

Fig. 198. 300-kWe SNAP-50/SPUR flow schematic - direct condensing 
TABLE XLVII

LIQUID-COOLED REACTOR SINGLE-FAILURE POINTS

COMPONEINT AND FUNCTION

POTENTIAL FAILURE MODES

FAILURE EFFECT

FUEL ELEMENT

Acts as heat source for

power plant.

Fuel corrosion by lithium.

Loss of criticality. Premature

CORE SUPPORT STRUCTURE

Maintains core integrity.

Radiation-induced material damage, flow-induced vibration, wear, weld, or fastening failure.

Premature shutdown, reactor disintegration.

PRESSURE VESSEL

Improves reactor power

lithium fluid.

Rupture of vessel from weld

failure and radiation-induced material damage.

REFLECTOR

Improves reactor power

distribution, lower critical

mass.

CONTROL DRUMS

Establishs power level by

varying their position.

\section{ACCUMULATOR}

Provides pressurized working

fluid to fluid loops at

startup.

\section{START VALVE}

Valve opens upon recelpt of electric start command

to allow pressurized

flutd flow from accumulator

to fluid loops. Start valve

remains open when electric

signal is removed and remains

open during system operation.

\section{BOILER}

Transfer heat from reactor loop to power conversion

loop.

FLOW CONTROL VALVE

Regulates alternator speed

and hence output electric

frequency.
With conduction and radiation cooling, no foreseen fallure modes.

Multiple failure of redundant elements. Drums could bind from warped reflector or failure of mechanical linkage.

Internal leakage through bellows due to manufacturing defect.

Valve falls to open at start.
Loss of coolant to reactor terminating operation.
None for single element. Several drums fail in would cause reactor shutdown; fall out would cause supercritical condition leading to reactor mechanical disintegration; fail in place would lead to premature shutdown.

Fluid in bellows, gas in fluid loop. System may not start or reduction in power capability.

System does not start.
Cracks due to material defect.

Fails open (contamination or corroston).

Fails closed (contamination or corrosion).

Bellows seal failure.
External leakage results in loss of working fluid and power loss. over temperature shutdown.

Excess flow to boller. During load transient turbine will run "wet". Low power until flow control valve can react.

Sys tem overheats, over temperature shutdown.

Cold liquid mixes with turbine inlet vapor. Turbine runs "wet". Power reduction if leak is small. Over temperature shutdown if leak is large. 
TABLE XLVII (Cont.)

COMPONENT AND FUNCTION

POTENTIAL FAILURE MODES

FAILURE EFFECT

CONDENSER EXIT AND TURBO-

ALTERNATOR ISOLATION VALVES

Used prior to startup to

isolate the evacuated

portion of the potassium

loop.

VOLTAGE REGULATOR

Provides field current to

alternator windings.

JET PUMP

Increases inlet pressure

to motor pump of power

conversion loop (prevents

pump cavitation).

TURBO-ALTERNATOR

Turbine spins alternator.

Alternator provides

electrical power output.

RADIATOR

Heat exchanger radiates heat from working fluid to space. Provides cooling for working fluid.

RADIATOR BYPASS VALVE/

TEMPERATURE SENSOR

Diverts flow around radiator to maintain constant jet condensor fluid loop temperature. Valve/Sensor is a simple fluidic/mechanical device.

RECTIFIERS

Changes ac to dc.
Stuck closed due to mechanical failure, contamination, or corrosion.

Open cfrcuit (as seen by a) ternator).

Short circuit (as seen by alternator).

No foreseen failure modes.

Turbine wheel rubs due to mechanical interference.

Bearing fallure caused by loss of film or mechanical failure.

Turbine housing cracks caused by thermal stresses, material defect.

Blade fallure.

External leakage caused by manufacturing defect, meteoroid puncture.

Stuck open caused by mechanical failure, contamination, or corrosion.

Stuck closed caused by mechanical fallure, contamination, or corrosion.

One rectifier fails open.

One rectifier falls short.
Fail to start. Loss of power output.

No fleld current to alternator. Loss of output from alternator.

Maximum field current to alternator. Alternator output vol tage varies with load. Low load; high volts. High load, low volts.

The jet is a static device which is required only to direct fluid flow.

Possible damage to rotating hardware and bearings and loss or decrease in power output.

Loss or decrease in power output.

External leakage results in loss of working fluid, loss of power output and over temperature.

Power plant shutdown.

External leakage results in loss of working fluid, loss of power output and shut down.

Working fluid becomes too hot. Reduction in power capablitity at beginning-of-life.

Working fluid becomes cooler than desirable. Reduction in power capability at end-of-life.

Ripple in power output. Low quality power.

Phase-to-phase short results in another rectifier to fail open or one alternator phase to fail open. Results in ripple in de power output. Low quality power. 


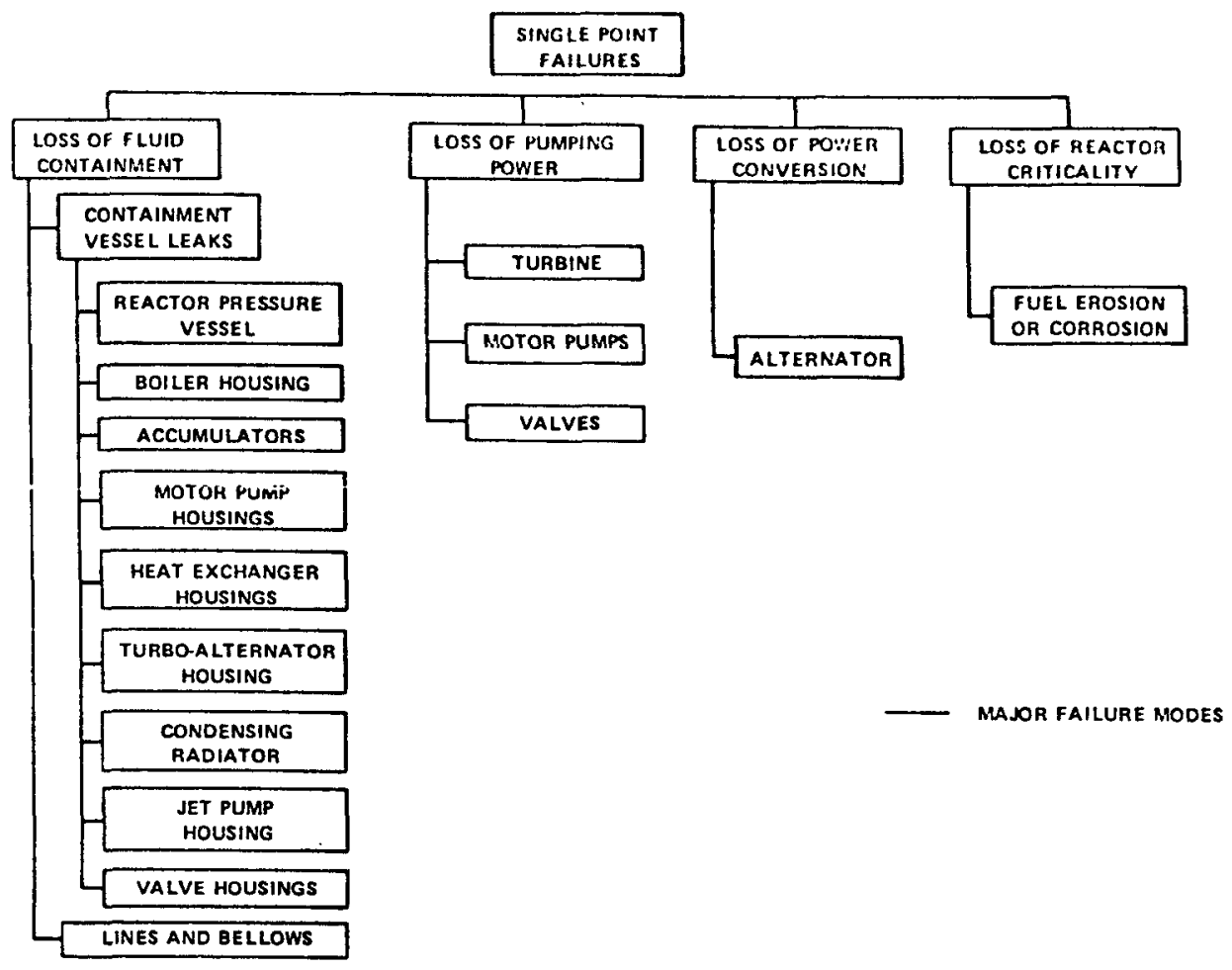

Fig. 199. Major failure modes for liquid-cooled reactors with dynamic converters.

The loss of fluid containment can occur in lines and bellows and in component housings in any of the fluid loops. This includes the reactor pressure vessel, boiler housing, accumulators, either motor pump, jet pump, heat exchangers, turboalternator, condensing radiator, or valve housing or in lines and bellows. The major potential contributors to such failures are micrometeoroid penetrations, weld or braze failures, and creep rupture. Motor and turboalternator housings are also exposed to hub bursts. Since some of the components are in high-temperature and high-radiation environments, material failures can occur after long exposures.

Loss of pumping power can result from structural difficulties or interruption of electric power to the motor pumps. Load switching that might unload the machinery and cause overspeeds must be avoided. Turbine whee 1 and pumps rubbing the housing caused by mechanical interference must be avoided with manufacturing and assembly procedures. Bearing failures are avoided by using fluid-type bearings without frictional surfaces. Thermal 
TABLE XLVIII

SINGLE-FAILURE POINT SUMMARY FOR LIQUID-COOLED SYSTEMS

WITH SINGLE CONVERTERS

\begin{tabular}{|c|c|c|c|}
\hline FAILURE R:ODE & COMPONENT & MECHANISM & $\begin{array}{l}\text { PERFORMANCE } \\
\text { SIGNIFICANCE }\end{array}$ \\
\hline LOSS OF FLUID CONTAINMENT & $\begin{array}{l}\text { REACTOR PRESSUAE VESSEL } \\
\text { BOILER } \\
\text { TURBO-ALTERNATOR IOOUSING } \\
\text { MOTOR YUNTS } \\
\text { HEAT EXCHANGEAS } \\
\text { ACCUMULATORS } \\
\text { CONDENSING RAOIATOR } \\
\text { JET PUMP HOUSING } \\
\text { LINES AND BELLOWS }\end{array}$ & $\begin{array}{l}\text { MICROMETEOROID PENETAATION } \\
\text { WELD AND BAAZE FAILURE } \\
\text { CREEP RUPTURE } \\
\text { FRACTURE OF THE BOLTS IN } \\
\text { TURBO MACHINERY } \\
\text { TURBOMACHINERY HUB BURSTS } \\
\text { RADIATION INOUCED MATERIAL } \\
\text { DAMAGE } \\
\text { MANUFACTURING DEFECTS } \\
\text { BELLOWS SEAL IEAKS }\end{array}$ & MAJOR \\
\hline LOSS OF PUNPING POWER & $\begin{array}{l}\text { TURBINE } \\
\text { MOTOR PUMPS } \\
\text { VALVES }\end{array}$ & $\begin{array}{l}\text { STRUCTURAL FATIGUE } \\
\text { TURBINE WHEEL RUBS } \\
\text { COMPRESSOR IMPELLER RUBS } \\
\text { FROM MISALIGNMENT OR } \\
\text { VIBRATION } \\
\text { BEARING FAILURES FROM } \\
\text { FRICTION DURING } \\
\text { STARTUP AND SHUTDOWN } \\
\text { VALVE HOUSING CONTAMINATION } \\
\text { OR CORROSION } \\
\text { SEAL LEAKS } \\
\text { FLOW INDUCED VIBRATION }\end{array}$ & MAJOR \\
\hline $\begin{array}{l}\text { LOSS OF CONVERSION } \\
\text { EOUIPMENT }\end{array}$ & ALTERNATOR & $\begin{array}{l}\text { LOSS OF INSULATION CAUSING } \\
\text { SHORT } \\
\text { OPEN CIRCUIT FROM LOSS OF } \\
\text { LOAD }\end{array}$ & MAJOR \\
\hline LOSS OF CRITICALITY & REACTOR FUEL & $\begin{array}{l}\text { CORROSION OF FUEL BY } \\
\text { LITHIUM }\end{array}$ & MAJOR \\
\hline
\end{tabular}

stress in the housing is avoided by carefully designing for the operating environment.

Loss of power conversion equipment could result from insulation short or open circuits caused by load interruptions.

Loss of reactor criticality can occur from erosion or corrosion of the reactor fuel with deposition of fuel outside the core. Because lithium is corrosive, cladding on the fuel is necessary to avoid failures.

To el iminate single failure points would require redundancy in the converter loop and the auxiliary power loops (Fig. 200). This would double the weight of these loops. The reactor is more difficult to make redundant. For the reactor core, conservative design of the fuel elements with an acceptable risk factor appears to be the only approach. The pressure vessel can be made redundant. Double-jacketed lines can be used throughout. Dual boilers and accumulators could be incorporated, but this would require high temperature valves in the reactor outlet as well as valves in the inlet. This alone adds 16 valves to the system. 
3. Heat-Pipe Reactor Power Plant with Dynamic Converters. In place of the reactor pressure vessel containment of a gas-cooled reactor, we are now concerned with a high-temperature heat exchanger between the core heat pipes and the Brayton converter loop. Also, we eliminate any concern with fuel erosion and corrosion because the design has no fluid flowing across the fuel material.

The method for eliminating single failure points is straightforward (Fig. 201). Redundant high-temperature heat exchangers and converter loops can be added without valves in the compressor and turbine lines and no need is seen for an emergency cooldown accumulator. Also, there is no need for a double-containment pressure vessel. There is a need to regulate the power between the dual converter loops. In normal operation, both loops would be contributing half the electric output. In case of a malfunction, one loop would contribute all the power. Regulating the gas pressure in the loops appears to be a straightforward way to accomplish this. This will involve

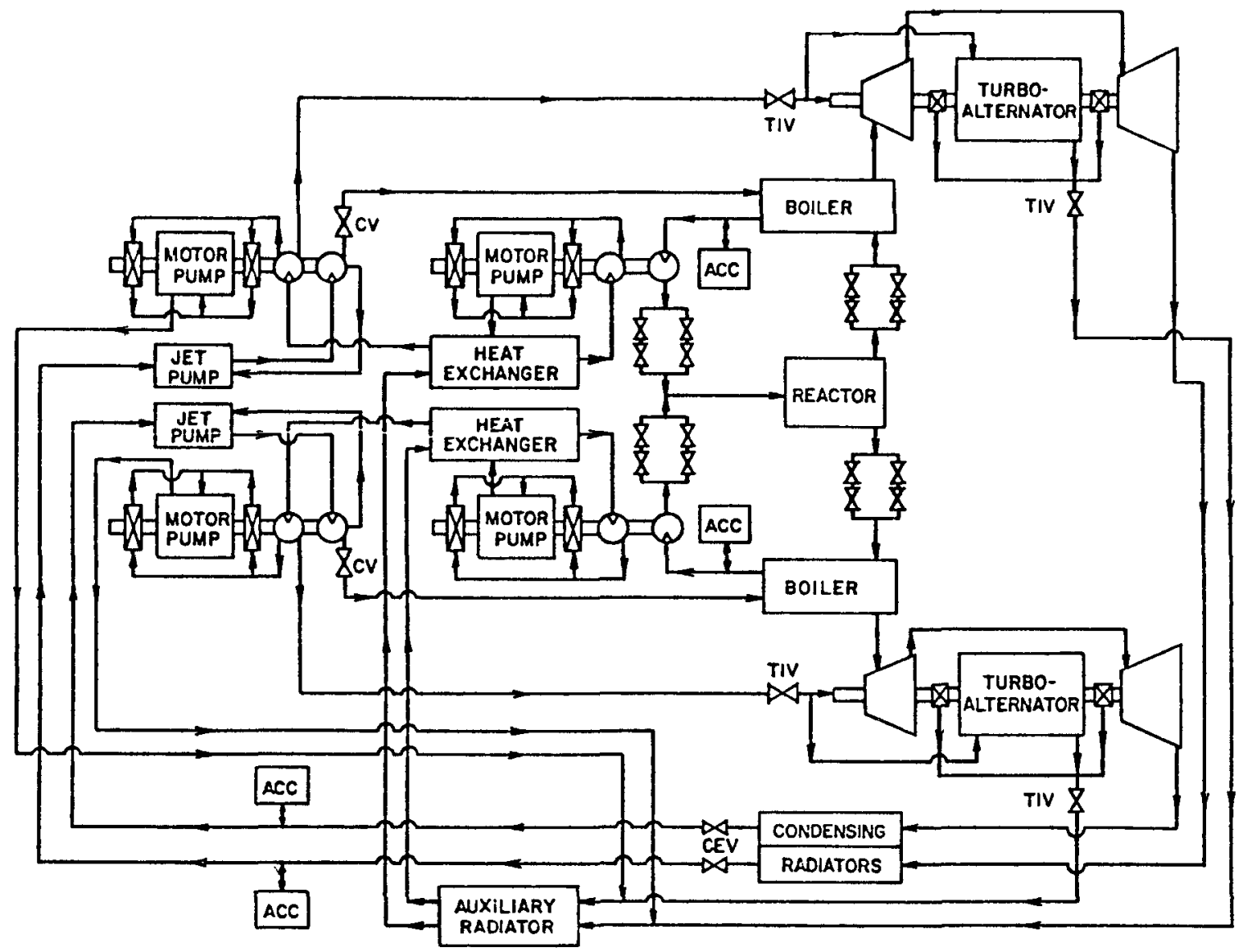

Fig. 200. Redundancy in the converter loop and auxiliary power loops. 
adding accumulators for power balancing. The same accumulators can be used to add gas to the loop to go from half to full power. Reactor power can be temporarily reduced during the time one loop is shutting down and the other is picking up the load so that the gas control valves can be made small. These valves should be made redundant.

4. Heat-Pipe Reactor with Thermoelectrics. No single-failure points have been identified (Table XLIX). Redundancy in the reactor, converter, radiator and control allows for multiple failures before loss of power plant performance would occur. The reactor has 90 heat-removal elements with 90 heat pipes. In case of a malfunction, the surrounding elements will remove the heat from the defective element. The fuel is encapsulated so that cracking or swelling will not allow fuel migration and subsequent loss of criticality. Redundant drum and control systems will allow single-failure points without loss of mission performance. For the converter, the elements are located on the 90 reactor heat pipes and arranged in a series-parallel matrix to allow a certain percent to fail. The heat-pipe radiator has been designed with multiple levels of redundancy with provisions to lose both stringers and circumferential heat pipes. For example, a $900-k W_{t}$ radiator has some 90 stringers and almost 10000 circumferential heat pipes.

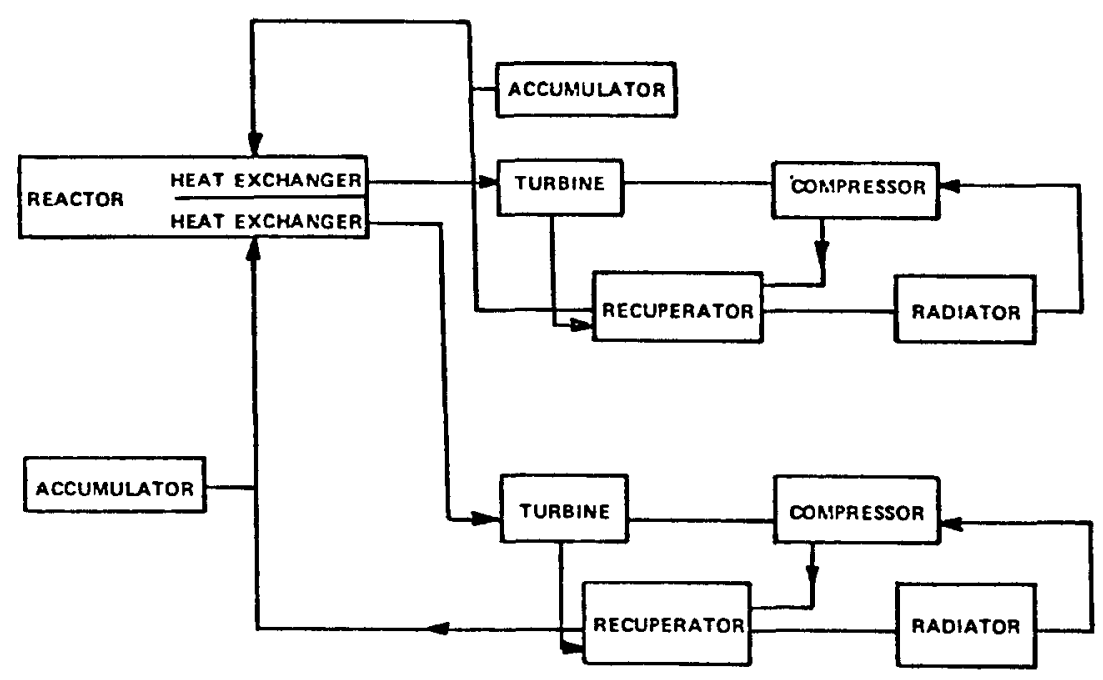

Fig. 201. Redundant elements in heat-pipe reactor with dynamic converters. 
TABLE XLIX

HEAT-PIPE REACTOR SINGLE-FAILURE POINTS WITH THERMOELECTRIC CONVERTERS

Component and function Potential Failure Modes

FUEL CLEMENT

Act as neat source for

power plant.

90 heat pipes used to remove heat and

isolated fuel from fluid system.

Loss of heat pipe will not affect

system output.

PERIPHERY COHPRESSION BANDS

None for single failures. Multiple failures affect core compression and integrity.

REFLECTOR

Improves reactor power distri-

bution, lower critical mass.

With conduction and radiation cooling. no foreseen failure modes.

CONTROL DRUMS

Establish power level by varying their position.

Redundant elerents require multiple failures. Drums could bind from reflector warpage or failure of mechanical linkage.
None for single element. Several drums fail-in would cause reactor shutdown; fail-out would cause supercritical condition leading to reactor mechanical disintegration; fait-in place would lead to premature shutdown.
THERMOELECTRIC CONVERTERS Convert thermal energy into electricity.

RADIATOR STRINGERS

Transfer reject heat from TE cold junction to radiator circumferential heat pipes.

RADIATOR CIRCUMFERENTIAL HEAT PIPES

Extract heat from stringer and

radiate reject heat to space.
Converters located on 90 heat pipes from

reactor. Cold junctions interconnected.

Design such that a certain percent can

fail without loss of power.

90 redundant elerents provide for $11 \%$

failure without loss of power.

Large number (several thousand) in design so that $20^{\circ}$ can be punctured by meteoroids without loss of performance.

\section{F. Combined Converter Cycles.}

The question here is whether a high temperature converter such as a thermionics and a lower-temperature converter such as a Brayton cycle can be combined into a power plant configuration to provide a lower-mass system. The fcllowing criteria were used in comparing 50 - to $150-\mathrm{kW}_{\mathrm{e}}$ thermionic reactors with and without an added Brayton converter.

- The reactor would need to operate at a heat pipe temperature of $1675 \mathrm{~K}$ for the thermionic converters; $\mathrm{UO}_{2}-40$ vol\% Mo was selected as the reactor fuel. A single-core design was selected to span the entire power range of interest. Customizing the core for a selected power level would cause less than a 10\% variation in reactor mass, and hence would lead to an insignificant effect on the conclusions.

The Brayton converter inlet temperature was selected on the bas is of using superalloy technology. The temperature is the same as the collector temperature for the thermionic converters. As such, the thermionic 
collector temperature would have to be $\sim 1125 \mathrm{~K}$ instead of $925 \mathrm{~K}$ without the Brayton engine. The loss in thermionic efficiency based on JPL data is - 13\%. To test the sensitivity of the calculations to the loss in thermionic efficiency, a $27 \%$ loss in efficiency was also analyzed.

- Shield mass was based on the payload being $25 \mathrm{~m}$ from the reactor center with a shield cone half-angle of $6^{\circ}$. The radiation tolerance of the payload based on a 7-yr life is assumed to be $10^{13}$ nvt and $10^{7}$ rad. The variations in shield mass is a function of the reactor power level.

- Thermionic converter mass is based on an assumed specific mass of $2.1 \mathrm{~kg} / \mathrm{kW}$ for $20 \%$ converter efficiency. The mass for $15 \%$ base efficiency is proportional to this specific mass using a ratio of efficiencies.

- Brayton converter mass is based on information from AiResearch Corporation using dual converters for added reliability.

- Radiator mass depends on the temperature and materials. The thermionic radiator is stainless steel and the Brayton radiator is Lockalloy and uses $1 \mathrm{~kg} / \mathrm{kW}_{\mathrm{t}}$.

Table L summarizes the masses of various system combinations. At $50 \mathrm{~kW}_{e}$, the bottoming cycle systems are 24-34\% heavier than a pure thermionic system. Furthermore, the radiator requires five times larger surface area. At $150 \mathrm{~kW}$ the system with the bottom cycle was $39 \%$ heavier than the one with only a thermionic converter. From this analysis, bottoming cycles do not appear to be an effective means to reduce overall power plant mass.

\section{G. Emergency Cooldown for Man-Rated Systems.}

In unmanned spacecraft, redundant power conversion equipment is used to extend the life of the power plant beyond that expected with singlefailure points. In case of multiple failures, in which all conversion equipment is lost, it is acceptable for the reactor to be subjected to extreme overtemperatures or even mechanical disassembly. In the void of space, such as in geosynchronous orbit, this does not introduce safety problems. However, if at some future time one wants to use a reactor with men in the vicinity, then emergencies shutdown must be performed in a safe and controlled manner. In fact, in a manned spacecraft or station parts of the electric converter and radiator might be replaced after shutdown. 
TABLE L

COMBINED CONVERTER CYCLES

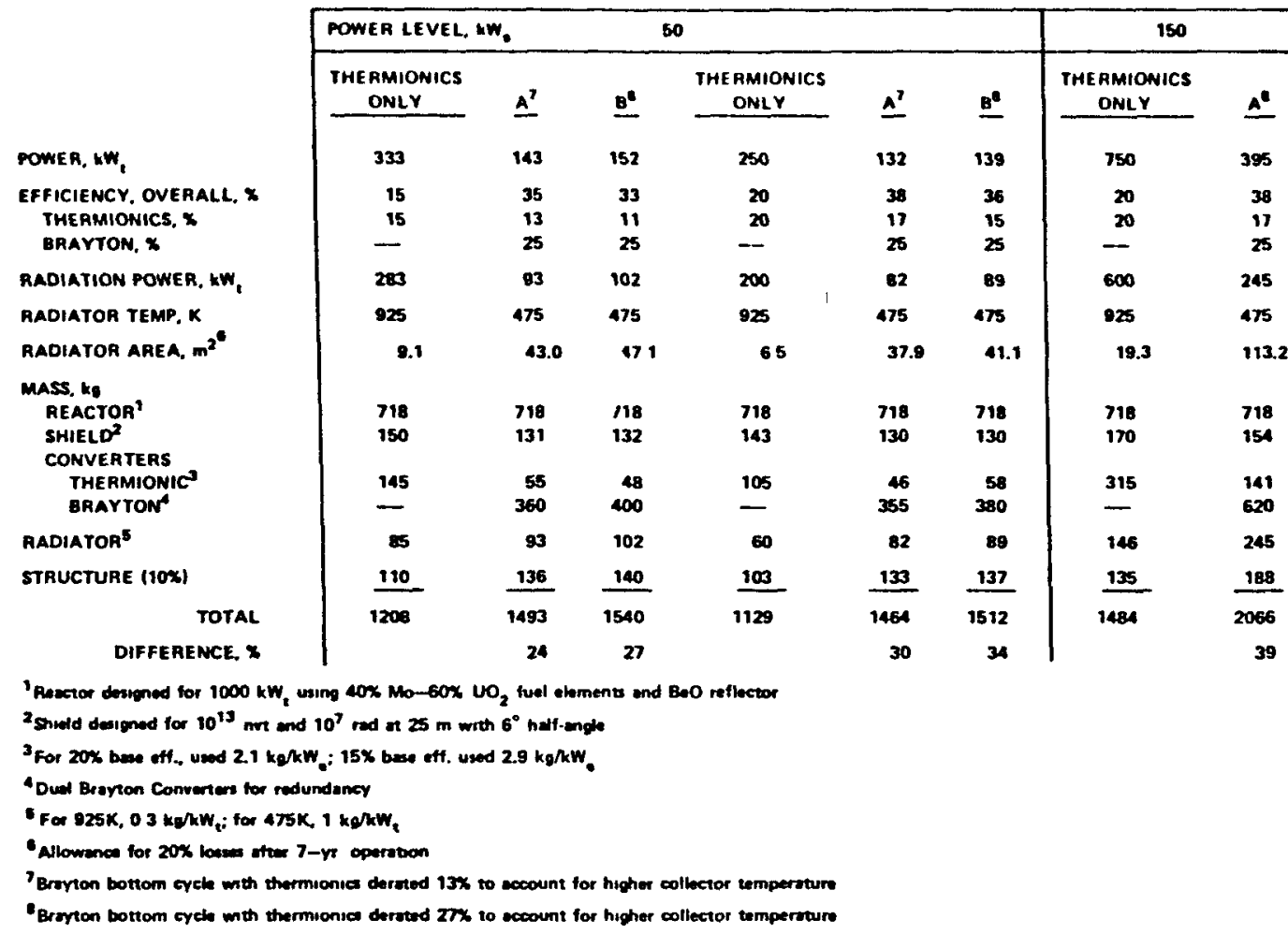

Provisions would need to be made in an emergency to shut down the power plant while maintaining parameters within certain limits.

With a gas- or liquid-cooled system, providing for emergency cooldown of a manned space station is cumbersome and adds weight to the system. Possible approaches include

(1) Emergency cooldown accumulator. Fig. 202 shows a typical cooldown curve. After 1 day, a $1-\mathrm{MW}_{\mathrm{t}}$ reactor is still producing $7 \mathrm{~kW}_{\mathrm{t}}$ of power. No convenient radiating path exists to space so that continuous cooling would be required to eliminate afterheat. In the first day over $1000 \mathrm{MJ}_{\mathrm{t}}$ must be removed. If $\mathrm{He}-\mathrm{Xe}$ is used and heated by $500 \mathrm{~K}, 4000 \mathrm{~kg}$ of coolant or over $500 \mathrm{~m}^{3}$ are needed the first day for after heat removal. A gas storage unit would be excessively heavy and large.

(2) Pumped-liquid storage system with a radiator. This system would require an altermate power source to drive the coolant through the reactor, a heat exchanger to the radiator, plus valves and a complex control system. It would be a complex addition to any power plant. 


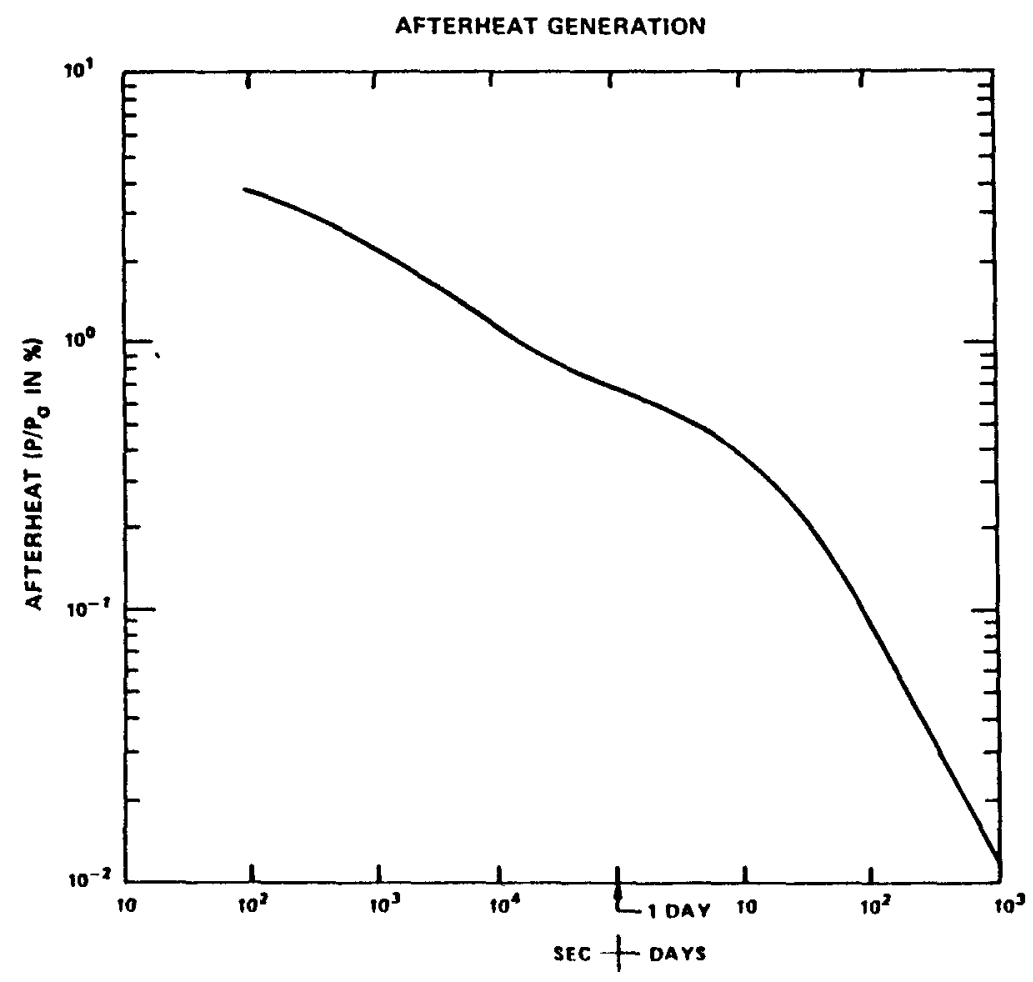

Fig. 202. Afterheat generation.

The heat-pipe reactor offers an alternative to an emergency cooldown accumulator (Fig. 203) and fluid storage system that is reliable, simple and lightweight. The reactor heat pipes are extended beyond the converter heat transfer system. To this added section is attached a high-temperature radiator designed to operate at $1275 \mathrm{~K}$. One square meter of radiator surface would eliminate $135 \mathrm{~kW}_{\mathrm{t}}$; so the radiator area can be kept small. During normal operation, the gas reservoir acts to prevent heat from reaching the emergency cooldown radiator. During an emergency shutdown, the heat not being removed by the converter would compress the gas and cause heat to be transferred to the emergency cooldown radiator. The amount of heat to be removed would be greatly reduced because the reactor would be in a shutdown mode.

Reactor and turbomachinery maintenance may require a manned approach to the system at some time after reactor shutdown. The most convenient way to express the gamma dose rates (neutrons will always be inconsequential by comparison) is as a time dependent fraction of the gamma dose rate during 
reactor operation. Results given in Fig. 204 are valid for decay times short compared with operating time, although the specific calculation was made for an operating time of $1 \mathrm{yr}$. Data for the calculation were taken from results reported by J. F. Perkins and R. W. King, "Energy Release from the Decay of Fusion Products," Nucl. Sci. and Eng. $\underline{3}, 726-746$ (1958).

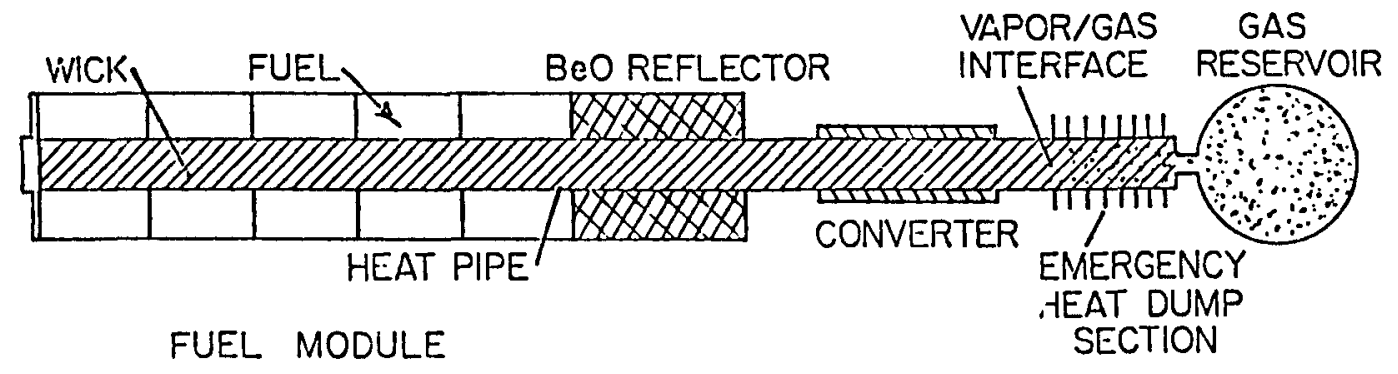

Fig. 203. Heat-pipe reactor emergency cooldown.

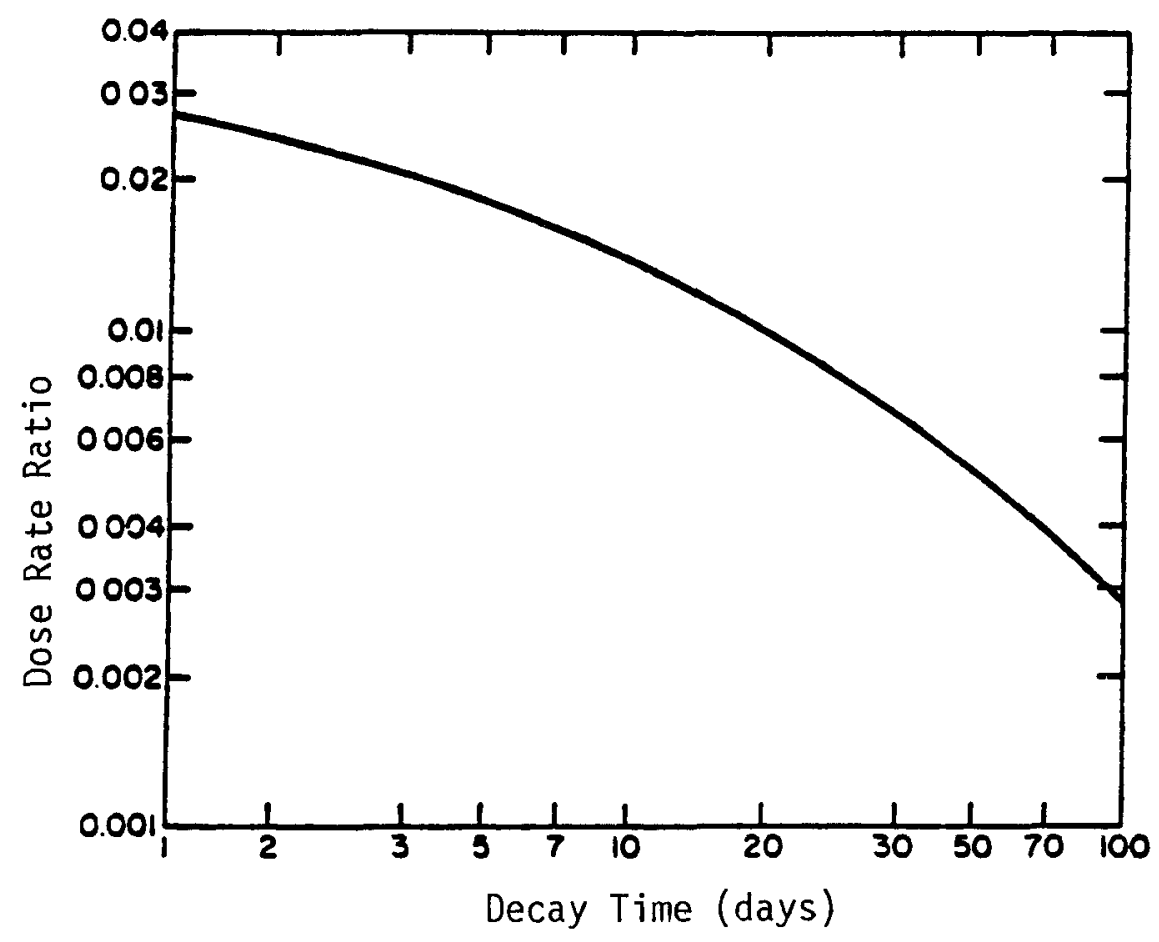

Fig. 204. Ratio of post-shutdown dose rate to that during operation (valid at any locations). 


\section{XI • OVERALL ASSESSMENT}

A. Selected Configuration

Following are the selected elements for a space nuclear power plant.

(1) A single standard reactor design is selected to cover the power range from $10-100 \mathrm{~kW}_{\mathrm{e}}$. The penalties at low power appear acceptable and development cost is significantly less than if several reactors were developed to meet different mission requirements.

(2) The reactor, regardless of converter, is the heat-pipe reactor. This is because of the high reliability that can be achieved by elimination of mechanical pumps and compressors; the elimination of single-failure points; the tolerance to material swelling, radiation damage and other environmental effects without loss of power; and the elimination of a pressure vessel for safety design.

(3) The prime fuel candidate is $\mathrm{UO}_{2}-20$ vol\% Mo. It is compatible with near-term converters, is based on highly developed technology and provides a technology base for higher-temperature future converters.

(4) The core heat pipe material is molybdenum. Molybdenum is compatible with the converter temperatures, is demonstrably fabricable, and lightweight.

(5) The converters are thermoelectric. These meet the weight goal, have been shown to be reliable, provide built-in component redundancy, and are the least expensive to develop.

(6) The radiator is a heat-pipe radiator using beryllium or nickellaminated beryllium. The design is lightweight, highly redundant, and eliminates the need for pumps.

The probability of successful development (development risk), growth potential, development cost, and cost benefit assessments indicate that the risks associated with $\mathrm{UO}_{2}$ are less than with $\mathrm{UC}$ even though $\mathrm{UO}_{2}$ operates at $1475 \mathrm{~K}$ and $\mathrm{UC}$ operates at $1375 \mathrm{~K}$ (Table LI). $\mathrm{UO}_{2}$ fuel is easier to manufacture, presents fewer swelling design problems, and chemically interacts less with the molybdenum heat pipes. Greater growth potential exists with $\mathrm{UO}_{2}$-fueled reactors. However, development risk for thermoelectric material is greater for a $\mathrm{UO}_{2}$ - than a UC-fueled reactor because higher converter efficiencies are needed to offset the higher weight of the reactor. 


\section{TABLE LI}

COMPARISON OF UC AND $\mathrm{UO}_{2}$ FUELS

$$
\left(1000-k W_{t}\right. \text { Design) }
$$

\begin{tabular}{|c|c|c|c|}
\hline FUEL SYSTEMS & UC- 10 at.\% ZrC & $\mathrm{UO}_{2}-40$ vol\% Mo & $\mathrm{UO}_{\overline{2}}-20$ v01\% Mo \\
\hline $\begin{array}{l}\text { Reactor mass }(\mathrm{kg}) \\
\text { Reactor diameter }(\mathrm{M}) \\
\mathrm{U}-235(\mathrm{~kg}) \\
\text { Shield (same converter) }\end{array}$ & $\begin{array}{l}415 \\
0.51 \\
108 \\
\text { Base }\end{array}$ & $\begin{array}{c}610 \\
0.58 \\
130 \\
\sim 20 \% \text { heavier }\end{array}$ & $\begin{aligned} & 475 \\
& 0.53 \\
& 100 \\
\sim 5 \% & \text { heavier }\end{aligned}$ \\
\hline$\frac{\text { FUEL FABRICATION }}{\text { Handling }}$ & Inert atmosphere & $\begin{array}{l}\text { No special } \\
\text { Problems }\end{array}$ & $\begin{array}{l}\text { No special } \\
\text { Problems }\end{array}$ \\
\hline $\begin{array}{l}\text { Method } \\
\quad \text { Current }\end{array}$ & Arc melting & $\begin{array}{l}\text { Press, sinter, } \\
\text { and machine }\end{array}$ & $\begin{array}{l}\text { Coated } \\
\text { particles, } \\
\text { press, heat } \\
\text { treat and } \\
\text { machine }\end{array}$ \\
\hline Future & $\begin{array}{l}\text { Extrusion and } \\
\text { reaction sintering }\end{array}$ & Same & Same \\
\hline $\begin{array}{l}\frac{D E S I G N}{\text { Puel swelling }(\%)} \\
\text { (Heat-pipe temp } 1400 \mathrm{~K} \text { ) }\end{array}$ & 8 & 0.1 & 6 \\
\hline $\begin{array}{l}\text { Mo-fuel compatibility } \\
\text { Thermal } \\
\text { Chemical }\end{array}$ & $\begin{array}{l}\text { Mismatched } \\
\text { Interactions start } \\
\text { at } 1475 \mathrm{~K}\end{array}$ & $\begin{array}{l}\text { Matched } \\
\text { None up to } \\
1975 \mathrm{~K}\end{array}$ & $\begin{array}{l}\text { Matched } \\
\text { None up to } \\
1975 \mathrm{~K}\end{array}$ \\
\hline TECHNOLOGY & $\begin{array}{l}\text { Less developed } \\
\text { (Rover, and LMFBR) }\end{array}$ & $\begin{array}{l}\text { Well developed } \\
\text { (LWR and LMFBR) }\end{array}$ & $\begin{array}{l}\text { Moder ately } \\
\text { developed } \\
\text { (LWR and } \\
\text { LMFBR) }\end{array}$ \\
\hline
\end{tabular}

The $\mathrm{Ni}$-Be laminated tubes for heat pipes must be developed. This presents no problems as nickel heat pipes with potassium fluid have been operated for $40000 \mathrm{~h}$.

Development cost would be $\$ 3-4$ million higher for the UC- than for $\mathrm{UO}_{2}$-fueled reactor. More effort would be needed to develop manufacturing methods and additional irradiation testing would be needed. However, a lower thermoelectric development cost partially offsets this increase in fuel development. 
Cost benefit analysis performed for a future demand of 20 power piants to provide power to satellites in geosynchronous orbit shows a savings of $\$ 830$ million over solar arrays with batteries. Development costs are estimated to be $\$ 150 \mathrm{milli}$ ion and production and delivery cost would be $\$ 280$ million, for a total of $\$ 430$ million for the 20 units. (It costs $\$ 1260$ million (excluding development cost) to provide the power with solar arrays with batteries.)

Table LII compares these selections with the NEP reactor. The major difference is the 300-K higher operating temperature. This leads to a fuel with a higher percentage of molybdenum to accommodate fuel swelling. The heat-pipe design is affected by the higher temperature and longer life. Another significant difference is the heat-pipe routing. For the NEP design the heat pipes penetrate the shield.

\section{B. Power Plant Configuration Assessment}

The options considered include heat-pipe, gas-cooled, and liquid-metal reactor designs; $U C, U_{2}$, and $U N$ fuels; thermionic, thermoelectric, Brayton, potassium Rankine, and Stirling converters; and heat-pipe, pumped fluid with fins, and pumped fluid with heat pipes radiators. These lead to 135 combinations without considering all the variations in thermoelectric matedifferent-temperature Brayton cycles and variations in thermoelectric materials. Selected configurations are discussed below in terms of the following parameters:

(1) System feasibility discusses the problems for near-term (late 1980s and early 1990s) and far-term (mid 1990s and beyond) missions.

(2) Risks and fallback options address the probability of resolving the feasibility problems with reasonable costs and schedules, and discuss the options if these problems should prove to be intractable.

(3) System performance predicts the flight performance characteristics, which determine the system's attractiveness to potential users after its feasibility, reliability, and durability have been demonstrated. These parameters will include the power that can be delivered in one and twoshuttle missions, the mass at $100 \mathrm{~kW}_{\mathrm{e}}$, the peak potential power from a

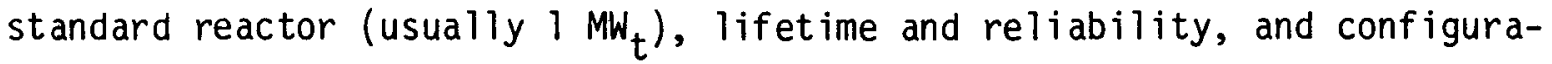
tional constraints.

(4) Cost discusses the variation from a base-line program. The program includes the technical feasibility phase of reactor conceptual 


\section{TABLE LII}

TECHNOLOGY COMPARISON (BASED ON CURRENT DESIGNS)

\begin{tabular}{|c|c|c|}
\hline & $\underline{\text { SPAR }}$ & NEP \\
\hline Power Level $\left(\mathrm{kW}_{\mathrm{t}}\right)$ & 1200 & 3000 \\
\hline Operating Lifetime (yr) & 7 & 10 \\
\hline Reliability & 0.98 & $\begin{array}{l}\text { High as possible } \\
\text { No single-failure } \\
\text { points }\end{array}$ \\
\hline Type & Fast spectrum & Fast spectrum \\
\hline $\begin{array}{l}\text { Core } \\
\text { Fuel } \\
\text { Heat transfer } \\
\text { Temperature } \\
\text { Wall material } \\
\text { Fluid } \\
\text { No. of heat pipes }\end{array}$ & $\begin{array}{c}\mathrm{UO}_{2}-20 \text { vol\%Mo } \\
\text { Heat pipes } \\
1375 \\
\mathrm{Mo} \\
\mathrm{Na} \\
90\end{array}$ & $\begin{array}{c}\mathrm{UO}_{2}-40 \text { vol\%Mo } \\
\text { Heat pipes } \\
1675 \\
\text { Mo } \\
\text { Li } \\
90\end{array}$ \\
\hline $\begin{array}{l}\text { Reflector } \\
\text { Material } \\
\text { Control material } \\
\text { Reactivity control mechanism }\end{array}$ & $\begin{array}{l}\text { Be } \\
\mathrm{B}_{4} \mathrm{C} \\
\text { Drums }\end{array}$ & $\begin{array}{l}\mathrm{BeO} \\
\mathrm{B}_{4} \mathrm{C} \\
\text { Drums }\end{array}$ \\
\hline $\begin{array}{l}\text { Shield } \\
\text { Neutron } \\
\text { Gamma } \\
\text { Penetrations }\end{array}$ & $\begin{array}{l}\text { LiH } \\
\text { W } \\
\text { None }\end{array}$ & $\begin{array}{l}\quad \stackrel{\mathrm{LiH}}{W} \\
\text { Heat Pipes to } \\
\text { converters }\end{array}$ \\
\hline Design & $\begin{array}{l}\text { Honeycomb } \\
\text { structure }\end{array}$ & $\begin{array}{l}\text { Honeycomb } \\
\text { structure }\end{array}$ \\
\hline
\end{tabular}

design, experimental verification of power plant components, and the design and testing of a ground demonstration power plant. This base-line program is estimated to cost $\$ 50-60$ million. ( $A 11$ costs are engineering estimates unsupported by detailed plans.)

(5) Scalability addresses the problems of requalifying of the power plant from one power level to another.

(6) Growth addresses the long-term potential improvements of a particular power plant configuration.

Reliability and single-failure analysis indicate that dual-converter systems are necessary to meet the mission goals for power plants with dynamic converters. Therefore, all configurations include sufficient redundancy 
to meet the reliability goal of 0.95 . Figure 194 provides a weight summary and Fig. 195 shows profiles of the various power plant configurations. For near-term power $\mathrm{plants}$ either thermoelectric or Brayton converter power plants can meet the weight requirements. The thermoelectric power plant occupies less of the shuttle bay volume. Thermionic power plants with good efficiency and high radiator temperatures, are attractive long-term system.

The following designs are discussed.

- Design A: Heat-pipe reactor with thermoelectric converters.

- Design B: Heat-pipe reactor with Brayton converters.

- Design C: Gas-cooled reactor with Brayton converters.

- Design D: Heat-pipe reactor with thermionic converters.

These designs are considered to cover the most attractive near-term and far-term options. The potassium Rankine cycle was eliminated from final consideration because it is a far-term system that in overall performance does not offer the advantages of thermionic systems; that is,

(1) it weighs more (at $100 \mathrm{~kW}_{e}$, it weighs $2130 \mathrm{~kg}$, whereas a thermionic system weighs at $1270 \mathrm{~kg}$ ),

(2) it does not have inherent redundancy, and

(3) it is not under active development or planned for development.

The Stirling cycle was eliminated for similar reasons and because there is no apparent solution to the heavyweight of the low-frequency alternator. Without significant reductions in alternator weights, the configuration is noncompetitive.

1. Design A: Heat-Pipe Reactor with Thermoelectric Converters. This power plant would include a $\mathrm{UO}_{2}-20$ vol\% Mo fueled, heat-pipe reactor, SiGe-GaP thermoelectric converter elements, and a conical or panel-shaped heat-pipe radiator.

\section{a. System Feasibility.}

(1) System efficiency and long-term stability of the SiGeGaP alloy are the largest uncertainties to resolve. SiGe TE has been demonstrated to provide good performance to $50 \mathrm{~kW}_{\mathrm{e}}$. If SiGe-GaP proves to be as good as current experiments indicate, then power plants to $100 \mathrm{~kW}_{\mathrm{e}}$ in a highly redundant arrangement without pumps or compressors are feasible.

(2) Reactor uncertainties include determining whetner to use a spacer or cermet fuel arrangement, designing to compensate for 
periphery heat pipes, and designing for core disintegration on atmospheric re-entry.

(3) The degree of bending molybdenum heat pipes around the shield must be experimentally determined.

(4) The feasibility of $\mathrm{Ni}-\mathrm{Be}$ or beryllium heat pipes for the radiator must be demonstrated.

b. Risks and Fallback Options.

(1) If the converter fails to achieve 9-10\% efficiency with a 775-K cold junction, then relaxation of the weight goal may be needed. This is possible since the shuttle is volume- rather than weight-limited in many proposed spacecraft.

(2) An experimental program on fuels should resolve the questions on fuel design. Periphery heat-pipe malfunctions can be accounted for in the design, and are not considered a major problem. A materials program will be needed to determine the best material for core compression. The ordered alloys under development at Oak Ridge National Laboratory have many desirable characteristics. They show high strength to a certain temperature and low strength beyond that temperature. The risk appears reasonably small.

(3) The heat-pipe bending around the shield appears feasible from a study of molybdenum tube behavior. However, the pipes could go through the shield if necessary.

(4) The demonstrated fabricability of extruding beryllium in iron containers and obtaining good metal bonds, plus the match of linear thermal expansion of nickel and beryllium indicates that $\mathrm{Ni}-\mathrm{Be}$ laminates are feasible. If not, titanium can be considered as a radiation material, but it would lead to heavier radiators and risk exceeding the power plant weight goal.

\section{c. System Performance.}

(1) The standard power with SiGe-GaP would be $1.2 \mathrm{MW}_{t}$ to provide a $100-\mathrm{kW}_{\mathrm{e}}$ power $\mathrm{plant}$ weight of $1660 \mathrm{~kg}$. A single shuttle could deliver $20-25 \mathrm{~kW}_{\mathrm{e}}$.

(2) Lifetime and reliability goals could probably be exceeded because of the inherent redundancy in the design. A reliability of 0.98 may be achieved. 
(3) The radiator for a $100-\mathrm{kW}_{\mathrm{e}}$ system is small enough to use fixed geometries in the stored and deployed configurations. A $50-\mathrm{kW}_{\mathrm{e}}$ power plant with conical-shaped radiator is $6.4 \mathrm{~m}$ overall. Other components can be packaged within the radiator.

d. Cost. This design is used as the base line to discuss cost differences for other power plant configurations.

e. Scalability. Scalability is excellent because of the modularity of all assemblies. Requalification for different power levels should be unnecessary.

f. Growth. As higher-temperature converters are developed, the molybdenum content of the fuel can be increased. This will permit the reactor to be operated at higher temperatures.

g. Summary. This configuration is the prime candidate for the base-line power plant. The major uncertainty is whether or not thermoelectric materials of sufficient efficiencies will be available.

2. Design B: Heat-Pipe Reactor with Brayton Converters. This power plant would have a turbine inlet temperature of $1275 \mathrm{~K}$ (reactor outlet temperature of $1375 \mathrm{~K}$ ) with dual Brayton units for redundancy. Each Brayton unit could deliver full power when operating by itself.

\section{a. System Feasibility.}

(1) Material problems exist in operating Brayton converters at $1275 \mathrm{~K}$. Refractory metals such as columbium would be required.

(2) The reproducibility, reliability, and durability of the turboalternator bearing is questionable. Difficulties were experiences with the BIPS foil bearing.

(3) The high-temperature heat exchanger is a complex component that will require considerable development effort.

(4) Statements on reactor uncertainties in Design A apply here.

(5) The design of a lightweight radiator is very difficult because of the low reject heat temperature. The Brayton fluid would need to be manifolded through the radiator, resulting in additional exposure of the gas containment components to meteoroids. The temperature levels are such that good heat-pipe fluids are lacking, leading to more bulky radiators. Radiator areas for a $50-\mathrm{kW}_{\mathrm{e}}$ power plant are $40 \%$ more than for 
thermoelectrics and $600 \%$ more than for thermionic power plants. A satisfactory design that meets our weight goal has not been achieved.

b. Risks and Fallback Options.

(1) Extensive materials work has been done on refractory metals. If these do not prove viable then superalloys could be used. However, this reduces the operating temperature $\sim 125 \mathrm{~K}$ and increases converter weights by $10-20 \%$.

(2) The bearing design could return to a tilting-pad concept such as used in the NASA-Lewis Brayton program, but this would reduce efficiency and specific power.

(3) Reasonable designs for the high-temperature heat exchanger have been satisfied.

(4) Radiator development is questionable within the weight constraints and would be complex. Packaging of larger power plants in the shuttle bay may require deployable geometrics; if so, the risk increases substantially.

\section{c. System Performance.}

(1) The Brayton cycle is comparable in weight to the thermoelectric power plant if a radiator can be successfully designed. However, there is less confidence in the weight values here than in those for Design A. If a radiator heat exchanger is used for a deployable radiator, the heat exchanger and pumps lead to very complex additions to the power plant.

(2) The reliability and lifetime goals can be met with redundant converter loops. The goal of 0.95 is as high as we will commit ourselves. With the heat pipe reactor and redundant Brayton loops, singlefailure points are eliminated.

(3) Potentially, a Brayton cycle could provide $250 \mathrm{~kW}$ or more with a $1-\mathrm{MW}_{\mathrm{t}}$ reactor. However, the radiator area would be $290 \mathrm{~m}^{2}$ and, if arranged in four radiating surface panels, exceeds the length of the shuttle bay. If we restrict the radiator to one shuttle bay length, a four-panel radiator with an $80 \%$ view factor would occupy $\sim 200 \mathrm{~m}^{2}$. This would leave room for a $170-\mathrm{kW}$ e power plant.

d. Costs. The Brayton cycle conversion unit would be more difficult than the thermoelectric to develop and qualify, adding some $\$ 10$ million to the program cost. The radiator would add several additional millions. 
e. Scalability. For each different power level, it is desirable to redesign and requalify the converter. This makes scalability more expensive than for a passive type converter.

f. Growth. Improved performance would require going to a higher-temperature Brayton cycle. This implies molybdenum turbines, niobium recuperators, and higher-temperature bearings. The reactor fuel would need to be adjusted with more molybdenum as converter temperature is increased.

g. Summary. The Brayton cycle with its inherent low-temperature radiator leads to large-volume systems. Its weight appears heavier than for thermoelectric designs even at $100 \mathrm{~kW}_{e}$. Material and bearing problems plague the designs even though many years have gone into its development. It is cansidered a much more risky program than Design $A$.

3. Design C: Gas-Cooled Reactor with Brayton Converters. The power plant consists of a gas-cooled reactor with two Brayton converter loops. Each loop is operated separately and can be isolated from the reactor by high-speed, high-temperature inlet and outlet valves in case of a gas leak. Separate operation is necessary to know which loop has suffered a failure. This also necessitates adding a high-pressure gas emergency cool down accumulator.

\section{a. System Feasibility:}

(1) Uncertainties on converter materials are the same as for Design $B$.

(2) Erosion and corrosion in the core must be avoided as these could be single-failure points. Also, gas leaks from the inlet valves and from the pressure vessel to the outlet valves offer opportunities for single-failure points unless double containment is used.

(3) Incorporating a pressure vessel in the design would increase the difficulties associated with safety requirements; in particular, disintegration of the core on atmospheric re-entry.

(4) The valves must operate at reactor outlet conditions (1375 K) and at high speeds that require new development items. A7so, a sophisticated control system would be necessary to detect and correct for converter failures.

(5) Radiator risks are the same as for Design $B$. 


\section{b. Risks and Fallback Options.}

(1) Using Xe-He as the working fluid and low velocity flow rates should alleviate worries about erosion and provide a long-life design at acceptable risk. Fuel swelling would require lining the flow passages and encapsulating the ends of the core. Provisions for swelling must be made in the fuel matrix.

(2) Isolation valves would be expensive and difficult to develop because of the high temperature (turbine inlet) and pressure involved. These items must be classified high-risk without any obvious alternative. Sensors for the valves and controls would involve considerable development.

(3) Meeting safety criteria would require an extensive experimental program.

(4) Risk in the converters and radiator are the same as for Design B.

c. System Performance.

(1) A $1-M W_{t}$ gas-cooled reactor with its reflector is slightly larger than a $1-M W_{t}$ heat-pipe reactor because of the structure and the pressure vessel. Extra valves and a high-pressure accumulator are needed. It is estimated that this increases overall power $\mathrm{plant}$ weight $\sim 200 \mathrm{~kg}$. Other weights would be similar to Design $B$.

(2) Reliability of 0.95 can be achieved with redundant converter loops, but at the increased weight as discussed. Without the redundancy, it is believed that the reliability goal cannot be met at reasonable cost and in reasonable time.

(3) Configuration constraints are the same as Design B.

d. Cost. It is estimated that reactor development cost would be higher because more in-pile tests are needed to ensure that fuel swelling would not effect the liner. This would add $\$ 5$ million in cost. Converter loop cost would also be higher than for Design $B$, adding another several million dollars for valves, accumulator, and controls.

e. Scalability. Requalification would be needed for each power level for the converters. A single reactor design would suffice.

f. Growth. The gas-cooled is mainly compatible with the Brayton and Stirling cycles. Growth would depend on improvements in these systems. Since there is no heat exchanger between the reactor and turbine, higher turbine temperatures can be achieved with the same reactor design. 
g. Summary. A gas-cooled reactor eliminates the hightemperature heat exchanger from a Brayton cycle mated with a heat-pipe reactor, but introduces high-temperature valves, accumulator, and controls. The valves are considered a high-risk item. The Brayton loop and radiator problems are unchanged from Design B. Single-failure points are minimized, but the reactor is not redundance in design. Qualifying for 7-yr missions is thus much more difficult.

4. Design D: Heat-Pipe Reactor with Thermionic Converters. A $\mathrm{UO}_{2}-40$ vol\% Mo fueled reactor operates at $1675 \mathrm{~K}$. Heat pipes to the thermionic converters are routed through the shield. The radiator is a heat-pipe radiator operating $\sim 900 \mathrm{~K}$.

a. System Feasibility.

(1) Thermionic converter assemblies are planned to be demonstrated in a NASA program by 1985. Problems include developing high temperature insulators and demonstrating higher performance.

(2) The high temperature required for thermionic converters introduce swelling problems with $\mathrm{UO}_{2}$ fuels.

(3) Traversing heat pipes through the shield complicates the shield design and assembly.

b. Risks and Fallback Options.

(1) Sialon has been tested as a thermionic insulator but is questionable in $1675-\mathrm{K}$ systems. Be0 may be an alternative. Reduced temperatures with lower performance is an alternative. To improve efficiency, methods are being explored to reduce the collector work function and reduce arc drop. With some $\$ 16$ million planned by NASA to develop thermionic converters for deep-space exploration, the risks appear low for far-term missions, but very high for near-term missions. NASA has an on-going development program to find a solution to the problems.

(2) In-pile test data is needed for $\mathrm{UO}_{2}-40$ vol\% Mo to resolve the amount of swelling that would occur. Extrapolation of other data indicates that the reactor design would be able to accommodate the expected swelling rates.

(3) The shield design is complicated by traversing heat pipes through it, but the risk appears tolerable. The pipes could be bent around the shield, but this would add weight to the power plant. 


\section{c. System Performance.}

(1) Thermionic power plants at $100 \mathrm{~kW}_{\mathrm{e}}$ are lighter (weighing $1270 \mathrm{~kg}$ ) than other options. At $15 \%$ efficiency, a $1-\mathrm{MW}_{t}$ reactor would deliver $150 \mathrm{~kW}_{\mathrm{e}}$. A single shuttle could deliver $15 \mathrm{~kW}_{\mathrm{e}}$ to the spacecraft.

(2) With inherent redundancy, reliability and lifetime goals can be met or exceeded.

(3) Shuttle contraints are minimized by the small radiator areas required. It requires the smallest radiator area of any configuration evaluated; one-fourth of the thermoelectric and one-sixth of Brayton cycles. A $50-\mathrm{kW}_{\mathrm{e}}$ power plant with a conical radiator is only $3.7 \mathrm{~m}$ overall (only $20 \%$ of the shuttle length). Some of this volume can be used to package other parts of the spacecraft.

d. Costs. Currently, $\$ 16$ million is budgeted by NASA through 1985 for the converter development. This is for the deep-space exploration missions. At the reactor temperatures of interest, extensive in-pile tests of fuel is needed. Thus, a $\$ 6$ million technical feasibility program is required. This would be offset by its applicability to NASA's future missions.

e. Scalability. The converter is modular in format, thus eliminating the need for requalification at different power levels.

f. Growth. The thermionic converter has applications to higher power missions, such as $400 \mathrm{~kW}_{\mathrm{e}}$. At these levels, converter efficiencies and high radiator temperatures are needed. Because of availability, future lightweight $100-\mathrm{kW}_{\mathrm{e}}$ power supplies may result from the $400-\mathrm{kW}_{\mathrm{e}}$ program. However current potential missions cannot be satisfied.

g. Summary. The thermionic converter is superior performance as far as weight and size in the $50-100 \mathrm{~kW}$ e range. However, it will not be available for missions until the mid to late 1990s. It requires a higher temperature reactor than all the other options and thus is not compatible in the reactor design. 
BLANK

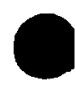


20. Donaldson, E. C., Kendall, R. F., and Manning, F. S., "Disperson and Tortuosity in Sandstones," paper SPE 6190 presented at SPE-AIME 51st Annual Fall Technical Conference and Exhibition, New Orleans (Oct. 3-6, 1976).

21. Moranville, M. B., Kessler, D. P., and Greenkorn, R. A., "Dispersion in Layered Porous Media," AIChE J. 23 (6), pp. 786-794 (1977).

22. Levich, V. G., Markin, V. S., and Chismadzhev, Y. A., "On Hydrodynamic Mixing in a Model of a Porous Medium with Stagnant Zones," Chem. Eng. Science 22, pp. 1357-1367 (1967).

23. Laughlin, A. W., "The Geothermal System of the Jemez Mountains, New Mexico and Its Exploration," a chapter to appear in The Jemez Mountains, New Mexico, edited by J. P. Muffler [to be published].

24. Roache, P. J., Computational Fluid Dynamics, Hermosa Publishers, Albuquérque, NM, p. $\overline{64}$ (1972). APPENDIX A - TWO-DIMENSIONAL OISPERSION AND TYPE CURVES

For the two-dimensional, steady flow case, equation (1) is rewritten as:

$$
\begin{array}{r}
\frac{\partial}{\partial x}\left(D_{x} \frac{\partial C}{\partial x}\right)+\frac{\partial}{\partial y}\left(D_{y} \frac{\partial C}{\partial y}\right)-u \frac{\partial C}{\partial x}-v \frac{\partial C}{\partial y}=\frac{\partial C}{\partial t} \\
\cdot . \cdot(A-1)
\end{array}
$$

where $D_{x}$ and $D_{y}$ are given by equation (7). The initial condition is:

$$
C=C(x, y, t=0)=0 \text { at all } x \text { and } y
$$

and with the injector located at $x=-a, y=0$ and the producer at $x=+a, y=0$, the boundary conditions are:

$$
\begin{array}{ll}
C(-a, 0, t)=C^{0} \text { at the injection well } t>0 \\
C(+\infty,+\infty, t)=0 & t>0
\end{array}
$$

Equation (A-1) can be expressed in dimensionless form as

$$
\begin{aligned}
& \frac{\partial}{\partial X}\left[\begin{array}{lll}
\alpha_{u} & \star & \frac{1}{a} \\
P^{\star}
\end{array}\right] \frac{\partial C_{\theta}}{\partial X^{-}}+\frac{\partial}{\partial Y}\left[\frac{k \alpha_{X}}{a} \phi_{v}^{\star}+\frac{1}{P e^{\star}}\right] \frac{\partial C_{\theta}}{\partial Y} \\
& -\Phi_{u}^{*} \frac{\partial C_{\theta}}{\partial Y}-\Phi_{v}^{*} \frac{\partial C_{\theta}}{\partial Y}=\frac{\partial C_{\theta}}{\partial \theta} \cdot \cdots \cdot(A-2)
\end{aligned}
$$

using equation (7) and the following definitions

$$
\begin{array}{lll}
x=x / a & P e^{*}=\frac{\dot{q}}{h \phi D^{\circ}} & k=\frac{\alpha_{y}}{\alpha_{x}} \\
y=y / a & \theta=\frac{\dot{q} t}{h \phi a^{2}} & \\
C_{\theta}=c / c^{\circ} & &
\end{array}
$$

$\Phi_{u}^{\star}$ and $\Phi_{v}^{\star}$ are the dimensionless velocity functions from the steady state flow solution:

$$
\begin{aligned}
& \Phi_{u}^{\star}=\frac{\text { ua } \phi h}{\dot{q}}=\frac{1}{2 \pi}\left[\frac{x+1}{(x+1)^{2}+y^{2}}-\frac{x-1}{(x-1)^{2}+y^{2}}\right] \\
& \Phi_{v}^{\star}=\frac{\operatorname{va} \phi h}{\dot{q}}=\frac{1}{2 \pi}\left[\frac{y}{(x+1)^{2}+y^{2}}-\frac{y}{(x-1)^{2}+y^{2}}\right]
\end{aligned}
$$$$
\text { ... }(A-3)
$$

Equation (A-2) was solved numerically using a modified finite difference approach with an upwind differencing technique suggested by Roache24. An alternating direction implicit algorithm resulted in stable and convergent results. The lower set of cells were center ed on the $x$-axis. Because of symmetry along this no flux boundary, the problem was solved only in the positive $y$ quadrants. Horizontally, a uniform mesh was used between wells and for 5 additional cells on either side. Vertically, the same uniform mesh size was extended by an equivalent number of cells as contained between wells. Horizontally and vertically beyond these boundaries; an expanding mesh size (e.g. $\left.\Delta X_{i}=1.5 \Delta X_{i-1}\right)$. For small values of $P e<5$, smaller time steps $\Delta \theta<0.005$ were required for convergence. Similar requirements were necessary if $\alpha_{x} / a>0.5$ with $k=0.1$.

Semi-logarithmic type curves were constructed to show the effects of $\mathrm{Pe}^{\star}, \alpha_{x} / \mathrm{a}$, and $k$. 
RESIDENCE-TIME DISTRIBUTION RESULTS

\section{EXPERIMENT}

Phase $1-1 \quad(2 / 9 / 78)$

Phase $1-2(3 / 1 / 78)$

Phase $1-3(3 / 23 / 78)$

Phase I $-4(4 / 7 / 78)$

\begin{tabular}{|c|c|c|c|c|}
\hline $\begin{array}{l}0 \\
10^{6} \\
\text { gal }\end{array}$ & $\underline{\mathrm{gpm}} \overline{\mathrm{q}}$ & $\begin{array}{c}\text { dye } \\
\text { recovery } \\
\text { (x) }\end{array}$ & $\begin{array}{l}\langle v\rangle \\
\text { galc }\end{array}$ & $\begin{array}{l}{[\mathrm{V}]} \\
\mathrm{gal}\end{array}$ \\
\hline 2.1 & 115 & 69 & 9089 & 6753 \\
\hline 6.9 & 208 & 65 & 9899 & 7644 \\
\hline 15.1 & 220 & $71^{a}$ & 14446 & 11904 \\
\hline 20.0 & 240 & $>65^{a}$ & 14855 & 12786 \\
\hline
\end{tabular}

\begin{tabular}{r}
$|v|$ at \\
$90 \%$ \\
gal \\
\hline 7728 \\
8160 \\
12218 \\
12998
\end{tabular}

$\sigma_{\theta}^{2}$

$\sigma_{\theta}^{2} \quad \sigma$

$\begin{array}{r}07 \\ (90 x) \\ \hline\end{array}$

$P e^{-1^{d}}$

0.65

0.44

0.591

0.62

0.43

0.942

0.51

0.42

0.944

0.47

0.39

1.120

${ }^{\mathrm{a} E s t i m a t e d}$ from extrapolation of the RTO tail shown in Fig. 7; actual recovery to 40,000 gal was $63 \%$ for I -3 and $57 \%$ for I -4 .

$b_{1} \mathrm{gpm}=6.31 \times 10^{-2} \mathrm{liters} / \mathrm{s}(\ell / 5)$.

$c_{1}$ gal $=3.785$ liters.

$\mathrm{Pe}^{-1}=0 \% / \mathrm{LL}=$ inverse Peclet number for one-dimensional, single zone fit.

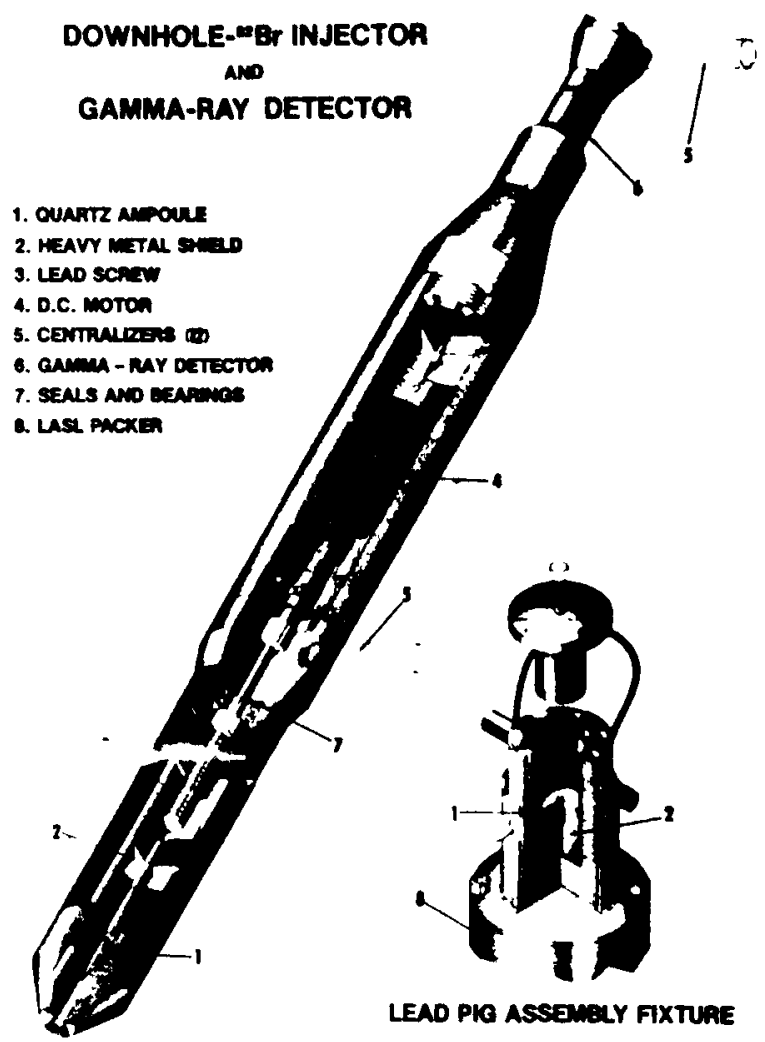

Fig. 1 - Schematic of combined $\mathrm{Br}^{\circ 2}$ injection system and gamma-ray detector.

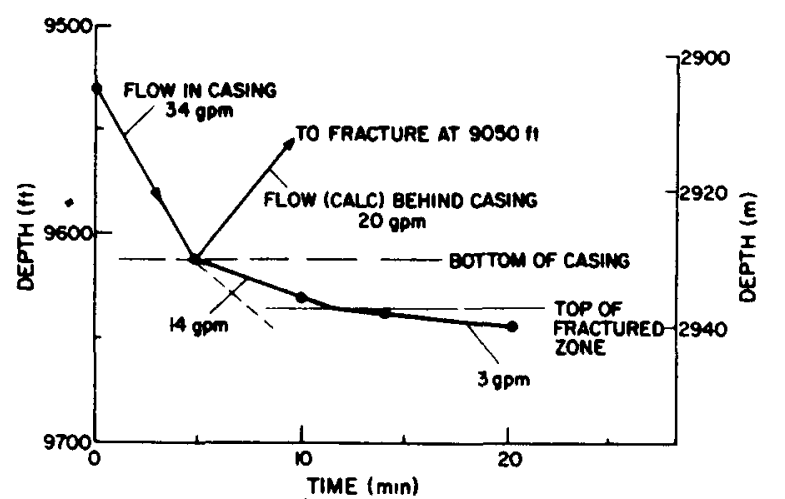

Fig. 2 - Movement of $I^{131}$ tracer showing flow both below and behind casing in the EE-1 wellbore.

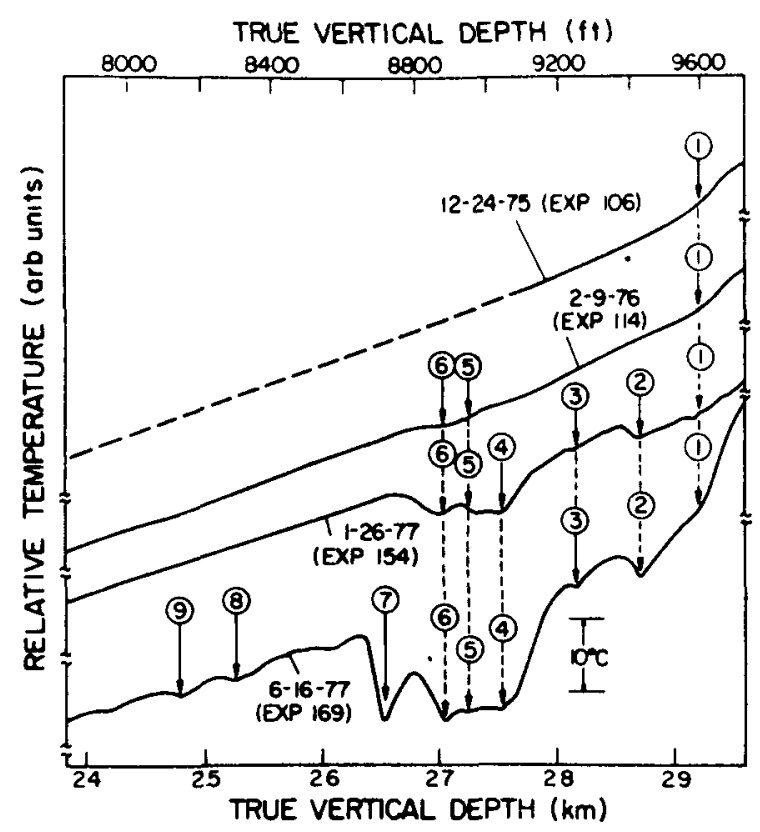

Fig. 3 - Sequential temperature surveys showing the evolution of multiple fracture connections in the EE- i injection wellbore. 


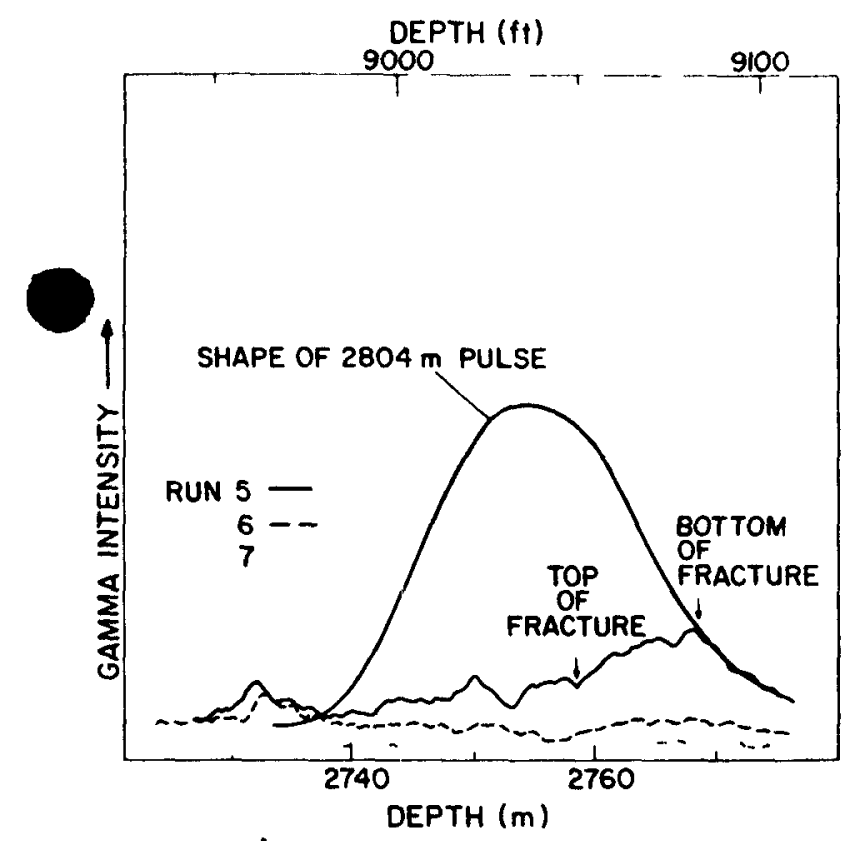

Fig. 4 - Tracer logs showing the disappearance of tracer into the fracture system at $\sim 2760 \mathrm{~m}(9050 \mathrm{ft})$ in the EE1 well lbore.

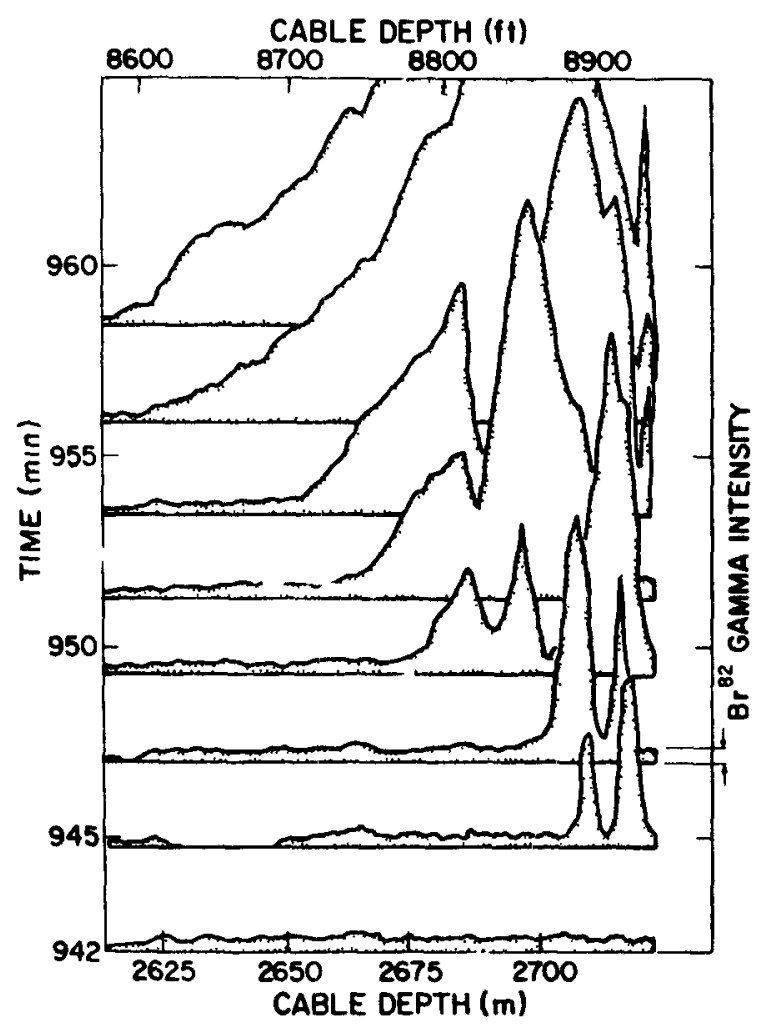

Fig. 6 - Logging sequence in GT-2B showing successive appearance of $\mathrm{Br}^{\circ 2}$ tracer at several production zones defined by fracture intersection.

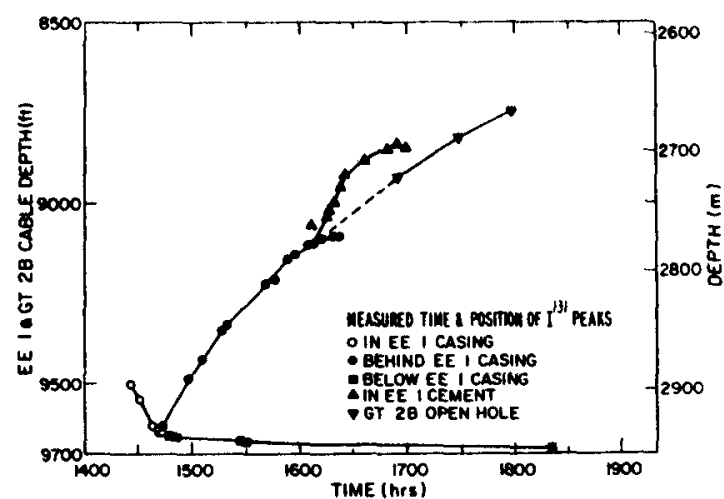

Fig. 5 - Tracer flow paths in the EE-1/GT-2B fracture system.

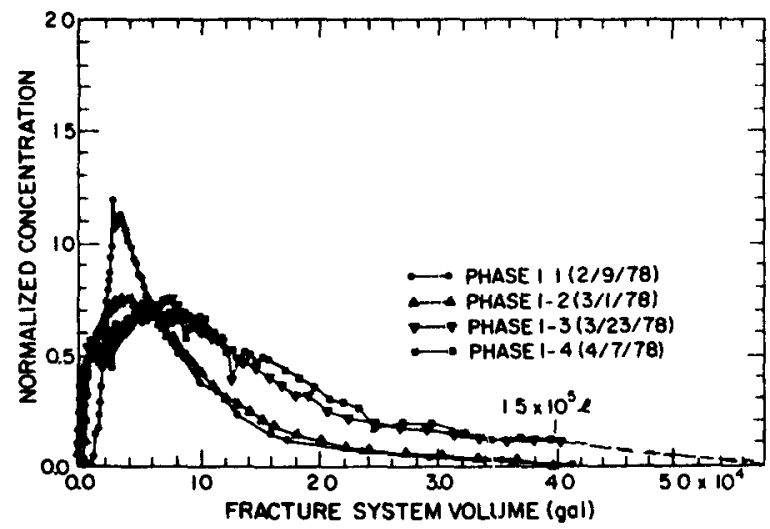

Fig. 7 - Normalized tracer concentration as a function of fracture system volume during the 75-day energy extraction field test of the EE-I/GT-2B system.

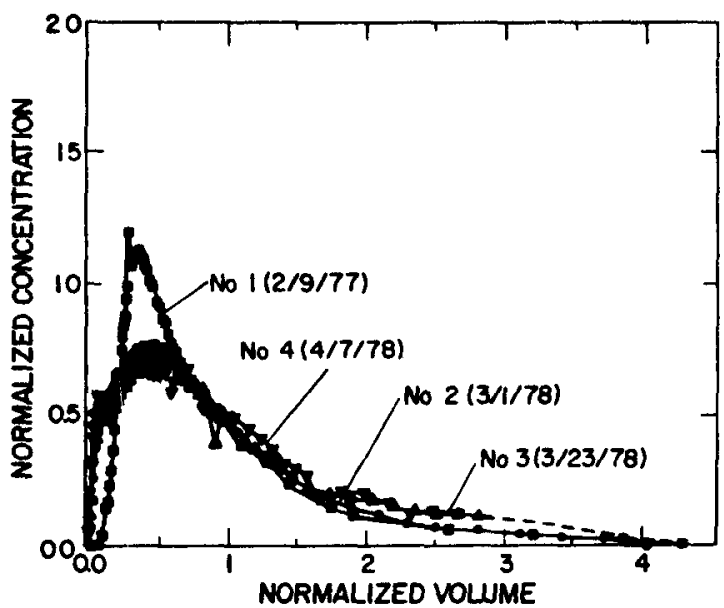

Fig. 8 - Normalized tracer concentration as a function of normalized fracture system volume or time during the 75-day energy extraction field test of the EE-1/GT-?B system. 


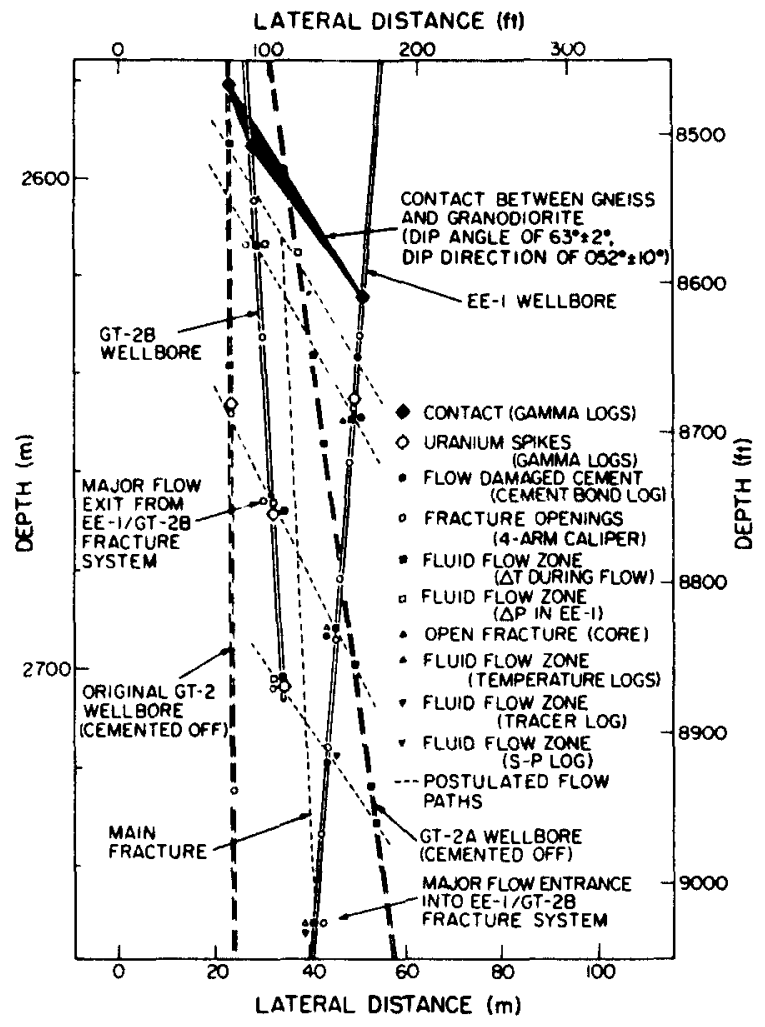

Fig. 9 - Elevation view showing the GT-2, GT-2A, GT-2B, and $E E-1$ wellbores with geophysical information shown and the fracture system model depicted with dotted lines.

ST - 2

TELEVIE'HER LOG $7 / 75$
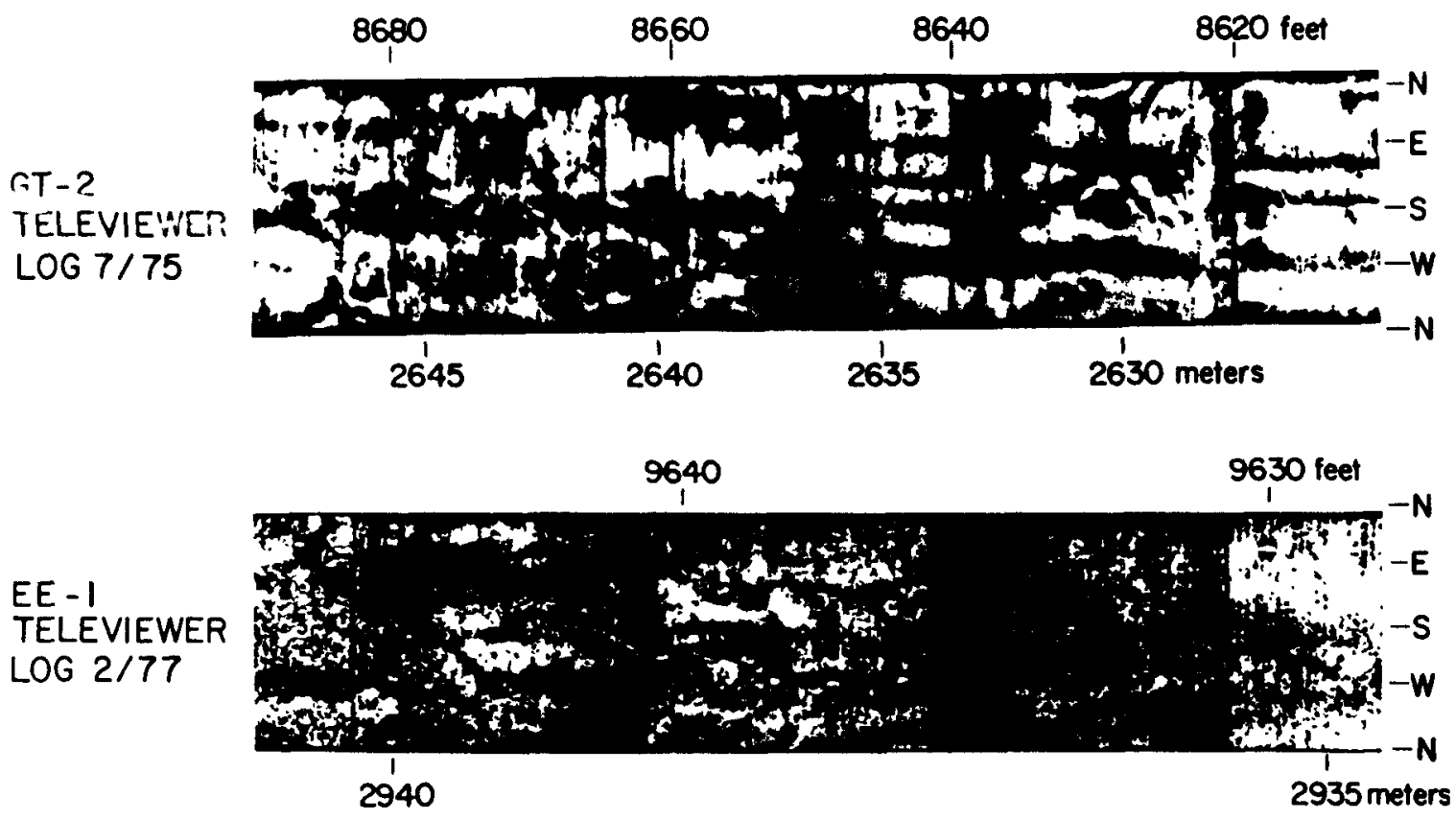

Fig. 10 - Borehole televiewer surveys from GT-2 and EE-1 showing complex sealed natural fracture systems that intersect the wellbores. (provided by S. Keys of the U.S. Geological Survey'). 


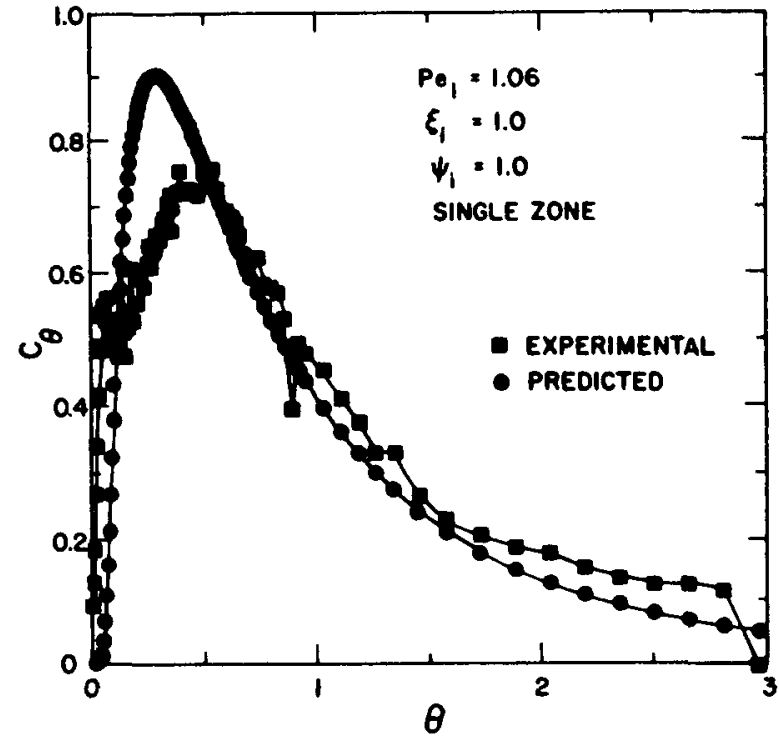

Fig. $11 \mathrm{~A}$

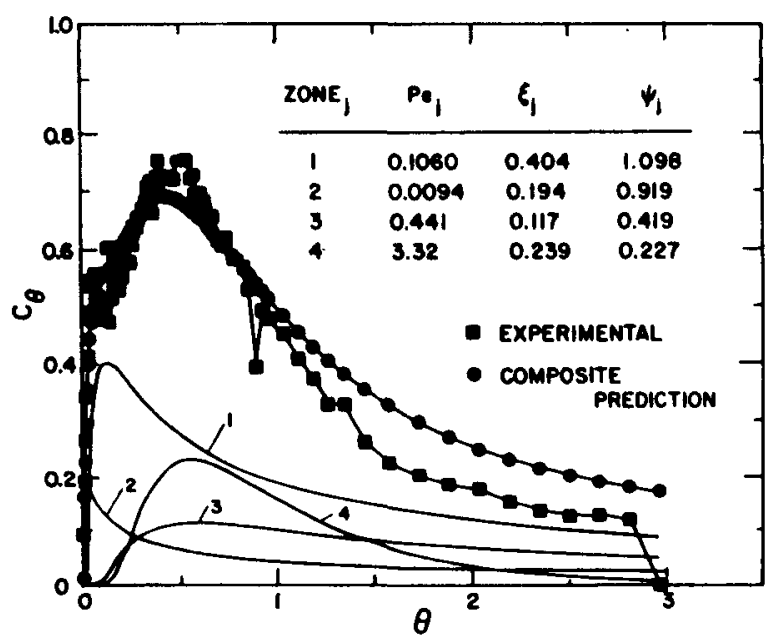

Fig. 118

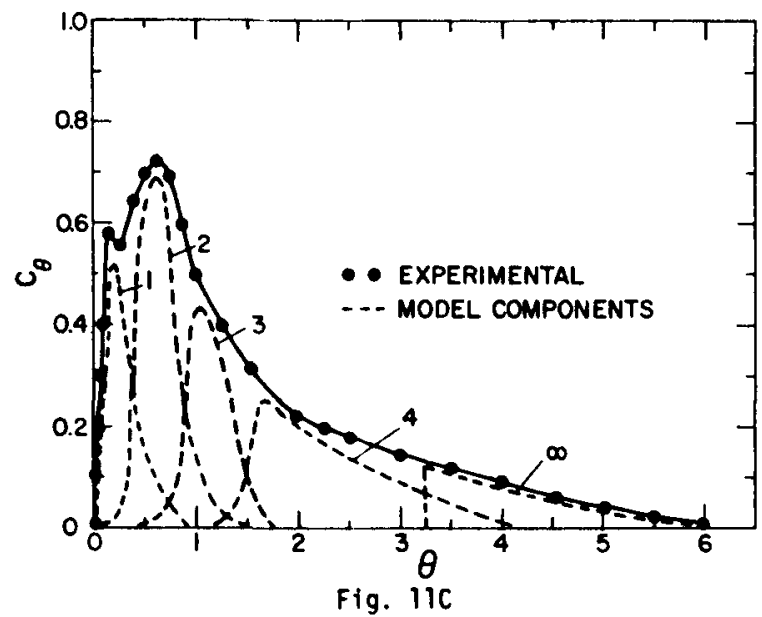

Fig. 11 - Experimental and predicted residence time distribution curves for one-dimensional dispersion of an injected tracer pulse during the phase I-3 test. Single- and multi-zone dispersion models are fit to the observed residence time distribution with fixed flow parameters. Peclet (Pe) number of each zone varied for optimal fit. (Parts $A, B$, and $C$ ).

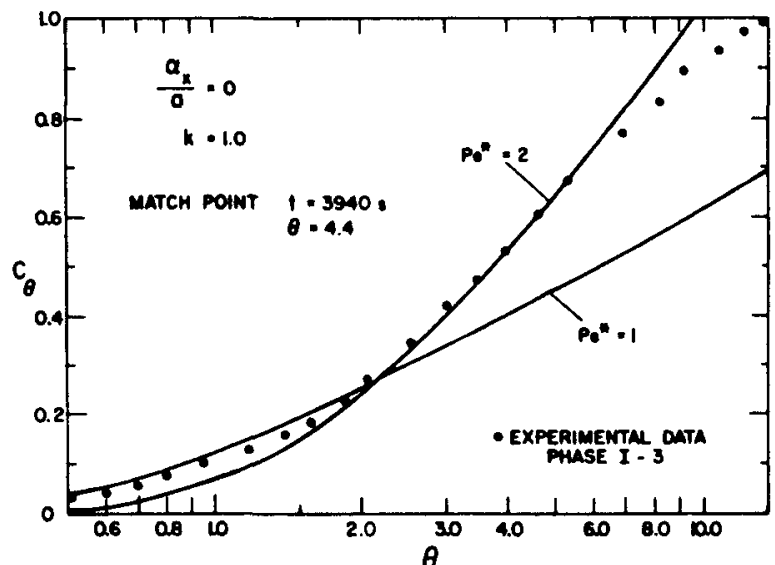

Fig. 12 - Type curve match using the two-dimensional dispersion model results with the integrated phase I-3 tracer data equivalent to a unit step input in concentration. Only formation dependent Peclet number (Pe*) variation shown. 